\title{
Estudo dos mecanismos de transporte de sódio, fosfato e amônio em colunas indeformadas de material inconsolidado residual de arenitos da Formação Adamantina
}

\author{
Dissertação apresentada à Escola de \\ Engenharia de São Carlos da Universidade \\ de São Paulo, como parte dos requisitos \\ para a obtenção do título de Mestre em \\ Ciências \\ Área de Concentração: Geotecnia \\ Orientador: Professor Doutor Lázaro \\ Valentin Zuquette
}

São Carlos, SP

2013

VERSÃO CORRIGIDA 
AUTORIZO A REPRODUÇÃO TOTAL OU PARCIAL DESTE TRABALHO, POR QUALQUER MEIO CONVENCIONAL OU ELETRÔNICO, PARA FINS DE ESTUDO E PESQUISA, DESDE QUE CITADA A FONTE.

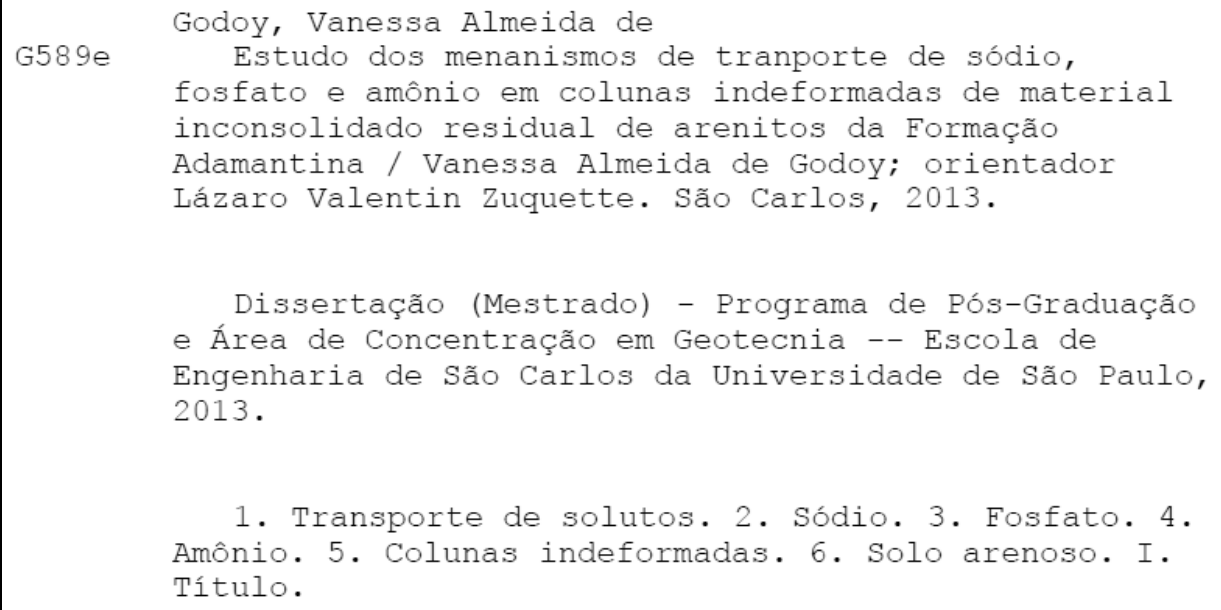




\section{FOLHA DE JULGAMENTO}

\section{Candidata: Bacharel VANESSA ALMEIDA DE GODOY.}

Título da dissertaçāo: "Estudo dos mecanismos de transporte de sódio, fosfato e amônio em colunas indeformadas de material inconsolidado residual de arenitos da Formaçāo Adamantina".

Data da defesa: 05/09/2013

\section{Comissão Julgadora:}

Prof, Titular Lázaro Valentin Zuquette (Orientador) (Escola de Engenharia de São Carlos/EESC)

Prof. Dr. Reinaldo Lorandi

(Universidade Federal de São Carlos/UFSCar)

Dra. Janaina Barrios Palma

(Arcadis Hidro Ambiente S.A.)

\section{Resultado:}
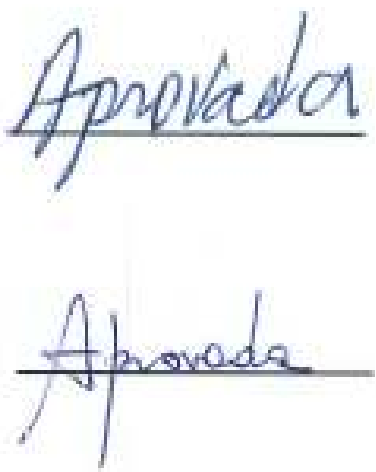

Apurvada

Coordenador do Programa de Pós-Graduação em Geotecnia:

Prof. Titular Osni José Pejon

Presidente da Comissão de Pós-Graduação:

Prot. Titular Denis Vinicius Coury 

Á minha mãe, Ednê, pelo amor incondicional, incentivo, compreensão e apoio em todos os momentos. 



\section{AGRADECIMENTOS}

À Deus por ter me permitido concluir esta etapa e por ter me mostrado que "escreve certo por linhas tortas".

Ao Professor Dr. Lázaro Zuquette pelo apoio profissional, suporte e amizade e por ter acreditado em mim e me estendido a mão quando mais precisei de sua ajuda: Muito obrigada!

Aos colegas da Geotecnia, em especial àqueles da minha turma de mestrado: Liz, Felipe (Loch), Bianca, Breno, Loana, Bruno e Gustavo (Zen) pelas risadas, festinhas, muitas horas de histórias absurdas, desabafos e estudo.

Aos colegas da Geotecnia afastados pelas voltas da vida, mas que sempre farão parte de memórias muito boas (Wanessão e Thiago).

Ao Breno por ter despendido horas e horas sendo professor de mecânica dos solos: Valeu Brenoso!

Aos amigos que fiz nesta cidade e que me proporcionaram momentos muito divertidos, em especial aos cangaceiros Vinicius (Coronel) e Amandita, à Alessandra pelas muitas festas animadas e à "peruanada" (Chino Pez, Chino, Mañuco, Flor, Pablito, Luis, Irma...) e muitos outros "gringos" que me acolheram como "um dos seus": Obrigada/Gracias!

Aos meus velhos amigos Joyce, Diego, Marcelo, Tiago, Dani, Paty e May, distantes, mas presentes para momentos sérios e quase sempre não sérios: Obrigada!

À minha família, em especial ao meu irmão (Rafael) e à minha mãe (Ednê), figura essencial na minha vida que, mesmo com o coração apertado e com lágrimas nos olhos em alguns momentos, sempre me apoiou: Muitíssimo obrigada!

Ao Gian Franco por ter sido tão paciente, por ter me ajudado em tudo que fiz durante o mestrado, ocupado horas com nossas discussões eruditas, por ser meu amigo, companheiro, consultor geotécnico e professor, por ter me mostrado um mundo completamente novo e fascinante e por fazer parte desta história: Muchas gracias ffx!

Àqueles que dificultaram o caminho, fazendo com ele ficasse mais interessante e que eu tivesse mais ânimo e força de vontade para alcançar meus objetivos: Obrigada!

Aos funcionários do departamento de Geotecnia que sempre se mostraram simpáticos e disponíveis para ajudar, em especial ao Sr. Antônio que ajudou muito na realização deste trabalho e que perdeu mais alguns fios de cabelo com a "morena" bagunçando no laboratório. 
Ao Júlio que disponibilizou o Laboratório de Saneamento da EESC/USP para realização de análises químicas.

Às meninas do Laboratório de Processos Biológicos da EESC/USP (Priscila, Carla e Raquel) que me auxiliaram em algumas análises químicas.

Ao professor Dr. Wilson Tadeu da Silva por ter ajudado na definição da área de trabalho.

Aos professores e funcionários da Escola Técnica Estadual "Astor Matos de Carvalho" por disponibilizarem a área para coleta de material e por terem sido sempre tão solícitos.

À CAPES - Coordenação de Aperfeiçoamento de Pessoal de Nível Superior, pelo auxílio financeiro que possibilitou o desenvolvimento deste trabalho. 
"Se avexe não

Toda caminhada começa No primeiro passo A natureza não tem pressa Segue seu compasso Inexoravelmente chega lá Se avexe não Obsere quem vai subindo a ladeira Seja princesa ou seja lavadeira Pra ir mais alto vai ter que suar..." Accioly Neto 



\section{RESUMO}

GODOY, V.A. Estudo dos mecanismos de transporte de sódio, fosfato e amônio em colunas indeformadas de material inconsolidado residual de arenitos da Formação Adamantina. 2013. 259p. Dissertação (Mestrado em Geotecnia), Escola de Engenharia de São Carlos, Universidade de São Paulo, 2013.

Esta dissertação apresentou um estudo dos mecanismos de transporte de sódio, fosfato e amônio em colunas indeformadas de material inconsolidado residual de arenitos da Formação Adamantina. Em campo foi realizada caracterização táctil visual do material, além de ensaios de condutividade hidráulica. Em laboratório, realizou-se ensaio de coluna em material indeformado, para que fossem obtidos os parâmetros de fluxo de água: velocidade linear média, velocidade de Darcy, vazão e condutividade hidráulica. Também foram obtidos os coeficientes de dispersão hidrodinâmica dos três íons estudados por meio de quatro métodos. Os fatores de retardamento dos íons foram obtidos por meio de três métodos. Para auxiliar nas análises, o solo foi caracterizado mineralógica, química, física e físico-químicamente. Adicionalmente foram feitas análises da porosimetria e estudo das trajetórias de transporte. As informações foram integradas para que fosse possível analisar os parâmetros de transporte de solutos no solo. Com esta pesquisa percebeu-se que o uso dos parâmetros de transporte em modelagem do transporte de contaminantes deve ser feito com cautela, observando tanto as características do solo (mineralógicas, físicas, físico-químicas) quanto os modelos conceituais e as limitações dos métodos utilizados.

Palavras chave: Transporte de solutos. Sódio. Fosfato. Amônio. Coluna indeformada. Solo arenoso. 



\begin{abstract}
GODOY, V.A. Study of sodium, phosphate and ammonium transport mechanisms in undisturbed columns of unconsolidated residual material of sandstones of the Adamantina Formation. 2013. 259p. Dissertação (Mestrado), Escola de Engenharia de São Carlos, Universidade de São Paulo, 2013.

This research aimed to study the transport mechanisms of sodium, phosphate and ammonium in undisturbed columns of unconsolidated residual material of the sandstones from the Adamantina Formation. At field, visual and tactile characterization of the material were performed as well as hydraulic conductivity tests . At laboratory, there were made column tests in undisturbed samples to obtain the parameters of water flow, i.e., average linear velocity, Darcy velocity, flow rate and hydraulic conductivity. Hydrodynamic dispersion coefficients of every studied ion were determined using four methods. The retardation factors of the three ions were obtained using three methods. To assist the analysis, the soil was mineralogical, chemistry, physically and physic-chemically characterized. We also analyzed the water retention curve, mercury intrusion porosimetry and solute transport trajectories. All available data were integrated for analyzing the parameters of solute transport in soil. The results showed that the use of transport parameters in modeling of contaminant transport should be done with caution, observing soil characteristics, the conceptual models and the limitations of the methods used.
\end{abstract}

Keywords: Solute transport. Sodium. Phosphate. Ammonium. Undisturbed columns. Sandy Soil. 



\section{LISTA DE FIGURAS}

Figura 2.1- Sequências metabólicas e grupos microbianos envolvidos na digestão anaeróbia

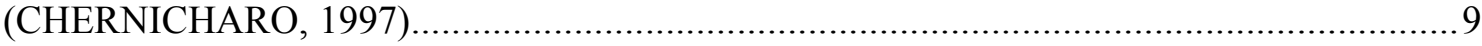

Figura 2.2- Biodigestor de modelo chinês (MARTELLI, 2011) ....................................... 11

Figura 2.3- Biodigestor de modelo indiano (MARTELLI, 2011) ...................................... 11

Figura 2.4- Biodigestor de modelo canadense (MARTELLI, 2011) ................................... 11

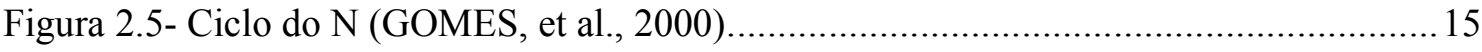

Figura 2.6- Influencia do pH na forma química do Nitrogênio na solução (Modificado de

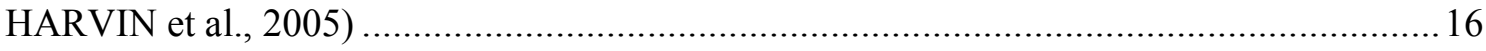

Figura 2.7- Ciclo do P (Modificado de HAVLIN et al., 2005) ............................................17

Figura 2.8- Influência do pH na forma química do P na solução (Modificado de HARVIN et

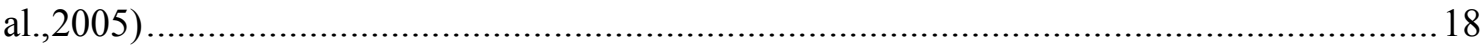

Figura 2.9- Método de infiltração lenta com irrigação por aspersão (VON SPERLING, 1996) 23

Figura 2.10- Material parental isotrópico e solo anisotrópico (JENNY, 1994)......................34

Figura 2.11- Perfil de solo esquemático com nomenclatura pedológica e geotécnica

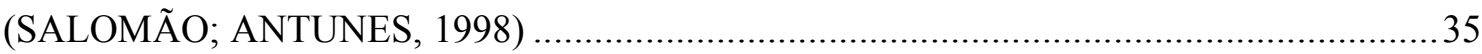

Figura 2.12- Diagrama Eh/pH mostrando a estabilidade dos óxidos de Fe e Mn, pirita e C (REDRAWN; ROSE; WEBB et al., 1979 apud ALLOWAY, 1995) ..................................42

Figura 2.13- Diagrama Eh/pH mostrando a estabilidade das espécies de P(PASEK, 2008) ...42

Figura 2.14- Diagrama Eh/pH mostrando a estabilidade das espécies de Na (TAKENO, 2005)

Figura 2.15- Diagrama Eh/pH mostrando a estabilidade das espécies de N (TAKENO, 2005) 
Figura 2.16- Classes texturais do solo (ABNT NBR 7182/82). 46

Figura 2.17- Representação da definição do potencial total da água no solo (VILAR, 2009) 48

Figura 2.18- Representação das definições de sucção total, matricial e osmótica (VILAR, 2002) .49

Figura 2.19- Infiltração acumulada e taxa de infiltração no tempo (FERNANDES, 2011)....51

Figura 2.20- Principais componentes da curva de retenção e água típica (FREDLUND e XING, 1994) .53

Figura 2.21- Estágios da curva de retenção para um meio poroso hipotético (modificado de VANAPALLI et al. 1996) .54

Figura 2.22- Curvas de retenção de água representativas para solos argilosos e arenosos e para solo com distribuição de poros bimodal (RODRIGUES, 2007). .55

Figura 2.23- Duas configurações do ensaio com papel filtro. a: Sucção total; b: Sucção matricial (modificado de MARINHO, 1994) 57

Figura 2.24- Elemento de volume de solo, através do qual a água está fluindo (modificado de REICHARDT, 1985) .59

Figura 2.25- Movimento macroscópico e unidimensional de contaminantes no solo por advecção (LEITE, 2001). 65

Figura 2.26- Efeitos que causam dispersão mecânica (Modificado de FETTER, 1993) .........66

Figura 2.27- Ilustração esquemática da difusão molecular (Modificado de ROWE; QUIGLEY; BOOKER, 1995). .67

Figura 2.28- Representação da tortuosidade em meios porosos (FETTER, 1993).................68

Figura 2.29- Espalhamento da solução contaminante por dispersão hidrodinâmica (Modificado de FREEZE; CHERRY, 1979) .72

Figura 2.30- Dispersão hidrodinâmica em um fluxo uniforme bidimensional em uma areia isotrópica: (a) fonte contínua; (b) fonte instantânea (Modificado de FREEZE; CHERRY, 1979). 
Figura 2.31- Modelo de Curva de chegada (Modificado de PANARAT, 2008). 73

Figura 2.32- Obtenção dos parâmetros $t_{0}$ e $m$ do método proposto por Singh (1998) (SINGH, 2002) .75

Figura 2.33- Típica curva de composição-efluente para deslocamento miscível em coluna arenosa (Modificado de PERKINS; JOHNSTON, 1963) 76

Figura 2.34- Representação da dupla camada elétrica e dupla camada difusa (LEITE, 2001) 77

Figura 2.35- Esquema hipotético do processo de adsorção não específica (LEITE, 2001) .....78

Figura 2.36- Esquema da precipitação de $\mathrm{Pb}$ na superfície de um argilomineral (LEITE, 2001) .80

Figura 2.37- Quelação do Cd com agente quelante sintético (EDTA) (TACK; MEERS, 2010) 81

Figura 2.38- Categorias e subgrupos de isotermas de sorção (GILES; SMITH; HUITSON,1974). .82

Figura 2.39- Representação gráfica das isotermas de Freundlich, Linear e Langmuir (Modificado de JURY, GARDNER; GARDNER, 1991) .82

Figura 2.40- Curva característica do transporte incluindo o efeito do retardamento (FREEZE; CHERRY, 1979)..... 86

Figura 2.41- Ilustração da concentração residente e concentração efluente (Modificado de SHACKELFORD, 1994). .87

Figura 2.42- Diferença entre o fator de retardamento obtido com $R_{d}=H$ e $R d=V v$ para $C / C_{0}$ $=0,5($ Modificado de SHACKELFORD, 1994) .88

Figura 2.43- Lei da conservação de massa para o volume elementar de solo (Modificado de FREEZE; CHERRY, 1979) 89

Figura 2.44- Esquematização do balando de massa (LEITE, 2001) 89

Figura 2.45- Procedimentos para ensaio de "batch test" (YONG; MOHAMED; WARKENTIN, 1992) 94 
Figura 2.46- Curva de chegada obtida com ensaio de coluna (Modificado de FREEZE; CHERRY, 1979)

Figura 2.47- Curvas de chegada para soluto com baixa e alta dispersividade (Modificado de MARTINEZ; SILVA; PEREIRA, 2010). .95

Figura 3.1- Localização da área de estudo. .98

Figura 3.2- Precipitação anual acumulada de 1938 a 2004 .99

Figura 3.3- Bacia Bauru com os grupos Bauru e Caiuá (modificado de FERNANDES, 1998)

Figura 3.4- Mapa topográfico com a localização do perfil da Figura 3.5 ............................ 103

Figura 3.5- Perfil litológico da área de estudo...... 103

Figura 3.6- Sistema Aquífero Bauru (DAEE, 2005). 104

Figura 3.7- Subdivisão hidroestratigráfica do Sistema Aquífero Bauru (PAULA E SILVA, 2003). 105

Figura 3.8- UGRHIs do Estado de São Paulo (MATSUMURA-TUNDISI, 2010)..... 106

Figura 3.9- Hidrografia da região de UGRHI 17 - Médio Paranapanema (Modificado de DAEE, 2006). 107

Figura 4.1- Hidrografia da região de UGRHI 17 - Médio Paranapanema (Modificado de DAEE, 2006). 109

Figura 4.2- Vista geral da área de coleta das amostras 111

Figura 4.3- a: Área irrigada com efluente há 3 anos; b: Área não irrigada com efluente (coleta

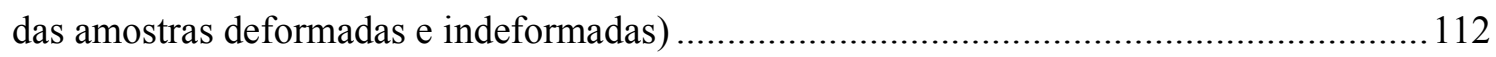

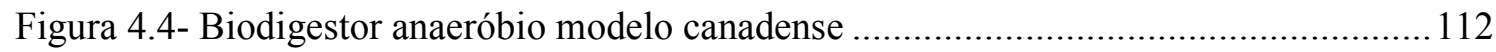

Figura 4.5- a e b: Cava para coleta das amostras; c: Coleta de amostras deformadas; d:Indeformadas. 113 
Figura 4.6- a e b: Abertura do furo; c: Injeção de água; d: Rebaixamento da água 114

Figura 4.7- Lâminas para o ensaio de DRX 116

Figura 4.8- a: Ensaio de granulometria: sedimentação; b: Ensaio de granulometria: peneiramento

Figura 4.9- pHmetro Digimed utilizado na pesquisa 118

Figura 4.10- Condutímetro ANALYSER utilizado na pesquisa 118

Figura 4.11- Ensaio de azul de metileno

Figura 4.12- Corpo de prova para ensaio de porosimetria

Figura 4.13- Equipamento para realização da porosimetria por intrusão de mercúrio

Figura 4.14- a: Moldagem dos anéis; b: Anéis moldados

Figura 4.15- a: Saturação dos anéis; b: Secagem dos anéis 124

Figura 4.16- a: Papel filtro em contato com o solo; b: Armazenamento dos anéis (FERNANDES, 2011) 124

Figura 4.17 a: Retificação das colunas; b: Filtro do fundo das colunas; c: Base de metal para suporte das colunas; e, d: Coluna conectada às mangueiras para entrada e saída de água .... 126

Figura 4.18- Montagem do ensaio de condutividade hidráulica (a: Regularizador de nível; b: Distribuidor de água; c: Mangueiras de borracha) 127

Figura 4.19- Montagem do ensaio de percolação de solução contaminante (a: regularizador de nível; b: reservatórios com soluções)

Figura 4.20- Amostras armazenadas em recipientes plásticos 129

Figura 4.21- Equipamentos utilizados para medições físico-químicas. a: fotômetro de chama; b: espectrofotômetro 129

Figura 5.1- Gráficos de difratometria de raios X para os três tratamentos realizados 135

Figura 5.2- Curvas granulométricas com e sem o uso de defloculante 136 
Figura 5.3- Gráfico de EDS 138

Figura 5.4- Diâmetro dos poros versus pressão aplicada 139

Figura 5.5- Pressão aplicada versus volume de mercúrio introduzido nos poros 140

Figura 5.6- Diâmetro dos poros versus volume acumulado de mercúrio introduzido na amostra 140

Figura 5.7- Diâmetro dos poros versus porcentagem do volume total de mercúrio introduzido

Figura 5.8- Colunas de solo com macroporosidade 142

Figura 5.9- Frequência versus diâmetro dos poros 142

Figura 5.10- Curva de retenção de água para a trajetória de secagem 143

Figura 5.11- Medidas do coeficiente de permeabilidade. 145

Figura 5.12- Medidas da vazão 145

Figura 5.13- valores de $\mathrm{pH}$ versus volume de poros durante percolação de $\mathrm{NaCl}$. 148

Figura 5.14- Condutividade elétrica versus volume de poros durante percolação de $\mathrm{NaCl}$... 149

Figura 5.15- Temperatura versus volume de poros durante percolação de $\mathrm{NaCl}$. 149

Figura 5.16- Curva de chegada do $\mathrm{Na}^{+}$ 150

Figura 5.17- Curva U versus \% de fluido percolado para $\mathrm{C}_{0}$ de $50 \mathrm{ppm}$ de sódio 152

Figura 5.18- Figura 3 Curva U versus \% de fluido percolado para $\mathrm{C}_{0}$ de $90 \mathrm{ppm}$ de sódio .. 152

Figura 5.19- Figura 3 Curva U versus $\%$ de fluido percolado para $\mathrm{C}_{0}$ de $117,5 \mathrm{ppm}$ de sódio 153

Figura 5.20- Obtenção dos parâmetros $\mathrm{t}_{0} \mathrm{e} \mathrm{m}$ a partir da curva de chegada para $\mathrm{C}_{0}$ de 50 ppm de sódio 154 
Figura 5.21- Obtenção dos parâmetros $\mathrm{t}_{0}$ e $\mathrm{m}$ a partir da curva de chegada para $\mathrm{C}_{0}$ de $90 \mathrm{ppm}$ de sódio 154

Figura 5.22- Obtenção dos parâmetros $t_{0}$ e $m$ a partir da curva de chegada para $C_{0}$ de 117,5 ppm de sódio 154

Figura 5.23- Obtenção do fator de retardamento pelo método de Freeze e Cherry (1979) e Shackelford $(1993 ; 1994)$ para $\mathrm{C}_{0}$ de 50 ppm de sódio 161

Figura 5.24- Obtenção do fator de retardamento pelo método de Freeze e Cherry (1979) e Shackelford $(1993 ; 1994)$ para $\mathrm{C}_{0}$ de 90 ppm de sódio 161

Figura 5.25- Obtenção do fator de retardamento pelo método de Freeze e Cherry (1979) e Shackelford $(1993 ; 1994)$ para $C_{0}$ de 117,5 ppm de sódio 161

Figura 5.26- Isoterma de sorção de sódio. 162

Figura 5.27- Ajuste dos dados experimentais de sódio ao modelo de isoterma Linear 162

Figura 5.28- Ajuste dos dados experimentais de sódio ao modelo de isoterma de Freundlich 163

Figura 5.29- Ajuste dos dados experimentais de sódio ao modelo de Langmuir (Langmuir I) 163

Figura 5.30- Ajuste dos dados experimentais de sódio ao modelo de Langmuir (Langmuir II) 163

Figura 5.31- Valores de $\mathrm{pH}$ versus volume de poros durante percolação de $\left(\mathrm{NH}_{4}\right)_{2} \mathrm{HPO}_{4} \ldots .167$

Figura 5.32- Valores de condutividade elétrica versus volume de poros durante percolação de $\left(\mathrm{NH}_{4}\right)_{2} \mathrm{HPO}_{4}$ 168

Figura 5.33- Valores de temperatura versus volume de poros durante percolação de $\left(\mathrm{NH}_{4}\right)_{2} \mathrm{HPO}_{4}$ 169

Figura 5.34- Curva de chegada de $\mathrm{PO}_{4}{ }^{3-}$ 170

Figura 5.35- Gráfico de EDS após percolação de $\left(\mathrm{NH}_{4}\right)_{2} \mathrm{HPO}_{4}$ 171 
Figura 5.37- Curva U versus \% de fluido percolado para $\mathrm{C}_{0}$ de $35 \mathrm{ppm}$ de fosfato...... 173

Figura 5.38- Curva U versus \% de fluido percolado para $\mathrm{C}_{0}$ de $65 \mathrm{ppm}$ de fosfato. 173

Figura 5.39- Curva U versus \% de fluido percolado para $\mathrm{C}_{0}$ de $95 \mathrm{ppm}$ de fosfato 173

Figura 5.40- Obtenção dos parâmetros $t_{0}$ e $m$ a partir da curva de chegada para $\mathrm{C}_{0}$ de 35 ppm de fosfato 174

Figura 5.41- Obtenção dos parâmetros $t_{0}$ e $m$ a partir da curva de chegada para $C_{0} 65$ ppm de fosfato 175

Figura 5.42- Obtenção dos parâmetros $t_{0}$ e $m$ a partir da curva de chegada para $\mathrm{C}_{0} 95$ ppm de fosfato 175

Figura 5.43- Obtenção do fator de retardamento pelo método de Freeze e Cherry (1979) e Shackelford (1993;1994) para $\mathrm{C}_{0}$ de 35 ppm de fosfato 179

Figura 5.44- Obtenção do fator de retardamento pelo método de Freeze e Cherry (1979) e Shackelford (1993;1994) para $\mathrm{C}_{0}$ de 65 ppm de fosfato 180

Figura 5.45- Obtenção do fator de retardamento pelo método de Freeze e Cherry (1979) e Shackelford (1993;1994) para $\mathrm{C}_{0}$ de 95 ppm de fosfato 180

Figura 5.46- Isoterma de sorção de fosfato 180

Figura 5.47- Ajuste dos dados experimentais de fosfato ao modelo de isoterma Linear....... 181

Figura 5.48- Ajuste dos dados experimentais de fosfato ao modelo de isoterma de Freundlich 181

Figura 5.49- Ajuste dos dados experimentais de fosfato ao modelo de Langmuir (Langmuir I)

Figura 5.50 Ajuste dos dados experimentais de fosfato ao modelo de Langmuir (Langmuir II)

Figura 5.51 Curva de chegada de $\mathrm{NH}_{4}^{+}$ 186 
Figura 5.52- Curva U versus \% de fluido percolado para $C_{0}$ de 13 ppm de amônio 188

Figura 5.53- Curva U versus \% de fluido percolado para $C_{0}$ de 24 ppm de amônio 188

Figura 5.54- Curva U versus \% de fluido percolado para $\mathrm{C}_{0}$ de $36 \mathrm{ppm}$ de amônio 188

Figura 5.55- Obtenção dos parâmetros $\mathrm{t}_{0}$ e $\mathrm{m}$ a partir da curva de chegada para $\mathrm{C}_{0}$ de $13 \mathrm{ppm}$ de amônio 189

Figura 5.56- Obtenção dos parâmetros $\mathrm{t}_{0}$ e $\mathrm{m}$ a partir da curva de chegada para $\mathrm{C}_{0} 24 \mathrm{ppm}$ de amônio 190

Figura 5.57- Obtenção dos parâmetros $\mathrm{t}_{0}$ e $\mathrm{m}$ a partir da curva de chegada para $\mathrm{C}_{0} 36 \mathrm{ppm}$ de amônio 190

Figura 5.58- Obtenção do fator de retardamento pelo método de Freeze e Cherry (1979) e Shackelford $(1993 ; 1994)$ para $\mathrm{C}_{0}$ de 13 ppm de amônio 194

Figura 5.59- Obtenção do fator de retardamento pelo método de Freeze e Cherry (1979) e Shackelford $(1993 ; 1994)$ para $\mathrm{C}_{0}$ de 24 ppm de amônio 195

Figura 5.60- Obtenção do fator de retardamento pelo método de Freeze e Cherry (1979) e Shackelford $(1993 ; 1994)$ para $\mathrm{C}_{0}$ de 36 ppm de amônio 195

Figura 5.61- Isoterma de sorção de amônio 196

Figura 5.62- Ajuste dos dados experimentais de amônio ao modelo de isoterma Linear...... 196

Figura 5.63- Ajuste dos dados experimentais de amônio ao modelo de isoterma de Freundlich 197

Figura 5.64- Ajuste dos dados experimentais de amônio ao modelo de Langmuir ( Langmuir I) 197

Figura 5.65 Ajuste dos dados experimentais de fosfato ao modelo de Langmuir ( Langmuir II) 197

Figura 5.66 Ensaio de trajetória de transporte: a:antes do ensaio; b:aplicação da solução de azul de metileno; c:constatação de caminho preferencial; d:corte transversal da coluna; e-f: coluna aberta mostrando macroporos e caminhos preferenciais 203 



\section{LISTA DE TABELAS}

Tabela 2.1-Composições químicas de efluentes de biodigestores anaeróbios 13

Tabela 2.2- Distribuição aproximada de N pelos sistemas Solo-Planta/Animal-Atmosférico (HAVLIN, ET AL., 2005) 14

Tabela 2.3 Minerais comuns nos solo (Modificado de SPOSITO, 1989). 38

Tabela 2.4- Equações de ajuste da curva de retenção de água e seus respectivos parâmetros (Modificado de PEIXOTO, 2011; MENDES, 2008 e FERNANDES, 2011) 56

Tabela 2.5- Valores típicos de dispersividade 71

Tabela 4.1 Equações de fator de retardamento para diferentes isotermas de sorção 133

Tabela 5.1 Valores da massa específica dos sólidos 136

Tabela 5.2 Parâmetros físico-químicos do solo 137

Tabela 5.3- Porcentagem dos elementos químicos no solo pelo EDS 138

Tabela 5.4- Características dos anéis moldados e do ensaio da trajetória de secagem..... 143

Tabela 5.5- Parâmetros de ajuste da curva de retenção de água do material inconsolidado.. 144

Tabela 5.6- Índices físicos das colunas estudadas 144

Tabela 5.7- Parâmetros de fluxo de água das colunas. 146

Tabela 5.8- Resultados dos ensaios de condutividade hidráulica in situ 146

Tabela 5.9- Características das soluções utilizadas 147

Tabela 5.10- Parâmetros $\mathrm{U}_{16}$ e $\mathrm{U}_{84}$ para diferentes colunas percoladas com $\mathrm{NaCl}$ 153

Tabela 5.11- Parâmetros $t_{0}$ e $m$ para as colunas percoladas com solução de $\mathrm{NaCl}$ 155

Tabela 5.12- Coeficiente de dispersividade longitudinal 155

Tabela 5.13- Coeficientes de dispersão hidrodinâmica para as colunas percoladas com $\mathrm{NaCl}$ 
Tabela 5.14- Velocidades lineares médias obtidas a partir do $D_{h}$ das colunas percoladas com $\mathrm{NaCl}$ 158

Tabela 5.15- Número de Péclet para as colunas percoladas com $\mathrm{NaCl}$.............................159

Tabela 5.16- Coeficientes de determinação para ajuste dos modelos das isotermas ............. 164

Tabela 5.17- Valores de fatores de retardamento de $\mathrm{Na}^{+}$obtidos com diferentes métodos ... 165

Tabela 5.18- Porcentagem dos elementos químicos no solo pelo EDS (antes e após percolação

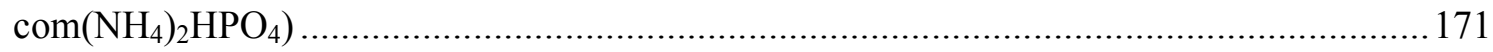

Tabela 5.19 Parâmetros $\mathrm{U}_{16}$ e $\mathrm{U}_{84}$ para diferentes colunas percoladas com fosfato..............174

Tabela 5.20 Parâmetros $t_{0}$ e $m$ das curvas de chegada de fosfato.................................... 175

Tabela 5.21- Coeficientes de dispersão hidrodinâmica para as colunas percoladas com $\mathrm{PO}_{4}{ }^{3-}$ 176

Tabela 5.22 Velocidades lineares médias obtidas a partir do $D_{h}$ das colunas percoladas com $\mathrm{PO}_{4}{ }^{3-}$ 177

Tabela 5.23 Números de Péclet obtidos a partir do $D_{h}$ das colunas percoladas com $\mathrm{PO}_{4}{ }^{3-} \ldots 178$

Tabela 5.24 Valores dos coeficientes de determinação para ajuste dos modelos das isotermas 182

Tabela 5.25 Valores dos fatores de retardamento de $\mathrm{PO}_{4}{ }^{3-}$ obtidos com diferentes métodos 182

Tabela 5.26 Parâmetros $\mathrm{U}_{16}$ e $\mathrm{U}_{84}$ para diferentes colunas percoladas com amônio.....

Tabela 5.27 Parâmetros $\mathrm{t}_{0}$ e m das curvas de chegada de amônio

Tabela 5.28- Coeficientes de dispersão hidrodinâmica para as colunas percoladas com $\mathrm{NH}_{4+}$

Tabela 5.29 Velocidades lineares médias obtidas a partir do $D_{h}$ das colunas percoladas com $\mathrm{NH}_{4}^{+}$ 192

Tabela 5.30 Números de Péclet obtidos a partir do $D_{h}$ das colunas percoladas com $\mathrm{NH}_{4}{ }^{+} \ldots 193$ 
Tabela 5.31Coeficientes de determinação para ajuste dos modelos das isotermas ............... 198

Tabela 5.32 Fatores de retardamento obtidos com diferentes métodos para amônio ............ 199

Tabela 5.33 - Parâmetros físico-químicos do solo após percolação das soluções ..................204 



\section{SUMÁRIO}

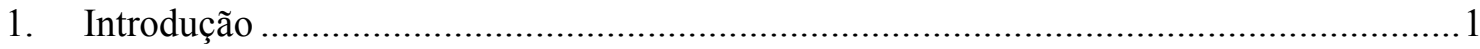

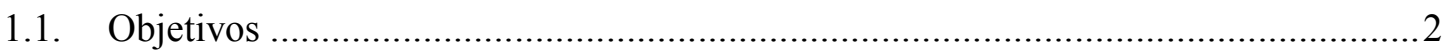

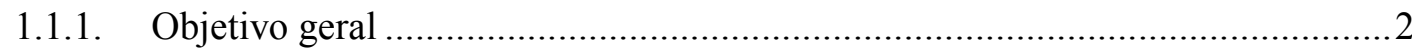

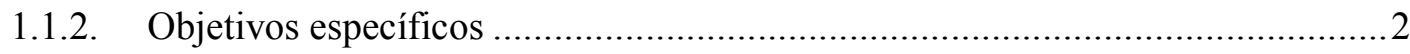

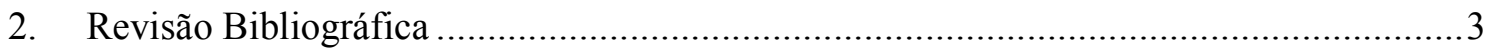

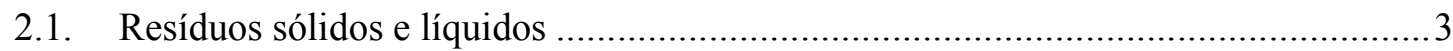

2.2. Resíduos líquidos: efluentes de tratamento de esgotos ........................................ 4

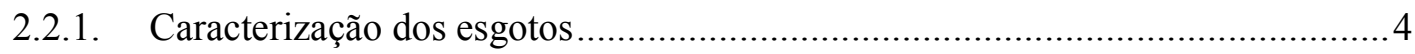

2.2.2. Tratamento de esgotos: níveis, operações, processos e sistemas........................5

2.2.3. Processos biológicos anaeróbios..........................................................

2.3. Composição dos efluentes de esgotos tratados ................................................... 12

2.4. Principais elementos químicos na composição dos efluentes líquidos ..................... 13

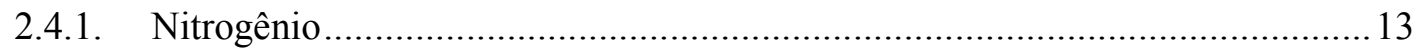

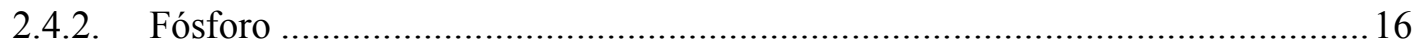

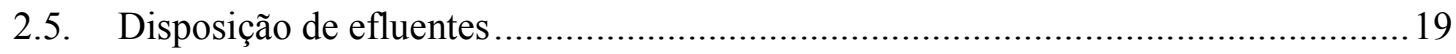

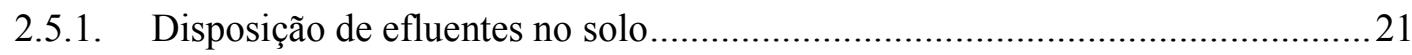

2.6. Aspectos positivos da disposição de efluentes no solo ........................................24

2.7. Aspectos negativos da disposição de efluentes no solo ........................................26

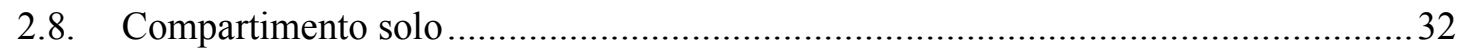

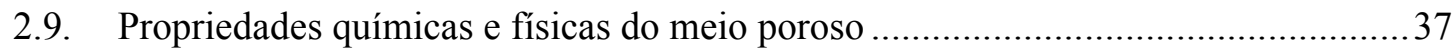

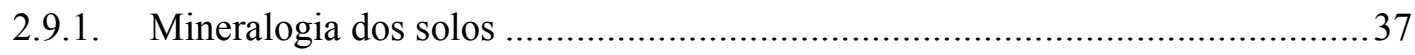


2.9.2. Capacidade de troca catiônica 39

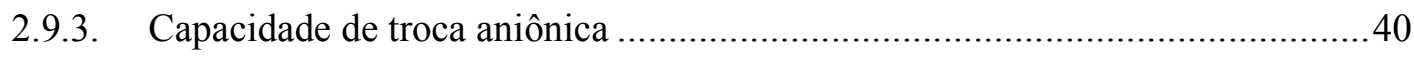

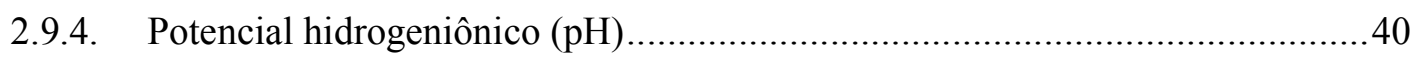

2.9.5. Potencial de oxidação e redução $($ Eh) .......................................................... 41

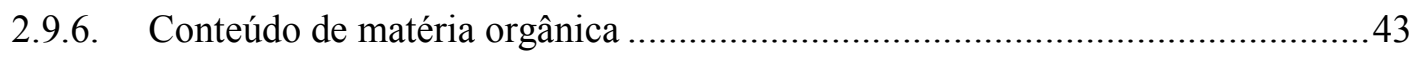

2.9.7. Balanço de cargas no solo: ponto de carga zero (PCZ)..................................43

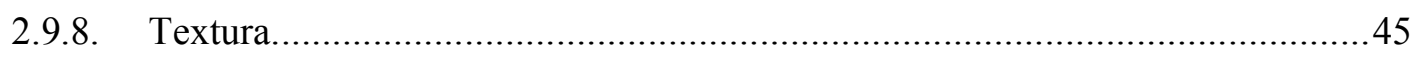

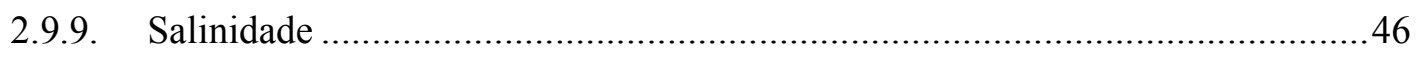

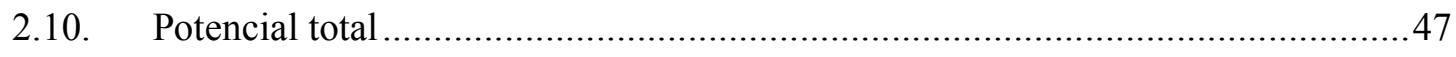

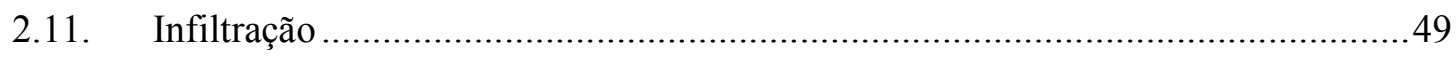

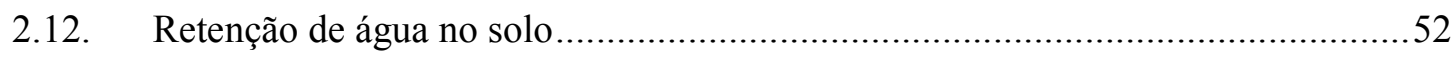

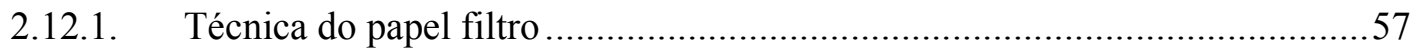

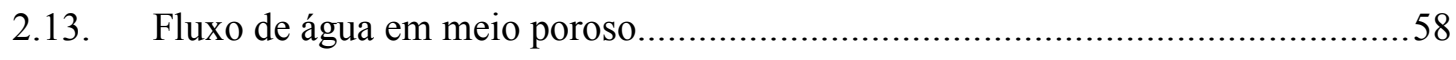

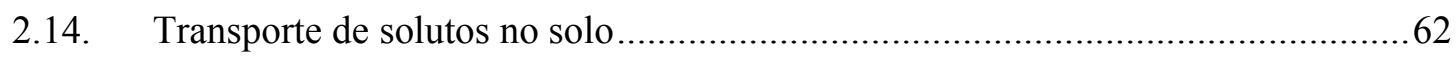

2.14.1. Mecanismos físicos de transporte de solutos no solo ..............................63

2.14.2. Mecanismos químicos de transporte de solutos no solo ..............................77

2.14.3. Outros processos: decaimento, meia vida e biodegradação.......................... 84

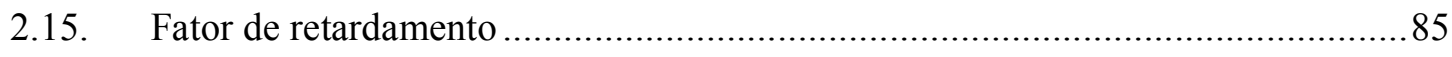

2.16. Formulação matemática do transporte de solutos no solo ..................................8 89

2.17. Estudo dos mecanismos de transporte de contaminantes em laboratório ..............92

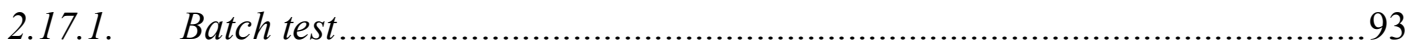




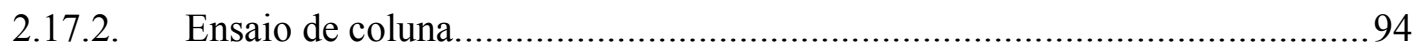

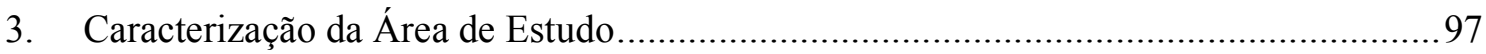

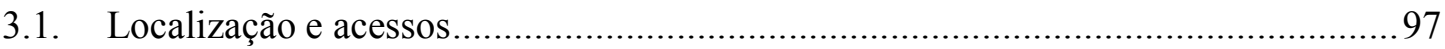

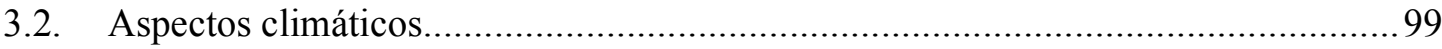

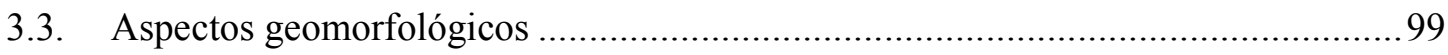

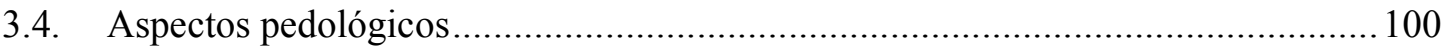

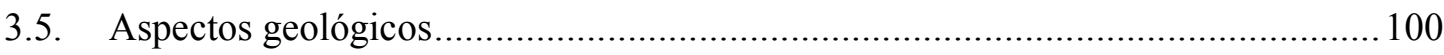

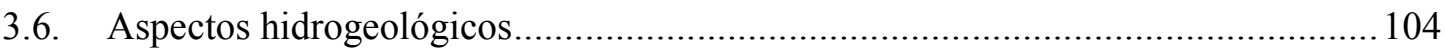

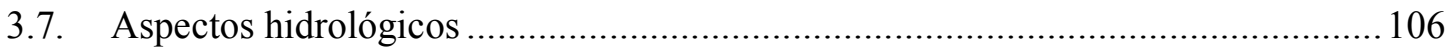

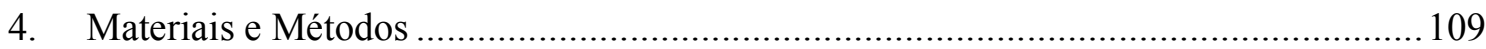

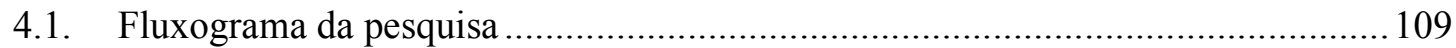

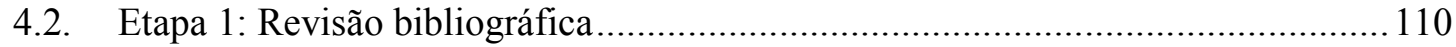

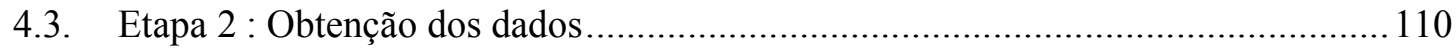

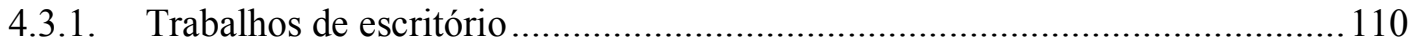

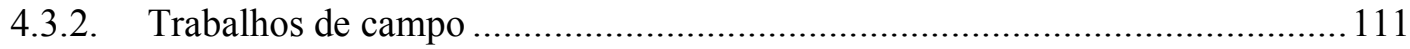

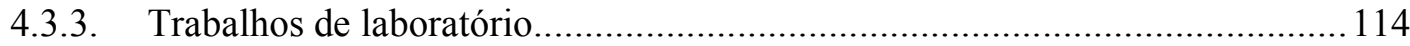

4.4. Etapas 3 e 4: Integração dos dados, análise dos resultados e finalização da

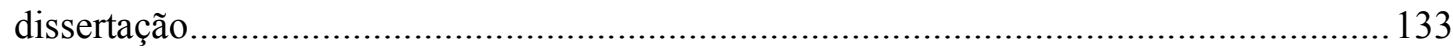

5. Resultados e Discussão...................................................................................... 135

5.1. Caracterização mineralógica................................................................... 135

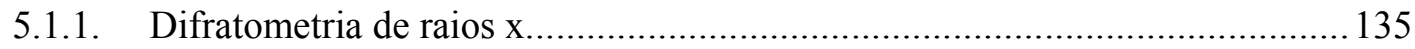

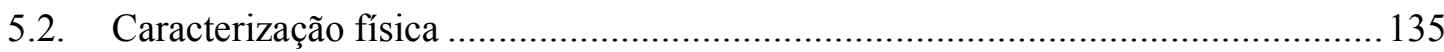


5.2.1. Análise granulométrica conjunta

5.2.2. Massa específica dos sólidos 136

5.3. Caracterização físico-química. 137

5.4. Análise de energia dispersiva (EDS). 137

5.5. Porosimetria por intrusão de mercúrio 138

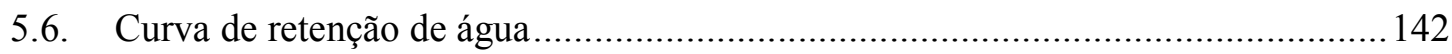

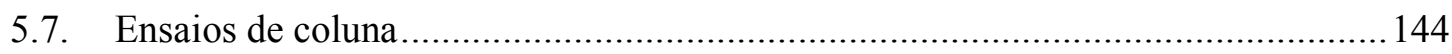

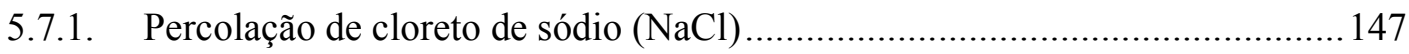

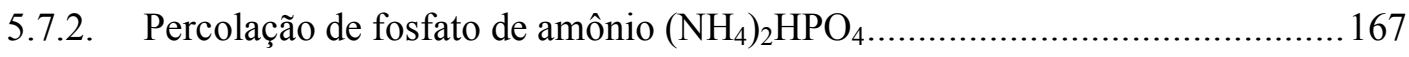

5.8. Coeficiente de dispersão hidrodinâmica: método de Ogata (1958) e Ogata e Banks (1961)201

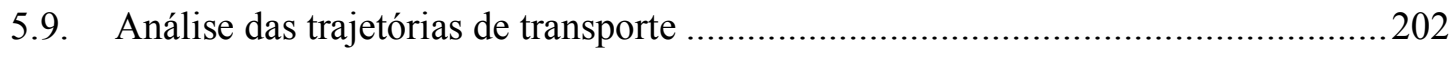

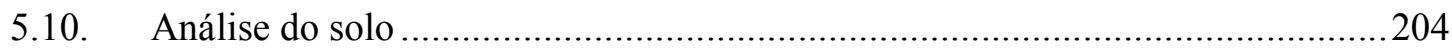

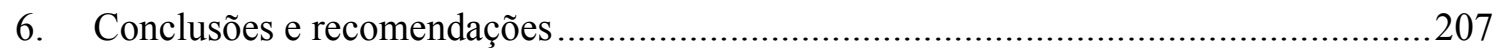




\section{INTRODUÇÃo}

O aumento populacional leva ao aumento da geração de resíduos, dos quais pode-se destacar os esgotos domésticos. Um dos produtos finais do tratamento de esgotos é o efluente que, devido à eficiência limitada de tais tratamentos, é rico em algumas espécies químicas como os nutrientes (nitrogênio e fósforo) e os sais (principalmente o cloreto de sódio). Esses resíduos líquidos normalmente são dispostos em corpos hídricos superficiais para que sejam diluídos. No entanto, o lançamento desses efluentes nos rios pode provocar desequilíbrio nutricional, levando à eutrofização e redução da fauna e flora aquática, além de provocar riscos à saúde da população por contágio de doenças devido à presença de microorganismos e substâncias químicas que podem estar presentes nesses resíduos.

Para lidar com esses problemas, desenvolveu-se a prática de irrigação de terras agrícolas com os efluentes provenientes de tratamento de esgotos, chamada de fertirrigação. A fertirrigação é utilizada mundialmente há muito tempo, mas ganha destaque em regiões onde existem solos pobres em matéria orgânica e em nutrientes, bem como em áreas onde há escassez de água para irrigação. Esta prática baseia-se no princípio de que o solo atua como um sistema filtrante, retendo os nutrientes presentes nos efluentes. Com isso há um aumento da fertilidade dos solos, aumentando também a produtividade agrícola. Além disso, há redução da contaminação de corpos hídricos superficiais, redução do consumo de água potável e redução do uso de fertilizantes, reduzindo os custos da agricultura.

Mesmo trazendo benefícios, o uso indiscriminado de efluentes na irrigação gera diversos problemas. As altas concentrações de nutrientes e, principalmente, de sais, podem alterar as propriedades dos solos, como condutividade hidráulica, taxa de infiltração, drenagem, resistência ao cisalhamento e retenção de água. Mudanças nessas propriedades podem resultar em alagamentos, aumento do escoamento superficial e, consequentemente da erosão. Quando ocorre a dispersão e a movimentação do fósforo e do nitrogênio no solo, seja por mecanismos físicos ou químicos, eles podem ser transportados para camadas inferiores do solo e assim contaminar os aquíferos, prejudicando o abastecimento da população. Na água, esses elementos podem ser absorvidos pelos organismos, causando sérios problemas de saúde. Desta maneira, o estudo dos mecanismos físicos e químicos de transporte dos principais elementos presentes em efluentes de esgotos é de fundamental importância para que a fertirrigação seja uma prática ambientalmente segura, além de subsidiarem o desenvolvimento de modelos matemáticos que auxiliam na gestão das áreas agrícolas. 
No ano de 2008 foi instalado um biodigestor anaeróbio de modelo canadense na área da Escola Técnica Estadual "Astor de Mattos Carvalho" na cidade de Cabrália Paulista no Estado de São Paulo, para tratamento do esgoto doméstico e da criação de animais. Desde que o biodigestor foi instalado, os efluentes gerados, ricos em nutrientes e em sódio, são utilizados para irrigar algumas áreas agrícolas da escola. A fertirrigação é realizada sem nenhum controle, o que pode causar problemas devido ao transporte do fósforo, nitrogênio e sódio. Além disso, geologicamente, Cabrália Paulista encontra-se sobre terrenos da Formação Adamantina, Grupo Bauru e hidrogeologicamente a região insere-se no Aquífero Adamantina, que está presente em grande extensão no Estado de São Paulo e, portanto, sua preservação possui grande importância estratégica. Diante deste contexto, esta pesquisa buscou avaliar a relação dos íons sódio, fosfato e amônio com os materiais da Formação Adamantina.

\subsection{OBJETIVOS}

\subsubsection{OBJETIVO GERAL}

Analisar os mecanismos de transporte de sódio, fosfato e amônio em colunas indeformadas de material inconsolidado residual de arenitos da Formação Adamantina, considerando os problemas de usos de fertilizantes e disposição de resíduos líquidos.

É importante ressaltar que os materiais escolhidos para serem estudados nesta pesquisa são aqueles que não foram irrigados com efluentes. Seria interessante a análise dos materiais que vêm sendo irrigados com os efluentes gerados no biodigestor da área de estudo, mas, como mencionado acima, a na área a fertirrigação é feita sem nenhum controle o que dificultaria a obtenção de resultados conclusivos. Ainda assim, por considerar interessante o entendimento da geração, tratamento e disposição de efluentes líquidos, na seção 2 é feita uma ampla revisão bibliográfica sobre o tema.

\subsubsection{OBJETIVOS ESPECÍFICOS}

- Caracterização mineralógica, física, físico-química e química do material;

- Obtenção dos parâmetros de fluxo de água do material inconsolidado residual arenoso indeformado;

- Obtenção do coeficiente de dispersão hidrodinâmica e do fator de retardamento do sódio, fosfato e amônio por quatro métodos e análise dos modelos conceituais desses métodos; 


\section{REVISÃo BibLIOGRÁFICA}

A revisão bibliográfica está didaticamente dividida em quatro partes. A primeira parte trata dos resíduos líquidos: como são gerados, tratados e dispostos. Dentre as opções de disposição final, é dado destaque à disposição no solo, mostrando os benefícios e problemas relacionados. A segunda parte foca no compartimento solo. Trata-se das propriedades do solo focando aquelas que podem influenciar o transporte de contaminantes. A terceira parte revisa a interação dos solutos com o meio poroso (solo). Nesta etapa são abordados os mecanismos físicos e químicos de transporte de solutos no solo, assim como as formas de obtenção dos parâmetros de fluxo de água e de transporte de solutos. Para finalizar esta seção, é mostrada a matemática do fenômeno de transporte de solutos em solos homogêneos, saturados e isotrópicos, tanto para solutos reativos quanto para solutos não reativos. Na quarta e última parte abordam-se os métodos laboratoriais mais utilizados para a obtenção dos parâmetros de fluxo de água e de transporte.

\subsection{RESÍDUOS SÓLIDOS E LÍQUIDOS}

Apesar de existirem diversas definições para o termo resíduo, a grande maioria dessas definições entende os resíduos como materiais, substâncias ou objetos, resultantes das atividades humanas, que são destinados à eliminação (ORGANISATION FOR ECONOMIC CO-OPERATION AND DEVELOPMENT, 1994; PONGRÁCZ e POHJOLA, 2004). Existem pesquisadores que procuram retirar da definição de resíduos a ideia de que são apenas destinados à eliminação e que não possuem valor econômico, pois se sabe que a gestão e gerenciamento de resíduos é um mercado muito promissor (PONGRÁCZ; POHJOLA, 2004).

Os resíduos são divididos entre sólidos e líquidos. Os resíduos sólidos são definidos pela Política Nacional de Resíduos Sólidos, Lei n 12.305/10, que é regulamentada pelo Decreto $n^{\circ} 7404$ de 23 de dezembro de 2010, como: material, substância, objeto ou bem descartado resultante de atividades humanas em sociedade, a cuja destinação final se procede, se propõe proceder ou se está obrigado a proceder, nos estados sólido ou semissólido, bem como gases contidos em recipientes e líquidos cujas particularidades tornem inviável o seu lançamento na rede pública de esgotos ou em corpos d'água, ou exijam para isso soluções técnicas ou economicamente inviáveis em face da melhor tecnologia disponível. Segundo a Política Nacional de Resíduos Sólidos, a fonte dos resíduos sólidos pode ser muito distinta 
como resíduos domiciliares, de limpeza urbana, industriais, de serviços de saúde, da construção civil, agrossilvopastoris, de serviços de transportes e de mineração (BRASIL, 2010).

Para os resíduos líquidos não existe uma política que regulamente, como ocorre com os resíduos sólidos. No entanto, no Estado do São Paulo, por meio da Companhia Ambiental do Estado de São Paulo (CETESB), existem normas e regulamentos que regem o gerenciamento, manuseio e disposição para diferentes tipos de resíduos líquidos. Dentre os principais resíduos líquidos encontram-se aqueles provenientes dos processos industriais, provenientes de aterros sanitários (chorume), gerados em laboratórios químicos, devidos ao tratamento de águas e de esgotos domésticos e industriais (COMPANHIA AMBIENTAL DO ESTADO DE SÃO PAULO, 1990; FEIDEN; CEREDA, 2001; TAVARES; BENDASSOLI, 2005).

\subsection{RESÍDUOS LÍQUIDOS: EFLUENTES DE TRATAMENTO DE ESGOTOS}

Alguns dos principais resíduos líquidos são provenientes de processos de tratamento de esgotos. Nesta seção serão detalhadas as características dos esgotos, a composição, os níveis, operações, processos e sistemas de tratamento, com ênfase aos processos biológicos anaeróbios.

\subsubsection{CARACTERIZAÇÃO DOS ESGOTOS}

Os esgotos são gerados a partir da utilização das águas destinadas para abastecimento, e suas características dependem dos usos da água e, desta forma, podem variar com o clima, situação social e econômica da população. As principais características são: físicas (cor, turbidez, temperatura, odor); químicas (sólidos totais, matéria orgânica, nitrogênio total, fósforo, $\mathrm{pH}$, alcalinidade, cloretos, óleos e graxas); e biológicas (presença de microorganismos) (RODRIGUES, 2003; VON SPERLING, 2005). Os principais parâmetros relativos aos esgotos são: sólidos; matéria orgânica; fósforo; nitrogênio; e microorganismos, alguns deles, indicadores de contaminação fecal (VON SPERLING, 2005).

Os sólidos podem ser classificados de acordo com seu tamanho (sólidos em suspensão e sólidos dissolvidos, que são as substâncias orgânicas e inorgânicas contidas num líquido sob formas moleculares, ionizadas ou micro-granulares), características químicas (sólidos voláteis 
e sólidos fixos) e decantabilidade (sólidos em suspensão sedimentáveis e sólidos em suspensão não sedimentáveis).

A matéria orgânica, baseada no carbono orgânico presente nos esgotos, é classificada quanto à forma e tamanho (particulada e solúvel) e quanto à biodegradabilidade (inerte e biodegradável). Geralmente não se tem necessidade de caracterizar a matéria orgânica em termos de proteínas, gorduras, carboidratos, etc. No entanto, face aos múltiplos compostos e formas em que esta pode se apresentar, existem diversos métodos para sua determinação. Dentre eles destacam-se os métodos de medição do consumo de oxigênio: Demanda Bioquímica de Oxigênio (DBO), Demanda Última de Oxigênio $\left(\mathrm{DBO}_{\mathrm{u}}\right)$ e Demanda Química de Oxigênio (DQO).

O nitrogênio pode estar na forma de nitrogênio molecular, nitrogênio orgânico, amônia livre, íon amônio, íon nitrito, íon nitrato, dependendo das condições nas quais se encontra o esgoto (esgoto bruto, efluente, etc.). O fósforo apresenta-se na forma de fosfatos na forma inorgânica (polifosfatos e ortofosfatos) e orgânica (ligada a compostos orgânicos). Pode também ser dividido quanto a sua forma como fósforo solúvel e fósforo particulado (INTERNATIONAL ASSOCIATION ON WATER QUALITY, 1995; VON SPERLING, 2005).

Os microorganismos são fundamentais na transformação da matéria orgânica dentro dos ciclos biogeoquímicos, no entanto estes organismos merecem destaque no que diz respeito à possibilidade de transmissão de doenças. Os principais microorganismos de interesse do ponto de vista de saúde pública são: bactérias, vírus, protozoários e helmintos. Os principais organismos indicadores de contaminação fecal são coliformes totais, coliformes fecais e Escherichia coli (VON SPERLING, 2005).

\subsubsection{TRATAMENTO DE ESGOTOS: NÍVEIS, OPERAÇÕES, PROCESSOS E SISTEMAS}

Os esgotos domésticos compõem-se $99,9 \%$ de água, sendo a fração restante $(0,01 \%)$ composta por sólidos orgânicos e inorgânicos, suspensos e dissolvidos, e microorganismos. Devido esta parcela de $0,01 \%$ é necessário que os esgotos sejam tratados (VON SPERLING, 2005). Os objetivos do tratamento de esgotos é a remoção de alguns componentes como sólidos, matéria orgânica, nitrogênio, fósforo e microorganismos e também de proteger, de maneira econômica e socialmente aceitável, o meio ambiente e a saúde pública. A remoção dos poluentes no tratamento deve ser tal que se adeque a qualidade do efluente aos padrões de 
lançamento e de qualidade do corpo receptor, determinados em função de seus usos previstos (BRASIL, 2005). A escolha do processo a ser utilizado para tratar o esgoto também deve ser fundamentada em um balanço entre critérios técnicos e econômicos analisando-se de maneira quantitativa e qualitativa cada alternativa disponível (VON SPERLING, 2005).

Os métodos de tratamento dividem-se em operações e processos unitários. Operações físicas unitárias são métodos de tratamento no qual predomina a aplicação de mecanismos físicos como, por exemplo, floculação, sedimentação e filtração. Processos químicos unitários são métodos de tratamento nos quais a remoção ou conversão de contaminantes dá-se pela introdução de produtos químicos ou devido a reações químicas como precipitação e desinfecção. Os processos biológicos unitários são métodos de tratamento nos quais a remoção de contaminantes ocorre por meio de atividade biológica, como a remoção da matéria orgânica, nitrificação e desnitrificação. A integração das operações e processos unitários compõe os sistemas de tratamento (METCALF; EDDY, 1991; VON SPERLING, 2005).

Segundo von Sperling $(2005 ; 1996)$, a remoção de poluentes no tratamento de esgotos de maneira adequada, considerando a legislação vigente, está associada ao nível de tratamento. O tratamento de esgotos é classificado em quatro níveis: preliminar; primário; secundário; e terciário (utilizado raramente no Brasil). $\mathrm{O}$ tratamento preliminar visa à remoção de grandes sólidos e areia para proteger as demais unidades de tratamento, os dispositivos de transporte (bombas e tubulações) e os corpos receptores. É feita com o uso de grades que impedem a passagem de pequenos pedaços de panos, papéis, pedaços de madeira, etc.; caixas de areia, para retenção deste material; e tanques de flutuação para retirada de óleos e graxas em casos de esgoto industrial com alto teor destas substâncias. Neste nível usam-se, fundamentalmente, operações físicas como a grade e o desarenador (caixa de areia) (KIZILOGLU et al., 2007; SAAE, 2006; VON SPERLING, 2005).

No nível do tratamento primário o objetivo é a remoção de sólidos sedimentáveis e de parte da matéria orgânica. Os esgotos fluem vagarosamente, permitindo que os sólidos em suspensão de maior densidade sedimentem gradualmente no fundo, formando o lodo primário bruto. Os materiais flutuantes como graxas e óleos, de menor densidade, são removidos na superfície. A eliminação média do DBO é de 30\%. Tanto no nível preliminar quanto no nível primário, predominam os mecanismos físicos de remoção de poluentes. Pode-se ter a associação de operações físicas e processos químicos unitários quando ocorre adição de cal e 
de agentes coagulantes como, por exemplo, sulfato de alumínio e cloreto férrico. Os principais sistemas de tratamento de esgotos a nível primário são o decantador circular e o decantador retangular de fluxo horizontal. Os tanques sépticos são também uma forma de tratamento primário. No entanto, percebe-se uma tendência para a substituição desses decantadores por reatores anaeróbicos (UASB) (KIZILOGLU et al., 2007; SAAE, 2006; VON SPERLING, 2005).

No nível secundário o foco é a remoção de matéria orgânica dissolvida, matéria orgânica em suspensão e eventuais nutrientes (fósforo e nitrogênio). Dependendo do processo de tratamento adotado, a remoção de organismos patogênicos também pode ser considerada como integrante do tratamento secundário. Após as fases primária e secundária a eliminação de DBO deve alcançar 90\%. Sua eficiência permite produzir um efluente em conformidade com o padrão de lançamento previsto na legislação ambiental. Basicamente, são reproduzidos os fenômenos naturais de estabilização da matéria orgânica que ocorrem no corpo receptor, sendo que a diferença está na maior velocidade do processo, na necessidade de utilização de uma área menor e na evolução do tratamento em condições controladas. Neste nível predominam os processos biológicos que, segundo Chernicharo et al. (1999), classificam-se em anaeróbios (lagoa anaeróbia, decanto-digestor ou fossa séptica, filtro anaeróbio, UASB e leito expandido) e aeróbios (filtração biológica, lagoas de estabilização a aeróbias, lagoas aeradas e valos de oxidação).

O nível terciário visa à remoção de poluentes específicos, como os compostos não biodegradáveis, ou ainda, à remoção complementar de poluentes não suficientemente removidos no tratamento secundário. No Brasil raramente os sistemas de tratamento de esgotos chegam a este nível (VON SPERLING, 2005).

O tratamento de esgoto geralmente é feito por uma combinação de processos físicos, químicos e biológicos, que reduzem a carga orgânica bem como as concentrações de outras substâncias e quantidade de microorganismos. Se um esgoto receber, antes de ser lançado em corpos hídricos, pelo menos o tratamento a nível secundário, será então considerado como tratado (FAUSTINO, 2007).

\subsubsection{Processos Biológicos ANAERóbios}

Os processos biológicos anaeróbios são sistemas em que ocorre a estabilização da matéria orgânica biodegradável na ausência de oxigênio molecular por meio de 
microorganismos. A estabilização da matéria orgânica por meio de processos anaeróbios tem como principais produtos o metano $\left(\mathrm{CH}_{4}\right)$ e o gás carbônico $\left(\mathrm{CO}_{2}\right)$, com pouca geração de lodo, pois apenas uma pequena parcela é convertida em biomassa. Água, gás sulfídrico, amônia e novas células bacterianas também são produtos da digestão anaeróbia. $\mathrm{O}$ material não estabilizado sai do sistema junto com o efluente numa faixa de 10 a 30\% de matéria orgânica (CHERNICHARO, 1997).

Atualmente os processos de digestão anaeróbia da matéria orgânica ganham destaque principalmente devido ao potencial energético gerado (biogás), pelo baixo custo operacional, baixa demanda de área, tolerância a elevadas cargas orgânicas e pouca geração de lodo (CHERNICHARO, 1997; FAUSTINO, 2007; SOUZA, 2003). Porém, as bactérias anaeróbias são susceptíveis à inibição por um grande número de compostos. Além disso, existe a possibilidade de geração de efluente com aspecto desagradável e a remoção de nitrogênio, fosforo e patógenos pode ser insatisfatória em algumas situações, sendo necessária alguma forma de pós-tratamento (CHERNICHARO, 1997).

De maneira geral, pode-se dividir o processo de digestão anaeróbia em quatro estágios principais: hidrólise, acidogênese, acetogênese e metanogênese. $O$ primeiro estágio consiste na hidrólise de materiais particulados complexos (polímeros) em moléculas menores, por meio de exoenzimas excretadas pelas bactérias fermentativas hidrolíticas, e assim podem atravessar as paredes celulares das bactérias fermentativas. A acidogênese consiste na formação de compostos mais simples a partir dos produtos solúveis da hidrólise. Os principais compostos formados na acidogênese são ácidos graxos voláteis. As bactérias fermentativas que dão origem a estes produtos são chamadas de acidogênicas. Na fase acetogênese, as bactérias acetogênicas realizam a oxidação dos produtos gerados na fase de acidogênese. Os produtos gerados por essas bactérias são acetado, hidrogênio e dióxido de carbono que serão utilizados pelas bactérias metanogênicas no próximo estágio do processo anaeróbio (CHERNICHARO, 1997; FAUSTINO, 2007; SOUZA, 2003).

Até o estágio de acetogênese não ocorre estabilização da matéria orgânica o que ocorre apenas na metanogênese. A metanogênese é a etapa final do processo global de degradação anaeróbia de compostos orgânicos em metano e dióxido de carbono. Esta degradação é realizada pelas bactérias metanogênicas que, em função de sua afinidade por substrato e magnitude de produção de metano, são divididas em dois grupos principais: metanogênicas acetoclásticas (que formam metano a partir do ácido acético ou metanol) e metanogênicas 
hidrogenotróficas (que produzem metano a partir de hidrogênio e dióxido de carbono) (CHERNICHARO, 1997; SOUZA, 2003). A Figura 2.1 ilustra as sequências metabólicas e grupos microbianos envolvidos na digestão anaeróbia.

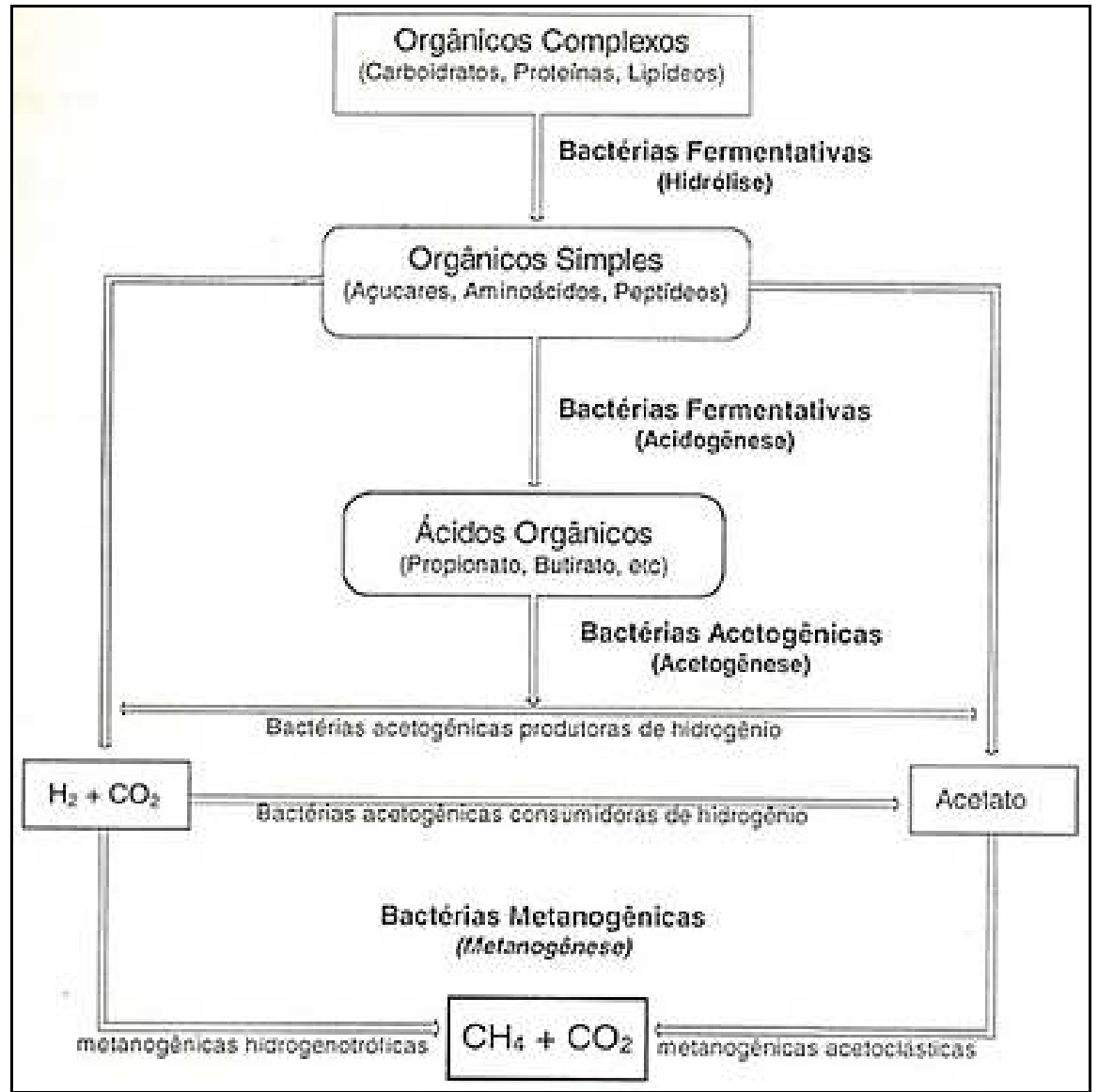

Figura 2.1- Sequências metabólicas e grupos microbianos envolvidos na digestão anaeróbia (CHERNICHARO, 1997)

Os sistemas anaeróbios podem ser divididos em dois grupos: sistemas de alta taxa e sistemas convencionais. Mesmo com a aplicação de elevadas cargas hidráulicas, os sistemas de alta taxa possuem capacidade de reter grandes quantidades de biomassa de elevada atividade ainda que haja a aplicação de baixos tempos de retenção hidráulica, mantendo, desta forma, um elevado tempo de retenção de sólidos. Incluem-se neste grupo sistemas de alta taxa com crescimento aderido (reatores de dois estágios, reatores de leito rotatório e reatores de leito expandido) e sistemas de alta taxa com crescimento disperso (reatores de dois estágios, reatores de chicanas, reatores de manta de lodo, reatores de leito granular expandido e reatores com recirculação interna) (CHERNICHARO, 1997; SOUZA, 2003).

Os sistemas convencionais são aqueles nos quais os reatores são operados com baixas cargas orgânicas volumétricas por não possuírem mecanismos de retenção de grandes 
quantidades de biomassa de elevada atividade. Além disso, não possuem mecanismos de retenção de sólidos no sistema. Neste grupo encontram-se os digestores de lodo, as lagoas anaeróbias e os biodigestores anaeróbios (CHERNICHARO, 1997).

\subsubsection{Biodigestor anaeróbio}

Biodigestor anaeróbio é uma câmara fechada em que a biomassa, juntamente com o afluente produzido (esterco e esgoto sanitário), é digerida por fermentação de resíduos orgânicos (proteínas, carboidratos e lipídeos), utilizando-se, em ambiente anaeróbio, de esterco bovino/ovino como meio inoculante de bactérias (BOLZONELLA et al., 2005; FAUSTINO, 2007; NOVAES; et al., 2002; MARTELLI, 2011). Como resultado desta fermentação tem-se o biogás e o efluente que pode ser aplicado no solo para fins de fertirrigação (MARTELLI, 2011).

Segundo Martelli (2011), pesquisas e desenvolvimentos acerca de biodigestores ocorreram com maior intensidade na Índia. Em 1939 foi desenvolvida pelo Instituto Indiano de Pesquisa Agrícola, em Kanpur, a primeira usina de biogás proveniente de esterco. Com isso houve grande difusão da metodologia de biodigestores atuando no tratamento de dejetos de animais, obtenção de biogás e uso de efluente na fertirrigação (NOGUEIRA, 1986). De acordo com Cunha (2007), a partir de 1958 a China começou a adotar o biodigestor para obtenção de biogás. Em 1973 devido à crise energética, a construção e utilização de biodigestores passaram a ser uma opção difundida entre países ricos e em desenvolvimento, sendo, no entanto, a China e a Índia os países que mais utilizaram essa tecnologia. Por este motivo, os modelos mais difundidos de biodigestores são os chineses e os indianos (Figura 2.2 e 2.3). Posteriormente o modelo canadense se difundiu (Figura 2.4).

O modelo chinês é mais rústico e é construído apenas de alvenaria e se mantém enterrado no solo. O modelo indiano também possui estrutura subterrânea, mas apresenta sua cúpula feita de ferro ou fibra. Já o modelo canadense é construído de forma horizontal, com sua largura em dimensões maiores que a profundidade, aumentando a área de incidência de raios solares e acelerando o processo de degradação dos resíduos orgânicos bem como a formação de biogás (CUNHA, 2007). 


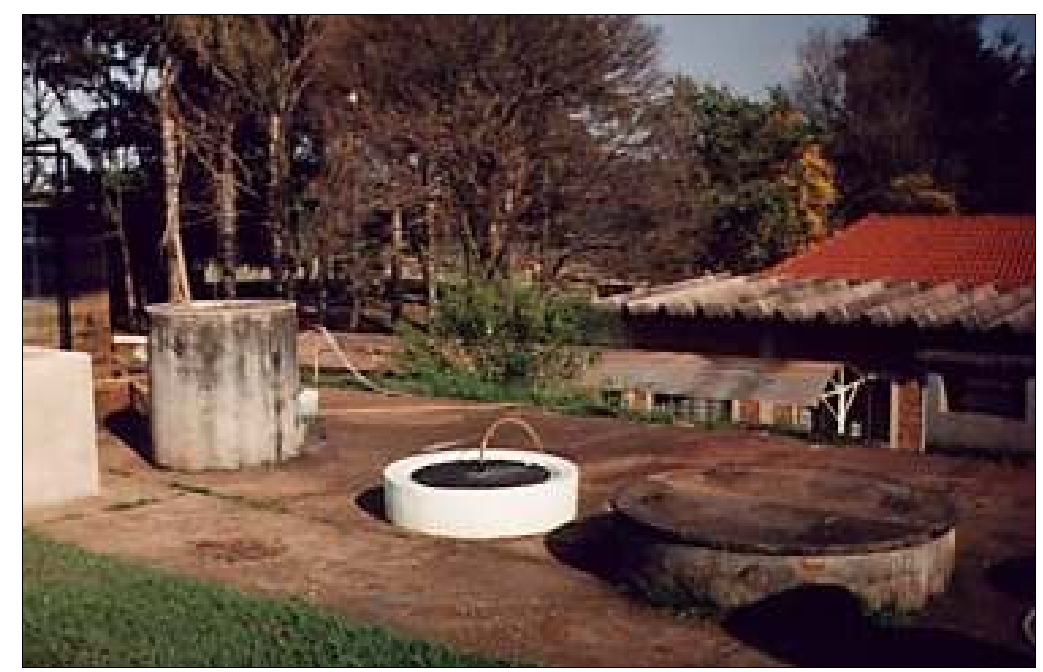

Figura 2.2- Biodigestor de modelo chinês (MARTELLI, 2011)

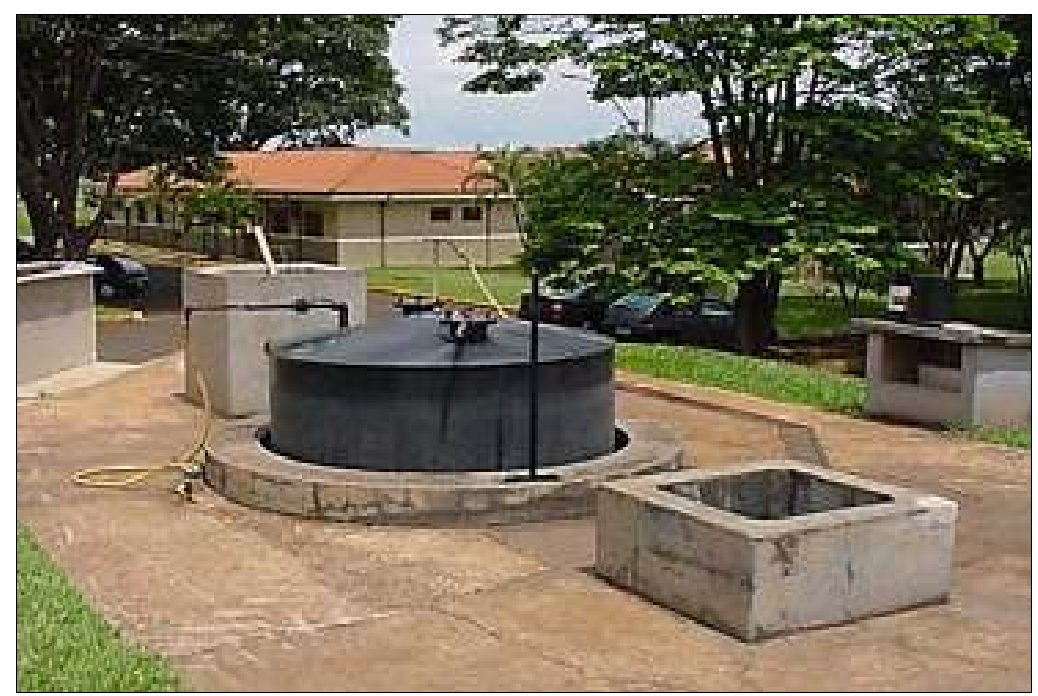

Figura 2.3- Biodigestor de modelo indiano (MARTELLI, 2011)

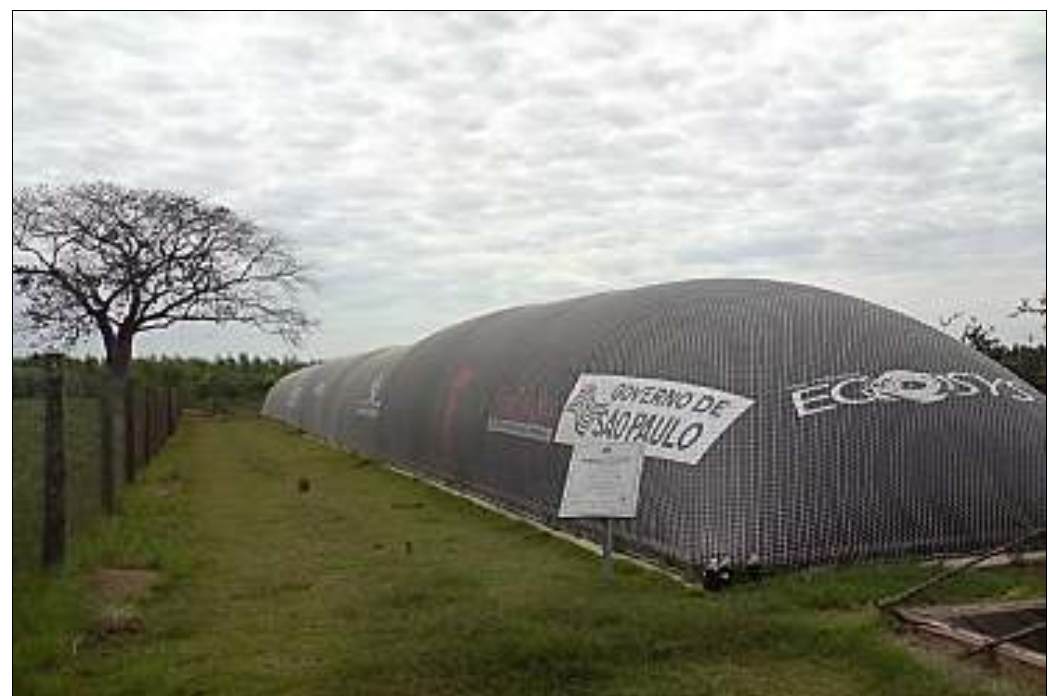

Figura 2.4- Biodigestor de modelo canadense (MARTELLI, 2011) 
De maneira geral, os biodigestores são compostos por duas partes: um tanque para abrigar e conduzir a digestão da biomassa e um gasômetro (campânula), para armazenar o biogás. O biodigestor pode funcionar com abastecimento diário de biomassa ou receber carga de biomassa correspondente à sua carga máxima, retendo-a por tempo indeterminado até que a digestão esteja completa (MARTELLI, 2011).

\subsection{COMPOSIÇÃO DOS EFLUENTES DE ESGOTOS TRATADOS}

Os efluentes gerados em tratamento de esgotos podem ser utilizados, ou reusados, para irrigação, dependendo de sua composição. Segundo Bowe e Chaney (1974) e Feigin, Ravina e Shalhevet (1991) a diferença entre usar água e usar efluente para irrigação está em alguns aspectos básicos relacionados à composição. Nos efluentes é encontrada uma variedade de

compostos orgânicos, normalmente não identificados individualmente. Além disso, os efluentes contêm macronutrientes, como o nitrogênio e o fósforo. O nitrogênio ocorre principalmente na forma de nitrato e amônia e o fósforo na forma de fosfato.

Também podem ser encontrados nos efluentes elementos essenciais às plantas. Esses elementos são determinados pela composição do esgoto bruto, da origem do efluente e do método de tratamento. Metais potencialmente tóxicos e microorganismos patogênicos podem fazer parte da composição dos efluentes, apesar de poderem ter suas concentrações bastante reduzidas durante o processo de tratamento (BOWER; CHANEY, 1974; FEIGIN; RAVINA; SHALHEVET, 1991).

Segundo Feigin, Ravina e Shalhevet (1991), as concentrações de $\mathrm{Ca}^{2+}$ e $\mathrm{Mg}^{2+}$ nos efluentes de esgoto tratado normalmente são semelhantes àquelas encontradas na água de irrigação, sendo que o aumento das concentrações de $\mathrm{Ca}^{2+}$ e $\mathrm{Mg}^{2+}$ reduzem os valores da relação entre as concentrações de sódio e de íons polivalentes na solução do solo.

Silva et al. (2012) avaliaram físico, química e microbiologicamente o efluente gerado em biodigestor anaeróbio. Concluíram que os valores de concentração dos elementos variaram significativamente, podendo, em alguns casos, o valor máximo para alguns elementos ser superior ao dobro do valor mínimo. Isso é um grande problema em se tratando de uso do efluente como fertilizante, pois torna difícil a dosagem precisa do elemento nutriente. A composição química de efluente de biodigestores anaeróbios obtidas na literatura foi resumida na Tabela 2.1 . 
Tabela 2.1-Composições químicas de efluentes de biodigestores anaeróbios

\begin{tabular}{|c|c|c|c|c|c|c|c|c|c|c|c|c|}
\hline \multirow{2}{*}{ Autor } & \multicolumn{12}{|c|}{ Composição de Efluentes de Biodigestor Anaeróbio mg $\mathrm{L}^{-1}$} \\
\hline & $\mathbf{N}$ & $\mathbf{P}$ & $\mathbf{K}$ & $\mathbf{C a}$ & Mg & $\mathbf{S}$ & $\mathbf{F e}$ & Mn & B & $\mathbf{Z n}$ & $\mathbf{C u}$ & $\mathbf{N a}$ \\
\hline $\begin{array}{l}\text { VILELA JUNIO, ARAÚJO e } \\
\text { FACTOR (2003) }\end{array}$ & 120 & 340 & 88 & 6,55 & 4,15 & 450 & 26,4 & 4,13 & 5,2 & 1,68 & $<$ L.D & N.A \\
\hline QUADROS et al. (2010) & 557 & 28 & 2103 & N.A & N.A & N.A & N.A & N.A & N.A & N.A & N.A & N.A \\
\hline $\begin{array}{l}\text { MARTELLI (2008); SILVA et al } \\
\qquad(\mathbf{2 0 1 2 )}\end{array}$ & 298 & 50,6 & 117 & 76,1 & 29,6 & 3,78 & 1,01 & 0,32 & N.A & 0,22 & 0,08 & 117 \\
\hline
\end{tabular}

N.A: elemento não analisado; <L.D: concentração abaixo do limite de detecção

Percebe-se que, no geral, os valores na composição dos efluentes diferem muito nas diferentes pesquisas. Essas diferenças são aceitáveis uma vez que a composição do efluente depende diretamente da composição do esgoto que, como dito anteriormente, depende de diversos outros fatores. Além disso, a geração do efluente é fortemente influenciada pela presença de esterco recém-coletado, usado no processo de biodigestão, que afetada diretamente o processo de biodigestão (FAUSTINO, 2007; FEIGIN; RAVINA; HALHEVET, 1991). Outro ponto a ser observado é a situação do efluente no momento da coleta, isto é, quantos dias ele está exposto ao sol, se foi coletado na parte superior do reservatório, se foi coletado na saída do biodigestor e etc. Estas diferentes condições podem afetar a mensuração dos compostos presentes nos efluentes e resultar em valores extremamente diferentes até mesmo para o mesmo efluente.

\subsection{PRINCIPAIS ELEMENTOS QUÍMICOS NA COMPOSIÇÃO DOS EFLUENTES LÍQUIDOS}

\subsubsection{NitrogêNIO}

O Nitrogênio, N, apesar de ser muito importante para o crescimento de plantas é geralmente deficiente em sistemas agrícolas que não cultivam leguminosas. Existem muitas fontes orgânicas e inorgânicas que fornecem $\mathrm{N}$ para o cultivo. No entanto, a maior parte do $\mathrm{N}$ fornecido para plantas é o $\mathrm{N}$ atmosférico na forma de $\mathrm{N}_{2}$ que não pode ser metabolizado diretamente pelas plantas. Por este motivo é necessário converter $\mathrm{o} \mathrm{N}_{2}$, amplamente disponível na atmosfera, como mostra a Tabela 2.2, em $\mathrm{N}$ disponível por meio de diversas reações químicas proporcionadas por microorganismos, descargas elétricas atmosféricas, 
formação de óxidos de $\mathrm{N}$ e desenvolvimento de fertilizantes sintéticos (HAVLIN, ET AL., 2005).

Tabela 2.2- Distribuição aproximada de N pelos sistemas Solo-Planta/Animal-Atmosférico (HAVLIN, ET AL., 2005)

\begin{tabular}{ccc}
\hline Fonte de N & Toneladas Métricas & \% do Total \\
\hline Atmosférico & $3,9 \mathrm{E}+15$ & 99,3840 \\
Oceano & $2,4 \mathrm{E}+13$ & 0,6116 \\
Solo & $1,5 \mathrm{E}+11$ & 0,0038 \\
Plantas & $1,5 \mathrm{E}+10$ & 0,00038 \\
Micróbios no Solo & $6,0 \mathrm{E}+09$ & 0,00015 \\
Animais & $2,0 \mathrm{E}+08$ & 0,0000005 \\
Pessoas & $1,0 \mathrm{E}+07$ & 0,00000025 \\
\hline
\end{tabular}

Naturalmente, as transformações do $\mathrm{N}$ são demonstradas pelo ciclo do $\mathrm{N}$, que envolve muitas transformações entre formas orgânicas e inorgânicas. A Figura 2.5 esquematiza o ciclo do N. O N total varia de $0,02 \%$ em subsolo a 2,5\% em solos orgânicos. Os componentes inorgânicos incluem amônio $\left(\mathrm{NH}_{4}^{+}\right)$, nitrito $\left(\mathrm{NO}_{2}{ }^{-}\right)$, nitrato $\left(\mathrm{NO}_{3}{ }^{-}\right)$, óxido nitroso $\left(\mathrm{N}_{2} \mathrm{O}\right)$, óxido nítrico (NO) e $\mathrm{N}$ elementar $\left(\mathrm{N}_{2}\right)$. Para as plantas, o amônio, o nitrito e o nitrato são as formas mais importantes. Essas formas são produzidas pela decomposição aeróbica da matéria orgânica do solo ou a partir da adição de fertilizantes. $\quad \mathrm{O} \mathrm{NH}_{4}{ }^{+}$pode ser fornecido a partir da mineralização do $\mathrm{N}$, ou pela adição de fertilizantes contendo $\mathrm{N}$, ou adubos contendo ou formando $\mathrm{NH}_{4}{ }^{+}$. Os compostos orgânicos ocorrem como proteínas, aminoácidos, açúcares e outros complexos que contenham N. A oxidação biológica de aminoácidos livres é uma importante fonte de $\mathrm{NH}_{4}^{+}$(HAVLIN, ET AL., 2005).

A quantidade de $\mathrm{N}$ disponível para ser absorvido pelas plantas depende dos diversos fatores que afetam a mineralização, imobilização, amonificação, nitrificação, desnitrificação e perdas de $\mathrm{NH}_{4}{ }^{+}$e $\mathrm{NO}_{3}{ }^{-}$pelo solo. A mineralização é a conversão de $\mathrm{N}$ orgânico $\mathrm{em} \mathrm{NH}_{4}{ }^{+}$. A imobilização é a conversão de $\mathrm{N}$ inorgânico para $\mathrm{N}$ orgânico e é, basicamente, o reverso da mineralização de $\mathrm{N}$. A nitrificação é a conversão do $\mathrm{NH}_{4}{ }^{+}$para $\mathrm{NO}_{3}{ }^{-}$através de oxidação microbiológica. A amonificação é a formação do $\mathrm{NH}_{4}{ }^{+}$a partir da amônia $\left(\mathrm{NH}_{3}\right)$. No solo, os fatores que afetam esses processos são: a proporção de $\mathrm{C}: \mathrm{N}$, quantidade de matéria orgânica, tipo e quantidade de argilomineral, temperatura, $\mathrm{pH}$, umidade e aeração do solo e da 
população de organismos nitrificantes. Isso por que esses fatores influenciam fortemente na quantidade da forma química do N presente no solo (HAVLIN, ET AL., 2005).

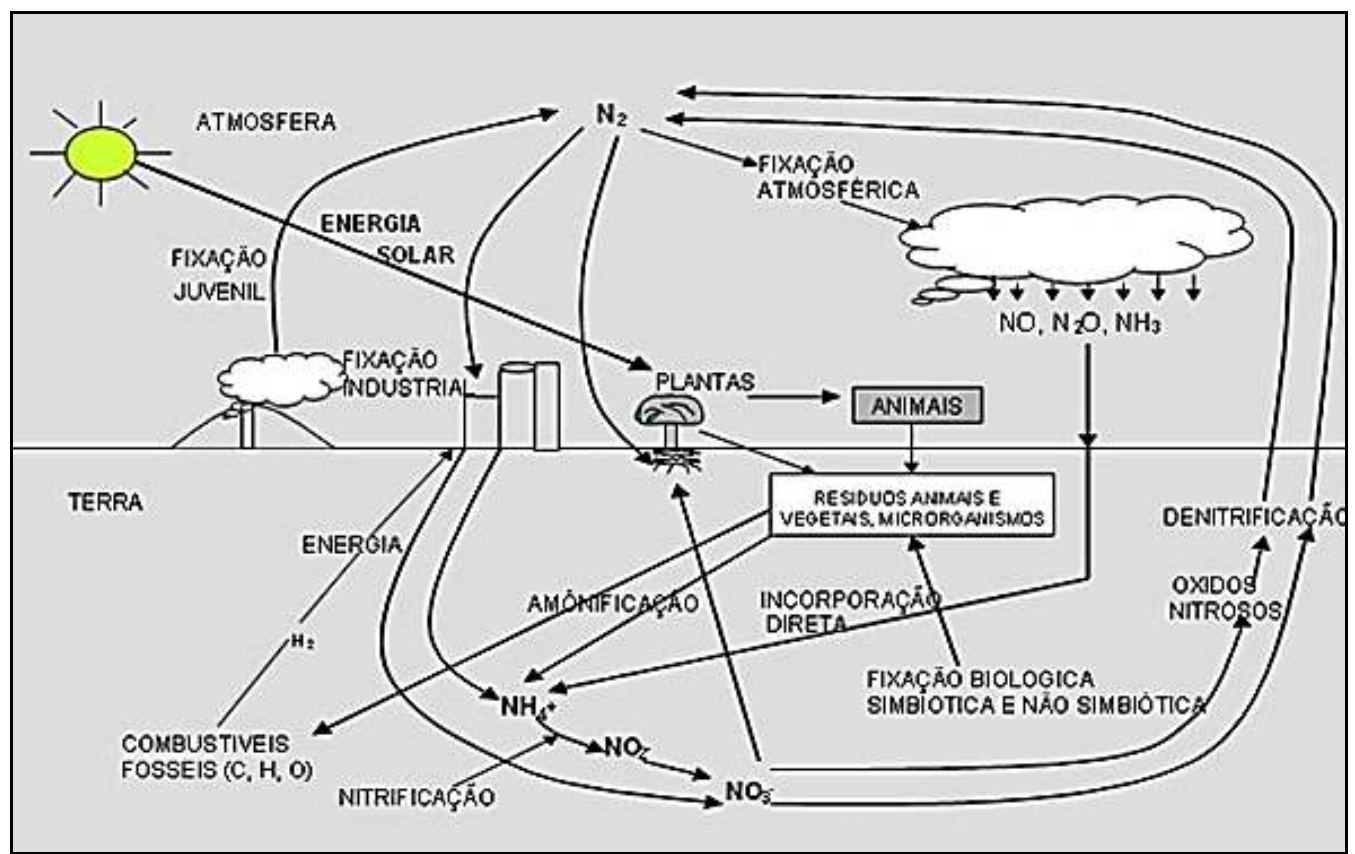

Figura 2.5- Ciclo do N (GOMES, et al., 2000)

Com a adição de carbono e $\mathrm{N}(\mathrm{C}: \mathrm{N})$, a planta pode absorver mais ou menos $\mathrm{N}$, indicando que está ocorrendo mineralização ou imobilização, respectivamente. Ou seja, uma variação na taxa de $\mathrm{C}: \mathrm{N}$ pode favorecer ou desfavorecer a mineralização ou a mineralização. A aeração do solo pode aumentar substancialmente a taxa de mineralização do N. Por outro lado, a redução da quantidade de matéria orgânica do solo reduz drasticamente a quantidade de $\mathrm{N}$ mineralizado. A umidade do solo é um fator de suma importância, pois a presença das bactérias é muito sensível à quantidade de água. A máxima nitrificação, por exemplo, deve ocorrer quando a umidade do solo está por volta de 70 a $80 \%$. Já quando a capacidade de campo do solo é excedida, ocorre a desnitrificação devido ao impedimento da difusão de $\mathrm{CO}_{2}$ pelo solo (HAVLIN, ET AL., 2005).

O tipo e quantidade de argilomineral são importantes, pois o amônio pode ser fixado no solo por argilas do tipo 2:1 (ver Seção 2.9.1), a partir de trocas catiônicas nas camadas desses argilominerais, principalmente com cátions $\mathrm{Ca}^{+2}, \mathrm{Na}^{+}, \mathrm{Mg}^{+2} \mathrm{e} \mathrm{H}^{+}$. A fixação de amônio é muito importante em termos ambientais, pois proporciona um grau de proteção contra a rápida nitrificação e subsequente lixiviação de $\mathrm{NO}^{2-}$. A temperatura do solo influencia a presença ou ausência de bactérias, assim como a velocidade das reações. O pH da solução do solo é outro fator de extrema importância. A nitrificação máxima ocorre com pH de 8,0 a 8,5, 
a desnitrificação é nula a pH abaixo de 5,0, mas aumenta com o aumento do $\mathrm{pH}$. $\mathrm{O} \mathrm{NH}_{4}^{+}$ começa a ser convertido em $\mathrm{NH}_{3}$ em $\mathrm{pH}$ acima de 8, como pode ser observado na Figura 2.6.

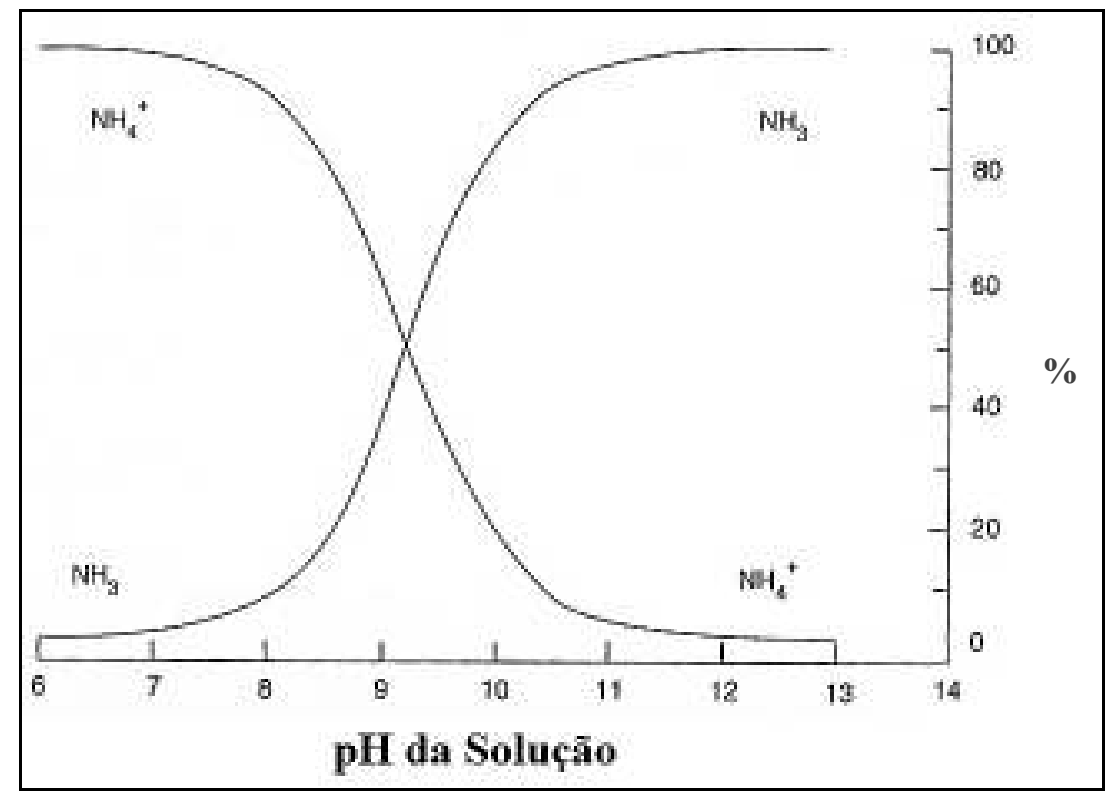

Figura 2.6- Influencia do $\mathrm{pH}$ na forma química do Nitrogênio na solução (Modificado de HARVIN et al., 2005)

\subsubsection{FóSFORO}

O fósforo, P, é essencial para todas as formas de vida na Terra e é principalmente armazenado em solos e sedimentos. O entendimento dos processos químicos, físicos e biológicos que afetam a disponibilidade do $\mathrm{P}$ para plantas, animais e humanos, é de fundamental importância para o desenvolvimento de práticas agrícolas sustentáveis. Analogamente, o conhecimento dos processos que controlam o transporte de fosforo dos solos para águas, e a disponibilidade de $\mathrm{P}$ para a biota aquática é de considerável significância devido ao conhecido papel do fosforo na eutrofização (SIMS; PIERZYNSKI, 2005). No entanto, o P é menos abundante nos solos do que o N. O fosforo total em solos superficiais varia de 0,005 a $0,15 \%$. Infelizmente, a quantidade de fosforo total nos solos tem pouca ou nenhuma relação com a disponibilidade de fosforo para as plantas, podendo esta ser ainda muito inferior à quantidade de solo total (HAVLIN et. al., 2005).

O P presente nos solos são de origens orgânicas e inorgânicas. Fontes orgânicas são, principalmente, efluentes de esgotos domésticos e de criação de animais e bactérias presentes no solo. As fontes inorgânicas são os fertilizantes, cujas principais fontes são as rochas 
fosfatadas, ácido fosfórico, fosfatos de cálcio, fosfatos de amônio, polifosfatos de amônio e o fosfato de potássio (HAVLIN et al., 2005).

Atingir boas práticas agrícolas com um maior aproveitamento do $\mathrm{P}$ disponível, bem como com a proteção do meio ambiente só é possível com o entendimento de como o fosforo se comporta em seu ciclo, conhecendo, ainda, os processos químicos e bioquímicos que controlam as formas, disponibilidade e mobilidade do P nos solos (SIMS; PIERZYNSKI, 2005). Os principais componentes do ciclo do fosforo são: dissolução-precipitação; sorçãodessorção; e, mineralização-imobilização. Todos esses processos afetam a concentração de fosforo na solução do solo e assim a quantidade de $\mathrm{P}$ que pode ser absorvido pelas plantas e também do P que pode ser transportado para aguas subterrâneas. A Figura 2.7 esquematiza o ciclo do $\mathrm{P}$ no solo. O P orgânico é mineralizado para $\mathrm{P}$ inorgânico, que não é absorvido pelas raízes nem imobilizado por microorganismos. Assim o P inorgânico pode ser adsorvido por alguns minerais ou precipitado como mineral secundário (Figura 2.7).

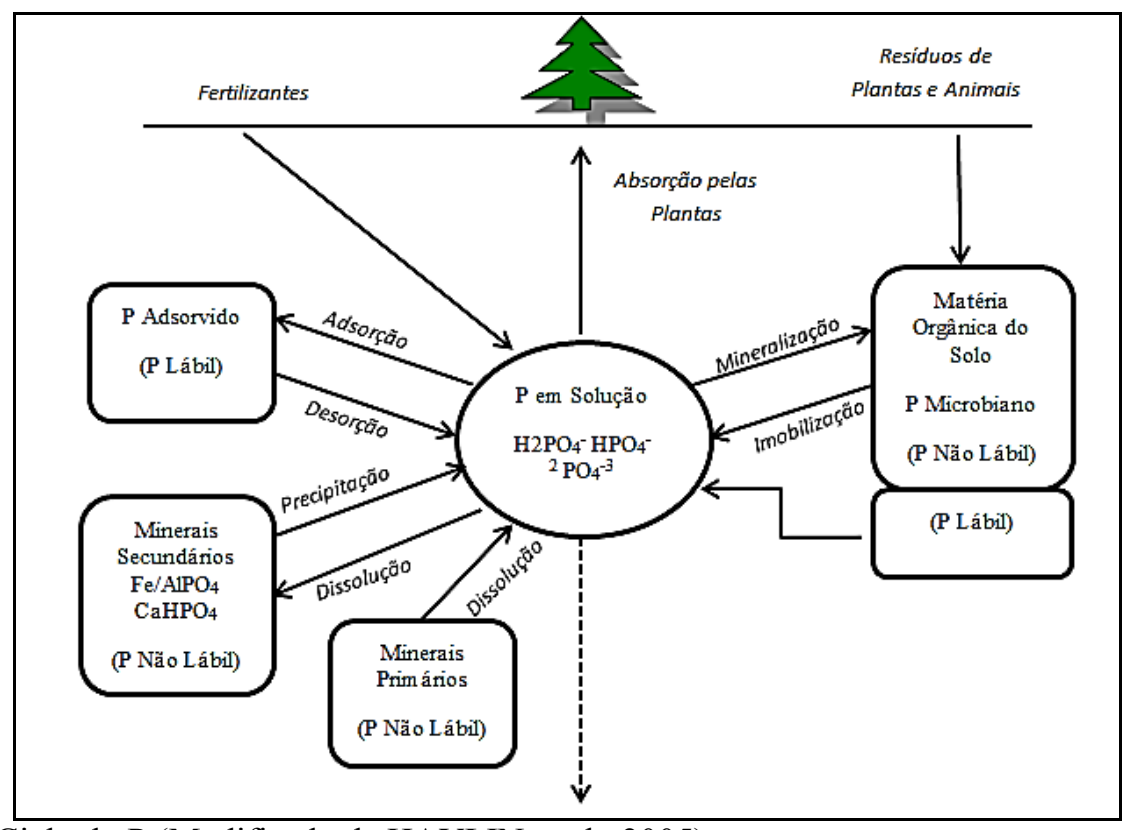

Figura 2.7- Ciclo do P (Modificado de HAVLIN et al., 2005)

As reações que envolvem os processos de adsorção e precipitação são chamadas de retenção de $\mathrm{P}$. A retenção aumenta com o aumento da temperatura e é extremamente dependente do pH. (SIMS; PIERZYNSKI, 2005; HAVLIN,et al., 2005). A Figura 2.8 mostra a influencia do $\mathrm{pH}$ na distribuição das espécies de ortofosfatos na solução. 


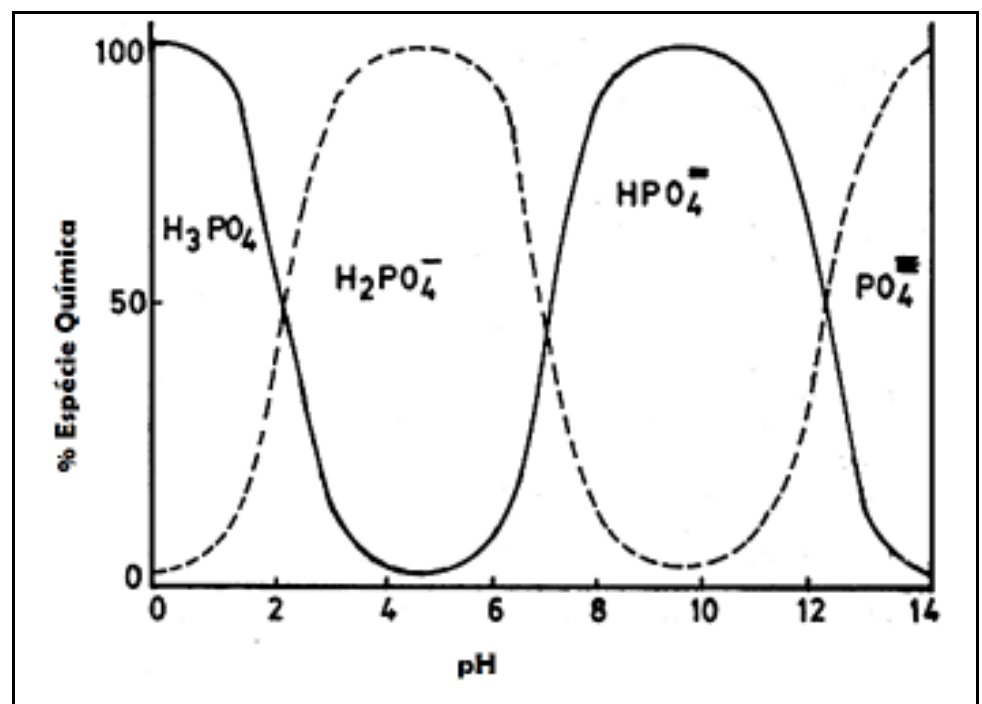

Figura 2.8- Influência do pH na forma química do P na solução (Modificado de HARVIN et al.,2005)

Em solos altamente intemperizados, como os Latossolos, os óxidos são os principais responsáveis pela retenção de fosfato. Em solos ácidos P inorgânico precipita como mineral secundário de $\mathrm{Fe}$ e $\mathrm{Al}$ e/ou é adsorvido na superfície de óxidos de $\mathrm{Fe}$ e $\mathrm{Al}$ e argilominerais. No entanto, adsorção de $\mathrm{P}$ por óxidos de $\mathrm{Fe}$ e $\mathrm{Al}$ reduz com o aumento do $\mathrm{pH}$. Os grupos $\mathrm{FeOH}$ e/ou $\mathrm{FeOH}_{2}{ }^{+}$da superfície dos óxidos reagem com o fosfato em solução e formam complexos do tipo $\mathrm{FeOP}\left(\mathrm{O}_{2}\right) \mathrm{OFe}$ (PARFITT et al., 1977).

Reações semelhantes ocorrem com caulinita e gibsita, onde o fosfato se liga a grupos $\mathrm{Al}(\mathrm{OH})_{2}{ }^{+} \mathrm{H}_{2} \mathrm{O}$ da superfície da gibsita e das arestas quebradas de caulinita e forma um complexo do tipo $\mathrm{AlOP}\left(\mathrm{O}_{2}\right) \mathrm{OAl}$ (PARFITT et al., 1977). Gibsita adsorve a maior quantidade de $\mathrm{P}$ em pH de 4 a 5. A retenção de $\mathrm{P}$ por Goetita reduz linearnente com pH entre 3 e 12. Em solos calcários e neutros, $\mathrm{P}$ inorgânico precipita como mineral secundário de Ca-P e Mg-P (em solos ricos em $\mathrm{Mg}$ ) e/ou é adsorvido nas superfícies dos minerais de $\mathrm{CaCO}_{3}$, explicando o aumento da retenção de $\mathrm{P}$ em solos alcalinos (HAVLIN, et al., 2005). A máxima quantidade de $\mathrm{P}$ disponível é encontrado em valores de pH cerca de 6,5(HAVLIN, et al., 2005;3 SIMS; PIERZYNSKI, 2005; PARFITT, et. al., 1977; STEVENSON; COLE 1986).

Além de influenciar na proporção dos ânions de P presentes na solução do solo, o pH influencia no potencial elétrico das cargas elétricas variáveis do solo (ver Seção 2.9.7), e, com o aumento do $\mathrm{pH}$, aumenta a formação de polímeros de alumínio com elevada capacidade de retenção de fosfato (HAYNES, 1982). Segundo Curtin, Syers e Bolan (1992), o potencial elétrico do solo torna-se mais negativo com a elevação do pH (entre 8 e 12) e, ao mesmo tempo, ocorre aumento na proporção de íons fosfatados divalentes em solução (Figura 2.8). O 
aumento de cargas negativas nos coloides do solo com a elevação do $\mathrm{pH}$, deveria provocar repulsão dos íons fosfatados. Porém, com o aumento da concentração de $\mathrm{HPO}_{4}{ }^{2}$ ocorre aumento das reações de adsorção específica com óxidos de alumínio e ferro, ocorrendo a adsorção deste íon.

Outros fatores como a constituição mineralógica do solo, CTC, CTA, saturação de P no solo e matéria orgânica também afetam as reações de retenção de P. As reações de adsorção e de dessorção são afetadas pelo tipo de superfície mineral em contato com a solução. Óxidos de Fe e Al são abundantes em solos ácidos e têm a capacidade de adsorver grandes quantidades de P da solução. Esses óxidos ocorrem nos solos como partículas, como hidróxidos de $\mathrm{Al}$ amorfos entre as camadas de aluminosilicatos expansíveis, que, devido à grande superfície específica, podem adsorver mais P do que as formas cristalinas (HAVLIN, et al., 2005; PARFITT et al., 1977).

A presença de cátions divalentes como o $\mathrm{Ca}^{2+}$, por exemplo, aumenta a retenção de $\mathrm{P}$ quando comparada com cátions monovalentes como o $\mathrm{Na}^{+}$. Cátions de $\mathrm{Ca}^{2+}$ podem ser trocados por cátions de $\mathrm{Al}^{3+}$, que estavam na superfície de argilominerais. Os cátions de $\mathrm{Al}^{3+}$ livres em solução podem formar complexos com os ortofosfatos, retendo o P no solo. Por outro lado, os ânions presentes no solo podem atuar como concorrentes com os ânions fosfatados, resultando em redução da adsorção destes (HAVLIN, et al., 2005; SIMS; PIERZYNSKI, 2005).

A matéria orgânica do solo aumenta a disponibilidade do P pela (o): i) formação de complexos organofosfatos que são mais facilmente assimilados pelas plantas; ii) troca aniônica de $\mathrm{H}_{2} \mathrm{PO}_{4}{ }^{-}$em locais de adsorção; iii) revestimento de óxidos de $\mathrm{Fe}$ e $\mathrm{Al}$ por substâncias húmicas, reduzindo a adsorção de $\mathrm{P}$; e, iv) aumento da quantidade de $\mathrm{P}$ orgânico mineralizado para P inorgânico. Ânions orgânicos produzidos a partir da decomposição da matéria orgânica formam complexos estáveis com $\mathrm{Fe}$ e $\mathrm{Al}$, deixando esses elementos indisponíveis para reagir com os ortofosfatos. Além disso, esses complexos podem trocar com os ortofosfatos ligados a Fe e Al. Os ânions mais eficientes na troca com os ortofosfatos são citrato, oxalato, tartarato e malato (HAVLIN, et al., 2005).

\subsection{DISPOSIÇÃO DE EFLUENTES}

A disposição dos efluentes vai depender de sua natureza, daí a importância de caracterizá-los. Normalmente os efluentes provenientes de tratamento de esgotos, após o 
devido tratamento, que, como dito anteriormente, vai depender do tipo de esgoto tratado e do uso que será dado ao efluente, são dispostos em corpos hídricos. Porém, é crescente a disposição de efluente em solos agrícolas, bem como outros usos para esses resíduos líquidos.

No Brasil, a Resolução Conama n ${ }^{0} 357 / 2005$, a qual substituiu a Resolução Conama ${ }^{\circ}$ 20/1986 especifica que: os efluentes de qualquer fonte poluidora somente poderão ser lançados, direta ou indiretamente, nos corpos de água, após o devido tratamento e desde que obedeçam às condições, padrões e exigências dispostos nesta Resolução e em outras normas aplicáveis (BRASIL, 2005).

O uso dos efluentes para qualquer atividade que seja no sentido de reaproveitar esse líquido é chamado de reuso. Westerhoff (1984) classifica reuso de água em duas grandes categorias: potável (direto e indireto) e não potável. O reuso potável direto: quando o esgoto recuperado, por meio de tratamento avançado, é diretamente reutilizado no sistema de água potável. Para isso o esgoto é recuperado utilizando-se de tratamento avançado é injetado diretamente no sistema de água potável. No Brasil não é recomendado este procedimento devido a dificuldades técnicas e econômicas (MANCUSO, 1992). Reuso potável indireto: caso em que o esgoto, após o tratamento, é disposto nas águas superficiais ou subterrâneas para diluição, purificação natural e subsequente captação, tratamento e finalmente utilizado como água potável.

O reuso não potável pode ser para fins industriais, recreacionais, domésticos e agrícolas. No caso da finalidade industrial, trata-se do reuso do efluente das Estações de Tratamento de Esgotos (ETE), convenientemente condicionado por tratamento posterior se necessário nos processos industriais. Sendo as indústrias as maiores consumidoras de água, o reuso afigura-se como uma alternativa tentadora (MANCUSO, 1992). O reuso não potável recreacional é aquele reservado à irrigação de plantas ornamentais, campos de esporte, parques, lagoas ornamentais, etc. O reuso não potável para fins domésticos é aquele em que a água serve para rega de jardins residenciais, para descargas sanitárias, lavagem de carros e a utilização deste tipo de água em grandes edifícios. O reuso não potável para fins agrícolas é classificado segundo o tipo de cultura que o utiliza, apresentando-se em dois grupos: 1) plantas não comestíveis, como silvicultura, pastagens, fibras e sementes; e, 2) plantas consumidas cozidas e cruas. 
Quando a finalidade é agrícola, embora a prática desta modalidade de reuso recaregue o lençol subterrâneo, o objetivo principal é a irrigação de plantas alimentícias, tais como árvores frutíferas e cereais, e plantas não alimentícias tais como pastagens e forrageiras. Em resumo, os efluentes podem ser dispostos tanto em corpos hídricos para as mais diversas finalidades, mas também pode ser disposto no solo (MANCUSO, 1992; WESTERHOFF, 1984).

\subsubsection{DISPOSIÇÃO DE EFLUENTES NO SOLO}

A disposição de efluentes no solo pode ser considerada como um processo natural de desinfecção de esgotos por meio de agentes físicos, químicos e biológicos (VON SPERLING, 2005). Em muitas partes do mundo verifica-se grande uso deste tipo de disposição, principalmente em países que sofrem de escassez hídrica (KIZILOGLU et al., 2007). No Vale do Mezquital, México, desde 1886 têm sido utilizados efluentes domésticos e industriais para irrigar solos. Na Austrália e países do Oriente Médio como Israel, Jordânia e Arábia Saudita, também é comum o uso do efluente para irrigar solos agrícolas devido à grande escassez de água superficial e subterrânea condicionada pela crescente demanda pelo setor agrícola (AL SALEM, 1996; GHARAIBEH; ELTAIF e AL-ABDULLAH, 2007; JIMÉNEZ-CISNEROS, 1995; RAMIREZ-FUENTES et al., 2002; TOZE, 2006).

No Brasil é crescente o uso dessa técnica por quatro motivos principais: i) poupar recursos hídricos; ii) recarregar aquíferos; iii) inserir nutrientes no solo; e, iv) redução da contaminação de corpos hídricos superficiais. Em países tropicais, como o Brasil, a utilização de efluentes para irrigar solos apresenta muitos aspectos positivos, uma vez que a temperatura a qual o solo está exposto favorece a mineralização da matéria orgânica e a disponibilização de nutrientes no solo (FAUSTINO, 2007). Dispor os efluentes no solo pode ser considerado como uma forma de disposição final ou de tratamento (primário, secundário ou terciário), ou ambos (VON SPERLING, 2005).

O efluente disposto no solo tem basicamente quatro destinos: i) retenção pelas plantas; ii) mover-se para a água subterrânea; iii) e; iv) retenção na matriz do solo. Assim, são muito importantes os estudos que relacionam o movimento e o destino dos solutos nos solos (VON SPERLING, 2005). 


\subsubsection{Tipos de disposição de efluente no solo}

Segundo von Sperling (2005) e Kruzic (1997), os tipos mais comuns de aplicação de efluentes no solo são divididos em: sistemas com base na água (terras úmidas construídas) e sistemas com base no solo. Dentre os sistemas com base no solo, os processos mais comuns são: infiltração rápida; infiltração subsuperficial; escoamento superficial; e, infiltração lenta. Essas técnicas geralmente fazem parte de um sistema de tratamento que inclui em etapa anterior um decantador primário ou uma fossa séptica.

A infiltração rápida consiste em aplicar efluente com altas velocidades de infiltração (terrenos com declividades suaves, de 4 a 6\%) para que o mesmo seja purificado pela ação filtrante do meio poroso, e, ao mesmo tempo, sirva para recarregar os reservatórios subterrâneos. Para que os efluentes tenham apenas o caminho vertical descendente são dispostos em tabuleiros sem revestimento. A aplicação deve ser intermitente a fim de que as condições aeróbias do solo sejam restabelecidas (VON SPERLING, 2005).

$\mathrm{Na}$ infiltração subsuperficial o esgoto pré-tratado é aplicado abaixo do nível do solo. De maneira geral, é o mesmo sistema de tratamento da infiltração rápida, com o porém de que a aplicação não é feita por inundação, mas sim subsuperficialmente por meio de formas de condução e aplicação enterradas no solo (VON SPERLING, 2005).

A aplicação com escoamento superficial, diferentemente dos métodos anteriores, gera efluente final. Consiste na aplicação de efluentes, de maneira controlada, fazendo com que eles escoem no solo até que se alcancem as canaletas de coleta. Assim, é necessário que se tenha certa declividade, entre 2 e $8 \%$. Além disso, novamente é necessário que a aplicação do efluente seja intermitente para as condições aeróbicas sejam restabelecidas. A presença de vegetação é importante na medida em que as plantas auxiliam na absorção dos nutrientes e dificultam o livre escoamento superficial do efluente, fazendo com que aumente a retenção de sólidos suspensos, a ação dos microorganismos do solo e também que se evite a erosão (VON SPERLING, 2005).

Os sistemas de infiltração lenta podem ser divididos em: sistemas de infiltração lenta e sistemas de irrigação de culturas ou fertirrigação. O primeiro tem o objetivo de tratar os esgotos e o segundo tem o objetivo principal de reusar a água para produção agrícola, sendo que o tratamento dos esgotos é um objetivo secundário (VON SPERLING, 2005). 


\subsection{Fertirrigação}

O uso do efluente em solos agrícolas é chamado de fertirrigação e é fundamentalmente um processos de infiltração lenta. A fertirrigação pode ser entendida como a descarga controlada de efluentes sobre o solo com a finalidade de suprir necessidades nutricionais de plantas. Deve-se, no entanto, avaliar as características microbiológicas e bioquímicas de acordo com o tipo de solo, cultura, sistema de irrigação e a forma como o produto será consumido, antes de efetuar a aplicação do efluente no solo. Neste processo as plantas removem os nutrientes e os microorganismos do solo removem as substâncias orgânicas presentes nos efluentes (VON SPERLING, 2005).

Esta técnica é aplicável para solos que tenham camada superficial espessa, argilosa e com boa drenagem, a fim de se prevenir contaminações. É muito importante a aeração do solo, pois em condições anaeróbias os efluentes podem provocar odores desagradáveis, além de atrair insetos. A irrigação de culturas com efluentes pode ser feita de quatro formas: inundação, sulcos, aspersão ou gotejamento (SOUZA, 2003; VON SPERLING, 2005).

Na Figura 2.9 apresenta-se um sistema de tratamento de esgoto com disposição final no solo com um sistema de infiltração lenta por aspersão.

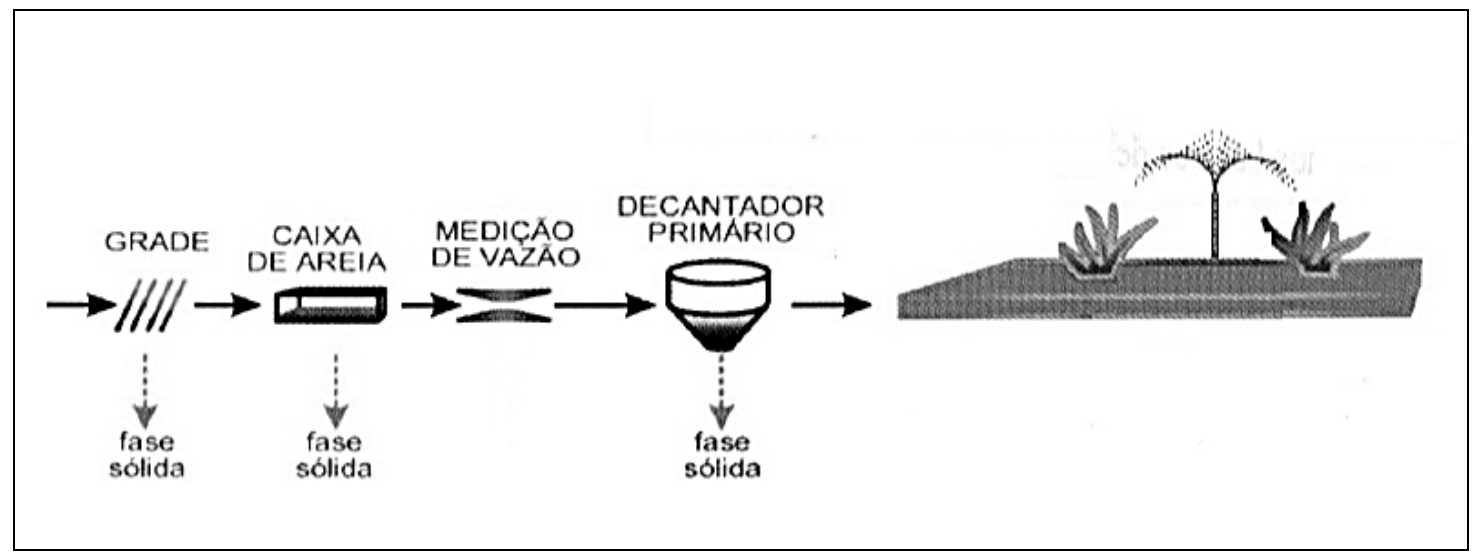

Figura 2.9- Método de infiltração lenta com irrigação por aspersão (VON SPERLING, 1996)

Segundo Von Sperling (2005), as principais vantagens dos sistemas de infiltração lenta são: elevada eficiência na remoção de DBO e de coliformes; satisfatória eficiência na remoção de $\mathrm{N}$ e $\mathrm{P}$; requisitos energéticos quase nulos; recarga do lençol subterrâneo; economia com nutrientes sintéticos; retorno financeiro no caso de aumento da produção agrícola; simples construção, operação e manutenção; custos operacionais muito baixos; não produzem lodo; proporcionam fertilização e condicionamento do solo; possuem boa 
resistência a variação de carga; e, são sistemas de tratamento e disposição final, ao mesmo tempo.

Por outro lado, alguns inconvenientes estão associados aos sistemas de infiltração lenta, entre eles destacam-se: necessidade de grande área; dependente das características do solo; dependente do clima e dos requisitos de nutrientes dos vegetais; possibilidade de efeitos químicos no solo, vegetais e água subterrânea; possibilidade de contaminação por contato dérmico e oral; e possibilidade de vermes e maus odores (VON SPERLING, 2005).

\subsection{ASPECTOS POSITIVOS DA DISPOSIÇÃo DE EFLUENTES NO SOLO}

O uso de efluente para irrigação tem sido considerado como uma solução técnica para minimizar a degradação do solo e para restaurar seus conteúdos de nutrientes (ANGIN; YAGANOGLU; TURAN, 2005; KIZILOGLU et al., 2007). Em países onde há muita demanda por água, mas pouca disponibilidade do recurso hídrico, o uso de fluentes tem ganhado destaque. Isto porque além dos efluentes suprirem necessidades nutricionais das plantas e reduzirem a pressão sobre os recursos hídricos, inserem água no solo e podem recarregar aquíferos que devido a grande demanda encontram-se em situação de superexploração (AL SALEM, 1996; GHARAIBEH; ELTAIF; AL-ABDULLAH, 2007; RAMIREZ-FUENTES et al., 2002; TOZE, 2006). Por estes motivos, existem diversas pesquisas avaliando os aspectos positivos e negativos relacionados à aplicação de efluentes em solos agrícolas (HARUVY, 1997; JIMÉNEZ-CISNEROS, 1995; MOHAMMAD RUSAN; HINNAWI; ROUSAN, 2007; RAMIREZ-FUENTES et al., 2002; TOZE, 2006).

Segundo Al Salem (1996), as principais vantagens do uso de efluentes tratados na região da Jordânia, Oriente Médio, são a prevenção da poluição das águas superficiais, subterrâneas e de barragens de água, a disposição de nutrientes em solos agrícolas e o fornecimento de grandes quantidades de água para essas áreas. Toze (2006) destacou a prevenção da eutrofização de corpos hídricos por nutrientes orgânicos e inorgânicos quando os efluentes são aplicados nos solos, assim como o aumento da fertilização dos solos e a redução do consumo de água doce, que poderia ser utilizada para atividades mais restritivas.

Kiziloglu et al. (2007) avaliaram, entre outros, os efeitos da irrigação com efluentes que passaram por diferentes níveis de tratamento de esgotos na concentração de macro, micronutrientes, crescimento de plantas e propriedades dos solos (CTC e conteúdo de matéria orgânica). Concluíram que ocorre aumento da CTC, do conteúdo de matéria orgânica, do N, P 
disponível e dos níveis de cátions trocáveis. Esses resultados se intensificam à medida que se reduz o nível do tratamento. Resultados similares foram obtidos por Angin, Yaganoglu e Turan (2005), porém sem a comparação dos resultados para diferentes níveis de tratamento de esgotos. Mohammad Rusan, Hinnawi e Rousan (2007) compararam solos irrigados com efluentes de esgotos domésticos por 2,5 e 10 anos com solos não irrigados com efluentes e verificaram que a aplicação de efluente aumenta o conteúdo de matéria orgânica e nutrientes no solo e este aumento está positivamente correlacionado com o tempo de aplicação.

Meli et al. (2002) ao estudarem solos de Casino, distrito de Catania, na Itália, identificaram que após 15 anos de irrigação com efluentes as concentrações de carbono solúvel e $\mathrm{N}$ aumentaram significativamente, mas foram dependentes das sazonalidades climáticas. Com isso concluíram que o uso de fertilizantes químicos pode ser reduzido drasticamente em solos irrigados com efluentes, sem afetar os resultados da produtividade.

Jiménez-Cisneros (1995), concluiu que uma mistura de efluentes domésticos e industriais aplicados nos solos do Vale do Mezquital, México, após tratamento primário, aumentou a produtividade agrícola. Kiziloglu et al. (2007) também verificaram que ocorre aumento do crescimento e da absorção de nutrientes pelas plantas após aplicação dos efluentes no solo. Meli et al. (2002) e Ramirez-Fuentes et al. (2002) verificam incremento da atividade metabólica de microorganismos e da fertilização em solos que foram irrigados com efluentes. Os efeitos da irrigação com efluentes de esgoto doméstico no crescimento de plantas também foram estudados por Rodrigues et al. (2009), que concluíram que o crescimento é favorecido pela irrigação com água residuária. Chakrabarti (1995) comparou o crescimento de culturas de arroz quando irrigadas com água subterrânea e quando irrigadas com efluentes. Chakrabarti (1995) notou que o crescimento das culturas foi maior quando submetidas à irrigação com efluentes. Além disso, segundo Chakrabarti (1995), depois de longo período de irrigação com efluentes, os requerimentos por nutrientes no solo reduzem significativamente.

Um aspecto importante no uso de efluentes na irrigação é que o solo pode servir de filtro biológico e reduzir as concentrações de patógenos. Ribas e Neto (2008) e Couracci Filho et al. (2002) estudaram a remoção natural de patógenos em sistemas de tratamento por disposição do efluente no solo. Ribas e Neto (2008) constataram que a eficiência na remoção de coliformes termotolerantes variou de 97 a 99,4\%. Esta eficiência pode estar relacionada à atuação de rizobactérias, por meio de predação, competição por espaço e nutrientes e atuação 
de sideróforos, bem como de fatores externos como temperatura ambiente e umidade do solo. Couracci Filho et al. (2002) constataram que o sistema de escoamento superficial foi eficiente na remoção de helmintos e protozoários, mas ainda necessitam de estudos complementares e processos de desinfecção para eliminação total desses patógenos.

De maneira geral, percebe-se que a irrigação de solos agrícolas com efluentes sob situações controladas aumenta a fertilidade dos solos, crescimento das plantas e reduz as concentrações de patógenos, o consumo de fertilizantes químicos, bem como os perigos de contaminação das águas subterrâneas, superficiais e das plantas.

\subsection{ASPECTOS NEGATIVOS DA DISPOSIÇÃO DE EFLUENTES NO SOLO}

Mesmo trazendo benefícios em termos de produtividade agrícola, redução do uso de fertilizantes e de água, melhora da fertilidade dos solos e etc., o uso de efluentes na irrigação gera diversos problemas. Esses problemas dependem, entre outras coisas, da composição do efluente e do tipo de solo (TOZE, 2006; AL SALEM, 1996; CORRÊA; MELO FILHO; BERNARDES, 2000). As altas concentrações de matéria orgânica, sais dissolvidos, P e N, bem como a presença de metais potencialmente tóxicos e microorganismos (vírus, bactérias, protozoários, ovos de helmintos e etc.), pode afetar a estrutura dos solos, contaminar águas subterrâneas, comprometer o abastecimento da população, além de gerar graves problemas de saúde (AL SALEM, 1996; TOZE, 2006).

Nem sempre os solos atuam como filtro biológico eficiente, como constatado por Ribas e Neto (2008) e Couracci Filho et al. (2002). Efluentes podem inserir nos solos alguns microorganismos como vírus, bactérias e protozoários (TOZE, 2006). Pesquisas indicam que os microorganismos podem migrar distâncias significativas tanto vertical quanto horizontalmente nas camadas do solo (CHEN, 1988; KESWICK; WANG; GERBA, 1982; STEWART; RENEAU, 1981). Gerba, Melnick e Wallis (1975) e Keswick and Gerba (1980) constataram migração de bactérias por mais de 830 metros e de vírus por 408 metros. Gerba, Melnick e Wallis (1975) relataram que E.coli sobreviveram até 4,5 meses em águas subterrâneas. A mobilidade dos microorganismos combinada com a alta capacidade de sobrevivência e a grande resistência dos vírus aumenta muito a chance de contaminação (STRAUB et al., 1995).

A adição de nutrientes necessários à qualidade do solo e ao crescimento de culturas é um benefício da irrigação com efluentes. No entanto, o aumento da quantidade de nutrientes 
aumenta igualmente a atividade microbiológica nos solos, como constatado por RamirezFuentes et al.( 2002), Balks, Mclay e Harfoot (1997) e Meli et al. (2002). O aumento da atividade microbiológica nos solos ocorre com a irrigação por meio de efluentes com altos níveis de carbono e N. Com o aumento da atividade microbiológica, ocorre aceleração da purificação do efluente. No entanto, excesso de microorganismos causam efeitos sérios na permeabilidade dos solos, pois atuam como películas que impedem o fluxo de água, prejudicando, desta forma, o crescimento de plantas e a qualidade dos solos.

Além da intensa atividade microbiológica, Mohammad Rusan, Hinnawi e Rousan (2007) e Haruvy (1997) chamam a atenção para os níveis de nitrato que, segundo eles, devem ser monitorados constantemente para que se evitem níveis críticos de acumulação que podem afetar negativamente a qualidade do solo e contaminar águas subterrâneas. Anami et al.(2008), estudaram o efeito da aplicação de águas residuárias da suinocultura tratada com reatores anaeróbios sobre as propriedades físico-químicas do solo e verificaram que o potencial de contaminação das águas subterrâneas pelo íon nitrato é bastante elevado. Tang et al.(2004) estudaram o caso da aplicação de efluentes nos solos agrícolas da região de Shijiazhuang, China, a fim de avaliar os impactos no meio ambiente. Segundo Tang et al.(2004), as concentrações de nitrato nas águas subterrâneas, onde o solo superficial foi irrigado com efluentes, apresentaram concentrações de nitrato até 3,5 vezes maior do que nas regiões em que apenas utilizam-se água de poços de bombeamento, estando as concentrações acima dos padrões de potabilidade estabelecidos pela WHO.

Por outro lado, Vidal et al. (2000) compararam as concentrações de nitrato, fosfato e carbono orgânico de solos de manguezais tratados com efluentes de esgotos domésticos (Site A) e com solos não tratados com efluentes (Site B). Verificaram que após um ano de experimento as concentrações de nitrato, fosfato e carbono orgânico no Site A e no Site B não tiveram diferenças significativas e que os solos e as plantas do Site A não foram contaminados em termos de conteúdo de nutrientes. Para Vidal et al. (2000) variações sazonais foram mais óbvias do que variações entre os diferentes locais. Na primavera e verão o conteúdo de $\mathrm{N}$ no solo foi menor do que nas outras estações, o que pode estar associado às altas temperaturas nesses períodos, o que facilita a degradação da matéria orgânica e a absorção de N pelas plantas.

Em se tratando de metais potencialmente tóxicos é mais importante o caso dos efluentes provenientes de esgotos industriais, porém efluentes de esgotos domésticos também 
podem conter estes metais. Existe muita preocupação em relação à possibilidade de absorção de metais por plantas, transferência para a cadeia trófica e à contaminação do solo e águas subterrâneas (TOZE, 2006; KIZILOGLU et al., 2007). Esses elementos, de um modo geral, têm afinidade por agrupamentos orgânicos contidos em frações do solo e em tecidos biológicos, que lhes conferem as propriedades de persistência, bioacumulação, biomagnificação na cadeia trófica e toxicidade, decorrentes de suas reações com ligantes difusores, macromoléculas e membranas. Nos humanos, esses elementos podem causar câncer e outros efeitos adversos sistêmicos (DUARTE; PASQUAL, 2000; DUFFUS, 2002; SALOMONS, 1995; TAVARES; CARVALHO, 1992).

Ofosu-Asiedu et al. (1999) examinaram a absorção de metais por plantas em áreas irrigadas com efluentes domésticos e industriais e concluíram que a absorção devido à adição de efluentes foi similar à adição natural (fonte litológica) dos metais no solo. Os resultados de Kiziloglu et al. (2007), mostraram que ocorre aumento da concentração desses metais à medida que se reduz o nível do tratamento do esgoto do qual o efluente é proveniente. Segundo pesquisa de Yim e Tam (1999), metais potencialmente tóxicos prejudicam o crescimento de plantas. Além disso, os efluentes contribuem com o enriquecimento dos solos com metais potencialmente tóxicos (MAPANDA et al., 2005). Em Beijing, China, em solos irrigados com efluentes contatou-se que a concentração desses elementos nas plantas foi muito superior do que nas plantas cultivadas na área referência (KHAN et al., 2008). Na Índia, o uso de efluentes na irrigação fez com que aumentasse a concentração de cádmio, chumbo e níquel nas partes comestíveis de vegetais, causando, em longo prazo, risco potencial alto à saúde da população (KUMAR SHARMA; AGRAWAL e MARSHALL, 2007).

Pesquisadores verificaram que as concentrações de metais nos efluentes e nos solos foram bastantes baixas, mas chamaram a atenção para o risco potencial caso a irrigação persista por muito tempo (RAMIREZ-FUENTES et al., 2002). Angelova et al. (2004) e Fazeli et al. (1998) examinaram a absorção de metais pelas plantas em solos irrigados com efluentes e verificaram que a absorção foi apenas de uma parcela muito reduzida da quantidade total presente no solo. No entanto, concluíram que existe risco à saúde da população. Esta conclusão mostrou-se adequada com outras pesquisas que indicam que conhecer apenas a concentração total de metais no solo fornece informação limitada sobre seu comportamento em termos de mobilidade e biodisponibilidade, pois assim se assume que todas as formas de um determinado metal têm o mesmo impacto no meio ambiente (DUBE et al., 2001; 
KABATA-PENDIAS e PENDIAS, 2001; MA e RAO, 1997; TESSIER; CAMPBELL e BISSON, 1979). Isto porque a sorção dos metais potencialmente tóxicos ocorre nos diferentes constituintes do solo, sendo que a solubilidade, mobilidade e biodisponibilidade serão determinadas de acordo com o constituinte com o qual o metal está associado com as propriedades do solo (KABALA e SINGH, 2001).

As extrações sequenciais feitas por Tam e Wong (1996) ao compararem solos tratados com efluentes com outros sem nenhum tratamento especial, mostraram que em solos que receberam efluentes a concentração de metais potencialmente tóxicos foi maior nas frações mais solúveis. Chang et al. (1984) encontraram metais em frações solúveis em solos irrigados com efluentes. Na pesquisa de Ahumada et al. (1999), as frações mais solúveis de metais foram identificadas em alface e menos solúveis em aipo, ambas plantas cultivas solos agrícolas irrigados por várias décadas com efluentes não tratados.

Mesmo com um comportamento geral esperado, ou seja, acúmulo em camadas superiores do perfil de solo, como identificado por Kiziloglu et al. (2007), devido à heterogeneidade e à variabilidade nas propriedades químicas, mineralógicas e físicas do solo, é extremamente difícil prever o destino e comportamento dos metais potencialmente tóxicos presentes no solo sem entender alguns fatores, como: potencial redox, capacidade de troca catiônica, conteúdo de matéria orgânica, quantidade e tipos de argilominerais, presença de óxidos e hidróxidos de ferro, magnésio e alumínio e valor do $\mathrm{pH}$, que ganha destaque no estudo da disponibilidade e mobilidade dos metais potencialmente tóxicos (ADRIANO, 1986; ALLOWAY, 1995b). Segundo Adriano (1986) e Alloway (1995), a mobilidade dos cátions metálicos aumenta à medida que se reduz o pH do solo. Com isso, geralmente, tem-se também o aumento da sua biodisponibilidade, ou seja, aumenta sua absorção pelos seres vivos. Excetuam-se dessa regra o arsênio, molibdênio e selênio que têm a mobilidade mais elevada em condições alcalinas.

Kiziloglu et al. (2007), Mohammad e Mazahreh (2003) e Vazquez-Montiel, Horan e Mara (1996) verificaram que, após irrigação dos solos com efluentes, ocorre redução do pH. Esta redução é atribuída à oxidação de componentes orgânicos e à nitrificação da amônia. Por outro lado, Mohammad Rusan, Hinnawi e Rousan (2007) concluíram que não existe um padrão consistente para os valores do $\mathrm{pH}$, podendo aumentar ou diminuir após aplicação de efluentes. Nos estudos de Schipper et al.(1996), houve aumento do pH após aplicação de efluentes no solo. Este aumento foi atribuído á química e ao conteúdo de cátions básicos do 
efluente (SCHIPPER et al., 1996). Duarte et al. (2008) em seus estudos, concluíram que o uso do efluente no solo não provocou alterações significativas no $\mathrm{pH}$.

Além do $\mathrm{pH}$, outras características físicas dos efluentes como o oxigênio dissolvido e sólidos suspensos merecem destaque em se tratando de irrigação, pois podem impactar o local onde os efluentes estão sendo dispostos, na medida que podem alterar a estrutura dos solos e, assim, algumas de suas propriedades geológico-geotécnicas como permeabilidade, densidade, porosidade, taxa de infiltração, retenção de água e etc. No entanto, a principal característica é a salinidade e, em particular, a concentração de sódio (TOZE, 2006).

Além da contaminação do meio, efluentes provenientes de esgotos domésticos, quanto aplicados no solo sem um critério adequado, podem provocar alterações em algumas propriedades geológico-geotécnicas dos solos, como porosidade, condutividade hidráulica, taxa de infiltração, drenagem, retenção de água, entre outras (CLANTON; LACK, 1987; COOK; KELLIHER; MCMAHON, 1994; THOMAS; SCHWARTZ; BENDIXEN, 1966; GLOAGUEN, 2005; GHARAIBEH; ELTAIF; AL-ABDULLAH, 2007; MATHAN, 1994). Estas alterações podem resultar em alagamentos, aumento do escoamento superficial e, consequentemente da erosão. Superfícies alagadas podem aumentar o fluxo preferencial de contaminantes através do solo e assim contaminar corpos hídricos superficiais e subterrâneos (RODRIGUES, 2003; VINTEN; MINGELGRIN e YARON, 1983).

Mathan (1994) realizou um estudo para avaliar efeitos do efluente na irrigação ao longo de um período de 10 a 15 anos sobre as propriedades físicas do solo, quando comparado com o solo irrigado com água de poço. Constatou que tanto a condutividade hidráulica quanto a porosidade total aumentou em relação ao solo controle (MATHAN, 1994). Sparling, Schipper e Russell (2001), ao realizarem experimentos de campo, identificaram aumento da condutividade hidraulica não saturada após irrigação com efluentes provenientes da indústria de laticínios. Os efeitos da matéria orgânica presente em efluentes que eram utilizados para irrigação, sobre a condutividade hidraulica de solos de Tel Aviv, Israel, foram estudados por Levy et al. (1999), que não observaram uma diminuição signficativa da condutividade hidraulica. Porém esses resultados não são os mais comuns, já que a grande maioria dos estudos tem mostrado redução da condutividade hidraulica após irrigação com efluentes.

Avaliaram-se a aplicação de efluentes em solos de Ar Ramtha, Jordânia, para aplicações de 2, 10 e 15 anos e concluiram-se que houve redução da condutividade hidraulica 
em todos os períodos analisados (GHARAIBEH; ELTAIF e AL-ABDULLAH, 2007). A aplicação de efluentes também reduziu a condutividade hidraulica de solos estudados por Vinten, Mingelgrin e Yaron (1983) e este efeito foi atribuído ao acúmulo de sólidos na superfície do solo. Abedi-Koupai et al. (2006) estudaram os efeitos da aplicação de efluentes em algumas propriedades físicas e químicas dos solos de Borkhar, Irã. Com os estudos perceberam-se que quando houve irrigação por aspersão a condutividade hidráulica aumentou em 0-15 e 15-30 cm de profundidade, mas diminuiu no sistema de irrigação por superfície. Segundo os pesquisadores, estes resultados podem estar relacionados com a produção de menor quantidade de material em suspensão pelo sistema de aspersão e, portanto, a menor possibilidade de entupimento dos poros do solo (ABEDI-KOUPAI et al., 2006). Outros pesquisadores também identificaram redução na condutividade hidraulica dos solos após irrigação com efluentes (AIELLO; CIRELLI; CONSOLI, 2007; CLANTON; LACK, 1987; COOK; KELLIHER; MCMAHON, 1994; THOMAS; SCHWARTZ; BENDIXEN, 1966; GLOAGUEN, 2005;BALKS; BOND; SMITH, 1998; BALKS; MCLAY; HARFOOT, 1997; GHARAIBEH; ELTAIF; AL-ABDULLAH, 2007; TARCHITZKY et al., 1999).

De acordo com Halliwell, Barlow e Nash (2001) e Magesan et al.(1999), as pesquisas indicam que a mudança no sistema poroso durante a irrigação é o fator dominante das perturbações nas propriedades geológico-geotécnicas, incluindo na condutividade hidráulica. As mudanças no sistema poroso são principalmente devido à colmatação física ou biológica dos poros do solo. A colmatação biológica geralmente é atribuída à formação de filme biológico (BALKS; MCLAY e HARFOOT, 1997; MAGESAN et al., 1999); A colmatação física normalmente é atribuída à: i) acúmulo de sólidos suspensos na superfície do solo (LEVY et al., 1999; TARCHITZKY et al., 1999); ii) formação de bolhas de ar (RICE, 1974); iii) colapso da estrutura do solo devido a dissolução da matéria orgânica (LIEFFERING; MCLAY, 1996; MITCHELL; NEVO, 1964; VANDEVIVERE ; BAVEYE, 1992); e, iv) colapso da estrutura do solo devido a dispersão e expansão das argilas provocada pelos íons sódio (HALLIWELL; BARLOW e NASH, 2001; FEIGIN; RAVINA e SHALHEVET, 1991; GLOAGUEN, 2005; MINHAS e SHARMA, 1986; RODRIGUES, 2003; TARCHITZKY et al., 1999). O efeito na estrutura faz possível que um solo argiloso possa ter valores de condutividade hidráulica saturada similares ou até mesmo superiores aos de solos arenosos (JARVIS e MESSING, 1995).

O efeito mais significativo do efluente na redução na condutividade hidráulica é decorrente do excesso de sódio (GLOAGUEN, 2005). Todos os solos contêm sais solúveis, 
mas quando em grandes concentrações, podem prejudicar o crescimento de plantas e a estrutura do solo (SANTOS, 2004). Existem três aspectos relacionados aos efluentes que constituem-se favoráveis à salinização e sodificação de solos quando utilizados na irrigação: i) concentração total de sais na água pode causar aumento da salinidade dos solos; ii) concentrações de íons como $\mathrm{Cl}^{-}$e $\mathrm{Na}^{+}$podem causar efeitos de desequilíbrio nutricional nas plantas; e, iii) as concentrações de alguns íons, como $\mathrm{Na}^{+}$, podem resultar em deterioração da estrutura do solo (FEIGIN; RAVINA; SHALHEVET, 1991).

O sódio é um elemento fundamental para a vida, no entanto, quando presente em sistemas agrícolas pode ser extremamente prejudicial. Como pôde ser observado na Tabela 2.1, geralmente o sódio está presente nos efluentes em grandes concentrações o que pode ser um problema. Qian e Mecham (2005) ao compararem, em solos dos Estados Unidos, os efeitos da irrigação com efluentes e com água de abastecimento verificaram que as concentrações de sódio aumentaram 481\% nas áreas irrigadas com efluentes. Após 4 ou 5 anos de irrigação com efluentes, Qian e Mecham (2005) constataram que houve aumento de 89 a 95\% no teor de sódio. O mesmo aumentou seis vezes após vinte e cinco anos de irrigação com efluentes na cidade de Léon, Guanajuato, México (ALVAREZ-BERNAL et al., 2006).

O excesso de sais em efluentes utilizados na irrigação pode afetar negativamente tanto o solo em termos estruturais quanto o crescimento das plantas e por isso necessita de monitoramento. Segundo Halliwell, Barlow e Nash (2001), Balks, Bond e Smith (1998), Feigin, Ravina e Shalhevet (1991) e Tarchitzky et al. (1999) a salinidade, na forma de íons sódio, pode afetar as propriedades do solo principalmente por causar expansão e dispersão de argilominerais e com isso deteriorar a estrutura do solo. As partículas dispersas movem-se pelo solo ocupando os espaços porosos com consequente deterioração da estrutura e das propriedades de infiltração de água e aeração. Esses efeitos de expansão e dispersão envolvem propriedades muito complexas como o $\mathrm{pH}$, textura do solo, tipo e quantidade de argilomineral, presença de matéria orgânica e óxidos de ferro e alumínio, entre outras (HALLIWELL; BARLOW; NASH, 2001; FEIGIN; RAVINA; SHALHEVET, 1991; TARCHITZKY et al., 1999).

\subsection{COMPARTIMENTO SOLO}

O solo é a base dos ecossistemas, cujas funções vão além do desenvolvimento da agricultura e do fornecimento de alimentos, incluindo: controle dos ciclos biogeoquímicos e 
da energia nos diferentes compartimentos ambientais; suporte de plantas, animais e do Homem; parte dos aquíferos e de depósitos minerais; manutenção da biodiversidade; e, filtro de materiais inseridos pelas atividades antrópicas, como por exemplo, dos contaminantes (JENNY, 1994; ALLOWAY, 1995a; TOLEDO; OLIVEIRA; MELFI, 2003). O conceito de solo depende da utilização, sendo que cada especialidade (engenharia, agronomia, geologia, etc.) possui uma definiç̧ão que atende aos seus objetivos (TOLEDO; OLIVEIRA; MELFI, 2003).

No entanto, segundo Jenny (1994) e Toledo, Oliveira e Melfi (2003) a definição que mais se adequa aos propósitos das Ciências da Terra é o de que o solo é o produto do intemperismo físico (alterações de ordem física no material parental - desagregação) e químico (alterações de ordem química no material parental - decomposição), do remanejamento e da organização das camadas superiores da crosta terrestre e, por fim, da pedogênese (formação do solo) sob ação da atmosfera, hidrosfera, biosfera e das trocas de energia envolvidas, fazendo com que ele seja um material em constante evolução. Segundo Toledo, Oliveira e Melfi (2003), a pedogênese ocorre quando as modificações causadas no material parental não forem apenas de ordem química e mineralógica, mas também de ordem estruturais.

De acordo com Jenny (1994), para que se tenha de fato uma noção concreta do que é o solo é necessário que se entenda o que é o perfil de solo. Mesmo que diferentes solos tenham propriedades muito distintas, possuem uma característica em comum: são anisotrópicos. Isso significa que a distribuição espacial do solo não é aleatória, mas depende de uma direção. Essa direção é aquela ao longo de uma linha que se estende desde a superfície do solo em direção ao centro da Terra, arbitrariamente denotado como sequência- $Z$ (eixo das propriedades do solo), que difere profundamente daquelas ao longo das linhas paralelas à superfície (Figura 2.10). A anisotropia dos solos é expressa pelo perfil do solo. Assim, um perfil de solo (ou perfil de alteração) é gerado em decorrência do intemperismo e da pedogênese e pode ser definido como a estruturação vertical dos diversos materiais geológicos que formam o solo. 


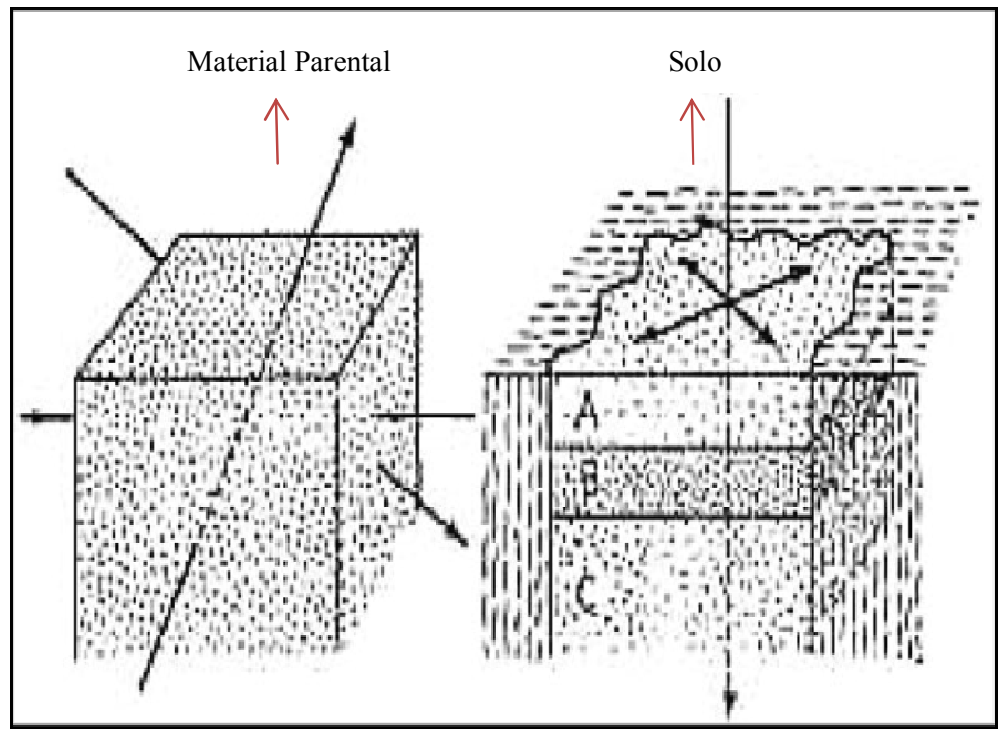

Figura 2.10- Material parental isotrópico e solo anisotrópico (JENNY, 1994)

Segundo Alloway (1995b), Hillel (1980) e Toledo, Oliveira e Melfi (2003), essa estruturação vertical dá-se em camadas (ou horizontes). De maneira típica, em um perfil pedológico existem os horizontes R, C, B, E, A e O (do material parental para cima) que podem, ainda, serem subdivididos:

R: Rocha ou material parental sem alteração;

C: Horizonte de rocha alterada (saprolito) com algumas estruturas e texturas da rocha conservadas e outras não; alumínio;

B: Horizonte de acúmulo de argila, matéria orgânica, óxidos e hidróxidos de ferro e

E: Horizonte de remoção de argila e óxidos;

A: Horizonte com matéria mineral e orgânica, além de alta atividade biológica;

O: Horizonte orgânico, rico em restos orgânicos em vias de decomposição.

Geotecnicamente, o perfil de solo é dividido em SM (solo maduro), SRJ (solo residual jovem) e rocha alterada. A Figura 2.11 ilustra os perfis esquemáticos com nomenclatura geotécnica e pedológica. 

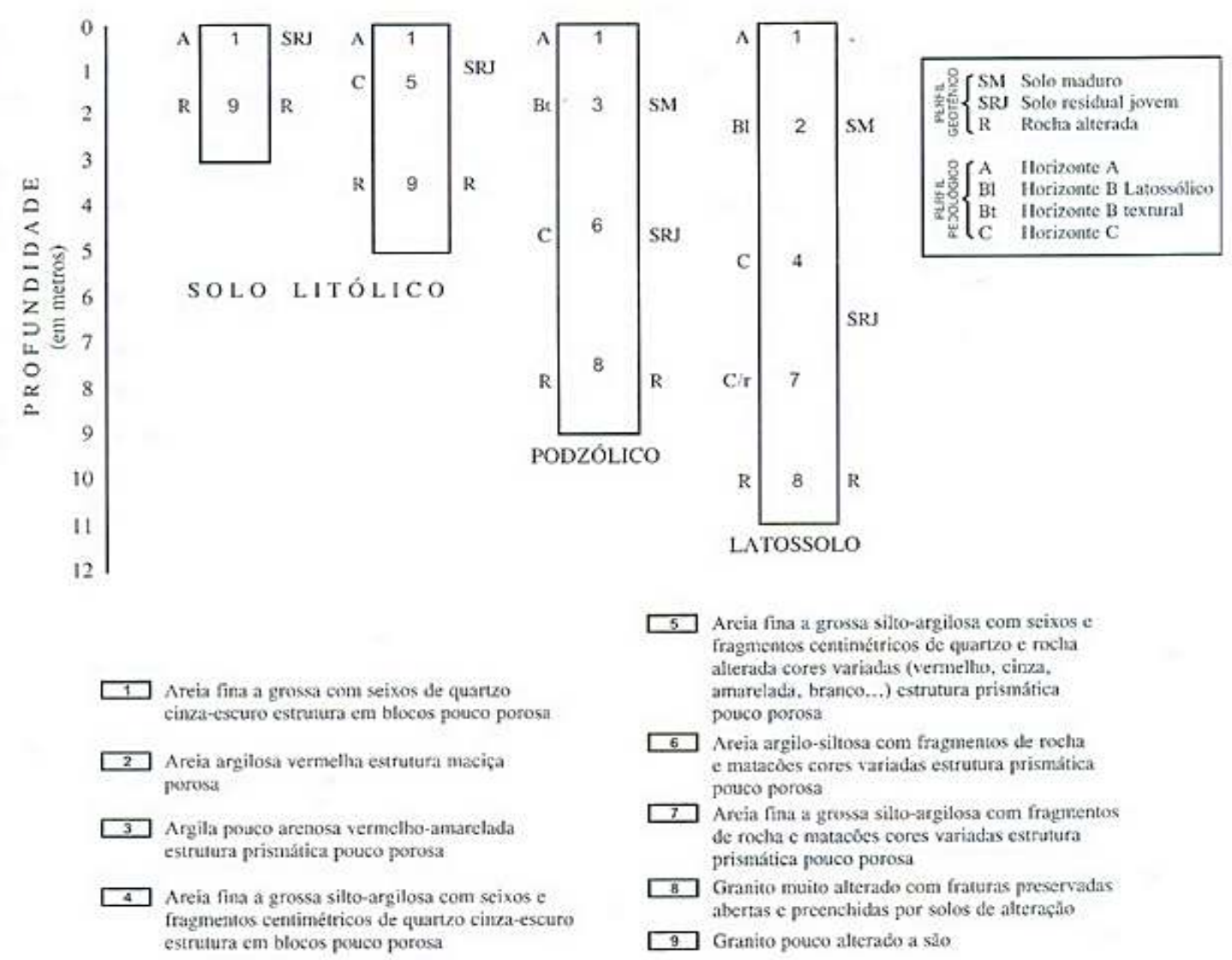

Figura 2.11- Perfil de solo esquemático com nomenclatura pedológica e geotécnica (SALOMÃO; ANTUNES, 1998)

Geralmente o solo é tratado como um sistema dinâmico, já que a ênfase é colocada sobre as mudanças de suas propriedades em função do tempo. O tempo necessário para alterar um material parental até que este se torne solo depende de outros fatores como o tipo de material parental e o clima, por exemplo. Desta forma, outras variáveis, além do tempo, também são de fundamental importância na formação do solo (JENNY, 1994; TOLEDO; OLIVEIRA e MELFI, 2003). Segundo Jenny (1994) e Alloway (1995b), as variáveis que definem o sistema solo são: clima, organismos, material parental, topografia e tempo.

O clima é o fator que isoladamente mais influencia na formação do solo. Isso porque ele determina o tipo e a velocidade do intemperismo. Segundo Jenny (1994) e Toledo, Oliveira e Melfi (2003), os dois principais componentes climáticos são a temperatura e umidade (precipitação), pois regulam a natureza e a velocidade das reações químicas envolvidas. Quanto maior a disponibilidade de água e mais frequente for sua renovação, mais completas serão as reações químicas do intemperismo. A temperatura tanto pode ajudar o 
intemperismo por acelerar os processos, quanto pode retarda-los, uma vez que pode aumentar a evaporação e reduzir a quantidade de água necessária para lixiviar os produtos solúveis (TOLEDO; OLIVEIRA; MELFI, 2003).

Os organismos (ou a biosfera) influenciam a formação do solo uma vez que a matéria orgânica no solo decompõe-se, liberando $\mathrm{CO}_{2}$, podendo reduzir o $\mathrm{pH}$ das águas de infiltração. Além disso, a biosfera permite a complexação de cátions dos minerais, colocando-os em solução. Segundo Toledo, Oliveira e Melfi (2003), os ácidos orgânicos produzidos pelos micro-organismos são capazes de extrair até mil vezes mais ferro e alumínio dos silicatos do que as águas pluviais.

O material de origem influencia o intemperismo uma vez que os diferentes minerais presentes em diferentes tipos de rochas possuem maior ou menor resistência à alteração. Os perfis de solo terão maior quantidade de minerais resistentes, como o quartzo, e menor quantidade dos minerais mais facilmente lixiviados. A composição mineralógica da rocha influência no $\mathrm{pH}$ das soluções percolantes através da troca de íons, podendo aumentar as reações de intemperismo e acelerar os processos de alteração. A textura da rocha parental pode facilitar ou dificultar o intemperismo. Rochas sedimentares tendem a se alterar mais rapidamente do que ígneas e metamórficas. Outras feições como juntas, fissuras, falhas também podem acelerar o processo de alteração (TOLEDO; OLIVEIRA; MELFI, 2003). A partir das características do material parental se verificarão as características do solo formado. Prescott e Hosking ${ }^{1}$ (1936 apud JENNY, 1994) encontraram forte correlação entre a quantidade de argila do solo e a composição mineralógica do material parental.

A topografia desempenha o papel de regular a velocidade do escoamento superficial das águas pluviais, controlando a quantidade de água que infiltra nos perfis. Quando não ocorre infiltração, não ocorre percolação por tempo suficiente para que a água entre em contato com o material e assim não se desenvolvem as reações de intemperismo e de formação do solo. Da mesma maneira, quando a topografia possui boa infiltração e má drenagem não há renovação da água, reduzindo a lixiviação dos produtos solúveis e perdendo a capacidade de promover a continuidade de reações que ataquem os minerais. Um relevo considerado ideal serial aquele com boa infiltração e boa drenagem, permitindo a eliminação dos produtos dissolvidos (JENNY, 1994; TOLEDO; OLIVEIRA; MELFI, 2003).

\footnotetext{
${ }^{1}$ PRESCOTT, J. A; HOSKING, J. S. Some red basaltic soils from Eastern Australia, Trans. Roy. Soc. South Australia, $60: 35-45,1936$.
} 


\subsection{PROPRIEDADES QUÍMICAS E FÍSICAS DO MEIO POROSO}

O solo é um meio heterogêneo complexo e, quando não saturado, é constituído por fase sólida (material mineral e matéria orgânica), líquida (águas com íons dissolvidos) e gasosa (dióxido de carbono e oxigênio) (ALLOWAY, 1995a; TOMSON et al., 2003).É É considerado como um filtro natural, sendo que vários mecanismos de ordem química, física e biológica atuam na remoção dos poluentes do solo, dependendo de condições climáticas, taxa de infiltração, aeração, relevo, tipo de cobertura vegetal e de algumas propriedades do solo. Segundo Adriano (1986), Alloway (1995a) e Adriano (2001), devido à heterogeneidade e a variabilidade nas propriedades químicas, mineralógicas e físicas do solo, é extremamente difícil prever o destino e comportamento contaminantes presentes no solo. Desta forma, é fundamental o conhecimento de algumas propriedades fundamentais do meio poroso, como por exemplo: mineralogia, capacidade de troca catiônica, capacidade de troca aniônica, $\mathrm{pH}$, potencial redox, conteúdo de matéria orgânica, textura e permeabilidade.

\subsubsection{Mineralogia dos SOlOS}

A presença de alguns minerais influencia diretamente o comportamento físico, químico e físico-químico dos solos. Segundo Sposito (1989), geralmente cerca de dois terços do solo corresponde à matéria sólida. Destes dois terços, $90 \%$ correspondem a componentes inorgânicos, exceto em solos orgânicos. A Tabela 2.3 mostra os minerais mais comuns nos solos, bem como sua principal importância.

Em estudos de contaminação de solos e água subterrânea, um destaque deve ser dado para os argilominerais, óxidos e hidróxidos. Argilominerais são filossilicatos hidratados de alumínio, contendo também cátions como ferro, cálcio, potássio, sódio, magnésio e outros, essencialmente naturais, que constituem as argilas (WILSON, 1939; CAILLÉ; HÉNIN, 1982a; SOUZA SANTOS, 1989). São produtos do intemperismos das rochas e possuem efeitos marcantes nas propriedades físicas e químicas dos solos (ALLOWAY, 1995a). 
Tabela 2.3 Minerais comuns nos solo (Modificado de SPOSITO, 1989)

\begin{tabular}{|c|c|}
\hline Nome & Importância \\
\hline Quartzo & Abundante em areais e siltes \\
\hline Feldspato & Abundante em solos que não são muito lixiviados \\
\hline Mica & Fonte de $\mathrm{K}$ em solos de zonas temperadas \\
\hline Anfibólio & $\begin{array}{l}\text { Facilmente intemperizado para argilominerais e } \\
\qquad \text { óxidos }\end{array}$ \\
\hline Piroxênio & Facilmente intemperizado \\
\hline Olivina & Facilmente intemperizado \\
\hline Caulinita & \\
\hline Esmectita & Abundante em argilas como produtos do \\
\hline Vermiculita & intemperismo; fonte de cátion trocáveis nos solos \\
\hline Clorita & \\
\hline Gibsita & Abundante em solos lixiviados \\
\hline Goetita & Óxido de ferro mais abundante \\
\hline Hematita & Abundante em regiões quentes \\
\hline Calcita & Carbonato mais abundante \\
\hline Gipso & Abundante em regiões áridas \\
\hline
\end{tabular}

Existem diversos grupos de argilominerais, mas, em termos estruturais, existem três principais grupos para o estudo da contaminação dos solos, a saber: caulinita, esmectita e mica (ilita). A caulinita tem a estrutura 1:1, ou seja, uma folha tetraédrica de $\mathrm{SiO}_{4}$ e uma folha octaédrica de Al, é pouco expansiva, possui distância basal da ordem de $7.3 \AA$, superfície específica ao redor de $15 \mathrm{~m}^{2} / \mathrm{g}$ e capacidade de troca catiônica (CTC) entre 3 e 15 meq por 100 gramas. A esmectita tem a estrutura 2:1, isto é, uma folha octaédrica arranjada entre duas folhas tetraédricas, possui distância basal variando de 10 a $20 \AA$, é muito expansiva, realiza substituições isomórficas e possui superfície específica de até $800 \mathrm{~m}^{2} / \mathrm{g}$. 
Essas características contribuem para uma CTC alta que varia de 80 a 150 meq por 100 gramas (CAILLÉ; HÉNIN, 1982b; SOUZA SANTOS, 1989). A ilita é a representante principal do grupo da mica, tem distância basal da ordem de $10 \AA$, superfície específica de até $80 \mathrm{~m}^{2} / \mathrm{g}$ e, devido à sua característica de não possuir cátions trocáveis entre as camadas da estrutura 2:1, é parcialmente expansiva, realiza substituições isomórficas e possui CTC que varia de 10 a 40 meq por 100 gramas (WILSON, 1939; CAILLÉ; HÉNIN, 1982b; SOUZA SANTOS, 1989).

Os óxidos de Fe e $\mathrm{Al}$ desempenham um importante papel no comportamento químico dos contaminantes nos solos. Esses óxidos ocorrem na fração argila $(<2 \mu \mathrm{m})$, são normalmente misturados com as argilas e possuem estrutura desordenada. Em condições onde o intemperismo é intenso (como em regiões tropicais) ocorre acúmulo desses minerais nos solos e nessas condições são mais abundantes que os argilominerais, sendo responsáveis pela adsorção de íons metálicos (ALLOWAY, 1995a). Em solos bem drenados, óxidos de Fe, Mn e Al precipitam da solução e podem ocorrer como: revestimento das partículas do solo onde são misturados com argilas. Variações nas condições redox e no pH tem efeito tanto nas quantidades de óxidos e hidróxidos presentes no solo, como também em suas capacidades de adsorção. Aumento de condições redutoras causa dissolução de óxidos e, consequentemente, a liberação dos seus íons adsorvidos (ALLOWAY, 1995a).

\subsubsection{CAPACIDADE DE TROCA CATIÔNICA}

A Capacidade de Troca Catiônica (CTC) refere-se à medida da capacidade do solo para adsorver cátions, de tal forma que eles possam ser prontamente dessorvidos por íons concorrentes (BACHE ${ }^{2}, 1979$ apud ALLOWAY, 1995b), e resulta principalmente do excesso de carga negativa nos coloides do solo. Existem, principalmente, dois tipos de carga negativa nos solos, cargas permanentes e variáveis (McBRIDE, 1989). Cargas negativas permanentes encontram-se nas superfícies dos argilominerais do solo e são geradas devido às substituições isomórficas de cátions coordenados com diferentes valências. A realização das substituições isomórficas, isto é, a substituição do Si tetravalente por Al trivalente e do Al por cátions monovalentes ou divalentes, faz com que sobrem cargas negativas na superfície das camadas dos argilominerais, aumentando assim a capacidade de adsorver cátions (ALLOWAY,

\footnotetext{
${ }^{2}$ BACHE, B.W., In The Encyclopedia of Soil Science, ed. Fairbridge, R.W. and Finkl, C.W. Dowden, Hurchinson \& Ross, Stroudsburg, Pa (1979), 487-492
} 
1995a). A magnitude das cargas geradas por substituições isomórficas normalmente não é afetada pelo pH (EVANGELOU; PHILLIPS, 2005).

As cargas negativas variáveis são geradas pelos grupos funcionais de matéria orgânica e na superfície de hidróxidos inorgânicos. As cargas variáveis são fortemente influenciadas pelo $\mathrm{pH}$ e pela força iônica, em que qualquer aumento no $\mathrm{pH}$ e na força iônica é seguido por um aumento das cargas negativas (SINGH; UEHARA, 1986). Em resumo, a CTC é amplamente dependente do tipo e quantidade de argilomineral, matéria orgânica e óxidos e hidróxidos de $\mathrm{Fe}, \mathrm{Al}$ e Mn. Estes componentes do solo possuem diferentes propriedades de troca catiônica e, portanto, têm diferentes capacidades de reter contaminantes e nutrientes (ADRIANO, 1986; SOUZA SANTOS, 1989). Os principais cátions trocáveis nos solos são o $\mathrm{Ca}^{2+}, \mathrm{Mg}^{2+}, \mathrm{H}^{+}, \mathrm{K}^{+}, \mathrm{Na}^{+} \mathrm{e} \mathrm{NH}_{4}^{+}$(FAUSTINO, 2007; EVANGELOU; PHILLIPS, 2005).

\subsubsection{CAPACIDADE DE TROCA ANIÔNICA}

A capacidade de troca aniônica (CTA) refere-se à medida da capacidade do solo para adsorver ânions. Os mecanismos pelos quais os ânions são adsorvidos são complexação de superfície e associação de íons. A complexação de superfície envolve a coordenação do ânion para uma hidroxila protonada, para um grupo amino ou para a superfície de um cátion metálico (SPOSITO, 1989). Os principais responsáveis pela troca aniônica nos solos são os óxidos e hidróxidos de ferro e alumínio. Além disso, a CTA é fortemente influenciada pelo pH da solução, pela espécie iônica do elemento químico e pela superfície do adsorvente. De maneira geral, com o aumento do pH ocorre redução da troca de ânions (EVANGELOU; PHILLIPS, 2005; RODRIGUES; SILVA, 2009; SPOSITO, 1989). Os principais ânions trocáveis nos solos são o $\mathrm{SO}_{4}{ }^{2-}, \mathrm{Cl}^{-}, \mathrm{NO}_{3}^{-}, \mathrm{H}_{2} \mathrm{O}_{4}^{-}, \mathrm{HPO}_{4}{ }^{2-}, \mathrm{HCO}_{3}^{-}$, e os ácidos húmicos (FAUSTINO, 2007).

\subsubsection{Potencial HidRogeniônico (PH)}

Por definição, pH de uma solução é a medida da alcalinidade e acidez ou a concentração de íons hidrogênio $\left(\mathrm{H}^{+}\right)$calculada em escala logarítmica variando de 1 (mais ácido) a 14 (mais básico ou alcalino) (PALMER, 1996). O pH do solo aplica-se à concentração do $\mathrm{H}^{+}$na solução presente nos poros dos solos. Segundo Bache ${ }^{2}$ (1979 apud ALLOWAY, 1995), é um conceito mais impreciso para solos do que para as soluções in vitro devido à heterogeneidade dos solos, à pequena porção de solução presente nos poros do solo e 
à adsorção do $\mathrm{H}^{+}$nas superfícies dos sólidos, o que pode fazer com que a mensuração do $\mathrm{pH}$ em laboratórios varie muito.

$\mathrm{O}$ pH do solo é afetado pelas alterações no potencial redox que ocorre em solos que ficam periodicamente alagados. De maneira geral, condições redutoras causam aumento do pH e condições oxidantes causam redução do pH (ALLOWAY, 1995a; SALOMONS, 1995; MAIA, 2004).O solo tem diversos mecanismos que servem como tampão na variação de $\mathrm{pH}$, como, por exemplo, a inserção de hidróxido de alumínio, $\mathrm{CO}_{2}$, carbonatos e outras reações de troca catiônica $\left(\mathrm{BACHE}^{2}, 1979\right.$ apud ALLOWAY, 1995a). Porém, mesmo na presença dos mecanismos tampão, o pH do solo pode diferir muito de local para local já que existem muitas variações químicas e físico-químicas no solo (ALLOWAY, 1995a).

Assim, o pH determina sob que forma os elementos químicos estarão nas soluções que percolam o solo, influencia na proporção dos íons, no potencial elétrico na superfície dos coloides com cargas variáveis e na formação de polímeros capazes de reter íons (HAYNES, 1982). Dependendo do $\mathrm{pH}$ e do Eh do solo pode-se prever se um determinado elemento aparecerá na forma catiônica, aniônica, na forma de um sal, hidróxidos e etc. Conhecendo-se a solubilidade dos produtos formados, pode-se também definir a mobilidade dos elementos o que, em se tratando de problemas de contaminação do solo e água subterrânea, é muito importante (ADRIANO, 1986; ALLOWAY, 1995b). O pH é uma propriedade físico-química da solução do solo que influencia fortemente outras propriedades, na medida que ele pode modificar drasticamente as reações químicas que ocorrem no solo e, portanto, todas as outras propriedades que dependem dessas reações.

\subsubsection{POTENCIAL DE OXIDAÇÃO E REDUÇÃo (EH)}

Solos são sujeitos a variações nas condições de oxidação-redução (redox) afetando principalmente os elementos carbono, nitrogênio, oxigênio, enxofre, ferro e manganês, embora também afete o argônio, arsênio, cromo, cobre, mercúrio e chumbo (ALLOWAY, 1995a). O equilíbrio redox é controlado pela atividade dos elétrons livres, que pode ser expressa pelo Eh, definido por Palmer (1996) como a medida da intensidade relativa das condições de oxidação ou redução em soluções. Em solos oxidados, o Eh pode variar de +400 a $+700 \mathrm{mV}$. Em sedimentos e solos inundados, o Eh pode variar de -400 a $+700 \mathrm{mV}$ (ADRIANO, 1986; 2001; ALLOWAY, 1995a). O efeito combinado das condições de Eh e $\mathrm{pH}$ afetam diretamente alguns óxidos de Fe e Mn. Estes óxidos podem ser dissolvidos em 
condições de redução de $\mathrm{pH}$ ou $\mathrm{Eh}$, sendo que os óxidos de $\mathrm{Mn}$ são mais facilmente dissolvidos do que os de Fe (Figura 2.12).

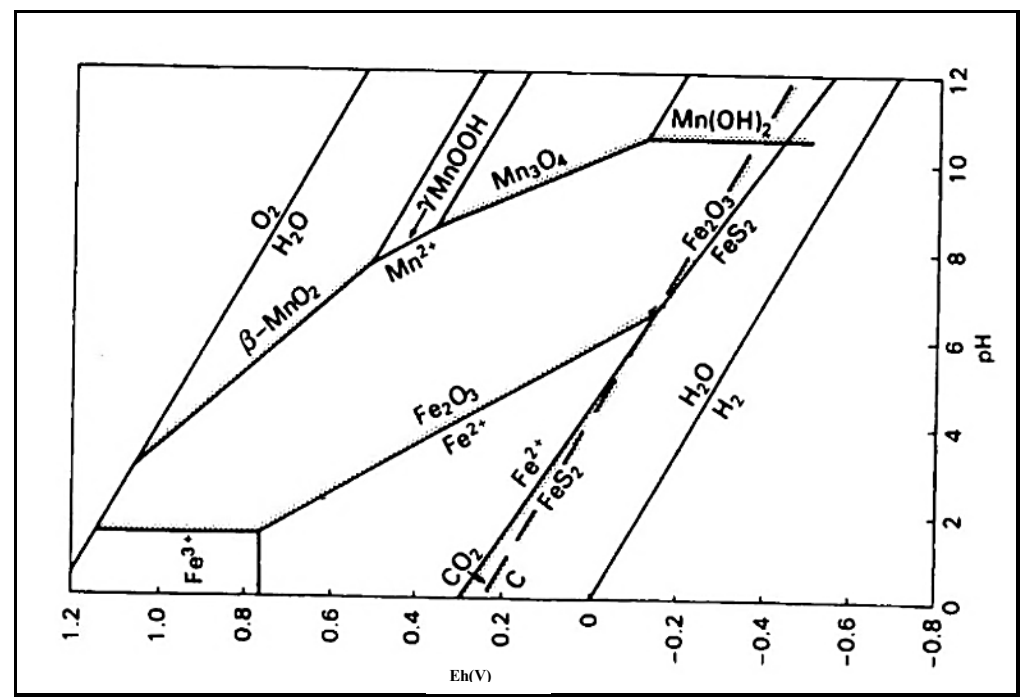

Figura 2.12- Diagrama Eh/pH mostrando a estabilidade dos óxidos de $\mathrm{Fe}$ e Mn, pirita e C (REDRAWN; ROSE; WEBB et al., 1979 apud ALLOWAY, 1995)

As Figuras 2.13, 2.14 e 2.15 mostram os diagramas de pH-Eh para fosforo, sódio e nitrogênio, respectivamente.

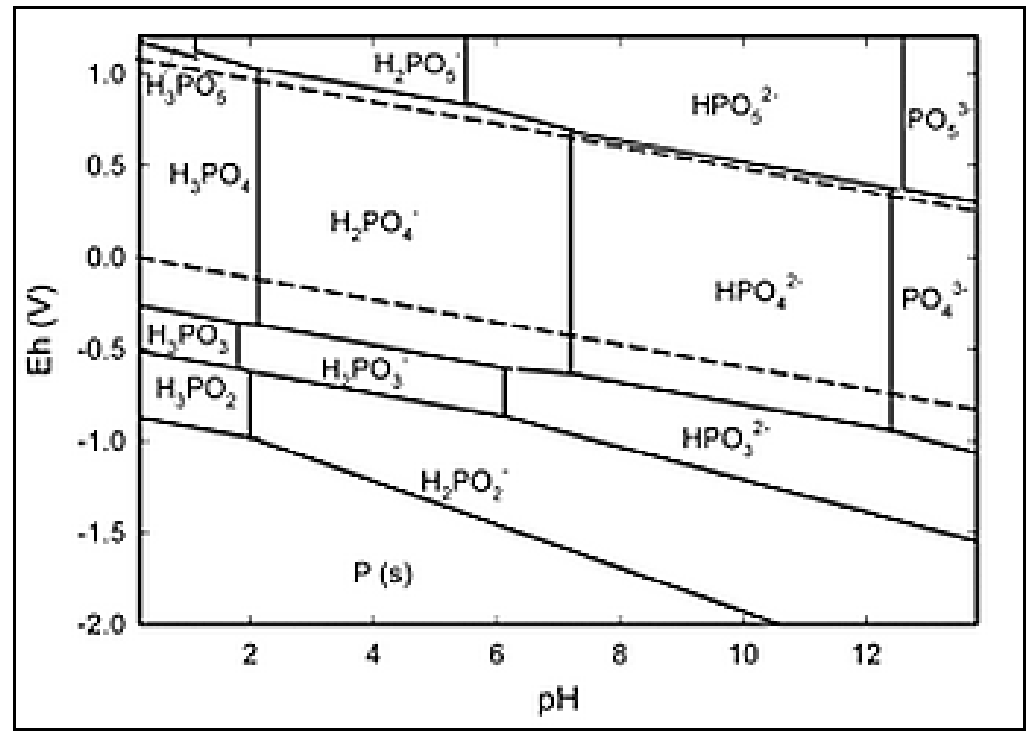

Figura 2.13- Diagrama Eh/pH mostrando a estabilidade das espécies de P(PASEK, 2008) 


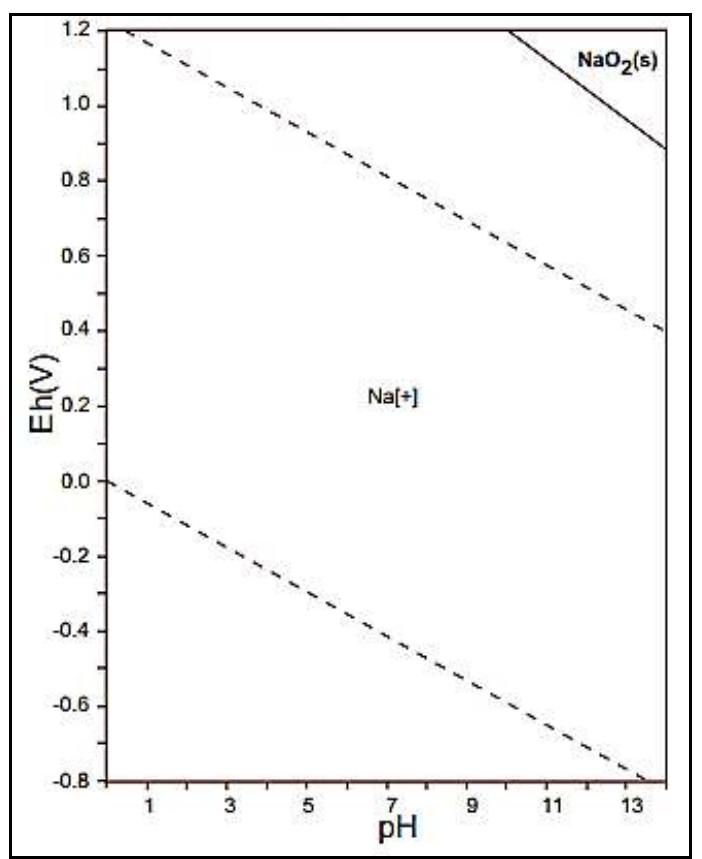

Figura 2.14- Diagrama Eh/pH mostrando a estabilidade das espécies de $\mathrm{Na}$ (TAKENO, 2005)

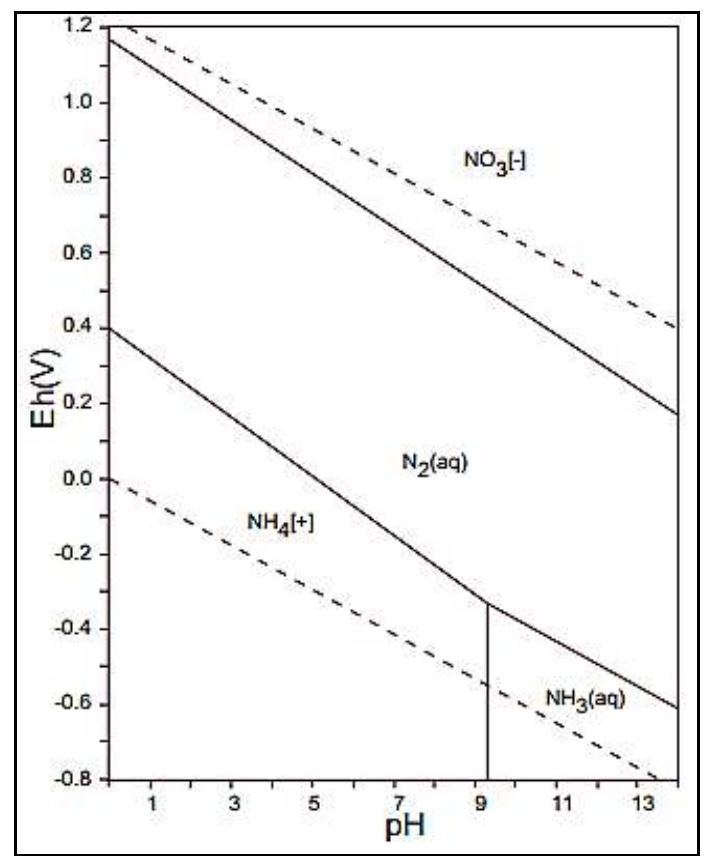

Figura 2.15- Diagrama $\mathrm{Eh} / \mathrm{pH}$ mostrando a estabilidade das espécies de N (TAKENO, 2005)

\subsubsection{CONTEÚDO DE MATÉRIA ORGÂNICA}

A matéria orgânica é um importante constituinte das partículas sólidas dos solos. A complexidade estrutural dos componentes orgânicos do solo tem, por enquanto, impedido a elaboração de uma tabela, como feito para os componentes inorgânicos. No entanto, estudos relacionados às substâncias orgânicas têm permitido que elas sejam divididas em substâncias não-húmica e húmicas (SPOSITO, 1989; ALLOWAY, 1995b). Substâncias húmicas, de maior interesse em se tratando de contaminação de solos, têm sido separadas em laboratórios em três frações: humina (insolúvel em condições ácidas e alcalinas); ácido húmico (solúvel em condições alcalinas e insolúvel em condições ácidas); e ácido fúlvico (solúvel tanto em condições ácidas quanto alcalinas) (ALLOWAY, 1995b). A importância na divisão das substâncias húmicas é decorrente das diferenças existentes entre essas três frações no que diz respeito a peso molecular, conteúdo de carbono, conteúdo de oxigênio, acidez e CTC, sendo: humina > ácido húmico > ácido fúlvico (HAYES; EDWARD, 2001).

\subsubsection{BALANÇO DE CARGAS NO SOLO: PONTO DE CARGA ZERO (PCZ)}

Cargas superficiais nas partículas sólidas se desenvolvem principalmente devido a dois mecanismos: através das substituições isomórficas entre íons de diferentes valências no solo, chamadas de cargas permanentes, ou através das reações de grupos funcionais com íons da 
solução do solo, chamadas de cargas variáveis. Quatro diferentes tipos de cargas superficiais contribuem para a carga líquida total nos solos, $\sigma_{t}$, de acordo com a Equação 1 (SPOSITO,1989; CASAGRANDE; CAMARGO, 1997):

$$
\sigma_{t}=\sigma_{0}+\sigma_{H}+\sigma_{i s}+\sigma_{o s}
$$

onde $\sigma_{0}$ é a carga permanente estrutural; $\sigma_{H}$ é a carga líquida de prótons; $\sigma_{i s}$ é a carga de complexo de esfera interna; e, $\sigma_{o s}$ é a carga de complexo de esfera externa.

A soma da carga líquida de prótons e a carga permanente estrutural é chamada de densidade de carga permanente, $\sigma_{p}$, e a soma das cargas de complexo de esfera externa e interna é a carga variável, $\sigma_{\mathrm{v}}$. Desta forma, a carga líquida total é:

$$
\sigma_{t}=\sigma_{p}+\sigma_{v}
$$

A carga líquida total pode ser negativa, positiva ou nula dependendo das condições químicas do solo (SPOSITO, 1989). Mesmo possuindo cargas elétricas, o sistema total do solo é eletricamente neutro. Assim, o $\sigma_{t}$ da Equação1 deve ser balanceado quando não for nulo. Para isso existe o $\sigma_{d}$, que representa as cargas dos íons em difusão na solução, incluindo $\mathrm{o} \mathrm{H}^{+}$e o $\mathrm{OH}^{-}$, que vão servir como carga de equilíbrio, como sugere a Equação 3:

$$
\sigma_{p}+\sigma_{D}=0
$$

O ponto de carga zero (PCZ) representa o valor de $\mathrm{pH}$ no qual a carga total do solo desaparece, assinalando o movimento livre dos íons na solução e o aumento das forças interpartículas que produzem a floculação. Desta maneira, o PCZ exerce um papel importante na formação do agregado do solo e na retenção de íons, reduzindo perdas por lixiviação, particularmente em cargas variáveis (SPOSITO, 1989; RAIJ, 1973).

Estudos da interação solo-contaminante devem considerar o PCZ para o entendimento dos processos que ocorrem, pois o PCZ é uma das mais importantes propriedades do solo para a descrição de fenômenos decorrentes da dupla camada elétrica de interfaces reversíveis (RAIJ, 1973; FONTES; CAMARGO; SPOSITO, 2001). Segundo Raij (1973) para latossolos, admite-se que valores de $\mathrm{pH}$ determinados em solução $1 \mathrm{~N}$ de $\mathrm{KCl}$ maiores do que valores de $\mathrm{pH}$ obtidos em água, delta $\mathrm{pH}$, indicam a existência de carga elétrica líquida 
positiva (MEKARU; UEHARA, 1972). Por outro lado, valores de $\mathrm{pH}$ em $\mathrm{KCl}$ menores do que valores de pH em água, indicam solo com carga elétrica líquida negativa Equação 4.

$$
\Delta p H=p H_{K C l}-p H_{H_{2} O}
$$

Após a determinação do pH em água e do pH em KCl, Keng e Uehara (1974) propuseram a Equação 5 para determinação do PCZ.

$$
P C Z=2 p H_{K C l}-p H_{H_{2} O}
$$

Quando o solo está com PCZ >1 ele tende a adsorver ânions, e quanto está com PCZ $<1$, a tendência é a adsorção de cátions. Dessa forma, com o pH igual ao PCZ, a capacidade de troca catiônica se iguala à capacidade de troca aniônica.

Além do PCZ, existem outros pontos de carga zero muito utilizado no estudo do comportamento elétrico dos solos, dentre eles o Ponto de Carga Protônica Líquida Zero (PCPLZ), Ponto de Carga Líquida Zero (PCLZ) e, mais recentemente o Ponto de Efeito Salino Nulo (PESN). O PCPLZ representa o valor de $\mathrm{pH}$ no qual a carga dada pelos íons determinadores de potencial $\mathrm{H}^{+}$e $\mathrm{OH}^{-}$desaparece e é importante em solos de carga variável onde a taxa de adsorção específica exerce influencia sobre o balanço total de cargas. O PCLZ é o ponto no qual a carga líquida de íons adsorvidos desaparece, com exceção do $\mathrm{H}^{+}$e $\mathrm{OH}^{-}$, ou seja, representa o pH onde a taxa de sorção de ânions e cátions se iguala, sempre com exceção do $\mathrm{H}^{+}$e $\mathrm{OH}^{-}$. O PESN representa um valor de $\mathrm{pH}$ em que a concentração salina da solução não tem efeito na carga da superfície das partículas do solo. Outros autores têm adotado o termo PESN por definirem o verdadeiro PCZ como o ponto no qual o balanço entre todas as cargas, inclusive as permanentes, seria zero, enquanto o PESN estaria relacionado somente com as cargas variáveis (SPOSITO, 1989; FONTES; CAMARGO; SPOSITO, 2001; SILVA et al., 1996; BENITES; MENDONÇA, 1998).

\subsubsection{TEXTURA}

A textura do solo refere-se à distribuição do tamanho das partículas do solo, ou seja, se um determinado solo é composto por partículas pequenas, intermediárias ou grandes. Quantitativamente, significa a proporção dos vários tamanhos de partículas que ocorrem em um dado solo, em massa. A textura é um atributo natural e permanente e frequentemente é usado para uma caracterização da composição física (HILLEL, 1980). O método tradicional 
de caracterização do tamanho das partículas do solo é a divisão das partículas em quatro classes texturais: argila, silte, areia e pedregulho. Na Figura 2.16 estão representadas as classes texturais adotadas pela Associação Brasileira de Normas Técnicas (ABNT).

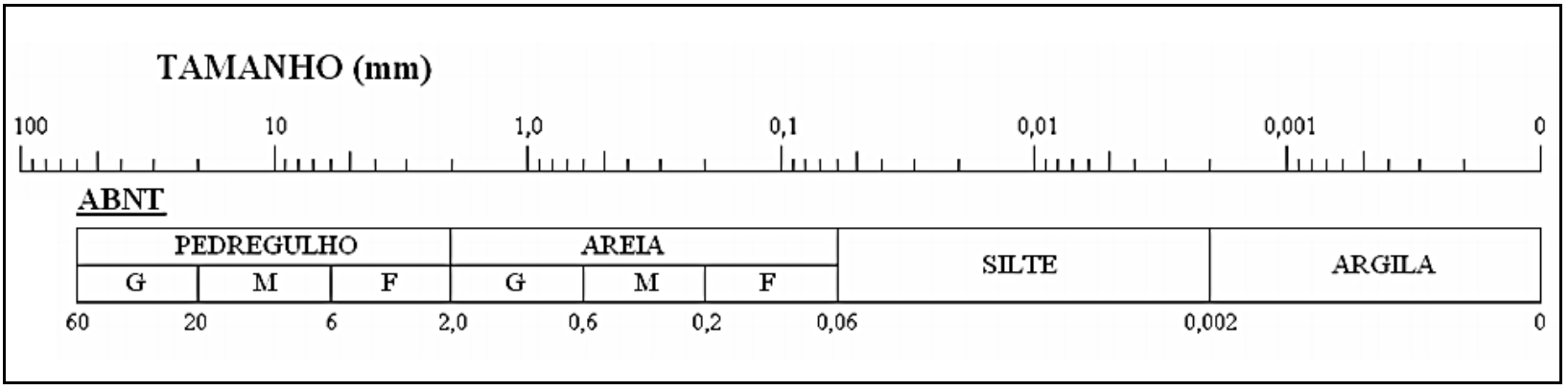

Figura 2.16- Classes texturais do solo (ABNT NBR 7181)

A textura, combinada com a estrutura e com outras propriedades do solo, é muito importante no que diz respeito à retenção e à movimentação de contaminantes.

\subsubsection{SALINIDADE}

Segundo Rengasamy e Olsson (1993), solos sódicos ácidos, caracterizados pelo acúmulo de $\mathrm{Na}^{+}$, alto nível de intemperismo e baixa CTC, são encontrados em regiões de alta

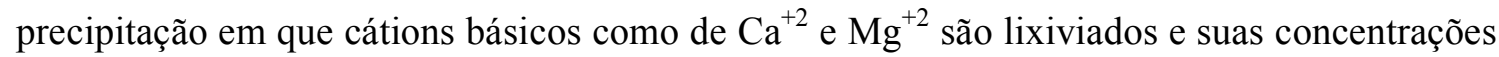
são baixas. Quando nesses solos passa a haver acúmulo de sais solúveis, geralmente é o $\mathrm{Na}^{+}$ que predomina na solução do solo e, desta forma pode passar a ser o cátion predominante no

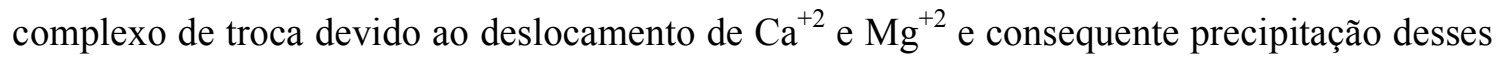
cátions na solução do solo (RICHARDS, 1954). A grande proporção de $\mathrm{Na}^{+}$nos sítios de troca dos minerais de argila reduz a atração entre partículas do solo ocasionando expansão e dispersão devido a alterações no percentual de sódio trocável (PST) do solo e elevados valores de razão de adsorção de sódio (RAS) (IRVINE e REID, 2001; RAIJ, 1991; RENGASAMY e OLSSON, 1993).

O grau de sodificação do solo depende da relação entre as concentrações de sódio e de íons polivalentes na solução do solo. Esta relação é medida pela RAS (SANTOS, 2004). A RAS é um índice que relaciona as concentrações do íon sódio com as concentrações dos íons cálcio e magnésio na água de irrigação, e é calculada a partir da Equação 6

$$
\mathrm{RAS}=\frac{\mathrm{Na}}{\sqrt{\frac{\mathrm{Ca}+\mathrm{Mg}}{2}}}
$$


Minhas e Sharma (1986) chamam a atenção para o fato de que a dispersão das argilas não é favorecida apenas pela alta RAS, mas também pela baixa condutividade elétrica que significa menor teor de íons polivalentes no solo, podendo resultar em maior deslocamento desses pelo íon sódio.

O PST é um índice que indica a proporção de sódio adsorvida no complexo de troca de cátions do solo e é determinado pela Equação 7.

$$
\operatorname{PST}=\frac{\mathrm{Na}_{\mathrm{t}}}{\mathrm{CTC} \times 100 \%}
$$

De acordo com Rengasamy e Olsson (1993) os valores de PST que causam deterioração do solo podem variar de local pra local. Na Austrália, nas superfícies das argilas, por exemplo, o PST é 6\% e o solo é considerado sódico com possibilidade de sofrer degradações estruturais. Nos estados Unidos, o valor de PST que causa algum problema estrutural no solo é de $15 \%$.

\subsection{Potencial total}

A água presente nos poros dos solos pode ser caracterizada pelo seu estado de energia. Para os solos não saturados este estado de energia é determinado através da soma das energias potencial e cinética. No entanto, devido ao movimento da água nos poros do solo ser muito lento, pode-se desprezar a energia cinética. Desta maneira, a energia total da água será igual à energia potencial que é determinada em função da posição e condição interna do solo (REICHARDT, 1985; HILLEL, 1970).

O potencial total da água no solo ( $\Psi)$ é, segundo Vilar (2009), o trabalho útil que deve ser realizado para conduzir um infinitesimal de água pura, reversível e isotermicamente, desde um reservatório, sob condições padronizadas, em uma determinada cota sujeita à pressão atmosférica (ponto A) até a água no solo, na cota de interesse (ponto B). A água espontaneamente tende a ir de um estado de maior energia para um estado de menor energia (Figura 2.17). Desta maneira, conhecendo-se os potenciais da água em diferentes pontos do solo, pode-se determinar sua tendência de movimento. 


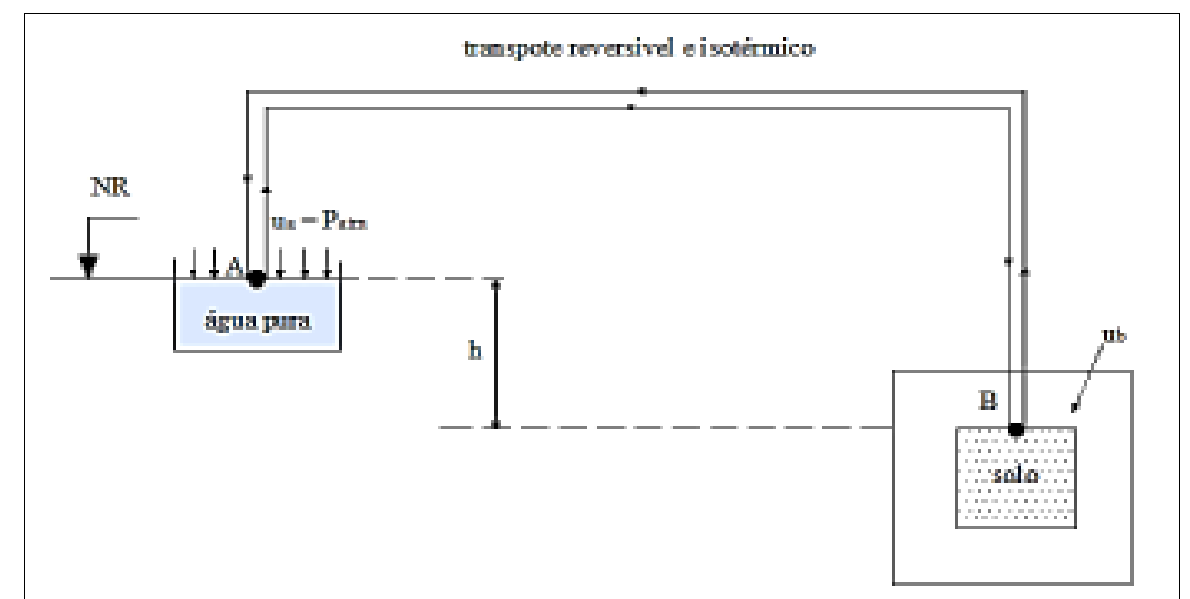

Figura 2.17- Representação da definição do potencial total da água no solo (VILAR, 2009)

O potencial total é composto principalmente pelos potenciais pneumático $\left(\Psi_{p n}\right)$, gravitacional $\left(\Psi_{Z}\right)$, matricial $\left(\Psi_{m a}\right)$, osmótico $\left(\Psi_{o g}\right.$, , e térmico que pode ser desprezado devido ao caráter isotérmico dos processos que ocorrem nos solos (LIBARDI, 1995; REICHARDT, 1996; VILAR, 2002). Desta maneira, o potencial total é dado pela Equação 8:

$$
\Psi_{\mathrm{Z}}=\Psi_{\mathrm{pn}}+\Psi_{\mathrm{Z}}+\Psi_{\mathrm{m}}+\Psi_{\mathrm{os}}
$$

Quando se admite que o potencial gravitacional e pneumático podem ser desprezados por não interferirem no equilíbrio do sistema, o potencial total será então dado apenas pelo somatório do potencial matricial e potencial osmótico. O potencial matricial é aquele que se relaciona às interações entre a matriz do solo e a água, que decorrem de forças associadas com a adsorção e a capilaridade. O potencial osmótico relaciona-se a influencia da presença de sais minerais e substâncias orgânicas na solução do solo. A componente osmótica não possui grande relevância no que diz respeito ao movimento da água, pois quando existem diferenças de concentração salina sem a presença de membranas, o movimento de sais é muito mais importante que o da água (REICHARDT, 1996; VILLAR, 2002).

O conhecimento do potencial da água no solo é essencial para que se entenda o comportamento dos solos não saturados. Isso porque a partir do potencial total da água no solo é possível que se defina o fenômeno da sucção. Villar (2009) definiu sucção total do solo $(S)$ como a pressão manométrica negativa, em relação à pressão externa de gás sobre a água do solo, que deve ser aplicada a um reservatório de água pura (à mesma cota e temperatura) de maneira que se mantenha o equilíbrio, através de uma membrana semipermeável, entre a água pura do reservatório e a água do solo (Figura 2.18). Sempre que o potencial total for 
dado apenas pelo potencial matricial e osmótico é possível relacionar diretamente a sucção total do solo com o potencial total (Equação 9). Assim, a sucção total será separada em sucção osmótica $\left(S_{o s}\right)$ e em sucção matricial $\left(S_{m}\right)$, ambas grandezas positivas que correspondem respectivamente ao potencial osmótico e matricial.

$$
S=S_{o s}+S_{m}
$$

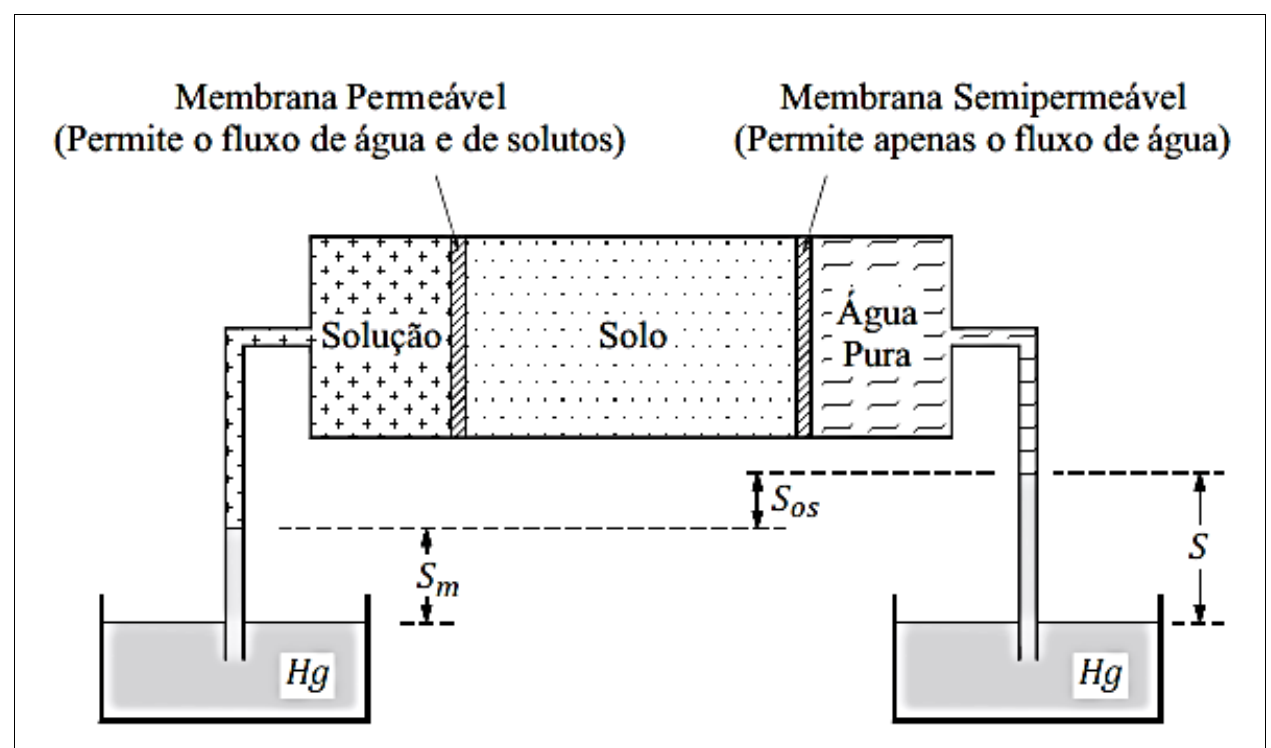

Figura 2.18- Representação das definições de sucção total, matricial e osmótica (VILAR, 2002)

O teor de umidade dos solos pode ser alterado devido a mudanças nas condições ambientais e de pressões aplicadas sobre o solo. O teor de umidade inicial de solos compactados parece ter uma relação direta com o componente de sucção matricial. Por outro lado, a sucção osmótica não parece ser sensível às mudanças no teor de umidade do solo. Como resultado, uma mudança na sucção total é bastante representativa de uma mudança na sucção matricial (FREDLUND e RAHARDJO, 1993). Assim sendo, de acordo com Villar (2002), em Mecânica dos Solos, quando se fala em sucção do solo, a não ser que se faça uma citação específica, fala-se, na verdade, sobre à sucção matricial.

\subsection{INFILTRAÇÃO}

Infiltração é definida como o fenômeno de entrada de água nas camadas de solo próximas à superfície do solo, a qual se movimenta no sentido de cima pra baixo e através de seus vazios, modificando aos poucos a umidade inicial deste solo (LIBARDI, 1995). Este processo pode acontecer por ação da gravidade e/ou capilaridade, e conforme ocorre o avanço da água pelo interior do solo, surge uma frente de molhamento (ou umedecimento) 
(FERNANDES, 2011). Além da quantidade de água disponível para infiltração, este processo depende, fundamentalmente, de alguns fatores, como: tipo de solo, umidade inicial do solo, cobertura vegetal, declividade do terreno, intensidade e duração da chuva, temperatura, dentro outros (LIBARDI, 1995).

A infiltração pode ser mensurada a partir da Infiltração Acumulada, Taxa de Infiltração e Capacidade de Infiltração. A Infiltração acumulada (I) refere-se ao volume de água infiltrada na superfície do solo por unidade de área e depende do teor de umidade volumétrica inicial ao longo da profundidade considerada. Pode ser calculada a partir da Equação 10. A capacidade de infiltração $(\mathrm{C} i)$ refere-se ao volume máximo de água por unidade de área que um solo consegue absorver em um determinado tempo.

$$
I=\int_{\theta_{i}}^{\theta_{\dot{s}}} z \cdot d \theta
$$

em que $I$ é infiltração acumulada, em $[\mathrm{L}], \sigma_{i}$ é o teor de umidade volumétrica incial do solo, em $\left[\mathrm{L}^{3} \mathrm{~L}^{-3}\right]$; Os é o teor de umidade volumétrica de saturação do solo, em [L3 L-3]; z é a profundidade so solo, e, [L].

A taxa de infiltração (i) está relacionada com a infiltração acumulada $(I)$ e é definida como o volume de água infiltrada que atravessa a unidade de área do solo por unidade de tempo (LIBARDI, 1995). Este termo também pode ser chamado de velocidade de infiltração (Equação 11).

$$
i=\frac{d I}{d t}
$$

em que $i$ é a taxa de infiltração, em $\left[\mathrm{L} \mathrm{T}^{-1}\right] ; I$ é a infiltração acumulada, em [L]; t é o tempo, em $[\mathrm{T}]$

A ifiltração acumulada e a taxa de infiltração são ilustradas na Figura 2.19. A taxa de infiltração é alta nos instantes iniciais e diminui ao longo do processo de infiltração. A infiltração acumulada, ao contrário, tende a aumentar ao longo do tempo até que se torne constante quando o processo estiver estabilizado. 


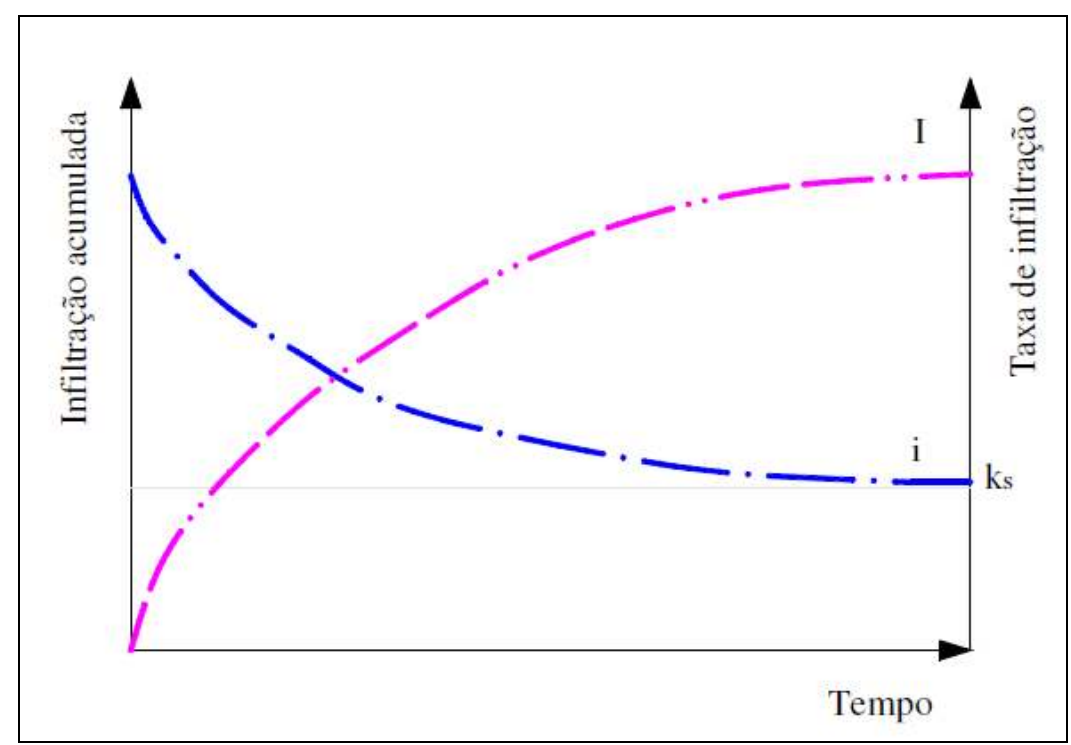

Figura 2.19- Infiltração acumulada e taxa de infiltração no tempo (FERNANDES, 2011)

A aplicação de efluente no solo pode alterar a taxa de infiltração, mas ainda não existe consenso sobre os resultados. Em estudos para investigar os efeitos da aplicação de efluentes tratados nas propriedades químicas e físicas de solos do Irã, Abedi-Koupai et al. (2006) verificaram que com o sistema de irrigação por aspersão houve aumento da taxa de infiltração. Resultado oposto foi obtido quando o sistema de irrigação foi o de superfície. Estes resultados podem estar relacionados com a produção de menor quantidade de material em suspensão pelo sistema de aspersão e, portanto, existe menor possibilidade de entupimento dos poros do solo (ABEDI-KOUPAI et al., 2006). Cook, Kelliher e McMahon (1994), estudaram os efeitos da irrigação com águas residuárias nas propriedades hidráulicas de um solo muito permeável. Verificaram que a taxa de infiltração diminuiu em 50\% após 32 meses de irrigação com águas residuárias. Isto foi atribuído ao entupimento dos poros do solo (COOK; KELLIHER; MCMAHON, 1994).

Abo-Ghobar (1993) constataram redução na taxa de infiltração após aplicação de efluente no solo. Estes autores atribuíram a redução na taxa de infiltração ao acúmulo de sólidos suspensos na superfície do solo. Baumhardt, Wendt e Moore (1992), reportaram que a taxa de infiltração aumentou quando a salinidade e sodicidade do solo reduziu ou quando a salinidade do efluente aplicado aumentou. Jnad et al. (2001) também constatou redução da taxa de infiltração após aplicação de efluente no solo. Outras pesquisas mostraram que a perda de infiltração depende do tipo de solo (quantidade de argila e $\mathrm{CaCO}_{3}$ ) e os mecanismos dominantes de formação da vedação. Portanto, para evitar um possível efeito deletério sobre a 
estrutura do solo, é necessário identificar as zonas sensíveis e solos antes da aplicação de efluentes para irrigação (LADO; BEN-HUR; ASSOULINE, 2005).

De maneira geral, os efeitos na taxa de infiltração são resultantes dos mesmos efeitos que atuam na redução da condutividade hidráulica dos solos, como, por exemplo, excesso de microorganismos, sólidos suspensos, colapso da estrutura do solo devido à dissolução da matéria orgânica ou devido à dispersão ou expensão de argilominerais (GLOAGUEN, 2005; MAGESAN et al., 1999; TARCHITZKY et al., 1999).

\subsection{RETENÇão de ÁGUA NO SOLO}

Quando ocorre o lançamento de efluentes, a princípio há um aumento da umidade na camada mais superficial do solo, até que o líquido infiltre e então a umidade subsuperficial vai aumentando enquanto que superficialmente vai diminuindo. Com a infiltração ocorre aumento do teor de umidade do solo e, inversamente, redução da sucção. Esta relação entre a quantidade de água retida no solo e a sucção é expressa pela curva de retenção de água (CRA). A quantidade de água presente no solo pode ser expressa pelo teor de umidade gravimétrico $(w)$, volumétrico $(\theta)$ ou pelo grau de saturação $(S r)$ (FREDLUND; RAHARDJO, 1993). A curva de retenção de água no solo tem se tornado o instrumento básico de caracterização dos solos não saturados, uma vez que trata da única forma de relacionar a sucção com um índice físico do solo. Esta curva é uma componente chave para a resolução de problemas de fluxo e de retenção de água, tanto na geotecnia quanto na agricultura e na movimentação de contaminantes. Além disso, a curva de retenção de água tem sido utilizada para previsão da resistência ao cisalhamento e da função condutividade hidráulica dos solos não saturados (FREDLUND; XING, 1994).

A Figura 2.20 apresenta as características principais da CRA durante a trajetória de secagem e de umedecimento. A CRA pode apresentar histerese, ou seja, os valores de sucção e umidade obtidos ao longo da CRA de secagem são diferentes daqueles obtidos ao longo da CRA de umedecimento, como se observa na Figura 2.20. A histerese pode ser atribuída a diversos fatores, entre eles, à geometria não uniforme dos poros que interfere nos fenômenos capilares, ao aprisionamento de ar nos vazios do solo durante o processo de umedecimento, à variação do ângulo de molhamento em processos de drenagem e à contração e expansão de argilominerais durante o seu secamento e umedecimento (FREDLUND e XING, 1994; MIGUEL e VILAR, 2009; REICHARDT, 1985). 


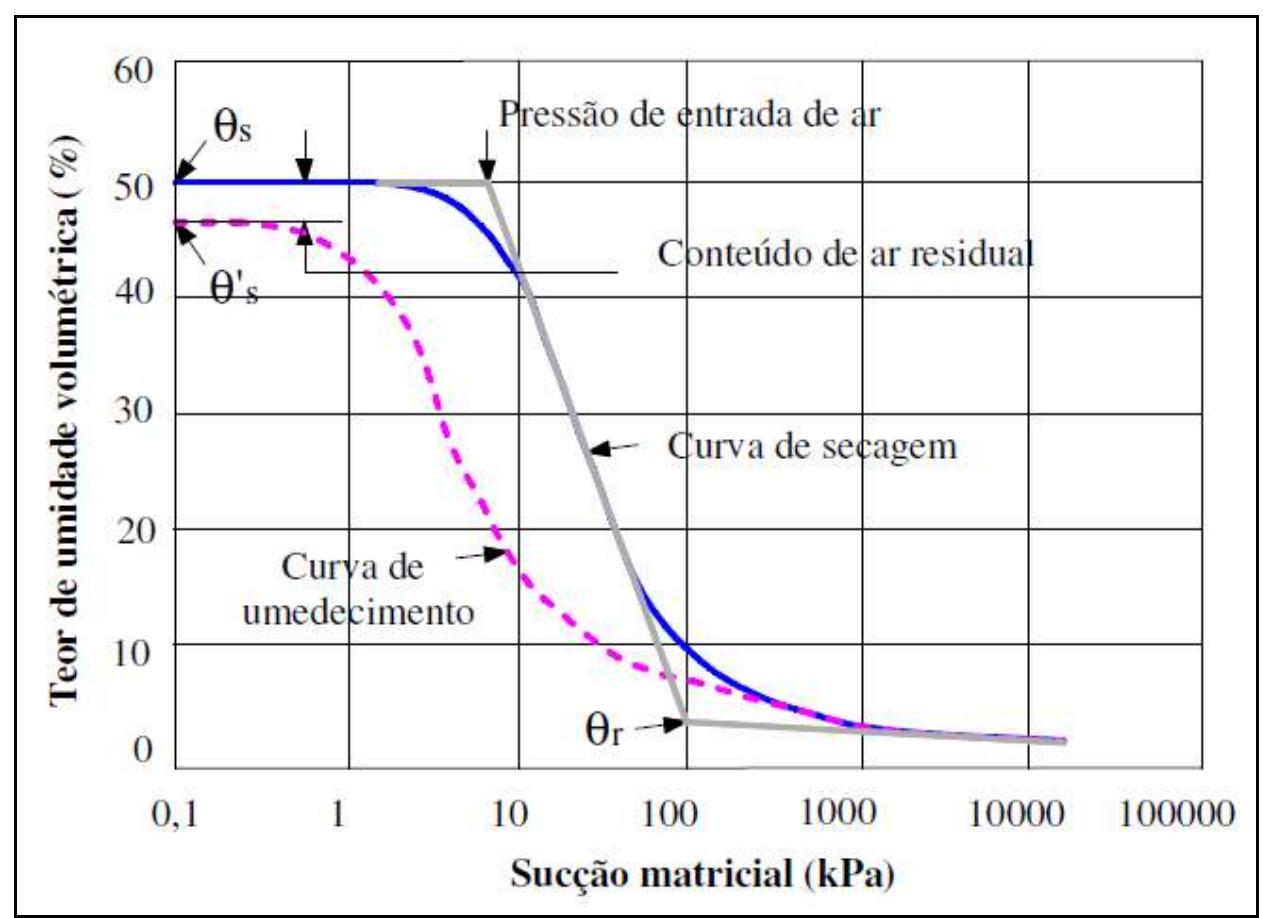

Figura 2.20- Principais componentes da curva de retenção e água típica (FREDLUND e XING, 1994)

Ainda se analisando a Figura 2.20, a partir do valor da sucção na condição saturada $\left(\theta_{s}\right)$, percorrendo a curva durante a trajetória de secagem, chega-se a pressão de entrada de ar e depois ao valor de sucção residual (umidade residual) $\left(\theta_{R}\right)$. O valor da pressão de entrada de ar é obtido estendendo-se o trecho de maior declividade da curva de retenção de água até a inserção com a horizontal que corresponde a Sr de 100\%, ou com a horizontal que corresponde a umidade de saturação. A coordenada no ponto onde ocorre a intersecção das duas retas corresponde à sucção que equivale à pressão de entrada de ar (VANAPALLI; FREDLUND; PUFAHL, 1999). A sucção residual (umidade residual) do solo corresponde a um grau de saturação abaixo do qual um acréscimo de sucção não provoca alteração significativa no teor de umidade (VANAPALLI; FREDLUND; PUFAHL, 1999; HILLEL et al., 1980; MIGUEL; VILAR, 2009).

Segundo Vanapalli et al. (1996), podem ser identificados quatro estágios de saturação ao longo da CRA: estágio de efeito de fronteira, estágio de transição primária, estágio de transição secundária e estágio residual de não saturação (Figura 2.21). No primeiro estágio, todos os poros do solo estão preenchidos com água. Esta situação permanece até que a sucção atinja o valor de entrada de ar. Este valor identifica o ponto no qual o ar entra nos poros de diâmetros maiores. No estágio de transição primária o solo começa a dessaturar. Esta dessaturação reduz ainda mais no estágio de transição secundária e com isso ocorre aumento 
significativo da sucção. No estágio residual de não saturação, grandes aumentos nos valores de sucção provocam pequenas mudanças no teor de umidade ou no grau de saturação do solo.

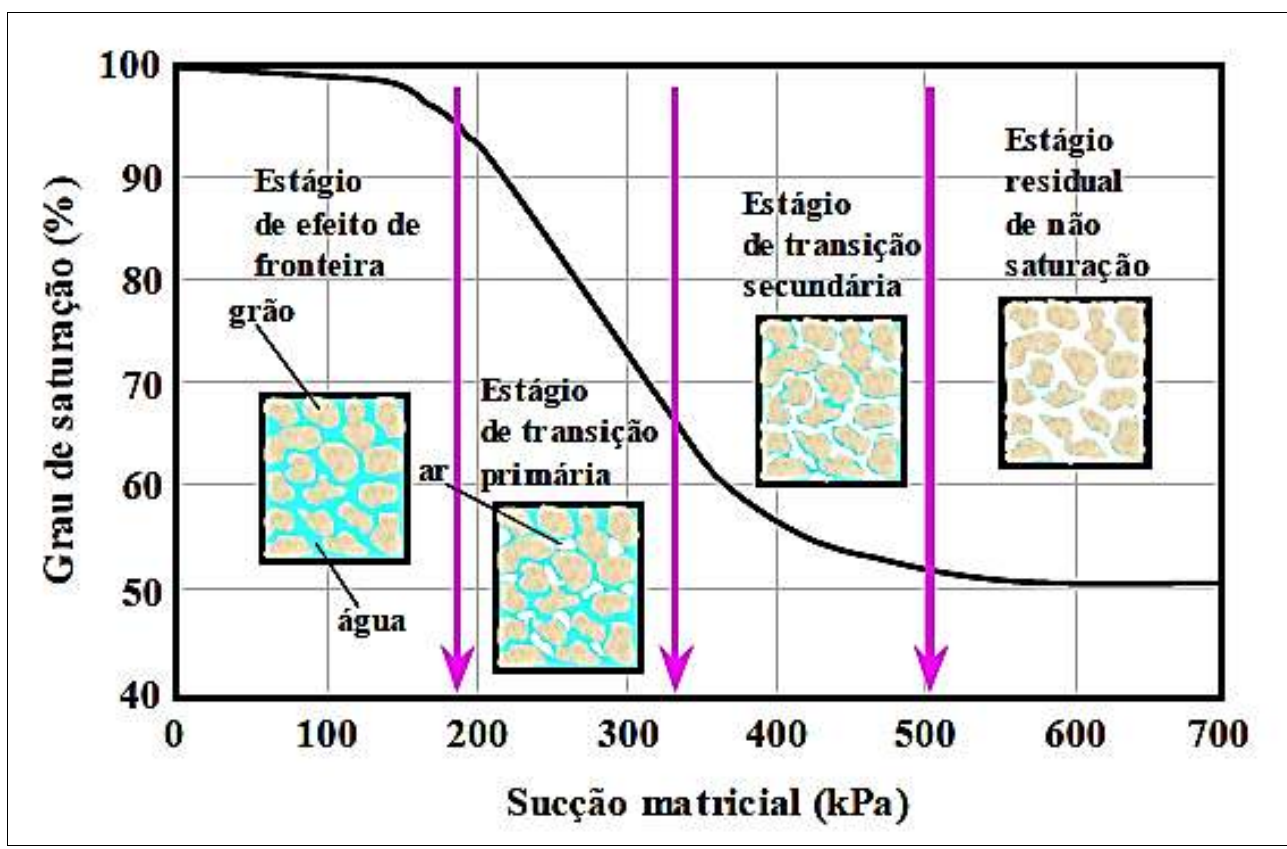

Figura 2.21- Estágios da curva de retenção para um meio poroso hipotético (modificado de VANAPALLI et al. 1996)

A forma da CRA além de depender da trajetória do ensaio (umedecimento ou secagem), também depende de algumas singularidades dos solos como, por exemplo: estrutura, tamanho e geometria dos poros, textura e mineralogia. A Figura (2.22) apresenta a CRA típica para solos argilosos e arenosos e para um solo com distribuição de poros do tipo bimodal, ou seja, de solos constituídos por uma porosidade dupla.

Observa-se na Figura 2.22 que para solos argilosos o desenvolvimento da sucção é maior do que para solos arenosos. Para um mesmo valor de sucção, os solos os solos arenosos tendem a reter mais água do que os solos argilosos. Isso pode ser explicado pelo fato de que os solos arenosos perdem água mais rapidamente, mostrado na rápida variação de umidade em curto intervalo de sucção, devido à existência de poros com diâmetros maiores do que àqueles dos solos argilosos. Os valores de entrada de ar e teor de umidade saturada $\left(\theta_{s}\right)$ geralmente aumentam com a plasticidade do solo (FREDLUND e XING, 1994). 


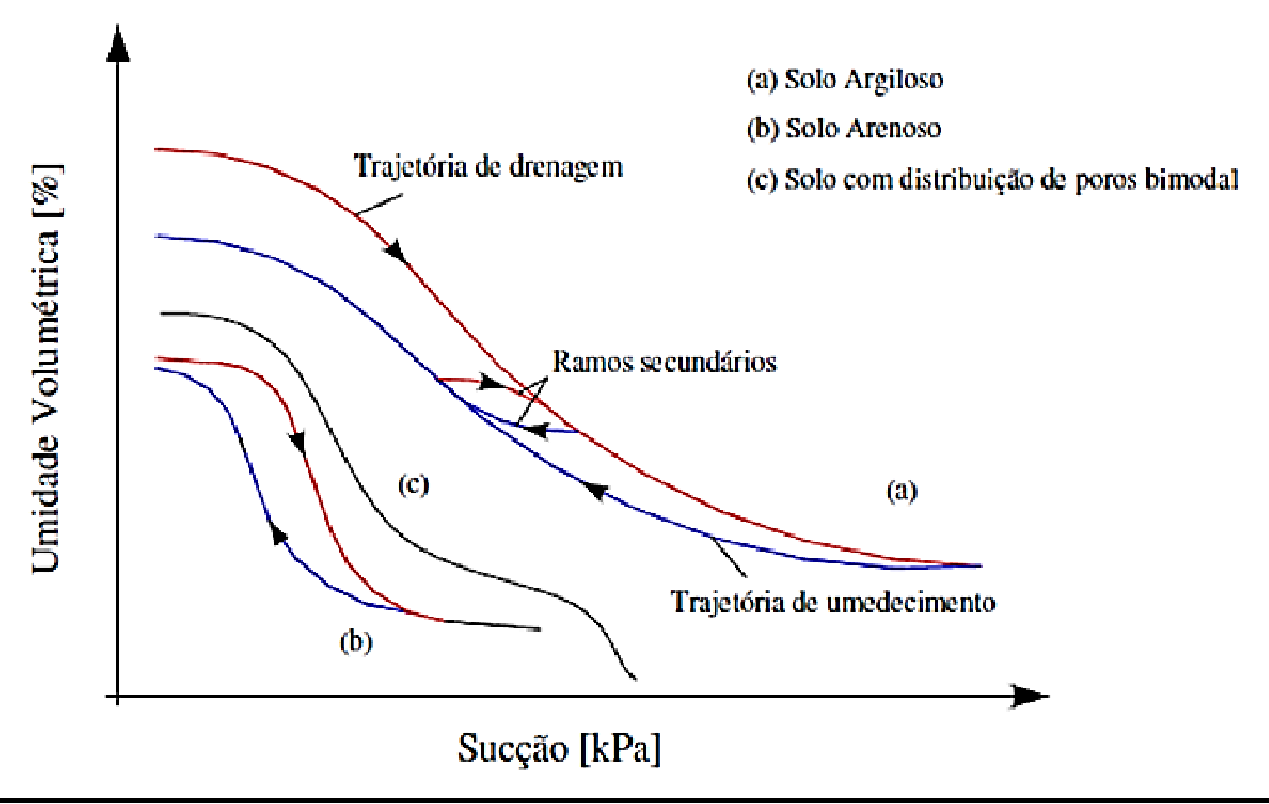

Figura 2.22- Curvas de retenção de água representativas para solos argilosos e arenosos e para solo com distribuição de poros bimodal (RODRIGUES, 2007)

Os valores experimentais da CRA podem ser ajustados matematicamente a modelos. Existem diversos modelos que podem ser utilizadas para ajustar as curvas de retenção de água (LEONG; RAHARDJO, 1997b). No entanto, de acordo com Gerscovich e Sayão (2002) os pontos experimentais das CRAs de solos brasileiros são mais bem ajustados pelos modelos propostos por Gardner (1958), van Genuchten (1980) Fredlund e Xing (1994). Esses modelos e seus parâmetros de ajuste são apresentados na Tabela 2.4.

Leong e Rahardjo (1997) chamam atenção para o fato de que os termos $q$, $\alpha$ e $a$ das equações de Gardner (1958), van Genuchten (1980) e Fredlund e Xing (1994), respectivamente, não se referem diretamente á pressão de entrada de ar, apesar de estarem relacionados com ela. Outro ponto importante, segundo Leong e Rahardjo (1997), é que as equações de van Genuchten (1980) e Fredlund e Xing (1994) possibilitam um ajuste da CRA em formato sigmoide que é o formato mais comum verificado na literatura. Além disso, essas equações apresentam melhor ajuste para uma maior variedade de solos (LEONG; RAHARDJO, 1997). 
Tabela 2.4- Equações de ajuste da curva de retenção de água e seus respectivos parâmetros (Modificado de PEIXOTO, 2011; MENDES, 2008 e FERNANDES, 2011)

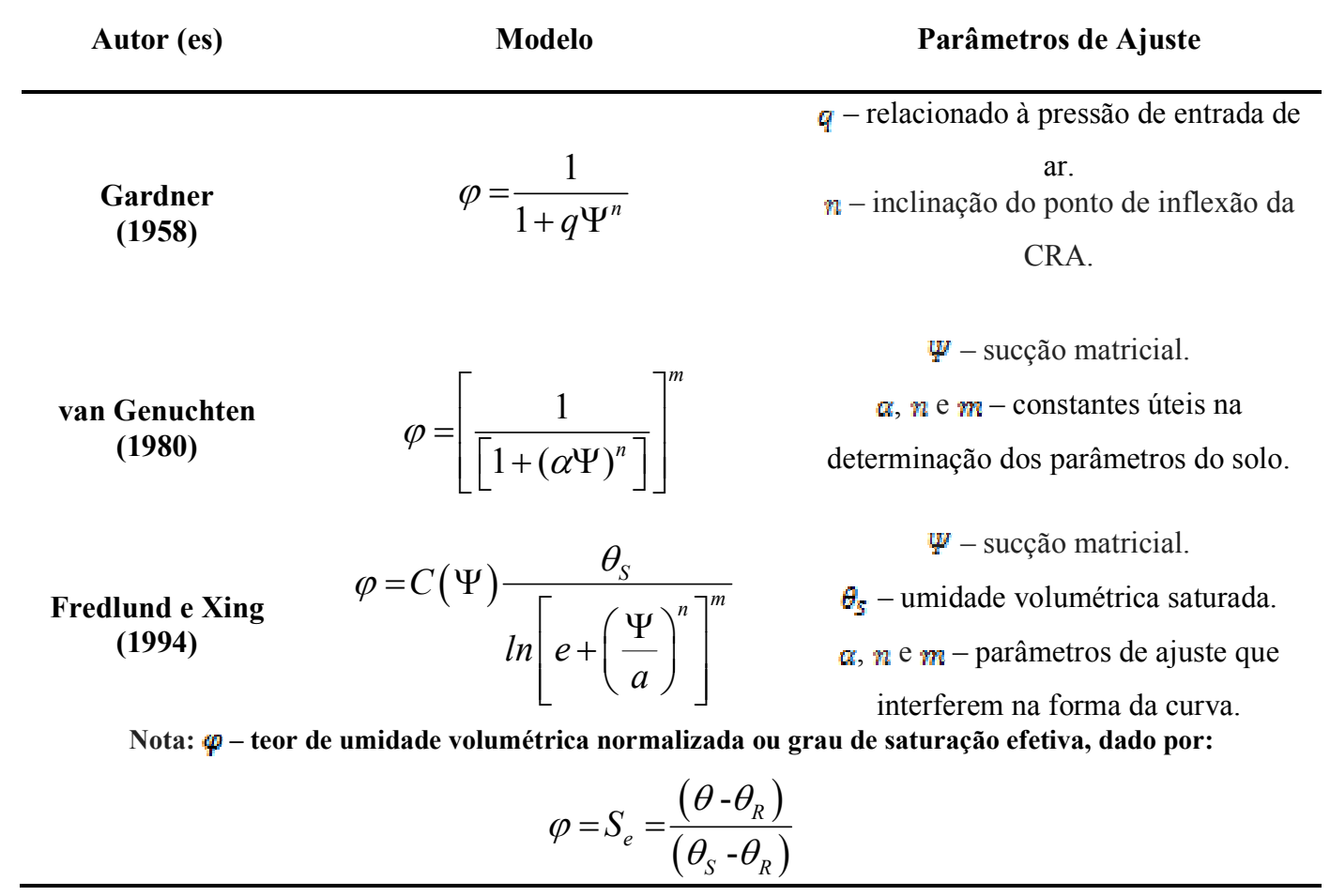

Marinho (1994) alerta que as equações da Tabela 2.4 podem ser aplicadas somente para ajustar pontos experimentais da CRA de solos que apresentem uma distribuição de poros do tipo monomodal. Para solos com porosidade bimodal (ou dupla), pode-se utilizar o modelo sugerido por Durner (1994), empregando-se a Equação 12:

$$
\mathrm{S}_{\mathrm{e}}=\mathrm{w}_{1} \cdot \frac{1}{\left[1+\left(\alpha_{1}|\Psi|\right)^{\mathrm{n}_{1}}\right]^{\mathrm{m}_{1}}}+\mathrm{w}_{2} \cdot \frac{1}{\left[1+\left(\alpha_{2}|\Psi|\right)^{\mathrm{n}_{2}}\right]^{\mathrm{m}_{2}}}
$$

onde: $w_{i}$ é o peso atribuído a cada sub-curva, onde $0<w_{i}<1$ e $w_{i}=1$. Os valores $\alpha_{\mathrm{i}}, \mathbf{n}_{\mathrm{j}}, \mathrm{m}_{\mathrm{i}}$ são os parâmetros das sub-curvas que estão sujeitas as seguintes condições $\alpha_{i}>0, n_{i}>1$ e $m_{i}$ $>0 ; \Psi$ é a sucção matricial; $s_{\mathbb{\Psi}}$ é a saturação efetiva, definida por:

$$
\mathrm{S}_{\mathrm{e}}=\frac{\left(\theta-\theta_{\mathrm{R}}\right)}{\left(\theta_{\mathrm{S}}-\theta_{\mathrm{R}}\right)}
$$

onde: $\theta_{k}$ e $\theta_{s}$ representam os teores de umidade volumétrica residual e saturada, respectivamente. 
A sucção, tanto na trajetória de secagem quando na trajetória de umedecimento, pode ser medida de maneira direta ou indireta. As principais técnicas de medição direta da sucção são: tensiômetros, funil de placa porosa, câmara com placa de alta pressão de entrada de ar (ou placa de sucção) e técnica de translação de eixos (LIBARDI, 1995; MARINHO, 1994; VILAR, 2009). As principais técnicas de medição indireta da sucção são: sensores de blocos porosos e a técnica do papel filtro (MARINHO, 1994; VILAR, 2009)

\subsubsection{TÉCNICA DO PAPEL FILTRO}

Esta técnica baseia-se no princípio da absorção e equilíbrio que existe quando em um recipiente hermeticamente fechado um material poroso (solo) com alguma umidade e sucção é colocado em contato com o papel filtro, cuja umidade é menor que a do material poroso, com sua curva de sucção previamente conhecida. Este papel absorverá água da amostra do material poroso até atingir, após determinado período de tempo, um estado de equilíbrio de sucção como solo. A sucção do solo é então determinada a partir do valor da umidade final do papel filtro e de sua curva característica de sucção (MARINHO, 1994).

O estado de quilíbrio entre ambos irá nos fornecer a mesma sucção no solo e no material poroso, porém com conteúdos de umidades diferentes. O fluxo de umidade entre o papel e o solo pode ocorrer através de fluxo capilar ou fluxo de vapor. A sucção matricial é medida com o fluxo capilar através do contato direto entre a amostra de solo e o papel filtro (Figura 2.23a). A sucção total é medida com o fluxo de vapor através de um espaço existente entre a amostra de solo e o papel filtro (Figura 2.23b) (MARINHO, 1994).

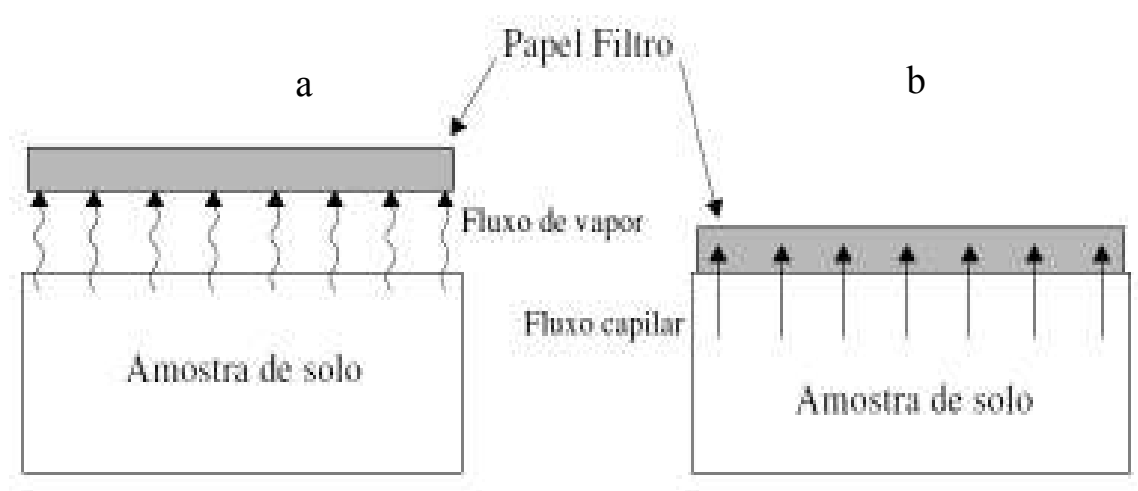

Figura 2.23- Duas configurações do ensaio com papel filtro. a: Sucção total; b: Sucção matricial (modificado de MARINHO, 1994)

Apesar de necessitar de extremo cuidado durante sua realização, esta técnica vem sendo muito ulizada por ser um método fácil, de baixo custo e que consegue cobrir uma 
grande faixa de sucç̧ão (LEONG; HE; RAHARDJO, 2002; MARINHO, 1994). Um dos principais cuidados diz respeito ao tempo de equilíbrio de sucção entre a amostra de solo e o papel filtro. Marinho (1994) sugeriu tempo de equilibrio para diferentes níveis de sucção. Além disso, obter um efetivo contato entre o papel filtro e o solo é bastante difícil, como relataram Fredlund e Rahardjo (1993) e Marinho e Oliveira (2006).

\subsection{FLUXO DE ÁGUA EM MEIO POROSO}

Segundo Jong van Lier e Libardi (1999), a condutividade hidráulica é um dos principais parâmetros para estudos relacionados ao fluxo de água no solo, como, por exemplo, drenagem, infiltração, percolação de contaminantes, nutrição de plantas, controle de erosão, etc. Deve ser entendida como um conjunto solo-fluido, que é influenciado por alguns fatores como textura, densidade, estrutura do solo, composição da solução aquosa, expansibilidade, complexo de troca iônico, atividade microbiana e a presença de ar nos poros (HILLEL, 1970).

Henry Darcy em 1856 definiu empiricamente condutividade hidráulica como uma constante de proporcionalidade, $k$, presente nas relações matemáticas resultantes de seus experimentos de infiltração vertical em colunas de areia homogêneas e saturadas e com isso definiu uma equação denominada de equação de Darcy. A Equação 14 descreve o movimento de água nos solos.

$$
q=-k_{s} \cdot \nabla \varphi_{t}
$$

em que $q$ é a a velocidade de Darcy, em $\left[\mathrm{L} \mathrm{T}^{-1}\right] ; k_{z}$ é a condutividade hidráulica saturada do solo, em $\left[\mathrm{L} \mathrm{T}^{-1}\right] ; \nabla \varphi_{t}$ é o gradiente de potencial total da água, em $\left[\mathrm{L} \mathrm{L}^{-1}\right]$.

Devido ao sentido do fluxo ser inverso ao do gradiente, ou seja, o movimento da água ocorre de pontos com maior potencial para pontos com menor potencial, a Equação 14 tem sinal negativo.

Em 1907, Buckinghan sugere que a equação de Darcy seja adaptada e que considere a condutividade hidráulica como função da área do espaço poroso do solo não ocupado por ar, sendo assim, dependente do conteúdo de água do meio. Desta maneira, tem-se a equação de Darcy-Buckinghan (Equação 15).

$$
q=-k(\theta) . \nabla \varphi_{t}
$$


em que $q$ é a densidade de fluxo, em $\left[\mathrm{L} \mathrm{T}^{-1}\right] ; \boldsymbol{k}(\theta)$ é a condutividade hidráulica em função do conteúdo volumétrico de água $(\theta)$ e $\nabla \varphi_{z}$ é o vetor gradiente de potencial total da água, em [L $\left.\mathrm{L}^{-1}\right]$ (RICHARDS, 1928).

A equação de Darcy-Buckinghan rege o fluxo de água no solo na condição saturada e não saturada em regime permanente. No entanto, em muitas situações o fluxo em meios porosos varia em função da posição e do tempo, ou seja, não há equilíbrio dinâmico e o regime de fluxo passa a ser chamado transiente. No caso de regime transiente, o movimento de água do solo é regido pela equação da continuidade. A equação da continuidade estabelece por meio de uma equação diferencial uma relação entre o volume de entrada e saída da água em um elemento de solo, o qual varia com o tempo e a posição. A Figura 2.24 traz um elemento de volume $(\Delta V)$ com dimensões delta $\Delta \mathrm{x}, \Delta \mathrm{y}, \Delta \mathrm{z}$, que está submetido a um fluxo de água, que pode ser decomposto nas três direções $(\mathrm{x}, \mathrm{y}, \mathrm{z})$ resultando em qx, qy e qz (REICHARDT, 1985).

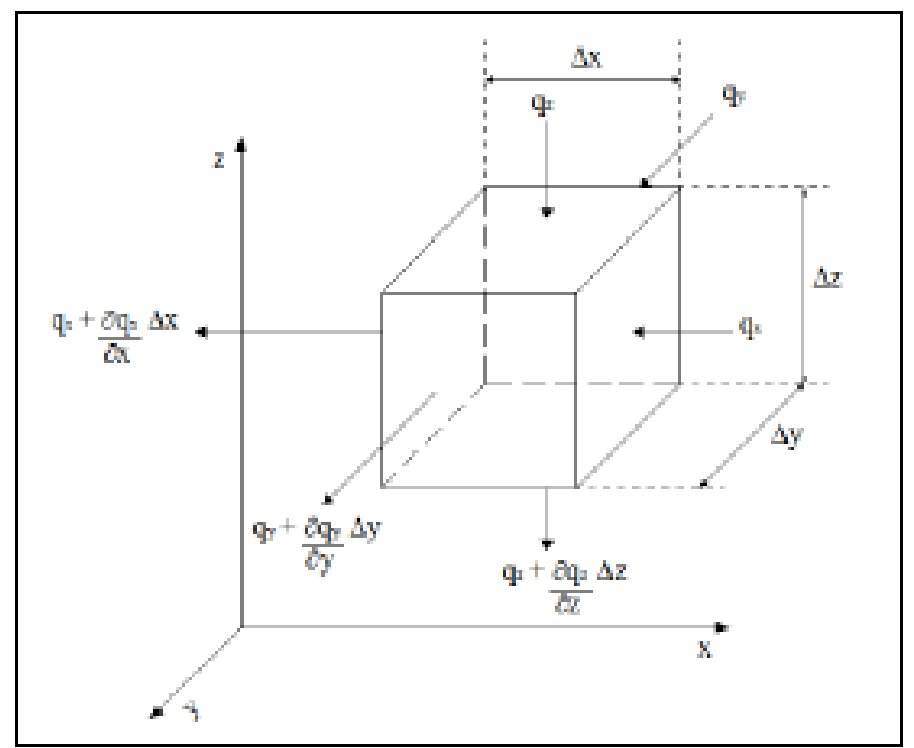

Figura 2.24- Elemento de volume de solo, através do qual a água está fluindo (modificado de REICHARDT, 1985)

O fluxo de entrada na direção x é determinado pelo volume de água que atravessa perpendicularmente a face $\mathrm{x}$ por unidade de tempo (Equação 16).

$$
Q_{x}=q_{x} \cdot \Delta y \cdot \Delta z
$$


em que $Q_{\alpha}$ é a vazão de entrada de água perpendicular à face x no elemento de solo, em $\left[\mathrm{L}^{3} \mathrm{~T}^{-}\right.$ $\left.{ }^{1}\right] ; q_{x}$ é a velocidade de Darcy na direção $\mathrm{x}, \mathrm{em}\left[\mathrm{L} \mathrm{T}^{-1}\right] ; \Delta y$ é a dimensão da face $\mathrm{y}, \mathrm{em}[\mathrm{L}] ; \Delta z$ é a dimensão da face $z$, em [L].

O fluxo de saída para a direção x pode ter uma variação $\left(\partial \mathrm{q}_{\mathrm{x}} / \partial \mathrm{x}\right)$ ao longo da dimensão $\Delta \mathrm{x}$ (Equação 17) (REICHARDT, 1985; REICHARDT, 1996).

$$
Q_{X}^{\prime}=\left(q_{x}+\frac{\partial q_{x}}{\partial x} \cdot \Delta y \cdot \Delta z\right)
$$

em que $Q_{X}^{\prime}$ é a vazão de saída de água perpendicular à face x no elemento de solo, em $\left[\mathrm{L}^{3} \mathrm{~T}^{-}\right.$ $\left.{ }^{1}\right] ; q_{x}$ é a densidade de fluxo na direção x, em $\left[\mathrm{L} \mathrm{T}^{-1}\right] ;\left(\partial q_{x} / \partial x\right)$ é a variação da densidade de fluxo ao longo da direção x, em $\left[\mathrm{L} \mathrm{T}^{-1}\right] ; \Delta y$ é a dimensão da face y, em [L]; $\Delta z$ é a dimensão da face $z$, em $[L]$.

A variação da vazão de água deste elemento de solo é igual a diferença entre a vazão de entrada de água e a vazão de saída de água durante um determinado tempo $(\Delta \mathrm{t})$ na direção $\mathrm{x}$, que pode ser determinada pela Equação 18

$$
\begin{gathered}
\Delta Q_{x}=Q_{x}-Q_{x}^{\prime} \\
\Delta Q_{x}=q_{x} \cdot \Delta y \cdot \Delta z \cdot \Delta t-\left[q_{x} \cdot \Delta y \cdot \Delta z \cdot \Delta t+\left(q_{x}+\frac{\partial q_{x}}{\partial x} \cdot \Delta x\right) \cdot \Delta y \cdot \Delta z \cdot \Delta t\right] \\
\Delta Q_{x}=-\left(\frac{\partial q_{x}}{\partial x}\right) \cdot \Delta x \cdot \Delta y \cdot \Delta z \cdot \Delta t
\end{gathered}
$$

em que:

$$
\begin{gathered}
\Delta V=\Delta x \cdot \Delta y \cdot \Delta z \\
\Delta Q_{x}=-\left(\frac{\partial q_{x}}{\partial x}\right) \cdot \Delta V \cdot \Delta t
\end{gathered}
$$

e que pode ser expressa para um tempo infinitesimal: 


$$
\frac{\partial Q_{x}}{\partial t}=-\left(\frac{\partial q_{x}}{\partial x}\right) \cdot \Delta V
$$

$\mathrm{O}$ cálculo da variação nas direções y e $\mathrm{z}$ é feita de maneira análoga à Equação 23. Portanto, pode-se dizer que a variação total de água neste elemento de solo é igual ao somatório dos fluxos nas direções x, y e z; como representa a Equação 24.

$$
\frac{\partial Q}{\partial t}=-\left[\frac{\partial q_{x}}{\partial x}+\frac{\partial q_{y}}{\partial y}+\frac{\partial q_{z}}{\partial z}\right] . \Delta V
$$

Dividindo a Equação 24 por $A V$, observa-se que a parcela $2 q / \partial t$ passa a variar com o teor de umidade volumétrico por umidade de tempo, $\partial \theta / \partial t$. Dessa forma, a Equação 25 representa a chamada equação da continuidade para fluxo de água no solo.

$$
\frac{\partial \theta}{\partial t}=-\left[\frac{\partial q_{x}}{\partial x}+\frac{\partial q_{y}}{\partial y}+\frac{\partial q_{z}}{\partial z}\right]
$$

Richards (1928) substituiu a equação de Darcy-Buckingham (Equação 15) na equação da continuidade (Equação 25) e obteve a equação diferencial geral que rege o movimento de água em solos não saturados. Esta equação é chamada de equação de Richards (Equacao 29).

$$
\begin{aligned}
& q_{x}=-k_{x}(\theta) \cdot\left(\frac{\partial \phi_{t}}{\partial x}\right) \\
& q_{y}=-k_{y}(\theta) \cdot\left(\frac{\partial \phi_{t}}{\partial y}\right) \\
& q_{z}=-k_{z}(\theta) \cdot\left(\frac{\partial \phi_{t}}{\partial z}\right)
\end{aligned}
$$

Portanto, substituindo-se as Equações 26, 27, e 28 na equação da continuidade, obtemos a equação de Richards, que é igual a:

$$
\frac{\partial \theta}{\partial t}=\frac{\partial}{\partial x}\left[k_{x}(\theta) \cdot\left(\frac{\partial \phi_{t}}{\partial x}\right)\right]+\frac{\partial}{\partial y}\left[k_{y}(\theta) \cdot\left(\frac{\partial \phi_{t}}{\partial y}\right)\right]+\frac{\partial}{\partial z}\left[k_{z}(\theta) \cdot\left(\frac{\partial \phi_{t}}{\partial z}\right)\right]
$$


Segundo Fredlund, Xing e Huang (1994) nenhuma propriedade do solo varia tanto quanto a condutividade hidráulica. Para solos saturados o coeficiente de condutividade hidráulica pode variar em mais de dez ordens de grandeza, quando se varia de um solo pedregulhento para um argiloso. Para solos não saturados, a variação de até dez ordens de grandeza pode ocorrer em um mesmo solo, dependendo do nível de sucção atuante. O coeficiente de condutividade hidráulica saturada, $k_{s}$, normalmente é representado em função do índice de vazios, e. Para solos não saturados, o coeficiente de condutividade hidráulica é função do índice de vazios e também do teor de umidade. Se a estrutura do for considerada como incompressível, dissociam-se os dois parâmetros em apenas um. Assim, o $k_{s}$ pode ser quantificado em relação ao índice de vazios e a função condutividade hidráulica em relação ao teor de umidade $(\theta)$.

Em resumo, os parâmetros fundamentais para o entendimento do fluxo de água em meios porosos são: a condutividade hidráulica, a vazão, a velocidade linear média, a velocidade de Darcy e o gradiente hidráulico. Esses parâmetros de fluxo de água são também muito importantes no estudo do transporte de solutos no solo, que será abordado na próxima seção.

\subsection{TRANSPORTE DE SOLUTOS NO SOLO}

A interação solo-soluto é de grande complexidade, pois podem ocorrer simultaneamente fenômenos físicos, químicos e biológicos. Essa complexidade, somada ao aspecto transiente dos fluidos e à grande variabilidade das condições geológicas e hidrogeológicas, fazem com que a formulação matemática do movimento de contaminantes seja bastante intrincada. Para lidar com essa dificuldade, simplifica-se a abordagem, para depois, com integração, efetuar a análise de problemas mais complexos.

Os processos físicos que controlam o transporte de solutos no solo são: advecção, difusão molecular, dispersão mecânica e dispersão hidrodinâmica. Os solutos podem também interagir com a matriz solo, sendo esses mecanismos de transporte de massa chamados de mecanismos químicos como a sorção, decaimento e biodegradação. Com os processos de sorção alguns solutos se movem mais devagar do que a água que os transporta, ocorrendo, assim, o retardamento. Já com o decaimento radioativo, a biodegradação e a precipitação, não ocorre necessariamente redução da velocidade de movimentação dos contaminantes, mas sim uma diminuição da concentração do soluto (FETTER, 1993; FREEZE; CHERRY, 1979). 
A seguir serão detalhados os principais mecanismos físicos e químicos de transporte de soluto em meios porosos saturados mostrando a formulação matemática inerente a cada fenômeno. Depois será mostrada a formulação matemática geral resultante da integração dos diversos fenômenos de transporte.

\subsubsection{MECANISMOS FÍSICOS DE TRANSPORTE DE SOLUTOS NO SOLO}

\subsubsection{Adveç̧ão}

Advecção é o mecanismo de transporte causado pela água em movimento segundo vetores de fluxo. Com o deslocamento da água, os solutos presentes nela se deslocam na direção das linhas de fluxo com a velocidade igual à velocidade linear média da água, sem que ocorra alteração da concentração, e com taxa de transporte diretamente proporcional à velocidade da água (SHACKELFORD, 1993; FREEZE; CHERRY, 1979; FETTER, 1993).

Em condições de escoamento laminar, a Lei de Darcy (Equação 30) descreve a velocidade de Darcy $(q)$ em meios porosos. Dividindo-se $q$ pela porosidade total efetiva do meio $\left(n_{e}\right)$ obtêm-se a velocidade linear média $(v)$ (Equação 31), que descreve a velocidade real do fluido (FETTER, 1993; FREEZE; CHERRY, 1979; LIBARD, 1995).

$$
\begin{gathered}
q=-\frac{Q}{A}=-k \frac{d h}{d l}=-k i \\
v=\frac{q}{n_{e}}=\frac{Q}{A n_{e}}
\end{gathered}
$$

em que $Q$ representa a vazão $\left[\mathrm{L}^{3} \mathrm{~T}^{-1}\right] ; h$ a carga hidráulica [L]; $l$ o comprimento do meio poroso [L]; $i$ o gradiente hidráulico [ ]; $A$ a área da seção transversal perpendicular ao fluxo $\left[\mathrm{L}^{2}\right]$; e, $n_{e}$ a porosidade efetiva total.

Segundo Freeze e Cherry (1979), a velocidade linear média reflete o fato de que o fluido pode fluir somente através dos poros interconectados do meio poroso. A velocidade de Darcy, por outro lado, representa o fluxo volumétrico do fluido através da seção transversal total.

No entanto, devido ao fato de muitas vezes os problemas de contaminação envolverem diferentes tipos de fluidos, é necessário que se verifique se as condições de fluxo laminar são satisfeitas, para que possa ser utilizada a Lei de Darcy. Bear (1972) utiliza o cálculo do 
número de Reynolds, Re (Equação 32), para verificar as condições de fluxo laminar. Segundo Bear (1972), a Lei de Darcy é válida para Re entre 1 e 10.

$$
\operatorname{Re}=\frac{\rho v d}{\mu}
$$

em que $\rho$ e $\mu$ são a densidade $\left[\mathrm{ML}^{-3}\right]$ e o coeficiente de viscosidade dinâmica do fluido, $\left[\mathrm{ML}^{-}\right.$ ${ }^{1} \mathrm{~T}^{-1}$ ], respectivamente; d representa o comprimento do meio poroso (tamanho médio dos poros, tamanho médio dos grãos, etc.) [L]; e, v representa a velocidade do fluido[LT $\left.{ }^{-1}\right]$.

O fluxo unidimensional de massa de uma espécie química por advecção través de uma área seccional unitária em uma unidade de tempo é igual à quantidade de água que flui multiplicada pela concentração, conforme Equação 33 (FETTER, 1993).

$$
F_{x}=v_{x} n_{e} C
$$

No caso unidimensional, a equação diferencial do transporte de solutos por advecção (FREEZE; CHERRY, 1979) é dada pela Equação 34, derivada na Seção 2.16.

$$
\frac{\partial C}{\partial t}=-v_{z} \frac{\partial C}{\partial z}
$$

onde $C$ representa a concentração do soluto $\left[\mathrm{M} / \mathrm{L}^{3}\right] ; v_{z}$ a velocidade da água nos poros na direção z [L/T]; $t$ o tempo [T]; e $z$ a coordenada vertical [L].

A Figura 2.25 ilustra o movimento de contaminantes por advecção para uma condição de fluxo macroscópico e unidimensional. Percebe-se que a frente de contaminação se movimenta junto com a solução inserida no recipiente. 


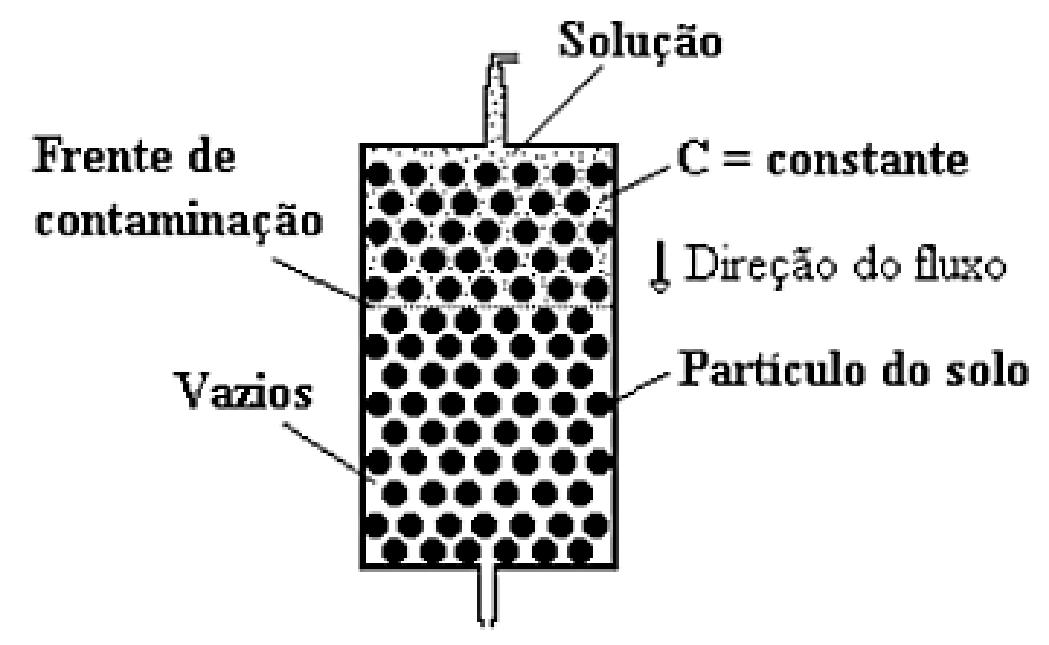

Figura 2.25- Movimento macroscópico e unidimensional de contaminantes no solo por advecção (LEITE, 2001)

\subsubsection{Dispersão mecânica}

Dispersão mecânica é o processo de espalhamento de um soluto, quando o mesmo é carregado por advecção, através do meio poroso (BEAR, 1972). A dispersão mecânica ocorre em razão de diferenças de velocidades de escoamento dos fluidos dentro de poros individuais diferentes. Essas diferenças na velocidade de escoamento podem ocorrer devido à variação das formas e tamanhos dos poros ao longo das linhas de fluxo e ao desvio da trajetória das partículas em decorrência da tortuosidade, reentrâncias e interligações entre os canais (BEAR, 1972; HILLEL, 1980; FREEZE; CHERRY, 1979). Segundo Freeze e Cherry (1979), tais diferenças na velocidade linear média estão relacionadas a três efeitos distintos (Figura 2.26): 1) Considerando um único canal de poro, a velocidade é menor à medida que se aproxima das paredes do poro, onde atua a força de atrito, e vai aumentando à medida que se aproxima do centro do poro; 2) Observando todo o canal de poro, há um aumento da velocidade quando o fluido percorre locais mais estritos no canal; e 3) O fluido não percorre trajetórias lineares, o que faz surgir o efeito da tortuosidade das trajetórias de fluxo. 


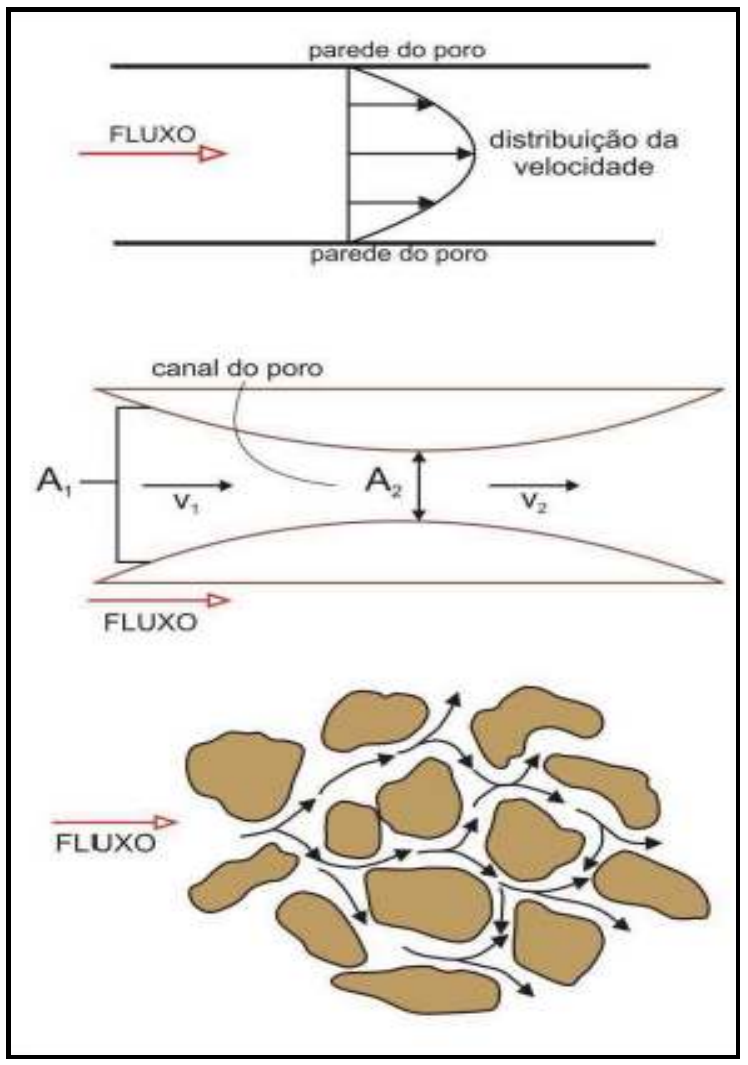

Figura 2.26- Efeitos que causam dispersão mecânica (Modificado de FETTER, 1993)

O coeficiente de dispersão mecânica, $D_{z}$, é definido como o produto entre a velocidade da água nos poros na direção $\mathrm{z}, v_{z}$, e o coeficiente de dispersividade dinâmica $\alpha$, que a propriedade de um meio poroso provocar a dispersão de um soluto que nele se desloca, Equação 35 (FREEZE; CHERRY, 1979).

$$
D_{z}=\alpha v_{z}
$$

Para a condição unidimensional, o fluxo de dispersão mecânica, pode ser expresso por:

$$
J_{h}=-D_{h} \frac{\partial C_{r}}{\partial x}
$$

\subsubsection{Difusão molecular}

Difusão ou difusão molecular é o mecanismo de transporte causado pelo gradiente de concentração existente em um fluido, ou seja, o soluto dissolvido em água se desloca de uma região de maior concentração para uma região de menor concentração, para que a concentração seja igualada em todo o fluido visando o equilíbrio (Figura 2.27). 


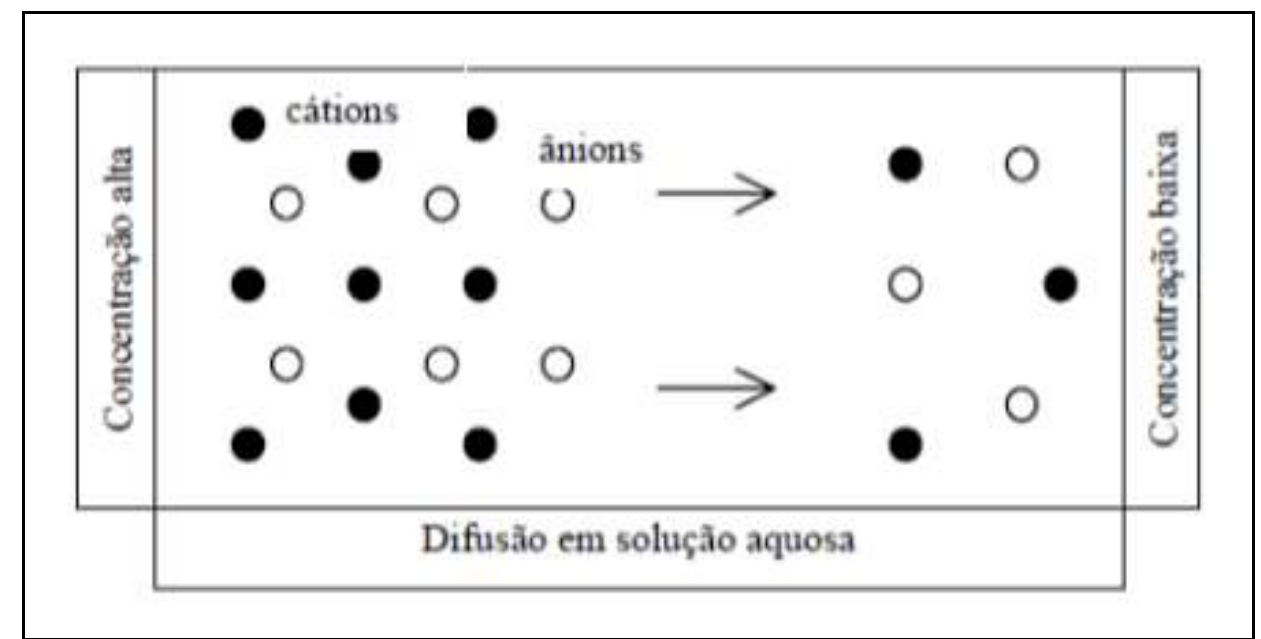

Figura 2.27- Ilustração esquemática da difusão molecular (Modificado de ROWE; QUIGLEY; BOOKER, 1995)

Segundo Crank (1975), FREEZE e Cherry (1979) e Fetter (1992), o transporte difusivo ocorre mesmo na ausência de gradiente hidráulico e chega ao fim apenas quando não há mais gradiente de concentração. A difusão ocorre em resposta a um gradiente de concentração e, em analogia com a primeira Lei de Fick (FETTER, 1993; CRANK, 1975) é dada pela Equação 37:

$$
J_{d}=-D \frac{\partial C}{\partial z}
$$

onde $J_{d}$ o fluxo de massa de soluto [M/ $\left.\mathrm{L}^{2} \mathrm{~T}^{-1}\right] ; D$ o coeficiente de difusão iônica ou molecular no meio poroso $\left[\mathrm{L}^{2} / \mathrm{T}\right] ; \partial C / \partial z$ o gradiente de concentração $\left[\mathrm{M} / \mathrm{L}^{4}\right]$. O sinal negativo da Equação 37, demostra que o movimento ocorre em sentido contrário ao do gradiente.

De maneira geral, os coeficientes de difusão variam de $1 \times 10^{-9}$ a $2 \times 10^{-9} \mathrm{~m}^{2} / \mathrm{s}$ à $25^{\circ} \mathrm{C}$ (SCHNOOR, 1992). Segundo Stokes e Robinson (1965), esses valores não variam muito com a concentração, mas podem reduzir em até $50 \%$ com uma variação de $5^{\circ} \mathrm{C}$. Existem situações em que a concentração varia com o tempo, t, para esses casos aplica-se então a Segunda Lei de Fick (FETTER, 1993), dada por:

$$
\frac{\partial C}{\partial t}=D \frac{\partial^{2} C}{\partial z^{2}}
$$

Devido à tortuosidade das trajetórias de fluxo, determinada por meio de ensaios de laboratório, verifica-se que em solos, a difusão é muito menor do que em água livre 
(MITCHEL, 1991;BEAR, 1972). Neste caso, usa-se um coeficiente de difusão efetiva, $D^{*}$, dado por:

$$
D^{*}=\tau D
$$

Em que $\tau$ é um fator de tortuosidade [ ] (BEAR, 1972), dado por:

$$
\tau=\left(\frac{L}{L_{e}}\right)^{2}
$$

onde $L$ é a distância em linha reta entre dois pontos que definem a trajetória do fluxo, e $L_{e}$ é a distância efetiva de transporte entre os mesmos pontos (Figura 2.28).

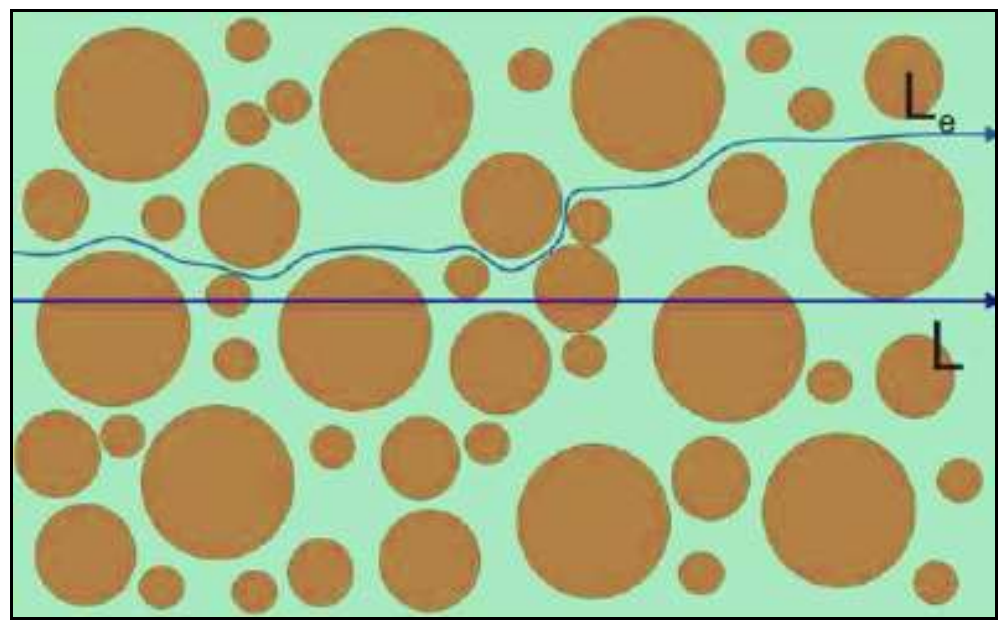

Figura 2.28- Representação da tortuosidade em meios porosos (FETTER, 1993)

Segundo van Genuchten e Wierenga (1986), os valores do fator de tortuosidade variam entre 0,3 e 0,7 para a maioria dos solos, e sempre é menor do que 1,0. Perkins e Johnson (1963) encontraram valor de tortuosidade de 0,707 para estudos com colunas de solos arenosos uniformes. Para Freeze e Cherry (1979), em estudos laboratoriais em materiais geológicos porosos os valores comuns de tortuosidade encontram-se entre 0,5 a 0,01 .

Em muitos estudos de contaminação de meios porosos, o $D^{*}$ é considerado como nulo (PERKINS; JOHNSON, 1963; BEAR, 1972; SHAKELFORD, 1994; FREEZE; CHERRY, 1979). Freeze e Cherry (1979) justifica isso usando a Equação 41 proposta por Crank (1975), para apropriadas condições de contorno.

$$
C(x, t)=C_{0} \operatorname{erfc}\left(\frac{x}{2 \sqrt{D^{*} t}}\right)
$$


onde $C$ é a concentração à distância $\mathrm{x}$ da fonte no tempo $t$ desde começou a difusão; $C_{0}$ é a concentração inicial, que permanece constante; e, erfc é a função erro complementar.

A erfc se relaciona com a distribuição normal, o que significa que a solução descrita pela Equação 41 é normalmente distribuída, como esperado para processos de difusão. A erfc relaciona-se com a função erro, erf, da seguinte forma:

$$
\operatorname{erfc}(\beta)=1-\operatorname{erf}(\beta)
$$

O valor de erfc $(\beta)$ é 0 para qualquer valor positivo de $\beta$ maior do que 3,0 e 1,0 para $\beta$ igual a zero. Para valores negativos de $\beta$ a erfc é computada a partir das seguintes relações:

$$
\operatorname{erfc}(-\beta)=1+\operatorname{erf}(\beta)
$$

Sendo que a erf $\beta$ é definida como:

$$
\operatorname{erf}(\beta)=\frac{2}{\sqrt{\pi}} \int_{0}^{\beta} e^{-t^{2}} d t
$$

A Equação 44 não pode ser resolvida analiticamente, no entanto, os valores de $\beta$ são tabulados por diversos autores, entre eles Freeze e Cherry (1979). Além disso, ela pode ser aproximada pela expressão analítica:

$$
\operatorname{erf}(\beta)=\sqrt{1-\exp \left(\frac{-4 \beta^{2}}{\pi}\right)}
$$

Adotando que $D^{*}$ é $5 \mathrm{E} 10-9 \mathrm{~m}^{2} / \mathrm{s}$, concentração relativa, $\mathrm{C} / \mathrm{C}_{0}$, de 0,01 e uma distância $\mathrm{x}$ de $10 \mathrm{~m}$, obteve-se um tempo de aproximadamente 478 anos, indicando que a difusão é um processo extremamente lento e, portanto, perde importância em meios com alto fluxo (FREEZE; CHERRY, 1979). Por outro lado, a difusão molecular efetiva é um mecanismo importante em regimes hidrogeológicos de baixo fluxo.

Regimes de alto fluxo são aqueles em que o número de Péclet, $P$, é $\geq 50$. O número de Péclet (Equação 46) representa o efeito relativo do transporte advectivo baseado na velocidade linear média em relação ao transporte dispersivo/difusivo, $D_{h}$, abordado em detalhe na próxima seção. Para $P \leq 1$ o processo de transporte dominante é a difusão (BEAR, 1979; SHAKELFORD, 1994). 


$$
P=\frac{v L}{D_{h}}
$$

\subsubsection{Dispersão hidrodinâmica}

O processo de difusão molecular não pode ser separado da dispersão mecânica no fluxo de água pelo solo. Esses dois mecanismos de transporte de solutos são combinados para que se obtenha o coeficiente de dispersão hidrodinâmica, $D_{h}$. A dispersão hidrodinâmica pode ocorrer tanto na direção do fluxo, denominada de dispersão longitudinal, ou perpendicular ao fluxo, chamada então de dispersão transversal. Assim, os coeficientes de dispersão hidrodinâmica longitudinal $D_{l}\left[\mathrm{~L}^{2} / \mathrm{T}\right]$ e de dispersão hidrodinâmica transversal $D_{t}\left[\mathrm{~L}^{2} / \mathrm{T}\right]$, são respectivamente (FETTER, 1993; FREEZE; CHERRY, 1979;BEAR, 1961):

$$
\begin{aligned}
& D_{l}=\alpha_{l} v_{z}+D^{*} \\
& D_{t}=\alpha_{t} v_{z}+D^{*}
\end{aligned}
$$

onde $v_{z}$ é a velocidade da água nos poros na direção z [L/T]; $D^{*}$ é o coeficiente de difusão efetiva $\left(D^{*}=\tau D\right)$, e $\tau$, o fator de tortuosidade do solo [ ]; $\alpha_{l}$ e $\alpha_{t}$ são coeficientes de dispersividade longitudinal e transversal [L], respectivamente; e, $\alpha_{l} v_{z}$ e $\alpha_{t} v_{z}$ são coeficientes de dispersão mecânica longitudinal e transversal $\left[\mathrm{L}^{2} / \mathrm{T}\right]$, respectivamente.

A dispersividade é provavelmente dependente da escala, com valores maiores para maiores distâncias de transporte (PICKENS; GRISAK, 1981). As dispersividades longitudinal e transversal são expressas respectivamente por:

$$
\begin{aligned}
& \alpha_{l}=\beta_{l} d \\
& \alpha_{t}=\beta_{t} d
\end{aligned}
$$

em que $d$ corresponde ao diâmetro interno do poro [L]; $\beta_{l}$ e $\beta_{t}$ tem valores da ordem de 1,75 e 0,055 , respectivamente.

Desta forma, as Equações 49 e 50 podem ser reescritas (SCHEIDEGGER, 1963) como: 


$$
\begin{aligned}
& D_{l}=1,75 d v_{z}+D^{*} \\
& D_{t}=0,055 v_{z}+D^{*}
\end{aligned}
$$

Existem diversos autores que propõem valores típicos ou equações para obtenção das dispersividades longitudinal e transversal. A Tabela 2.5 resume as proposições mais utilizadas.

Tabela 2.5- Valores típicos de dispersividade

$\begin{array}{lcc}\text { Proposição } & \text { Observação } & \text { Autor } \\ \alpha_{L} \approx \frac{x^{4}}{100} & \begin{array}{c}\text { Para } \mathrm{x}^{1}<10 \text { metros, sendo }{ }^{1} \mathrm{a} \\ \text { escala de análise }\end{array} & \begin{array}{c}\text { Yeh, Gelhar e Gutjahr (1985) e } \\ \text { Rowe, Quigley e Booker (1995) }\end{array} \\ \alpha_{L} \approx 200 & \text { Para } \mathrm{x}^{1}>10 \text { metros } & \text { Yeh, Gelhar e Gutjahr (1985) e } \\ \alpha_{L} \approx 0,1 x & \text { Rowe, Quigley e Booker (1995) } \\ \frac{\alpha_{L}}{\alpha_{t}}=0,3 & \text { para materiais grosseiros } & \text { Fetter (1993) } \\ \frac{\alpha_{L}}{\alpha_{t}}=0,1 & \text { para outros materiais } & \text { Domenico e Schwartz (1990) }\end{array}$

O efeito da dispersão pode ser simulado em laboratório através do ensaio de coluna (detalhado na Seção 2.17.2), que consiste na passagem de fluxo unidimensional através de uma amostra de solo saturado com água. Considerando fluxo permanente, a partir de $t=0$, uma solução com concentração inicial conhecida, $C_{0}$ passa a ser introduzida constantemente no solo. Essa solução passa a permear no solo e a expulsar a água dos vazios. Inicialmente a separação da água e da solução é bem delineada, no entanto, com o passar do tempo, deixa de ser bem definida passando a ter uma faixa de transição entre a solução que avança e a água. A concentração do soluto nessa faixa de transição varia desde a concentração inicial $\left(C=C_{0}\right)$ até zero (FREZZE; CHERRY, 1979). A Figura 2.29 esquematiza o avanço da solução contaminante no solo saturado em um experimento de coluna. 


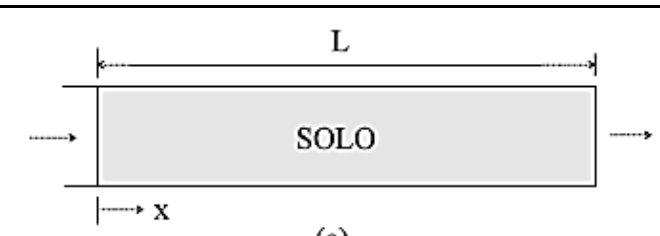

(a)

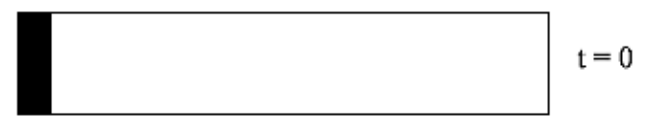

(b)

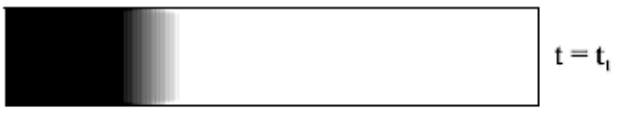

(c)

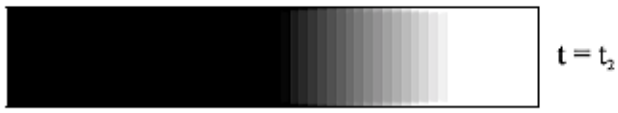

(d)

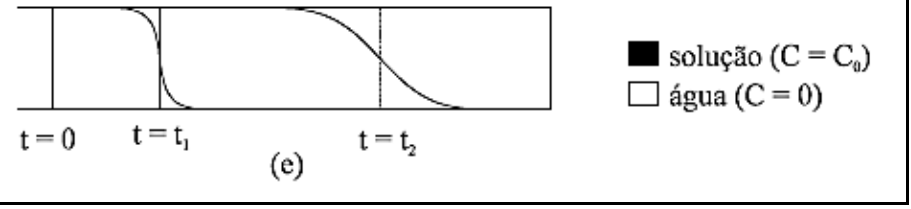

Figura 2.29- Espalhamento da solução contaminante por dispersão hidrodinâmica (Modificado de FREEZE; CHERRY, 1979)

Para fluxo não confinado e/ou bi ou tridimensional, que não pode ser representado pelo do ensaio de coluna da Figura 2.29, deve-se considerar a $D_{t}$. Um esquema do fenômeno da dispersão para o fluxo horizontal bidimensional, em que se tem as componentes longitudinal e transversal da dispersão hidrodinâmica, é apresentado na Figura 2.30.

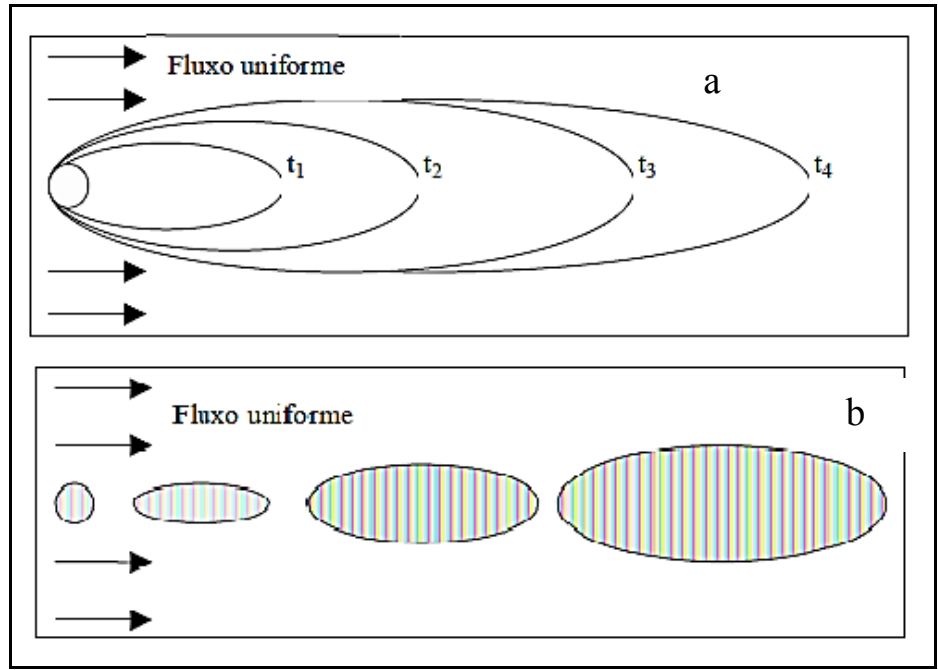

Figura 2.30- Dispersão hidrodinâmica em um fluxo uniforme bidimensional em uma areia isotrópica: (a) fonte contínua; (b) fonte instantânea (Modificado de FREEZE; CHERRY, 1979) 
O Coeficiente de dispersão hidrodinâmica é um dos parâmetros mais importantes a serem obtidos em estudos de contaminação de solos. Sua determinação pode ser feita através das Equações 47 e 48 propostas por Bear (1961) combinadas com as proposições para a dispersividade indicadas na Tabela 2.5, mas também a partir de ensaios de coluna. O ensaio de coluna produz como resultado final a curva característica do transporte de solutos chamada de curva de chegada (ou breakthrough curve) que consiste num gráfico da distribuição da concentração relativa $\left(C / C_{0}\right)$ em função do tempo, que pode ser expresso de maneira adimensional como volume de poros, $V p$ ou $V v$ (Figura 2.31) (detalhado na Seção 2.17).

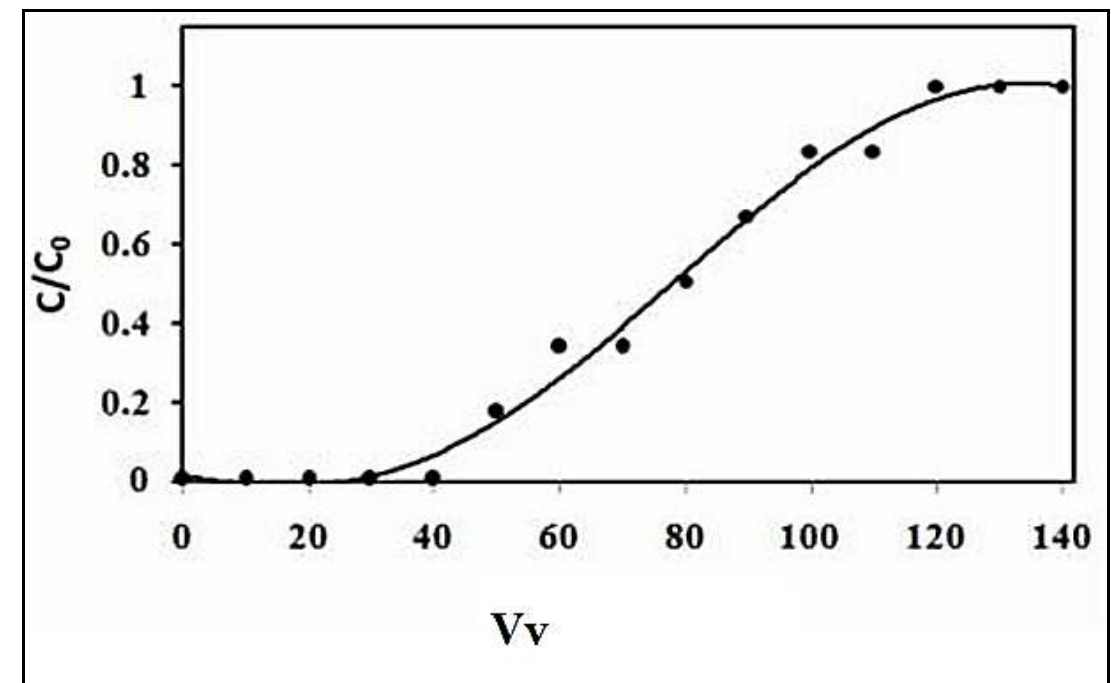

Figura 2.31- Modelo de Curva de chegada (Modificado de PANARAT, 2008)

Para simplificar e facilitar as análises, o $D_{l}$ pode ser considerado como $D_{h}$ quando: i) se analisa apenas a dispersão no sentido do fluxo;e, ii) se adota $D^{*}$ como nulo, como discutido anteriormente. Para estas situações, existem diversos métodos para a obtenção do $D_{h}$ a partir dos ensaios de coluna.

propuseram uma equação (Equação 53) que é solução para a equação diferencial parcial (Equação 87) que governa o processo de transporte advectivo-dispersivo em um meio homogêneo e isotrópico, com as condições de contorno adequadas e um fluxo constante através da coluna de solo. A Equação 87 (equação diferencial transporte advectivo) será detalhada na Seção 2.16. Aqui o enfoque será dado à obtenção do $D_{h}$.

$$
\frac{C}{C_{0}}=\frac{1}{2}\left[\operatorname{erfc}\left(\frac{L-v t}{2 \sqrt{D_{h} t}}\right)+\exp \left(\frac{v L}{D_{h}}\right) \operatorname{erfc}\left(\frac{L+v t}{2 \sqrt{D_{h} t}}\right)\right]
$$


sendo $L$ o comprimento da coluna de solo [L] quando a concentração de saída é observada no final da coluna de solo, $v$ a velocidade linear média $\left[\mathrm{LT}^{-1}\right]$ e $t$ o tempo [T].

O segundo termo da Equação 53 pode ser negligenciado quando o $P>100$. Segundo Singh (2002), em ensaios de coluna geralmente o $P$ é maior do que 100 quando a coluna é preenchida com material arenoso. Assim, negligenciando o segundo termo da Equação 53, a mesma torna-se:

$$
\frac{C}{C_{0}}=\frac{1}{2}\left[\operatorname{erfc}\left(\frac{L-v t}{2 \sqrt{D_{h} t}}\right)\right]
$$

A partir da Equação 54, conhecendo os valores de concentração reativa da curva de chegada e usando valores tabulados de função erro complementar, o coeficiente de dispersão hidrodinâmica pode ser calculado. Cada ponto na curva de chegada retorna um valor de $D_{h}$. Com a média desses valores, um valor médio de $D_{h}$ pode ser obtido. Este é um dos métodos mais utilizados para a obtenção do $D_{h}$, porém Singh (1998) ressalta que a Equação 54 tem sido amplamente usada para a obtenção do $D_{h}$ em estudos prévios.

Singh (1998) propôs um método no qual o $D_{h}$ é calculado a partir da curva de chegada. Derivando-se a Equação 54 com respeito a $t$ e igualando a zero, obtêm-se condições de pico, ou seja, o tempo de pico e a o valor de pico da derivada da $C / C_{0}$, denotados por $t_{0}$ e $m$, respectivamente. A partir das condições de pico, com a Equação 55 obtem-se o $D_{h}$.

$$
D_{h}=\frac{L^{2}}{4 \pi m^{2} t_{0}^{3}}
$$

Os parâmetros $t_{0}$ e $m$ são determinados diretamente da curva de chegada, em que $t_{0}$ é o tempo [T] quando $C / C_{0}=0,5 ; m$ é a inclinação da reta tangente ao ponto de $C / C_{0}=0,5$ na curva de chegada. A Figura 2.32 mostra um exemplo de obtenção dos parâmetros $t_{0}$ e $m$, que, para esta curva de chegada, são 23,2 min e $0,217 \mathrm{~min}^{-1}$ respectivamente.

Singh $(1998 ; 2002)$ comparou os valores de $D_{h}$ obtido com seu método com aqueles obtidos com o método proposto por Ogata (1958) e encontrou valores muito parecidos. Com este método o $D_{h}$ pode ser obtido mesmo sem que se conheça a velocidade linear média. Assim, os erros na estimativa do coeficiente de dispersão hidrodinâmica devido à medição da velocidade linear média são completamente eliminados. Além disso, é possível obter o $D_{h}$ 
sem que a curva de chegada esteja completa $\left(C / C_{0}=1\right)$. Contudo, este método também pode apresentar erros para casos em que o $P$ é menor do que 100 (SINGH, 2002).

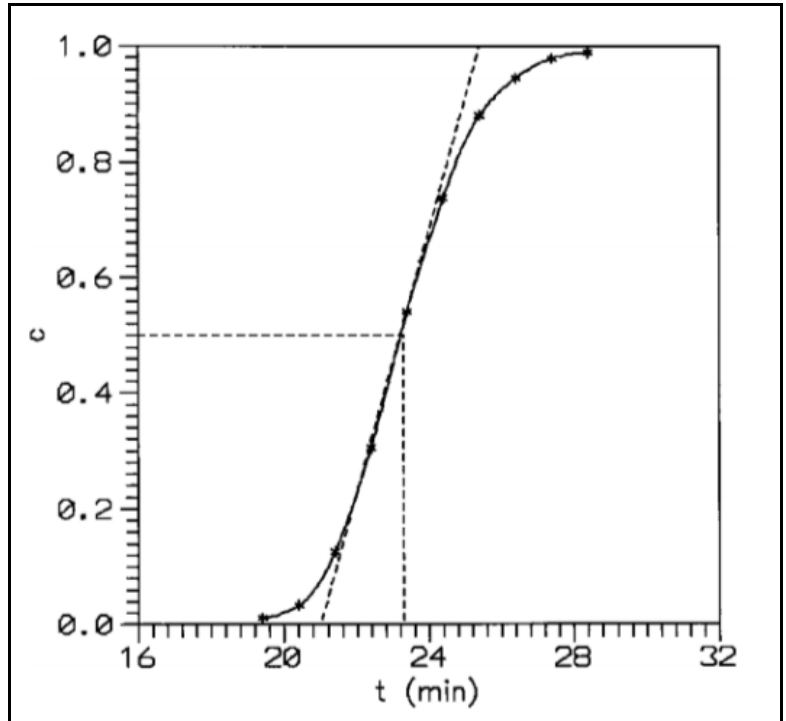

Figura 2.32- Obtenção dos parâmetros $t_{0}$ e $m$ do método proposto por Singh (1998) (SINGH, 2002)

Outro método para obtenção do $D_{h}$ foi proposto por Brigham, Reed e Dew (1961). Neste método o argumento da função erro $(\operatorname{erfc}(\beta)=1-\operatorname{erf}(\beta))$ da Equação 54, indica que sob uma taxa de fluxo e coeficiente de dispersão hidrodinâmica constantes, o espalhamento dos solutos (faixa de transição) é proporcional à raiz quadrada da distância percorrida.

Considerando que a Equação 54 define o perfil de concentração no meio poroso a um dado tempo, enquanto que os dados experimentais fornecem a concentração a um dado ponto em que o crescimento da faixa de transição dá-se para além do observador, as seguintes substituições podem ser feitas.

$$
L-v t=\left(\frac{V p-V}{V p}\right)
$$

em que:

$$
t=T\left(\frac{V}{V p}\right)
$$

em que $V$ é o volume total de solução inserido na coluna de solo $\left[\mathrm{L}^{3}\right]$ e $T$ é o tempo necessário para inserir um volume de poros na coluna [T]. Com isso, o argumento da função erro tornase: 


$$
\frac{L-v t}{2 \sqrt{D_{h} t}}=\frac{L(V p-V)}{2 \sqrt{D_{h} T V p}}=\frac{L}{2 \sqrt{D_{h} T V p}}(U)
$$

onde:

$$
U=\frac{V p-V}{\sqrt{V p}}
$$

Com isso, Brigham, Reed e Dew (1961) a partir da relação empírica (Figura 2.33) propôs que com o parâmetro $U$, relacionado à porcentagem de fluido deslocado em uma coluna, é possível obter o $D_{h}$ através da Equação 60 .

$$
D_{h}=\frac{1}{V p T}\left[\frac{L\left(U_{90}-U_{10}\right)}{3,625}\right]^{2}
$$

Em 1974 Brigham reformulou a Equação 60 para experimentos com colunas curtas e com isso $D_{h}$ é calculado de:

$$
D_{h}=v L\left(\frac{U_{84}-U_{16}}{8}\right)^{2}
$$

em que $U_{i}$ é o $U$ quando o efluente contem $i \%$ do fluido deslocado.

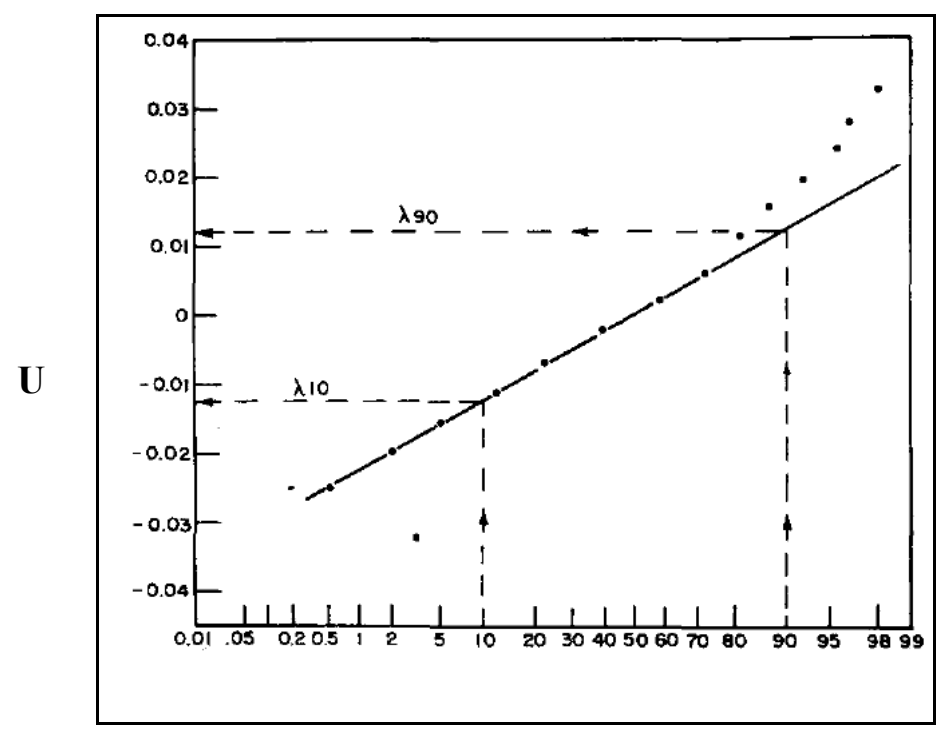

Figura 2.33- Típica curva de composição-efluente para deslocamento miscível em coluna arenosa (Modificado de PERKINS; JOHNSTON, 1963)

$\%$ de Fluido Deslocado 


\subsubsection{MECANISMOS QUíMICOS DE TRANSPORTE DE SOLUTOS NO SOLO}

\subsubsection{Sorção}

Sorção pode ser amplamente definida como a retenção de constituintes químicos através da transferência de íons da fase aquosa para a fase sólida (YONG; MOHAMED; WARKENTIN, 1992; ALLOWAY, 1995a; ADRIANO, 2001). Pode representar os efeitos combinados da adsorção não específica, adsorção específica, precipitação e complexação. Existem vários fenômenos que podem contribuir com a sorção, mas as interações químicas constituem-se o foco no estudo das interações solo-contaminantes. (YONG; MOHAMED; WARKENTIN, 1992). Segundo Soares (2004) e Bradl (2004), o termo sorção deve ser usado quando não se pode distinguir qual o mecanismo de remoção do soluto da solução.

\subsubsection{2. $\quad$ Adsorção não específica (adsorção física)}

Adsorção não específica é um processo fundamentalmente eletrostático no qual os contaminantes da solução do solo são atraídos para as superfícies dos constituintes do solo por causa de cargas elétricas livres nas superfícies dos mesmos (YONG; MOHAMED; WARKENTIN, 1992; BRADL, 2004). Cargas elétricas na superfície das partículas faz com que íons de cargas opostas vindos da solução circundante se aproximem, para que assim ocorra um equilíbrio eletrostático. Esses íons que se situam junto à superfície de uma região definida, constituem a dupla camada elétrica. Devido a maior concentração de íons de cargas opostas próximas à superfície, o mecanismo de difusão molecular passa a ser efetivo e algumas dessas cargas são transportadas para distâncias maiores da superfície, constituindo a dupla camada difusa Figura 2.34.

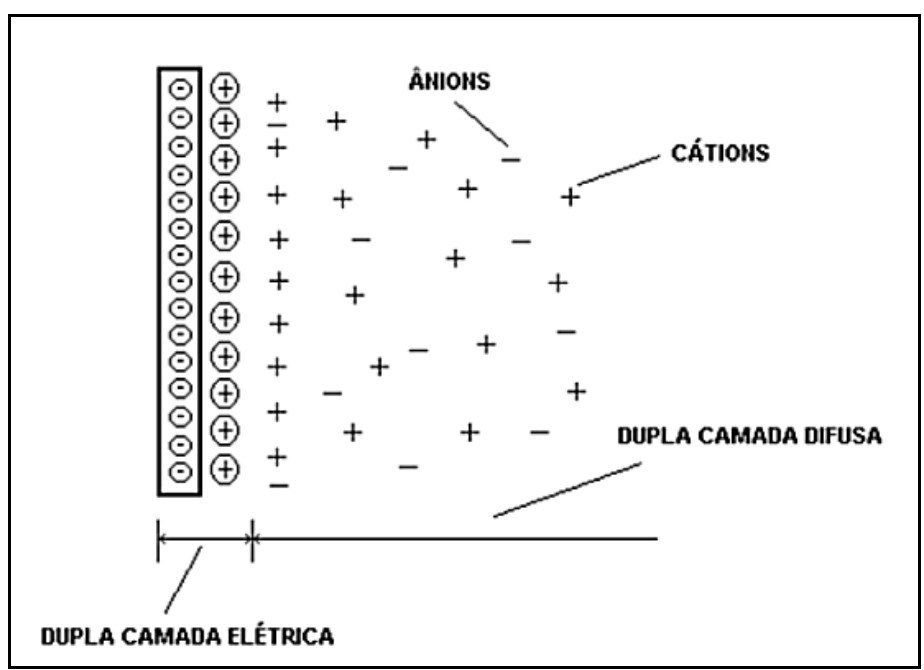

Figura 2.34- Representação da dupla camada elétrica e dupla camada difusa (LEITE, 2001) 
Quando cátions de menor valência são substituídos por cátions de maior valência, como, por exemplo, as substituições isomórficas, surgem cargas permanentes na superfície dos coloides do solo, criando assim locais onde ocorrem as trocas catiônicas (Figura 2.35). Os cátions que estão livres na solução do solo são atraídos para os locais onde há cargas negativas, sendo que a força de atração é proporcional ao potencial iônico de cada elemento. Em condições ácidas, com pH abaixo do PCZ, desenvolvem-se cargas positivas e assim ânions podem ser atraídos para a superfície, caracterizando-se assim a troca aniônica, fenômeno de menor ocorrência quando comparado com a troca catiônica (ALLOWAY, 1995a; ADRIANO 2001).

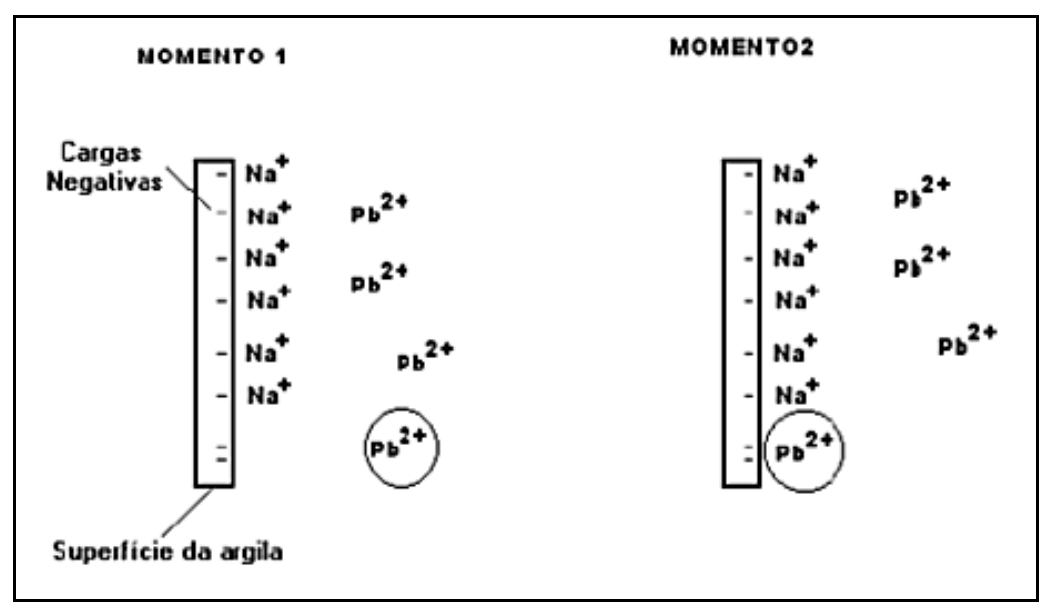

Figura 2.35- Esquema hipotético do processo de adsorção não específica (LEITE, 2001)

A afinidade entre os cátions e as superfícies depende da carga elétrica, do raio hidratado e da configuração molecular do cátion. Geralmente, cátions de maior valência são adsorvidos preferencialmente, e cátions de menor raio tendem a substituir os de maior raio. No entanto, no caso de soluções com alta concentração de determinado cátion, este poderá substituir um cátion de maior preferência para a adsorção. Em geral, a ordem de retenção é a seguinte: $\mathrm{Al}^{3+}>\mathrm{H}^{+}>\mathrm{Ca}^{2+}>\mathrm{Mg}^{2+}>\mathrm{K}^{+}>\mathrm{NH}_{4}^{+}>\mathrm{Na}^{+}$(ADRIANO, 2001).

A adsorção não específica possui as seguintes características: é reversível; possui difusão molecular controlada; é estequiométrica; e, em muitos casos, há alguma seletividade ou preferência de um íon em relação a outro pelo adsorvente, sendo que, de maneira geral, quanto maior a valência maior será a adsorção (YONG; MOHAMED; WARKENTIN, 1992; ALLOWAY, 1995a).

\subsection{Adsorção específica}

É aquela onde os íons são adsorvidos por outras forças que não potencial elétrico. Envolve a troca de cátions e ânions com ligantes da superfície para formar ligações 
parcialmente iônicas ou covalentes através de átomos de $\mathrm{O}$ ou de grupos funcionais como a hidroxila (OH) (KEENEY, 1979). A energia das ligações existentes na adsorção específica é cerca de 50 vezes maior do que aquela da adsorção não específica. Por este motivo, a adsorção específica tem sido usada para explicar a razão pela qual o solo adsorve íons em concentrações superiores à sua CTC (KNOX; SABATINI; CANTER, 1993). Segundo Alloway (1995a), os óxidos e hidróxidos de Fe e Al são os principais constituintes do solo envolvidos nas reações de adsorção específica, sendo que de maneira geral, substâncias amorfas (óxidos mal cristalizados) possuem grande superfície específica e elevada capacidade de adsorção, por possuírem cargas variáveis.

\subsection{Precipitação e co-precipitação}

Segundo Young, Mohamed e Warkentin (1992), precipitação pode ser definida como a transferência de solutos da fase aquosa para a interface, resultando em uma nova substância na forma de uma nova fase sólida solúvel. Essa transferência ocorre quando uma determinada substância na solução passa a apresentar concentração superior ao seu grau de solubilidade. Por outro lado, a co-precipitação pode ser entendida como a simultânea precipitação de um agente químico em conjunto com outros elementos por qualquer mecanismo e sob qualquer taxa.

O processo de precipitação ocorre em duas fases: nucleação e crescimento da partícula. Os principais fatores que controlam a precipitação são o $\mathrm{pH}$ do material geológico e da fase líquida, a temperatura da solução Eh e a concentração dos contaminantes. Quando existem condições físico-químicas e concentrações apropriadas de íons, muitos íons presentes na solução do solo podem formar precipitados insolúveis muito importantes na redução da mobilidade, solubilidade e consequentemente disponibilidade (ALLOWAY, 1995a). Segundo Moreira (2004), estes fenômenos (precipitação e co-precipitação) estão mais relacionados a solos alcalinos e calcários. A Figura 2.36 mostra a precipitação do Chumbo, $\mathrm{Pb}$, junto à superfície de um argilomineral. 


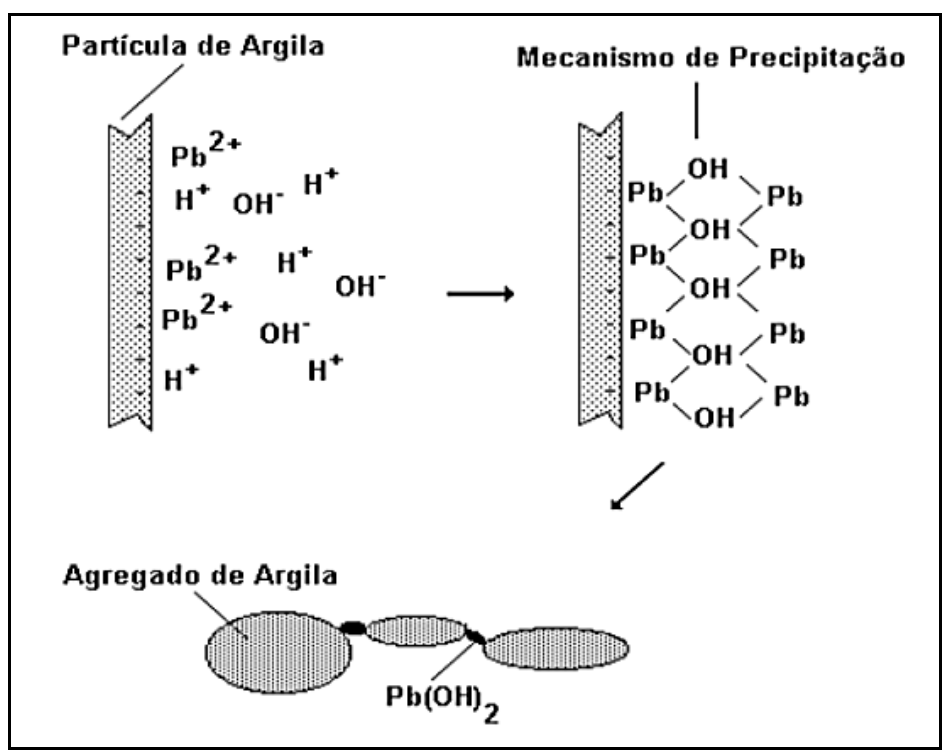

Figura 2.36- Esquema da precipitação de Pb na superfície de um argilomineral (LEITE, 2001)

\subsection{Complexação (inorgânica e orgânica)}

A complexação ocorre quando um cátion metálico central liga-se, por ligações covalentes, a dois ou mais grupos orgânicos ou inorgânicos. Os ligantes inorgânicos que poderão reagir com os metais incluem os ânions $\mathrm{OH}^{-}, \mathrm{Cl}^{-}, \mathrm{SO}_{4}{ }^{3-}, \mathrm{CO}_{3}{ }^{2-}{\mathrm{e} \mathrm{PO}^{3-}}_{3}$. Os grupos funcionais orgânicos incluem carboxila, fenol, álcool e carbonila (YONG; MOHAMED; WARKENTIN 1992; ALLOWAY, 1995a). Os complexos de metais com ligantes inorgânicos são muito mais fracos do que aqueles formados com ligantes orgânicos (YONG; MOHAMED; WARKENTIN 1992).

Uma vez que os elétrons para a ligação covalente são fornecidos apenas pelo ligante, a ligação é chamada de covalente coordenada e o metal é chamado de composto coordenado. Quando um ligante possui mais de um átomo ligante e assim consegue a coordenação com mais de uma posição, chama-se multidentado. Complexação por coordenação com monodentado é chamada de quelação (Figura 2.37) e o complexo formado é chamado de quelato (YONG; MOHAMED; WARKENTIN 1992). 


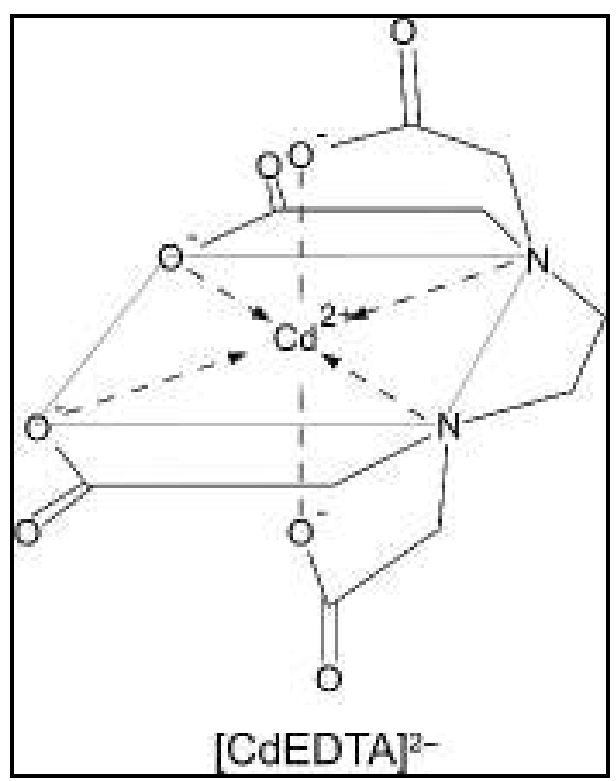

Figura 2.37- Quelação do Cd com agente quelante sintético (EDTA) (TACK; MEERS, 2010)

O complexo formado tem comportamento e propriedades diferentes do que do metal não complexado. No exemplo da Figura 2.37, antes da complexação o íon Cd apresenta carga positiva, em contraste o quelato possui carga negativa (TACK; MEERS, 2010). Segundo Yong, Mohamed e Warkentin (1992), com o aumento do pH ocorre aumento da estabilidade dos complexos devido ao aumento da ionização dos grupos funcionais. A ordem de estabilidade dos metais decresce na seguinte ordem: $\mathrm{Cu}>\mathrm{Fe}=\mathrm{Al}>\mathrm{Mn}=\mathrm{Co}>\mathrm{Zn}$ (ALLOWAY, 1995a).

\subsection{Isotermas de sorção}

A sorção pode ser determinada experimentalmente pela avaliação de quanto um soluto pode ser sorvido por um material (solo, sedimento ou rocha). Quando a taxa de sorção é relativamente rápida em comparação com o movimento da água nos poros do material poroso, assume-se que existe uma situação de equilíbrio e a sorção é instantânea. Este tipo de sorção pode ser analisada por uma reação que envolve os sítios de sorção e os componentes químicos em solução. Quando a sorção não é rápida, comparada com o fluxo de água no meio poroso, o soluto não ficará em equilíbrio com a fase sorvida. Assim, um modelo de sorção cinética será necessário para descrever o processo (TRAVIS; ETNIER, 1981).

Em situação de equilíbrio, os resultados dos experimentos são plotados em um gráfico chamado isoterma de sorção, que mostra a concentração de soluto na solução $\left(C_{e}\right)$ versus a quantidade sorvida no material $(S)$ (FETTER, 1993). Uma isoterma de sorção 
pode ser enquadrada em quatro categorias: S (sigmoidal); L (Langmuir); H (alta afinidade); e, C (partição constante). E subdividida em 4 subgrupos (Figura 2.38)().

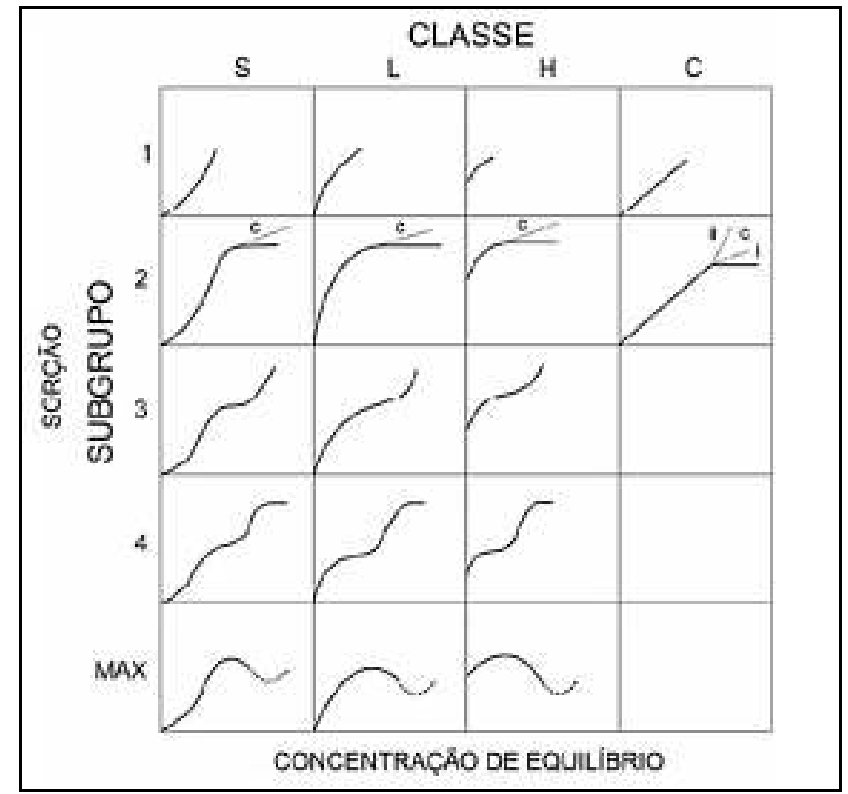

Figura 2.38- Categorias e subgrupos de isotermas de sorção (GILES; SMITH; HUITSON,1974)

As isotermas L são representadas em termos matemáticos como equações de Langmuir e Freundlich e as C como lineares (Figura 2.39). Essas isotermas são as mais utilizadas e serão detalhadas nas próximas seções (FREUNDLICH, 1906; LANGMUIR, 1916; FETTER, 1993; FREEZE, CHERRY, 1979).

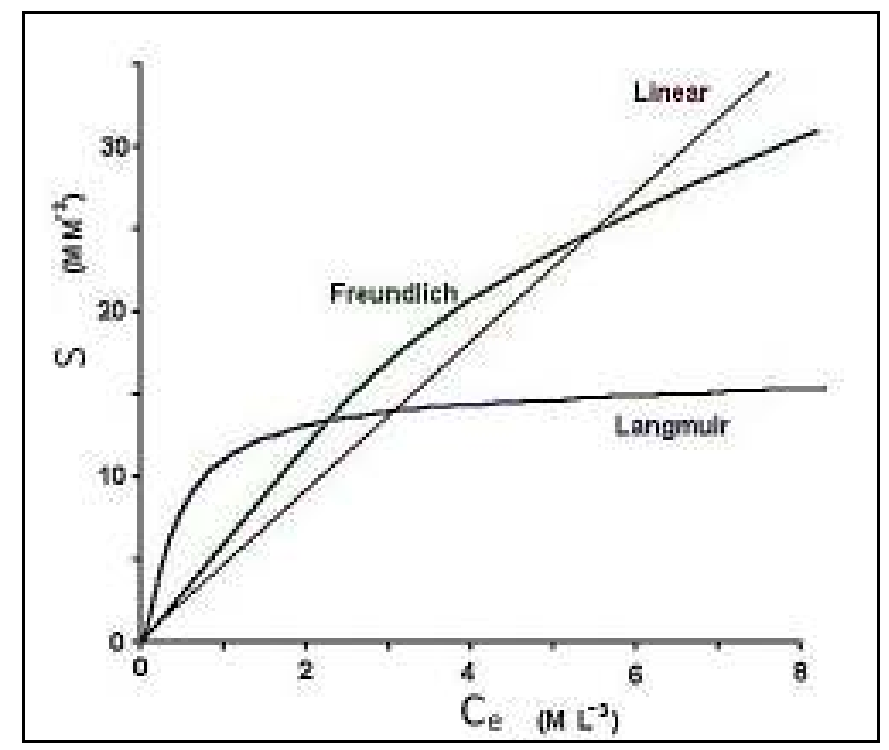

Figura 2.39- Representação gráfica das isotermas de Freundlich, Linear e Langmuir (Modificado de JURY, GARDNER; GARDNER, 1991) 
Observando a Figura 2.39 verifica-se que quando a concentração de soluto na solução é baixa, a relação $\mathrm{S} / \mathrm{C}_{\mathrm{e}}$ é linear, tanto na isoterma de Langmuir quanto na de Freundlich. Isto indica que a isoterma linear, ajustada para baixos valores de Ce, produzirá resultados próximos aos daquelas isotermas. Assim, quando se analisa solutos com baixas concentrações, a isoterma linear pode resultar em bons resultados. Por outro lado, em soluções com altas concentrações, como os efluentes líquidos, o ajuste linear pode não ser o mais adequado.

\subsection{Isoterma Linear}

Se existir uma relação direta e linear entre $S$ e $C_{e}$, tem-se uma isoterma linear, que prevê a sorção de soluto em concentrações infinitamente crescentes, o que é uma limitação desse modelo visto que o material normalmente possui capacidade limitada de sorção(Figura 2.39). A isoterma linear é representada pela Equação 62.

$$
S=K_{d} C_{e}
$$

em que o $K_{d}$ representa o coeficiente de distribuição expresso pelo coeficiente angular da reta em $\left[\mathrm{LM}^{-1}\right]$.

\subsection{Isoterma de Freundlich}

A isoterma de Freundlich representa melhor o fenômeno da sorção, quando comparada com a isoterma linear, pois representa uma relação não linear de $S$ e $C_{e}$ Equação 63 .

$$
S=K_{f} C_{e}^{N}
$$

onde $K_{f}$ é o coeficiente de partição de Freundlich $\left[\mathrm{L}^{3} \mathrm{M}^{-1}\right]$ e N é o coeficiente exponencial de Freundlich.

Os parâmetros $K_{f}$ e $N$ poderão ser obtidos através da construção de um gráfico de $\mathrm{S}(\mathrm{Ce})$ com escala logarítmica, sendo $N$ o coeficiente angular da reta obtida e $\log K_{f}$ é o seu intercepto no eixo das ordenadas, de acordo com a Equação 64 (FETTER, 1993; CHERRY; FREEZE, 1979).

$$
\log S=N \log C_{e}+\log K_{f}
$$

\subsection{Isoterma de Langmuir}


A isoterma de Langmuir foi desenvolvida assumindo que a sorção tem um limite finito e quando todos os sítios de sorção estão preenchidos, não há mais sorção, ocorrendo uma estabilização. Segundo esta isoterma a sorção é expressa pela Equação 65.

$$
S=\frac{S_{m} b C_{e}}{1+b C_{e}}
$$

em que $S_{m}$ é a quantidade máxima de soluto adsorvida pelo solo $\left[\mathrm{MM}^{-1}\right]$ e $b$ é uma constante de adsorção relacionada à energia de ligação $\left[\mathrm{L}^{3} \mathrm{M}^{-1}\right]$.

Os parâmetros $S_{m}$ e $b$ são obtidos a partir da linearização da Equação 65. Os dois principais métodos de linearização são Langmuir I e Langmuir II.

Para a linearização com Langmuir I, primeiro constrói-se um gráfico $\left(C_{e} / S\right)$ versus $\left(C_{e}\right)$. Com isso, $\left(1 / S_{m}\right)$ e $\left(1 / S_{m} b\right)$ correspondem, respectivamente, ao coeficiente angular da reta e ao intercepto da reta no eixo das ordenadas do diagrama $\left(C_{e} / S\right)$ versus $\left(C_{e}\right)$, assim, com a Equação 66, obtém-se a sorção.

$$
\frac{C_{e}}{S}=\frac{1}{S_{m} b}+\frac{C_{e}}{S_{m}}
$$

Para a linearização com Langmuir II, constrói-se um diagrama $(1 / S)$ versus $\left(1 / C_{e}\right)$, com isso, $\left(1 / S_{m} b\right)$ e $\left(1 / S_{m}\right)$ representam o coeficiente angular da reta e o intercepto da reta no eixo das ordenadas desse diagrama (FETTER, 1993; CHERRY; FREEZE, 1979). Com a Equação 67, obtém-se a sorção.

$$
\frac{1}{S}=\frac{1}{b S_{m} C_{e}}+\frac{1}{S_{m}}
$$

Os parâmetros das isotermas de Langmuir e Freundlich também podem ser obtidos por meio de regressão não linear.

\subsubsection{OUTROS PROCESSOS: DECAIMENTO, MEIA VIDA E BIODEGRADAÇÃo}

As reações podem ser definidas de zero ordem, primeira ordem e de segunda ordem. Uma reação de primeira ordem especifica o decaimento exponencial da concentração no tempo, onde a curva de concentração aproxima-se de forma assíntota do zero no tempo (CHAPRA, 1997). Quando se estuda poluentes radioativos, se tem o decaimento radioativo 
que é a perda de energia de um elemento radioativo, devido à emissão de partículas $\alpha, \beta$ e $\gamma$. O intervalo de tempo usado para quantificar o decaimento radioativo de uma amostra de átomos é conhecido como meia vida. A meia vida de uma reação é o tempo necessário para que a concentração chegue à metade da concentração inicial (CHAPRA, 1997).

Se $C_{0}$ é a concentração inicial de uma amostra, após certo tempo $\mathrm{t}=\mathrm{t}_{1} / 2$ (meia vida), a concentração na amostra será $C_{0} / 2$. Como a lei do decaimento é uma função exponencial, em termos de concentração pode ser representada pela Equação 68.

$$
C(t)=C_{0} e^{-\lambda t}
$$

A biodegradação, muito importante no caso de contaminantes orgânicos, é a troca produzida por um sistema biológico de uma substância orgânica em outra, independentemente da extensão da mudança. É chamada de biodegradação primária quando a substância orgânica perde somente uma propriedade específica em decorrência da ação de um sistema biológico e de mineralização ou biodegradação final quando a biodegradação se estende até a conversão total dos compostos orgânicos em biomassa, dióxido de carbono, água e sais minerais (ROBERTSON; ALEXANDER, 1994).

\subsection{FATOR DE RETARDAMENTO}

Devido aos diversos mecanismos físicos, químicos e biológicos que ocorrem na interação entre a solução e o solo, a velocidade real de percolação da água, $v$, difere da velocidade do soluto, $v_{c}$, Equação 69.

$$
R_{d}=\frac{v}{v_{c}}=\frac{v t_{c}}{L}
$$

em que $t_{c}$ representa o tempo necessário para o centro de massa do soluto migrando alcance o final da coluna de comprimento $L$.

O retardamento é um dos principais parâmetros a ser obtidos nos estudos do transporte de solutos nos meios porosos. Quando os solutos não interagem com o meio poroso (não reativos) o $R_{d}$ é 1, representando que a velocidade de percolação do contaminante é a mesma que da água. Solutos com $R_{d}>1$ são chamados de solutos reativos (SHAKELFORD, 1994; FREEZE; CHERRY,1979). A Figura 2.40 ilustra a curva característica do transporte para as situações com e sem retardamento. 


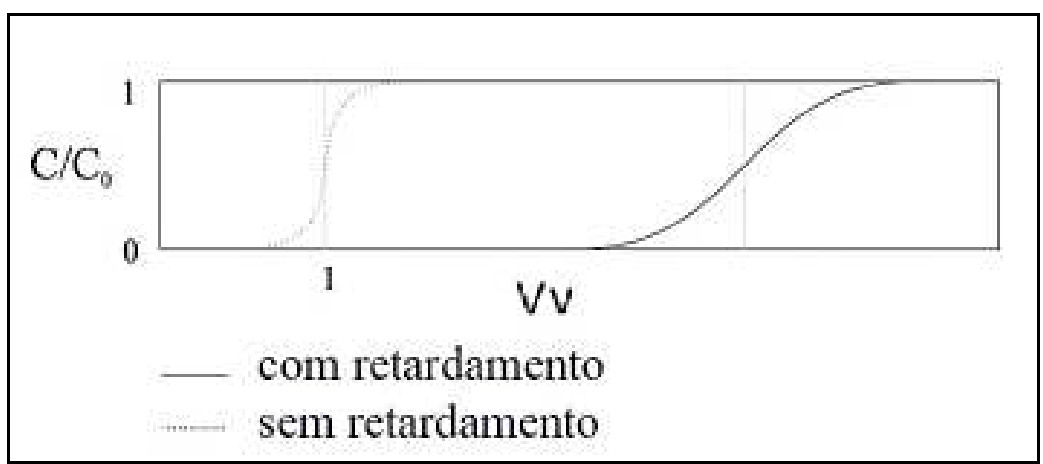

Figura 2.40- Curva característica do transporte incluindo o efeito do retardamento (FREEZE; CHERRY, 1979)

O $R_{d}$ pode ser obtido por meio de ensaios de coluna ou "batch test" (Seção 2.17) a partir de diversos métodos, dependendo do comportamento do contaminante, dos tipos de reações envolvidas, da velocidade do fluxo de água e de soluto, número de Péclet, entre outros. A seguir serão revisados alguns dos métodos usados para determinação do fator de retardamento.

\section{Método da concentração relativa igual a 0.5}

Um dos métodos mais utilizado para a determinação do $R_{d}$ a partir de ensaios de coluna foi proposto por Freeze e Cherry (1979) e Shackelford (1993;1994). É baseado em equações desenvolvidas empiricamente por Hiester e Vermeulen (1952) e aplicadas pela primeira vez em problemas de água subterrânea por Higgins (1959) e depois por Baetsle (1967). Seguindo este método, quando há uma fonte de concentração contínua: $R_{d}=V p$ quando a $C_{0} / C$ é 0,5 . Isso porque neste caso é assumido que o centro de massa ocorre quando $C_{0} / C=0,5$ (SHACKELFORD, 1994; FREEZE; CHERRY, 1979). No entanto, este método é baseado na premissa de que ocorre apenas fluxo advectivo à $C_{0} / C=0,5$ e que o fluxo seja de alta velocidade $(P>50)$, o que nem sempre é verdade. Além disso, este método deve ser usado apenas quando se admite que a adsorção é rápida e reversível e que obedece a uma isoterma linear (FREEZE; CHERRY, 1979; SHACKELFORD, 1994).

\section{Método da área acima da curva de chegada}

Outro método bastante utilizado para a determinação do $R_{d}$ a partir de ensaios de coluna foi proposto por van Genuchten e Parker (1984), com base nas equações de Lapidus e Amundson (1952) considerando o balanço de massa para uma coluna finita de seção transversal $A$ constante e comprimento $L$ (Equação 70). 


$$
v \int_{0}^{t}\left[C_{0}-C_{e}(t)\right] d t=R_{d} \int_{0}^{L} C_{r}(x, t) d x
$$

em que $C_{e}$ e $C_{r}$ são, respectivamente a concentração no efluente e concentração residente (Figura 2.41).

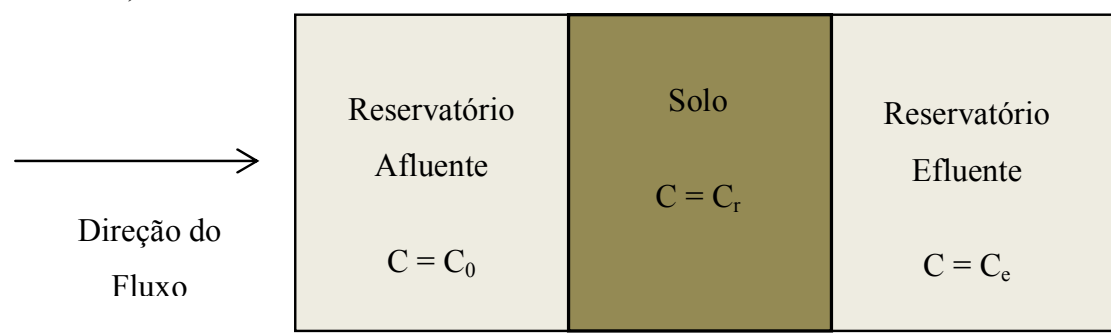

Figura 2.41- Ilustração da concentração residente e concentração efluente (Modificado de SHACKELFORD, 1994)

Dividindo-se a Equação 70 por $C_{0}$ e integrando-se o termo à esquerda em termos de volume de poros, $V v$, então:

$$
L \int_{0}^{V v}\left[1-\frac{C_{e}(V v)}{C_{0}}\right] d V v=\frac{R d}{C_{0}} \int_{0}^{L} C r(x, t) d x
$$

Para $V v=\infty, C_{r}(0 \leq \mathrm{x} \geq \mathrm{L}) \cong C_{0}$, assim a Equação 71 pode ser reescrita como:

$$
\int_{0}^{\infty}\left[1-\frac{C_{e}(V v)}{C_{0}}\right] d V v=R_{d}=H
$$

Em que $H$, chamado de "holdup" por Lapidus e Amundson (1952), é a área acima da curva de chegada (Figura 2.42). O $H$ é obtido de maneira diferente de acordo com o modelo analítico adotado para representar a curva de chegada.

Para o caso em que se aplica a Equação 53:

$$
H=R_{d}
$$

Para o modelo dado pela Equação 54:

$$
H=R_{d}\left[1+\left[\frac{1}{P}\right]\right]
$$


Segundo Shakelford (1994) e van Genuchten e Parker (1984), apenas a Equação 74, fornece uma correta avaliação do $R_{d}$ para qualquer $P$, sendo que a Equação 73 normalmente apresenta grandes erros para $P<10$.

A Figura 2.42 ilustra as diferenças no valor de $R_{d}$ utilizando os dois métodos abordados acima.

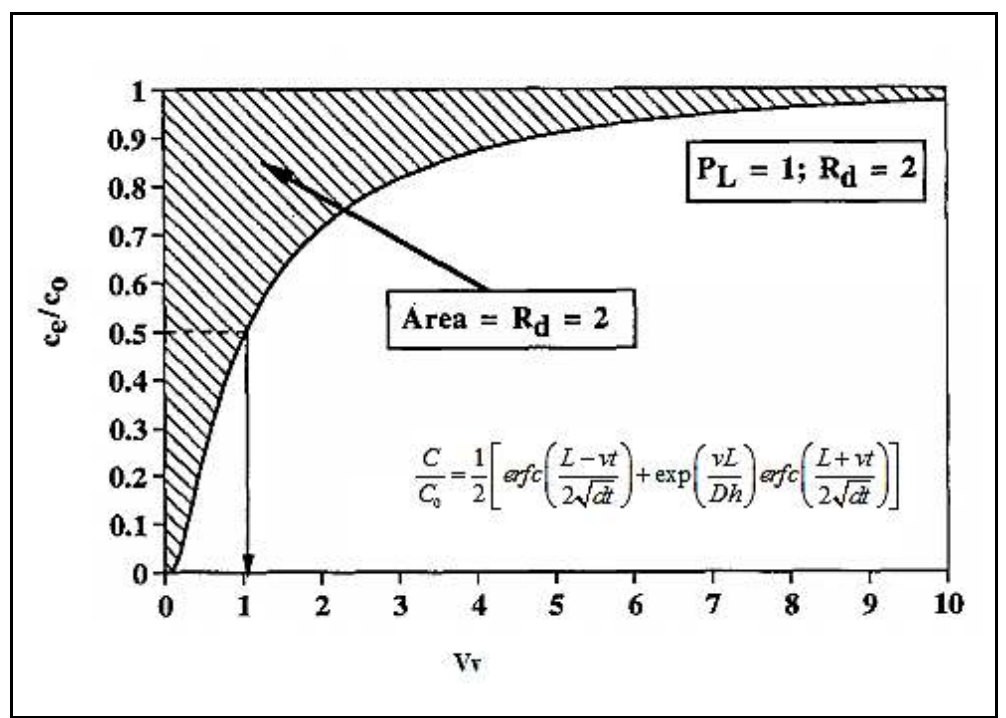

Figura 2.42- Diferença entre o fator de retardamento obtido com $\mathrm{R}_{\mathrm{d}}=\mathrm{H}$ e $\mathrm{Rd}=\mathrm{Vv}$ para $\mathrm{C} / \mathrm{C}_{0}=$ 0,5(Modificado de SHACKELFORD, 1994)

\section{Método da isoterma de sorção}

Outro método que normalmente é utilizado para obter o $R_{d}$ a partir de ensaio de batch testes, mas que também pode ser utilizado em ensaios de coluna, é a determinação do $R_{d}$ a partir das isotermas de sorção.

Para isoterma Linear (Equação 75):

$$
R_{d}=1+\frac{\rho_{d}}{n} K_{d}
$$

Para isoterma de Freundlich (Equação 76):

$$
R_{d}=1+\frac{\rho_{d}}{n} K_{f} C_{e m}^{N-1}
$$

Para a isoterma de Langmuir (Equação 77): 


$$
R_{d}=1+\frac{\rho_{d}}{n} \frac{b S_{m}}{1+b C_{e m}}
$$

em que $n$ representa a porosidade para solos saturados, e a umidade volumétrica para solos não saturados, $\rho_{d}$ é a massa específica seca do solo $\left[\mathrm{ML}^{-3}\right]$.

\subsection{FORMULAÇÃO MATEMÁTICA DO TRANSPORTE DE SOLUTOS NO SOLO}

Os processos que envolvem o transporte de contaminantes em meios porosos podem ser representados matematicamente através de equações diferenciais desenvolvidas com base na conservação da massa do soluto na solução percolante (Figura 2.43). Essa representação é realizada adotando-se uma série de simplificações devido à complexidade dos diversos mecanismos envolvidos.

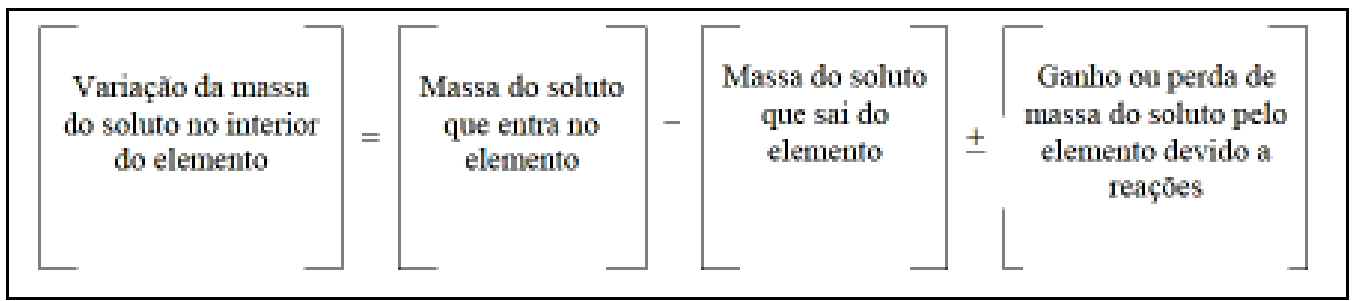

Figura 2.43- Lei da conservação de massa para o volume elementar de solo (Modificado de FREEZE; CHERRY, 1979)

A base da formulação matemática do transporte de solutos no solo reside na análise da variação da concentração de massa. Esta análise é feita considerando-se o fluxo do soluto através de um volume elementar de solo, como ilustrado na Figura 2.44.

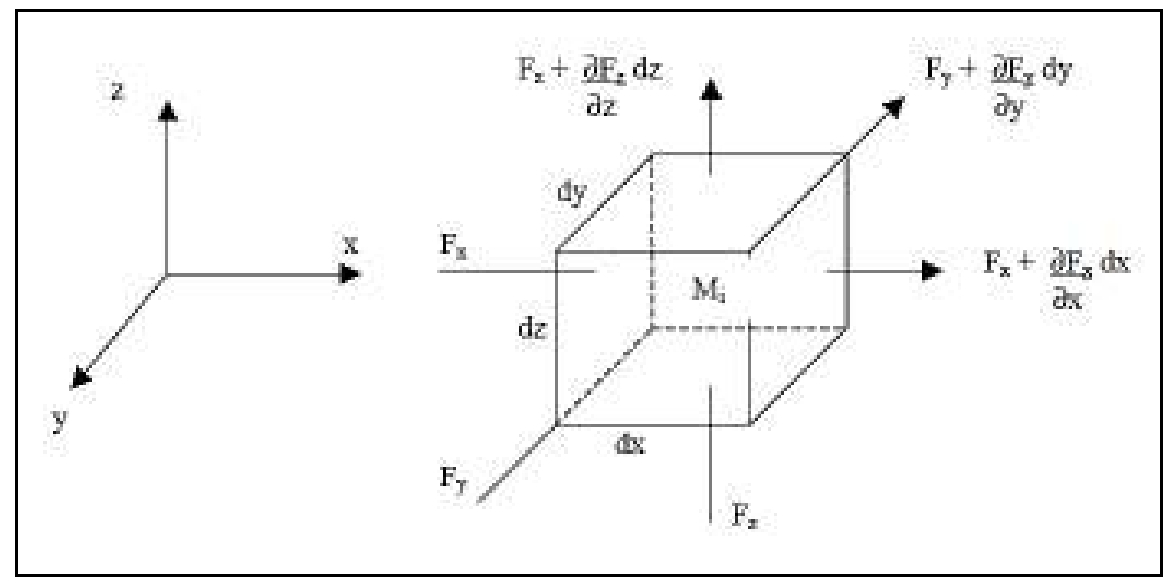

Figura 2.44- Esquematização do balando de massa (LEITE, 2001) 
A massa de soluto transportada na direção $\mathrm{x}$, por unidade de tempo, segundo os mecanismos de advecção e dispersão hidrodinâmica, pode ser representado como (FREEZE; CHERRY, 1979):

$$
\begin{gathered}
M_{\text {soluto }}=n C v_{x} d A(\text { Advecção }) \\
M_{\text {soluto }}=D_{x} \frac{\partial n C}{\partial x} d A(\text { Dispersão })
\end{gathered}
$$

em que $v_{x}$ é a velocidade média do fluido na direção x [ $\left.\mathrm{LT}^{-1}\right], d A$ é a área da seção transversal do elemento $\left[\mathrm{L}^{2}\right], n C$ representa a massa do soluto por unidade de volume do meio $\left[\mathrm{ML}^{-3}\right] \mathrm{e}$ $D_{x}$ é o coeficiente de dispersão hidrodinâmica na direção x $\left[\mathrm{L}^{2} \mathrm{~T}^{-1}\right]$.

Considerando tanto os efeitos da dispersão hidrodinâmica quando os efeitos da advecção e assumindo que a massa do soluto por unidade de área, por unidade de tempo, é representada por $F_{x}$, então (FREEZE; CHERRY, 1979):

$$
F_{x}=n C v_{x}-n D_{x} \frac{\partial C}{\partial x}
$$

O sinal negativo antes do termo que representa a dispersão hidrodinâmica indica que o contaminante se move de ponto de maior concentração para pontos de menor concentração.

Adotando que o meio é homogêneo, então a porosidade é constante e, $\partial \mathrm{nC} / \partial \mathrm{t}=\mathrm{n}$ $\partial \mathrm{C} / \partial \mathrm{t}$. Assim, a massa total de soluto que entra $\left(M_{E}\right)$ e a massa que sai $\left(M_{S}\right)$ do elemento de solo da Figura 2.44, por unidade de tempo, na direção x, são, respectivamente:

$$
\begin{gathered}
M_{E}=F_{x} d_{y} d_{z} \\
M_{s}=\left(F_{x}+\frac{\partial F_{x} d_{x}}{\partial x}\right) d_{y} d_{z}
\end{gathered}
$$

A variação de massa do soluto no interior do elemento $\Delta M_{i}$, segundo o princípio da conservação de massa, é dada pela diferença entre a massa que sai e a massa que entra do elemento, conforme Figura 2.43. Considerando um soluto não reativo, tem-se:

$$
\Delta M_{i}=\left(F_{x}+\frac{\partial F_{x} d_{x}}{\partial x}\right) d_{y} d_{z}-F_{x} d_{y} d_{z}=\frac{\partial F_{x}}{\partial x} d_{x} d_{y} d_{z}
$$


Que, em temos de concentração, é dada por:

$$
\Delta M_{i}=\frac{\partial(n C)}{\partial t} V=-n \frac{\partial C}{\partial t} d_{x} d_{y} d_{z}
$$

Igualando as Equações 83 e 84, obtém-se a expressão completa para o fluxo unidimensional.

$$
\frac{\partial F_{x}}{\partial x}=-n \frac{\partial C}{\partial t}
$$

Substituindo 83 em 85 e cancelando n nos dois lados:

$$
\frac{\partial}{\partial x}\left(D_{x} \frac{\partial C}{\partial x}\right)-\frac{\partial}{\partial x} v_{x}=\frac{\partial C}{\partial t}
$$

Rearranjando obtém-se:

$$
D_{x} \frac{\partial^{2} C}{\partial x^{2}}-v_{x} \frac{\partial C}{\partial}=\frac{\partial C}{\partial t}
$$

A solução da Equação 87 permite que se obtenha a concentração no espaço e no tempo $C(x, t)$. No caso de problemas reais de contaminação, são necessárias análises bi ou tridimensionais. Para estes casos, métodos numéricos devem ser utilizados para que se obtenha a solução das equações de transporte (FREEZE e CHERRY, 1979).

$\mathrm{Na}$ equação geral do transporte de contaminantes no solo (Equação 87), também pode ser considerados os mecanismos de sorção, representados pelo fator de retardamento. Assim, a Equação 87 pode ser reescrita como:

$$
R d \frac{\partial C}{\partial t}=D_{h x} \frac{\partial^{2} C}{\partial x^{2}}-v_{x} \frac{\partial C}{\partial x}
$$

em que $R_{d}$ é o fator de retardamento e sua obtenção deve ser feita de acordo com o método mais adequado, conforme discutido na Seção 2.15

Na Equação 87 também podem ser inseridas reações de decaimento sendo, então, reescrita como (CORDAZZO; MALISKA; CORSEUIL, 1999): 


$$
R_{d} \frac{\partial C}{\partial t}=D_{h x} \frac{\partial^{2} C}{\partial x^{2}}-v_{x} \frac{\partial C}{\partial x}-R_{d}(\lambda C+S)_{\text {cinético }}
$$

Os métodos analíticos para solução da equação da advecção-dispersão envolvem a solução de equações diferenciais parciais, baseados nas condições de contorno iniciais. As condições especificam a interação entre a área sob investigação e o ambiente externo. Para ensaios de coluna, ou seja, um problema unidimensional, a condição de contorno aplicada é aquela que considera a concentração constante e concentração inicial de soluto na coluna igual a zero.

$$
\begin{array}{ll}
C(x, 0)=0 & x \geq 0 \\
C(0, t)=C_{0} & t \geq 0 \\
C(\infty, t)=0 & t \geq 0
\end{array}
$$

Para estas condições de contorno, a solução para a Equação 87 (advecção dispersão) é a equação proposta por Ogata (1958), previamente mencionada na Seção 2.14.1.

Quando se desconsidera o segundo termo da Equação 53, devido ao $D^{*}$ ser muito baixo, tem-se a Equação 54, que é uma solução simplificada:

$$
\frac{C}{C_{0}}=\frac{1}{2}\left[\operatorname{erfc}\left(\frac{L-v t}{2 \sqrt{D_{h} t}}\right)\right]
$$

Soluções analíticas para a Equação 87 com outras condições de contorno são descritas por Ogata e Banks (1961) e Ogata (1970).

\subsection{ESTUDO DOS MECANISMOS DE TRANSPORTE DE CONTAMINANTES EM LABORATÓRIO}

Como visto anteriormente, os mecanismos de transporte de contaminantes podem ser físicos, químicos e também contar com outros processos como degradação e precipitação. Estudos dos mecanismos químicos focam a obtenção dos parâmetros da sorção, como por exemplo, os parâmetros oriundos das isotermas e o fator de retardamento, como discutido na Seção 2.14.2. Para este caso, o ensaio mais utilizado em laboratório é o ensaio de equilíbrio em lote, conhecido também como batch test, por meio de relações empíricas. Quando se objetiva estudar os mecanismos físicos e químicos envolvidos no transporte de determinado contaminante é necessário que se obtenha os parâmetros de fluxo de água como a 
condutividade hidráulica, velocidade de Darcy, velocidade linear média, vazão e gradiente hidráulico. A partir dos parâmetros de fluxo, obtêm-se então os parâmetros de transporte como o coeficiente de dispersão hidrodinâmica, o número de Péclet e o fator de retardamento. Nesta situação, o ensaio laboratorial mais utilizado para a obtenção tanto dos parâmetros de fluxo de água quanto os parâmetros de transporte de solutos é o ensaio de coluna. A seguir o ensaio de "batch test" e o ensaio de coluna serão detalhados.

\subsubsection{BATCH TEST}

O "batch test" consiste em colocar uma massa de solo em contato e agitação contínua com soluções contaminantes em concentrações variadas a uma determinada temperatura. Podem ser realizados de duas maneiras: 1) variando-se a concentração de soluto em solução e mantendo-se constante a massa de solo; ou, 2)deixando-se invariável a concentração de soluto e utilizando diferentes razões soluto/solução. Quando se atinge o tempo de equilíbrio físicoquímico, ou seja, ponto onde não há mais retenção pelo material sorvente, analisa-se o extrato aquoso, sendo a quantidade da espécie química sorvida pelo solo determinada pela Equação 90.

$$
S=\frac{\left(C_{0}-C_{e}\right) V 1000}{M}
$$

em que $S$ é a massa de soluto sorvida por unidade de massa $\left[\mathrm{MM}^{-1}\right], C_{0}$ representa a concentração inicial da solução $\left[\mathrm{ML}^{-3}\right], C_{e}$ é a concentração final da solução em equilíbrio[

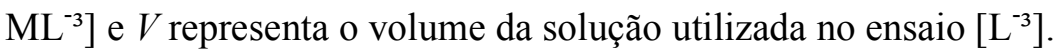

As vantagens do ensaio de "batch test" estão na simplicidade do aparato experimental, na operacionalidade e facilidade de realização. As desvantagens relacionam-se com à maior exposição das partículas às soluções contaminantes, podendo não representar as condições reais de exposição, o que pode superestimar a capacidade de sorção do solo. Apesar de simples, devido a grande quantidade de parâmetros envolvidos os ensaios de "batch test" necessitam de rigoroso controle sobre todas as possíveis variáveis, o que dificulta a uniformização dos ensaios. Segundo Roy et al. (1992) as principais variáveis que devem ser controladas são: preparação dos materiais; temperatura; $\mathrm{pH}$; força iônica da solução; método de rotação e separação das fases; e, razão solo: solução. A Figura 2.45 esquematiza os procedimentos básicos para um ensaio de "batch test". 


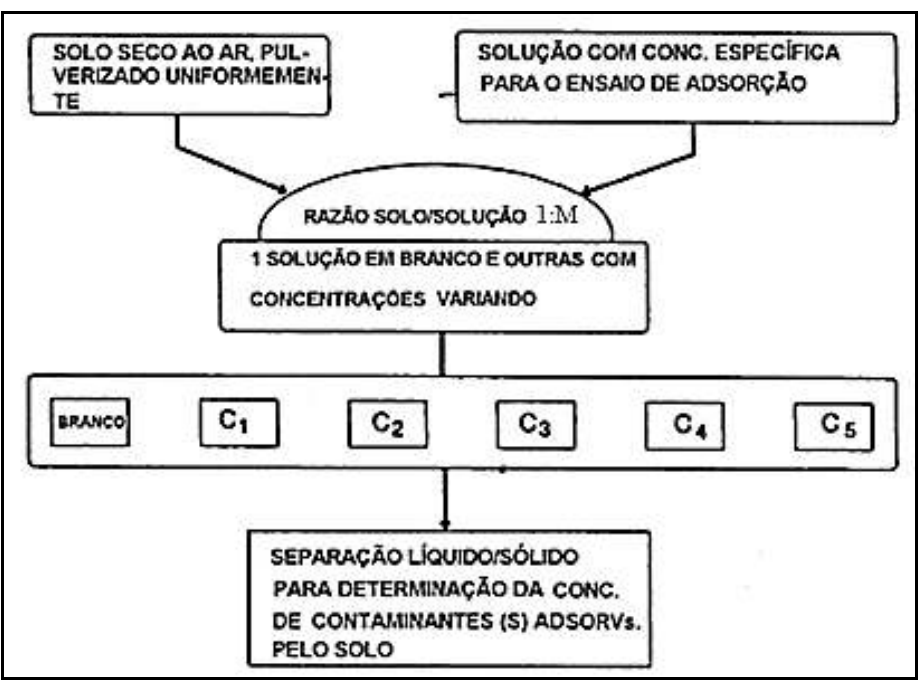

Figura 2.45- Procedimentos para ensaio de "batch test" (YONG; MOHAMED; WARKENTIN, 1992)

Segundo Knox, Sabatini e Canter (1993), os ensaios de "batch test" devem ser usados apenas como investigação preliminar, sendo que seus resultados devem ser confirmados por ensaios de coluna.

Algumas pesquisas que utilizaram o "batch test" para determinar a sorção dos contaminantes no solo foram Wentzel, Mbewe e Ekama (1995), Wentzel et al. (1999), Lookman et al. (2004), Kuai e Verstraete (1998), Lange et al. (2002); Zuquette, Silva e Garcia (2008), entre tantos outros.

\subsubsection{ENSAIO DE COLUNA}

Ensaio de coluna é aquele em que é simulada a percolação ou o contato de fluidos com solos, com o objetivo de estudar o fluxo da solução bem como suas interações. Neste ensaio, um tubo é preenchido com solo e em seguida é saturado com água. A água flui através da coluna até um estado de fluxo permanente, como em um permeâmetro. Em seguida, insere-se uma solução com um contaminante, para que, substitua a água. A concentração inicial do soluto na coluna de solo é zero e a concentração inicial da solução é $C_{0}$.

Assim, um ensaio de coluna é composto por três componentes: um reservatório fonte onde é colocada a solução contaminante; o corpo de prova, que pode ser de solo indeformado, compactado ou deformado; e, um reservatório de coleta da solução que atravessou o corpo de prova. Os procedimentos podem variar de estudo para estudo, porém o objetivo básico é o mesmo: o contato entre o solo e a solução contaminantes (FULLER; WARRICK, 1986). 
Os resultados dos ensaios de coluna normalmente são expressos sob a forma um gráfico denominado curva de chegada (ou breakthrough curve) Figura 2.46. Neste gráfico são plotadas as concentrações relativas $\left(C / C_{0}\right)$ versus o tempo, $t$, (ou o volume de poros, $V v$, percolados. O Vv é obtido através das Equações 91 ou 92 (FREEZE; CHERRY, 1979).

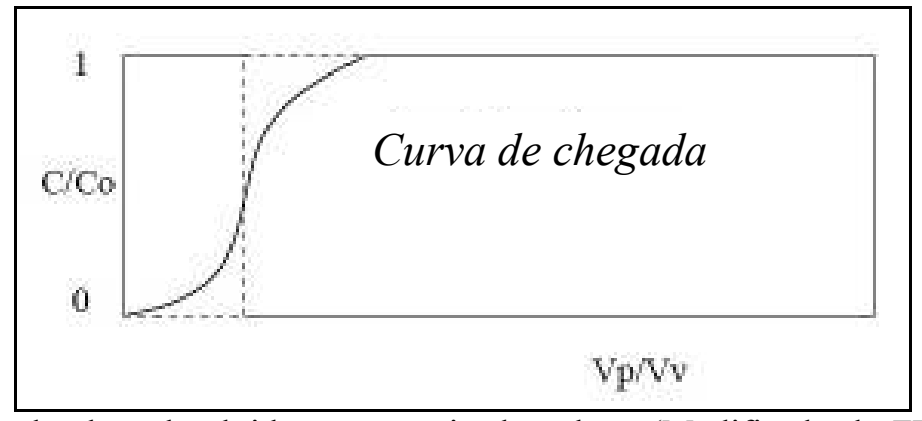

Figura 2.46- Curva de chegada obtida com ensaio de coluna (Modificado de FREEZE; CHERRY, 1979)

$$
\begin{gathered}
V_{p}=\frac{V}{V_{v}} \\
V_{p}=\frac{Q t}{A L n}
\end{gathered}
$$

em que $V$ é o volume de líquido percolado $\left[\mathrm{L}^{3}\right], V v$ é o volume de vazios do solo $\left[\mathrm{L}^{3}\right], Q$ é a vazão $\left[\mathrm{L}^{3} / \mathrm{T}\right], t$ é o tempo [T], $A$ é a área da seção transversal da coluna de solo $\left[\mathrm{L}^{2}\right], L$ é comprimento da coluna [L] e $n$ é a porosidade total [ ].

O formato da curva de chegada indica o mecanismo de transporte que deve estar atuando no material. Quanto maior a declividade das curvas, mais rápido é o transporte dos solutos e, portanto, deve estar ocorrendo advecção. Quando as curvas são mais horizontalizadas, diz-se que trata-se de um meio com alta dispersividade do soluto. A Figura 2.47 ilustra essas situações.

Figura 2.47- Curvas de chegada para soluto com baixa e alta dispersividade (Modificado de MARTINEZ; SILVA; PEREIRA, 2010) 
De acordo com Shackelford (1995), os ensaios de coluna podem ser utilizados no estudo da migração de nutrientes em solos não saturados, na avaliação do destino e transporte de contaminantes em sistemas de aquíferos regionais, ente outras aplicações. Esses ensaios também permitem a avaliação dos efeitos de reações químicas e biológicas no destino de contaminantes durante o transporte. Com os ensaios de coluna obtêm-se os parâmetros de transporte como o coeficiente de dispersão hidrodinâmica, o fator de retardamento, número de Péclet, entre outros, como discutido nas seções anteriores (SHACKELFORD, 1994; FREEZE; CHERRY, 1979; GENUCHTEN; PARKER, 1984, LAPIDUS; AMUNDSON, 1952; BRIGHAM; REED; DEW 1961). Esses ensaios são mais realísticos, quando comparados com "batch tests", por simularem melhor as condições de campo. No entanto, as principais desvantagens desses ensaios são a complexidade do aparato experimental e o tempo gasto para a realização dos ensaios, principalmente com baixa permeabilidade (KNOX; SABATINI; CANTER, 1993).

Algumas pesquisas que utilizaram o ensaio de coluna para estudar o transporte de contaminantes no solo foram Buddemeier e Hunt (1988), Saiers e Hornberger (1996), Jonge, Kjaergaard e Moldrup (2004), Rowe, Caers e Barone (1988), Addel e Luthy (1995), Toran e Palumbo (1992); Zuquette et al. (1997); Leite (2001), Rossi, Miranda e Duarte (2007), entre outros. 


\section{CaracterizaÇão da Área de Estudo}

Nesta seção são abordados aspectos gerais da área de estudo. Com isso buscou-se uma melhor compreensão acerca das características geológicas, hidrogeológicas, hidrológicas e climáticas. A caracterização da área de estudo é considerada como o ponto de partida para o entendimento dos processos de fluxo de água e transporte de contaminantes no solo.

\subsection{LOCALIZAÇÃo E ACESSOS}

A área de estudo localiza-se no município de Cabrália Paulista que se encontra na região Centro-Oeste do Estado de São Paulo, entre as latitudes s $22^{\circ} 37^{\prime}$ e $22^{\circ} 56^{\prime} \mathrm{S}$ e longitudes $49^{\circ} 31^{\prime}$ e $49^{\circ} 45^{\prime} \mathrm{W}$, com altitude média de $511 \mathrm{~m}$. O município possui uma área superficial de $236 \mathrm{~km}^{2}$.

Cabrália encontra-se distante $350 \mathrm{~km}$ da capital São Paulo sendo que seu principal acesso é pela rodovia SP-280, distante $35 \mathrm{~km}$ da sede do município no sentido Santa Cruz do Rio Pardo via rodovia SP-225. O município é acessado pelas rodovias SP-225 e SP-293 que a coloca em comunicação no sentido leste-oeste do Estado de São Paulo com as cidades de Duartina (11 km), pela rodovia SP 293, Lucianópolis via Duartina (25 km) e Ubirajara (35 $\mathrm{km})$. No sentido oeste-leste, pela rodovia SP 225, com as cidades de Piratininga $(25 \mathrm{~km})$, Bauru (37 km) e Pederneiras (67 km. No sentido sul, encontra-se Paulistânia (25 km), Santa Cruz do Rio Pardo $(53 \mathrm{Km})$ e Ourinhos $(90 \mathrm{Km})$, pela rodovia SP-225 até Ourinhos, onde se encontra a rodovia BR-153.

A área de estudo esta ao lado da Rodovia Lourenço Louzano (sentido Cabrália Paulista - Rodovia Engenheiro João Baptista Cabral Renno), cerca de 500 metros da pista, em área pertencente à Escola Técnica Estadual “Astor de Mattos Carvalho” (Figura 3.1). 


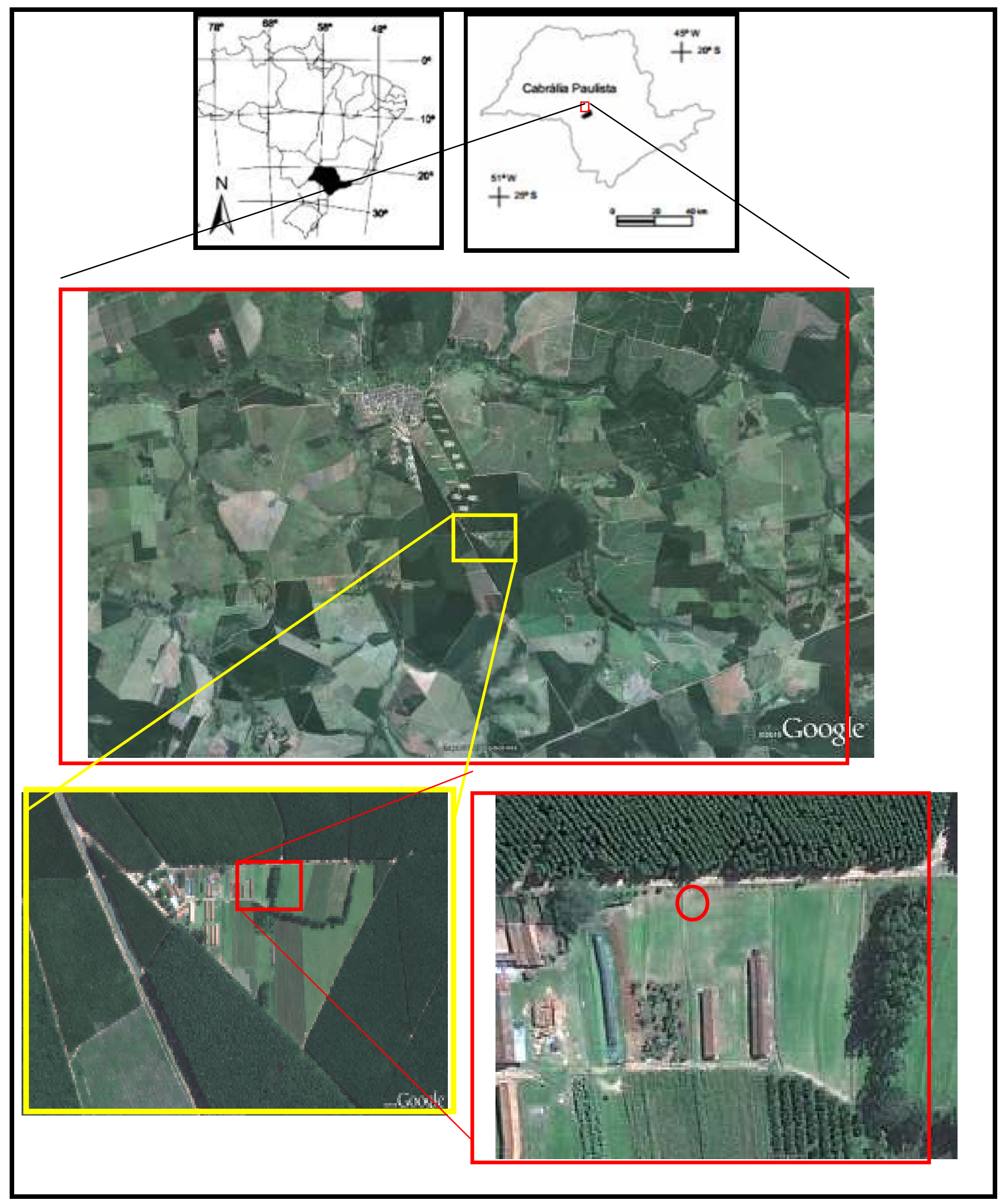

Figura 3.1- Localização da área de estudo

Local de coleta das amostras deformadas e indeformadas 


\subsection{ASPeCtos ClimÁticos}

De acordo com a classificação climática de Köppen (1936), o clima da região de Cabrália Paulista é classificado como $\boldsymbol{C} \boldsymbol{f} \boldsymbol{a}$, ou seja, clima subtropical úmido com Verão quente.

De acordo com o bando de dados pluviométricos do Estado de São Paulo, a precipitação anual acumulada em Cabrália Paulista de 1938 a 2004 é mostrada na Figura 3.2.

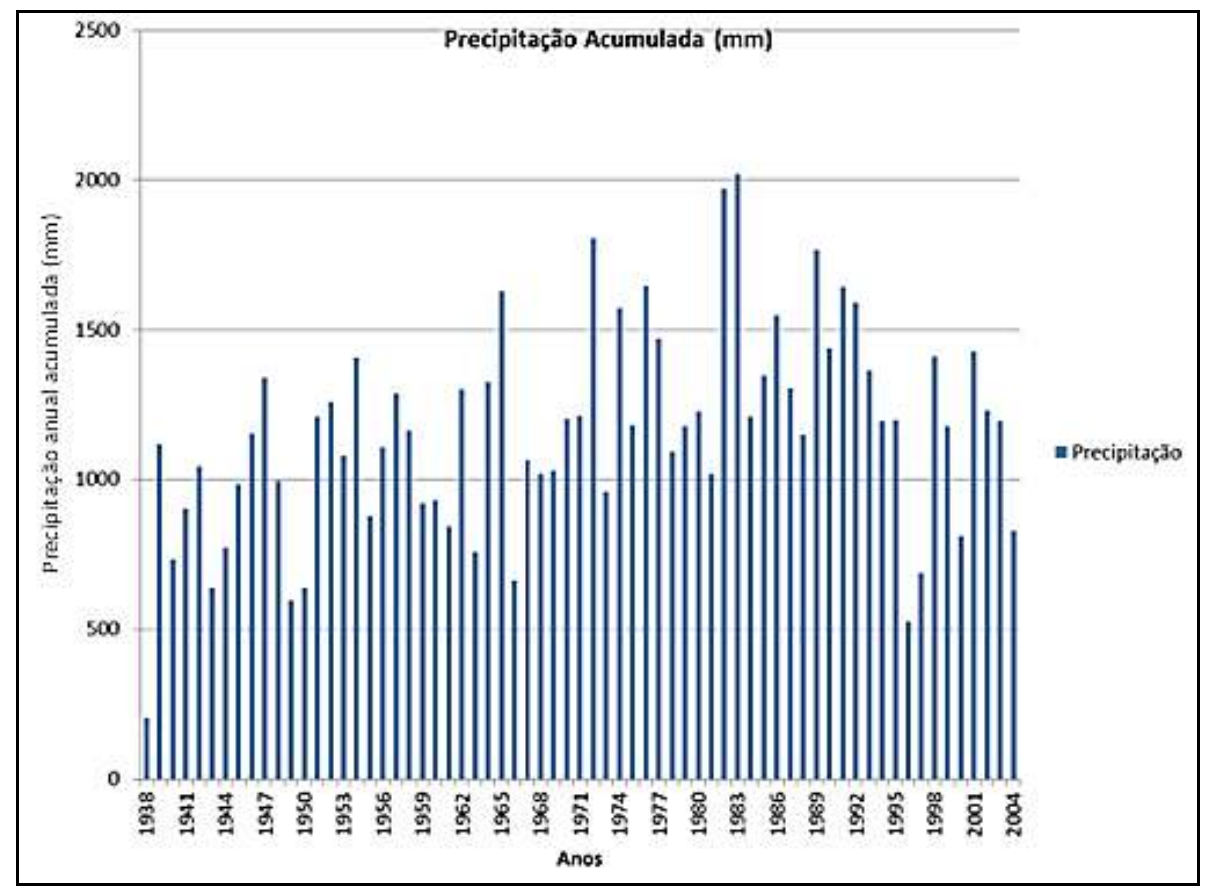

Figura 3.2- Precipitação anual acumulada de 1938 a 2004

\subsection{ASPECTOS GEOMORFOLÓGICOS}

Em escala regional, o relevo de Cabrália Paulista, segundo Ponçano (1981), apresentase constituído geomorfologicamente por: colinas amplas, morrotes alongados e espigões com altitudes médias que variam de 500 a 640 metros do fundo de vale até o topo do espigão. Colinas amplas onde predominam interflúvios com área superior a $4 \mathrm{~km}^{2}$, topos extensos e aplainados e vertentes com perfis retilíneos a convexos. As drenagens neste tipo de relevo são de baixa densidade, padrão subdentrítico com vales abertos e planícies aluviais interiores restritas, com a presença eventual de lagoas perenes ou intermitentes. Morrotes alongados e espigões onde predominam interflúvios sem orientação preferencial com topos angulosos e achatados, vertentes ravinadas com perfis retilíneos com drenagem de média a alta densidade, padrão dentrítico e vales fechados. 


\subsection{ASPECTOS PEDOLÓGICOS}

Os principais tipos de solos identificados em Cabrália Paulista são Latossolo, Gleissolo e Argissolo. Os Argissolos compreendem solos com horizonte B textural e argila de atividade baixa, conhecidos anteriormente como Podzólico Vermelho-Amarelo, parte das Terras Roxas Estruturadas e similares, Terras Brunas, Podzólico Amarelo e Podzólico Vermelho escuro de acordo com classificação de EMBRAPA (1999). Gleissolos são solos com horizonte glei, conhecidos como glei úmido ou pouco úmido, hidromórfico cinzento ou glei tiomórfíco. Compreendem uma classe de solo cuja característica mais importante é a presença de horizonte glei a menos de $80 \mathrm{~cm}$ de profundidade, resultante de marcante processo de redução devido à proximidade do lençol freático. Nesta categoria estão incluídos os solos glei pouco úmidos eutróficos e distróficos (EMBRAPA,1999). Esses solos apresentam uma camada superficial de material orgânico (horizonte turfoso) inferior a $40 \mathrm{~cm}$ de espessura, desenvolvem-se em planícies aluviais onde é comum a ocorrência de extratos e apresentam grande diversidade textural, ocorrendo desde arenosa até argilosa, predominando esta última.

$\mathrm{Na}$ área de estudo o tipo de solo encontrado é o Latossolo. Latossolos são solos altamente intemperizados, profundos e bem drenados, constituídos predominantemente por sesquióxidos, minerais de argila do tipo 1:1 (caulinita) e quartzo. Os óxidos de ferro livre contribuem para a agregação das partículas de silte e argila, fazendo com que esses solos, sejam bem arejados e friáveis, com ótimas propriedades físicas. Entretanto, a baixa atividade das argilas e dos óxidos de ferro faz com que sejam em geral deficientes em nutrientes. O perfil do solo apresenta sequência de horizontes $\mathrm{A}, \mathrm{B}$ e $\mathrm{C}$ com pequena diferenciação entre eles. A textura pouco varia com a profundidade, uma vez que não apresentam horizonte superficial de acúmulo de argila.

\subsection{ASPECTOS GEOLÓGICOS}

A área de estudo pertence à unidade geotectônica denominada Bacia Sedimentar do Paraná, que é uma ampla região sedimentar do continente sul-americano que inclui porções do Brasil, Paraguai, Argentina e Uruguai, num total de aproximadamente 1,5 milhões de metros quadrados (MILANI; FRANÇA; SCHNEIDER, 1994). Segundo Almeida e Melo (1981), a Bacia do Paraná trata-se de uma grande superfície formada pela deposição de sedimentos e derrames de lavas basálticas. Seu contorno atual é definido por limites erosivos relacionados à história geotectônica Meso-Cenozoica do continente. O trecho que inclui o sudeste brasileiro, onde se localiza Cabrália Paulista, foi modelado por erosão em função do 
soerguimento crustal associado ao rifle do Atlântico Sul, com uma remoção da Seção sedimentar estimada em 2.500m (MILANI; FRANÇA; SCHNEIDER, 2007).

Segundo Milani (1997), no registro estratigráfico da Bacia do Paraná existem seis unidades de ampla escala, na forma de pacotes rochosos. Cada uma dessas unidades representam intervalos temporais com algumas dezenas de milhões de anos de duração e envelopados por superfícies de discordância de caráter inter-regional, a saber: Rio Ivaí (Ordoviciano Siluriano), Paraná (Devoniano), Gondwana I(Carbonífero-Eotriássico), Gondwana II (Meso a Neotriássico), Gondwana III (Neojurássico-Eocretáceo) e Bauru (Neocretáceo).

Cabrália Paulista encontra-se sobre litologias encontradas na Bacia do Paraná, pertencentes ao Grupo Bauru. O Grupo Bauru compreende um pacote sedimentar de idade Cretácea, que aflora em área de cerca de 117.000 km² no Estado de São Paulo (DAEE 1990), tendo como substrato as rochas basálticas da Formação Serra Geral e, localmente, os sedimentos das formações Botucatu e Piramboia, como na região de Bauru (SP) e Agudos (SP) (SUGUIO et al.1977, PAULA E SILVA; CAVAGUTI, 1994). A Figura 3.3 mostra a Bacia Bauru com os grupos Bauru e Caiuá, de acordo com Fernandes (1998). 


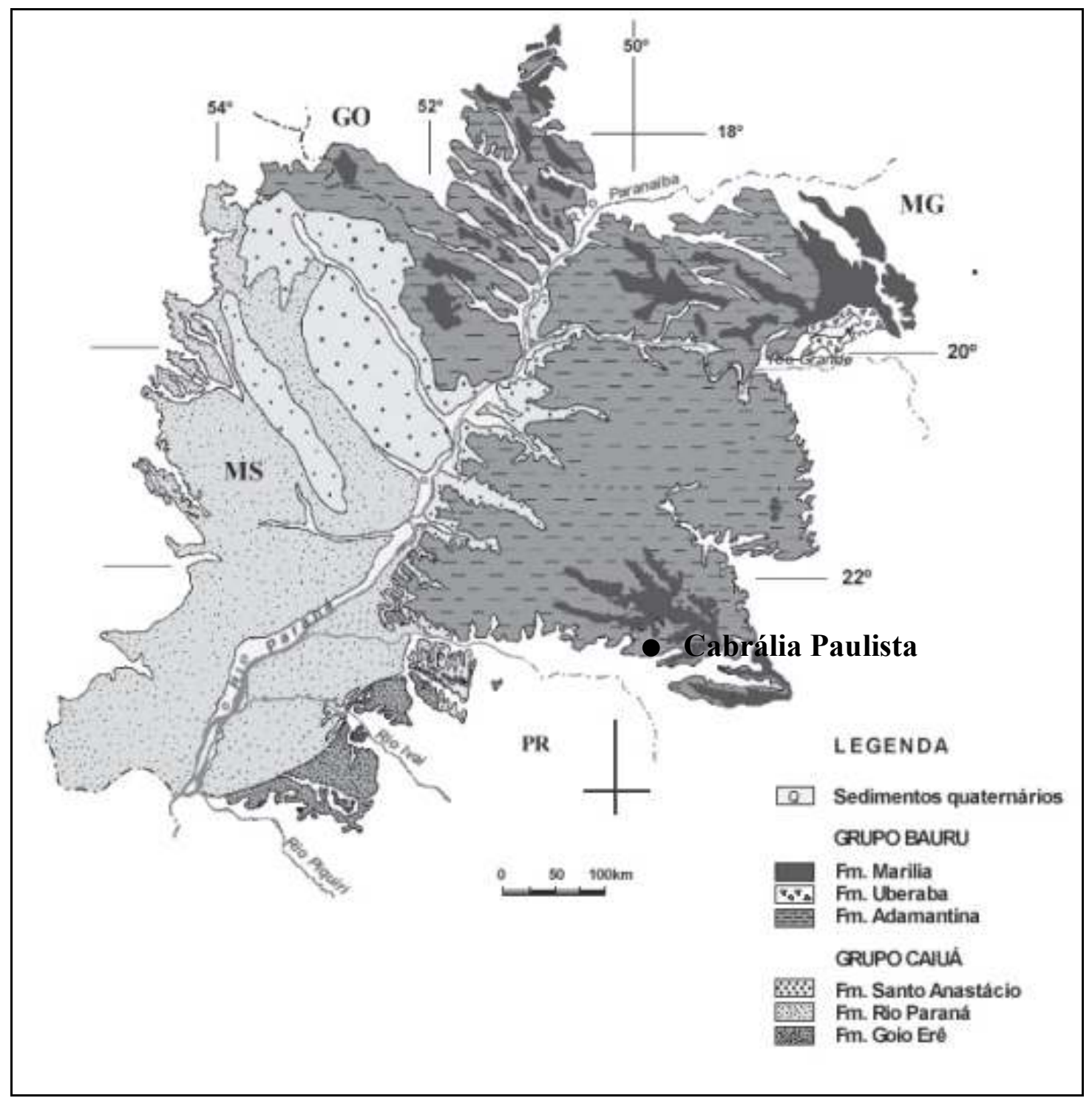

Figura 3.3- Bacia Bauru com os grupos Bauru e Caiuá (modificado de FERNANDES, 1998)

A Figura 3.5 mostra um perfil detalhado da área (a partir da Seção A:A' - Figura 3.4), com destaque para a área de estudo. 


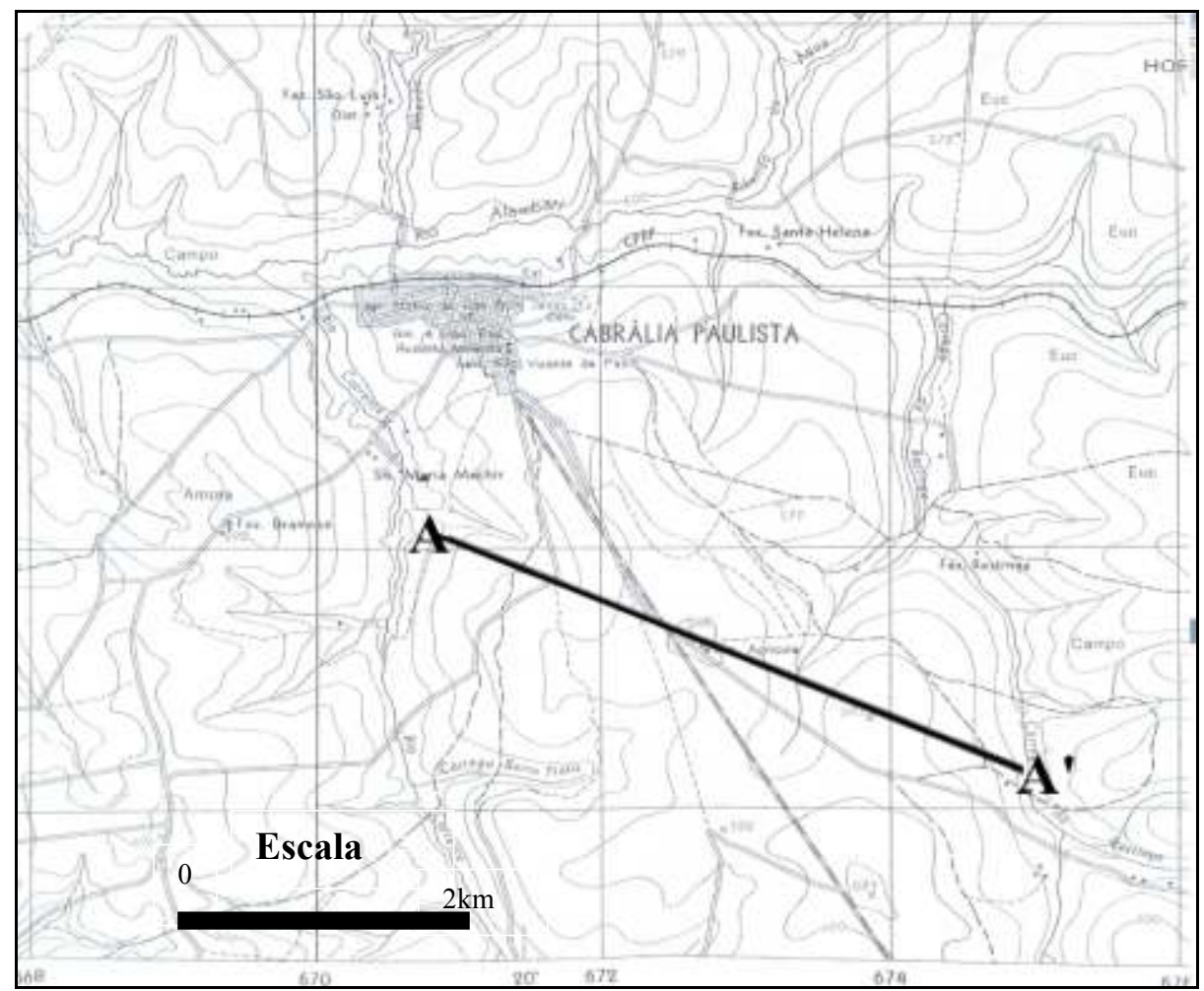

Figura 3.4- Mapa topográfico com a localização do perfil da Figura 3.5

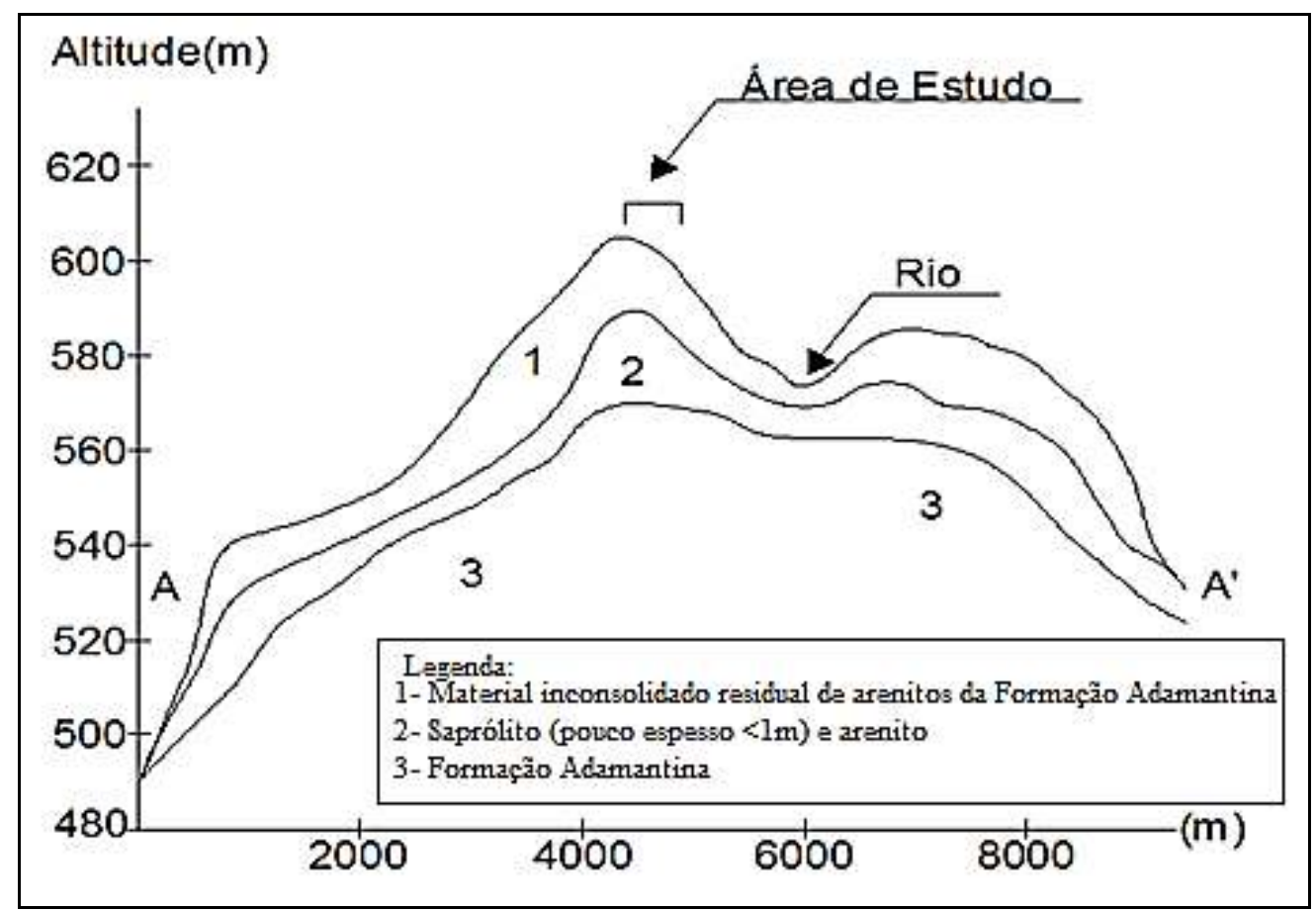

Figura 3.5- Perfil litológico da área de estudo

Como pode ser observado na Figura 3.5, a área de estudo está situada sobre material inconsolidado residual de arenitos da Formação Adamantina. Segundo Mendonça e Aragoni (1986), a Formação Adamantina foi proposta por Soares et al. (1980) como um conjunto de 
fáceis compostas por bancos de arenito de granulação fina a muito fina de cor rosa a castanho, portando estratificação cruzada, intercalados a bancos de lamitos, siltitos e arenitos lamíticos. Esta formação é delimitada inferiormente, de maneira discordante, pelos basaltos da Formação Serra Geral e com a Formação Santo Anastácio. O contato superior é concordante interdigitado a abrupto com a Formação Marília (PAULA E SILVA; CHANG; CAETANOCHANG, 2003).

\subsection{ASPECTOS HIDROGEOLÓGICOS}

Cabrália Paulista situa-se sobre o Sistema Aquífero Bauru (SAB) (Figura 3.6), que ocupa aproximadamente a metade oeste do território do Estado de São Paulo, possuindo uma área aproximada de $96.880 \mathrm{~km}^{2}$.

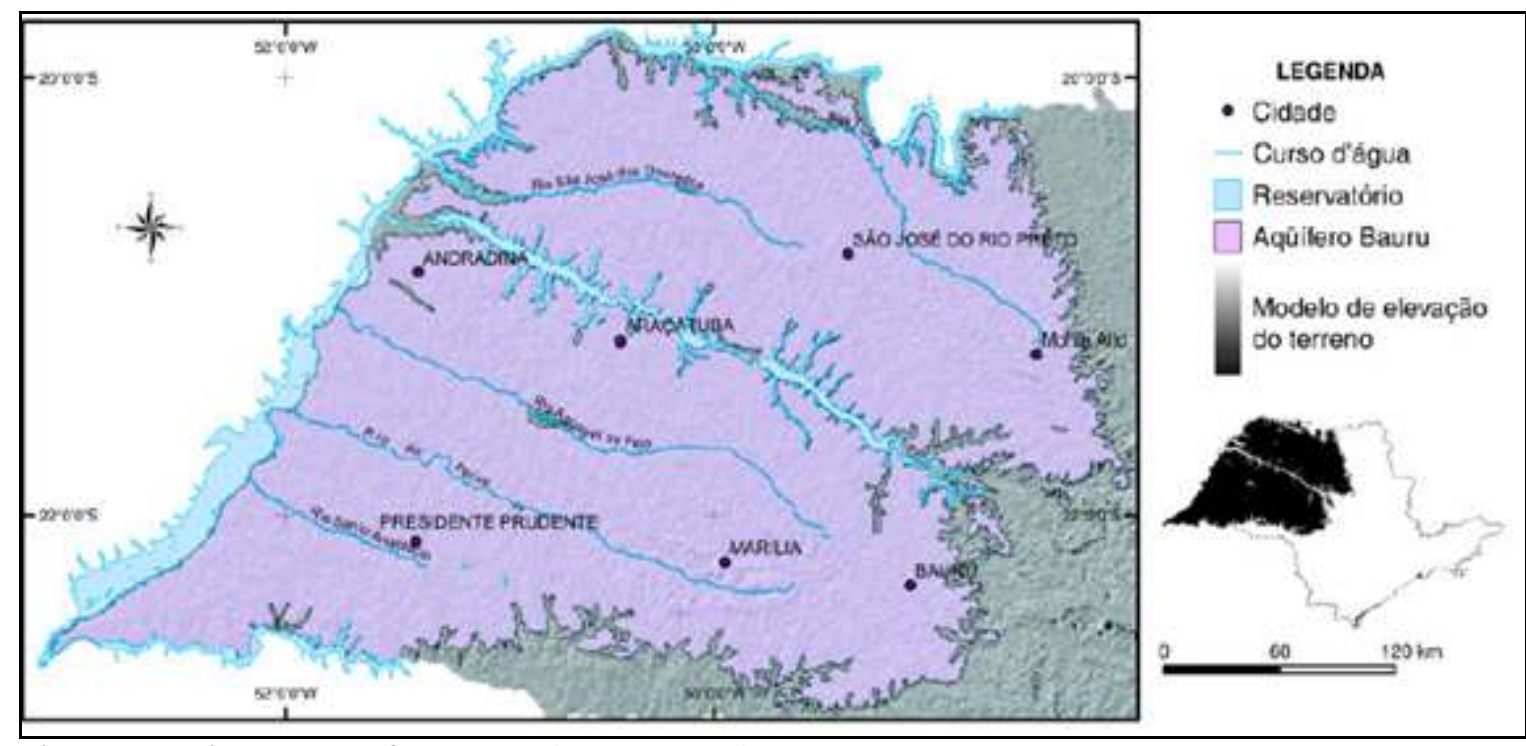

Figura 3.6- Sistema Aquífero Bauru (DAEE, 2005)

Hidroestratigráficamente o SAB é dividido em duas unidades: a unidade Aquífera Bauru Inferior, representada por arenitos e arenitos sílticos pertencentes às formações Caiuá e Santo Anastácio; e, a unidade Aquífera Bauru Médio/Superior, constituída por arenitos, arenitos sílticos, lamitos e arenitos conglomeráticos, pertencentes às formações Adamantina e Marília (ROCHA, et al., 1979). O SAB é limitado a oeste e noroeste pelo rio Paraná, a norte pelo rio Grande, a sul pelo rio Paranapanema e pelas áreas de afloramento da Formação Serra Geral, que delimitam também o aquífero na região leste.

Este sistema aquífero é constituído pelas três formações geológicas mais antigas do Grupo Bauru (Formação Caiuá, Formação Santo Anastácio e Formação Adamantina). Cada uma dessas formações constituem unidades aquíferas independentes quando ocorrem 
isoladamente (MENDONÇA; GUTIERRE, 2000). A Figura 3.7 mostra a subdivisão hidroestratigráfica do Grupo Bauru.

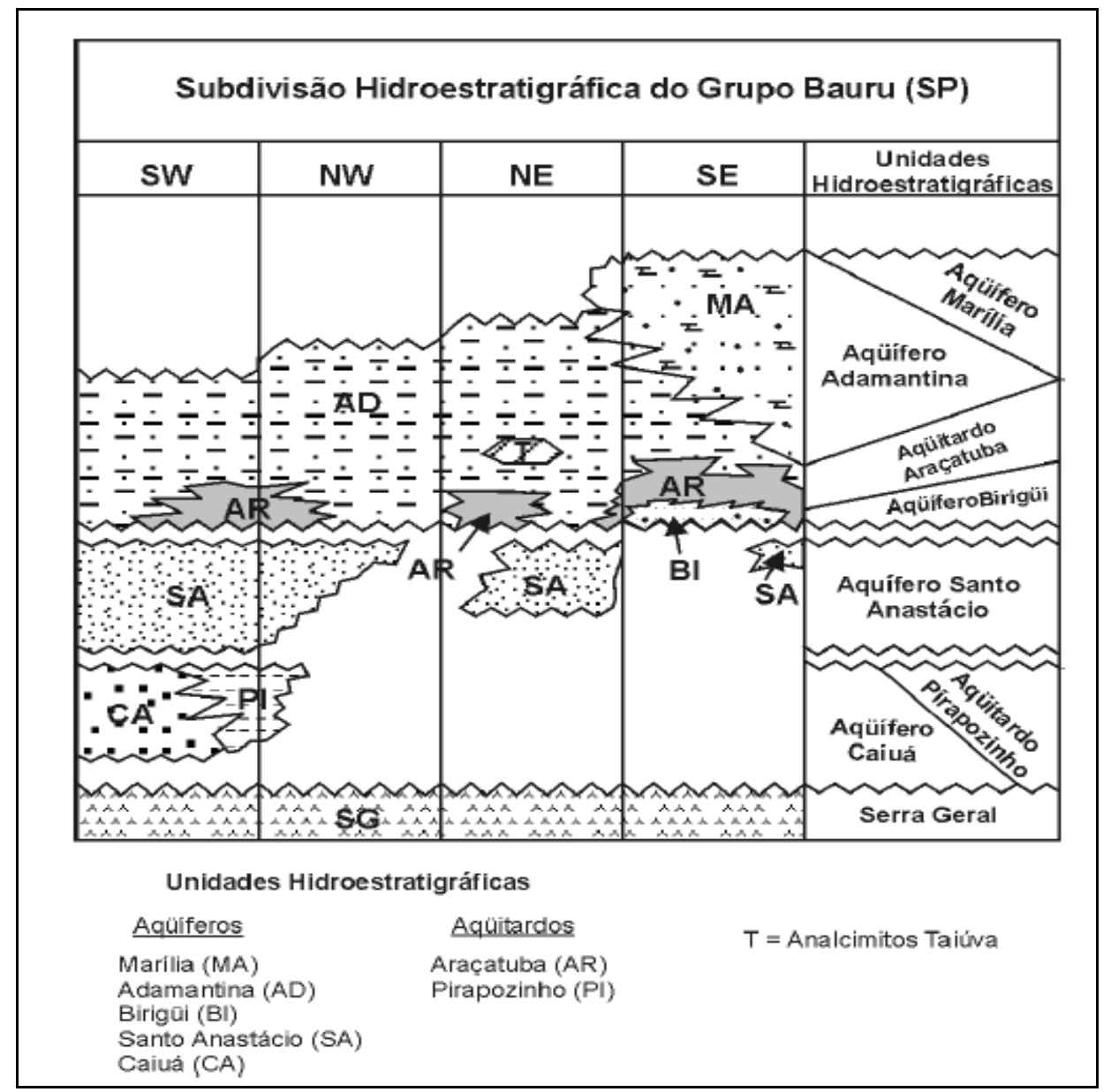

Figura 3.7- Subdivisão hidroestratigráfica do Sistema Aquífero Bauru (PAULA E SILVA, 2003)

A área de estudo encontra-se sobre o Aquífero Adamantina, que ocorre em no município de Cabrália Paulista e aflora nas cotas topográficas mais baixas. Apresenta extensão regional, com uma área de aproximadamente $99.600 \mathrm{~km}^{2}$ (PAULA E SILVA; CHANG; CAETANO-CHANG, 2005). É do tipo livre, regionalmente semi-confinado, de porosidade primária e é limitado inferiormente pelos basaltos da Formação Serra Geral. O semiconfinamento é decorrente principalmente das variações de permeabilidade dos sedimentos em função do maior ou menor teor de argila da matriz, ou de camadas pelíticas que se intercalam aos corpos arenosos. Em função de sua constituição litológica, na qual bancos de arenitos intercalam-se com bancos de siltitos ou arenitos lamíticos, constitui um aquífero que fornece, em geral, baixos valores hidrodinâmicos, tendo a sua produtividade relacionada à espessura das camadas arenosas atravessadas. Suas principais características hidrodinâmicas são, em média, as seguintes: vazões de 5 à $50 \mathrm{~m}^{3} / \mathrm{h}$; condutividade hidráulica 
de 1E10-7 a 1E10-3 m/s; gradiente hidráulico de 0,008 a 3,42; velocidade de fluxo de 8,7E107 a 2,3 E10-2 m/s e transmissividade de 10 a 100 m²/dia (MENDONÇA; ARAGONI, 1986; MENDONÇA; GUTIERRE, 2000).

\subsection{ASPECTOS HIDROLÓGICOS}

Cabrália Paulista encontra-se na Unidade de Gerenciamento de Recursos Hídricos (UGRHI) 17 Médio Paranapanema (Figura 3.8).

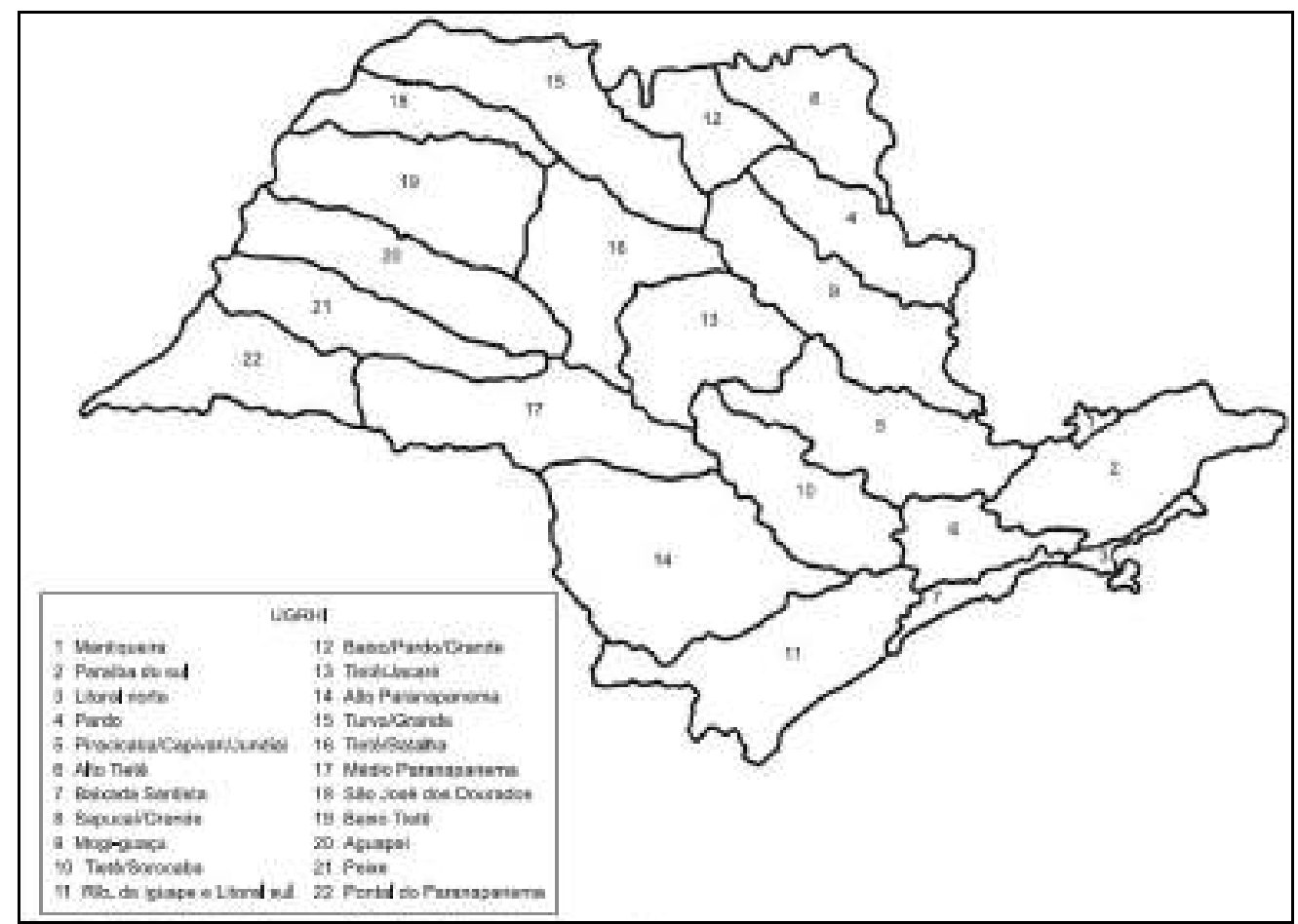

Figura 3.8- UGRHIs do Estado de São Paulo (MATSUMURA-TUNDISI, 2010)

A Hidrografia do município de Cabrália Paulista corresponde à área drenada principalmente pelo rio Alambari, que tem sua nascente nas proximidades do distrito de Brasília Paulista, município de Piratininga, e é um afluente da margem direita do rio Turvo e este por sua vez deságua no rio Paranapanema (Figura 3.9). 


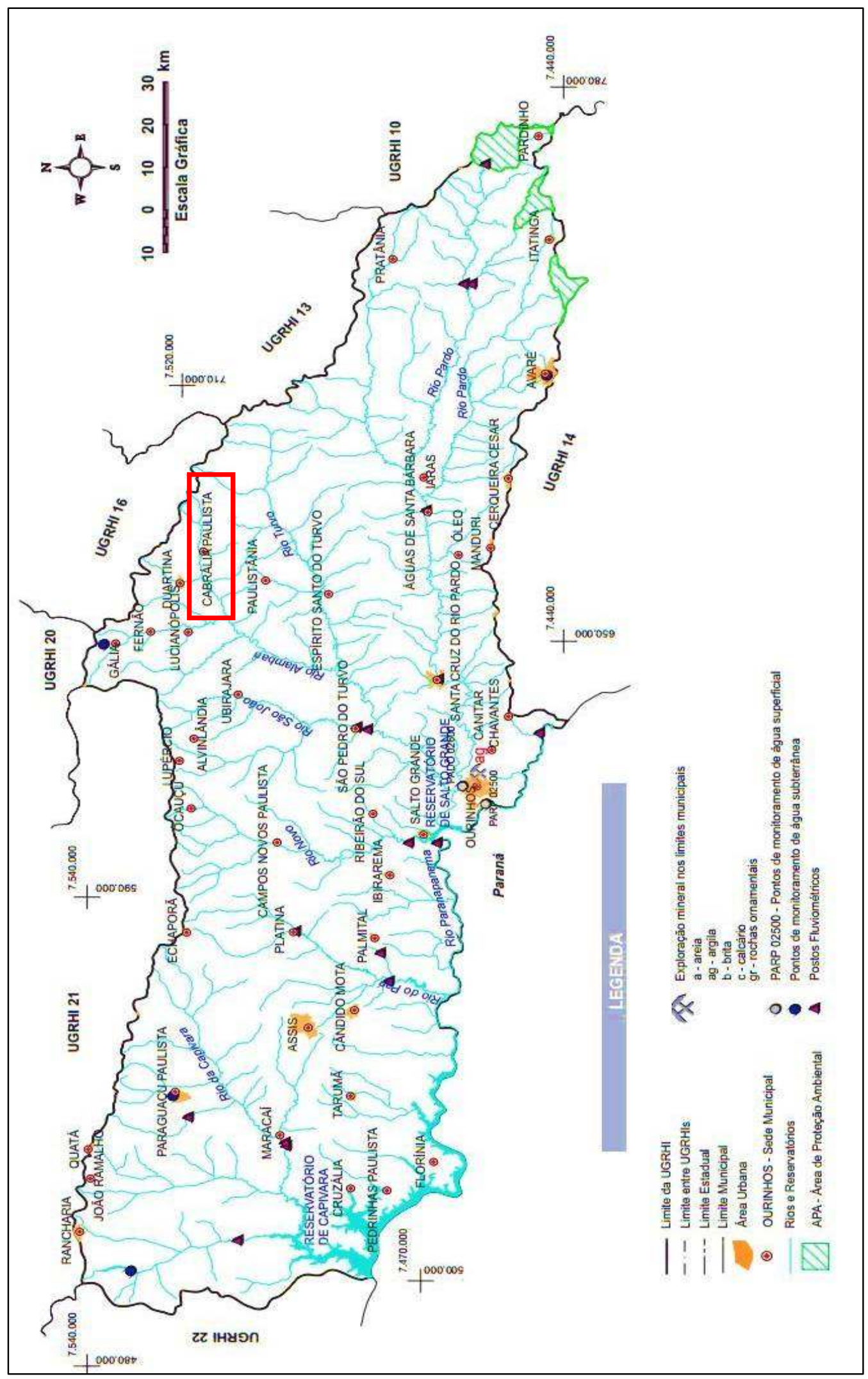

Figura 3.9- Hidrografia da região de UGRHI 17 - Médio Paranapanema (Modificado de DAEE, 2006) 


\section{Materiais e Métodos}

O desenvolvimento desta pesquisa deu-se em algumas etapas estrategicamente posicionadas de maneira que os trabalhos realizados em uma etapa dessem subsídios para as outras etapas. A seguir serão detalhadas todas as etapas realizadas para o desenvolvimento desta pesquisa.

\subsection{FLUXOGRAMA DA PESQUISA}

Na Figura 4.1 encontra-se o fluxograma com a sequência das principais etapas do estudo.

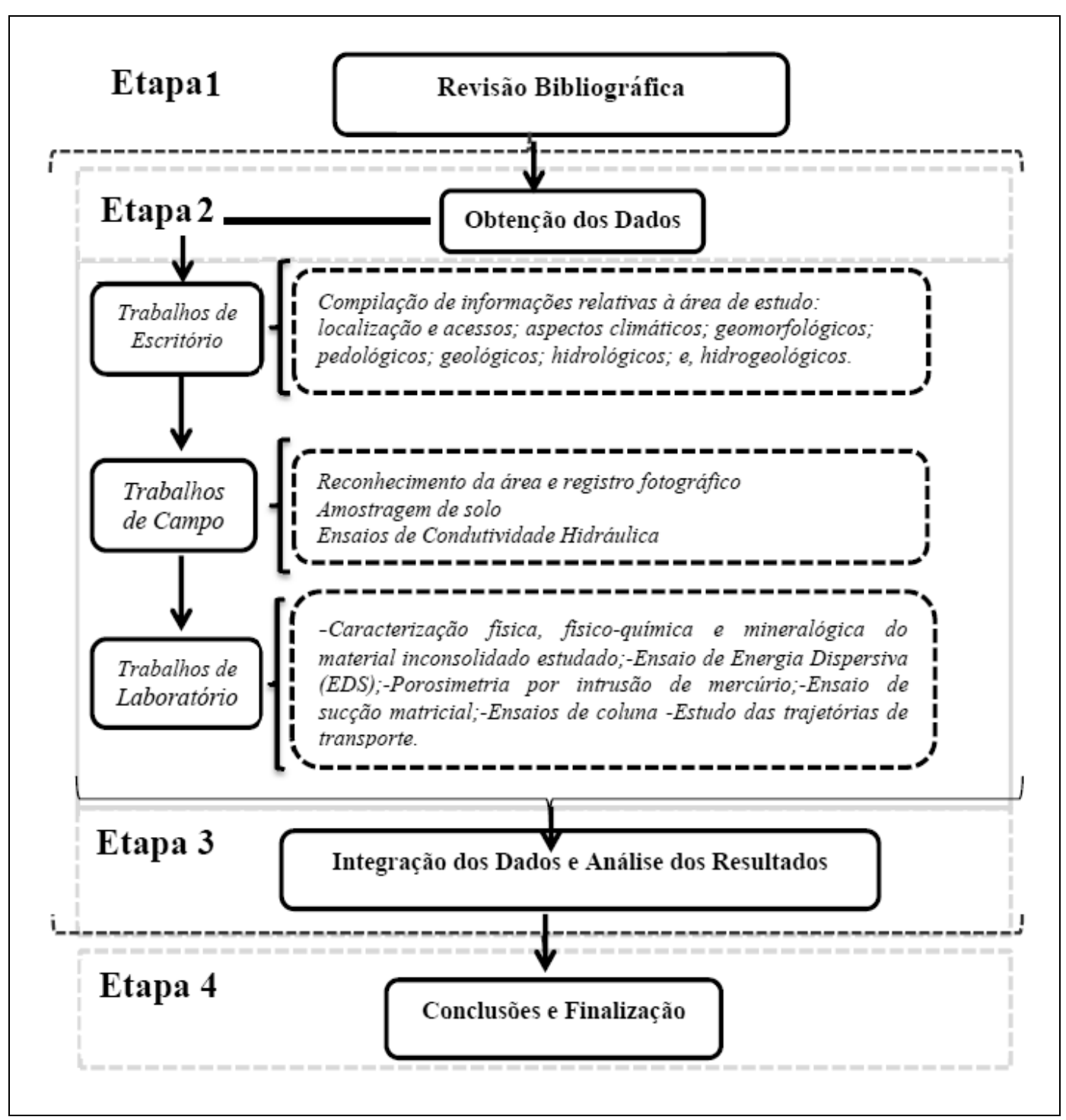

Figura 4.1- Fluxograma da pesquisa 


\subsection{ETAPA 1: REVISÃO BIBLIOGRÁFICA}

Esta etapa teve como objetivo fornecer a base teórica necessária para o entendimento do problema estudado e subsidiar o entendimento e discussão dos resultados. Para isso, foi subdividida em quatro partes. A primeira parte buscou fornecer subsídios para o entendimento da problemática de geração e disposição de resíduos. Abordaram-se os diversos tipos de tratamento de esgotos, bem como a disposição final do efluente gerado. Focou-se na disposição no solo dos efluentes provenientes de biodigestores anaeróbios, mostrando os estudos que trazem os benefícios e também os problemas relacionados à irrigação de solos agrícolas com efluentes. Na segunda parte estudaram-se as características e propriedades dos solos saturados e não saturados. Na terceira parte foram revisados os aspectos do movimento da água no solo e os mecanismos de transporte de solutos nos solos, bem como a formulação matemática do fenômeno de transporte de contaminantes. Na quarta e última parte, revisaramse os tipos de estudos da interação solo-contaminantes (laboratoriais e em campo) e detalharam-se os ensaios de colunas, utilizados nesta pesquisa. É importante ressaltar que esta etapa, apesar de ser chamada de "Etapa 1", esteve presente durante toda a realização do trabalho.

\subsection{ETAPA 2 : OBTENÇÃo DOS DADOS}

A obtenção de dados deu-se por meio de trabalhos de escritório, de campo e laboratoriais.

\subsubsection{TRABALHOS DE ESCRITÓRIO}

Em escritório foram compiladas as informações relativas à localização da área, uso do solo, aspectos climáticos, geológicos, hidrológicos e hidrogeológicos. Obteve-se essas informações em mapas, artigos científicos, livros e sites oficiais de banco de dados como o site da Agência Nacional de Águas, Departamento de Águas e Energia Elétrica, Instituto Geográfico e Cartográfico do Estado de São Paulo e Instituto Brasileiro de Geografia e Estatística. As informações obtidas nesta etapa encontram-se detalhadas na Seção 3 "Caracterização da área de estudo". 


\subsubsection{TRABALHOS DE CAMPO}

Inicialmente fez-se um reconhecimento da área e registro fotográfico. Neste reconhecimento foram obtidas informações do uso e manejo das terras, amostragens de solo e ensaios de condutividade hidráulica in situ.

\subsubsection{Reconhecimento da área e registro fotográfico}

As informações de uso de manejo do solo foram obtidas diretamente na escola técnica estadual "Astor de Mattos Carvalho" com os funcionários responsáveis. A área estudada (Figura 4.2) não é utilizada para nenhuma prática agrícola e nunca recebeu nenhuma forma de fertilização.

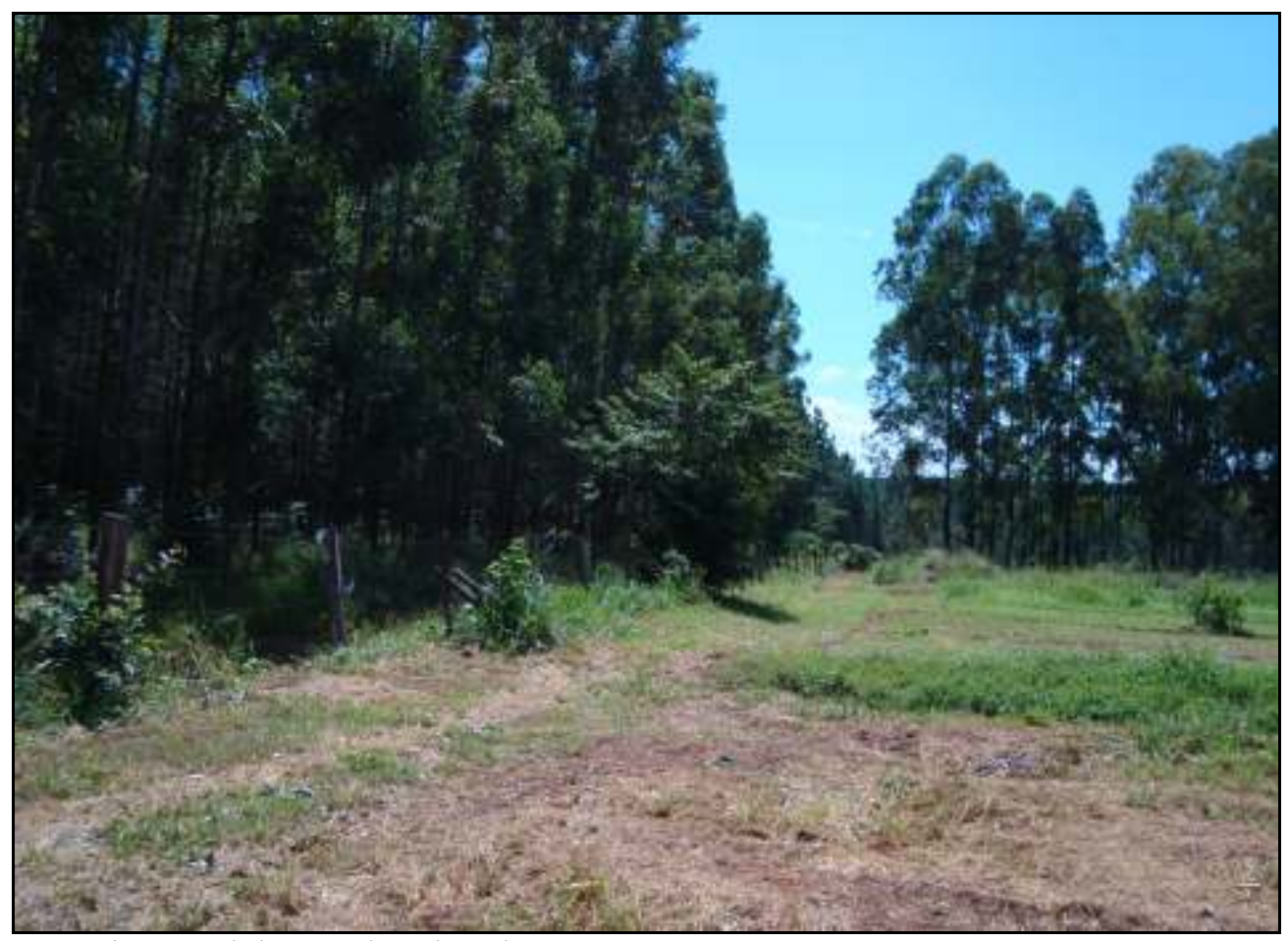

Figura 4.2- Vista geral da área de coleta das amostras

As áreas vizinhas à área estudada estão sendo irrigadas há três (Figuras 4.3b e 4.3a) e há cinco anos com efluentes provenientes do biodigestor anaeróbio (Figura 4.4) e são utilizadas para o cultivo de cana-de-açúcar. 


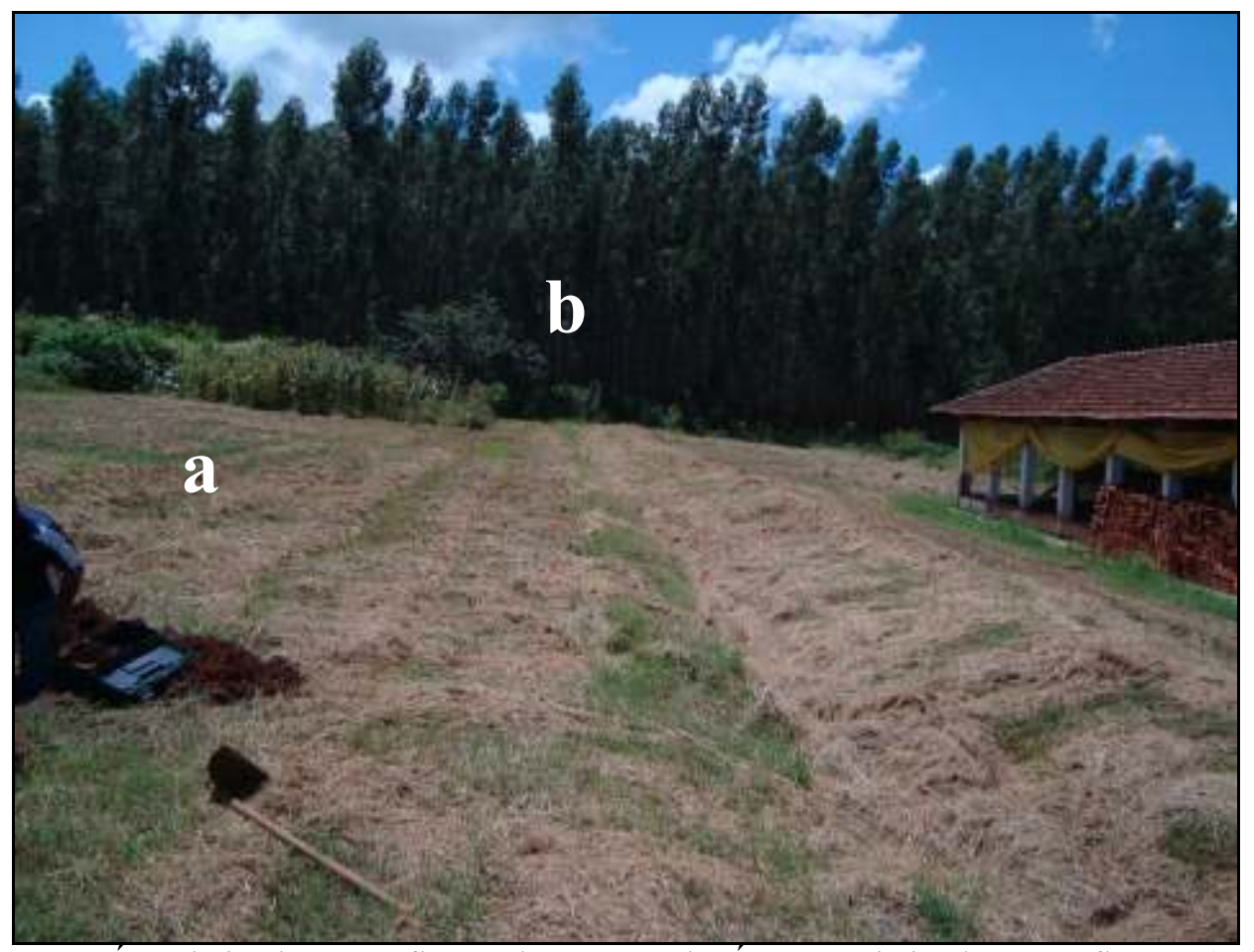

Figura 4.3- a: Área irrigada com efluente há 3 anos; b: Área não irrigada com efluente (coleta das amostras deformadas e indeformadas)

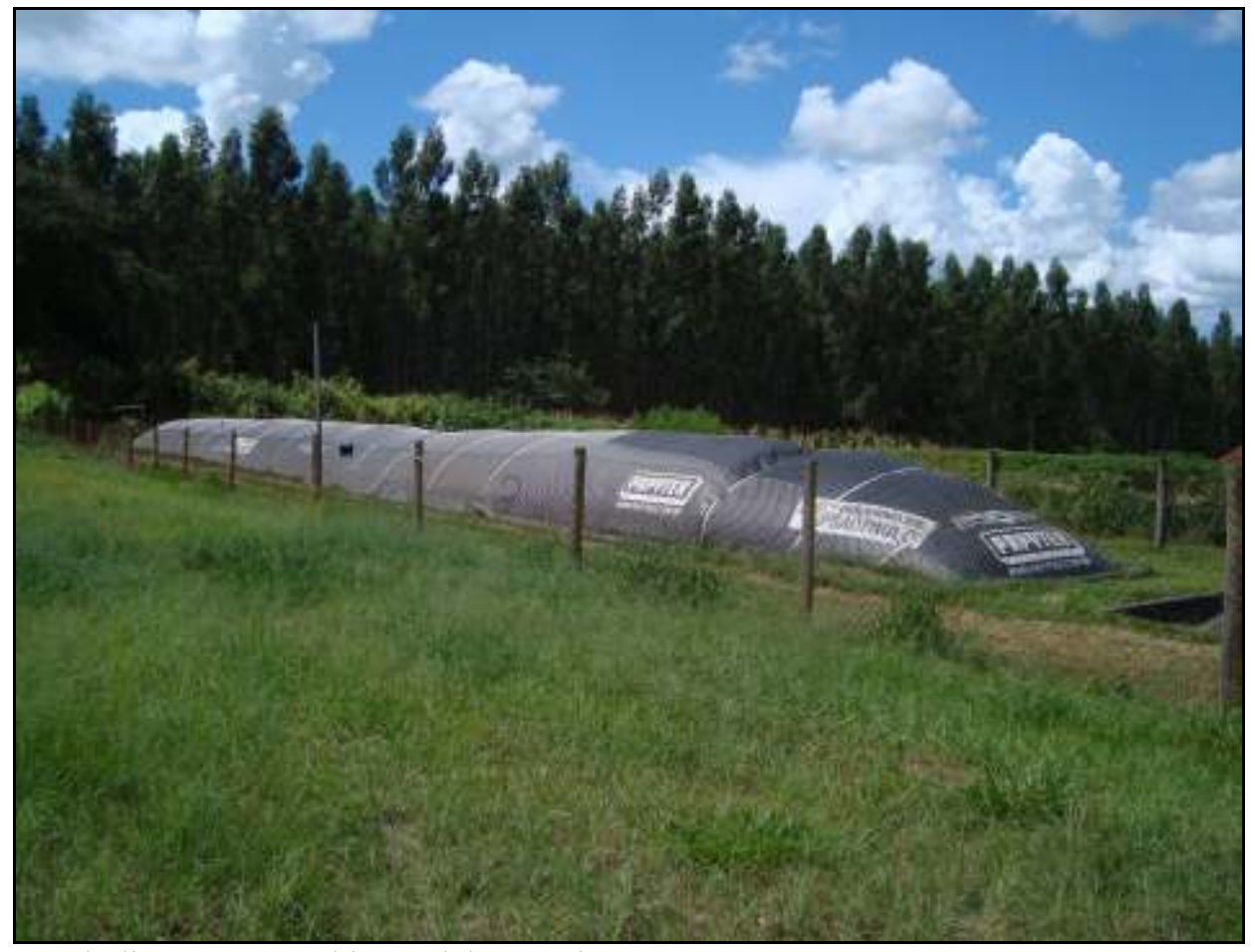

Figura 4.4- Biodigestor anaeróbio modelo canadense

Este biodigestor foi instalado na escola em 2008, por meio de uma parceria entre a Embrapa Instrumentação Agropecuária e a Firestone Building Products, e recebe esgoto doméstico dos banheiros do alojamento estudantil que existe na área, e também esgoto da 
criação de suínos. Os efluentes são aplicados no solo sem nenhum controle de volume, temperatura, $\mathrm{pH}$ e concentração dos componentes.

\subsubsection{Amostragem de solo}

Foram coletadas amostras deformadas e indeformadas (Figura 4.5c e 4.5d), adotando cuidados na extração das amostras no que diz respeito à ausência de anomalias e presença de matéria orgânica (raízes). As amostras deformadas foram retiradas da profundidade de 30-60 cm e foram utilizadas para os ensaios de caracterização física, físico-química e mineralógicas (Etapa 3). As amostras foram armazenadas em sacos plásticos identificados e posteriormente acondicionadas em caixas de isopor.
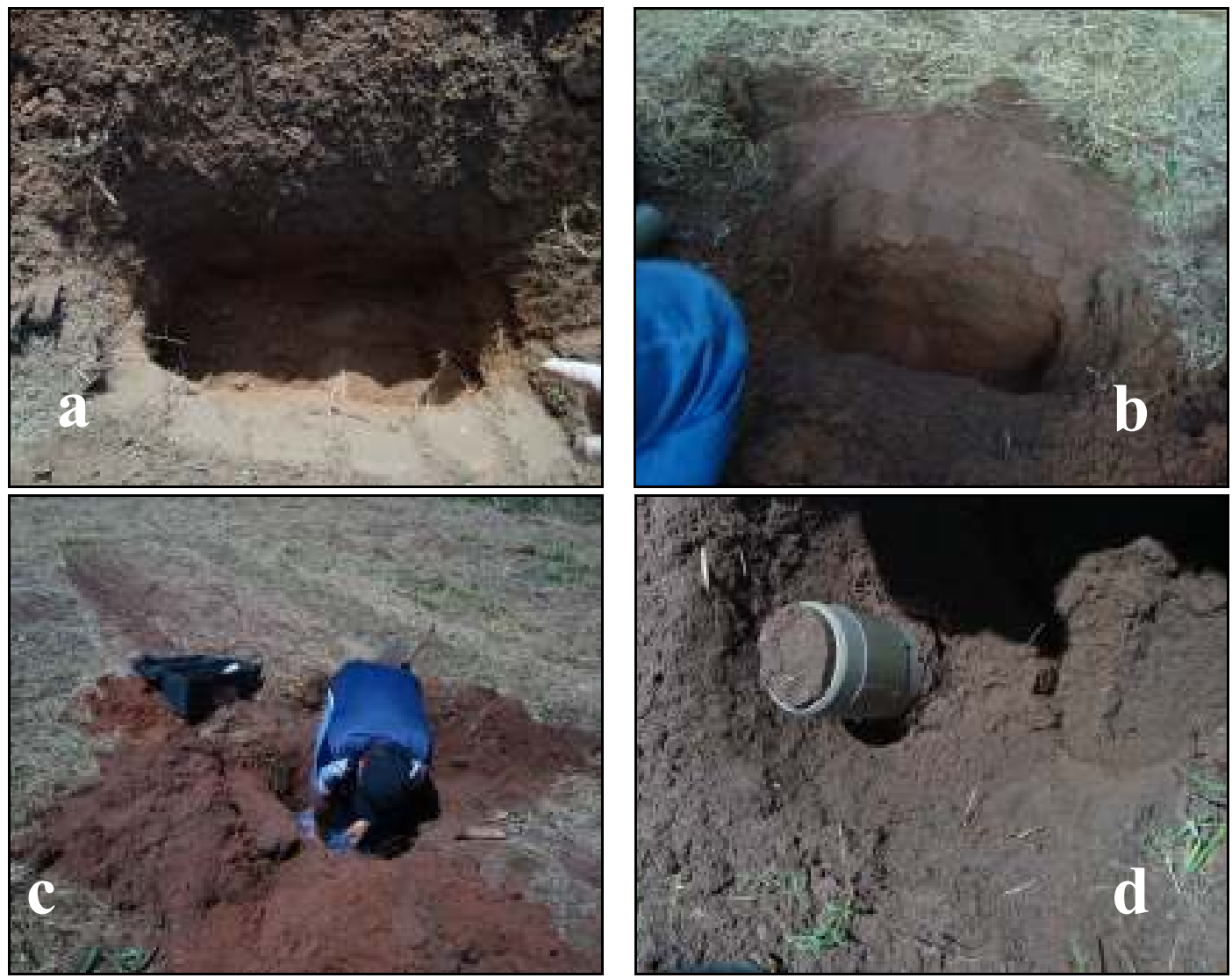

Figura 4.5- a e b: Cava para coleta das amostras; c: Coleta de amostras deformadas; d:Indeformadas

As amostras indeformadas foram coletadas em uma profundidade de 60 centímetros em trincheira escavada manualmente. Foram coletados 15 cilindros de PVC de parede rígida. 3 Colunas de PVC foram coletadas para a moldagem dos corpos de prova utilizados no ensaio de sucção matricial. Os cilindros de PVC possuem $150 \mathrm{~mm}$ de altura e 97,2 mm de diâmetro interno. 
Todas as amostras indeformadas coletadas foram identificadas, cuidadosamente envolvidas em papel filme, para evitar a perda de umidade, depois envolvidas em uma camada espessa de plástico bolha para proteger as amostras contra impactos que pudessem comprometer a estrutura do solo, e finalmente acondicionadas em caixas de isopor.

\subsubsection{Ensaios de condutividade hidráulica}

A condutividade hidráulica foi determinada na camada superior $(0-65 \mathrm{~cm})$ e inferior $(0-195 \mathrm{~cm})$, por meio do ensaio de rebaixamento a nível variável por injeção de água, de acordo com o método proposto por ABGE (1996) (Figura 4.6a-d).
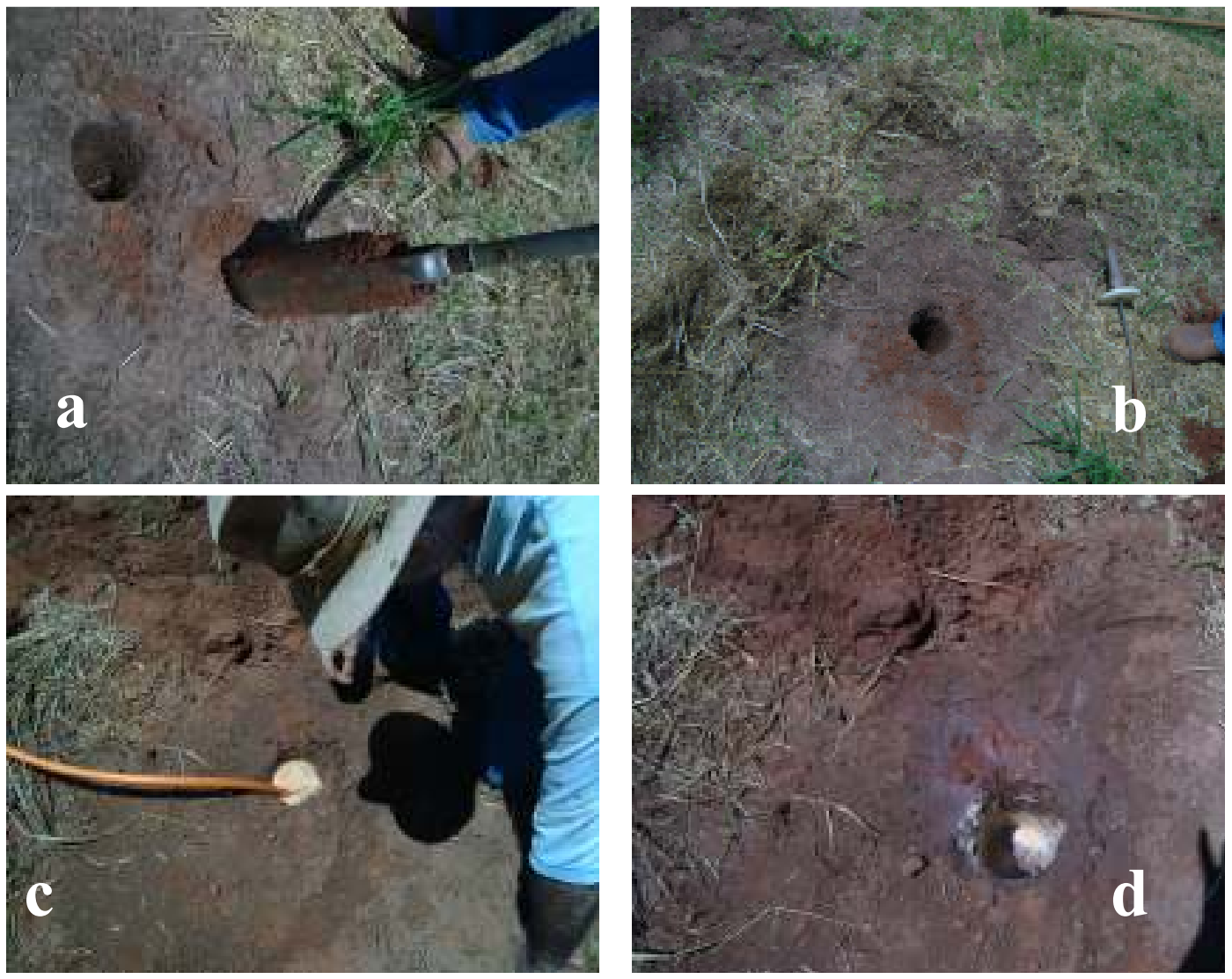

Figura 4.6- a e b: Abertura do furo; c: Injeção de água; d: Rebaixamento da água

\subsubsection{TRABALHOS DE LABORATÓRIO}

\subsubsection{Caracterização do material inconsolidado}

Segundo Leite (2001), em de estudos de contaminação é necessário um refinamento na avaliação do comportamento físico, físico-químico e também mineralógico do solo, devido à complexidade das reações envolvidas. Desta maneira, as seções a seguir mostrarão os 
métodos usados para a caracterização do material. Inicialmente, o material inconsolidado foi seco à temperatura ambiente, destorroado, peneirado e quarteado e em seguida iniciaram-se as caracterizações.

\subsection{Caracterização mineralógica}

\subsection{Ensaio de difratometria de raios $X$}

A difração de raios $X(D R X)$ consiste na incidência de um feixe de raios $X$ em um mineral, gerando o fenômeno da difração. A identificação se dá pelo fato de que cada mineral possui um modelo próprio de difração nos planos estruturais. A difração ocorre segundo a lei de Bragg (Equação 93), que relaciona a distância entre os planos que a originam (característica de cada mineral) com o ângulo de difração (WILSON, 1939; SOUZA SANTOS 1989).

$$
n \lambda=2 d \cdot \operatorname{sen} \theta
$$

onde $n$ é o número inteiro (ordem de reflexão); $\lambda$ é o comprimento de onda dos raios $\mathrm{X}$ incidentes; $d$ é a distância interplanar; e, $\theta$ é o ângulo de difração.

Pelo fato da difração de raios $\mathrm{X}$ apresentar um grande número de picos (difrações), a identificação a partir desse método é indicada para misturas de argilominerais, uma vez que pode haver a sobreposição de alguns picos, mas nunca de todos (SOUZA SANTOS, 1989).

Para que seja feita a identificação, é necessário que o solo seja depositado em lâminas de vidro. A etapa de preparação das lâminas que serão inseridas no difratrômetro, equipamento que realiza a difração dos raios X, é de muita importância, pois quando feita de maneira adequada, permite que ocorra a orientação preferencial das partículas de argila e, assim, a intensificação das reflexões basais, auxiliando na identificação mineralógica qualitativa dos argilominerais (BRINDLEY, 1964 ${ }^{3}$ apud SOUZA SANTOS, 1989). As lâminas utilizadas podem ser submetidas a diversos tratamentos (secagem à temperatura ambiente, tratamento químico com etilenoglicol e secagem à temperatura de $550{ }^{\circ} \mathrm{C}$ ) e assim os resultados desses tratamentos podem ser associados, possibilitando uma diferenciação dos

\footnotetext{
${ }^{3}$ BRINDLEY, G. W.; BROWN, G. Crystal Structures of Clay Minerals and Their X-Ray Identification. Londres, Mineralogical Society, 1980. 495p.
} 
grupos de argilominerais com mesma distância interplanar ou diferenciação dentro de um mesmo grupo (WILSON, 1939; SOUZA SANTOS, 1989).

O tratamento químico com etilenoglicol é utilizado devido ao fato de que alguns argilominerais o adsorve entre as camadas basais, fazendo com que ocorra aumento da distância interplanar basal (SOUZA SANTOS, 1989). O tratamento térmico é feito para que se observem alterações na distância interplanar basal e o comportamento dos argilominerais às temperaturas entre 500 e $600{ }^{\circ} \mathrm{C}$ (WILSON, 1939; SOUZA SANTOS, 1989). Tanto as alterações relacionadas ao tratamento com etilenoglicol, quanto àquelas relacionadas ao tratamento térmico, estão bem documentadas na literatura o que facilita a identificação dos argilominerais.

Neste trabalho, aplicou-se o método do pó para a preparação das lâminas para a realização da difração de raios-x foi realizada, conforme Azaroff e Buerguer (1953) e Leite (2001) (Figura 4.7). Foram preparadas três lâminas com solo que não passou pela percolação de contaminantes e três lâminas para o solo que passou pela percolação da solução de $\left(\mathrm{NH}_{4}\right)_{2} \mathrm{HPO}_{4}$. Cada uma dessas lâminas passou por um tratamento diferenciado antes de serem submetidas às análises. Duas lâminas secaram a temperatura ambiente, duas secaram em mufla à $550^{\circ} \mathrm{C}$ e duas lâminas passaram por um tratamento de etilenoglicerol por 24 horas antes de serem analisadas, conforme proposto em Santos (1989). Estas lâminas foram analisadas em Difratrômetro de Raios X. O ensaio foi realizado no Instituto de Física de São Carlos da Universidade de São Paulo (IFSC-USP) no Grupo de Crescimento de Cristais e Materiais Cerâmicos.

Figura 4.7- Lâminas para o ensaio de DRX 
Os resultados de todos esses tratamentos foram obtidos na forma de gráficos de intensidade em relação ao $2 \theta$ (duas vezes o ângulo de difração), sendo que as curvas caracterizam o(os) argilomineral (ais) presente (s). O cálculo da distância interplanar basal e a identificação dos argilominerais existentes nas amostras foi realizado com base na lei de Bragg (Equação 93) e nas tabelas encontradas em Switzer et al. ${ }^{4}$ (1948, apud SOUZA SANTOS, 1989) e em Brown ${ }^{5}$ (1981, apud SOUZA SANTOS, 1989).

\subsection{Caracterização física do solo}

A análise granulométrica conjunta foi realizada de acordo com a norma da Associação Brasileira de Normas Técnicas (ABNT) NBR 7181/1984 - Solo - Análise granulométrica, utilizando defloculante (hexametafosfato de sódio) e também sem defloculante (Figura 4.8a e $4.8 b)$.
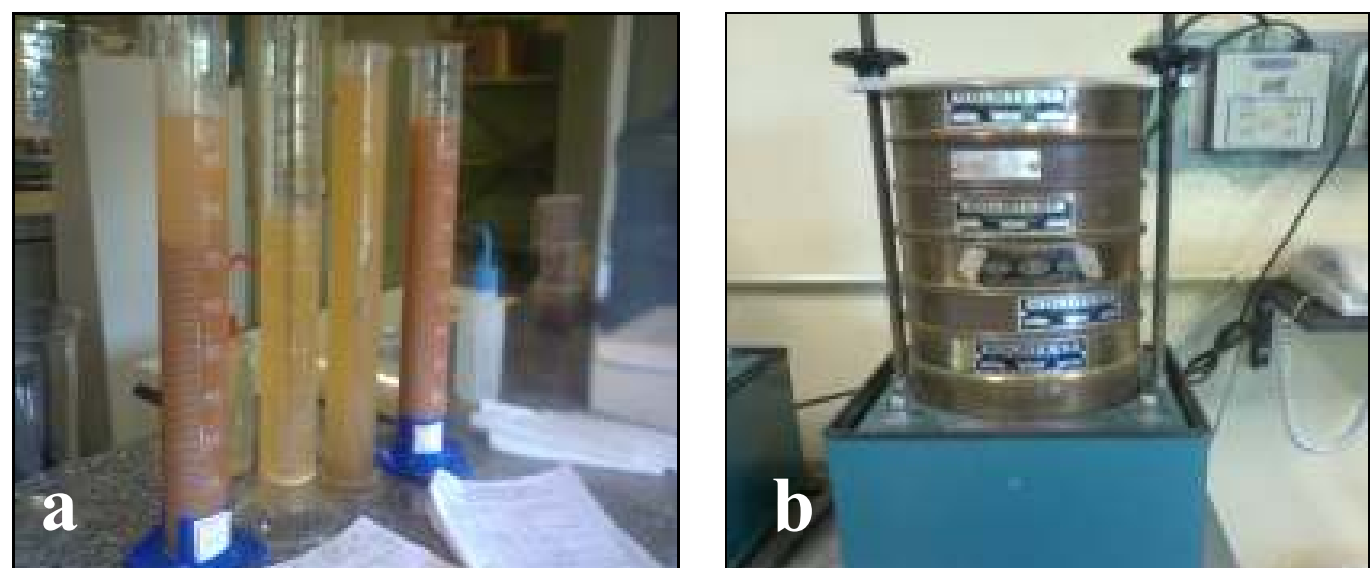

Figura 4.8- a: Ensaio de granulometria: sedimentação; b: Ensaio de granulometria: peneiramento

A determinação da massa específica do solo foi realizada de acordo com a norma da ABNT NBR 6508/1984 - Grãos de solos que passam na peneira de 4,8 mm - Determinação da massa específica - Método de ensaio.

\subsection{Caracterização físico-química do solo}

A solução do solo para as medições físico-químicas foi obtida de acordo com o método da EMBRAPA (1997). O pH $\left(\mathrm{H}_{2} \mathrm{O}\right.$ e $\left.\mathrm{KCl}\right)$ da solução do solo foi determinado em um

\footnotetext{
${ }^{4}$ BROWN, G. The X-ray identification and crystal structures of clay minerals. London: Mineralogical Society. 1961. $544 \mathrm{p}$.

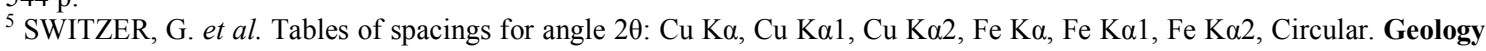
Survey Circular n. 29, 1948
} 
pHmetro da marca Digimed modelo DM21, o Eh em um pHmetro da marca MICRONAL modelo B374 e a condutividade elétrica foi determinada por meio de um condutímetro da marca ANALYSER modelo 650 (Figuras 4.9 e 4.10)

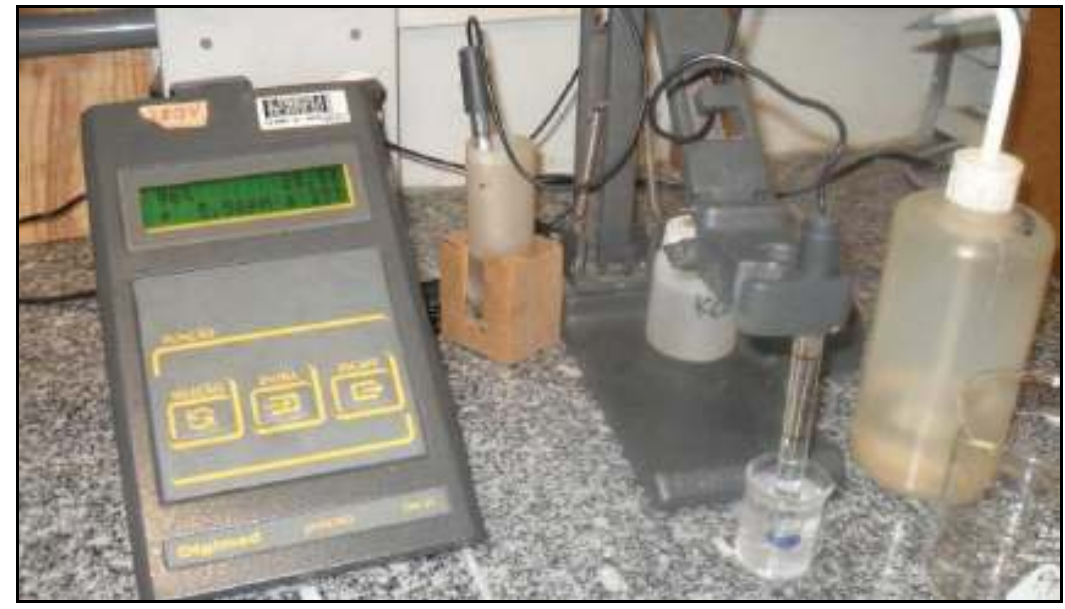

Figura 4.9- pHmetro Digimed utilizado na pesquisa

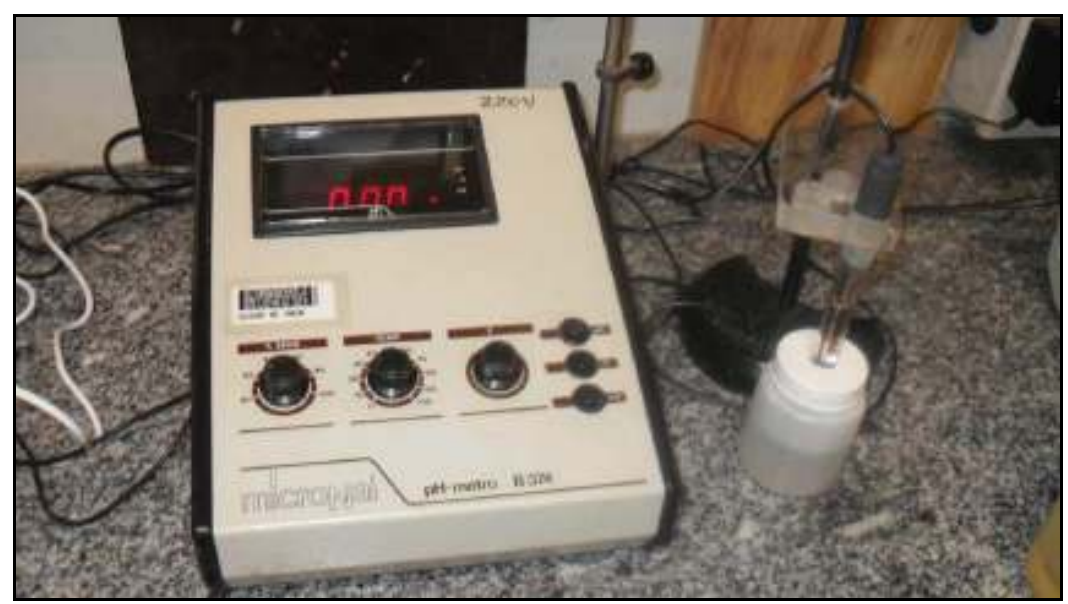

Figura 4.10- Condutímetro ANALYSER utilizado na pesquisa

O delta $\mathrm{pH}, \Delta \mathrm{pH}$, foi determinado de acordo com Mekaru e Uehara (1972), através da Equação 4, mencionada na seção 2.9.7

$$
\Delta p H=p H_{K C l}-p H_{H_{2} O}
$$

O ponto de carga zero, PCZ, foi determinado conforme equação proposta por Keng e Uehara (1974) (Equação 5).

$$
P C Z=2 p H_{K C l}-p H_{H_{2} O}
$$


Esses ensaios de caracterização físico-química foram realizados antes e depois dos ensaios de percolação de das soluções, para que se pudessem analisar as possíveis alterações.

O teor de matéria orgânica foi determinado em triplicata de acordo com a norma da ABNT/NBR 136001996 - Solo - Determinação do teor de matéria orgânica por queima a $440{ }^{\circ} \mathrm{C}$.

\subsection{Ensaio de adsorção de azul de metileno}

O azul de metileno (cloridrato de metiltiamina) é um corante orgânico catiônico que, em solução aquosa, apresenta-se dissociado em ânion cloreto e cátion azul de metileno $\left(\mathrm{C}_{16} \mathrm{H}_{18} \mathrm{~N}_{3} \mathrm{~S}^{+}\right)$. O uso do azul de metileno na identificação de argilominerais recebeu o nome de "método de adsorção de azul de metileno". O uso do método de adsorção de azul de metileno teve início com Lan em 1997 e foi modificado por Pejon (1992) e é até os dias de hoje utilizado para caracterizar o comportamento físico-químico da fração fina dos solos com finalidades geotécnicas (PEJON, 1992).

Esse método permite que se determine a capacidade de troca catiônica (CTC) e a superfície específica (SE) dos argilominerais, bem como o índice de atividade da fração argilosa (Acb) e, assim, que se avalie o comportamento laterítico da amostra com uma probabilidade de acerto de $85 \%$ (PEJON, 1992). Neste trabalho utilizou-se o método de adsorção de azul de metileno proposto por PEJON (1992) (Figuras 4.11a e 4.11b).
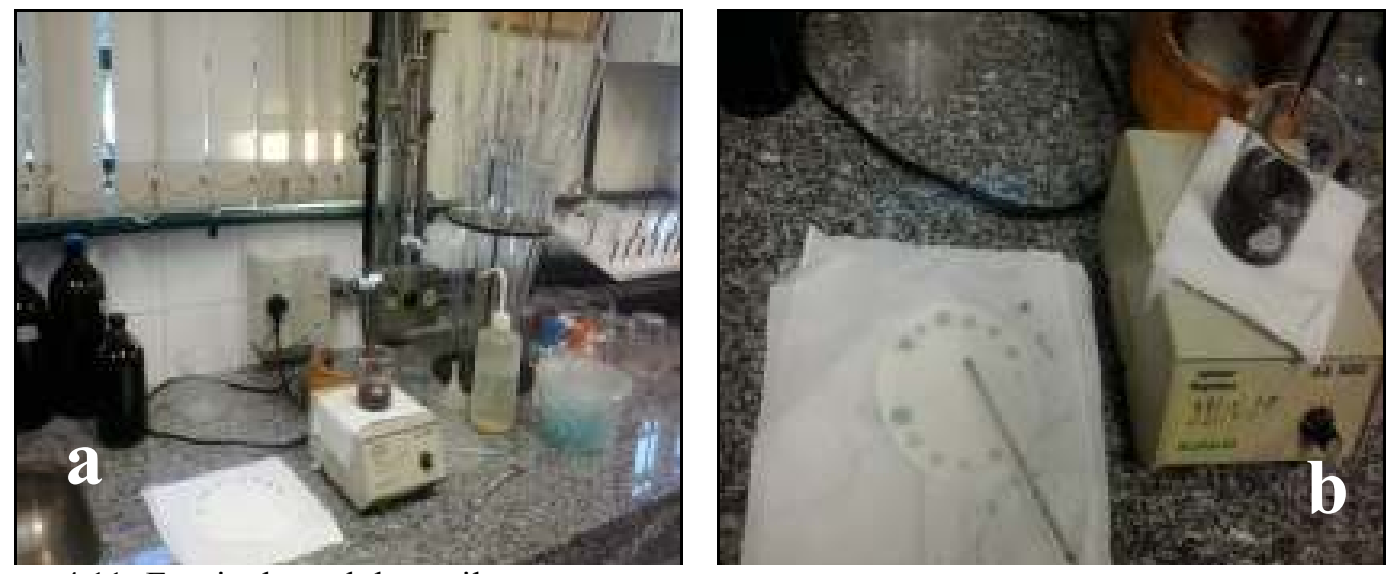

Figura 4.11- Ensaio de azul de metileno

A capacidade de troca catiônica, CTC, foi obtida através da Equação 94:

$$
C T C=\frac{0,46893 V}{M}
$$


em que $V$ é o volume da solução de azul de metileno utilizado [ $\left.\mathrm{ML}^{-3}\right] ; M$ é a massa de solo seco [M]; e, o valor 0,46893 corresponde à normalidade da solução de azul de metileno multiplicada por 100 .

O valor de adsorção de azul de metileno, $V_{b}$, que pode ser entendido como a massa de azul de metileno necessária para recobrir, com uma camada monomolecular, as partículas contidas em 100g de solo, foi determinado pela Equação 95.

$$
V_{b}=\frac{1,5 V}{M 10}
$$

A determinação da superfície específica, que compreende a área interna mais a área externa, é possível quando a superfície dos argilominerais fica recoberta por uma camada monomolecular de cátions azul de metileno, permitindo desta forma, uma vez conhecida as dimensões desta molécula, conhecer a área recoberta (PEJON, 1992). Determinamos a superfície específica, SE, através da Equação 96 em que o valor 3,67 representa a superfície recoberta por $1 \mathrm{ml}$ de solução de azul de metileno na concentração 1,5 g/L.

$$
S E=\frac{3,67 V}{M}
$$

A atividade da fração argila, $A_{c b}$, que indica o potencial de variação do volume da argila, foi obtida através da Equação 97.

$$
A_{c b}=\frac{V_{b} 100}{\% \arg \text { ila }}
$$

\subsubsection{Análise de energia dispersiva (EDS)}

A análise de energia dispersiva é muito importante na caracterização microscópica de materiais geológicos. A técnica funciona como um feixe de elétrons que incide sobre um mineral, assim, os elétrons mais externos dos átomos e os íons constituintes são excitados, mudando de níveis energéticos. Ao retornarem para sua posição inicial, liberam a energia adquirida que é emitida em comprimento de onda no espectro de raios X. Um detector instalado na câmara de vácuo do microscópio eletrônico de varredura associado ao EDS mede a energia associada a esse elétron. Como os elétrons de um determinado átomo possuem 
diferentes energias, é possível determinar quais os elementos químicos estão presentes naquele local.

Os ensaios de EDS foram realizados na Central de Análises Químicas Instrumentais do Instituto de Química de São Carlos (CAQI/IQSC/USP) em um equipamento EDX LINK ANALYTICAL, (Isis System Series 200), com detector de SiLi Pentafet, janela ultrafina ATW II (Atmosphere Thin Window), de resolução de $133 \mathrm{eV}$ à $5,9 \mathrm{keV}$ e área de $10 \mathrm{~mm}^{2}$ quadrado, acoplado a um Microscópio Elet rônico ZEISS LEO 440 (Cambridge, England). Utilizou-se padrão de Co para calibração, feixe de elétrons de $20 \mathrm{kV}$, distância focal de 25 $\mathrm{mm}$, dead time de $30 \%$, corrente de 2,82A e I probe de $950 \mathrm{pA}$. A área da amostra analisada foi de $1,2 \mathrm{~mm} \times 1,2 \mathrm{~mm}$. Foram analisadas amostras do solo natural e que passou pela percolado pela solução de $\left(\mathrm{NH}_{4}\right)_{2} \mathrm{HPO}_{4}$.

\subsubsection{Porosimetria por intrusão de mercúrio}

A técnica de porosimetria por intrusão de mercúrio foi desenvolvida por Washburn (1921) para que se obtivesse a distribuição do diâmetro dos poros existentes em um material. Esta técnica baseia-se na penetração de mercúrio nos poros do solo, que se dá apenas sob pressão devido ao mercúrio ser um fluido não-molhante. A pressão para penetração do mercúrio deve ser maior, quanto menor for o diâmetro do poro, conforme a Equação 98.

$$
P=\frac{-4 T_{s} \cos \alpha}{D}
$$

em que $T_{S}$ é a tensão superficial; $\alpha$ é o ângulo de contato entre o líquido e a superfície do sólido; $P$ é a pressão aplicada; e, $D$ é o diâmetro do poro;

Durante o ensaio, à medida que se aumenta a pressão, os volumes de mercúrio inseridos na amostra são monitorados. A partir dos diferenciais $\mathrm{dV} / \mathrm{dP}$, utilizando a Equação 98, obtêm-se os diferenciais $\mathrm{dV} / \mathrm{dD}$, que permitem a obtenção da distribuição dos poros da amostra.

Para a realização do ensaio de porosimetria por intrusão de mercúrio, três corpos de prova foram moldados em formato cilíndrico (topo, meio e base) de uma coluna indeformada, cada um com aproximadamente $2 \mathrm{~cm}$ de altura e 1,5 cm de diâmetro (Figura 4.12). 


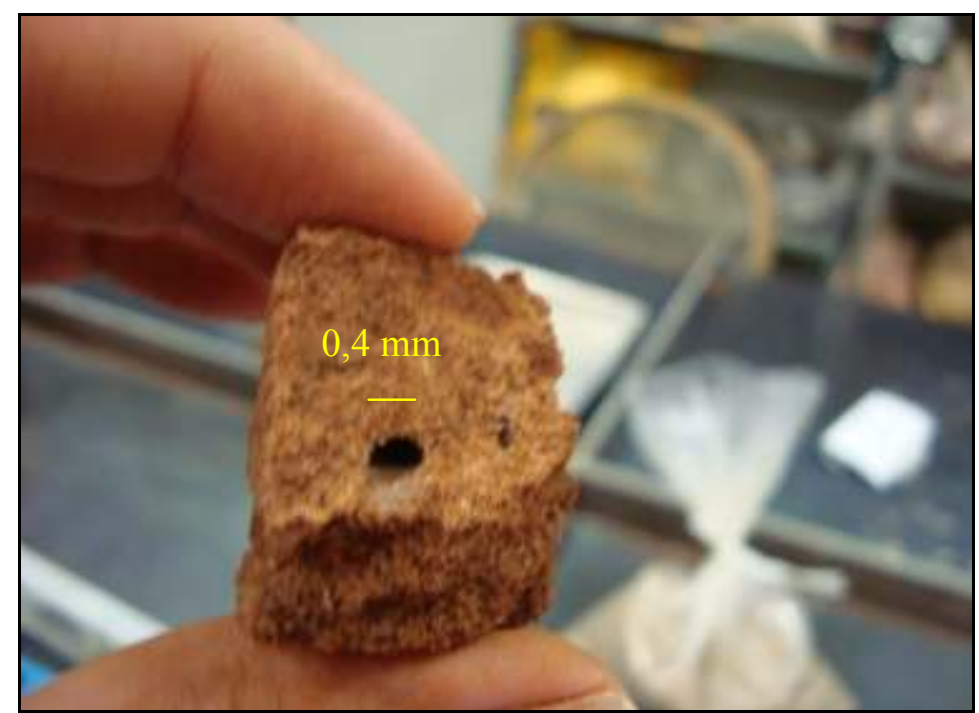

Figura 4.12- Corpo de prova para ensaio de porosimetria

Estes corpos de prova foram secos à temperatura ambiente e posteriormente inseridos no penetrômetro do porosímetro para serem ensaiadas. O aparelho utilizado nestes ensaios foi o "Poresize 9320 - Micromeritics Instrument Corporation" (Figura 4.13), com capacidade máxima de aplicação de 30000 psi de pressão. Os ensaios foram realizados no Instituto de Física de São Carlos da Universidade de São Paulo no Grupo de Crescimento de Cristais e Materiais Cerâmicos.

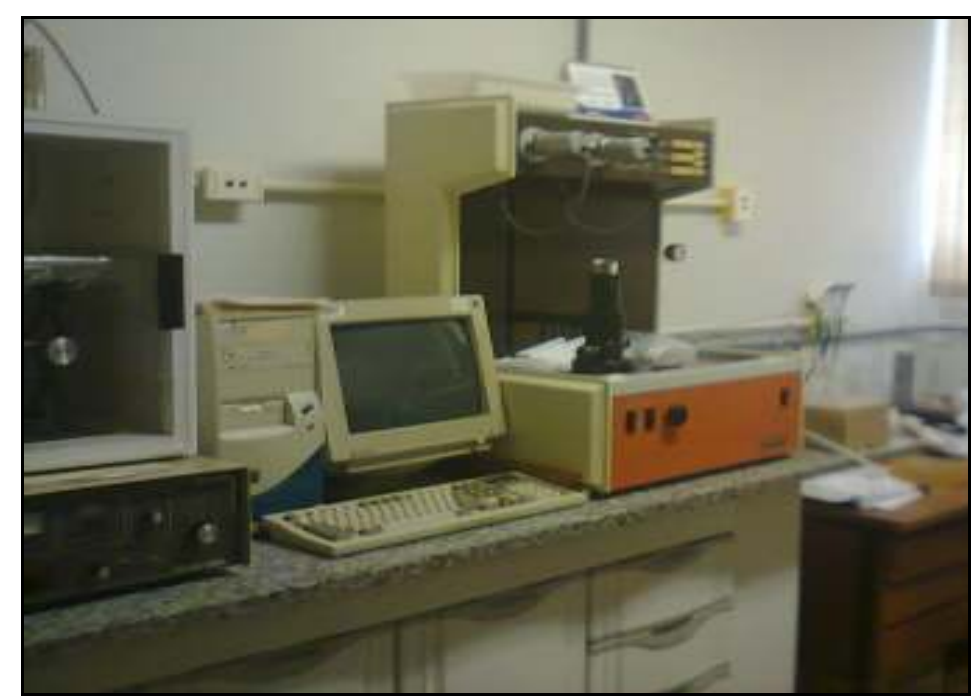

Figura 4.13- Equipamento para realização da porosimetria por intrusão de mercúrio

\subsubsection{Obtenção da curva de retenção de água}

A sucção matricial do solo foi obtida por meio da curva de retenção de água, a qual foi obtida apenas para a trajetória de secagem. Empregou-se técnica do Papel Filtro (MARINHO, 
1994), descrita na Seção 2.12.5. Os corpos de prova foram moldados a partir das colunas de amostras indeformadas (Figura 4.14 a e $4.14 \mathrm{~b}$ ).
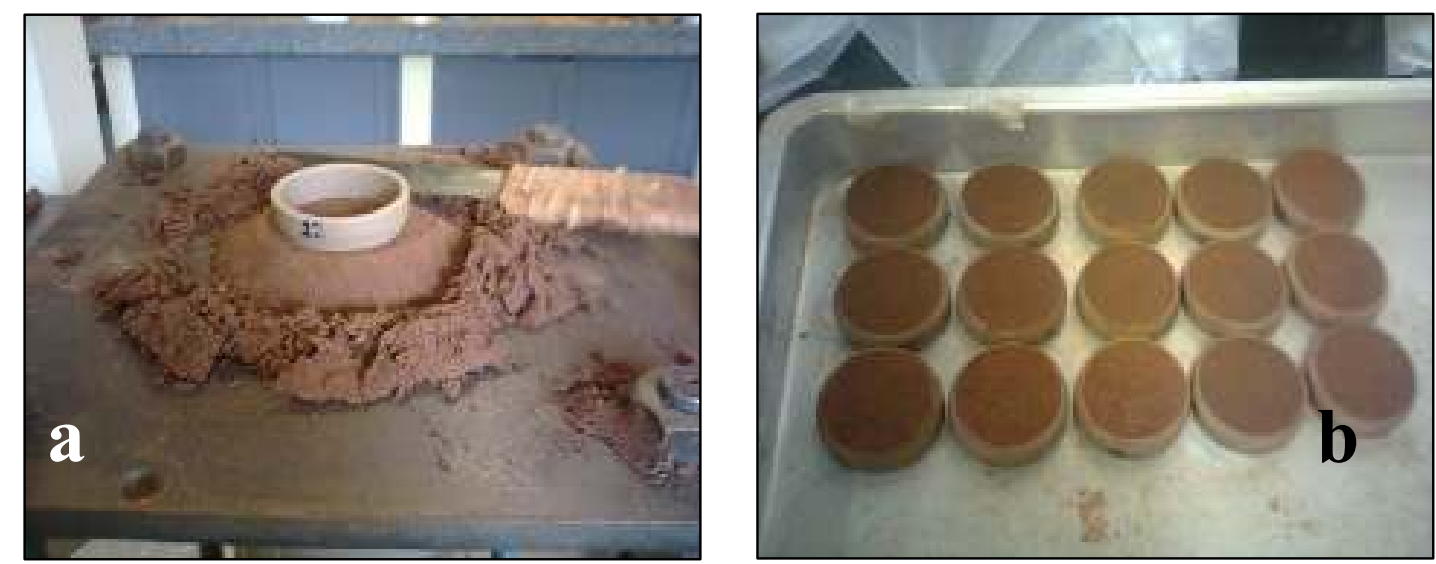

Figura 4.14- a: Moldagem dos anéis; b: Anéis moldados

O papel filtro utilizado foi o Whatman Número 42 e no cálculo da sucção matricial foram empregadas as Equações 99 e 100 de Chandler et al (1992), para umidades menores ou iguais a $47 \%$ e para umidades maiores a $47 \%$.

$$
\begin{gathered}
w_{\text {papel }} \leq 47 \% \rightarrow \Psi_{\text {papel }}=10^{\left(4,84-0,0622 . w_{\text {papel }}\right)} \\
w_{\text {papel }}>47 \% \rightarrow \Psi_{\text {papel }}=10^{\left(6,05-2,48 \cdot \log w_{\text {papel }}\right)}
\end{gathered}
$$

em que $\Psi_{\text {papei }}$ é a sucção do papel filtro, em $\left[\mathrm{M} \mathrm{L}^{-1} \mathrm{~T}^{-2}\right] ; w_{\text {papel }}$ é a umidade gravimétrica do papel filtro, em $\left[\mathrm{M} \mathrm{M}^{-1}\right]$.

Inicialmente todos os corpos de prova (anel mais a amostra de solo) foram pesados um por um na balança eletrônica com precisão de 4 casa decimais. Em seguida, todos os corpos de prova foram colocados sobre uma placa porosa parcialmente submersa em um recipiente com lâmina de água deionizada, utilizando papel filtro comum para contato entre a placa e cada corpo de prova (Figura 4.15a). Os corpos de prova foram saturados por 24 horas. Posteriormente, cada corpo de prova foi retirado da placa porosa para secagem (Figura 4.15b) à temperatura ambiente, sendo feitas pesagens periódicas até que fosse atingida a massa correspondente aos teores de umidade gravimétricos estabelecidos previamente. 

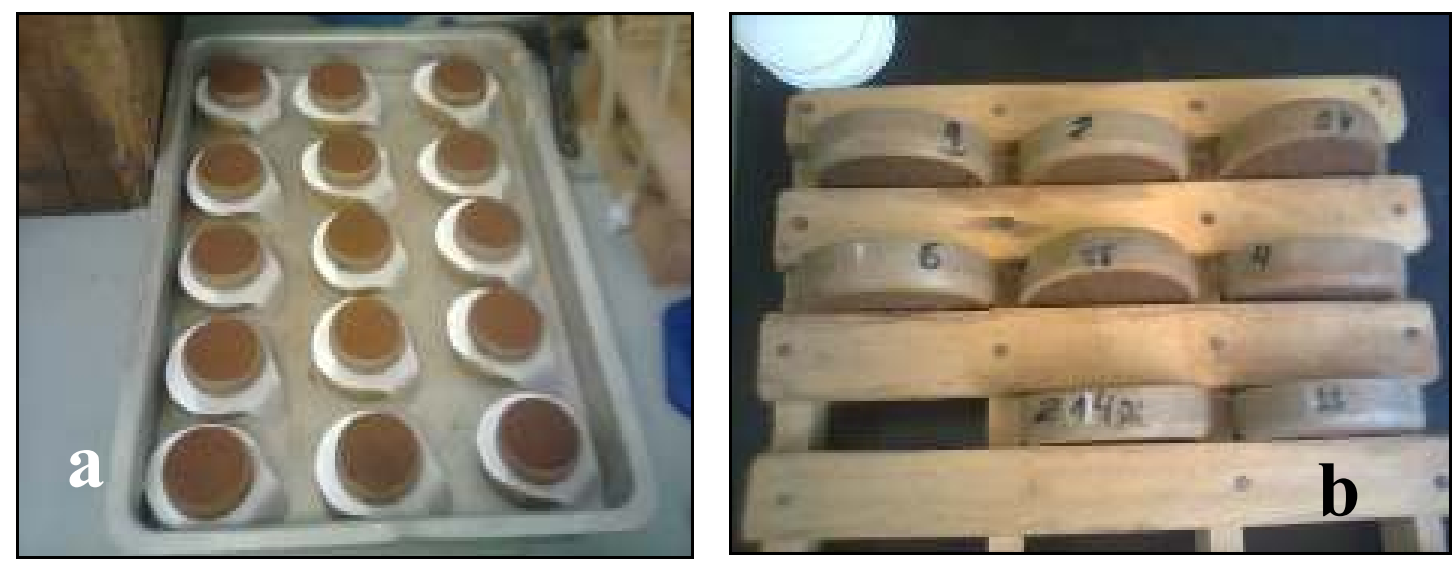

Figura 4.15- a: Saturação dos anéis; b: Secagem dos anéis

Alcançada a massa desejada o ensaio seguiu os seguintes passos:

1. Colocou-se papel filtro Whatman $\mathrm{N}^{\circ} 42$ em contato com as faces de cada corpo de prova. Para garantir o contato entre o papel filtro do topo e da base da amostra de solo, foi utilizado um disco de PVC (Figura 4.16a);

2. Envolveram-se os conjuntos (papel filtro, corpo de prova e disco de PVC) com um filme plástico e fita adesiva (Figura 4.16b);
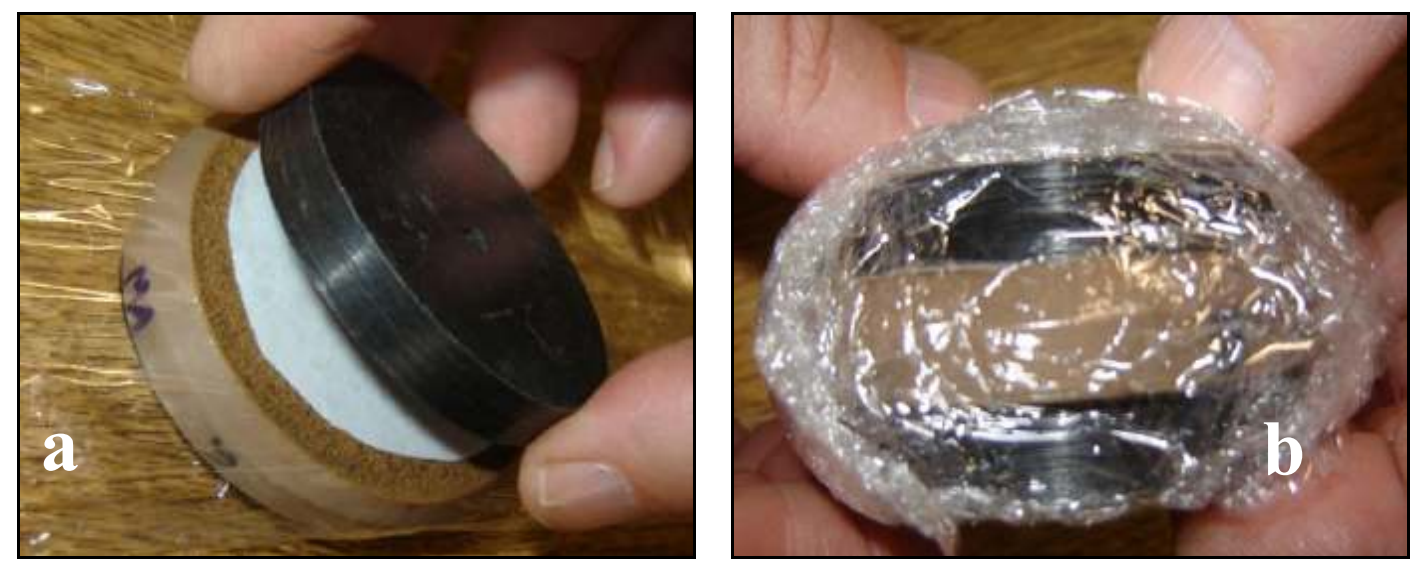

Figura 4.16- a: Papel filtro em contato com o solo; b: Armazenamento dos anéis (FERNANDES, 2011)

3. Armazenou-se cada conjunto em um recipiente hermeticamente fechado. Este período de armazenamento dependeu do teor de umidade gravimétrica do solo. Nestes ensaios, as amostras de solos mais úmidas foram retiradas após 15 dias e as amostras de solos mais secos com 8 dias;

4. Alcançado o período adequado de armazenamento, cada conjunto foi desmontado e os papéis filtros úmidos foram retirados com o auxílio de uma pinça;

5. Determinou-se o teor de umidade gravimétrica do solo para cada corpo de prova; 
6. Pesaram-se, em balança com precisão de até quatro casas decimais, os papéis filtro úmidos;

7. Os papéis filtro úmidos foram secos em estufa à $110^{\circ} \mathrm{C}$ durante 5 horas;

8. Pesaram-se, em balança com precisão de até quatro casas decimais, os papéis filtro secos;

9. Obtiveram-se os teores de umidade gravimétrico dos papéis filtro;

10. Obtiveram-se os valores de sucção matricial;

11. Graficou-se a curva de retenção de água;

12. Ajustaram-se os dados experimentais à equação de Durner (1994) por meio do software comercial Mathematica 9.0 da Wolfram Research

\subsubsection{Ensaios de coluna}

O ensaio de coluna foi utilizado nesta pesquisa tanto para a obtenção dos parâmetros de fluxo de água, quanto dos parâmetros de transporte de solutos. A seguir será apresentado o equipamento utilizado no ensaio de coluna, a montagem do ensaio, a saturação das colunas, a preparação das soluções contaminantes percoladas, a realização dos ensaios e a coleta e análise do percolado e, depois do ensaio, do solo.

\subsection{Montagem do ensaio}

De cada cilindro de PVC com amostra indeformada coletados no campo retiraram-se três cápsulas para obtenção da umidade. Posteriormente, as colunas indeformadas foram retificadas, pesadas e medidas (Figura 4.17a).

Os próprios cilindros de PVC utilizados para extração das amostras indeformadas de solo constituíram permeâmetros nos quais foram realizados ensaios de condutividade hidráulica com fluxo ascendente, que possibilitaram a obtenção do coeficiente de permeabilidade, da vazão, da velocidade de Darcy e da velocidade linear média. Para a realização dos ensaios de condutividade hidráulica os cilindros de PVC foram acoplados à tampas de PVC nas duas extremidades. Na base dessas tampas havia duas placas circulares de material plástico com diversos furos e entre essas duas placas havia um tecido que serviu de filtro para evitar a passagem de partículas de solo que poderiam entupir as mangueiras (Figura 4.17b). Após rosqueadas as tampas superiores e inferiores, as colunas foram fixadas na base de metal através de quatro tirantes com roscas e parafusos (Figura 4.17c). Assim, os corpos de prova de amostras indeformadas foram mantidos isolados, apenas com a alimentação da água 
ou da solução contaminante e com uma saída para a coleta do percolado. Em cada uma das extremidades foram acopladas mangueiras de borracha para entrada e saída da água e, posteriormente, das soluções contaminantes (Figura 4.17d)
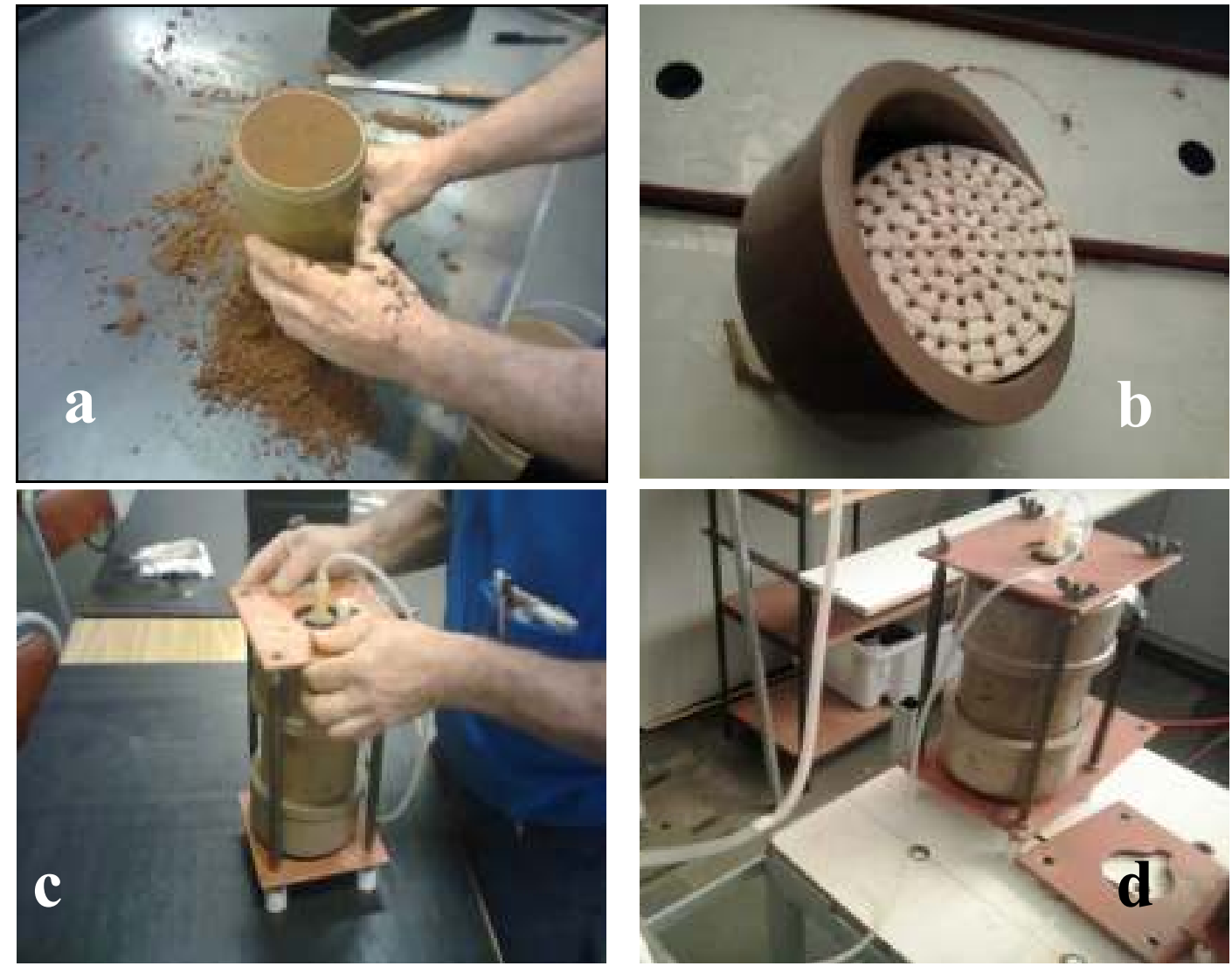

Figura 4.17 a: Retificação das colunas; b: Filtro do fundo das colunas; c: Base de metal para suporte das colunas; e, d: Coluna conectada às mangueiras para entrada e saída de água

Essas mangueiras foram conectadas no distribuidor de água que por usa vez estava conectado no regularizador de nível (Figura 4.18). As colunas utilizadas no ensaio de condutividade hidráulica foram aproveitadas para o ensaio de percolação das soluções contaminantes. Para isso, as mangueiras de borracha que estavam conectadas na extremidade superior das colunas e no distribuidor de água, foram desconectadas do distribuidor e foram, então, conectadas diretamente nos regularizadores de nível (Figura 4.19a), que já estavam com as soluções contaminantes. Os regularizadores de nível estavam conectados nos reservatórios com 20 litros de solução (Figura 4.19b). 


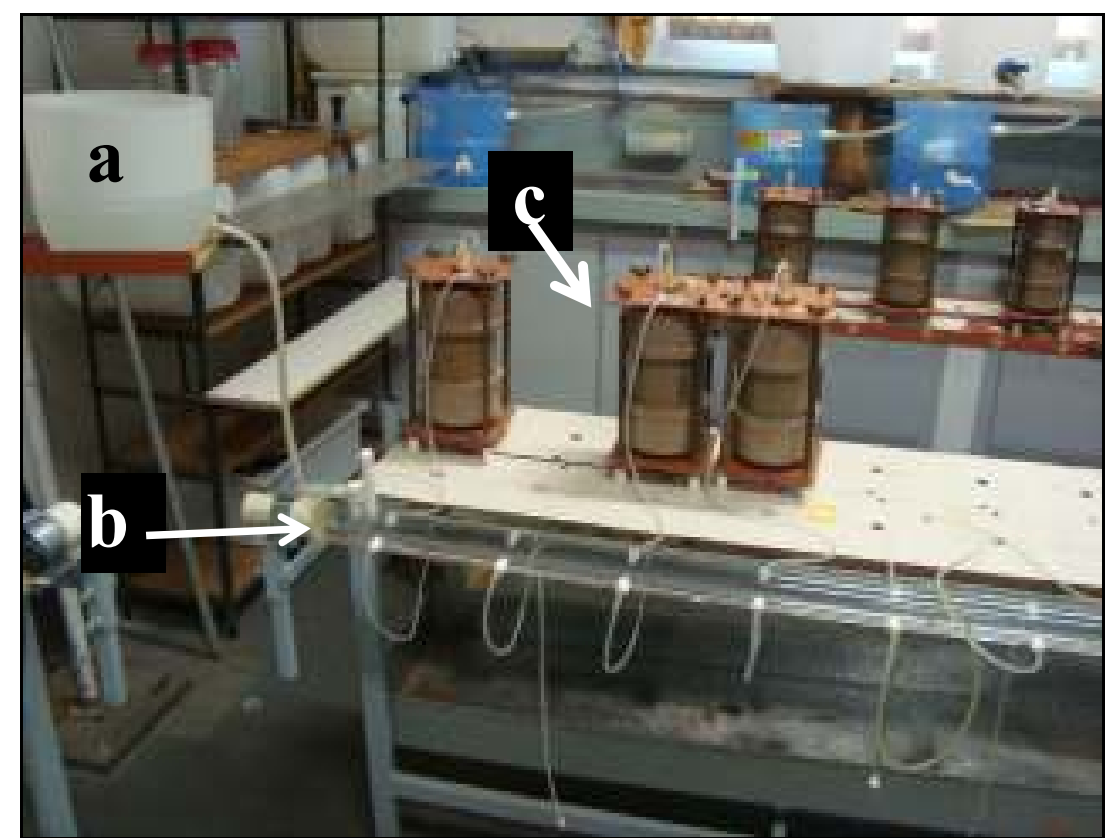

Figura 4.18- Montagem do ensaio de condutividade hidráulica (a: Regularizador de nível; b: Distribuidor de água; c: Mangueiras de borracha)

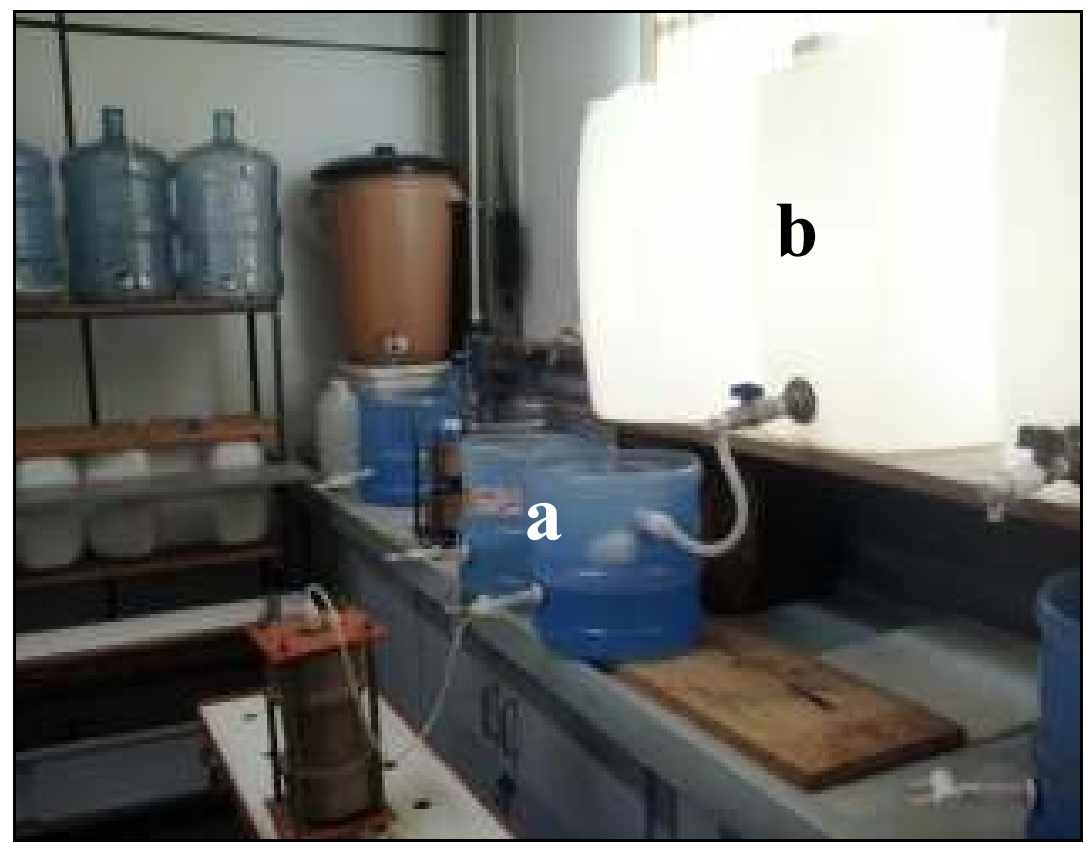

Figura 4.19- Montagem do ensaio de percolação de solução contaminante (a: regularizador de nível; b: reservatórios com soluções)

\subsubsection{5. $\quad$ Obtenção dos parâmetros de fluxo de água}

O ensaio de condutividade hidráulica e a saturação das colunas de solo duraram trinta dias, possibilitando também a limpeza das colunas e a retirada de bolhas de ar presentes em seu interior. O gradiente hidráulico nas colunas foi mantido constante $(1,5)$ devido à presença 
do regularizador de nível. Durante este período o $\mathrm{pH}$ da água que era inserida nas colunas foi controlado e mantido entre 6,5 e 7,2. Quando houve a estabilização da condutividade hidráulica, inverteu-se o fluxo de água para a finalização do processo de saturação. Depois da estabilização da condutividade hidráulica, combinando com outros ensaios realizados, foram obtidos os seguintes parâmetros de fluxo de cada coluna: condutividade hidráulica saturada (DARCY, 1986); velocidade de Darcy (DARCY, 1986); vazão (REICHARDT, 1985; REICHARDT, 1996) e velocidade linear média, (FREEZE; CHERRY,1979).

\subsubsection{6. $\quad$ Ensaio de percolação de soluções contaminantes}

\subsection{Preparação das soluções contaminantes}

Foram preparadas três soluções de $\mathrm{NaCl}$ e três soluções $\left(\mathrm{NH}_{4}\right)_{2} \mathrm{HPO}_{4}$. A escolha das concentrações utilizadas foi baseada nas concentrações de $\mathrm{Na}^{+}, \mathrm{NH}_{4}{ }^{+}$e $\mathrm{PO}_{4}{ }^{3-}$ em efluentes analisados por Quadros et al., (2010), Martelli (2008), Silva et al. (2012) e Vilela Junior, Araújo e Factor (2003). Durante a preparação dessas soluções o pH da água destilada foi controlado e mantido entre 7,0 e 7,3.

Concluída a saturação das colunas, foram inseridas as soluções de $\mathrm{NaCl}$ e $\left(\mathrm{NH}_{4}\right)_{2} \mathrm{HPO}_{4}$ nos reservatórios e iniciaram as percolações das colunas. Esta percolação ocorreu com fluxo descendente e foi mantido um gradiente hidráulico máximo de 1,5.

\subsection{Percolação das soluções contaminantes}

Três colunas foram percoladas com $\mathrm{NaCl}$ e três com $\left(\mathrm{NH}_{4}\right)_{2} \mathrm{HPO}_{4}$. Os percolados das colunas foram coletados a cada volume de poros e armazenados em recipientes plásticos (Figura 4.20). Ao final de quinze volumes de poros para as colunas percoladas com $\mathrm{NaCl}$ e vinte volumes de poros para as colunas percoladas com $\left(\mathrm{NH}_{4}\right)_{2} \mathrm{HPO}_{4}{ }^{3-}$, o ensaio foi encerrado. As colunas foram, então, percoladas durante três volumes de poros com água destilada com $\mathrm{pH}$ variando de 6,8 a 7,2. Como a coleta nas amostras foi realizada em um volume de poros completo, a plotagem dos resultados na curva de chegada deu-se considerando que o resultado de concentração obtido em cada recipiente plástico é a média da concentração de determinado volume de poros e, por isso, a plotagem encontra-se sempre em valores de 0.5. 


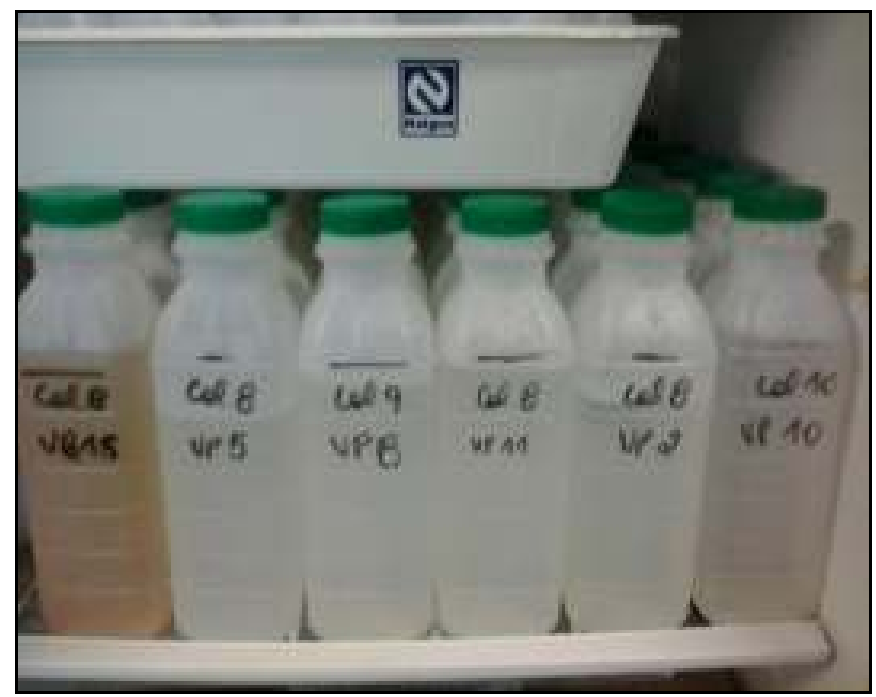

Figura 4.20- Amostras armazenadas em recipientes plásticos

\subsection{3. $\quad$ Análise das soluções lixiviadas}

Imediatamente, para cada amostra coletada, foi medida a temperatura, o $\mathrm{pH}$ e a condutividade elétrica. Em seguida as amostras foram armazenadas a $4{ }^{\circ} \mathrm{C}$ e posteriormente diluídas a uma proporção de 1:99ml. A água destilada utilizada nas diluições teve o pH controlado entre 6,6 e 7,2. A partir das soluções diluídas foram determinadas as concentrações de $\mathrm{Na}^{+}$com o fotômetro de chama MICRONAL modelo B26 (Figura 4.21a).
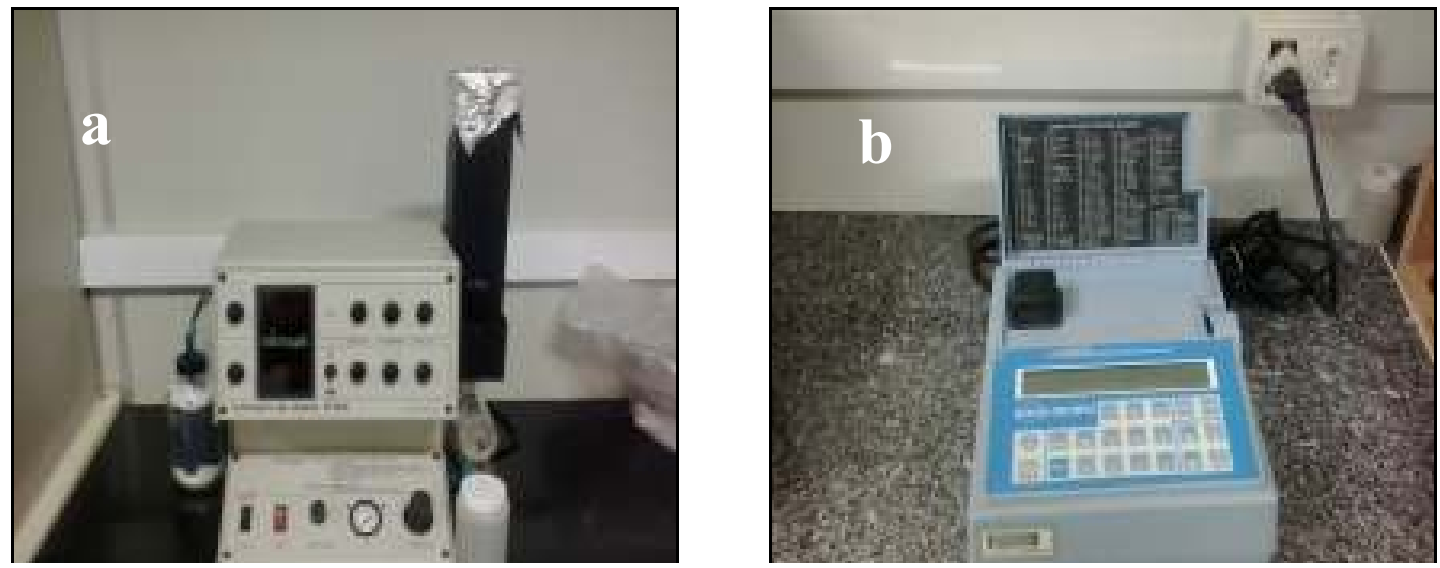

Figura 4.21- Equipamentos utilizados para medições físico-químicas. a: fotômetro de chama; b: espectrofotômetro

Para a determinação das concentrações $\mathrm{PO}_{4}{ }^{3-}$ foi necessário alcalinizar as soluções com pH variando de 13 a 14 (HAVLIN, et al., 2005). Depois de alcalinizadas, inseriu-se o reagente PhosVer 3 e as determinações foram feitas com o espectrofotômetro HACH modelo 2010 (Figura 4.21b). Para as análises de $\mathrm{NH}^{4+}$ o $\mathrm{pH}$ das amostras foi mantido entre 6 e 7. Após verificação do $\mathrm{pH}$, as soluções foram diluídas e inseriram-se os reagentes de Nessler. As 
concentrações foram determinadas com o espectrofotômetro HACH modelo 2010 (Figura 4.21b).

A partir das análises químicas obtiveram-se as concentrações relativas $(\mathrm{C} / \mathrm{Co})$. Com os dados das concentrações relativas versus o volume de poros percolados do efluente, obtiveram-se as curvas de chegada para os íons estudados $\left(\mathrm{Na}^{+}, \mathrm{NH}_{4}{ }^{+}\right.$e $\left.\mathrm{PO}_{4}{ }^{3-}\right)$. A partir dessas curvas foram determinados os parâmetros de transporte de solutos no solo.

\subsection{Obtenção dos parâmetros de transporte}

Em combinação com as outras análises feitas neste trabalho, foram obtidos os seguintes parâmetros de transporte: coeficiente de dispersão hidrodinâmica, $D h$, e fator de retardamento, $\mathrm{Rd}$. Esses parâmetros foram obtidos para os íons $\left(\mathrm{Na}^{+}, \mathrm{PO}_{4}{ }^{3} \mathrm{e} \mathrm{NH}_{4}{ }^{+}\right)$.

\subsection{1. Coeficiente de dispersão hidrodinâmica}

Os coeficientes de dispersão hidrodinâmica foram obtidos através de quatro métodos.

1) O primeiro método utilizado foi proposto por Ogata (1958) onde se descartando o segundo membro da Equação 53, conforme Ogata e Banks (1961) e trabalha-se apenas com a Equação 54:

$$
\frac{C}{C_{0}}=\frac{1}{2}\left[\operatorname{erfc}\left(\frac{L-v t}{2 \sqrt{D_{h} t}}\right)\right]
$$

A partir da Equação 54, conhecendo os valores de concentração reativa da curva de chegada e usando valores tabulados de função erro complementar, o coeficiente de dispersão hidrodinâmica pode ser obtido da seguinte maneira: cada ponto na curva de chegada retorna um valor de $D_{h}$, tirando a média desses valores, um valor médio de $D_{h}$ pode ser obtido.

2) O segundo método, proposto inicialmente por Brigham, Reed e Dew (1961), foi reformulado para experimentos com colunas curtas por Brigham (1974). Com este método o $D_{h}$ é obtido da Equação 61:

$$
D_{h}=v L\left(\frac{U_{84}-U_{16}}{8}\right)^{2}
$$


3) No terceiro método utilizado, proposto por Singh $(1998 ; 2002)$, o $D_{h}$ é obtido através da Equação 55:

$$
D_{h}=\frac{L^{2}}{4 \pi m^{2} t_{0}^{3}}
$$

4) No quarto método utilizado, o $D_{h}$ foi obtido através da Equação 51 proposta por Bear (1961).

$$
D_{l}=1,75 d v_{z}+D^{*}
$$

em que $\alpha_{l}$ é o coeficiente de dispersividade longitudinal que foi obtido por meio de três métodos: Yeh, Gelhar e Gutjahr (1985) e Rowe, Quigley e Booker (1995), Fetter (1993) e Scheidegger (1963).

Para o uso desta equação, o $D_{l}$ foi considerado como $D_{h}$, pois se analisou apenas a dispersão no sentido do fluxo. Além disso, adotou-se que $D^{*}$ é nulo, assim como outros autores (PERKINS, JOHNSON, 1963; BEAR, 1972SHAKELFORD, 1994; FREEZE, CHERRY, 1979).

\subsection{2. Fator de retardamento}

Os fatores de retardamento para os três íons estudados foram obtidos por três métodos:

1) O primeiro método utilizado foi proposto por van Genuchten e Parker (1984) em que o valor de $R_{d}$ corresponde à área acima da curva de chegada $\left(H=R_{d}\right)$, assumindo que a curva de chegada segue o modelo analítico proposto por Lapidus e Amundson (1952) (reescrito por Ogata, 1958 e Bear, 1972), Equação 53.

Adicionalmente, foram calculados os fatores de retardamento assumindo que a Equação 54 governa o modelo analítico da curva de chagada. Para isso foi necessária a obtenção do número Péclet que foi, então calculado para os a partir do $D_{h}$ obtido com os quatro métodos propostos na Seção anterior.

$$
\frac{C}{C_{0}}=\frac{1}{2}\left[\operatorname{erfc}\left(\frac{L-v t}{2 \sqrt{D_{h} t}}\right)\right]
$$

2) O segundo método utilizado foi proposto por Freeze e Cherry (1979) e Shackelford $(1993 ; 1994)$. É baseado em equações desenvolvidas empiricamente por Hiester e Vermeullen 
(1952) e aplicadas pela primeira vez em problemas de água subterrânea por Higgins (1959) e Baetsle (1967). Neste método o $R_{d}=V p$ quando $C_{0} / C$ é 0,5 . Este método foi utilizado assumindo que a adsorção é rápida e reversível e que obedece a uma isoterma linear;

3) No terceiro método utilizado o $R_{d}$ foi calculado através da prévia obtenção das constantes de sorção. Essas constantes foram obtidas por meio da construção da isoterma de sorção a partir da curva de chegada, de acordo com os seguintes passos:

I. Construiu-se um gráfico $Z$ de concentração $(\mathrm{mg} / \mathrm{L})$ versus volume percolado (em litros) equivalente à curva de chegada;

II. Calculou-se a área total do gráfico Z. Este valor representa a massa total (em mg) de soluto que foi inserida na coluna de solo;

III. Obteve-se a área sobre a curva, $A 1$, do gráfico $Z$. A área $A 1$ corresponde à massa total de soluto retida no solo(em $\mathrm{mg})$;

IV. Dividiu-se a área sobre a curva, $A 1$ pela massa seca de solo no interior da coluna e obteve-se a massa sorvida, $S$, de soluto por unidade de massa de solo (em $\mathrm{mg} / \mathrm{mg}$ );

V. Obteve-se a área sob a curva, $A 2$, do gráfico $Z$. A área $A 2$ corresponde à massa de equilíbrio, ou seja, a massa de soluto que não foi retida pelo solo (em mg);

VI. Dividiu-se a área $A 2$ pelo volume total percolado $\left(\mathrm{em}^{3}\right)$ e obteve-se a concentração de equilíbrio, $C e\left(\mathrm{em} \mathrm{mg} / \mathrm{cm}^{3}\right)$;

VII. Para cada valor de massa sorvida há um valor de concentração de equilíbrio correspondente. Com isso constrói-se um gráfico de $S$ versus $C e$, denominado isoterma de sorção.

Com a obtenção dos pontos de S versus Ce ajustou-se os dados experimentais aos modelos das isotermas Linear, de Freundlich e de Langmuir (FRENDLICH, 1906; LANGMUIR, 1916; FETTER, 1999; FREEZE, CHERRY, 1979) para verificar qual modelo fornecia o melhor coeficiente de determinação. Para a realização desses ajustes utilizou-se o software comercial Mathematica 9.0 da Wolfram Research. Para a isoterma de Langmuir foram feitos dois ajuste lineares (Langmuir I e Langmuir II) e um não linear. Em seguida aplicaram-se as equações para a determinação do fator de retardamento Tabela 4.1 
Tabela 4.1 Equações de fator de retardamento para diferentes isotermas de sorção

\begin{tabular}{clc}
\hline Isoterma Linear & $\begin{array}{c}\text { Isoterma de } \\
\text { Freundlich }\end{array}$ & $\begin{array}{c}\text { Isoterma de } \\
\text { Langmuir }\end{array}$ \\
\hline$R_{d}=1+\frac{\rho_{d}}{n} K_{d}$ & $R_{d}=1+\frac{\rho_{d}}{n} K_{f} C_{e m}^{N-1}$ & $R_{d}=1+\frac{\rho_{d}}{n} \frac{b S_{m}}{1+b C_{e m}}$ \\
\hline
\end{tabular}

Este método de construção de isotermas só pôde ser utilizado porque haviam três concentrações diferentes para cada soluto percolado, permitindo a obtenção de uma curva com pelo menos quatro pontos (origem e três concentrações).

\subsubsection{Análise do solo}

Com o término da percolação dos contaminantes, as colunas foram secas ao ar e as amostras indeformadas de solo foram sacadas dos cilindros de PVC para que se observasse a integridade das colunas. Em seguida foi retirada uma amostra do topo, uma do meio e uma da base de cada coluna para que se obtivessem o $\mathrm{pH}\left(\mathrm{H}_{2} \mathrm{O}\right.$ e $\left.\mathrm{KCl}\right)$ e a C.E .

\subsubsection{Análise das trajetórias de transporte}

Em uma amostra indeformada de solo não saturado, foi percolada uma solução de azul de metileno a uma concentração de 3g/L. Foram percolados 1,5 litros dessa solução. Durante a percolação colocou-se um papel filtro na base da coluna para que os caminhos preferenciais fossem marcados na área da seção transversal da coluna. Após a percolação, o solo foi colocado para escorrer o excesso de solução. Depois, a amostra de solo foi sacada do cilindro de PVC e foi cortada longitudinalmente para que observássemos as trajetórias do azul de metileno e se analisasse a sorção e o fluxo da solução por caminhos preferenciais (macroporos).

\subsection{EtAPAS 3 E 4: InTEgRaÇão dos dados, ANÁlise dos RESUltados E FINALIZAÇÃo DA DISSERTAÇÃo}

Com a caracterização física, físico-química e mineralógica, juntamente dos resultados dos demais ensaios realizados neste trabalho, os dados foram analisados conjuntamente e discutidos para que obtivéssemos as análises dos resultados e as conclusões, para finalização da dissertação. 


\section{RESUltados E DiscusSão}

\subsection{CaracterizaÇão Mineralógica}

\subsubsection{DIFRATOMETRIA DE RAIOS $X$}

A caracterização mineralógica, realizada por meio de difratometria de raios X, detectou que os principais minerais presentes no solo são: quartzo $\left(\mathrm{SiO}_{2}\right)$, caulinita $\left(\mathrm{Al}_{2} \mathrm{Si}_{2} \mathrm{O}_{5}(\mathrm{OH})_{4}\right)$, gibsita $\left(\mathrm{Al}(\mathrm{OH})_{3}\right)$ e haloisita $\left(\mathrm{Al}_{2} \mathrm{Si}_{2} \mathrm{O}_{5}(\mathrm{OH})_{4} \cdot 2 \mathrm{H}_{2} \mathrm{O}\right)$. Esses minerais eram esperados dadas as características dos latossolos. Não foram identificados minerais com ferro na composição, como por exemplo goethita, indicando que o ferro deste solo não encontra-se em forma cristalina. A Figura 5.1 indica os difratrômetros de raios $\mathrm{X}$ para os três tratamentos realizados (natural, térmico e com etilenoglicerol).

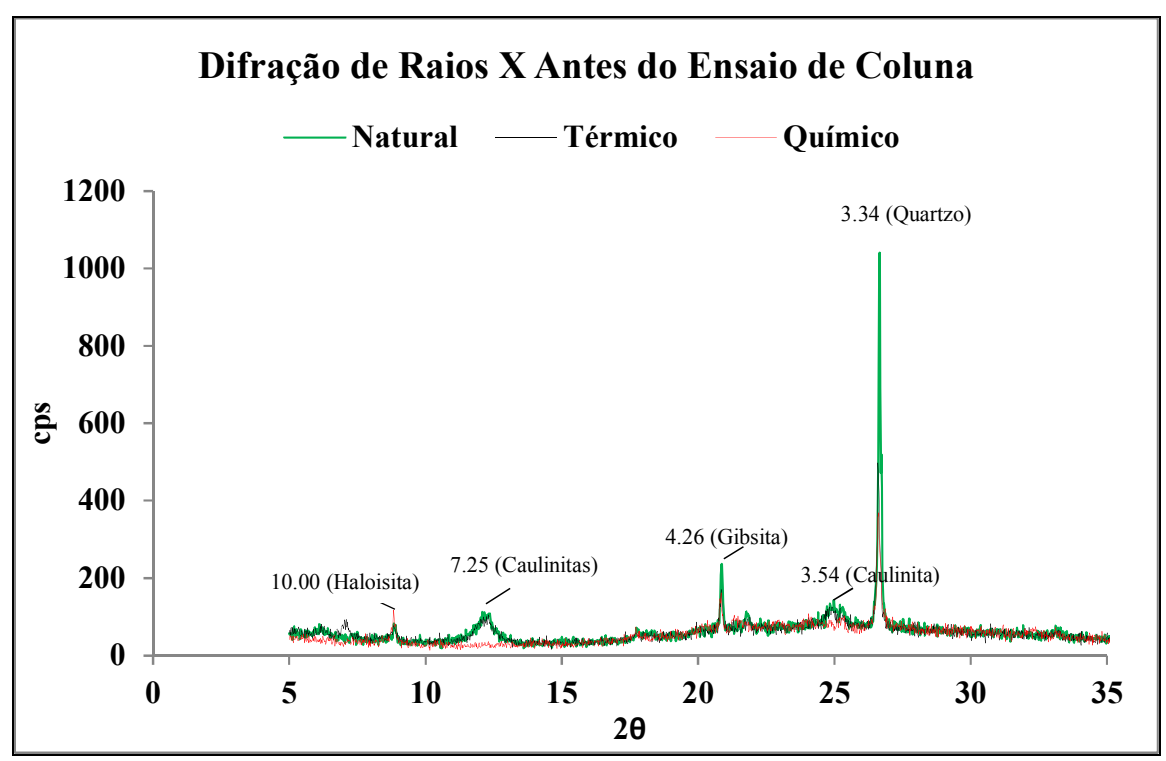

Figura 5.1- Gráficos de difratometria de raios X para os três tratamentos realizados

\subsection{CARACTERIZAÇão Física}

\subsubsection{ANÁLISE GRANULOMÉTRICA CONJUNTA}

Foram feitas análises granulométricas conjuntas com e sem defloculante (hexametafosfato de sódio). A Figura 5.2 apresenta as curvas granulométricas obtidas para o material inconsolidado. Pode-se perceber que, como esperado, a análise com defloculante apresentou maior porcentagem de argila $(16,1 \%)$ do que a análise sem o uso de defloculante $(10,5 \%)$. Além disso, percebeu-se que o solo é predominantemente arenoso para os dois 
ensaios realizados (79,3 e 79,4\% de areia com e sem defloculante, respectivamente). Esses resultados mostram-se coerentes com os esperados para o solo desta área por se tratar de material inconsolidado residual de arenitos.

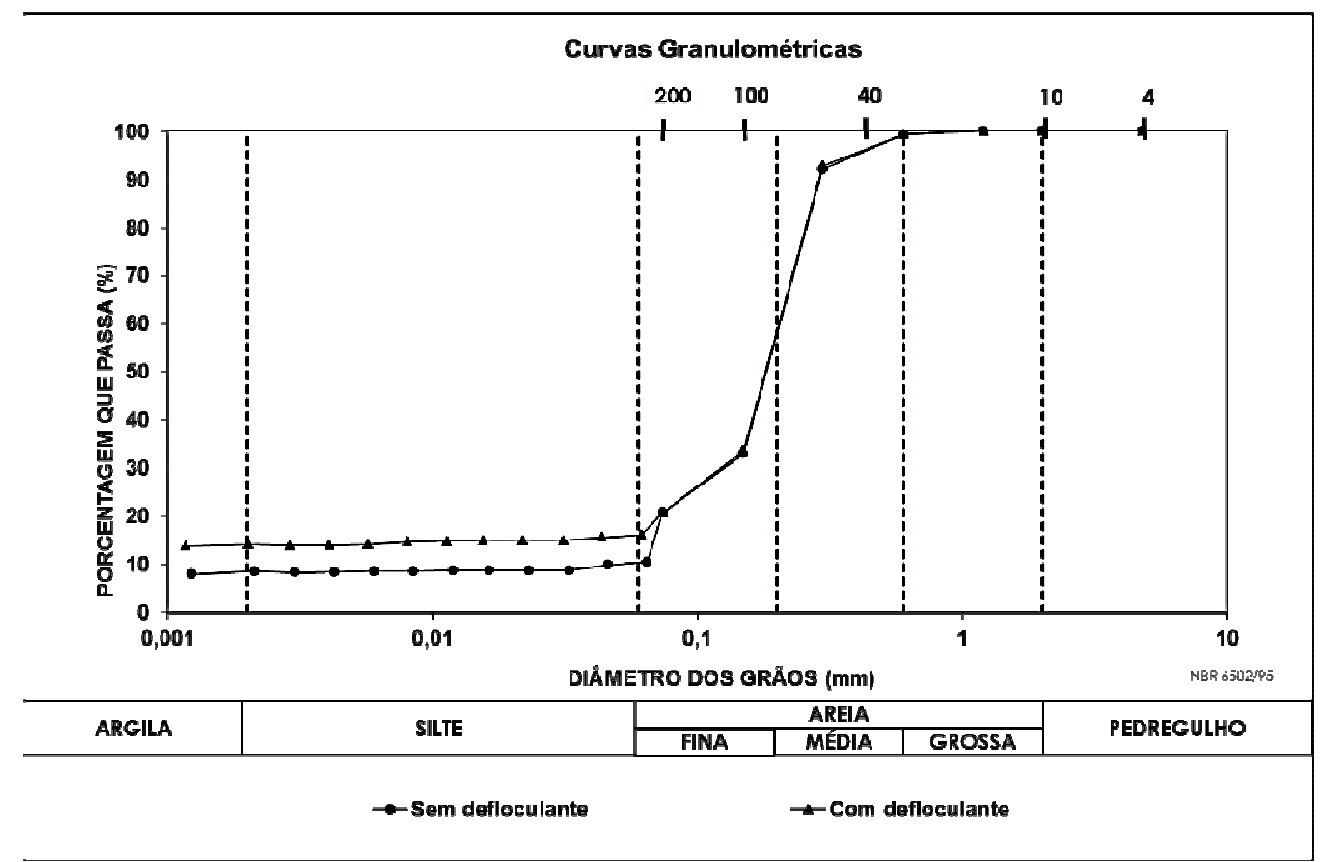

Figura 5.2- Curvas granulométricas com e sem o uso de defloculante

\subsubsection{MASSA ESPECÍfICA DOS SÓlidOS}

Foram realizadas análises da massa específica dos sólidos em três profundidades diferentes para que se verificassem alterações no perfil de solo, conforme indicado na Tabela 5.1. Os resultados variaram de 2,604 a $2,654 \mathrm{~g} / \mathrm{cm}^{3}$ que são valores coerentes para materiais arenosos, conforme indicado por Nogueira (2005). Percebe-se que o solo apresenta pouca alteração em profundidade, indicando que se trata de um solo homogêneo em termos desta propriedade.

Tabela 5.1 Valores da massa específica dos sólidos

Massa específica dos sólidos - $\left(\mathrm{g} / \mathrm{cm}^{3}\right)$

\begin{tabular}{ccc}
\hline $\mathbf{A 1}: \mathbf{1 1}-\mathbf{2 6} \mathbf{~ c m}$ & $\mathbf{A 2 :} \mathbf{6 0}-\mathbf{8 1} \mathbf{~ c m}$ & $\mathbf{A 3 :} \mathbf{1 4 0}-\mathbf{1 7 7} \mathbf{~ c m}$ \\
\hline 2,604 & 2,654 & 2,636 \\
\hline
\end{tabular}




\subsection{CARACTERIZAÇÃo FÍSICO-QUíMICA}

A caracterização físico-química foi realizada com o objetivo de entender as reações que poderiam ocorrer com os solutos e o solo analisado. A Tabela 5.2 traz um resumo das características físico-químicas do solo analisado.

Tabela 5.2 Parâmetros físico-químicos do solo

\begin{tabular}{|c|c|c|c|c|c|c|c|c|c|c|}
\hline \multicolumn{2}{|c|}{$\mathrm{pH}$} & \multirow[b]{2}{*}{$\Delta \mathrm{pH}$} & \multirow[b]{2}{*}{ PCZ } & \multirow{2}{*}{$\begin{array}{c}\text { Eh } \\
(\mathbf{m V})\end{array}$} & \multirow{2}{*}{$\begin{array}{l}\text { C.E } \\
(\mathrm{mS})\end{array}$} & \multirow{2}{*}{$\begin{array}{l}\text { CTC } \\
\text { meq/ } \\
100 \mathrm{~g}\end{array}$} & \multirow{2}{*}{$\begin{array}{c}\mathrm{Vb} \\
\mathrm{g} / \mathbf{1 0 0} \\
\mathrm{g}\end{array}$} & \multirow{2}{*}{$\underset{\mathbf{m}^{2} / \mathbf{g E}}{\mathbf{S E}}$} & \multirow[b]{2}{*}{ Acb } & \multirow{2}{*}{$\begin{array}{l}\text { M.O } \\
(\%)^{1}\end{array}$} \\
\hline $\mathrm{pH}_{(\mathbf{H 2 0 )}}$ & $\mathrm{pH}_{(\mathrm{KCl})}$ & & & & & & & & & \\
\hline 5,23 & 4,20 & $-1,03$ & 4,18 & 264 & 55,70 & 0.152 & 0.048 & 1.18 & 0.465 & 1,18 \\
\hline
\end{tabular}

Em relação ao $\mathrm{pH}$ em $\mathrm{H}_{2} \mathrm{O}$ e em $\mathrm{KCl}$, os resultados mostram que o solo é fortemente ácido, o que é uma característica típica de solos dessa região, como constatou Coelho e VidalTorrado (2003). O $\Delta \mathrm{pH}$ negativo e o PCZ menor do que o $\mathrm{pH}$ do solo indica que neste material existe predomínio de cargas negativas, o que favorece a adsorção de cátions. A condutividade elétrica indica que existem baixas concentrações de sais dissolvidos. Este solo é considerado pobre em matéria orgânica, parâmetro importante a ser considerado na análise de adsorção de íons.

Os valores de $\mathrm{CTC}, \mathrm{Vb}, \mathrm{SE}$ e Acb obtidos indicam que o material possui baixa capacidade de retenção de cátions. A fração argila é de baixa atividade e possui pequena superfície específica, o que geralmente reduz a adsorção de cátions, como discutido na Seção 2.9, quando comparado com solos que possuem alta CTC e alta atividade da fração argila e superfície específica. Segundo Lautrin ${ }^{6}$ (1989 apud Pejon 1992), materiais com atividade da fração argila menores do que 3,0, para a porcentagem de argila presente neste solo $(10,5 \%)$, são considerados como não argilosos.

\subsection{ANÁlISE DE ENERGIA DISPERSIVA (EDS)}

Com a análise de energia dispersiva pôde-se obter uma resposta quali-quantitativa dos principais elementos químicos presentes no solo. Observando a Figura 5.3 percebe-se que os principais elementos presentes são oxigênio, silício, alumínio, ferro e titânio, mostrando resultados coerentes para latossolo. Com esta análise constata-se que neste solo há ferro,

${ }^{6}$ LAUTRIN, D. Essai au bleu de methylene-utilisation pratique des parametres derives de l'essai au bleu de methylene dans les projets de genie civil. bulletin de liaison des laboratoires des ponts et chaussées, n. 160, 1989. 
mesmo que não cristalino, como mostrou a DRX. Este ferro não cristalino, assim como o alumínio, pode recobrir partículas de quartzo e alterarem as cargas superficiais presentes no material, aumentando a capacidade de sorção.

De acordo com a Tabela 5.3 pode-se perceber que a quantidade de fosforo total presente no solo é $0,16 \%$, valor próximo daquele indicado por Harvlin et al. (2005). Isto indica que solo contém uma quantidade natural de $\mathrm{P}$ antes mesmo que se aplique efluentes contendo este elemento. Considerando que a área da amostra analisada foi de $1,2 \mathrm{~mm} \times 1,2 \mathrm{~mm}$ e assumindo que o feixe de elétrons que incide sobre a superfície da amostra penetra $0,5 \mathrm{~mm}$, tem-se um volume analisado de $0,72 \mathrm{~mm}^{3}$. Portanto, em cada $0,0072 \mathrm{~cm}^{3}$ de solo, tem-se $0,16 \%$ de $\mathrm{P}$, quantia que pode ser considerada significativa.

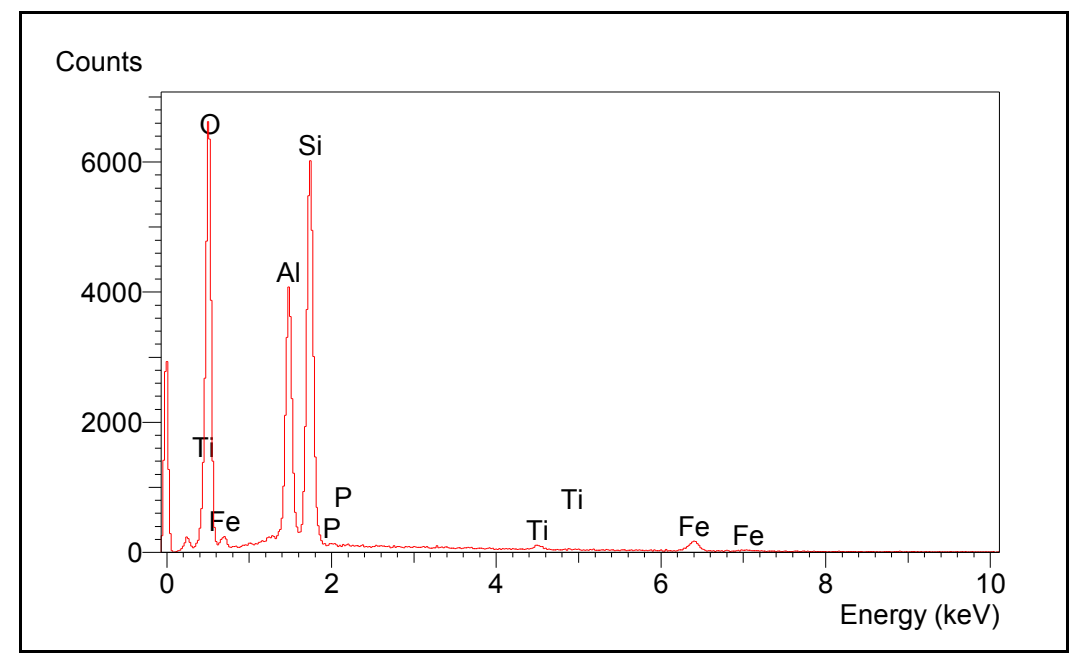

Figura 5.3- Gráfico de EDS

Tabela 5.3- Porcentagem dos elementos químicos no solo pelo EDS

\begin{tabular}{cccccccc}
\hline Elemento & $\mathbf{O}$ & $\mathbf{A l}$ & $\mathbf{S i}$ & $\mathbf{P}$ & $\mathbf{T i}$ & $\mathbf{F e}$ & Total \\
\hline$\%$ & 62,22 & 10,19 & 24,71 & 0,16 & 0,46 & 2,26 & 100 \\
\hline
\end{tabular}

A análise de EDS também foi realizada para o solo percolado com solução de $\left(\mathrm{NH}_{4}\right)_{2} \mathrm{HPO}_{4}$ e esses resultados encontram-se na Seção 5.7.2 juntamente com os resultados da percolação desta solução.

\subsection{POROSIMETRIA POR INTRUSÃO DE MERCÚRIO}

A porosimetria por intrusão de mercúrio foi realizada para se analisar a suspeita de que no solo estudado havia dupla e macroporosidade. O conhecimento da distribuição de tamanho 
dos poros é fator muito importante no estudo e na modelagem do transporte de solutos no solo, já que alterações na distribuição dos diâmetros dos poros pode modificar a trajetória dos solutos, a velocidade linear média do fluxo, bem como o mecanismo de transporte atuante.

A Figura 5.4 mostra uma relação linear entre a pressão aplicada e o diâmetro do poro, mostrando que quanto menor o diâmetro do poro, maior a pressão necessária para inserir mercúrio no mesmo.

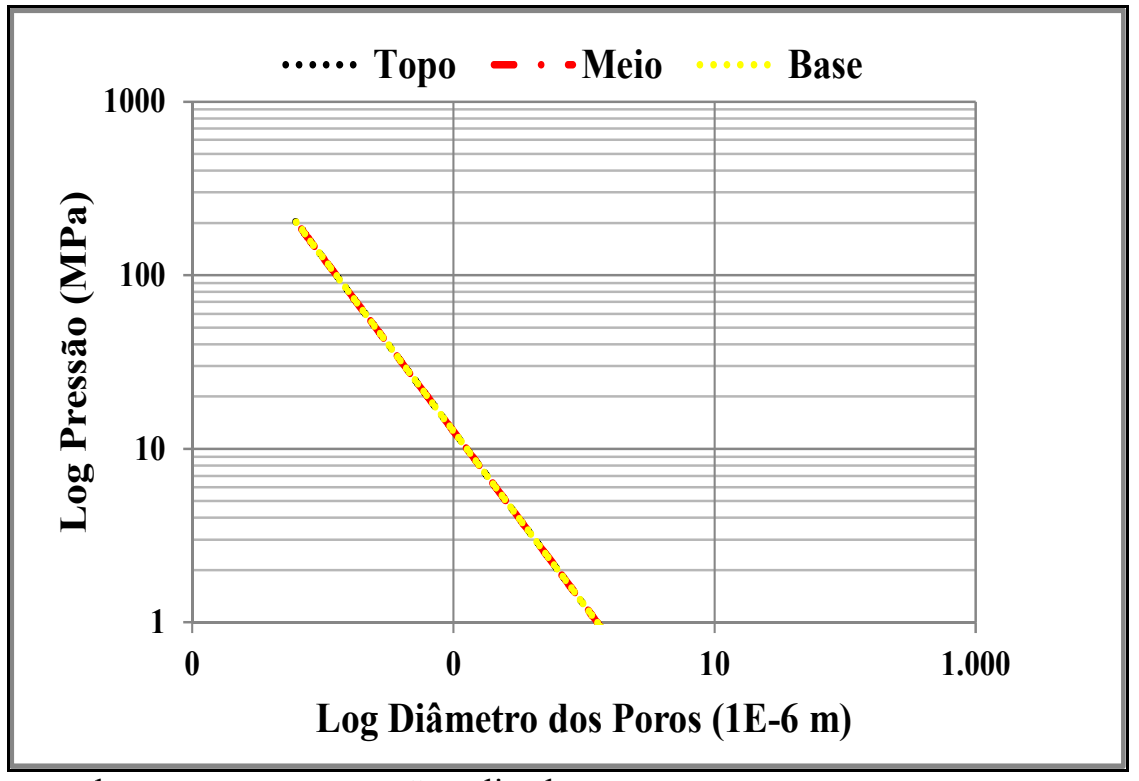

Figura 5.4- Diâmetro dos poros versus pressão aplicada

Quando se incrementa a pressão, maior quantidade de mercúrio é inserida no corpo de prova (Figura 5.5), até que se atinja um equilíbrio, significando que mesmo com aumento de pressão não terá acréscimo de mercúrio introduzido na amostra. A Figura 5.6 apresenta a relação entre o volume acumulado de mercúrio e o diâmetro do poro, indicando que com o aumento do volume acumulado, aumenta o número de poros menores que são preenchidos pelo mesmo. 


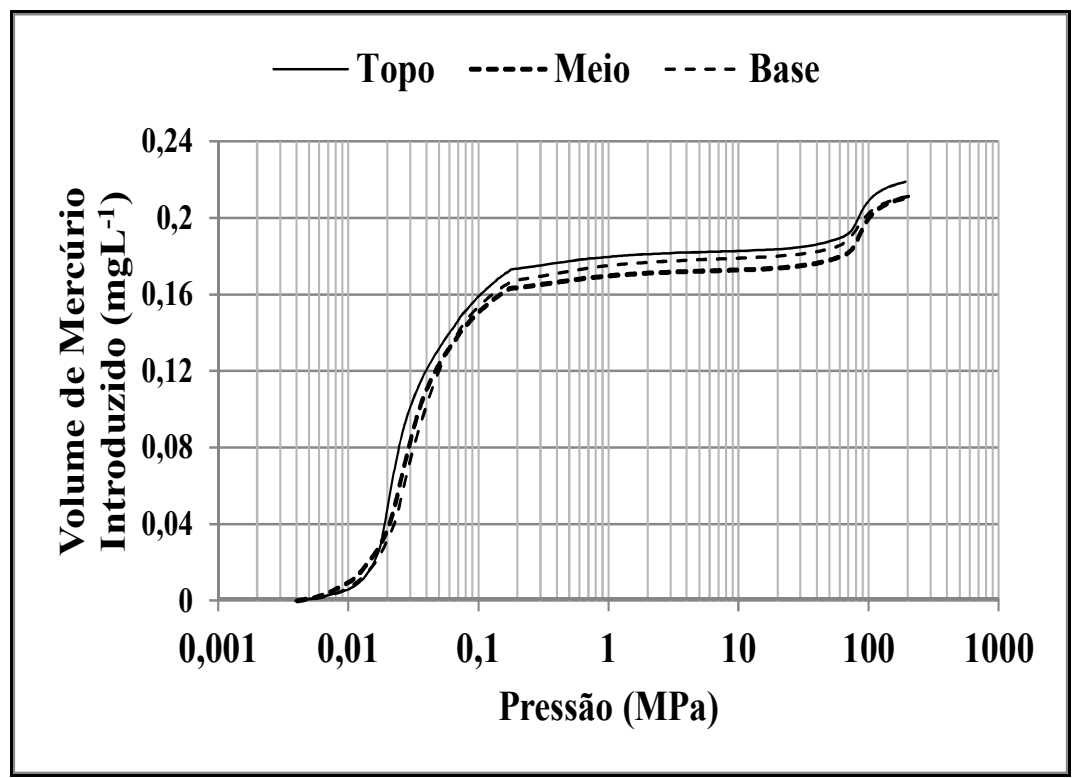

Figura 5.5- Pressão aplicada versus volume de mercúrio introduzido nos poros

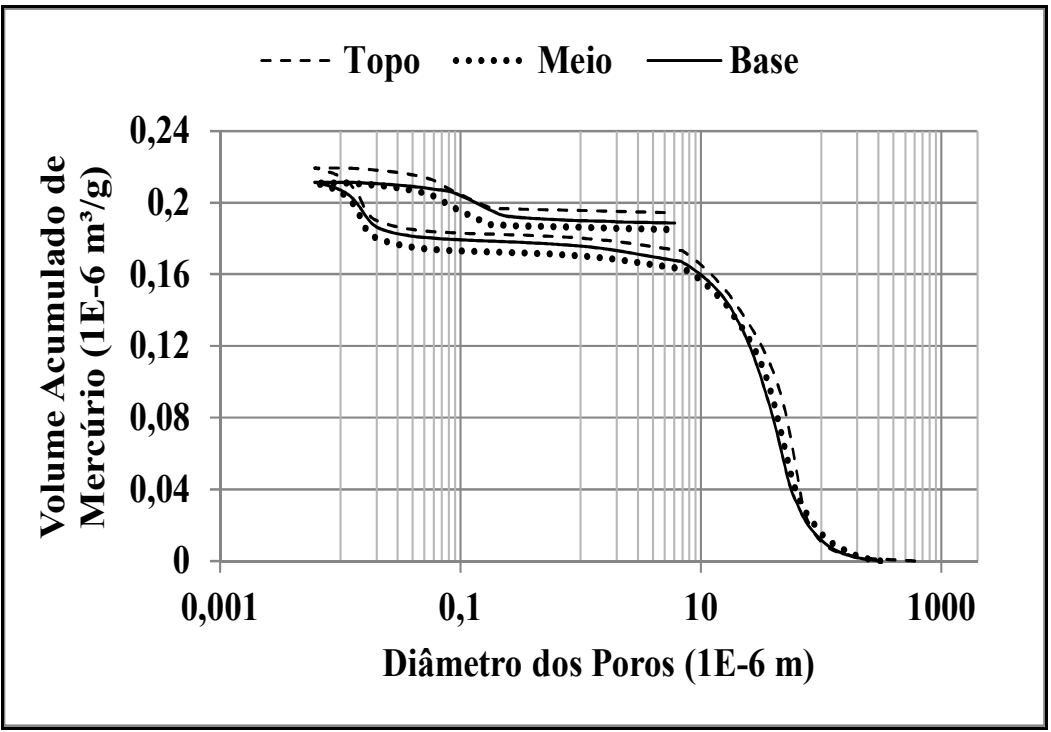

Figura 5.6- Diâmetro dos poros versus volume acumulado de mercúrio introduzido na amostra

Com a análise das duas figuras anteriores (5.5 e 5.6), é possível observar na Figura 5.7 que a uma dada porcentagem todos os poros são maiores ou iguais ao valor de diâmetro correspondente a essa porcentagem. Para o solo analisado, segundo a classificação de Koorevaar, Menelik e Dirksen (1983), tem-se 5\% de macroporos, ou seja, poros maiores que $100 \mu \mathrm{m}$. 


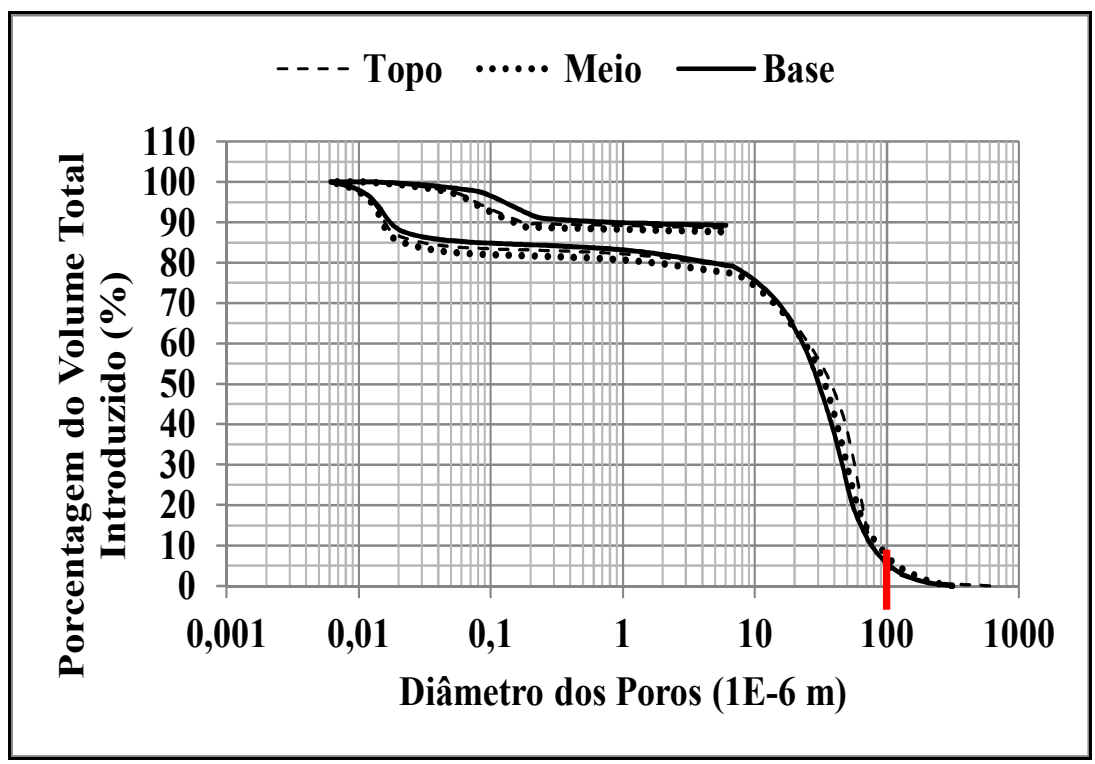

Figura 5.7- Diâmetro dos poros versus porcentagem do volume total de mercúrio introduzido

No entanto, com a observação das colunas de solo percebe-se que existiam poros maiores do que $100 \mu \mathrm{m}$ e que não foram mostrados com o ensaio de porosimetria por intrusão de mercúrio, portanto, acredita-se que o solo tenha mais do que 5\% de macroporosidade. A Figura 5.8 a-d apresenta colunas de solo com macroporos.
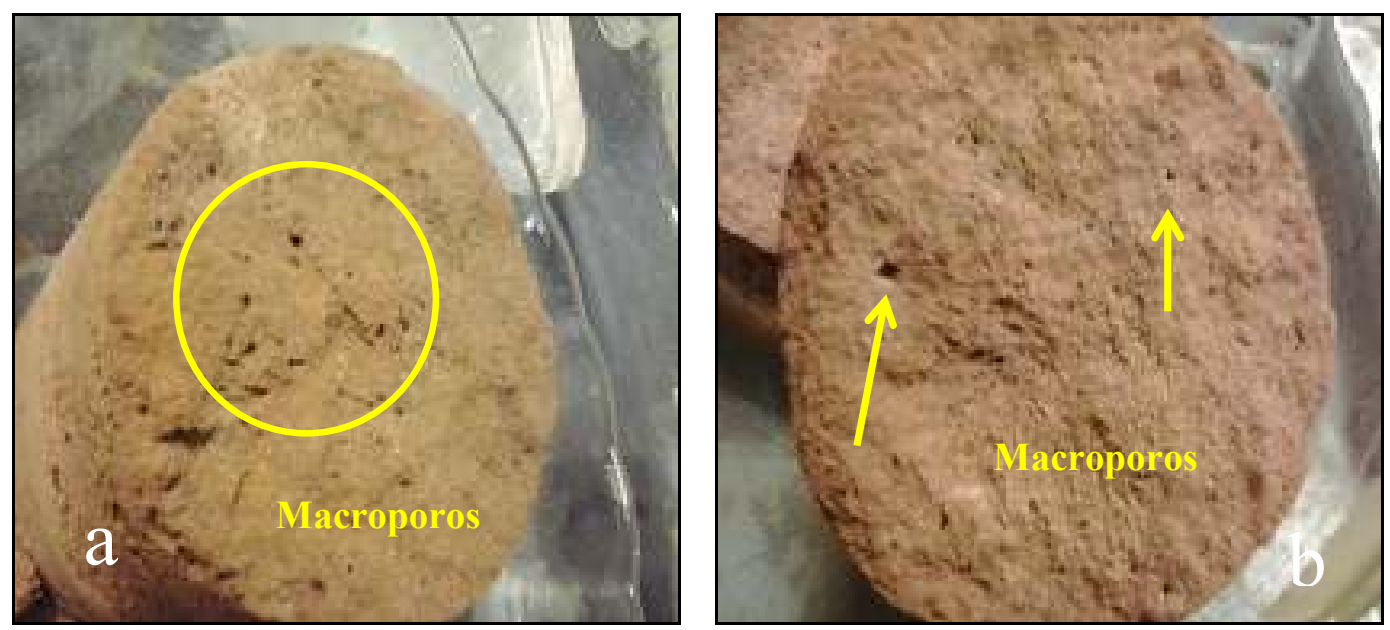

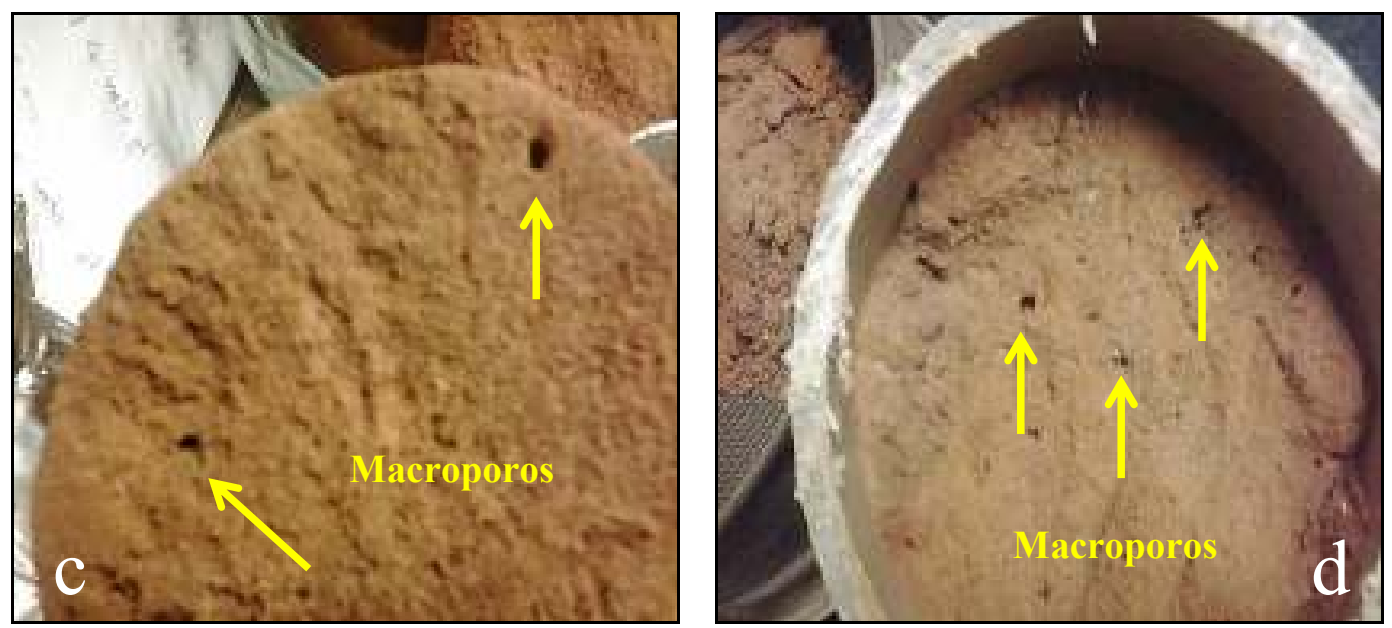

Figura 5.8- Colunas de solo com macroporosidade

Analisando a frequência dos diâmetros dos poros (Figura 5.9), observa-se que se trata de um material com dupla porosidade, sendo que uma parte do material possui área com frequência significativa de poros com diâmetro de cerca de $0,01 \mu \mathrm{m}$ e outra parcela entre $10 \mathrm{e}$ $100 \mu \mathrm{m}$.

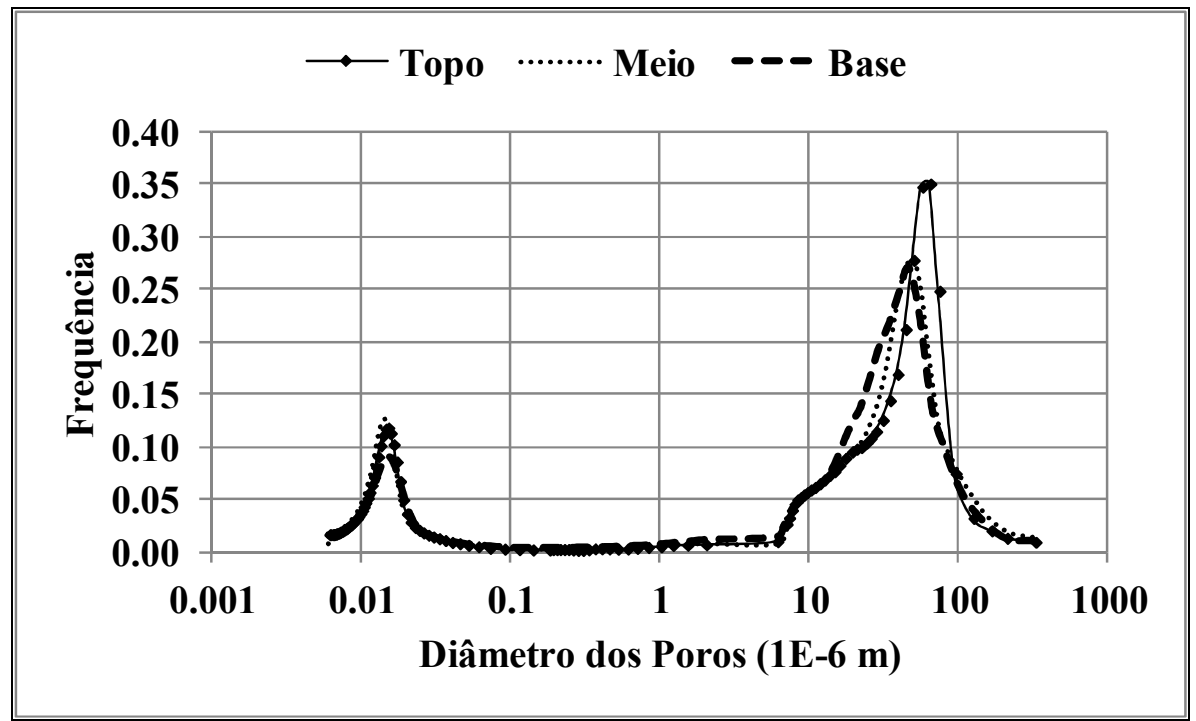

Figura 5.9- Frequência versus diâmetro dos poros

\subsection{CURVA de RETENÇÃo de ÁGUA}

Os parâmetros hidráulicos de retenção de água no solo são informações de grande importância uma vez que estas informações são necessárias para a modelagem de fluxo nos materiais inconsolidados, além de serem cruciais na modelagem do transporte de solutos em meio não saturado. A Tabela 5.4 mostra as características dos anéis moldados para realização 
do ensaio da trajetória de secagem. Nota-se que a umidade de saturação esta de acordo com o esperado para uma areia pouco argilosa, como o solo analisado nesta pesquisa.

Tabela 5.4- Características dos anéis moldados e do ensaio da trajetória de secagem

\begin{tabular}{|c|c|c|c|c|c|c|c|c|}
\hline $\begin{array}{l}\text { Anel } \\
\mathbf{n}^{0}\end{array}$ & $\begin{array}{c}\text { Psat }+ \text { Anel } \\
\text { g }\end{array}$ & $\begin{array}{c}\text { Tara Anel } \\
\text { g }\end{array}$ & $\begin{array}{c}M_{1} \text { (Solo) } \\
\mathrm{g}\end{array}$ & $\begin{array}{c}\text { w (Satur) } \\
\%\end{array}$ & $\begin{array}{c}\mathrm{M}_{\mathrm{S}} \\
\text { (sólidos) } \\
\mathrm{g}\end{array}$ & $\begin{array}{c}\text { w (Final) } \\
\%\end{array}$ & $\begin{array}{c}\mathbf{M}_{2} \text { (solo) } \\
\mathrm{g}\end{array}$ & $\begin{array}{c}M_{F}\left(M_{2}+A\right) \\
g\end{array}$ \\
\hline 1 & 44,2200 & 8,330 & 35,8900 & 19,8 & 29,9583 & 19,8 & 35,8900 & 44,2200 \\
\hline 2 & 41,1200 & 7,180 & 33,9400 & 19,8 & 28,3306 & 17,2 & 33,2034 & 40,3834 \\
\hline 3 & 41,9900 & 7,510 & 34,4800 & 19,8 & 28,7813 & 18,5 & 34,1058 & 41,6158 \\
\hline 4 & 41,4100 & 7,490 & 33,9200 & 19,8 & 28,3139 & 15,9 & 32,8158 & 40,3058 \\
\hline 5 & 38,0300 & 7,440 & 30,5900 & 19,8 & 25,5342 & 14,6 & 29,2622 & 36,7022 \\
\hline 6 & 42,5300 & 7,730 & 34,8000 & 19,8 & 29,0484 & 13,3 & 32,9119 & 40,6419 \\
\hline 7 & 41,5800 & 7,240 & 34,3400 & 19,8 & 28,6644 & 12,0 & 32,1042 & 39,3442 \\
\hline 8 & 40,9900 & 7,480 & 33,5100 & 19,8 & 27,9716 & 10,0 & 30,7688 & 38,2488 \\
\hline 9 & 41,2100 & 7,360 & 33,8500 & 19,8 & 28,2554 & 7,0 & 30,2333 & $\mathbf{3 7 , 5 9 3 3}$ \\
\hline 10 & 42,5900 & 6,980 & 35,6100 & 19,8 & 29,7245 & 4,0 & 30,9135 & $\mathbf{3 7 , 8 9 3 5}$ \\
\hline 11 & 40,9000 & 7,700 & 33,2000 & 19,8 & 27,7129 & 1,0 & 27,9900 & 35,6900 \\
\hline
\end{tabular}

A Figura 5.10 apresenta a curva de retenção de água obtida para este solo. Percebe-se que a curva está adequada para características de solos arenosos com uma inclinação brusca entre 100 e $60 \%$ de saturação. Novamente é possível se observar a dupla porosidade, indicada por dois picos.

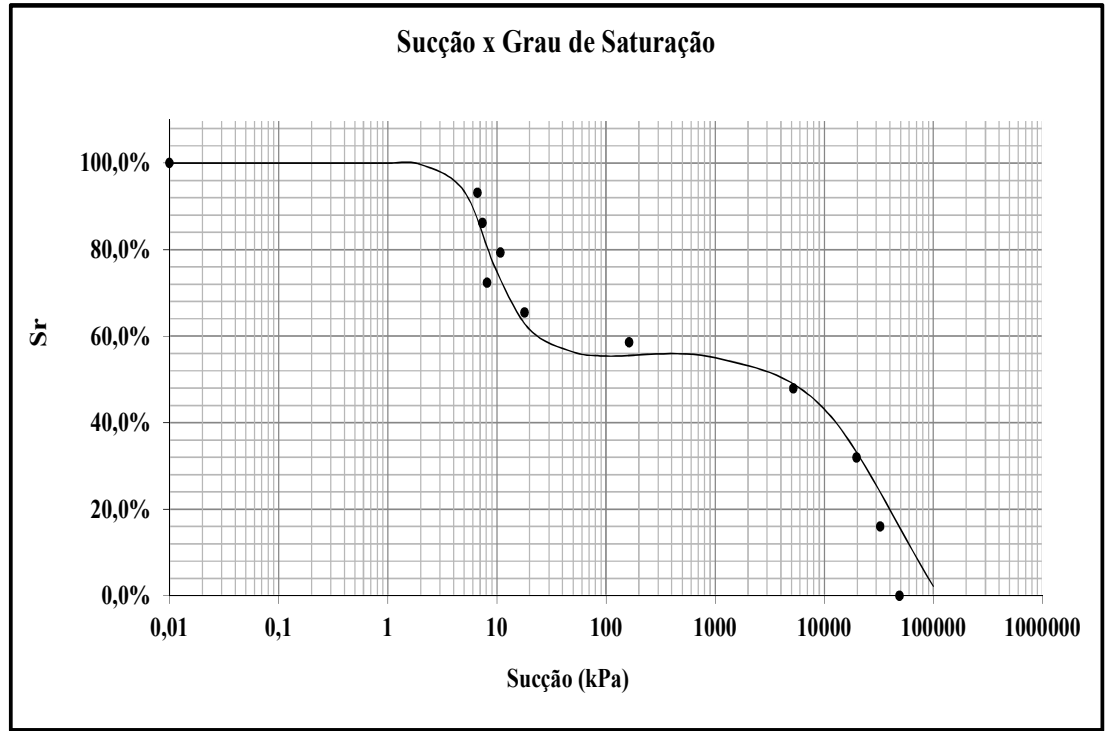

Figura 5.10- Curva de retenção de água para a trajetória de secagem 
Tabela 5.5 traz os parâmetros das curvas de retenção de água do material inconsolidado, segundo o modelo de Durner (1994).

Tabela 5.5- Parâmetros de ajuste da curva de retenção de água do material inconsolidado

\begin{tabular}{cccccccc}
\hline $\mathbf{W}_{\mathbf{1}}$ & $\mathbf{W}_{\mathbf{2}}$ & $\boldsymbol{\alpha}_{\mathbf{1}}$ & $\boldsymbol{\alpha}_{\mathbf{2}}$ & $\mathbf{m}_{\mathbf{1}}$ & $\mathbf{m}_{\mathbf{2}}$ & $\mathbf{n}_{\mathbf{1}}$ & $\mathbf{n}_{\mathbf{2}}$ \\
\hline $\mathbf{0 , 5 9}$ & 0.41 & 0,0008 & 0,14 & 0,7 & 0,5 & 1,5 & 0,7 \\
\hline
\end{tabular}

Os resultados sugerem que o material apresenta baixa pressão de entrada de ar (4kPa) e trechos de dessaturação acentuados em que uma pequena variação da sucção representa uma variação de umidade significativa em termos percentuais, o que é esperado para materiais arenosos como ressaltaram Fredlund e Xing (1994).

\subsection{ENSAIOS DE COLUNA}

Os ensaios de coluna foram realizados com o objetivo de se obter os parâmetros de fluxo de água subterrânea e de transporte de solutos. A Tabela 5.6 mostra as características físicas de cada uma das colunas indeformadas analisadas. Nota-se que as colunas apresentam características físicas muito próximas, indicando que se trata de um solo com baixa heterogeneidade, na profundidade analisada (60 centímetros). Os valores de índice de vazios encontram-se menores do que o esperado para este tipo de solo. Os valores de massa específica seca encontram-se superiores do que o esperado para este tipo de material.

Tabela 5.6- Índices físicos das colunas estudadas

\begin{tabular}{|c|c|c|c|c|c|c|c|c|c|c|c|}
\hline Coluna & $\begin{array}{c}\mathrm{V} \\
(\mathrm{ml})\end{array}$ & $\begin{array}{c}w \\
(\%)\end{array}$ & $\begin{array}{c}M_{\text {úmida }} \\
\text { (g) }\end{array}$ & $\begin{array}{c}M_{\text {seca }} \\
\text { (g) }\end{array}$ & $\begin{array}{c}\rho \\
\left(\mathrm{g} / \mathrm{cm}^{3}\right)\end{array}$ & $\begin{array}{c}\rho_{\mathrm{d}} \\
\left(\mathrm{g} / \mathrm{cm}^{3}\right)\end{array}$ & e & n (\%) & $n_{e}(\%)$ & $\begin{array}{c}\text { Vs } \\
(\mathrm{ml})\end{array}$ & $\begin{array}{l}\mathrm{Vv} \\
(\mathrm{ml})\end{array}$ \\
\hline 3 & 1121,95 & 10,41 & 2025,2 & 1834,25 & 1,8050 & 1810,68 & 0,62 & 38,39 & 21 & 691,12 & 430,82 \\
\hline 6 & 1121,95 & 11,23 & 2108,8 & 1895,89 & 1,8795 & 1,6898 & 0,57 & 36,32 & 21 & 714,35 & 407,59 \\
\hline 7 & 1121,95 & 9,02 & 2037,56 & 1868,97 & 1,8160 & 1,6658 & 0,59 & 37,23 & 21 & 704,21 & 417,73 \\
\hline 8 & 1121,95 & 10,42 & 1960,36 & 1775,37 & 1,7472 & 1,5824 & 0,67 & 40,37 & 21 & 668,94 & 453,00 \\
\hline 9 & 1121,95 & 10,60 & 2007,59 & 1815,18 & 1,7893 & 1,6178 & 0,64 & 39,04 & 21 & 683,94 & 438,00 \\
\hline 10 & 1121,95 & 10,51 & 2000,98 & 1810,68 & 1,7834 & 1,6138 & 0,64 & 39,19 & 21 & 682,24 & 439,70 \\
\hline
\end{tabular}

Para a obtenção dos parâmetros de fluxo de água subterrânea realizaram-se, em cada coluna de solo, sete medidas de condutividade hidráulica e vazão durante o período de um mês, mantendo a carga hidráulica constante de 1,5. Com a estabilização dos valores, iniciaram-se as determinações da condutividade hidráulica saturada, da velocidade de Darcy, 
da velocidade linear média e da vazão, valores utilizados posteriormente nos cálculos dos parâmetros de transporte de solutos. As Figuras 5.11 e 5.12 mostram as medições da condutividade hidráulica saturada e da vazão até se obter a estabilização dos valores.

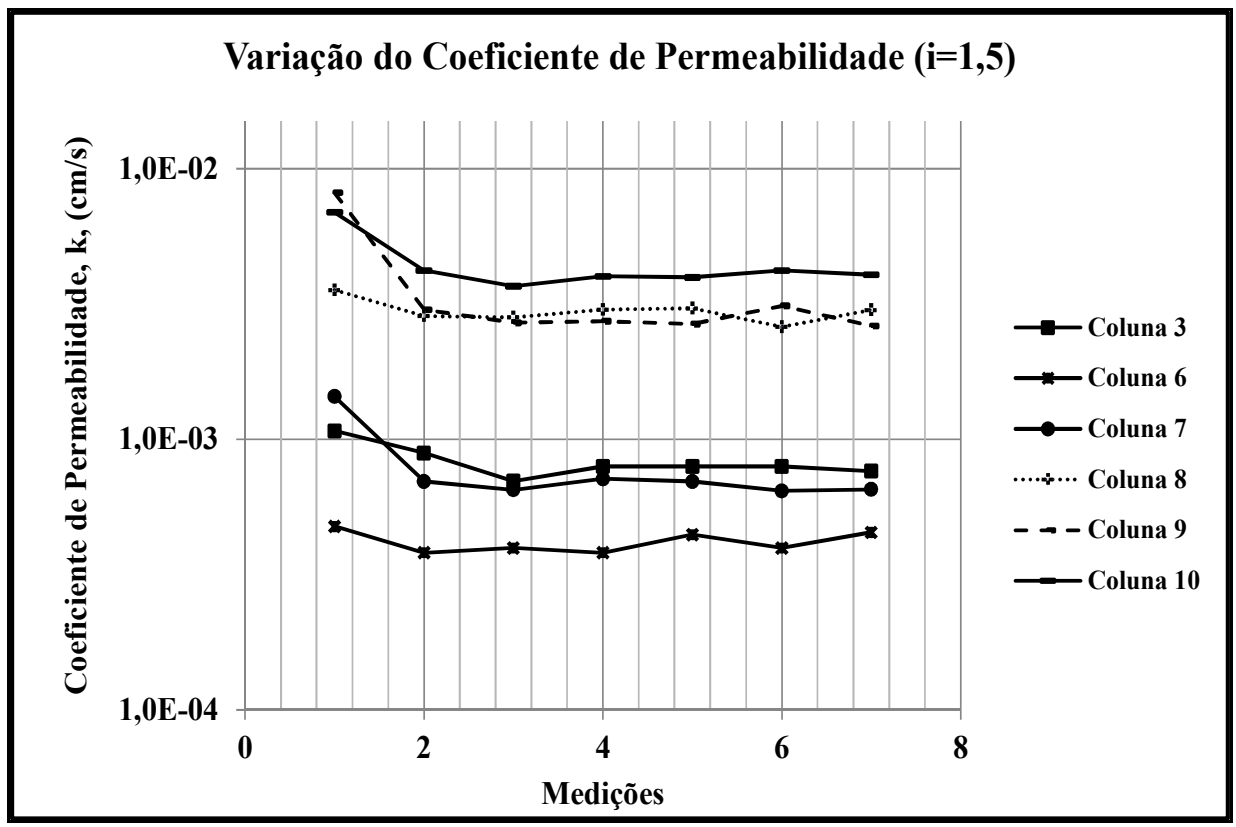

Figura 5.11- Medidas do coeficiente de permeabilidade

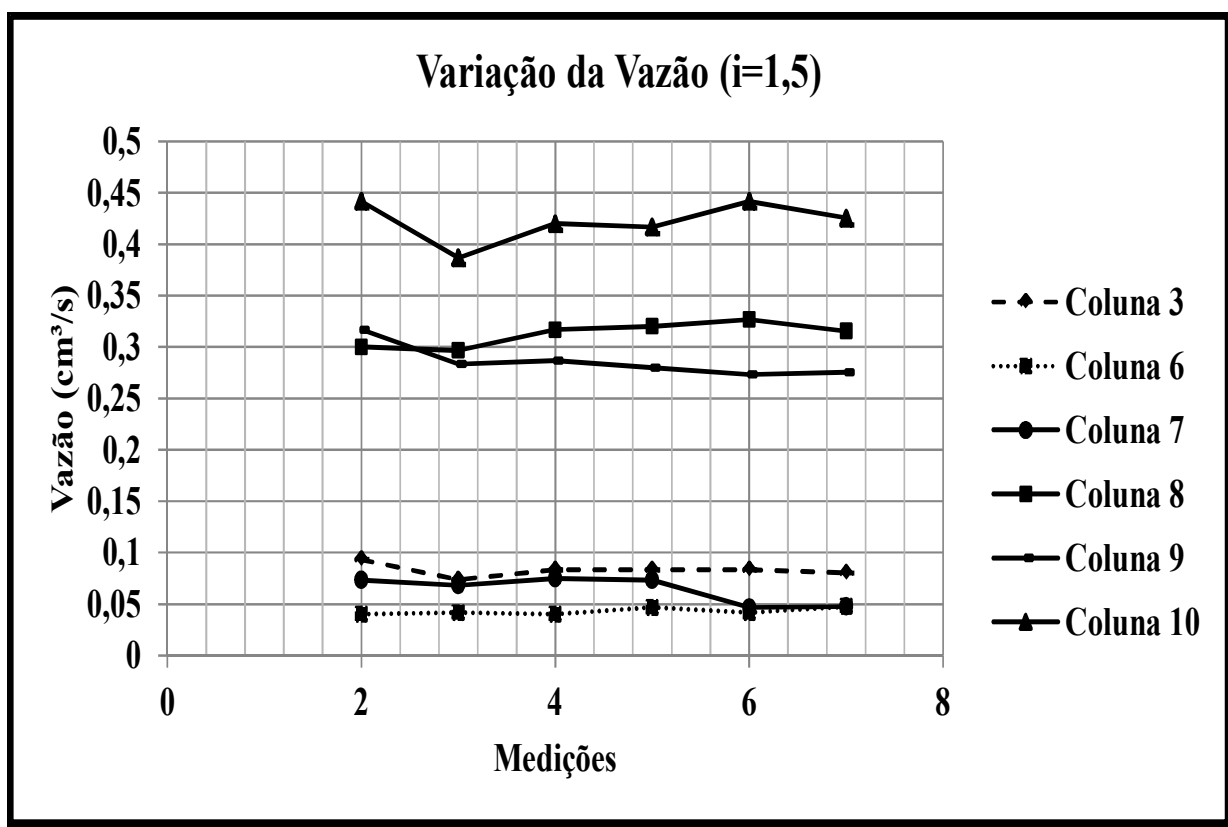

Figura 5.12- Medidas da vazão

Percebe-se que as colunas 3,6 e 7 tiveram a condutividade hidráulica na ordem de 10E$4 \mathrm{~cm} / \mathrm{s}$ e as colunas 8,9 e 10 na ordem de $10 \mathrm{E}-03 \mathrm{~cm} / \mathrm{s}$. Por este motivo, optou-se por agrupar as colunas 3,6 e 7 para que posteriormente fossem percoladas as soluções de $\mathrm{NaCl}$ e as 
colunas 8,9 e 10 para que nelas fossem percolados as soluções de $\left(\mathrm{NH}_{4}\right)_{2} \mathrm{HPO}_{4}$. Esta decisão foi tomada para que se evitassem efeitos de diferentes condutividades hidráulicas para um mesmo contaminante em seus parâmetros de transporte. A Tabela 5.7 resume os parâmetros de fluxo de água subterrânea para as seis colunas analisadas. Nota-se que o coeficiente de permeabilidade está dentro do esperado para solos arenosos. A velocidade linear média pode ser considerada alta e isto provavelmente esta relacionado com a presença de macroporos conectados.

Tabela 5.7- Parâmetros de fluxo de água das colunas

\begin{tabular}{ccccccc}
\hline & Coluna3 & Coluna 6 & Coluna 7 & Coluna8 & Coluna 9 & Coluna 10 \\
\hline $\mathbf{k}_{\text {sat }}(\mathbf{c m} / \mathbf{s})$ & $8,30 \mathrm{E}-04$ & $4,19 \mathrm{E}-04$ & $7,86 \mathrm{E}-04$ & $3,060 \mathrm{E}-03$ & $3,50 \mathrm{E}-03$ & $4,43 \mathrm{E}-03$ \\
$\mathbf{i}$ & 1,5 & 1,5 & 1,5 & 1,5 & 1,5 & 1,5 \\
$\boldsymbol{Q}(\mathbf{c m} 3 / \mathbf{s})$ & $8,28 \mathrm{E}-02$ & $4,29 \mathrm{E}-02$ & $6,40 \mathrm{E}-02$ & $3,13 \mathrm{E}-01$ & $2,86 \mathrm{E}-01$ & $4,22 \mathrm{E}$ \\
$\boldsymbol{q}(\mathbf{c m} / \mathbf{s})$ & $1,25 \mathrm{E}-03$ & $6,29 \mathrm{E}-04$ & $1,18 \mathrm{E}-03$ & $4,59 \mathrm{E}-03$ & $5,25 \mathrm{E}-03$ & $6,65 \mathrm{E}-03$ \\
$\boldsymbol{n e}$ & 0,21 & 0,21 & 0,21 & 0,21 & 0,21 & 0,21 \\
$\boldsymbol{v}(\mathbf{c m} / \mathbf{s})$ & $5,93 \mathrm{E}-03$ & $2,99 \mathrm{E}-03$ & $5,61 \mathrm{E}-03$ & $2,18 \mathrm{E}-02$ & $2,50 \mathrm{E}-02$ & $3,16 \mathrm{E}-02$ \\
\hline
\end{tabular}

Além do ensaio de condutividade hidráulica em laboratório, realizaram-se dois ensaios de condutividade hidráulica in situ, do tipo ensaio de rebaixamento a nível variável por injeção de água. A Tabela 5.8 mostra os resultados desses ensaios. Os valores estão na mesma ordem de grandeza dos valores obtidos em laboratório para as colunas 3, 6 e 7 e também se encontram dentro de uma faixa de condutividade hidráulica esperada para solos arenosos.

Tabela 5.8- Resultados dos ensaios de condutividade hidráulica in situ

\begin{tabular}{cc}
\hline Camada & Condutividade Hidráulica $(\mathbf{c m} / \mathbf{s})$ \\
\hline Superior $(\mathbf{0}-\mathbf{6 5} \mathbf{~ c m})$ & $2,99 \mathrm{E}-04$ \\
Inferior $(\mathbf{0}-\mathbf{1 9 5} \mathbf{~ c m )}$ & $9,18 \mathrm{E}-04$ \\
\hline
\end{tabular}

Depois de obtidos os parâmetros de fluxo de água, iniciaram-se os ensaios de coluna. A Tabela 5.9 mostra as características das soluções. Reduções na temperatura das soluções de $\mathrm{NaCl}$, quando comparadas com a temperatura da água destilada utilizada para preparo das soluções, podem estar relacionadas à absorção de energia durante a dissociação de $\mathrm{NaCl}$ em $\mathrm{Na}^{+}$e $\mathrm{Cl}^{-}$que é, essencialmente, uma reação endotérmica. Por outro lado, aumento na temperatura das soluções de $\left(\mathrm{NH}_{4}\right)_{2} \mathrm{HPO}_{4}$ podem se relacionar com a liberação de energia devido à dissociação do fosfato de amônio em $\mathrm{NH} 4+\mathrm{e}_{2} \mathrm{PO}_{4}{ }^{-}$,que é uma reação exotérmica. 
Tabela 5.9- Características das soluções utilizadas

\begin{tabular}{cccccccc}
\hline Íon & Solução & $\begin{array}{c}\mathbf{p H ~} \mathbf{H}_{\mathbf{2}} \mathbf{O} \\
\mathbf{d e s t i l a d a}\end{array}$ & $\begin{array}{c}\mathbf{p H} \\
\text { solucão }\end{array}$ & $\mathbf{C}_{\mathbf{0}}(\mathbf{p p m})$ & $\begin{array}{c}\mathbf{C . E} \\
\mathbf{( u S / c m})\end{array}$ & $\begin{array}{c}\mathbf{T}(\mathbf{C}) \\
\text { Solucão }\end{array}$ & $\begin{array}{c}\mathbf{T}(\mathbf{C}) \\
\text { água }\end{array}$ \\
\hline & 1 & 6,92 & 7,5 & 50 & 275 & 22,75 & 22,50 \\
$\mathbf{N a}^{+}$ & 2 & 6,92 & 7,5 & 90 & 580 & 22,50 & 22,00 \\
& 3 & 7,00 & 7,3 & 117,5 & 790 & 22,75 & 22,00 \\
& 1 & 6,90 & 7,10 & 35 & 80 & 23,25 & 22,50 \\
$\mathbf{P O}_{4}{ }^{3-}$ & 2 & 6,90 & 7,10 & 65 & 150 & 23,25 & 22,50 \\
& 3 & 7,15 & 7,20 & 95 & 185 & 23,50 & 22,50 \\
& 1 & 6,90 & 7,10 & 13 & 80 & 23,25 & 22,50 \\
$\mathbf{N H}_{4}{ }^{+}$ & 2 & 6,90 & 7,10 & 24 & 150 & 23,25 & 22,50 \\
& 3 & 7,15 & 7,20 & 36 & 185 & 23,50 & 22,50 \\
\hline
\end{tabular}

\subsubsection{PerColaÇÃo de ClORETO de Sódio (NACL)}

\subsubsection{Análise do ensaio de coluna}

Durante a percolação das soluções de $\mathrm{NaCl}$ monitoraram-se o $\mathrm{pH}$ a condutividade elétrica e a temperatura das amostras efluentes. A Figura 5.13, 5.14 e 5.15 mostram os resultados desses monitoramentos.

Verifica-se que o $\mathrm{pH}$ no início do ensaio estava mais alto quando comparado com os pHs das concentrações iniciais (Tabela 5.9). No entanto, nota-se que com o passar do tempo há tendência à estabilização de $\mathrm{pH}$, sendo que este é maior quanto maior for a concentração da solução percolante. Após a lavagem durante três volumes de poros com água destilada, percebe-se que o $\mathrm{pH}$ aumentou levemente em todas as colunas, chegando próximo aos valores de $\mathrm{pH}$ da água destilada pura, ou seja, 7,2. 


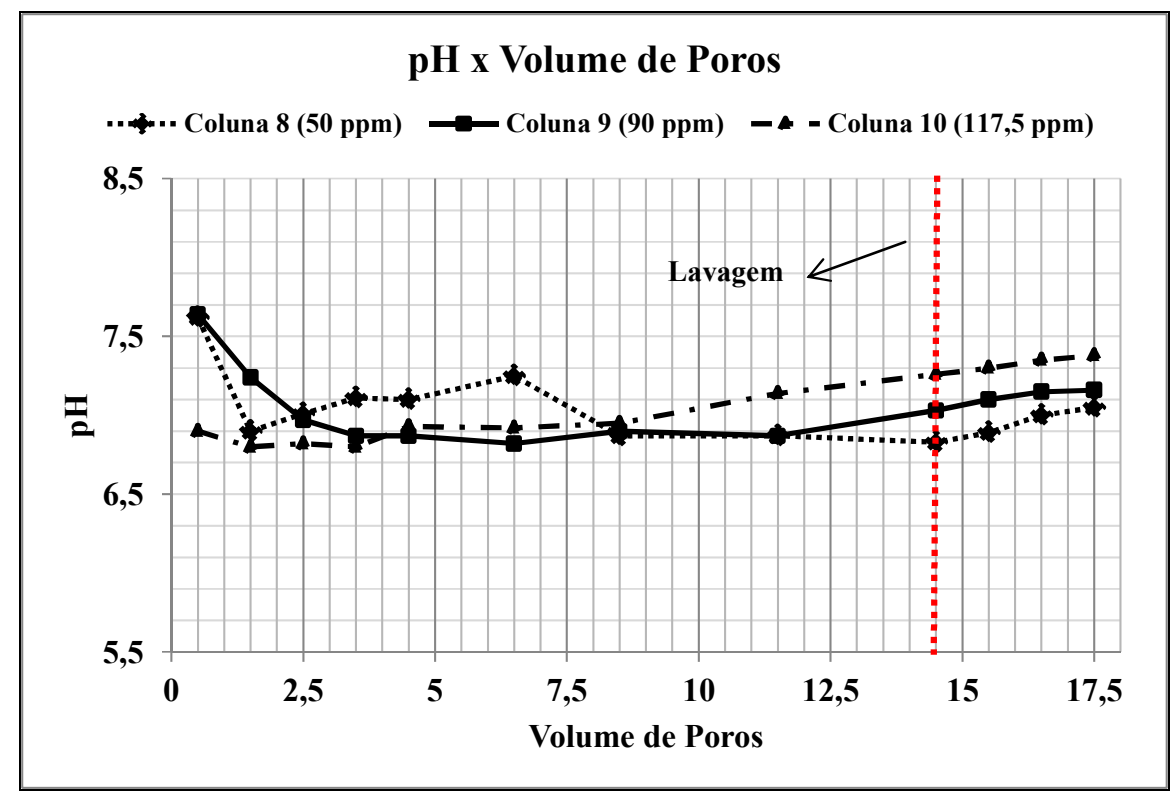

Figura 5.13- valores de $\mathrm{pH}$ versus volume de poros durante percolação de $\mathrm{NaCl}$

O gráfico de condutividade elétrica versus o volume de poros (Figura 5.14) indica que, houve aumento da concentração de sais com o passar do volume percolado o que está associado com o aumento da concentração de $\mathrm{Na}^{+}$em solução. A condutividade elétrica é maior quanto maior a concentração da solução contaminante, devido a maior quantidade de íons $\mathrm{Na}^{+}$em solução. Percebe-se que logo no início do ensaio as condutividades elétricas das colunas 9 e 10 estavam altas, comparando com a condutividade elétrica da água que saía da coluna de solo $(15 \mathrm{mS})$. Isso indica que, para essas colunas, no primeiro volume de solo percolado já se constatava a presença de íons dissolvidos em solução, o que pode ser confirmado com a observação da curva de chegada (Figura 5.16). A partir de 5 volumes de poros percolados, ocorre uma estabilização nos valores de condutividade hidráulica. Ao final da percolação das soluções de $\mathrm{NaCl}$ (antes da lavagem), as C.E. estavam muito próximas dos valores das concentrações iniciais, como pode ser observado na Tabela 5.9.

Após a lavagem com água destilada (destaque na Figura 5.16), verifica-se que no primeiro volume de poros há um leve aumento da condutividade elétrica, o que pode evidenciar a lavagem das soluções que estavam imobilizadas em alguns reservatórios na coluna de solo. Após o segundo volume de poros de lavagem há uma redução da C.E devido a redução da concentração de solutos na solução que sai das colunas. 


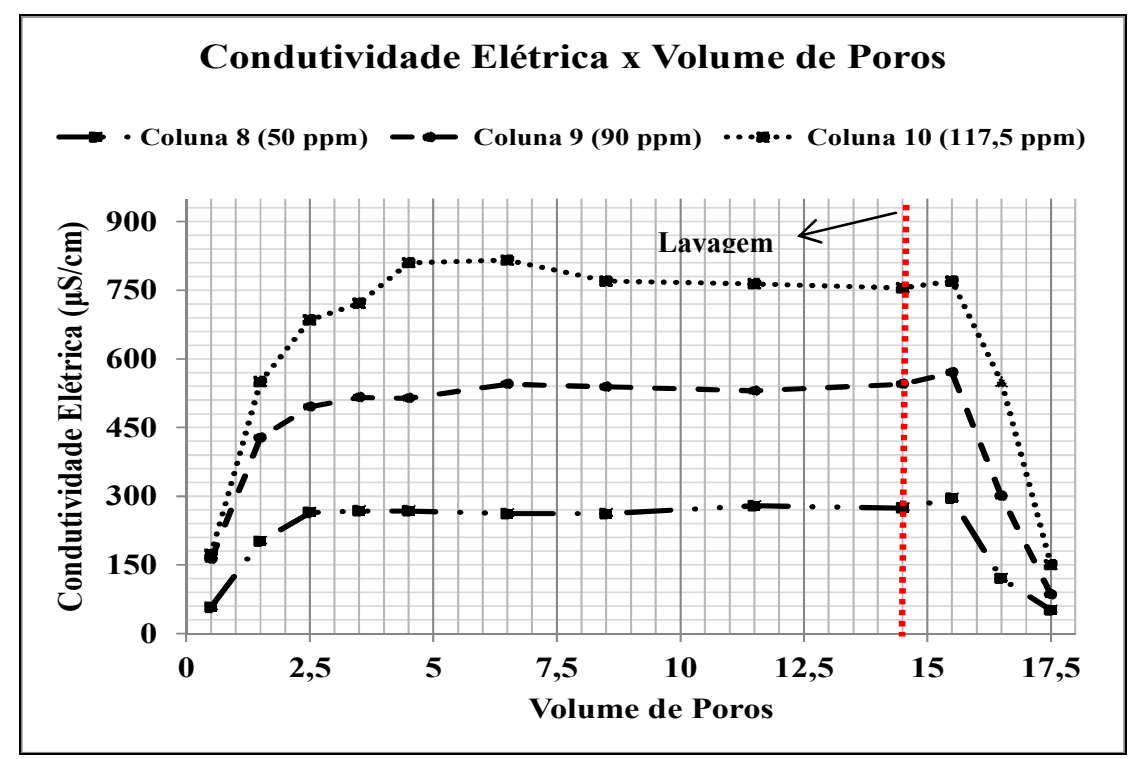

Figura 5.14- Condutividade elétrica versus volume de poros durante percolação de $\mathrm{NaCl}$

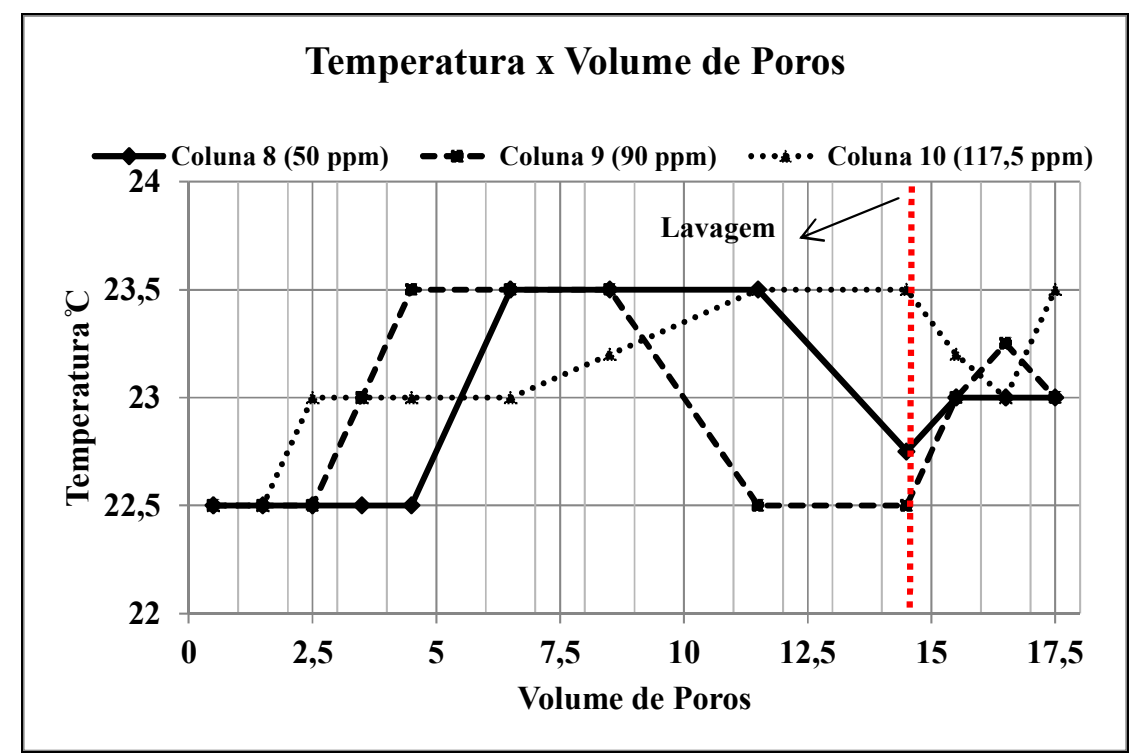

Figura 5.15- Temperatura versus volume de poros durante percolação de $\mathrm{NaCl}$

Em relação à temperatura, percebe-se que houve variação de no máximo 1 grau durante o ensaio (Figura 5.15). As oscilações verificadas são justificáveis pelo período em que os ensaios foram realizados e estão relacionas com a condutividade hidráulica de cada coluna (Tabela 5.7). Nota-se que a coluna 10, onde percolou a concentração de 117,5 ppm, possui a maior condutividade hidráulica dentre as três colunas $(4,43 \mathrm{E}-03 \mathrm{~cm} / \mathrm{s})$. Com isto, quando o ensaio nesta coluna já estava encerrado, as outras colunas ainda estavam com o ensaio em andamento e, devido às oscilações diárias de temperatura, terminaram no período da noite quando a temperatura ambiente já tinha reduzido, mostrando a queda de temperatura ao final 
do ensaio das colunas 8 e 9. Após a lavagem com água destilada, há uma tendência de que as temperaturas cheguem a $23{ }^{\circ} \mathrm{C}$, valores próximos da temperatura da água destilada.

\subsubsection{Curva de chegada de sódio}

A Figura 5.16 ilustra as curvas de chegada obtidas para as três concentrações de $\mathrm{Na}^{+}$.

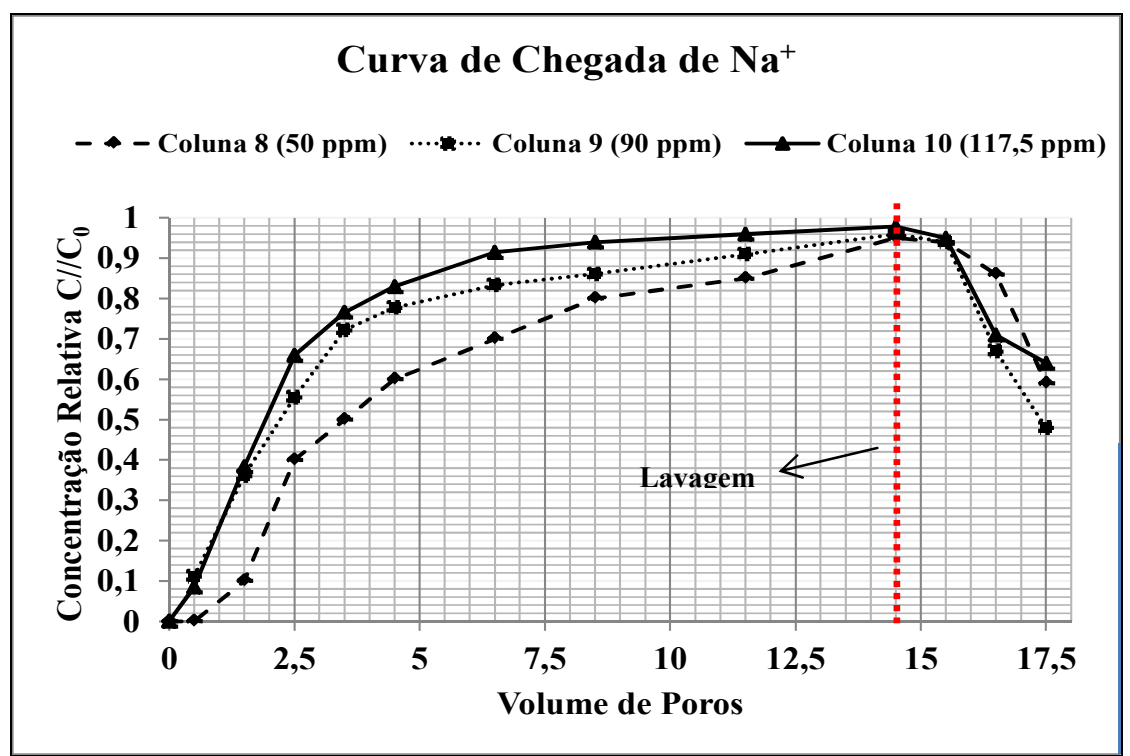

Figura 5.16- Curva de chegada do $\mathrm{Na}^{+}$

O ensaio percolou 15 volumes de poros da solução de $\mathrm{NaCl}$, mas esta quantidade de solução não foi suficiente para que as curvas alcançassem o equilíbrio das concentrações relativas, ou seja, a unidade. À 15 volumes de poros a coluna 8, 9 e 10 possuíam concentração relativa de 0,95, 096 e 0,97, respectivamente. Como esses valores são muito próximos de 1,0, realizou-se extrapolação das três curvas até a unidade para que fosse possível realizar as análises. Com isso, o volume de poro considerado nos cálculos é de 17,5 e não de 14,5. Após a lavagem com água destilada, nota-se redução da concentração relativa, indicando redução na concentração de $\mathrm{Na}^{+}$na solução do solo. Esta redução não foi muito significativa após o primeiro volume de poros de lavagem, indicando que o íon $\mathrm{Na}^{+}$ainda estava saindo na solução efluente.

Apesar de se tratar de um solo com baixa CTC, baixo teor de matéria orgânica e sem a presença de argilominerais $2: 1$, percebe-se que o sódio esta sendo retido pelo solo. Esta retenção de sódio no solo pode estar ocorrendo devido à adsorção não específica que mesmo ocorrendo em pequenas quantidades devido às características mineralógicas do solo, pode ser capaz de atuar fortemente na retenção do sódio. Além disso, este solo possui $\Delta \mathrm{pH}$ e PCZ 
negativo, o que significa que a carga total do solo é negativa, favorecendo a adsorção de cátions como o $\mathrm{Na}^{+}$.

No entanto, solutos reativos normalmente demoram em aparecer na solução efluente fazendo com que as curvas de chegada tenham o formato sigmoide (FREEZE; CHERRY, 1979; SHACKELFORD, 1994; FETTER, 1993). As curvas de chegada do sódio mostram que para as concentrações iniciais de 90 e 117,5 ppm, no primeiro volume de poros analisado já apareceram concentrações do íon na solução efluente. Isto pode indicar que parte do soluto estava saindo da coluna com a mesma velocidade linear média que a água, sugerindo a ocorrência de advecção pelos caminhos preferenciais como por exemplo, os macroporos apresentados na Seção 5.5. Por outro lado, foi necessário percolar 17,5 volumes de poros de solução para que a concentração relativa alcançasse a unidade. Desta maneira, acredita-se que devido à dupla porosidade presente neste material, parte dos solutos está saindo da coluna de solo devido à advecção, preferencialmente pelos macroporos, e parte está sendo retardada devido à passagem pelos microporos que, muitas vezes, podem não estar interconectados. Assim, o retardamento pode estar ocorrendo principalmente devido à presença da dupla porosidade e, com menor importância, devido à mecanismos químicos de transporte de solutos.

\subsection{Coeficiente de dispersão hidrodinâmica: sódio}

Conforme descrito na Seção 4.3.3, o coeficiente de dispersão hidrodinâmica seria obtido por quatro métodos. No entanto, o método proposto por Ogata (1958) e Ogata e Banks (1961), não pôde ser utilizado para determinar o $D_{h}$ de nenhum dos íons estudados nesta pesquisa. Os problemas encontrados no uso deste método são discutidos separadamente na Seção 5.8.

A seguir apresenta-se a obtenção do $D_{h}$ do sódio a partir de cada método separadamente e, posteriormente, os valores de $D_{h}$ obtidos pelos diferentes métodos são mostrados na Tabela 5.13 e então analisados.

\section{Primeiro método:}

Para a utilização do método proposto pro Brigham, Reed e Hunt (1961) e Brigham (1974), primeiro é necessário construir gráficos de U (parâmetro da função erro, Equação 59) 
versus \% de fluido deslocado, conforme detalhado na Seção 2.14.1. As Figuras 5.17, 5.18 e 5.19 mostram esses gráficos obtidos para as três colunas estudadas.

$$
U=\frac{V p-V}{\sqrt{V p}}
$$

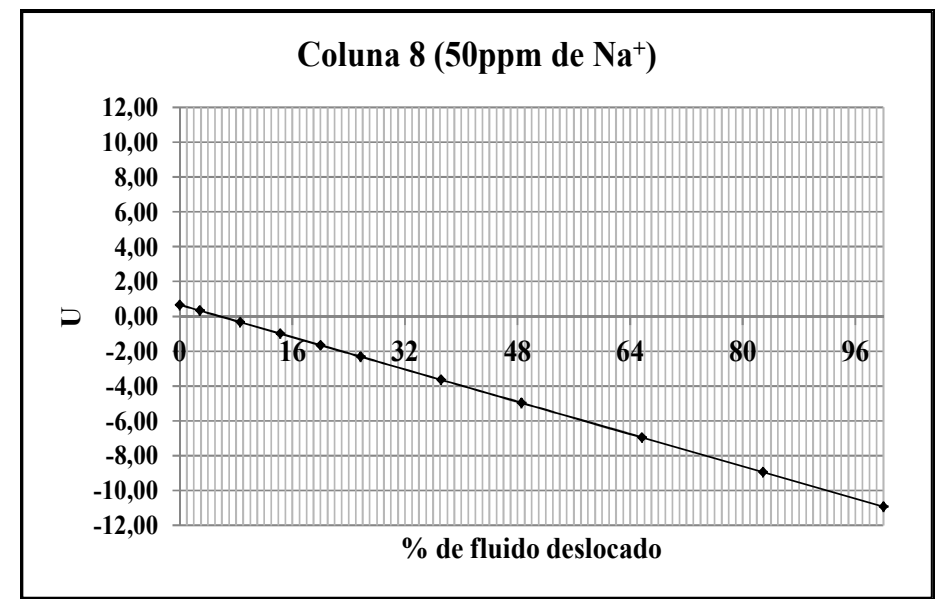

Figura 5.17- Curva U versus \% de fluido percolado para $\mathrm{C}_{0}$ de 50 ppm de sódio

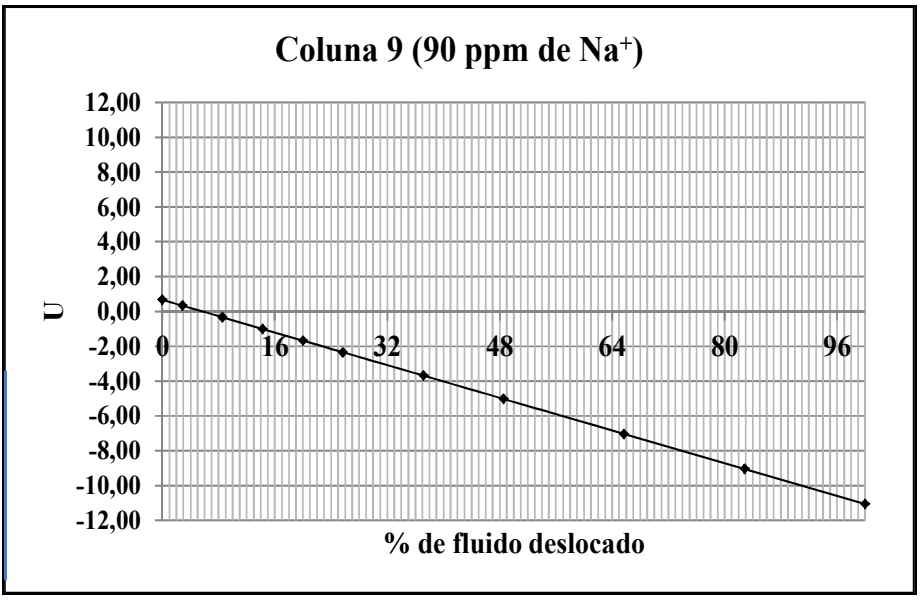

Figura 5.18- Figura 3 Curva U versus \% de fluido percolado para $\mathrm{C}_{0}$ de $90 \mathrm{ppm}$ de sódio 


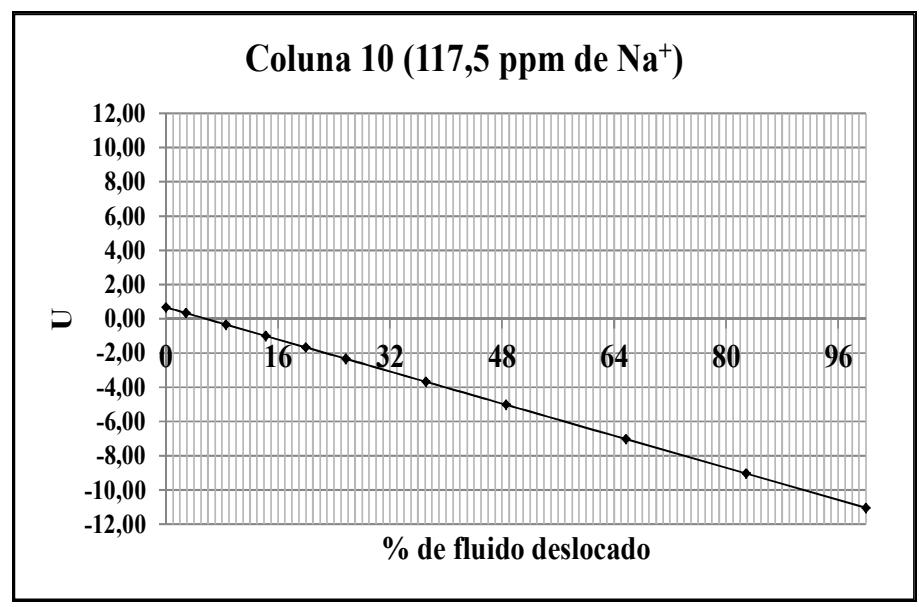

Figura 5.19- Figura 3 Curva U versus $\%$ de fluido percolado para $\mathrm{C}_{0}$ de $117,5 \mathrm{ppm}$ de sódio

Tabela 5.10- Parâmetros $\mathrm{U}_{16}$ e $\mathrm{U}_{84}$ para diferentes colunas percoladas com $\mathrm{NaCl}$

\begin{tabular}{|c|c|c|c|c|c|}
\hline \multicolumn{2}{|c|}{ Coluna $8\left(50{\left.\mathrm{ppm} \mathrm{de} \mathrm{Na}^{+}\right)}^{-}\right.$} & \multicolumn{2}{|c|}{ Coluna 9 (90 ppm de $\mathrm{Na}^{+}$) } & \multicolumn{2}{|c|}{ Coluna $10\left(117,5\right.$ ppm de $\left.\mathrm{Na}^{+}\right)$} \\
\hline $\mathbf{U}_{16}$ & $\overline{\mathbf{U}_{84}}$ & $\mathrm{U}_{16}$ & $\overline{\mathbf{U}_{84}}$ & $\mathrm{U}_{16}$ & $\mathbf{U}_{84}$ \\
\hline$-1,193$ & $-9,080$ & $-1,206$ & $-9,181$ & $-1,204$ & $-9,169$ \\
\hline
\end{tabular}

Os gráficos são praticamente iguais para as três colunas. Isto porque os volumes de poros das colunas são muito parecidos $(0,439,0,449$ e $0,448 \mathrm{~L}$ para as colunas 8,9 e 10 respectivamente). Assim sendo, o $U$ e a $\%$ de fluido deslocado possuem valores muito parecidos para as três colunas. Desta maneira, a diferenças significativas no $D_{h}$ entre as diferentes colunas se dará apenas por diferenças nas velocidades lineares médias. Após a construção dos gráficos, obteve-se o $D_{h}$ para cada coluna a partir da Equação 61 .

$$
D_{h}=v L\left(\frac{U_{84}-U_{16}}{8}\right)^{2}
$$

\section{Segundo método:}

Para obter o $D_{h}$ a partir do método proposto por Singh $(1998 ; 2002)$ é necessário que se determine os parâmetros $t 0$ e $m$ a partir da curva de chegada, conforme descrito na Seção 2.14.1. As Figuras 5.20, 5.21 e 5.22 mostram a obtenção gráfica desses valores e na Tabela 5.11 encontram-se os valores desses parâmetros para as três colunas analisadas. 


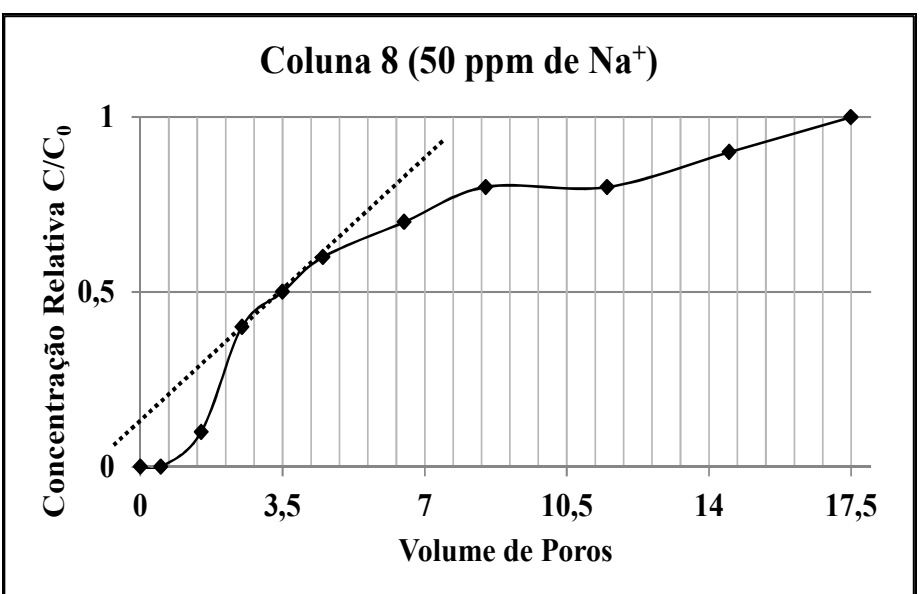

Figura 5.20- Obtenção dos parâmetros $\mathrm{t}_{0} \mathrm{e} \mathrm{m}$ a partir da curva de chegada para $\mathrm{C}_{0}$ de $50 \mathrm{ppm}$ de sódio

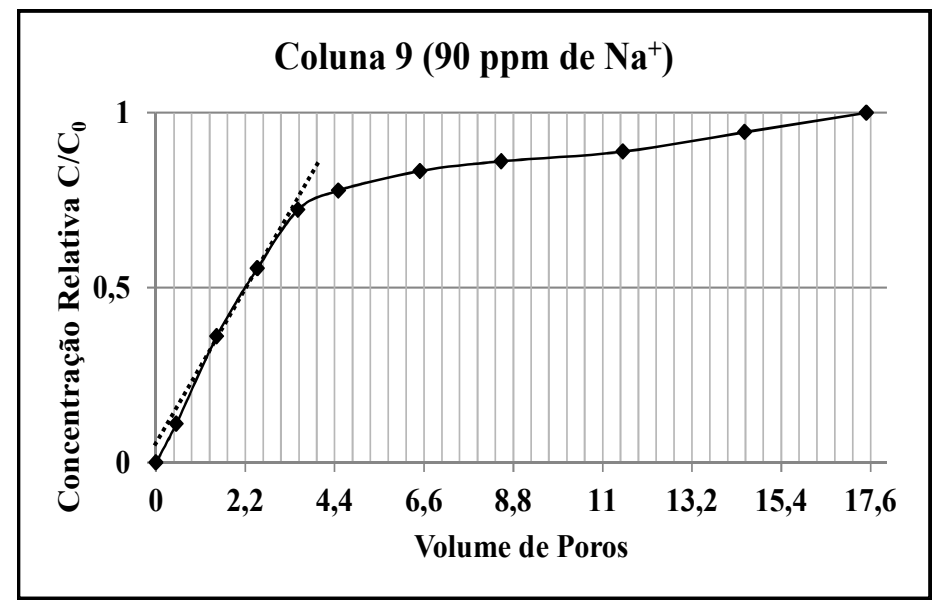

Figura 5.21- Obtenção dos parâmetros $\mathrm{t}_{0}$ e $\mathrm{m}$ a partir da curva de chegada para $\mathrm{C}_{0}$ de 90 ppm de sódio

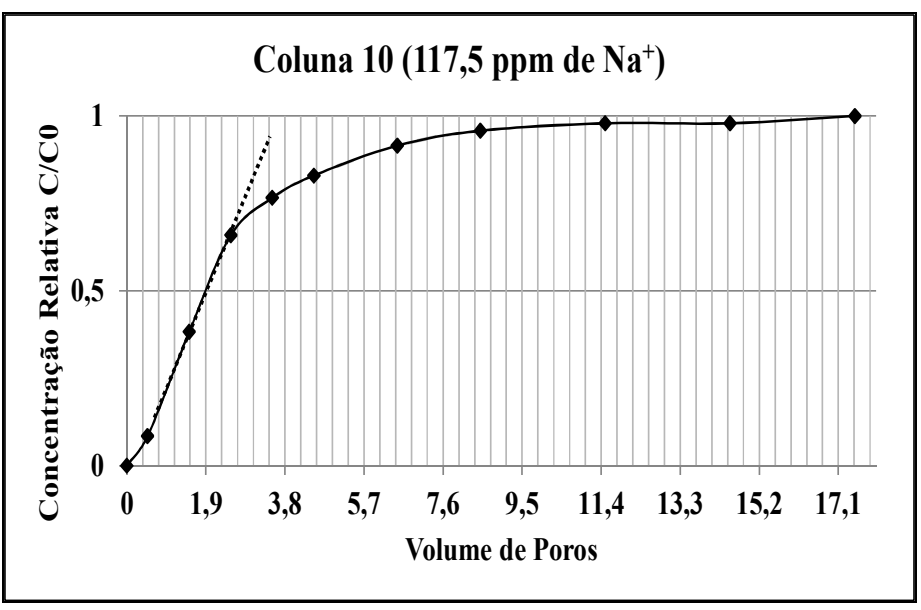

Figura 5.22- Obtenção dos parâmetros $\mathrm{t}_{0} \mathrm{e} \mathrm{m}$ a partir da curva de chegada para $\mathrm{C}_{0}$ de $117,5 \mathrm{ppm}$ de sódio 
Tabela 5.11- Parâmetros $t_{0}$ e $m$ para as colunas percoladas com solução de $\mathrm{NaCl}$

\begin{tabular}{cccccc}
\hline \multicolumn{2}{c}{ Coluna $8\left(50 \mathbf{~ p p m ~ d e ~} \mathrm{Na}^{+}\right)$} & \multicolumn{2}{c}{ Coluna $9\left(90 \mathbf{~ p p m ~ d e ~} \mathbf{N a}^{+}\right)$} & \multicolumn{2}{c}{ Coluna $10\left(117,5 \mathbf{p p m ~ d e ~ N a}^{+}\right)$} \\
\hline $\boldsymbol{t}_{\boldsymbol{0}}(\mathbf{m i n})$ & $\boldsymbol{m}\left(\mathbf{m i n}^{-1}\right)$ & $\boldsymbol{t}_{\boldsymbol{\theta}}(\mathbf{m i n})$ & $\boldsymbol{m}\left(\mathbf{m i n}^{-1}\right)$ & $\boldsymbol{t}_{\boldsymbol{0}}(\mathbf{m i n})$ & $\boldsymbol{m}_{\left(\mathbf{m i n}^{-1}\right)}$ \\
$\mathbf{8 4 , 5 4}$ & 0,100 & 56,17 & 0,194 & 32,99 & 0,276 \\
\hline
\end{tabular}

Após a obtenção dos parâmetros $t_{0}$ e $m$, calculou-se o $D_{h}$ para as três colunas, de acordo com a Equação 55.

$$
D_{h}=\frac{L^{2}}{4 \pi m^{2} t_{0}^{3}}
$$

\section{Terceiro Método:}

Para obtenção do $D_{h}$ pelo método proposto por Bear (1961) foi necessário obter o coeficiente de dispersividade longitudinal, $\alpha_{l}$, com três métodos distintos, previamente mencionados na Seção 2.14.1.

Tabela 5.12- Coeficiente de dispersividade longitudinal

\begin{tabular}{ccc}
\hline \multicolumn{2}{c}{ Coeficiente de Dispersividade Longitudinal (m) } \\
\hline Scheidegger (1963) & Gelhar et al. (1985) & Fetter (1993) \\
$\mathbf{1 , 7 5 E - 0 5}$ & $5,06 \mathrm{E}-06$ & $1,5 \mathrm{E}-2$ \\
\hline
\end{tabular}

Percebe-se que os valores de $\alpha_{l}$ diferem bastante entre os três métodos utilizados e que o $\alpha_{l}$ é extremamente dependente da escala de análise, ou seja, do comprimento do meio estudado, neste caso, do comprimento da coluna. Com isso, no momento de utilizar esse parâmetro em modelagens do transporte de solutos é necessário ter bastante cuidado na escolha do método. Para os ensaios de coluna realizados nesta pesquisa o método proposto por Fetter (1993) se mostra mais adequado por retornar valor de 1,5 cm para o $\alpha_{l}$, que é mais coerente do que os valores obtidos com os outros métodos, pois estão muito menores do que o esperado para coluna de solos arenosos, conforme Freeze e Cherry (1979) e Pickens e Grisak, (1981).

Para o uso do método proposto por Bear (1961) se considerou que o $D^{*}$ era nulo, como sugeriu Singh (1998). Com isso o $D_{h}$ foi calculado por meio da Equação 51.

$$
D_{l}=1,75 d v_{z}+D^{*}
$$


A Tabela 5.13 mostra os resultados dos coeficientes de dispersão hidrodinâmica obtidos com os três métodos utilizados.

Tabela 5.13- Coeficientes de dispersão hidrodinâmica para as colunas percoladas com $\mathrm{NaCl}$

Coeficiente de Dispersão Hidrodinâmica $\left(\mathrm{m}^{2} / \mathrm{min}\right)$

\begin{tabular}{cccc}
\hline Método & $\begin{array}{c}\text { Coluna 8 } \\
\left(\mathbf{5 0} \mathbf{~ p p m ~ d e ~} \mathbf{~ a}^{+}\right)\end{array}$ & $\begin{array}{c}\text { Coluna 9 } \\
\left.\mathbf{( 9 0} \mathbf{~ p p m ~ d e ~} \mathbf{~ N a}^{+}\right)\end{array}$ & $\begin{array}{c}\text { Coluna 10 } \\
\left.\mathbf{( 1 1 7 , 5 ~} \mathbf{~ p p m ~ d e ~} \mathbf{~ a ~}^{+}\right)\end{array}$ \\
Brigham (1974) & $1,91 \mathrm{E}-03$ & $2,24 \mathrm{E}-03$ & $2,82 \mathrm{E}-03$ \\
Singh (1998) & $2,96 \mathrm{E}-07$ & $2,68 \mathrm{E}-07$ & $6,54 \mathrm{E}-07$ \\
Bear (1961) & $1,97 \mathrm{E}-04$ & $2,25 \mathrm{E}-04$ & $2,85 \mathrm{E}-04$ \\
\hline
\end{tabular}

O método proposto por Brigham (1974) foi pensado para colunas curtas de solo arenoso, como as colunas estudadas neste trabalho. Os valores de $D_{h}$ aqui obtidos apresentamse próximos de valores de $D_{h}$ obtidos em outros ensaios de coluna com solo arenoso (SINGH, 2002; OGATA, 1958). Porém, como a equação proposta por Brigham, Reed e Hunt (1961) e depois por Brigham (1974) é baseada em relações empíricas para outros materiais, ela pode não ser representativa do material estudado nesta pesquisa. No entanto, o método proposto por Brigham (1974) leva em consideração que o espalhamento dos solutos no solo está relacionado com o parâmetro $U$ que, por sua vez, tem uma relação direta com a \% de fluido deslocado, como pode ser observado nas Figuras 5.17, 5.18 e 5.19, o que poderia representar bem o mecanismo de dispersão no solo. Além disso, a Equação 61 é baseada na Equação 53 proposta por Ogata (1958) e Ogata e Banks (1961) que, segundo Shackelford (1994), é a que melhor representa o transporte de solutos para as condições de contorno adequadas, como discutido na Seção 2.14.1.

$$
\frac{C}{C_{0}}=\frac{1}{2}\left[\operatorname{erfc}\left(\frac{L-v t}{2 \sqrt{D_{h} t}}\right)+\exp \left(\frac{v L}{D_{h}}\right) \operatorname{erfc}\left(\frac{L+v t}{2 \sqrt{D_{h} t}}\right)\right]
$$

Porém, a Equação 53 pode não ser adequada para obter o $D_{h}$ do $\mathrm{Na}^{+}$quando a advecção está atuando no transporte dos solutos, fazendo com que não fosse possível obter o $D_{h}$ pelo método proposto por Ogata (1958) e Ogata e Banks (1961), que será discutido detalhadamente na Seção 5.8. Outro ponto a ser observado é que os valores de $D_{h}$ para as três colunas analisadas aumentam conforme aumenta a velocidade linear média, já que a diferença 
$U_{16}-U_{84}$ é muito próxima para as três colunas e que os valores de $L$ são iguais para as colunas.

Os valores de $D_{h}$ obtidos com o método proposto por Singh (1998) se apresentaram muito inferiores aos obtidos com os outros métodos. Valores de $D_{h}$ na ordem de 10E-7 $\mathrm{m}^{2} / \mathrm{min}$ indicam que a dispersão hidrodinâmica não deve ser o processo predominante no transporte de $\mathrm{Na}^{+}$, como seria esperado. Essa grande diferença no valor do $D_{h}$ pode estar relacionada ao fato de que este método não utiliza diretamente os valores da velocidade linear média, nem dados de vazão, condutividade hidráulica saturada e porosidade efetiva, podendo ser menos influenciado por erros nesses parâmetros, o que é uma vantagem no uso deste método.

Os parâmetros $m$ e $t_{0}$, obtidos diretamente das curvas de chegada podem ser fortemente influenciados por pequenas mudanças nessas curvas. Por exemplo, a obtenção da concentração relativa em um intervalo de volume de poros que não seja a média de um volume de poro (como aconteceu nesta pesquisa), pode alterar mesmo que levemente o formato da curva e assim alterar os parâmetros $m$ e $t_{0}$, modificando o $D_{h}$. Mais uma vez, é importante destacar que o solo estudado nesta pesquisa é um solo natural, indeformado e com todas as heterogeneidades que podem ser encontradas no meio físico e que a equação proposta por Singh (1998) é baseada em solos homogêneos, com curvas de chegada que segue perfeitamente o formato sigmoide, o que não ocorreu nesta pesquisa.

Os coeficientes de dispersão hidrodinâmica obtidos com o método proposto por Bear (1961) apresentaram relação com a velocidade linear média, sendo que quanto maior esta, maior o $D_{h}$. Este método é bastante usado para a determinação do $D_{h}$, porém é fortemente influenciado pela determinação do $\alpha_{l}$ com todas as dificuldades envolvidas, como discutidas previamente.

Considerando que as colunas de solo estudadas nesta pesquisa possuem grande presença dos macroporos (Figura 5.8 e 5.9) e que eles estão influenciando diretamente os mecanismos de transporte atuantes, acredita-se que a velocidade linear média esteja representando a velocidade do fluxo predominantemente por esses macroporos e que por isso os valores de $D_{h}$ estejam tão divergentes entre os três métodos, principalmente entre aqueles que consideram a velocidade linear média na equação de obtenção do $D_{h}$ (Brigham, 1974 e Bear 1961) e o que não considera (Singh, 1998). 
Por isso, utilizando a Equação 54 para concentração relativa igual a 0,5, realizou-se o caminho contrário, onde, a partir do $D_{h}$, obteve-se a velocidade linear média para verificar se os valores ficariam muito diferentes daqueles medidos no laboratório.

$$
\frac{C}{C_{0}}=\frac{1}{2}\left[\operatorname{erfc}\left(\frac{L-v t}{2 \sqrt{D_{h} t}}\right)\right]
$$

Escolheu-se a concentração relativa igual a 0,5 , por ela ser utilizada no método de Brigham (1974) e Singh (1998) para a obtenção dos parâmetros utilizados no cálculo do $D_{h}$. A Tabela 5.14 mostras os resultados dessa análise.

Tabela 5.14- Velocidades lineares médias obtidas a partir do $D_{h}$ das colunas percoladas com $\mathrm{NaCl}$

Velocidade linear média a partir do $D_{h}(\mathrm{~m} / \mathrm{min})$

\begin{tabular}{|c|c|c|c|}
\hline Método & $\begin{array}{l}\text { Coluna } 8\left(50 \mathrm{ppm} \text { de } \mathrm{Na}^{+}\right) \\
\quad v \text { medida }=1,31 \mathrm{E}-2\end{array}$ & $\begin{array}{l}\text { Coluna } 9\left(90 \text { ppm de } \mathrm{Na}^{+}\right) \\
\qquad v \text { medida }=1,50 \mathrm{E}-2\end{array}$ & $\begin{array}{c}\text { Coluna } 10(117,5 \text { ppm de } \\
\left.\mathrm{Na}^{+}\right) \\
v \text { medida }=1,90 \text { E-2 }\end{array}$ \\
\hline $\begin{array}{c}D_{h} \text { por } \\
\text { Brigham (1974) }\end{array}$ & $-1,27 \mathrm{E}-02$ & $-1,47 \mathrm{E}-02$ & $-1,18 \mathrm{E}-02$ \\
\hline $\begin{array}{c}D_{h} \text { por } \\
\text { Singh (1998) }\end{array}$ & $1,20 \mathrm{E}-02$ & $1,14 \mathrm{E}-02$ & $1,67 \mathrm{E}-02$ \\
\hline $\begin{array}{c}D_{h} \text { por } \\
\text { Bear }(1961)\end{array}$ & $4,32 \mathrm{E}-3$ & $3,36 \mathrm{E}-03$ & $5,79 \mathrm{E}-03$ \\
\hline
\end{tabular}

Percebe-se que utilizando o $D_{h}$ obtido com o método de Brigham (1974) a velocidade linear média resultou em valores negativos. Esses valores negativos indicam que não seria possível obter o $D_{h}$ a partir da Equação 54 utilizando a velocidade linear média calculada dos ensaios de coluna, devido à relação $L-v t$ ser negativa. As velocidades obtidas com o $D_{h}$ a partir do método proposto por Bear (1961) ficaram menores do que a velocidade linear média calculada a partir das médias dos valores de $k$ medidos durante os ensaios de coluna, mas a diferença foi de apenas $10 \%$ o que pode estar dentro de um erro aceitável levando em consideração todas as variabilidades as quais esses ensaios estão sujeitos.

Por outro lado, as velocidades obtidas com o $D_{h}$ do método proposto por Singh (1998) são muito próximas daquelas obtidas com os ensaios de coluna, indicando que o coeficiente de dispersão hidrodinâmica obtido com o método proposto por Singh (1998) está coerente com os dados experimentais obtidos nos ensaios de coluna e que, provavelmente, representa bem a dispersão de $\mathrm{Na}^{+}$que está ocorrendo neste material. Além disso, a velocidade medida em laboratório provavelmente está mais relacionada com a macroporosidade e não está 
representando bem a velocidade linear média nos microporos. Com isso, observa-se que provavelmente o $D_{h}$ mais coerente para esses solos estudados é realmente muito baixo, mostrando que a dispersão não é o principal mecanismo atuante no transporte do $\mathrm{Na}^{+}$, mas sim a advecção.

Para ajudar na análise da possibilidade da existência do fluxo advectivo calculou-se o número de Péclet, $P$, para cada coluna, utilizando os $D_{h}$ obtidos com os três métodos. A análise da Tabela 5.15 mostra que os valores de $D_{h}$ obtidos com o método proposto por Brigham, Reed e Hunt (1974) retornam $\mathrm{P}<1$, indicando que o mecanismo de transporte dominante é a difusão o que não se mostra adequado dadas as características dos solutos e do solo. Isto porque a difusão atua principalmente em solos com $k$ muito pequena e com contaminantes de baixa mobilidade como os metais potencialmente tóxicos.

Tabela 5.15- Número de Péclet para as colunas percoladas com $\mathrm{NaCl}$

\section{Número de Péclet}

\begin{tabular}{|c|c|c|c|}
\hline Método & $\begin{array}{c}\text { Coluna } 8 \\
\left(50 \mathrm{ppm} \text { de } \mathrm{Na}^{+}\right)\end{array}$ & $\begin{array}{c}\text { Coluna } 9 \\
\left(90 \text { ppm de } \mathrm{Na}^{+}\right)\end{array}$ & $\begin{array}{c}\text { Coluna } 10 \\
\left(117,5 \text { ppm de } \mathrm{Na}^{+}\right)\end{array}$ \\
\hline $\begin{array}{c}D_{h} \text { por } \\
\text { Brigham (1974) }\end{array}$ & 1,03 & 1,00 & 1,01 \\
\hline $\begin{array}{c}D_{h} \text { por } \\
\text { Singh }(1998)\end{array}$ & 6646,75 & 8396,72 & 4357,44 \\
\hline $\begin{array}{c}D_{h} \text { por } \\
\text { Bear }(1961)\end{array}$ & 9,99 & 10,00 & 10,00 \\
\hline
\end{tabular}

Utilizando o $D_{h}$ obtido pelo método proposto por Bear (1972) percebe-se que o número de Péclet ficou um pouco mais alto $(P=10)$, porém ainda assim é abaixo do que seria esperado para ensaios de colunas com material arenoso que normalmente possuem $\mathrm{P}>50$, segundo Shackelford (1994). O Péclet obtido a partir do $D_{h}$ calculado pelo método de Singh (1998) resultou em valores acima de 4mil o que é muito alto e indica que existe um regime de alto fluxo em que a advecção predomina sobre a difusão. Isto provavelmente está relacionado a alta velocidade linear média obtida nos ensaios de coluna.

\subsubsection{2. $\quad$ Fator de retardamento: sódio}

Conforme Seção 2.14.2, o fator de retardamento foi obtido por meio de três métodos. A seguir será mostrada a obtenção do $R_{d}$ do $\mathrm{Na}^{+}$a partir de cada método separadamente e, posteriormente, os valores de $R_{d}$ obtidos pelos diferentes métodos são mostrados na Tabela 5.17 e então analisados. 


\section{Primeiro método:}

O primeiro método utilizado foi proposto por van Genuchten e Parker (1984) e o $R_{d}$ é obtido através do cálculo da área acima da curva de chegada, $H$, conforme detalhado na Seção 2.14.2. Assim, quando se assume que a Equação 53 é solução para a Equação 87, utiliza-se a Equação 73 para determinar o $R_{d}$.

$$
\begin{gathered}
\frac{C}{C_{0}}=\frac{1}{2}\left[\operatorname{erfc}\left(\frac{L-v t}{2 \sqrt{D_{h} t}}\right)+\exp \left(\frac{v L}{D_{h}}\right) \operatorname{erfc}\left(\frac{L+v t}{2 \sqrt{D_{h} t}}\right)\right] \\
D_{x} \frac{\partial^{2} C}{\partial x^{2}}-v_{x} \frac{\partial C}{\partial}=\frac{\partial C}{\partial t} \\
H=R_{d}
\end{gathered}
$$

Quando se utiliza a Equação 54 para a solução da Equação 87, o fator de retardamento é obtido pela Equação 74 e, portanto, na Tabela 5.17 também se encontram os resultados desses retardamentos para os diferentes números de Péclet calculados.

$$
\begin{gathered}
\frac{C}{C_{0}}=\frac{1}{2}\left[\operatorname{erfc}\left(\frac{L-v t}{2 \sqrt{D_{h} t}}\right)\right] \\
H=R_{d}\left[1+\left[\frac{1}{P}\right]\right]
\end{gathered}
$$

\section{Segundo método:}

No segundo método utilizado, proposto por Freeze e Cherry (1979) e Shackelford (1993;1994), o $R_{d}$ é igual ao número de volume de poros quando a concentração relativa é igual a 0,5 . As Figuras 5.23, 5.24 e 5.25 mostram a obtenção do $R_{d}$ por este método. 


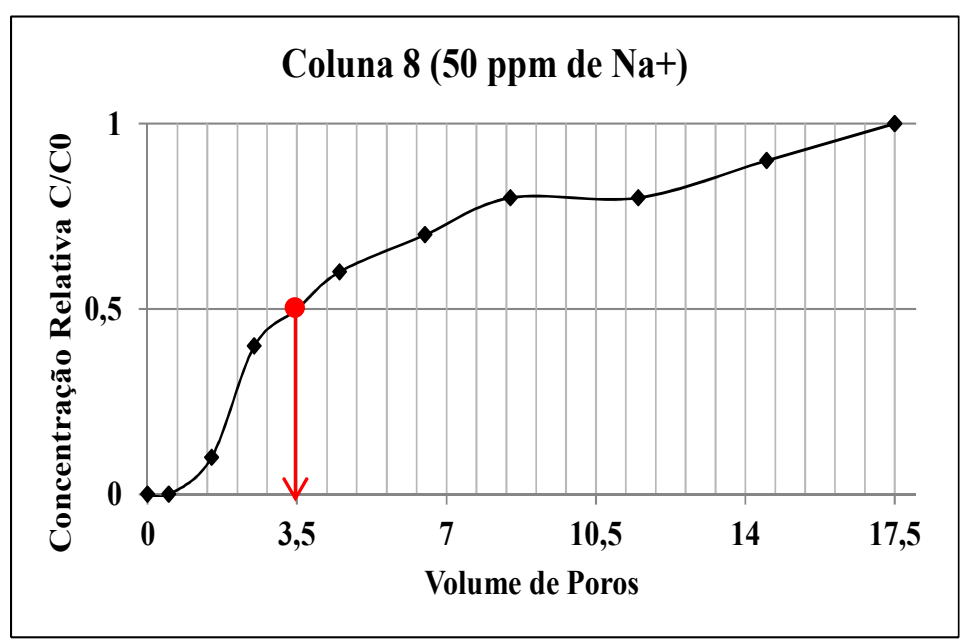

Figura 5.23- Obtenção do fator de retardamento pelo método de Freeze e Cherry (1979) e Shackelford $(1993 ; 1994)$ para $\mathrm{C}_{0}$ de 50 ppm de sódio

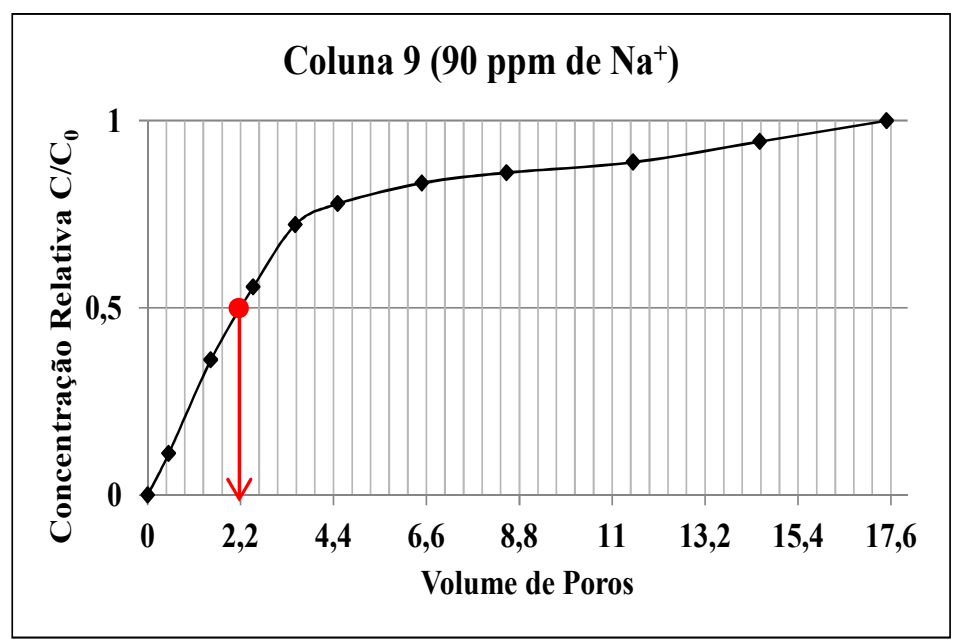

Figura 5.24- Obtenção do fator de retardamento pelo método de Freeze e Cherry (1979) e Shackelford $(1993 ; 1994)$ para $C_{0}$ de 90 ppm de sódio

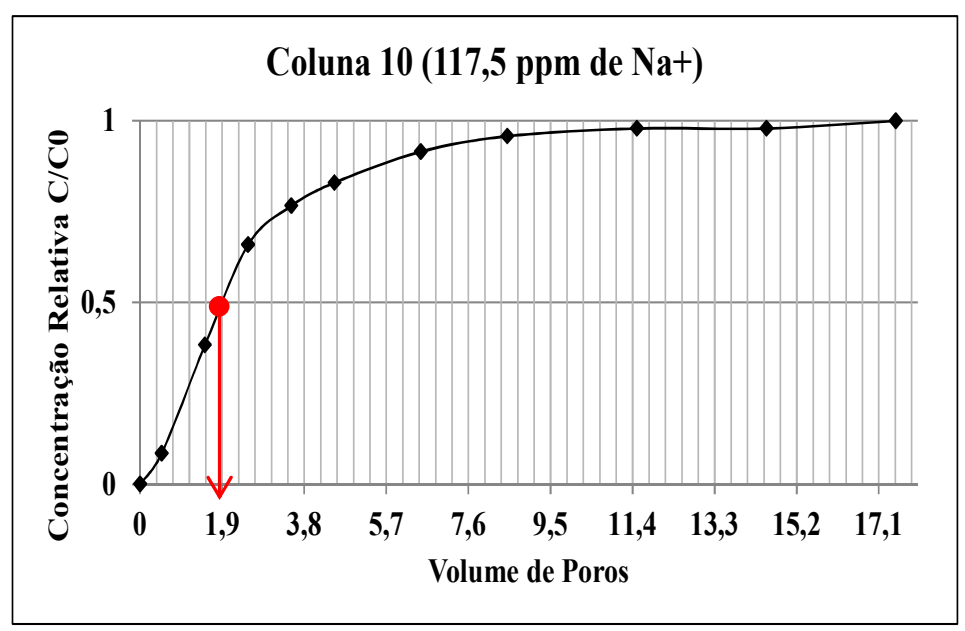

Figura 5.25- Obtenção do fator de retardamento pelo método de Freeze e Cherry (1979) e Shackelford $(1993 ; 1994)$ para $C_{0}$ de 117,5 ppm de sódio

\section{Terceiro método:}


O terceiro método utilizado permitiu a obtenção do $R_{d}$ por meio da construção da isoterma de sorção para o $\mathrm{Na}^{+}$(Figura 5.26)

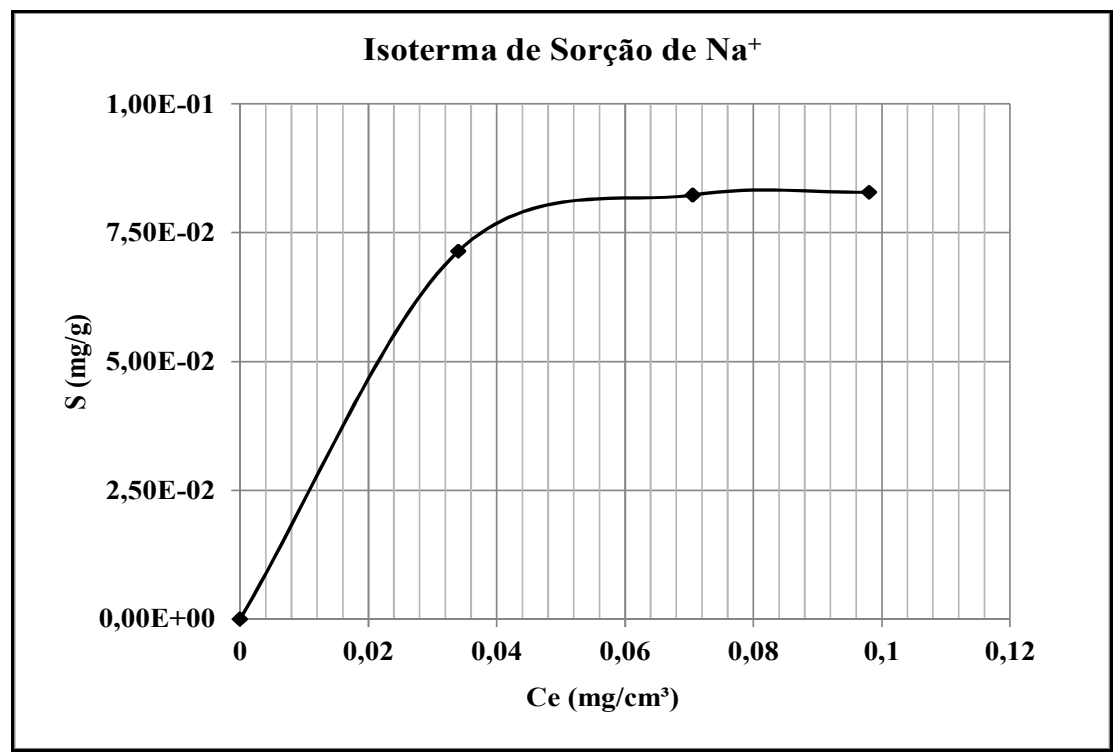

Figura 5.26- Isoterma de sorção de sódio

Com a isoterma construída, realizaram-se os procedimentos de linearização para verificar qual a isoterma melhor se ajustava aos dados experimentais (Figuras 5.27, 5.28, 5.29 e 5.29).

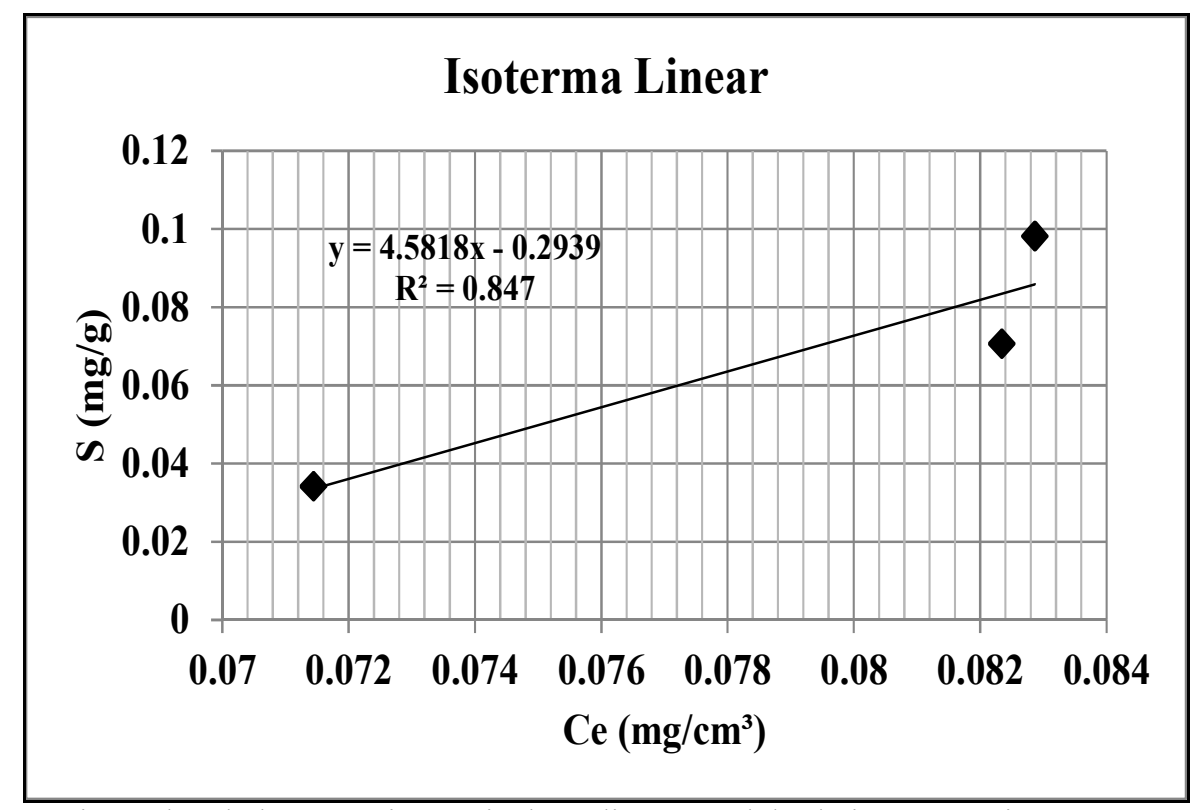

Figura 5.27- Ajuste dos dados experimentais de sódio ao modelo de isoterma Linear 


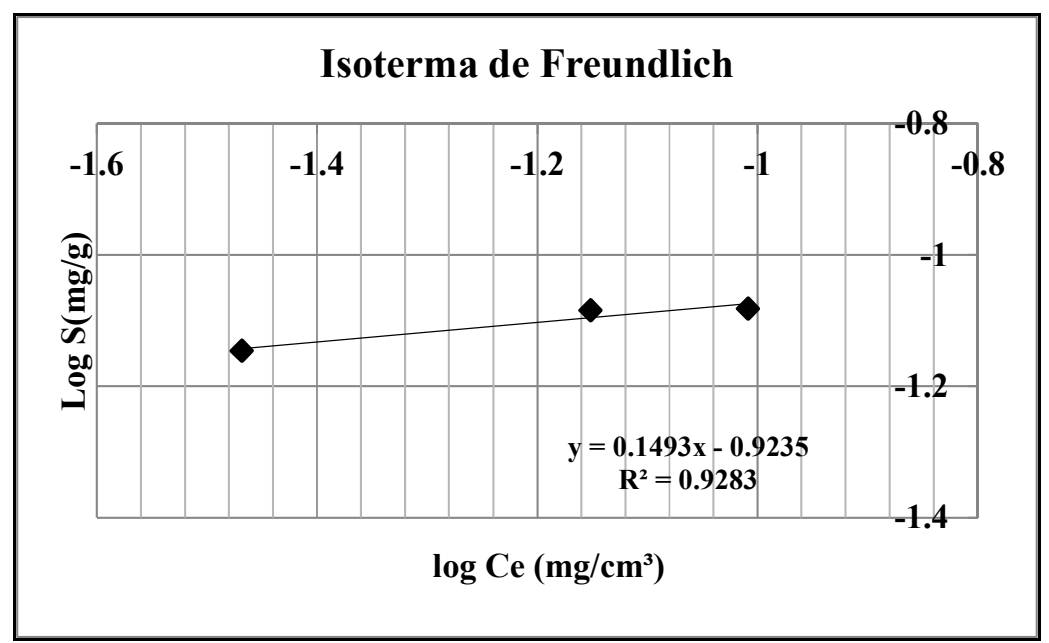

Figura 5.28- Ajuste dos dados experimentais de sódio ao modelo de isoterma de Freundlich

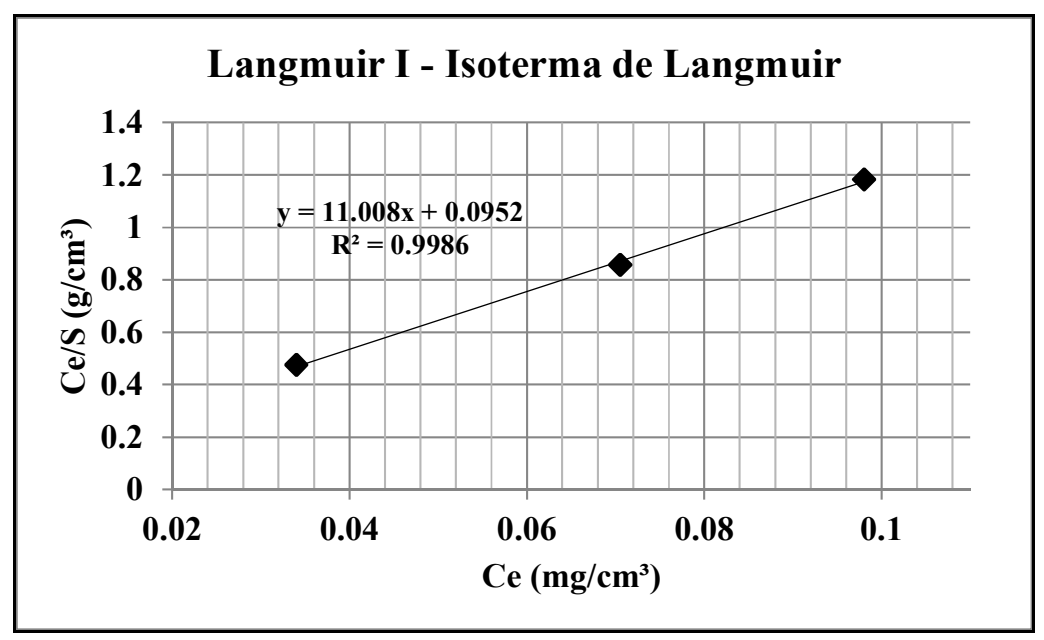

Figura 5.29- Ajuste dos dados experimentais de sódio ao modelo de Langmuir (Langmuir I)

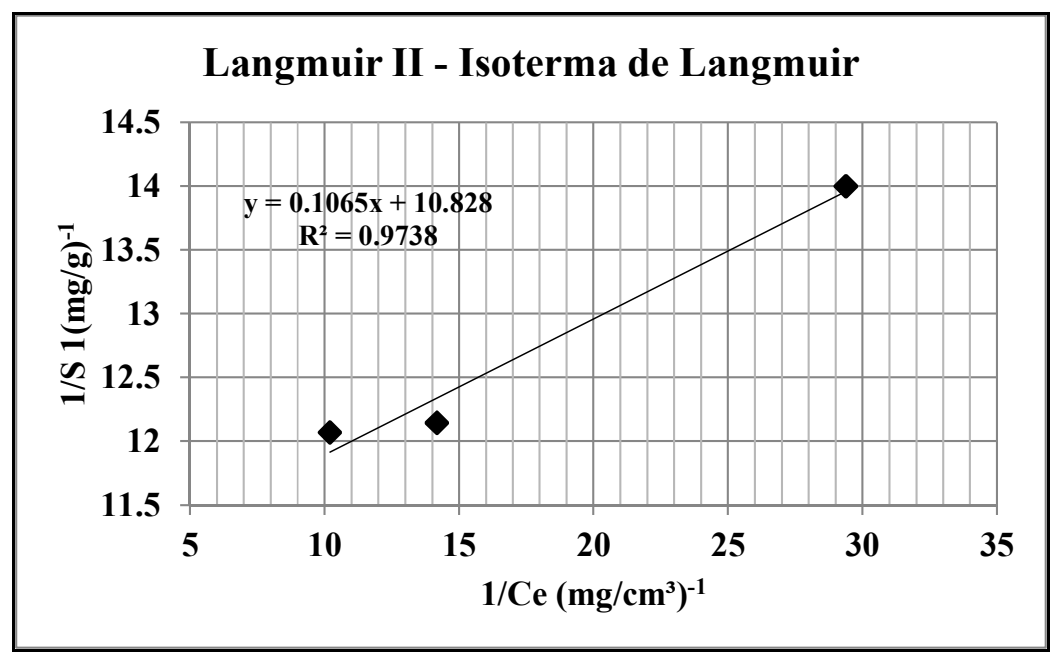

Figura 5.30- Ajuste dos dados experimentais de sódio ao modelo de Langmuir (Langmuir II) 
A Tabela 5.16 mostra os coeficientes de determinação para cada um dos ajustes realizados.

Tabela 5.16- Coeficientes de determinação para ajuste dos modelos das isotermas

\begin{tabular}{cc}
\hline Modelo & $\begin{array}{c}\text { Coeficiente de Determinação } \\
\mathbf{R}^{2}\end{array}$ \\
Linear & 0,8470 \\
Freundlich & 0,9283 \\
Langmuir I & 0,9986 \\
Langmuir II & 0,9738 \\
Langmuir por regressão não & \\
linear & \\
\hline
\end{tabular}

1 regressão não linear feita por meio do software comercial Mathematica 9.0 da Wolfram Research

Como todos os modelos mostraram bons ajustes com os dados experimentais, obtiveram-se os fatores de retardamento para todos os modelos ajustados.

A Tabela 5.17 mostra os resultados dos fatores de retardamento obtidos com os três métodos utilizados.

Os valores de retardamento obtidos com o método de van Genuchten e Parker (1984) para a situação em que a área acima da curva de chegada é igual ao $R_{d}$ são muito próximos daqueles obtidos a partir da Equação 74, exceto para a situação em que no cálculo do número de Péclet foi considerado o $D_{h}$ obtido pelo método de Brigham (1974).

$$
H=R_{d}\left[1+\left[\frac{1}{P}\right]\right]
$$

Isto indica mais uma vez que o $D_{h}$ obtido com o método proposto por Brigham (1974) provavelmente não representa bem a dispersão de $\mathrm{Na}^{+}$no solo estudado devido as limitações abordadas anteriormente. Os $R_{d}$ obtidos a partir do $D_{h}$ calculado com o método proposto por Singh (1998) são praticamente iguais à área acima da curva de chegada, o que indica que neste método o balanço de massa esta sendo considerado adequadamente, e que a Equação 54 provavelmente seria a mais adequada para analisar o transporte de $\mathrm{Na}^{+}$no solo desta pesquisa. 


$$
\frac{C}{C_{0}}=\frac{1}{2}\left[\operatorname{erfc}\left(\frac{L-v t}{2 \sqrt{D_{h} t}}\right)\right]
$$

Percebe-se que os valores de retardamentos guardam uma tendência no que diz respeito à concentração inicial da solução, sendo que quanto maior a concentração inicial, menor será o $R_{d}$. Isto pode ser justificado pelo fato de que, para um mesmo solo, quanto maior a concentração do contaminante, maior será a quantidade de soluto que não será retido, assumindo que os sítios de sorção serão os mesmo e que eles serão ocupados por uma quantidade fixa de soluto. Assim, quanto mais soluto se adiciona, mais soluto ficará livre na solução do solo e será, então, constatada na solução efluente da coluna de solo.

Tabela 5.17- Valores de fatores de retardamento de $\mathrm{Na}^{+}$obtidos com diferentes métodos

Fator de Retardamento de $\mathrm{Na}^{+}$

\begin{tabular}{|c|c|c|c|c|}
\hline Método & $\begin{array}{c}\text { Coluna } 8 \\
\left(50 \mathrm{ppm} \mathrm{de} \mathrm{Na}^{+}\right)\end{array}$ & $\begin{array}{c}\text { Coluna } 9 \\
(90 \mathrm{ppm} \text { de } \\
\left.\mathrm{Na}^{+}\right)\end{array}$ & $\begin{array}{c}\text { Coluna } 10 \\
(117,5 \text { ppm de } \\
\left.\mathrm{Na}^{+}\right)\end{array}$ & Média \\
\hline $\begin{array}{c}\text { van Genuchten e Parker (1984) } \\
\text { H = Rd }\end{array}$ & 5,60 & 3,79 & 2,74 & 4,04 \\
\hline $\begin{array}{c}\text { van Genuchten e Parker (1984) } \\
\text { H = Rd }[1+(1 / P)](\text { P com Dh de } \\
\text { Brigham, 1974) }\end{array}$ & 2,84 & 1,89 & 1,37 & 2,04 \\
\hline $\begin{array}{c}\text { van Genuchten e Parker (1984) } \\
\text { H = Rd [1+(1/P)] (P com Dh de } \\
\text { Singh, 1998) }\end{array}$ & 5,59 & 3,79 & 2,73 & 4,04 \\
\hline $\begin{array}{c}\text { van Genuchten e Parker (1984) } \\
\text { H = Rd [1+(1/P)] (P com Dh de } \\
\text { Bear 1961) }\end{array}$ & 5,09 & 3,45 & 2,49 & 3,68 \\
\hline $\begin{array}{l}\text { Freeze e Cherry }(1979) \text { e } \\
\text { Shackelford }(1993 ; 1994)\end{array}$ & 3,50 & 2,20 & 1,90 & 2,53 \\
\hline Isoterma Linear & \multicolumn{4}{|c|}{8,37} \\
\hline Freundlich & \multicolumn{4}{|c|}{4,46} \\
\hline Langmuir I & \multicolumn{4}{|c|}{4,42} \\
\hline Langmuir II & \multicolumn{4}{|c|}{4,44} \\
\hline Langmuir Não Linear & \multicolumn{4}{|c|}{4,45} \\
\hline
\end{tabular}


Os retardamentos obtidos com os ajustes das isotermas são muito próximos entre si, exceto aquele obtido para a isoterma linear, mostrando que o comportamento do solo provavelmente não é de sorção infinita de $\mathrm{Na}^{+}$, como o esperado. Observa-se que os valores de retardamento não estão muito altos e indicam que o retardamento que está ocorrendo provavelmente não se relaciona à fenômenos químicos, mas sim devido a mecanismos físicos devido a presença de poros não conectados que dificultam a saída do sódio. Observando a Tabela 5.2 (características físico-químicas do material), nota-se que o máximo $S(0,08287$ $\mathrm{mg} / \mathrm{g})$ para a isoterma de sorção de $\mathrm{Na}^{+}$é maior do que a CTC do solo $(0,00152 \mathrm{mg} / \mathrm{g})$ o que indica que a retenção dos solutos neste solo não está ocorrendo por troca catiônica, mas sim por mecanismos físicos.

A despeito disso, os dados experimentais se mostram muito bem ajustados aos modelos das isotermas, indicando que este provavelmente foi um método que forneceu valores de $R_{d}$ de sódio aceitáveis para este material. Outra observação a ser feita é que a média dos valores de $R_{d}$ calculados pelo método de van Genuchten e Parker (1984), estão muito próximas dos valores de retardamento obtidos com os ajustes das isotermas, levando a considerar que os métodos, apesar de serem diferentes em seu modelo conceitual, podem retornar resultados muito próximos. No entanto, a obtenção do $R_{d}$ a partir das isotermas fornece um único valor de $R_{d}$ médio para o solo, o que pode subestimar ou superestimar esse valor na modelagem do transporte de solutos.

O método proposto por Freeze e Cherry (1979) e Shackelford (1994) assume que a sorção no material obedece a uma isoterma linear. Como provavelmente não é o que acontece neste solo, como pode ser visto com o ajuste das isotermas, os retardamentos obtidos com este método estão muito abaixo dos outros valores de retardamento. Portanto, por considerar que normalmente a sorção nos materiais tem um limite, os valores de $R_{d}$ obtidos com os ajustes das isotermas de Langmuir provavelmente melhor representam o comportamento de retardamento deste solo.

Os retardamentos de sódio obtidos nesta pesquisa apresentam-se superiores àqueles obtidos em outros estudos (SANTOS; LIMA; BORGES JÚNIOR, 2010; MELO et al., 2006). De acordo com Jury, Gardner e Gardner (1991), valores de retardamento acima de 3 indicam alta interação solo-soluto, demonstrando que o íon é muito reativo. No entanto, acredita-se que o sódio está sendo retido no solo e que este retardamento provavelmente não se relaciona a fenômenos de interação química, mas sim devido à fenômenos físicos pelo atraso da 
velocidade linear do sódio em relação à velocidade da água condicionado pelas características de dupla porosidade deste solo.

\subsubsection{PERCOLAÇÃO de FOSFATO DE AMÔNIO $\left(\mathrm{NH}_{4}\right)_{2} \mathrm{HPO}_{4}$}

\subsubsection{Análise do ensaio de coluna}

Durante a percolação das soluções de $\left(\mathrm{NH}_{4}\right)_{2} \mathrm{HPO}_{4}$ monitoraram-se $\mathrm{o} \quad \mathrm{pH}$ a condutividade elétrica e a temperatura das amostras efluentes. As Figuras 5.31, 5.32 e 5.33 mostram os resultados desses monitoramentos. Verifica-se que o $\mathrm{pH}$ variou de 7,0 a 7,6 durante toda a duração dos ensaios e que o valor do $\mathrm{pH}$ das soluções efluentes no início do ensaio estava mais alto, quando comparado com os valores de $\mathrm{pH}$ das concentrações iniciais (Tabela 5.9). No entanto, percebe-se que com o decorrer do ensaio, para as três concentrações, os valores de $\mathrm{pH}$ diminuem até alcançarem um certo equilíbrio no final dos ensaios. Após a lavagem das colunas com água destilada, nota-se que houve pouca variação do $\mathrm{pH}$ das soluções efluentes, mas com leve tendência a aumento de 7,15 para 7,30, em média.

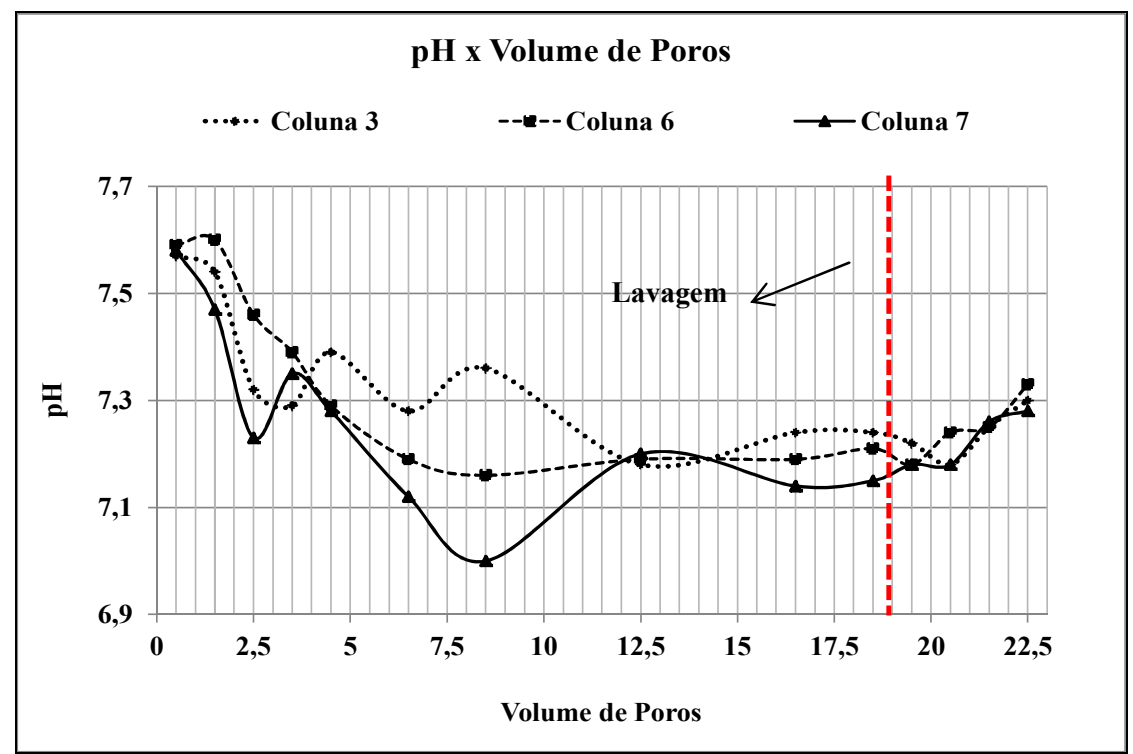

Figura 5.31- Valores de $\mathrm{pH}$ versus volume de poros durante percolação de $\left(\mathrm{NH}_{4}\right)_{2} \mathrm{HPO}_{4}$

O gráfico de condutividade elétrica versus o volume de poros (Figura 5.31) mostra que no início do ensaio a condutividade elétrica oscilou bastante entre as três colunas. Além disso, em 1,5 volumes de poros percebe-se que a condutividade elétrica já indicava a presença de íons em solução, ainda que os valores não aumentassem muito. Isto pode indicar que as soluções estavam saindo da coluna de solo, mas não tão rápido quanto ocorreu após 5 
volumes de poros, o que pode ser confirmado com a observação da curva de chegada (Figura 5.34).

A partir de 6,5 volumes de poros percebe-se que a condutividade elétrica cresce em todas as colunas, sendo que quanto maior a concentração inicial maiores são as condutividades elétricas, em decorrência do aumento da quantidade de íons solúveis em solução. Ao final do ensaio as C.E. estavam menores do que os valores das C.E das concentrações iniciais, como pode ser observado na Tabela 5.9, o que pode ser explicado por uma redução na concentração dos íons $\mathrm{H}_{2} \mathrm{PO}^{-}$e de $\mathrm{NH}_{4}{ }^{+}$em solução, quando comparada com a concentração na desses íons na solução inicial, devido suas reações com os componentes do solo. Após a lavagem das colunas com água destilada, nota-se que no primeiro volume de poros há aumento da condutividade elétrica, devido à lavagem dos íons que ainda estavam na coluna. Após o segundo volume de poros de água destilada, nota-se que houve redução da condutividade elétrica, mas os valores da coluna 7 não chegaram próximo das C.E. iniciais do ensaio, indicando que ainda havia íons em solução.

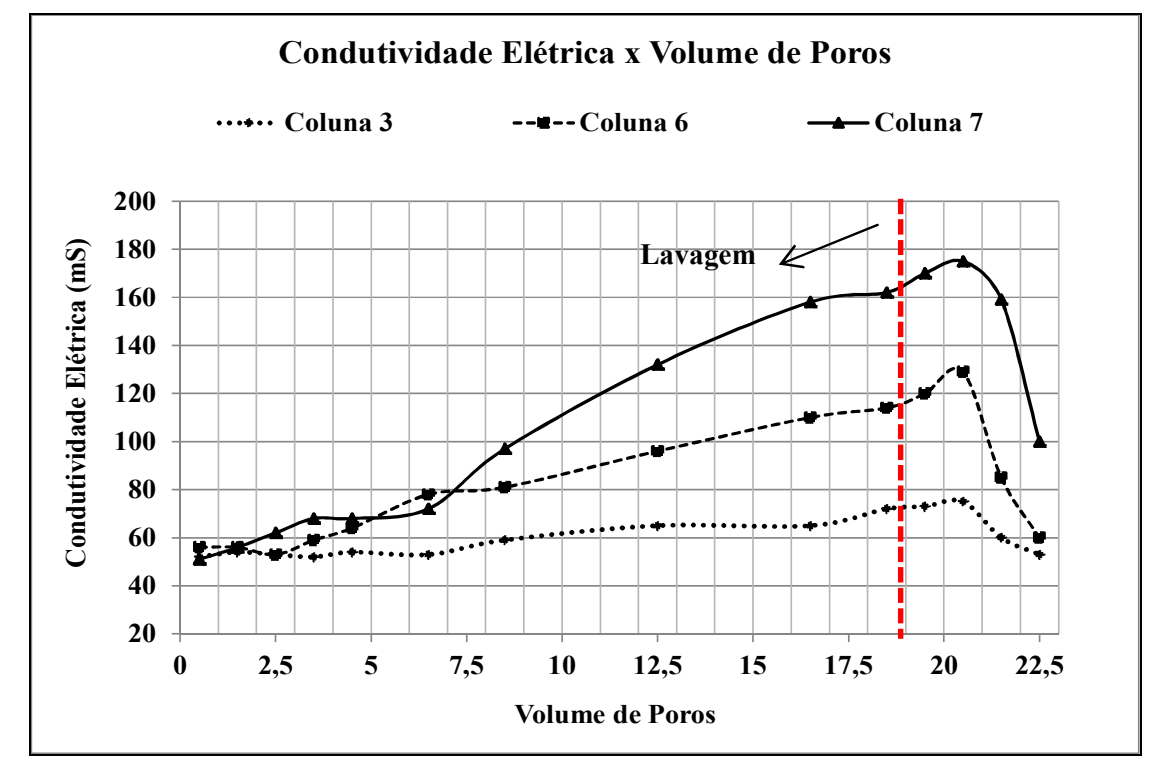

Figura 5.32- Valores de condutividade elétrica versus volume de poros durante percolação de $\left(\mathrm{NH}_{4}\right)_{2} \mathrm{HPO}_{4}$

Em relação à temperatura, percebe-se que houve pouca oscilação durante o ensaio (Figura 5.31). Essas oscilações podem estar relacionadas com a condutividade hidráulica de cada coluna (Tabela 5.7) o que fez com que as amostras efluentes fossem coletadas em diferentes períodos de tempo e, portanto, em diferentes temperaturas ambientes. Apesar dessas oscilações, percebe-se que durante todo o ensaio a temperatura das soluções efluentes 
variou de 22,5 a $23,5^{\circ} \mathrm{C}$. Após a lavagem com água destilada, nota-se que as temperaturas se estabilizaram em $23^{\circ} \mathrm{C}$ em todas as colunas.

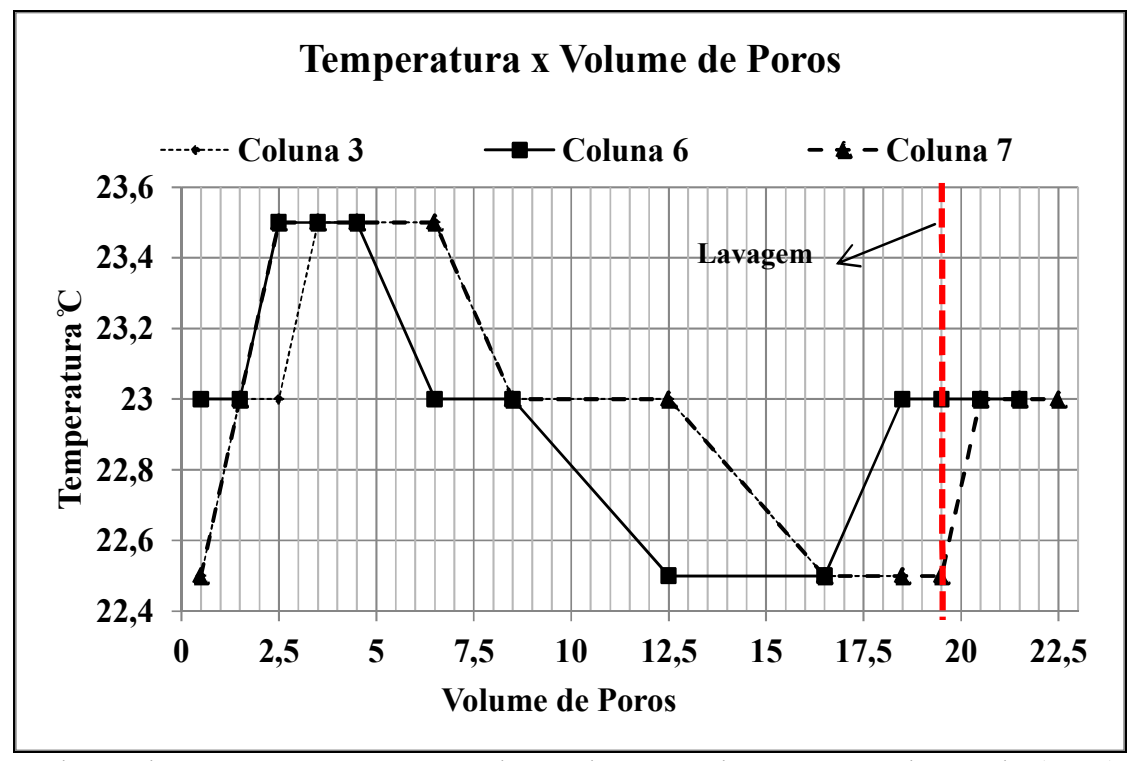

Figura 5.33- Valores de temperatura versus volume de poros durante percolação de $\left(\mathrm{NH}_{4}\right)_{2} \mathrm{HPO}_{4}$

\subsubsection{Curva de chegada de fosfato}

Foram percolados 19,5 volumes de poros, mas as soluções efluentes provenientes das colunas 6 e 7 atingiram o equilíbrio em 15,5 e 12,5 volumes de poros, respectivamente, indicando que o retardamento nessas colunas foi menor. A partir de 1,0 volumes de poros começou-se a constatar a presença de fosfato nas soluções efluente, indicando que a movimentação deste ânion nas colunas de solo estava ocorrendo de maneira rápida provavelmente por caminhos preferenciais. Até 2,0 volumes de poros há oscilação nos valores da concentração relativa sem um padrão entre as três curvas. Após 2,5 volumes de poros notase um crescente aumento na concentração relativa com o passar da percolação. Este aumento é mais rápido na coluna que percolou a solução com maior concentração (Coluna 7) e mais lento na coluna pela qual percolou a solução com menor concentração (Coluna 3), tendo a Coluna 6 valores intermediários. Isto significa que quanto maior a concentração da solução inicial, mais rápido ele é detectado na solução efluente Isto pode ser justificado pelo fato de que, para um mesmo solo, quanto maior a concentração da solução inicial, maior será a quantidade de soluto que não será retido, visto que. os sítios de sorção serão os mesmo e que eles serão ocupados por uma quantidade fixa de soluto. Após a lavagem com água destilada, nota-se lenta redução das concentrações relativas, indicando que o fosfato realmente estava 
sendo retido pelo solo. A Figura 5.32 ilustra as curvas de chegada obtidas para as três concentrações de $\mathrm{PO}_{4}{ }^{3-}$.

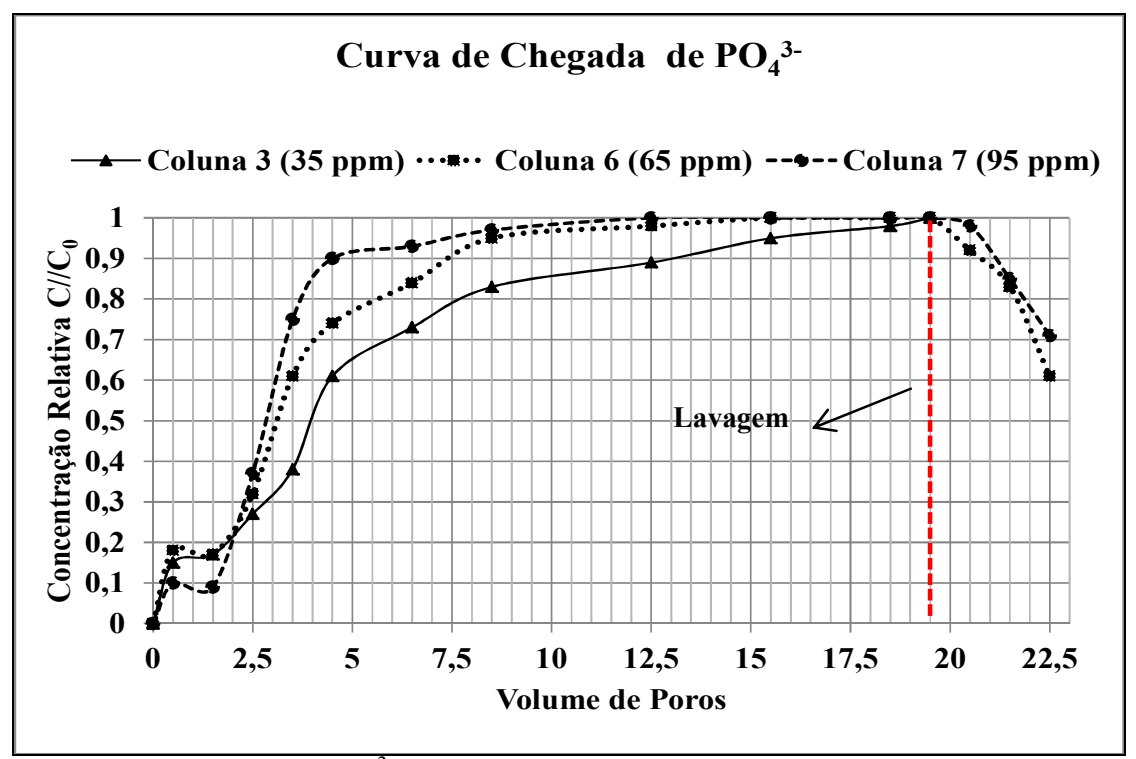

Figura 5.34- Curva de chegada de $\mathrm{PO}_{4}{ }^{3-}$

As curvas de chegada indicam que apesar de parte do fosfato estar se movimentando por advecção, parte está sendo retido pelo solo, seja por mecanismos físicos ou químicos. Por se tratar de um solo carregado negativamente, indicado pelo PCZ e $\Delta \mathrm{pH}$ negativos (Tabela 5.2), não era esperada uma retenção do fosfato por mecanismos de adsorção não específica. Contudo, como pôde ser verificado na análise de EDS, neste solo existe grande quantidade de alumínio, oxigênio e, em menor quantidade, ferro que em $\mathrm{pH}$ ácido, como o pH do solo estudado, podem reagir com o fosfato e formar compostos insolúveis por mecanismos de adsorção específica (HAVLIN, ET AL., 2005; KHASAWNEH et al., 1980; PARFITT, et al., 1997). Além disso, a análise de DRX indicou a presenta de caulinita e outros minerais que possuem grupos $\mathrm{AlOHH}_{2} \mathrm{O}$ aos quais os fosfatos se ligam, ficando adsorvidos na superfície desses minerais.

Para constatar se o fosfato realmente ficou retido na matriz do solo, depois da percolação da solução de $\left(\mathrm{NH}_{4}\right)_{2} \mathrm{HPO}_{4}$ analisou-se o solo para verificar se houve aumento da quantidade de fosforo no mesmo. A Figura 5.35 mostra o resultado da análise de EDS após a percolação de $\left(\mathrm{NH}_{4}\right)_{2} \mathrm{HPO}_{4}$ e a Tabela 5.18 mostras os resultados das porcentagens dos elementos presentes no solo. Percebe-se que houve aumento de $82 \%$ na quantidade de $\mathrm{P}$ presente no solo, indicando que este composto realmente ficou retido na matriz do solo. Analisando a Tabela 5.18 verifica-se que houve aumento na quantidade de ferro e redução na 
quantidade oxigênio e alumínio. Isto pode estar relacionado às variações naturais devido a heterogeneidades dos solos, ou, no caso do oxigênio às reações com $\mathrm{NH}_{4}{ }^{+}$, que formam moléculas de água e que, portanto, retiram o oxigênio do solo.

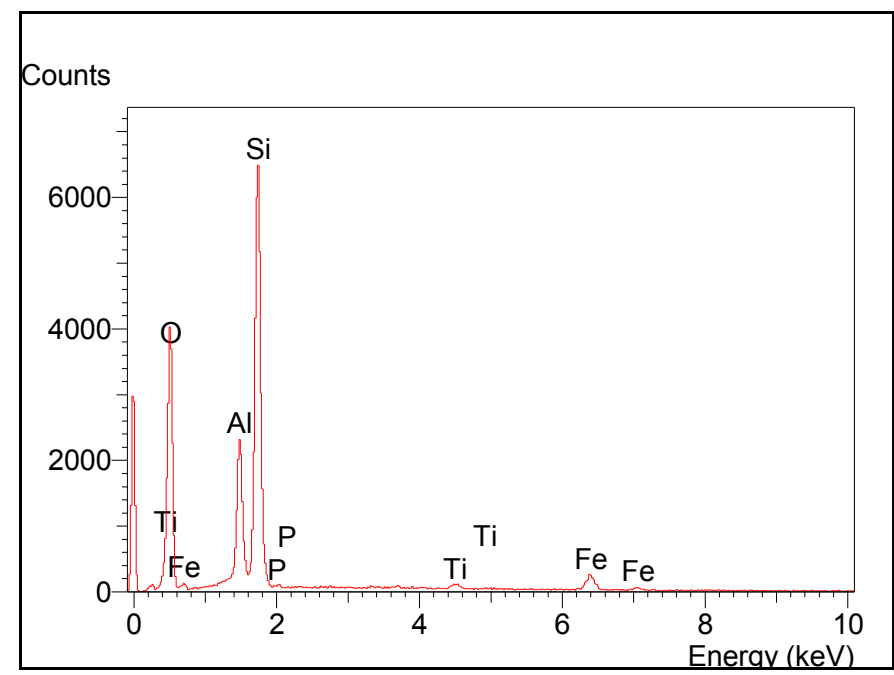

Figura 5.35- Gráfico de EDS após percolação de $\left(\mathrm{NH}_{4}\right)_{2} \mathrm{HPO}_{4}$

Tabela 5.18- Porcentagem dos elementos químicos no solo pelo EDS (antes e após percolação $\left.\operatorname{com}\left(\mathrm{NH}_{4}\right)_{2} \mathrm{HPO}_{4}\right)$

Antes da Percolação de $\left(\mathrm{NH}_{4}\right)_{2} \mathrm{HPO}_{4}$

\begin{tabular}{|c|c|c|c|c|c|c|c|}
\hline Elemento & $\mathbf{O}$ & Al & $\mathbf{S i}$ & $\mathbf{P}$ & $\mathbf{T i}$ & $\mathbf{F e}$ & Total \\
\hline$\%$ & 62,22 & 10,19 & 24,71 & 0,16 & 0,46 & 2,26 & 100 \\
\hline \multicolumn{8}{|c|}{ Após a Percolação de $\left(\mathrm{NH}_{4}\right)_{2} \mathrm{HPO}_{4}$} \\
\hline Elemento & O & Al & $\mathbf{S i}$ & $\mathbf{P}$ & $\mathbf{T i}$ & $\mathbf{F e}$ & Total \\
\hline$\%$ & 58,87 & 8,89 & 27,72 & 0,29 & 0,70 & 2,78 & 100 \\
\hline
\end{tabular}

Para verificar se após a passagem das soluções de $\left(\mathrm{NH}_{4}\right)_{2} \mathrm{HPO}_{4}$ realmente se formaram minerais constituídos por fosfato, ferro, oxigênio e alumínio, realizou-se difrações de raios $\mathrm{X}$ em amostras do solo. A Figura 5.36 mostra os resultados da DRX após a percolação das soluções de $\left(\mathrm{NH}_{4}\right)_{2} \mathrm{HPO}_{4}$. Comparando com as difrações realizadas antes da percolação das soluções (Figura 5.1), constata-se que os mesmos minerais estiveram presentes. Minerais de fósforo não foram identificados. Apesar disso, o fosfato pode ter se ligado às formas não cristalinas do ferro, que são fortes adsorventes, fazendo com que ele continuasse presente no solo. 
Figura 5.36- DRX

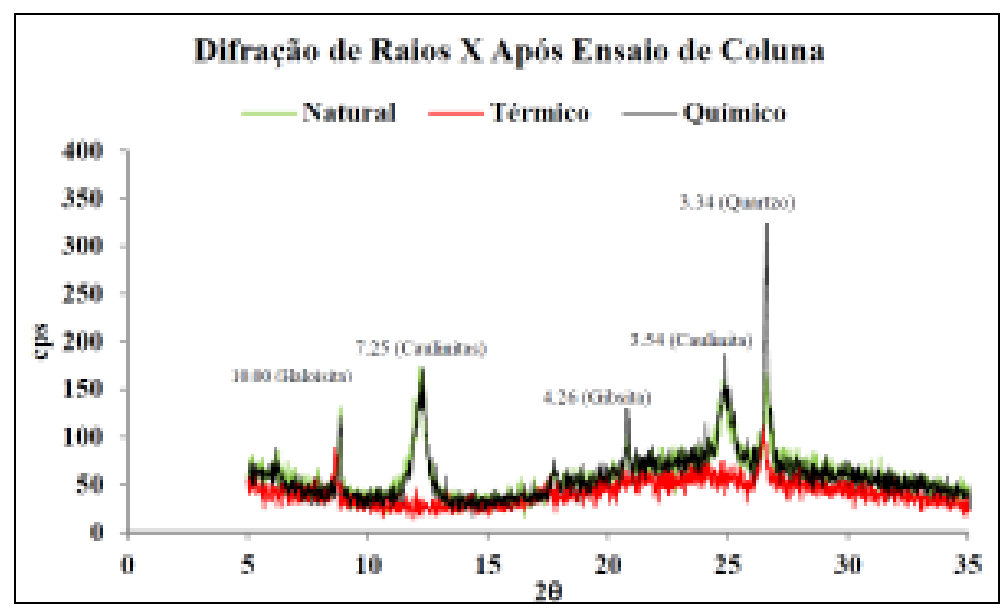

Em relação aos mecanismos físicos, pode estar ocorrendo retardamento na velocidade de percolação do fosfato devido à dupla porosidade presente neste material (Figuras 5.8 e 5.9). Com isso, parte dos solutos pode estar saindo da coluna de solo devido à advecção, preferencialmente pelos macroporos, e parte pode estar sendo retardada devido à passagem pelos microporos que, muitas vezes, podem não ser interconectados, fazendo com que o íon não saia da coluna de solo durante todo o ensaio. A despeito disso, quando o fosfato percola pelos microporos há um maior contato do ânion com o solo, favorecendo as reações de adsorção específica e aumentando o retardamento deste íon. A presença de caminhos preferenciais foi constata pela análise da trajetória dos solutos, apresentada na Seção 5.9.

\subsection{Coeficiente de dispersão hidrodinâmica: fosfato}

Os valores do coeficiente de dispersão para o $\mathrm{PO}_{4}{ }^{3-}$ também foram obtidos por três métodos, pois o método proposto por Ogata (1958) e Ogata e Banks (1961) não se mostrou adequado, como discutido na Seção 5.7.1.2.3 . As dificuldades encontradas no uso deste método encontra-se detalhadas na Seção 5.8 .

A seguir será mostrada a obtenção do $D_{h}$ a partir de cada método separadamente e, posteriormente, os valores de $D_{h}$ obtidos pelos diferentes métodos são mostrados na Tabela 5.21 e então analisados.

\section{Primeiro método:}

Para a utilização do método proposto pro Brigham, Reed e Hunt (1961) e Brigham (1974), primeiro é necessário construir gráficos de U versus \% de fluido deslocado, conforme 
detalhado na Seção 2.14.1. As Figuras 5.37, 5.38 e 5.39 mostram esses gráficos obtidos para as três colunas onde percolaram as soluções com $\mathrm{PO}_{4}{ }^{3-}$

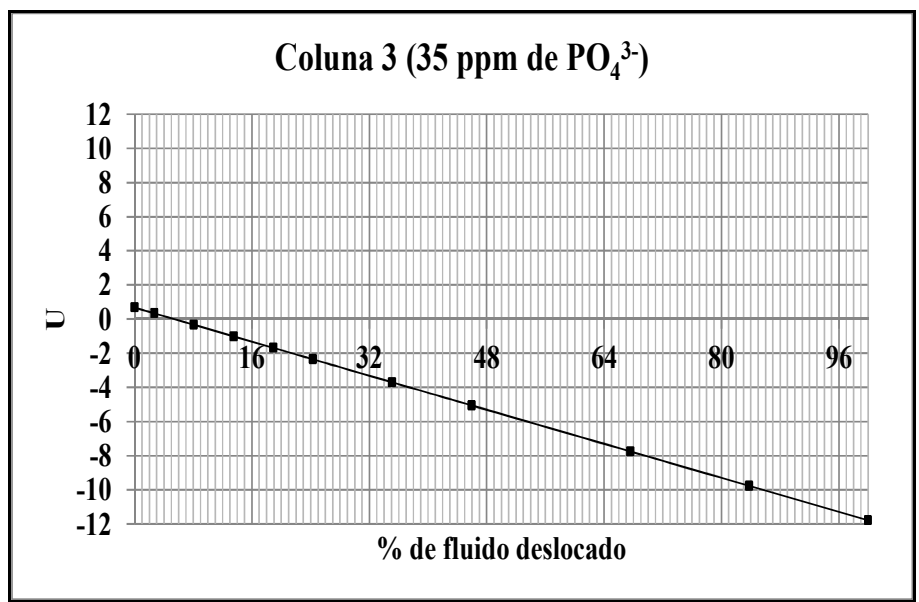

Figura 5.37- Curva U versus \% de fluido percolado para $\mathrm{C}_{0}$ de $35 \mathrm{ppm}$ de fosfato

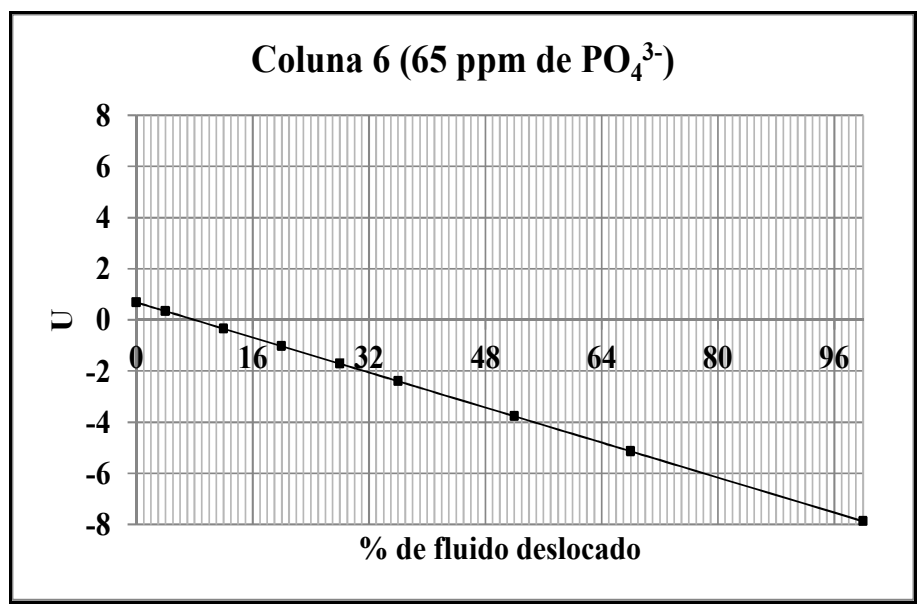

Figura 5.38- Curva U versus \% de fluido percolado para $\mathrm{C}_{0}$ de $65 \mathrm{ppm}$ de fosfato

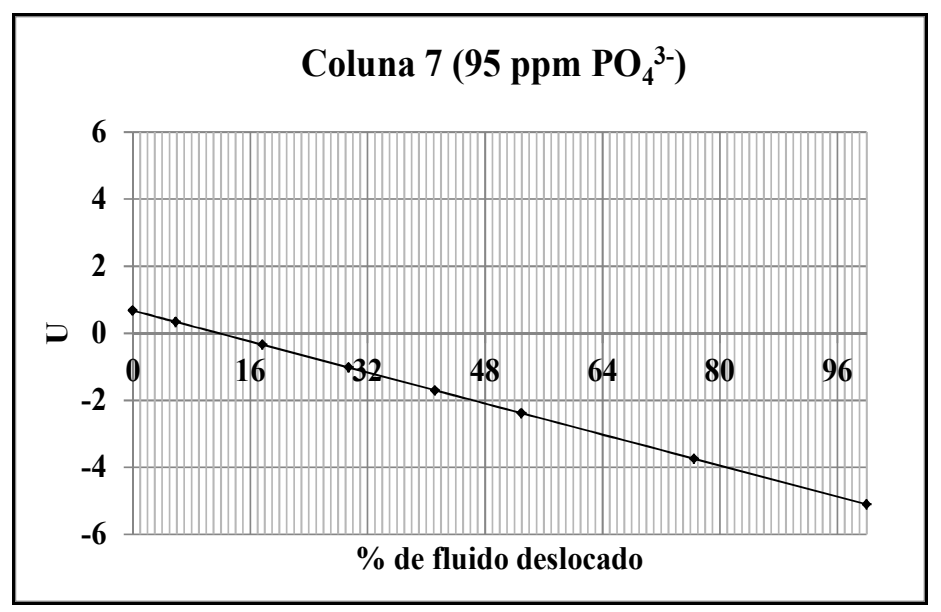

Figura 5.39- Curva $\mathrm{U}$ versus $\%$ de fluido percolado para $\mathrm{C}_{0}$ de $95 \mathrm{ppm}$ de fosfato 
Tabela 5.19 Parâmetros $\mathrm{U}_{16}$ e $\mathrm{U}_{84}$ para diferentes colunas percoladas com fosfato

\begin{tabular}{|c|c|c|c|c|c|}
\hline \multicolumn{2}{|c|}{$\begin{array}{c}\text { Coluna } 3 \\
\left(35 \mathrm{ppm} \text { de } \mathrm{PO}_{4}{ }^{3-}\right)\end{array}$} & \multicolumn{2}{|c|}{$\begin{array}{c}\text { Coluna } 6 \\
\left(65 \mathrm{ppm} \mathrm{de} \mathrm{PO}_{4}{ }^{3-}\right)\end{array}$} & \multicolumn{2}{|c|}{$\begin{array}{c}\text { Coluna } 7 \\
\left(95 \text { ppm de } \mathrm{PO}_{4}{ }^{3-}\right)\end{array}$} \\
\hline $\mathbf{U}_{16}$ & $\mathbf{U}_{84}$ & $\mathbf{U}_{16}$ & $\mathbf{U}_{84}$ & $\mathbf{U}_{16}$ & $\mathbf{U}_{84}$ \\
\hline$-1,32$ & $-9,80$ & $-0,685$ & $-6,05$ & $-0,245$ & $-4,175$ \\
\hline
\end{tabular}

Após a construção dos gráficos, obteve-se o $D_{h}$ para cada coluna a partir da Equação 61

$$
D_{h}=v L\left(\frac{U_{84}-U_{16}}{8}\right)^{2}
$$

\section{Segundo método:}

Para obter o $D_{h}$ a partir do método proposto por Singh $(1998 ; 2002)$ é necessário que se determine os parâmetros $t_{0}$ e $m$ a partir da curva de chegada, conforme descrito na Seção 2.14.1. As Figuras 5.40, 5.41 e 5.42 mostram a obtenção gráfica desses valores e na Tabela 5.20 encontram-se os valores desses parâmetros para as três colunas percoladas com $\mathrm{PO}_{4}{ }^{3-}$.

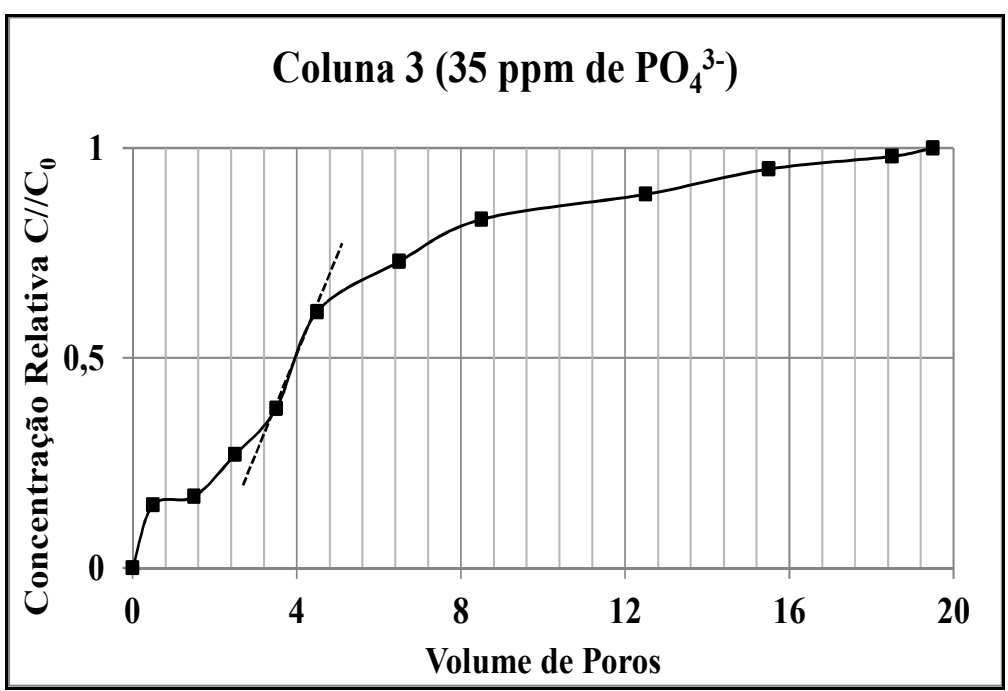

Figura 5.40- Obtenção dos parâmetros $t_{0}$ e $m$ a partir da curva de chegada para $\mathrm{C}_{0}$ de $35 \mathrm{ppm}$ de fosfato 


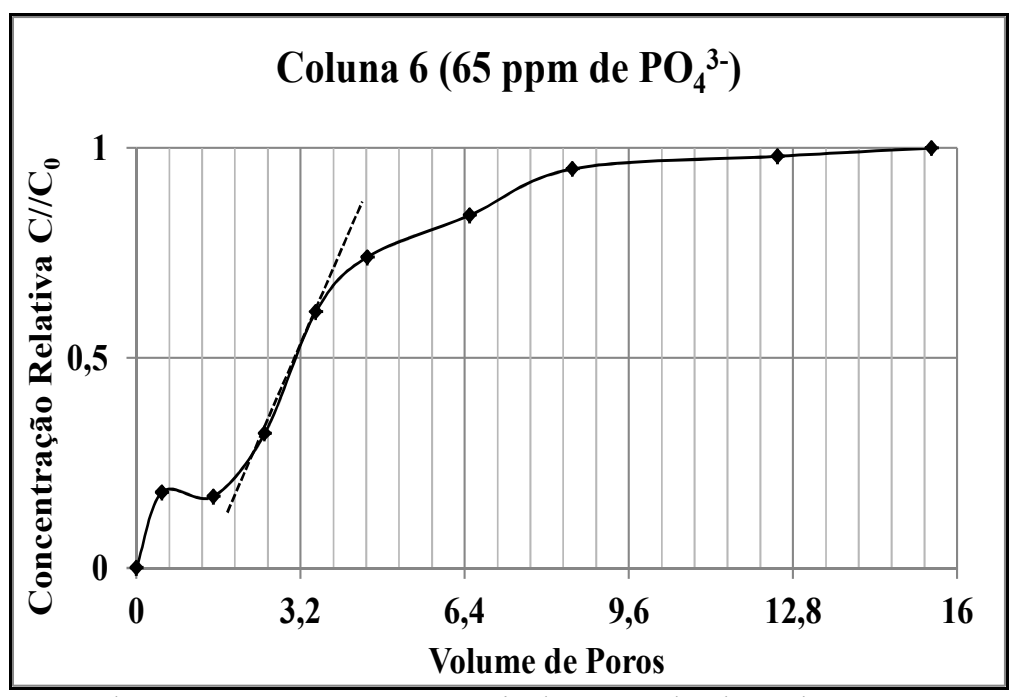

Figura 5.41- Obtenção dos parâmetros $t_{0} \mathrm{e} m$ a partir da curva de chegada para $\mathrm{C}_{0} 65 \mathrm{ppm}$ de fosfato

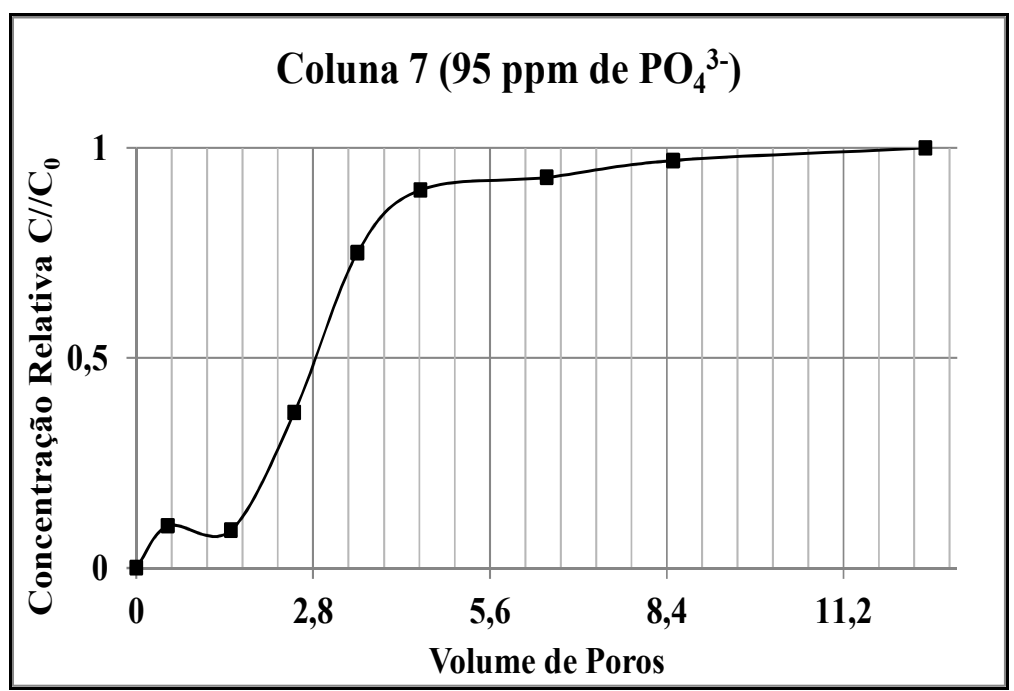

Figura 5.42- Obtenção dos parâmetros $t_{0} \mathrm{e} m$ a partir da curva de chegada para $\mathrm{C}_{0} 95 \mathrm{ppm}$ de fosfato

Tabela 5.20 Parâmetros $\mathrm{t}_{0} \mathrm{e} \mathrm{m}$ das curvas de chegada de fosfato

\begin{tabular}{|c|c|c|c|c|c|}
\hline \multicolumn{2}{|c|}{$\begin{array}{c}\text { Coluna } 3 \\
\left(35 \mathrm{ppm} \text { de } \mathrm{PO}_{4}{ }^{3-}\right)\end{array}$} & \multicolumn{2}{|c|}{$\begin{array}{c}\text { Coluna } 6 \\
\left(65 \mathrm{ppm} \mathrm{de} \mathrm{PO}_{4}{ }^{3-}\right)\end{array}$} & \multicolumn{2}{|c|}{$\begin{array}{c}\text { Coluna } 7 \\
\left(95 \text { ppm de } \mathrm{PO}_{4}{ }^{3-}\right)\end{array}$} \\
\hline $\mathbf{t}_{0}(\min )$ & $\mathrm{m}\left(\mathrm{min}^{-1}\right)$ & $\mathbf{t}_{0}(\min )$ & $m\left(\min ^{-1}\right)$ & $\overline{t_{0}(\min )}$ & $m\left(\min ^{-1}\right)$ \\
\hline 346,7 & 4,35 & 506,41 & 3,45 & 304,42 & 2,63 \\
\hline
\end{tabular}

Após a obtenção dos parâmetros $t_{0}$ e $m$, calculou-se o $D_{h}$ para as três colunas, de acordo com a Equação 55

$$
D_{h}=\frac{L^{2}}{4 \pi m^{2} t_{0}{ }^{3}}
$$




\section{Terceiro método:}

Para obtenção do $D_{h}$ pelo método proposto por Bear (1961), utilizou-se o coeficiente de dispersividade longitudinal de acordo com o método proposto por Fetter (1993), conforme discutido na Seção 5.7.1.2.

Considerando $D^{*}$ como nulo, como sugeriu Singh (1998), calculou-se o $D_{h}$ por meio da Equação 51.

$$
D_{l}=1,75 d v_{z}+D^{*}
$$

A Tabela 5.21 mostra os resultados dos coeficientes de dispersão hidrodinâmica obtidos com os três métodos utilizados.

Tabela 5.21- Coeficientes de dispersão hidrodinâmica para as colunas percoladas com $\mathrm{PO}_{4}{ }^{3-}$

\begin{tabular}{|c|c|c|c|}
\hline \multicolumn{4}{|c|}{ Coeficiente de Dispersão Hidrodinâmica do $\mathrm{PO}_{4}{ }^{3-}\left(\mathrm{m}^{2} / \mathrm{min}\right)$} \\
\hline Método & $\begin{array}{c}\text { Coluna } 3 \\
\left(35 \text { ppm de } \mathrm{PO}_{4}{ }^{3-}\right)\end{array}$ & $\begin{array}{c}\text { Coluna } 6 \\
\left(65 \mathrm{ppm} \text { de } \mathrm{PO}_{4}{ }^{3-}\right)\end{array}$ & $\begin{array}{c}\text { Coluna } 7 \\
\left(95 \text { ppm de } \mathrm{PO}_{4}{ }^{3-}\right)\end{array}$ \\
\hline Brigham (1974) & $5,99 \mathrm{E}-04$ & $1,21 \mathrm{E}-04$ & $1,22 \mathrm{E}-04$ \\
\hline Singh (1998) & $2,27 \mathrm{E}-12$ & $1,16 \mathrm{E}-12$ & $7,97 \mathrm{E}-10$ \\
\hline Bear (1961) & $1,97 \mathrm{E}-04$ & $2,25 \mathrm{E}-04$ & $2,85 \mathrm{E}-04$ \\
\hline
\end{tabular}

Os valores de $D_{h}$ de $\mathrm{PO}_{4}{ }^{3-}$ obtidos com o método proposto por Bear (1961) e Brigham (1974) apresentam-se muito próximos para as três colunas. Por outro lado, os coeficientes de dispersão hidrodinâmica de $\mathrm{PO}_{4}{ }^{3-}$ calculados com o método proposto por Singh (1998) apresentou valores muito menores do que àqueles calculados com os outros dois métodos.

Levando em consideração os efeitos da macroporosidade (Figuras 5.8 e 5.9) e que ela está influenciando diretamente os mecanismos de transporte atuantes, acredita-se que a velocidade linear média esteja representando a velocidade do fluxo predominantemente por esses macroporos e que por isso, os valores de $D_{h}$ de $\mathrm{PO}_{4}{ }^{3-}$ estejam tão divergentes entre os diversos métodos, principalmente entre aqueles que consideram a velocidade linear média na equação de obtenção do $D_{h}$ (Brigham, 1974 e Bear 1961) e o que não considera (Singh, 1998). Por isso, com o objetivo de verificar se os valores ficariam muito diferentes daqueles medidos no laboratório, utilizando a Equação 54 para concentração relativa igual a 0,5, realizou-se uma retroanálise, onde a partir do $D_{h}$ obteve-se a velocidade linear média. Escolheu-se a 
concentração relativa igual a 0,5 , por ela ser utilizada no método de Brigham (1974) e Singh(1998) para a obtenção dos parâmetros utilizados no cálculo do $D_{h}$. A Tabela 5.22 apresenta os resultados dessa análise.

Utilizando o $D_{h}$ do $\mathrm{PO}_{4}{ }^{3-}$ obtido com os métodos de Brigham (1974) e Bear (1961) a velocidade linear média resultou em valores negativos. Isto sugere que o $D_{h}$ obtido com os métodos de Brigham (1974) e Bear (1961) provavelmente não representa bem a dispersão do $\mathrm{PO}_{4}{ }^{3-}$ para o solo estudado nesta pesquisa. Isso pode ser justificado pelo fato de que a equação proposta por Brigham (1974) é baseada em relações empíricas para outros materiais, e, portanto, ela pode não ser representativa do material estudado nesta pesquisa. Além disso, o método proposto por Bear (1961) apesar de ser bastante usado, é fortemente influenciado pela determinação do $\alpha_{1}$ com todas as dificuldades envolvidas, como discutidas previamente na Seção (5.7.1) e, portanto, sua utilização deve ser feita com cuidado.

Tabela 5.22 Velocidades lineares médias obtidas a partir do $D_{h}$ das colunas percoladas com $\mathrm{PO}_{4}{ }^{3-}$

Velocidade linear média a partir do $D_{h}(\mathrm{~m} / \mathrm{min})$

\begin{tabular}{|c|c|c|c|}
\hline Método & $\begin{array}{c}\text { Coluna } 3 \\
\left(35 \text { ppm de } \mathrm{PO}_{4}{ }^{3-}\right) \\
v \text { medida }=3,56 \mathrm{E}-03\end{array}$ & $\begin{array}{c}\text { Coluna } 6 \\
\left(65 \text { ppm de } \mathrm{PO}_{4}{ }^{3-}\right) \\
\text { v medida }=1,79 \mathrm{E}-03\end{array}$ & $\begin{array}{c}\text { Coluna } 7 \\
\left(95 \text { ppm de } \mathrm{PO}_{4}{ }^{3-}\right) \\
\text { v medida }=3,37 \mathrm{E}-03\end{array}$ \\
\hline $\begin{array}{c}D_{h} \text { por } \\
\text { Brigham (1974) }\end{array}$ & $-3,97 \mathrm{E}-03$ & $-5,77 \mathrm{E}-04$ & $-2,37 \mathrm{E}-04$ \\
\hline $\begin{array}{c}D_{h} \text { por } \\
\text { Singh }(1998)\end{array}$ & $3,46 \mathrm{E}-03$ & $1,90 \mathrm{E}-03$ & $2,75 \mathrm{E}-03$ \\
\hline $\begin{array}{c}D_{h} \text { por } \\
\text { Bear (1961) }\end{array}$ & $-8,03 \mathrm{E}-04$ & $-1,48 \mathrm{E}-03$ & $-1,82 \mathrm{E}-03$ \\
\hline
\end{tabular}

As velocidades obtidas a partir do $D_{h}$ de $\mathrm{PO}_{4}{ }^{3-}$ calculado com o método de Singh (1998) resultaram em valores muito próximos dos valores obtidos por meio dos ensaios de coluna. Isto sugere que os coeficientes de dispersão hidrodinâmica obtidos com o método proposto por Singh (1998) pode representar bem a dispersão do $\mathrm{PO}_{4}{ }^{3-}$ neste solo. No entanto, seus valores são muito inferiores quando comparados com aqueles obtidos com os outros métodos e essa grande diferença pode estar relacionada ao fato de que este método não utiliza a velocidade linear média, nem dados de vazão, área da seção transversal, condutividade hidráulica saturada e porosidade efetiva, podendo ser menos influenciado por erros nesses parâmetros, o que é uma vantagem no uso deste método.

No entanto, os parâmetros $m$ e $t_{0}$, obtidos diretamente das curvas de chegada, podem ser fortemente influenciados por pequenas mudanças nessas curvas. Essas pequenas mudanças 
podem ocorrer por pequenas alterações nos resultados químicos, bem como devido a coleta das amostras efluentes em um intervalo diferente de volume de poros.

Com a análise dos diferentes métodos de obtenção do $D_{h}$, observa-se que aquele proposto por Singh (1998) apesar de suas limitações discutidas previamente, ao resultar em valores de $D_{h}$ na ordem de $10 \mathrm{E}-10 \mathrm{~m}^{2} / \mathrm{min}$ sugerem que a dispersão hidrodinâmica não deve ser o processo predominante no transporte de fosfato no solo estudado. Para ajudar na análise desta possibilidade, calculou-se o número de Péclet para cada coluna utilizando todos os $D_{h}$ obtidos com os três métodos.

Tabela 5.23 Números de Péclet obtidos a partir do $D_{h}$ das colunas percoladas com $\mathrm{PO}_{4}{ }^{3-}$

\section{Número de Péclet}

\begin{tabular}{|c|c|c|c|}
\hline Método & $\begin{array}{c}\text { Coluna } 3 \\
\left(35 \text { ppm de } \mathrm{PO}_{4}{ }^{3-} \text { ) }\right.\end{array}$ & $\begin{array}{c}\text { Coluna } 6 \\
\left(65 \text { ppm de } \mathrm{PO}_{4}{ }^{3-}\right)\end{array}$ & 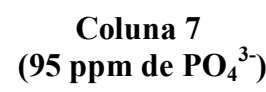 \\
\hline Brigham (1974) & 0,89 & 2,22 & 4,14 \\
\hline Singh (1998) & $2,35 \mathrm{E} 08$ & $2,32 \mathrm{E}+08$ & $6,34 \mathrm{E} 05$ \\
\hline Bear (1961) & 2,71 & 1,20 & 1,77 \\
\hline
\end{tabular}

A análise da Tabela 5.23 mostra que os valores de $D_{h}$ obtidos com o método proposto por Brigham (1974) e Bear (1961) retornam $P$ entre 0,89 e 4,14. Estes valores de número de Péclet indicam que o mecanismo de transporte dominante é a difusão. Isto não é coerente dada as características do soluto e do solo, visto que a difusão atua principalmente em solos com $k$ muito pequeno e com soluto de baixa mobilidade como os metais potencialmente tóxicos. O Péclet obtido a partir do $D_{h}$ calculado pelo método de Singh (1998) resultou na ordem de $10 \mathrm{E}+08$ a 10E+05 indicando que existe um regime de alto fluxo em que a advecção predomina sobre a difusão. Isto provavelmente está relacionado a alta velocidade linear média obtida nos ensaios de coluna. E, como discutido anteriormente, a alta velocidade obtidas nestas colunas dá-se devido à presença de macroporos conectados.

\subsubsection{4. $\quad$ Fator de retardamento}

$\mathrm{O}$ fator de retardamento do $\mathrm{PO}_{4}{ }^{3-}$ foi obtido por meio de três métodos. A seguir será mostrada a obtenção do $R_{d}$ a partir de cada método separadamente e, posteriormente, os valores de $R_{d}$ obtidos pelos diferentes métodos são mostrados na Tabela 5.25 e então analisados. 


\section{Primeiro método:}

O primeiro método utilizado foi proposto por van Genuchten e Parker (1984) e o $R_{d}$ é obtido através do cálculo da área acima da curva de chegada, $H$, conforme detalhado na Seção 2.14.2. Na Tabela 5.25 também se encontram os resultados desses retardamentos para os diferentes números de Péclet calculados.

\section{Segundo método:}

No segundo método utilizado, proposto por Freeze e Cherry (1979) e Shackelford $(1993 ; 1994)$, o $R_{d}$. é o número de volume de poros quando a concentração relativa igual a 0,5. As Figuras 5.43, 5.44 e 5.45 mostram a obtenção do $R_{d}$ do $\mathrm{PO}_{4}{ }^{3-}$ por este método.

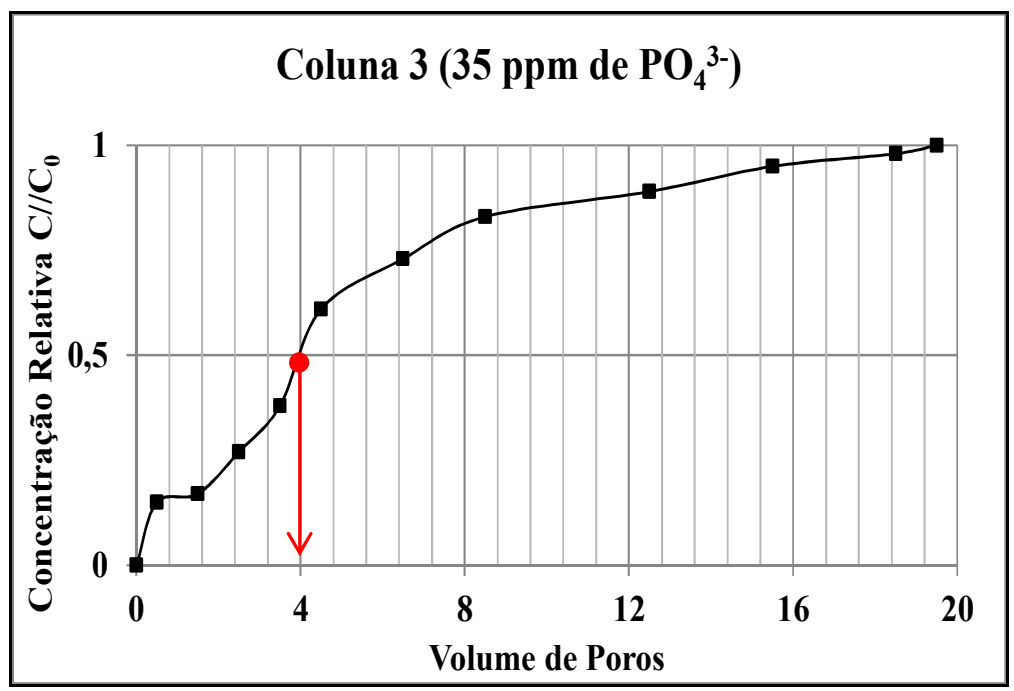

Figura 5.43- Obtenção do fator de retardamento pelo método de Freeze e Cherry (1979) e Shackelford $(1993 ; 1994)$ para $\mathrm{C}_{0}$ de 35 ppm de fosfato

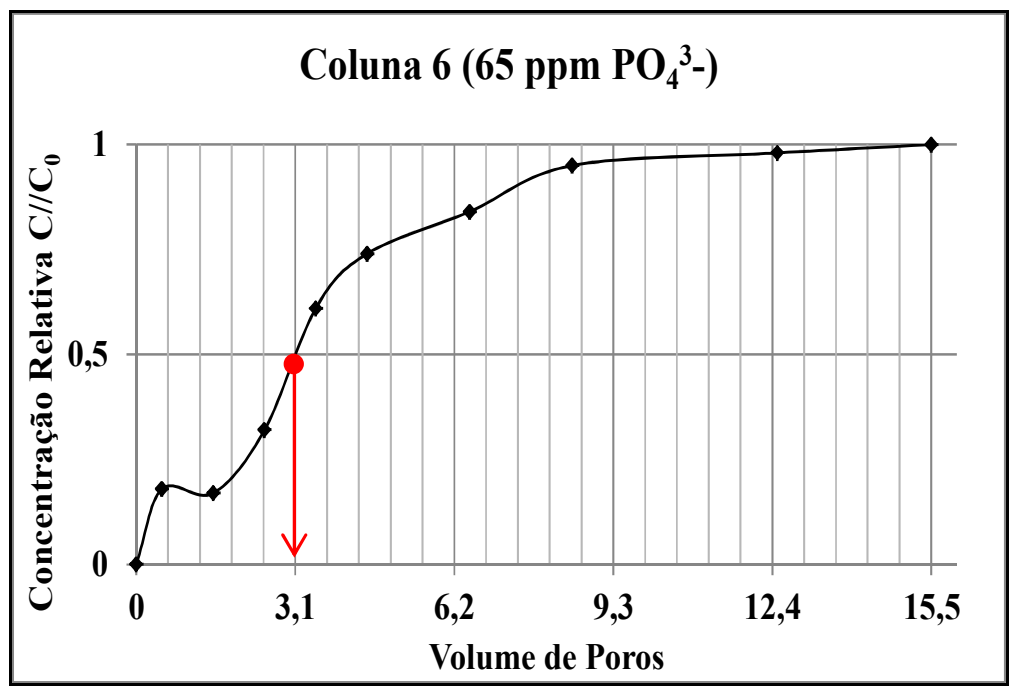


Figura 5.44- Obtenção do fator de retardamento pelo método de Freeze e Cherry (1979) e Shackelford $(1993 ; 1994)$ para $C_{0}$ de 65 ppm de fosfato

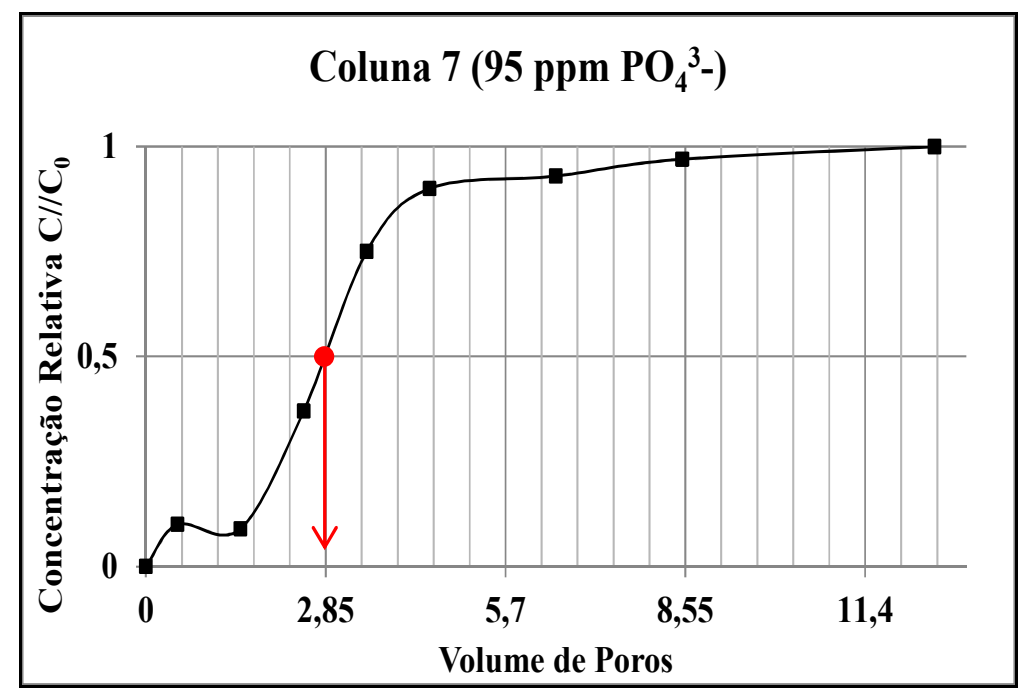

Figura 5.45- Obtenção do fator de retardamento pelo método de Freeze e Cherry (1979) e Shackelford $(1993 ; 1994)$ para $\mathrm{C}_{0}$ de $95 \mathrm{ppm}$ de fosfato

\section{Terceiro método:}

O terceiro método utilizado permitiu a obtenção do $R_{d}$ por meio da construção da isoterma de sorção para o $\mathrm{PO}_{4}{ }^{3-}$ (Figura 5.46)

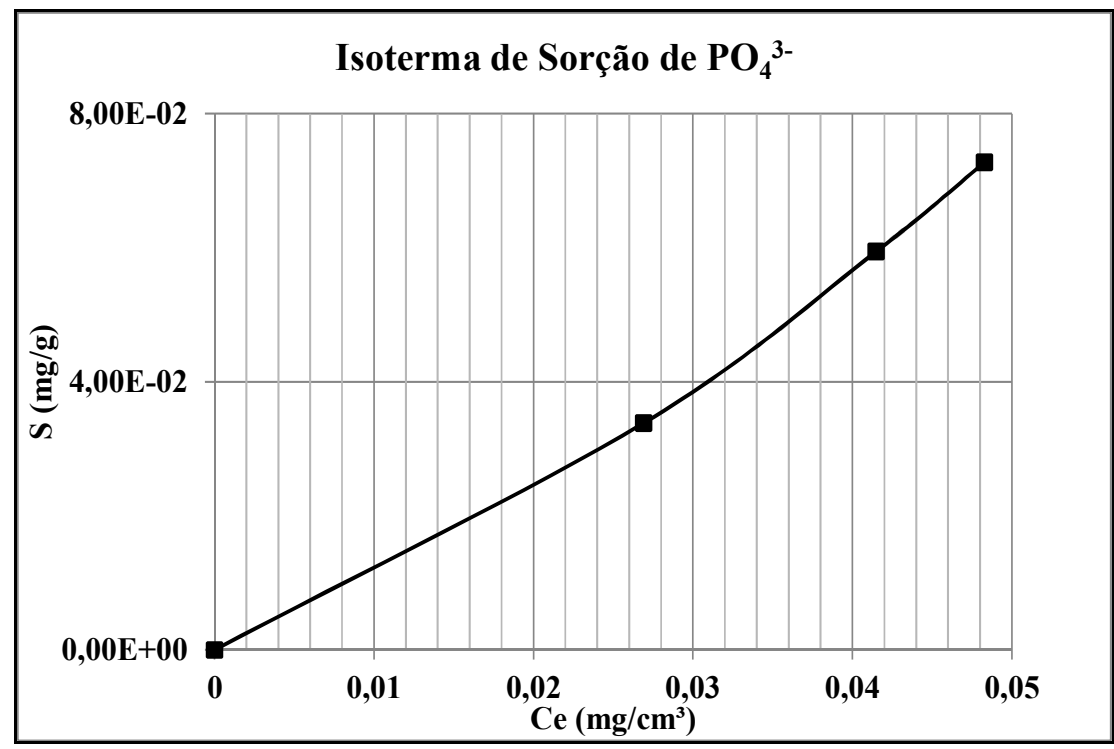

Figura 5.46- Isoterma de sorção de fosfato

Com a isoterma construída, realizaram-se os procedimentos de linearização para verificar qual o ajuste dos diferentes modelos de isotermas aos dados experimentais (Figuras 5.47 a 6.50$)$ 


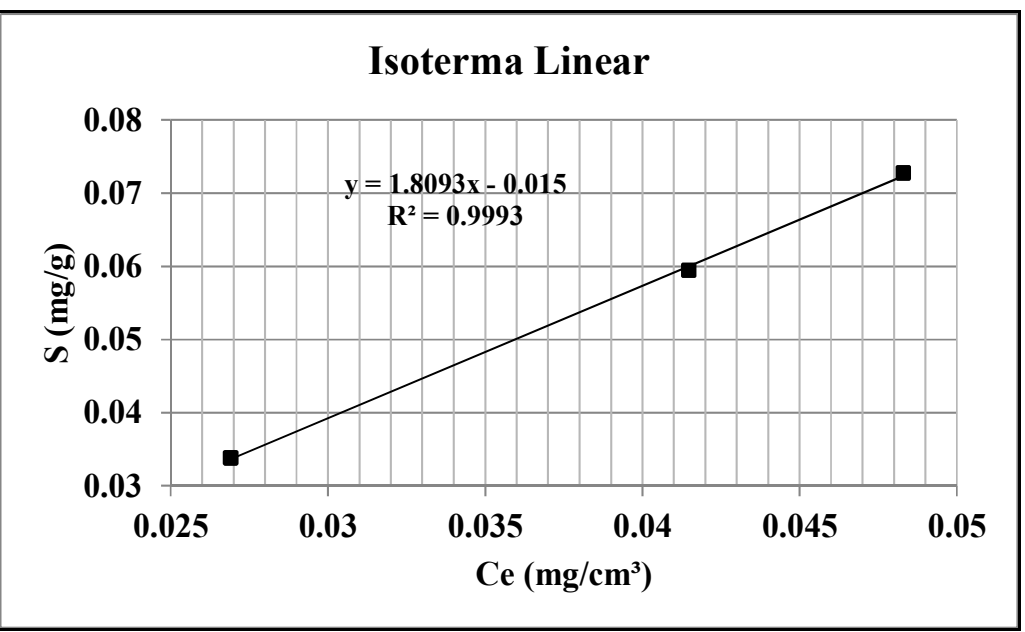

Figura 5.47- Ajuste dos dados experimentais de fosfato ao modelo de isoterma Linear

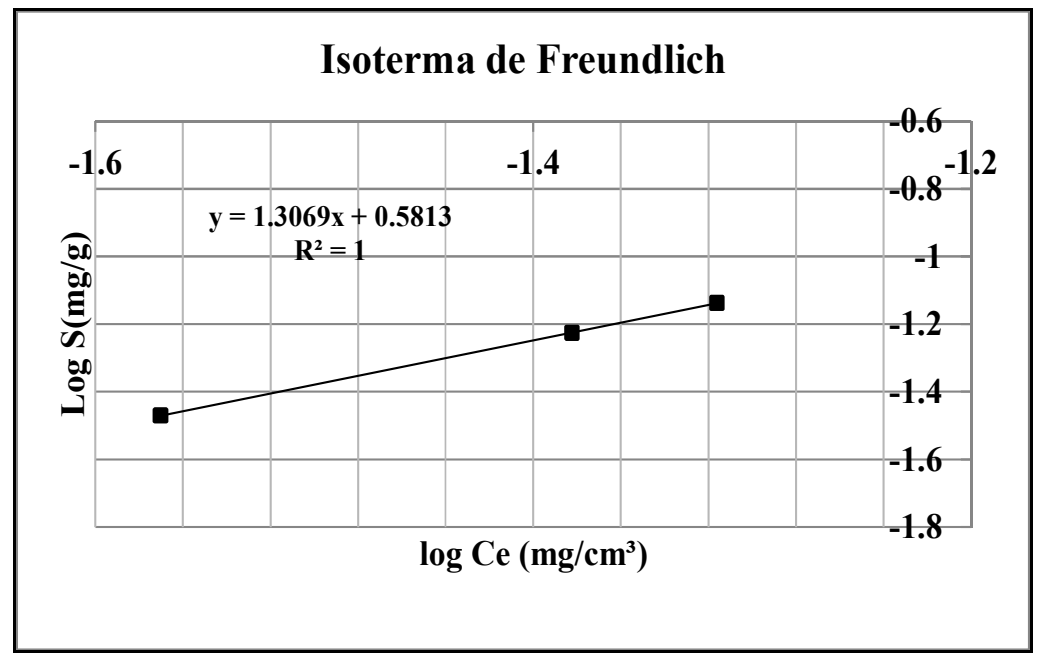

Figura 5.48- Ajuste dos dados experimentais de fosfato ao modelo de isoterma de Freundlich

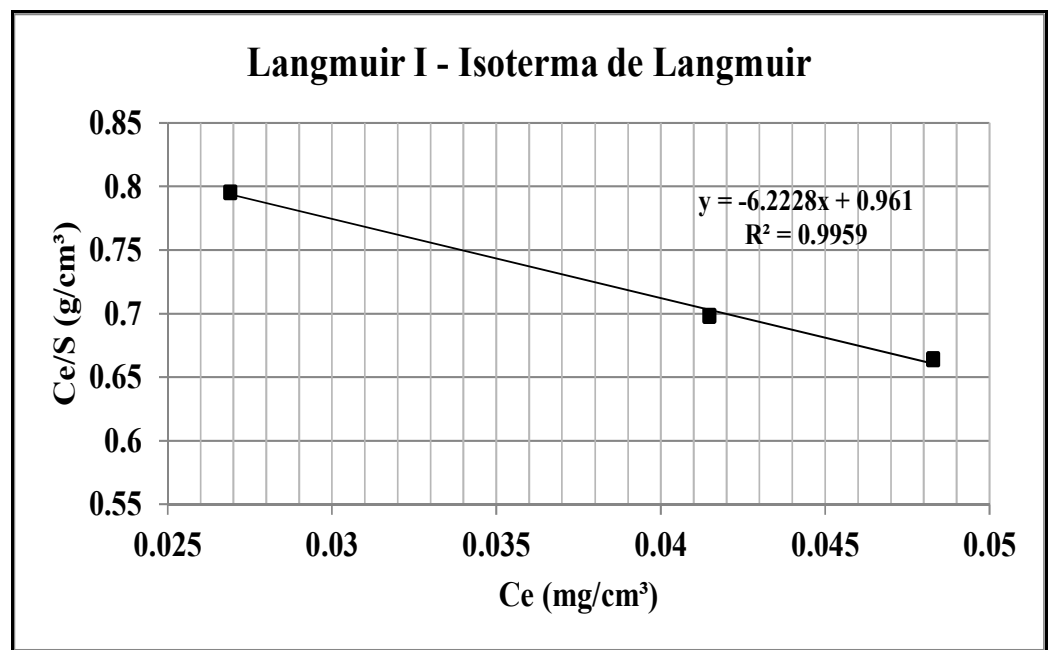

Figura 5.49- Ajuste dos dados experimentais de fosfato ao modelo de Langmuir (Langmuir I) 


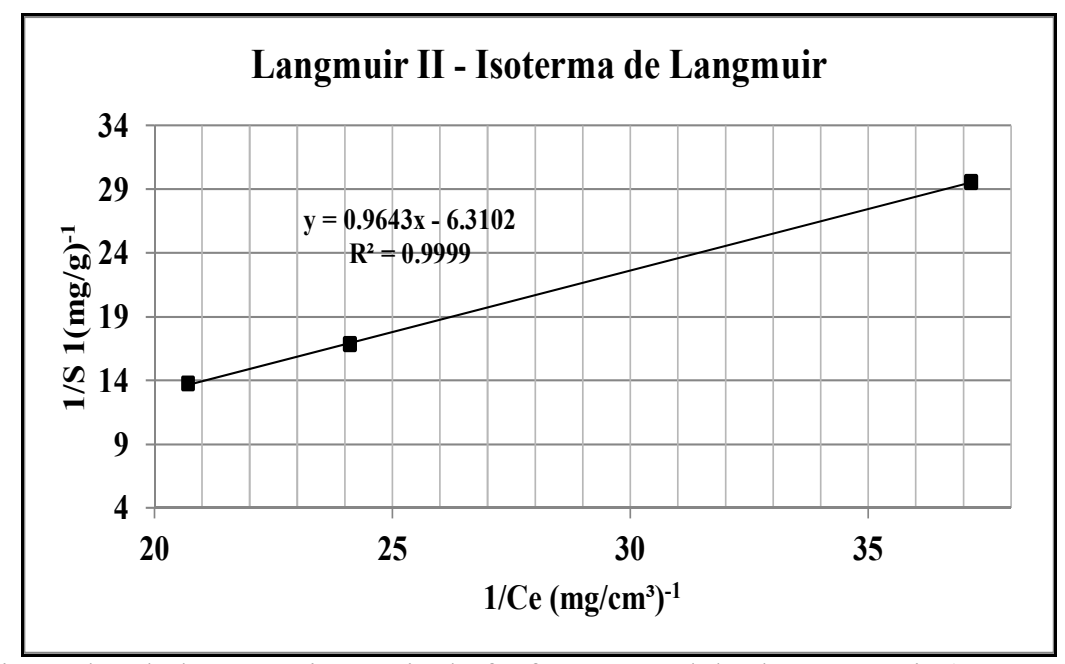

Figura 5.50 Ajuste dos dados experimentais de fosfato ao modelo de Langmuir (Langmuir II)

A Tabela 5.24 mostra os coeficientes de determinação para cada um dos ajustes realizados.

Tabela 5.24 Valores dos coeficientes de determinação para ajuste dos modelos das isotermas

\begin{tabular}{cc}
\hline Modelo & $\begin{array}{c}\text { Coeficiente de } \\
\text { Determinação R }\end{array}$ \\
\hline Linear & 0,9930 \\
Freundlich & 1 \\
Langmuir I & 0,9959 \\
Langmuir II & 0,9999 \\
$\begin{array}{c}\text { Langmuir por regressão } \\
\text { não linear }\end{array}$ & 0.9965 \\
\hline
\end{tabular}

1 regressão não linear feita por meio do software comercial Mathematica 9.0 da Wolfram Research

Como todos os modelos mostraram bons ajustes com os dados experimentais, obtiveram-se os fatores de retardamento para todos os modelos ajustados.

A Tabela 5.25 mostra os resultados dos fatores de retardamento obtidos com os três métodos utilizados.

Os valores de retardamento de fosfato obtidos com o método de van Genuchten e Parker (1984) para a situação em que a área acima da curva de chegada é igual ao $R_{d}$, são iguais àqueles obtidos a partir da Equação 74 na situação em que o número de Péclet é calculado a partir do $D_{h}$ obtido com o método proposto por Singh (1998), mostrando que o balanço de massa está sendo considerado adequadamente por este método. 


$$
H=R_{d}\left[1+\left[\frac{1}{P}\right]\right]
$$

Para as situações em que no cálculo do número de Péclet foi considerado o $D_{h}$ obtido pelo método de Brigham (1974) e por Bear (1962), nota-se que os retardamentos ficaram bem menores do que os valores obtidos com os outros métodos. Os retardamentos obtidos com o método proposto por Freeze e Cherry (1979) e Shackelford (1994) diferem muito pouco daqueles obtidos com o método proposto por van Genuchten e Parker (1984).

Tabela 5.25 Valores dos fatores de retardamento de $\mathrm{PO}_{4}{ }^{3-}$ obtidos com diferentes métodos

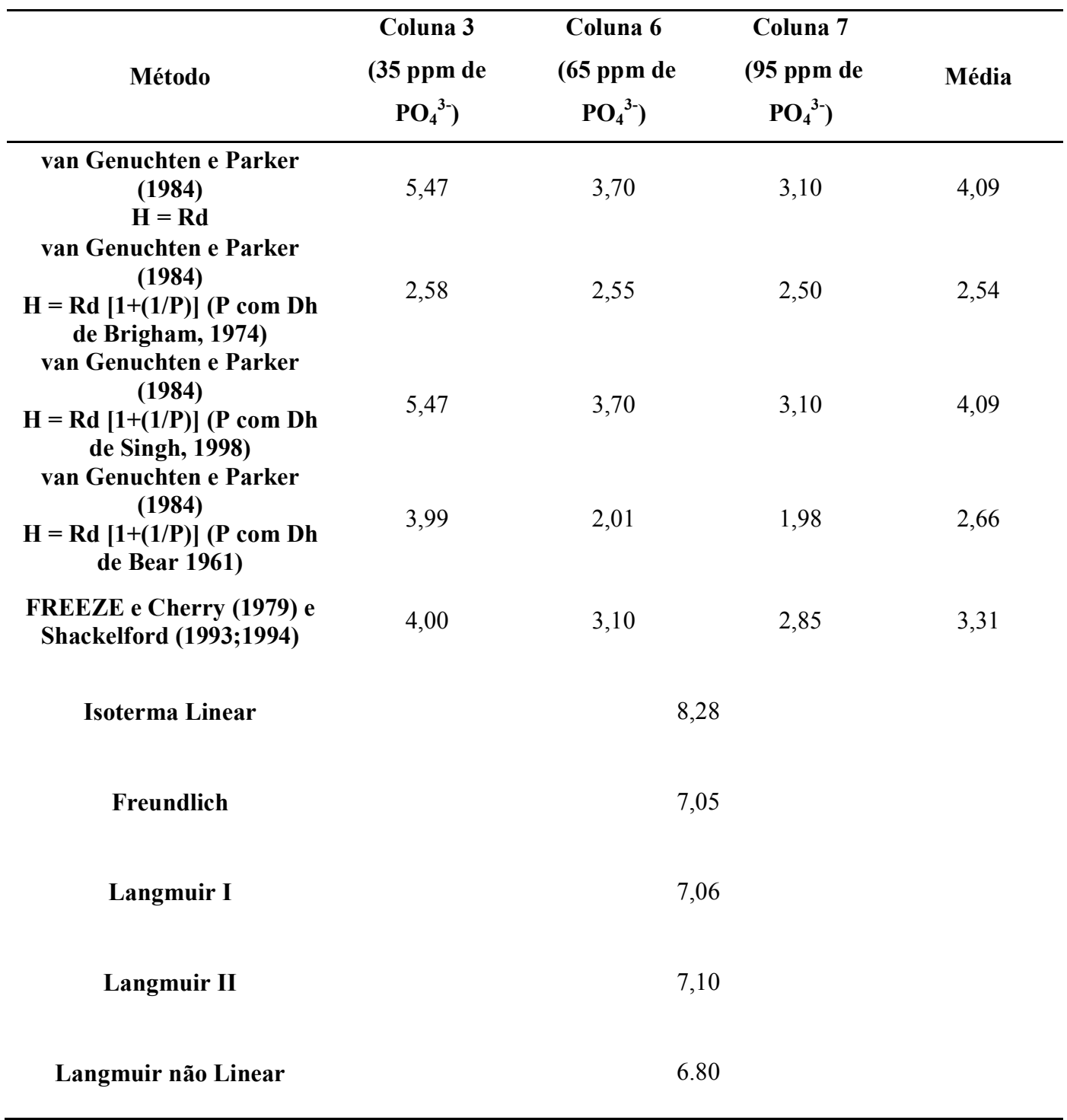

Os retardamentos guardam uma tendência no que diz respeito à concentração inicial da solução de $\mathrm{PO}_{4}{ }^{3-}$, sendo que quanto maior a concentração inicial, menor será o $R_{d}$, o que 
também foi verificado para o sódio (Seção 5.7.1). Observando a Tabela 5.2 (características físico-químicas do material), nota-se que o máximo $S(0,160 \mathrm{mg} / \mathrm{g})$ para a isoterma de sorção de $\mathrm{PO}_{4}{ }^{3-}$ é maior do que a CTC do solo $(0,00152 \mathrm{mg} / \mathrm{g})$ o que pode sugerir que a retenção dos solutos neste solo não está ocorrendo por troca catiônica, mas sim por mecanismos de adsorção específica, como sugeriu Knox, Sabatini e Canter (1993), e/ou por mecanismos físicos.

Em relação aos retardamentos de $\mathrm{PO}_{4}{ }^{3-}$ obtidos com os ajustes das isotermas, constatase que eles são muito próximos entre si, exceto aquele obtido para a isoterma linear, mostrando que o comportamento do solo, como o esperado, provavelmente não é de sorção infinita. Observa-se que os valores de retardamento obtidos com os ajustes das isotermas estão relativamente altos quando comparados com os retardamentos obtidos com os outros métodos. Porém, os dados experimentais se mostram bem ajustados aos modelos de todas as isotermas, o que indica que este provavelmente foi um método que forneceu valores de $R_{d}$ aceitáveis para $\mathrm{OPO}_{4}{ }^{3-}$ neste material.

É possível que a sorção do fosfato obedeça à isoterma de Freundlich considerando que muitos solutos reagem como se o solo possuísse diferentes tipos de sítios de sorção com capacidade ilimitada de sorção (JURY; GARDNER; GARDNER, 1991). No entanto, o principal responsável pelas reações de adsorção específica é o pH do solo, que não teve alterações significativas durante o ensaio e, portanto, os sítios de sorção específica não devem ter se alterado a ponto de serem considerados ilimitados. Assim, por considerar que normalmente a sorção nos materiais tem um limite, os valores de $R_{d}$ obtidos com os ajustes das isotermas de Langmuir provavelmente melhor representam o comportamento de sorção de $\mathrm{PO}_{4}{ }^{3-}$ deste solo, apesar da isoterma de Freundlich apresentar o melhor ajuste com um coeficiente de determinação igual a 1

Os valores de retardamento do fosfato obtidos com os ajustes dos modelos das isotermas são maiores do que os valores obtidos com os outros métodos. Como a obtenção do $R_{d}$ por meio de isotermas resulta em apenas um valor para todo o material, pode estar subestimando ou superestimando o retardamento do fosfato no solo. No entanto, a construção da isoterma leva em consideração o que está ocorrendo no solo com as massas sorvidas e não sorvidas pelo solo, ou seja, considera o comportamento real de sorção do íon pelo material, podendo ser um método que, apesar de pouco utilizado, represente bem o $R_{d}$ do fosfato. 
Por fim, considera-se que o fosfato está sendo retido no solo e que este retardamento provavelmente se relaciona a fenômenos químicos, mais precisamente à adsorção específica por óxidos de alumínio e ferro, todos em grande quantidade neste solo, como pode ser visto na Figura 5.35 e na Tabela 5.18. Além disso, pode estar ocorrendo atraso na velocidade linear do fosfato em relação à velocidade da água devido às características de dupla porosidade deste solo, como mencionado previamente.

\subsubsection{Curva de chegada de amônio}

A determinação das concentrações relativas de amônio foi bastante complexa apesar do controle do $\mathrm{pH}$ e Eh das soluções efluentes, para que realmente fossem medidas as concentrações de $\mathrm{NH}_{4}^{+}$, além de todos os cuidados com a manipulação das amostras. Inicialmente tentou-se determinar as concentrações de amônio nas soluções efluentes por meio do espectrofotômetro HACH. No entanto, as concentrações relativas estavam resultando em valores negativos, mesmo com a diluição adequada para o limite de detecção do equipamento. Em seguida experimentou-se a cromatografia de íons, que também resultou em valores negativos ou nulos de concentração, o que não se mostra coerente. Realizaram novas medidas em espectrofotômetro $\mathrm{HACH}$ até que se obtivesse um padrão das medições para que pudéssemos confiar nos resultados.

Esses problemas na obtenção das concentrações do amônio chamam a atenção, principalmente porque normalmente não se menciona nas pesquisas as dificuldades em se obter os resultados químicos. Além disso, os pesquisadores que forem trabalhar com esses resultados devem analisá-los e se atentarem às condições de campo e resultados esperados, considerando que os laboratórios podem variar em suas análises e que os resultados finais nem sempre representam o que está ocorrendo no solo. Curvas de chegada de amônio perfeitamente sigmoides merecem atenção, pois podem estar fugindo muito do real comportamento deste íon no solo.

A Figura 5.51 ilustra as curvas de chegada obtidas para as três concentrações de $\mathrm{NH}_{4}^{+}$. 


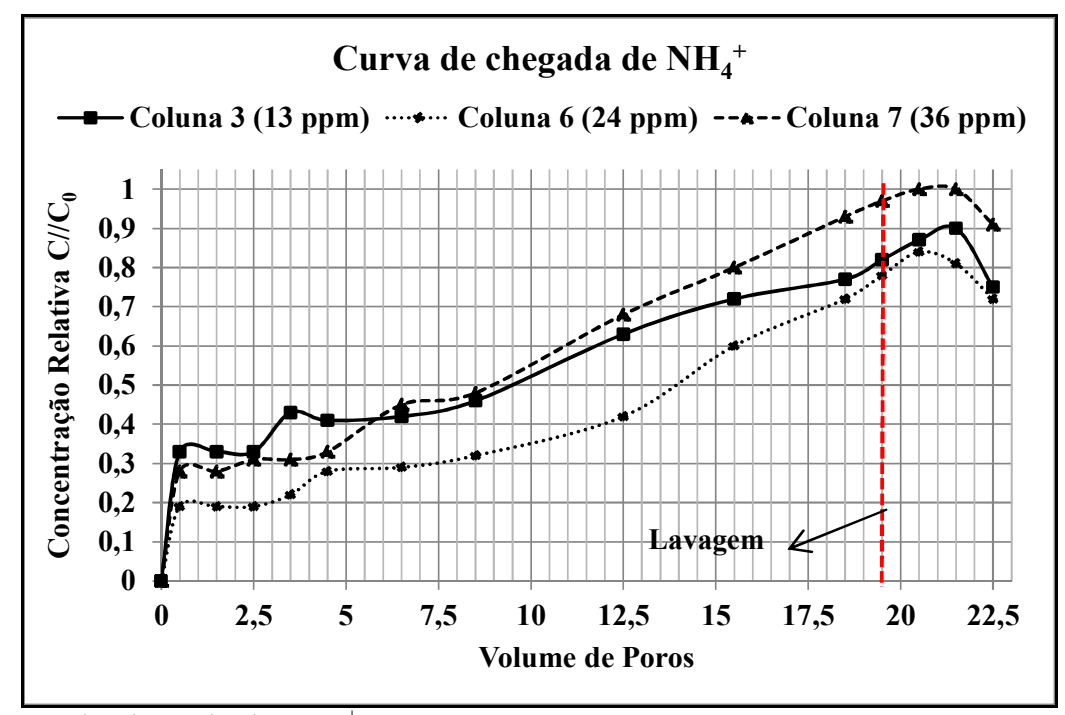

Figura 5.51 Curva de chegada de $\mathrm{NH}_{4}^{+}$

$\mathrm{O}$ ensaio percolou 19,5 volumes de poros da solução de $\left(\mathrm{NH}_{4}\right)_{2} \mathrm{HPO}_{4}$, mas esta quantidade de solução não foi suficiente para que as curvas referentes às concentrações iniciais de $\mathrm{NH}_{4}{ }^{+}$iguais à 13 e 24 ppm (Coluna 3 e 6, respectivamente) alcançassem o equilíbrio das concentrações relativas, ou seja, a unidade. A demora em alcançar a unidade entre $C_{0}$ e $C$ indica que o solo está retendo o amônio, apesar de ter baixa CTC, baixo teor de matéria orgânica e ausência de argilominerais 2:1. Esta retenção de amônio pode estar ocorrendo por meio da adsorção não específica que, mesmo ocorrendo em pequenas quantidades, devido às características mineralógicas do solo, pode ser capaz de atuar fortemente na retenção deste íon pelo solo. Além disso, este solo possui $\Delta \mathrm{pH}$ e PCZ negativo, o que significa que a carga total do solo é negativa, indicando o favorecimento da adsorção de cátions como o $\mathrm{NH}_{4}^{+}$.

No entanto, solutos reativos, ou seja, aqueles que reagem com o solo e ficam retidos nele, normalmente demoram em aparecer na solução efluente (FREEZE; CHERRY, 1979; SHACKELFORD, 1994; FETTER, 1993), o que não foi verificado nesta pesquisa As curvas de chegada do amônio mostram que em 1,0 volume de poros já apareceram concentrações do íon na solução efluente. Isto indica que parte do soluto estava saindo da coluna com a mesma velocidade linear média que a água, o que caracteriza o transporte advectivo. Até 5,0 volumes de poros percebe-se que as concentrações relativas permanecem estáveis para as três curvas de chegada. Diferentemente dos outros íons estudados nesta pesquisa, a coluna por onde percolou a solução com a menor concentração inicial (Coluna 3) apresenta as maiores concentrações relativas de 1,0 a 5,0 volumes de poros, indicando que o retardamento nesta coluna estava sendo menor e que o mecanismo de advecção poderia estar atuando mais 
intensamente. Após 6,5 volumes de poros nota-se que as concentrações relativas crescem quase que linearmente para as três colunas. Após a lavagem com água destilada, nota-se que no primeiro volume de poros houve aumento da concentração relativa, pela lavagem dos íons que estavam retidos no solo. A partir do segundo volume de poros de água destilada, percebese redução da concentração relativa, sendo que nas colunas 3 e 6 não se alcança a unidade da concentração relativa. Este comportamento durante a lavagem ressalta que o fosfato realmente ficou retido no solo e que por isso ele não saiu nas soluções efluentes, principalmente nas colunas 3 e 6 .

Como a única coluna que alcançou a unidade na concentração relativa foi a 7 , mais uma vez nota-se que quanto maior a concentração inicial, menor é o retardamento ocorrido. Além disso, a constatação de íons nos primeiros volumes de poros das soluções efluentes mostra que o transporte advectivo está presente nestas colunas. Assim, acredita-se que devido à dupla porosidade presente neste material parte dos solutos está saindo da coluna de solo devido à advecção, preferencialmente pelos macroporos, e parte está sendo retardada devido à adsorção não específica e pela passagem pelos microporos que, muitas vezes, podem não estar interconectados.

\subsection{Coeficiente de dispersão hidrodinâmica: amônio}

Apesar de as colunas 3 e 6 não terem alcançado a concentração relativa de equilíbrio durante o ensaio, os valores do coeficiente de dispersão para o $\mathrm{NH}_{4}{ }^{+}$também foram obtidos por três métodos, visto que a $C / C_{0}=1$ não é requisito de nenhum dos métodos utilizados.

As colunas percoladas com $\mathrm{NH}_{4}{ }^{+}$foram as mesmas percoladas com $\mathrm{PO}_{4}{ }^{3-}$ (Coluna 3, Coluna 6 e Coluna 7). Assim sendo, o método proposto por Ogata (1958) e Ogata e Banks (1961) novamente não se mostrou adequado para o calculo do $D_{h} \mathrm{NH}_{4}{ }^{+}$e as limitações desse método são discutidas na Seção 5.8 .

A seguir será mostrada a obtenção do $D_{h}$ a partir de cada método separadamente e, posteriormente, os valores de $D_{h}$ obtidos pelos diferentes métodos são mostrados na Tabela 5.28 e então analisados.

\section{Primeiro método:}

Para a utilização do método proposto pro Brigham, Reed e Hunt (1961) e Brigham (1974), primeiro é necessário construir gráficos de U versus \% de fluido deslocado, conforme 
detalhado na Seção 3.14.1. As Figuras 5.52, 5.53 e 5.54 mostram esses gráficos obtidos para as três colunas onde percolaram as soluções com $\mathrm{NH}_{4}^{+}$

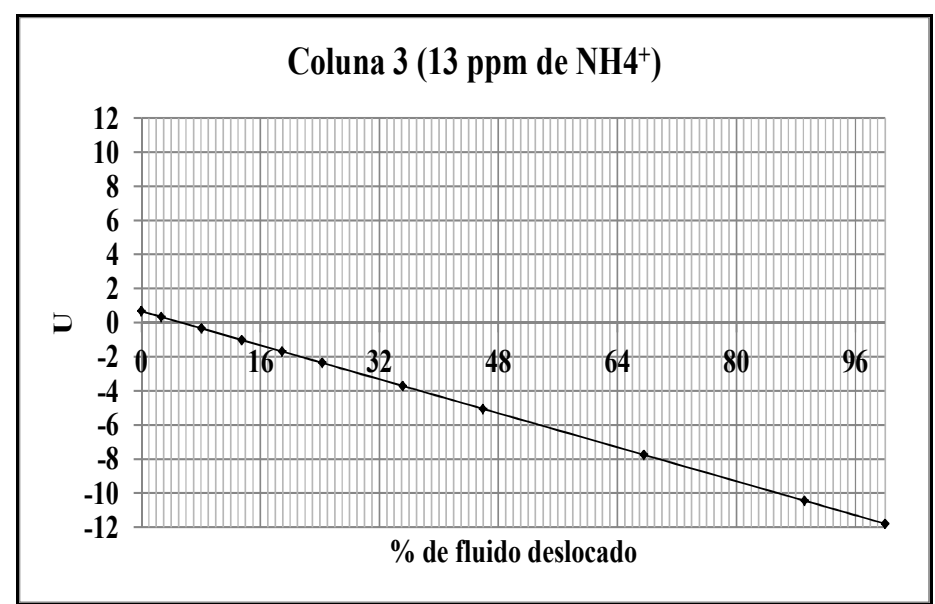

Figura 5.52- Curva U versus \% de fluido percolado para $C_{0}$ de 13 ppm de amônio

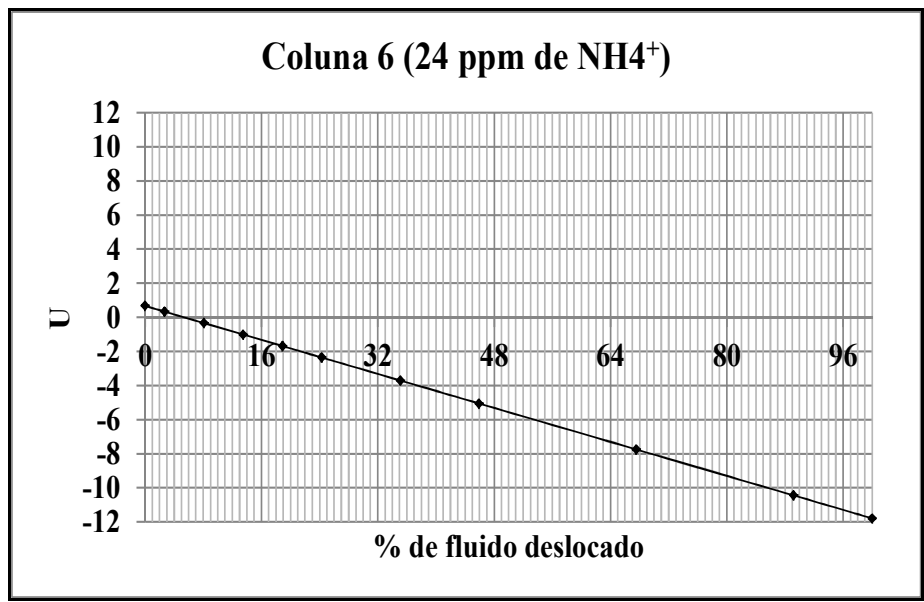

Figura 5.53- Curva U versus \% de fluido percolado para $C_{0}$ de 24 ppm de amônio

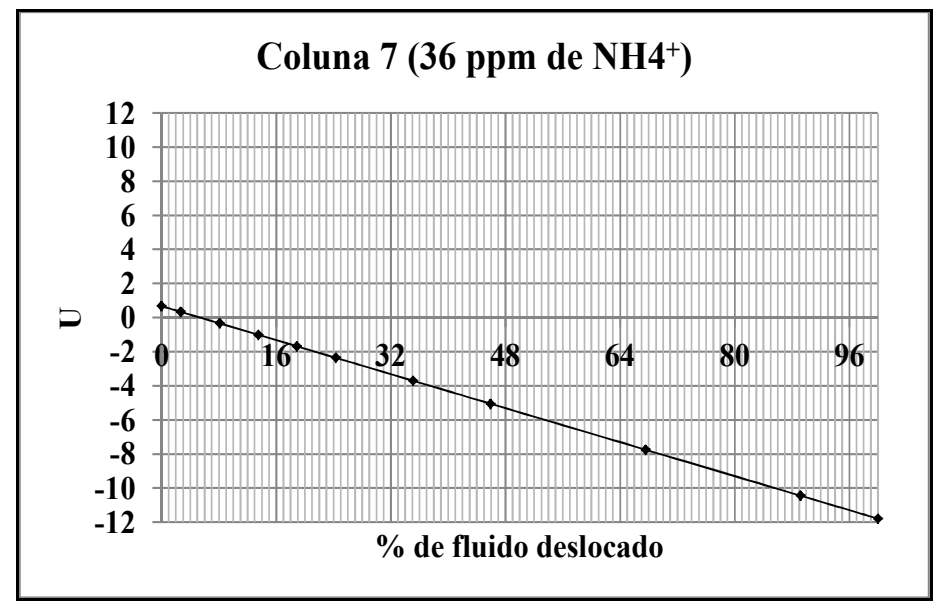

Figura 5.54- Curva U versus \% de fluido percolado para $\mathrm{C}_{0}$ de $36 \mathrm{ppm}$ de amônio 
Tabela 5.26 Parâmetros $\mathrm{U}_{16}$ e $\mathrm{U}_{84}$ para diferentes colunas percoladas com amônio

\begin{tabular}{cccccc}
\hline \multicolumn{2}{c}{ Coluna 3 } & \multicolumn{2}{c}{ Coluna 6 } & \multicolumn{2}{c}{ Coluna 7 } \\
\multicolumn{2}{c}{$\left(\mathbf{1 3 p p m ~ d e ~} \mathbf{N H}_{4}{ }^{+}\right)$} & \multicolumn{2}{c}{$\left.\mathbf{( 2 4} \mathbf{~ p p m ~ d e ~} \mathbf{N H}_{\mathbf{4}}{ }^{+}\right)$} & \multicolumn{2}{c}{$\left.\mathbf{( 3 6 p p m ~ d e ~} \mathbf{N H}_{\mathbf{4}}{ }^{+}\right)$} \\
\hline $\mathbf{U}_{\mathbf{1 6}}$ & $\mathbf{U}_{\mathbf{8 4}}$ & $\mathbf{U}_{\mathbf{1 6}}$ & $\mathbf{U}_{\mathbf{8 4}}$ & $\mathbf{U}_{\mathbf{1 6}}$ & $\mathbf{U}_{\mathbf{8 4}}$ \\
$\mathbf{- 1 , 4 2}$ & $-10,36$ & $-1,45$ & $-10,53$ & $-1,49$ & $-10,45$ \\
\hline
\end{tabular}

Após a construção dos gráficos, obteve-se o $D_{h}$ para cada coluna a partir da Equação 70. Os resultados do $D_{h}$ encontram-se na Tabela 5.28, juntamente dos resultados obtidos por outros métodos.

\section{Terceiro método:}

Para obter o $D_{h}$ a partir do método proposto por Singh (1998) é necessário que se determine os parâmetros $t_{0}$ e $m$ a partir da curva de chegada, conforme descrito na Seção 3.14.1. As Figuras 5.55, 5.56 e 5.57 mostram a obtenção gráfica desses valores e na Tabela 5.27 encontram-se os valores desses parâmetros para as três colunas analisadas.

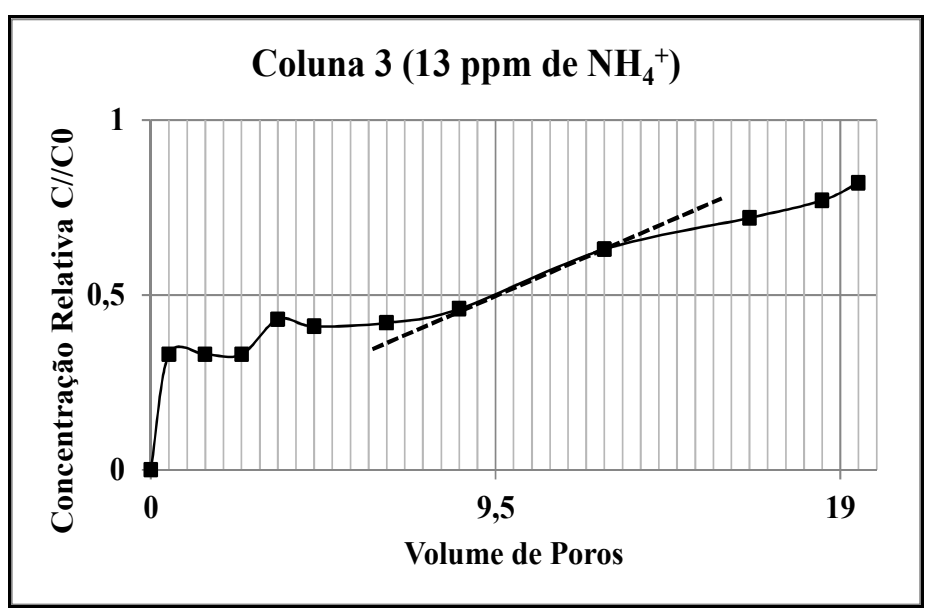

Figura 5.55- Obtenção dos parâmetros $\mathrm{t}_{0} \mathrm{e} \mathrm{m}$ a partir da curva de chegada para $\mathrm{C}_{0}$ de 13 ppm de amônio 


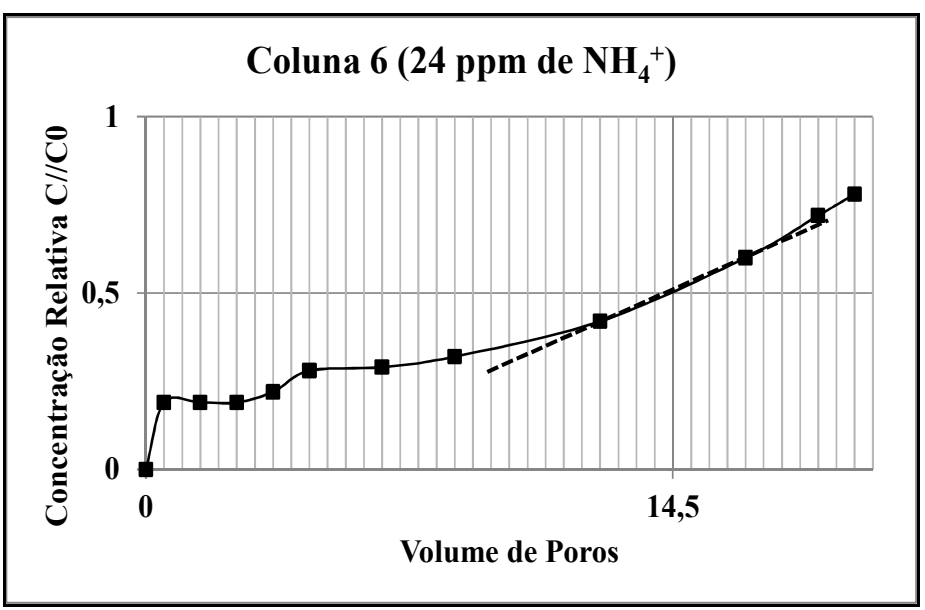

Figura 5.56- Obtenção dos parâmetros $\mathrm{t}_{0} \mathrm{e} \mathrm{m}$ a partir da curva de chegada para $\mathrm{C}_{0} 24$ ppm de amônio

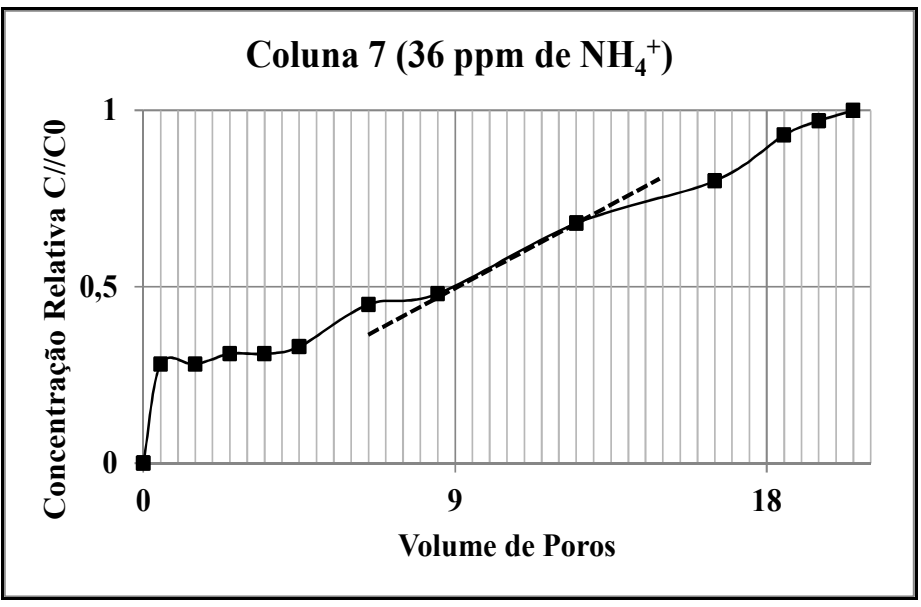

Figura 5.57- Obtenção dos parâmetros $\mathrm{t}_{0} \mathrm{e} \mathrm{m}$ a partir da curva de chegada para $\mathrm{C}_{0} 36 \mathrm{ppm}$ de amônio

Tabela 5.27 Parâmetros $\mathrm{t}_{0}$ e $\mathrm{m}$ das curvas de chegada de amônio

\begin{tabular}{|c|c|c|c|c|c|}
\hline \multicolumn{2}{|c|}{$\begin{array}{c}\text { Coluna } 3 \\
\left(13 p p m \text { de } \mathrm{NH}_{4}^{+}\right)\end{array}$} & \multicolumn{2}{|c|}{$\begin{array}{c}\text { Coluna } 6 \\
\left(24 \mathrm{ppm} \text { de } \mathrm{NH}_{4}^{+}\right)\end{array}$} & \multicolumn{2}{|c|}{$\begin{array}{c}\text { Coluna } 7 \\
\left(36 p p m \text { de } \mathrm{NH}_{4}^{+}\right)\end{array}$} \\
\hline$t_{0}(\min )$ & $\mathrm{m}\left(\mathrm{min}^{-1}\right)$ & $\overline{t_{0}(\min )}$ & $m\left(\min ^{-1}\right)$ & $\mathbf{t}_{0}(\min )$ & $m\left(\min ^{-1}\right)$ \\
\hline 823,43 & 0,0425 & 2294,68 & 0,045 & 978,49 & 0,104 \\
\hline
\end{tabular}

Após a obtenção dos parâmetros $t_{0}$ e $m$, calculou-se o $D_{h}$ para as três colunas, de acordo com a Equação 55.

$$
D_{h}=\frac{L^{2}}{4 \pi m^{2} t_{0}^{3}}
$$




\section{Quarto método:}

Para obtenção do $D_{h}$ pelo método proposto por Bear (1961) utilizou-se o coeficiente de dispersividade longitudinal de acordo com o método proposto por Fetter (1993), pelos motivos discutidos na Seção 5.7.1.

Considerando $D^{*}$ como nulo, como sugeriu Singh (1998), calculou-se o $D_{h}$ por meio da Equação 51.

A Tabela 5.28 mostra os resultados dos coeficientes de dispersão hidrodinâmica obtidos com os três métodos utilizados.

Tabela 5.28- Coeficientes de dispersão hidrodinâmica para as colunas percoladas com $\mathrm{NH}_{4+}$

Coeficiente de Dispersão Hidrodinâmica de $\mathrm{NH}_{4}{ }^{+}\left(\mathrm{m}^{2} / \mathrm{min}\right)$

\begin{tabular}{|c|c|c|c|}
\hline Método & $\begin{array}{c}\text { Coluna } 3 \\
\left(13 p p m \text { de } \mathrm{NH}_{4}^{+}\right)\end{array}$ & $\begin{array}{c}\text { Coluna } 6 \\
\left(24 \mathrm{ppm} \text { de } \mathrm{NH}_{4}^{+}\right)\end{array}$ & $\begin{array}{c}\text { Coluna } 7 \\
\left(36 p p m \text { de } \mathrm{NH}_{4}^{+}\right)\end{array}$ \\
\hline Brigham (1974) & $5,32 \mathrm{E}-03$ & $2,77 \mathrm{E}-03$ & $5,07 \mathrm{E}-03$ \\
\hline Singh (1998) & 1,77E-09 & $7,31 \mathrm{E}-11$ & $2,40 \mathrm{E}-11$ \\
\hline Bear (1961) & $1,97 \mathrm{E}-04$ & $2,25 \mathrm{E}-04$ & $2,85 \mathrm{E}-04$ \\
\hline
\end{tabular}

Os valores de $D_{h}$ de $\mathrm{NH}_{4}{ }^{+}$obtidos com o método proposto por Bear (1961) e Brigham (1974) apresentaram valores muito maiores quando comparados com valores obtidos com o método proposto por Singh (1998). Assim, utilizando os métodos propostos por Bear (1961) e Brigham (1974), o mecanismo de transporte predominante seria a dispersão, assim como constatou Shackelford (1994). Por outro lado, valores de $D_{h}$ na ordem de $10 \mathrm{E}-07 \mathrm{~m}^{2} / \mathrm{min}$, como os de Singh (1998), indicam que a dispersão não é um mecanismo importante no transporte de $\mathrm{NH}_{4}{ }^{+}$neste solo.

As colunas de solo estudadas nesta pesquisa possuem grande presença dos macroporos (Figuras 5.8 e 5.9) e eles estão influenciando diretamente os mecanismos de transporte atuantes. Desta maneira, acredita-se que a velocidade linear média esteja representando a velocidade do fluxo predominantemente por esses macroporos e que por isso os valores de $D_{h}$ estejam tão divergentes entre os diversos métodos, principalmente entre aqueles que consideram a velocidade linear média na equação de obtenção do $D_{h}$ (Brigham, 1974 e Bear 1961) e o que não considera (Singh, 1998). Por isso, mais uma vez utilizando a Equação 54, para concentração relativa igual a 0,5 , realizou-se uma retroanálise, onde, a partir do $D_{h}$, 
obteve-se a velocidade linear média, para verificar se os valores ficariam muito diferentes daqueles medidos no laboratório.

$$
\frac{C}{C_{0}}=\frac{1}{2}\left[\operatorname{erfc}\left(\frac{L-v t}{2 \sqrt{D_{h} t}}\right)\right]
$$

Escolheu-se a concentração relativa igual a 0,5 , por ela ser utilizada no método de Brigham e Singh para a obtenção dos parâmetros utilizados para obtenção do $D_{h}$. A Tabela 5.29 mostras os resultados dessa análise.

Tabela 5.29 Velocidades lineares médias obtidas a partir do $D_{h}$ das colunas percoladas com $\mathrm{NH}_{4}^{+}$

Velocidade linear média a partir do $D_{h}(\mathrm{~m} / \mathrm{min})$

\begin{tabular}{|c|c|c|c|}
\hline Método & $\begin{array}{c}\text { Coluna } 3 \\
\left(35 \text { ppm de } \mathrm{NH}_{4}{ }^{+}\right) \\
v \text { medida }=3,56 \mathrm{E}-03\end{array}$ & $\begin{array}{c}\text { Coluna } 6 \\
\left(65 \text { ppm de } \mathrm{NH}_{4}{ }^{+}\right) \\
\text {v medida }=1,79 \mathrm{E}-03\end{array}$ & $\begin{array}{c}\text { Coluna } 7 \\
\left(95 \text { ppm de } \mathrm{NH}_{4}^{+}\right) \\
\text {v medida }=3,37 \mathrm{E}-03\end{array}$ \\
\hline $\begin{array}{c}D_{h} \text { por } \\
\text { Brigham (1974) }\end{array}$ & $-1,87 \mathrm{E}-02$ & $-9,94 \mathrm{E}-03$ & $-1,66 \mathrm{E}-02$ \\
\hline $\begin{array}{c}D_{h} \text { por } \\
\text { Singh (1998) }\end{array}$ & $3,45 \mathrm{E}-03$ & 1,89E-03 & $2,76 \mathrm{E}-03$ \\
\hline $\begin{array}{c}D_{h} \text { por } \\
\text { Bear }(1961)\end{array}$ & $-8,03 \mathrm{E}-04$ & $-1,48 \mathrm{E}-03$ & $-1,82 \mathrm{E}-03$ \\
\hline
\end{tabular}

A partir do $D_{h}$ obtido com os métodos de Brigham (1974) e Bear (1961) a velocidade linear média resultou em valores negativos. Esses valores negativos indicam que não seria possível obter o $D_{h}$ do $\mathrm{NH}_{4}{ }^{+}$com a velocidade linear média calculada dos ensaios de coluna, devido à relação $L-v t$ da Equação 54 ser negativa, indicando que o $D_{h}$ obtido com os métodos de Brigham (1974) e Bear (1961) provavelmente não representa bem o solo estudado nesta pesquisa. Isso pode ser justificado pelo fato de que a equação proposta por Brigham (1974), é baseada em relações empíricas para outros materiais, e, portanto, ela pode não ser representativa do material estudado nesta pesquisa. Além disso, o método proposto por Bear (1961), apesar de ser bastante usado, é fortemente influenciado pela determinação do $\alpha_{1}$ com todas as dificuldades envolvidas, como discutidas previamente, e, portanto, sua utilização deve ser feita com cautela.

As velocidades obtidas a partir do $D_{h}$ do $\mathrm{NH}_{4}{ }^{+}$calculado com o método de Singh (1998) novamente mostraram valores muito próximos com os valores obtidos por meio dos ensaios de coluna. Isso sugere que os coeficientes de dispersão hidrodinâmica do $\mathrm{NH}_{4}^{+}$ obtidos com o método proposto por Singh (1998) pode representar bem a dispersão deste íon 
no solo analisado. Seus valores são muito inferiores quando comparados com aqueles obtidos com os outros métodos. Essa grande diferença no valor do $D_{h}$ pode estar relacionada ao fato de que este método não utiliza a velocidade linear média, nem dados de vazão, área da seção transversal, condutividade hidráulica saturada e porosidade efetiva, podendo ser menos influenciado por erros nesses parâmetros, o que é uma vantagem no uso deste método. Devido às características de dupla porosidade das colunas estudadas, é possível que esses parâmetros tenham sido fortemente influenciados pelos macroporos e, portanto, represente principalmente o fluxo por esses canais preferenciais.

Com a análise dos diferentes métodos de obtenção do $D_{h}$, do $\mathrm{NH}_{4}{ }^{+}$observa-se que aquele proposto por Singh (1998) apesar de suas limitações discutidas previamente, ao resultar em valores de $D_{h}$ na ordem de $10 \mathrm{E}-11$ a $10 \mathrm{E}-09 \mathrm{~m}^{2} / \mathrm{min}$ indicam que a dispersão não deve ser o processo predominante no transporte de $\mathrm{NH}_{4}{ }^{+}$no material estudado nesta pesquisa. Para ajudar na análise desta possibilidade, calculou-se o número de Péclet para cada coluna utilizando todos os $D_{h}$ do $\mathrm{NH}_{4}^{+}$obtidos com os três métodos.

Tabela 5.30 Números de Péclet obtidos a partir do $D_{h}$ das colunas percoladas com $\mathrm{NH}_{4}{ }^{+}$

\section{Número de Péclet}

\begin{tabular}{cccc}
\hline Método & $\begin{array}{c}\text { Coluna 3 } \\
\left(\mathbf{1 3 p p m ~ d e ~} \mathbf{N H}_{\mathbf{4}}{ }^{+}\right)\end{array}$ & $\begin{array}{c}\text { Coluna 6 } \\
\left(\mathbf{2 4} \mathbf{~ p p m ~ d e ~} \mathbf{~ H}_{\mathbf{4}}{ }^{+}\right)\end{array}$ & $\begin{array}{c}\text { Coluna 7 } \\
\left(\mathbf{3 6 p p m ~ d e ~} \mathbf{~ H}_{4}{ }^{+}\right)\end{array}$ \\
Brigham (1974) & 0,10 & 0,10 & 0,10 \\
Singh (1998) & $3,01 \mathrm{E}+05$ & $3,68 \mathrm{E}+06$ & $2,10 \mathrm{E}+07$ \\
Bear (1961) & 2,71 & 1,20 & 1,77 \\
\hline
\end{tabular}

A análise da Tabela 5.30 mostra que os valores de $D_{h}$ obtidos com o método proposto por Brigham (1974) e Bear (1961) retornam P entre 0,10 e 4,14. Estes valores de número de Péclet indicam que o mecanismo de transporte dominante é a difusão. Isto não é coerente com as características do soluto e do solo, visto que a difusão atua principalmente em solos com $k$ muito pequeno e com soluto de baixa mobilidade como os metais potencialmente tóxicos. $\mathrm{O}$ número de Péclet obtido a partir do $D_{h}$ calculado pelo método de Singh (1998) resultou na ordem de $10 \mathrm{E}+05$ a $10 \mathrm{E}+07$ é indicando que existe um regime de alto fluxo em que a advecção predomina sobre a difusão no transporte de $\mathrm{NH}_{4}^{+}$. Isto provavelmente está relacionado a alta velocidade linear média obtida nos ensaios de coluna. 


\subsubsection{6. $\quad$ Fator de retardamento}

Conforme Seção 2.14.2, o fator de retardamento foi obtido por meio de três métodos. A seguir será mostrada a obtenção do $R_{d}$ a partir de cada método separadamente e, posteriormente, os valores de $R_{d}$ obtidos pelos diferentes métodos são mostrados na Tabela 5.32 e então analisados.

\section{Primeiro método:}

O primeiro método utilizado foi proposto por van Genuchten e Parker (1984) e o $R_{d}$ é obtido através do cálculo da área acima da curva de chegada, $H$, conforme detalhado na Seção 3.14.2. Este método deve ser utilizado quando a concentração relativa atinge o equilíbrio. Assim sendo, apenas a curva de chegada relativa à coluna 7 permitiu a obtenção do $R_{d}$ do $\mathrm{NH}_{4}{ }^{+}$por este método

\section{Segundo método:}

No segundo método utilizado, proposto por Freeze e Cherry (1979) e Shackelford (1993;1994), o $R_{d}$ é igual ao número de volume de poros quando a concentração relativa é igual a 0,5 . As Figuras 5.58, 5.59 e 5.60 mostram a obtenção do $R_{d}$ do $\mathrm{NH}_{4}^{+}$por este método.

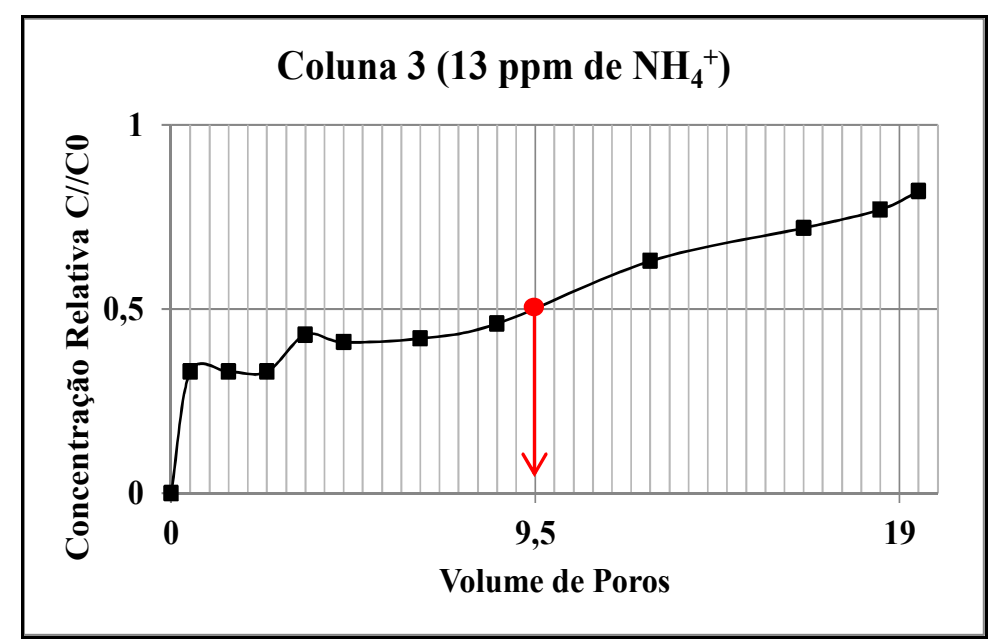

Figura 5.58- Obtenção do fator de retardamento pelo método de Freeze e Cherry (1979) e Shackelford $(1993 ; 1994)$ para $C_{0}$ de 13 ppm de amônio 


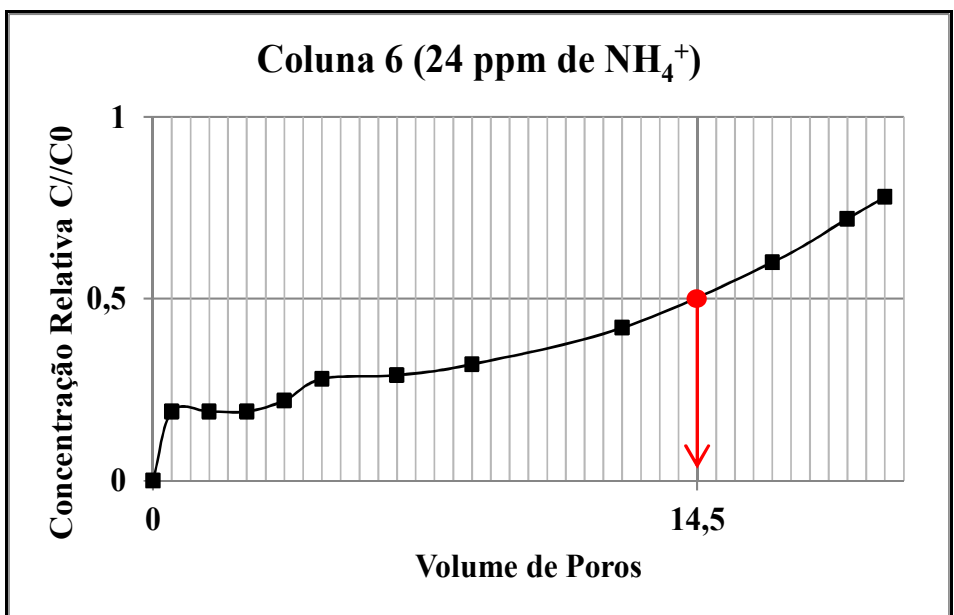

Figura 5.59- Obtenção do fator de retardamento pelo método de Freeze e Cherry (1979) e Shackelford $(1993 ; 1994)$ para $C_{0}$ de 24 ppm de amônio

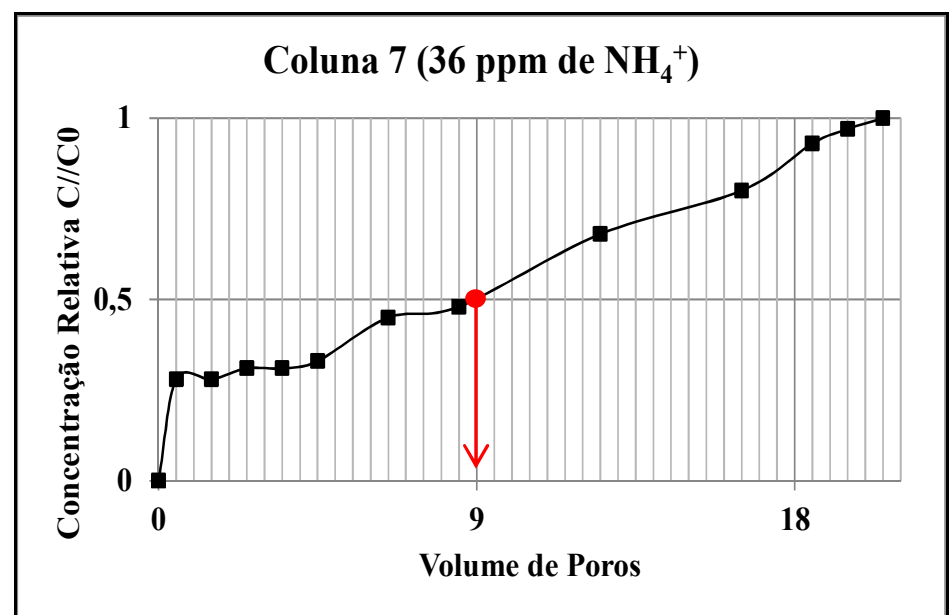

Figura 5.60- Obtenção do fator de retardamento pelo método de Freeze e Cherry (1979) e Shackelford $(1993 ; 1994)$ para $C_{0}$ de 36 ppm de amônio

\section{Terceiro método:}

O terceiro método utilizado permitiu a obtenção do $R_{d}$ por meio da construção da isoterma de sorção para o $\mathrm{NH}_{4}^{+}$(Figura 5 61). 


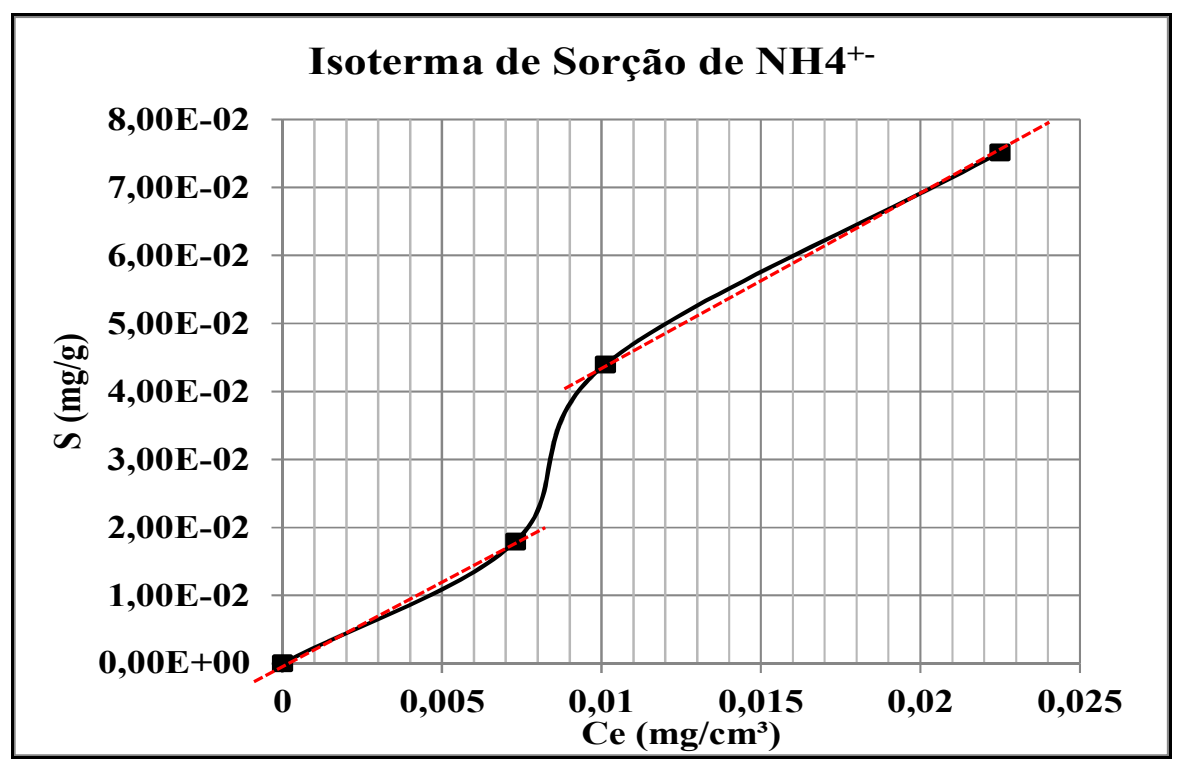

Figura 5.61- Isoterma de sorção de amônio

Nota-se que esta isoterma apresenta duas regiões lineares o que pode representar que a baixas concentrações, o comportamento é de sorção linear, mas ao se trabalhar com altas concentrações, ainda maiores do que as concentrações utilizadas nesta pesquisa, poderia se constatar que a segunda região poderia representar a região linear de algum outro tipo de isoterma não linear.

Com a isoterma construída, realizaram-se os procedimentos de linearização para verificar qual o ajuste dos diferentes modelos de isotermas aos dados experimentais (Figuras 5.62 a 5.65$)$

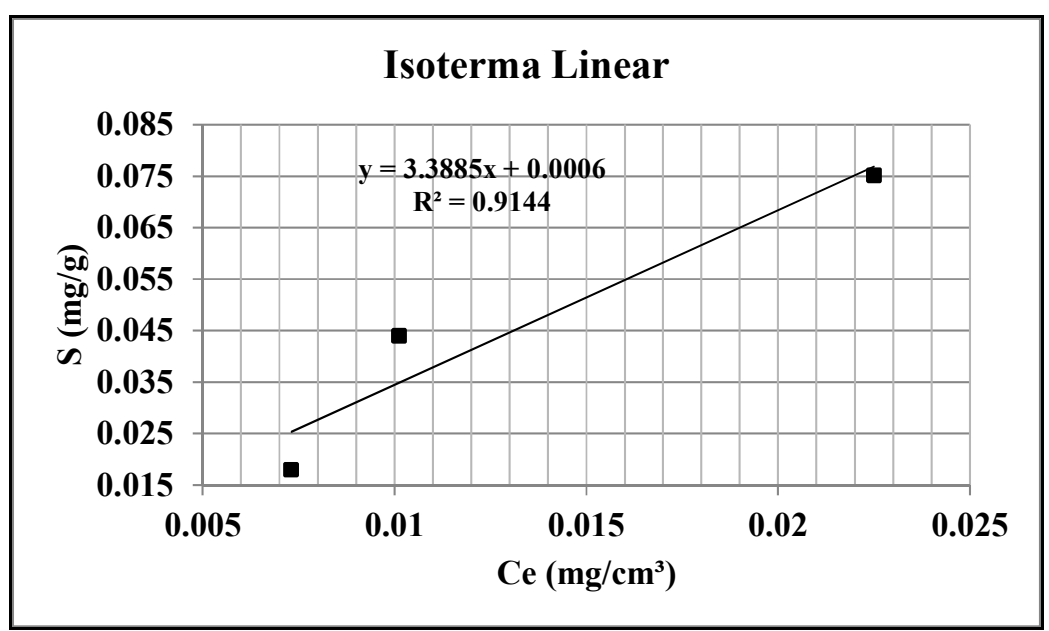

Figura 5.62- Ajuste dos dados experimentais de amônio ao modelo de isoterma Linear 


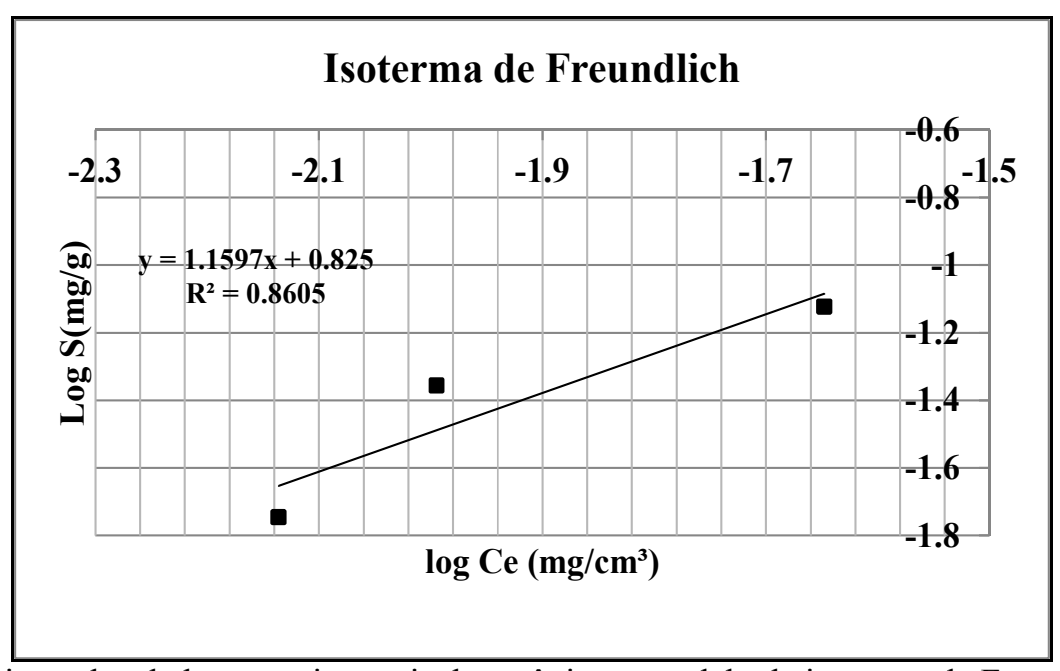

Figura 5.63- Ajuste dos dados experimentais de amônio ao modelo de isoterma de Freundlich

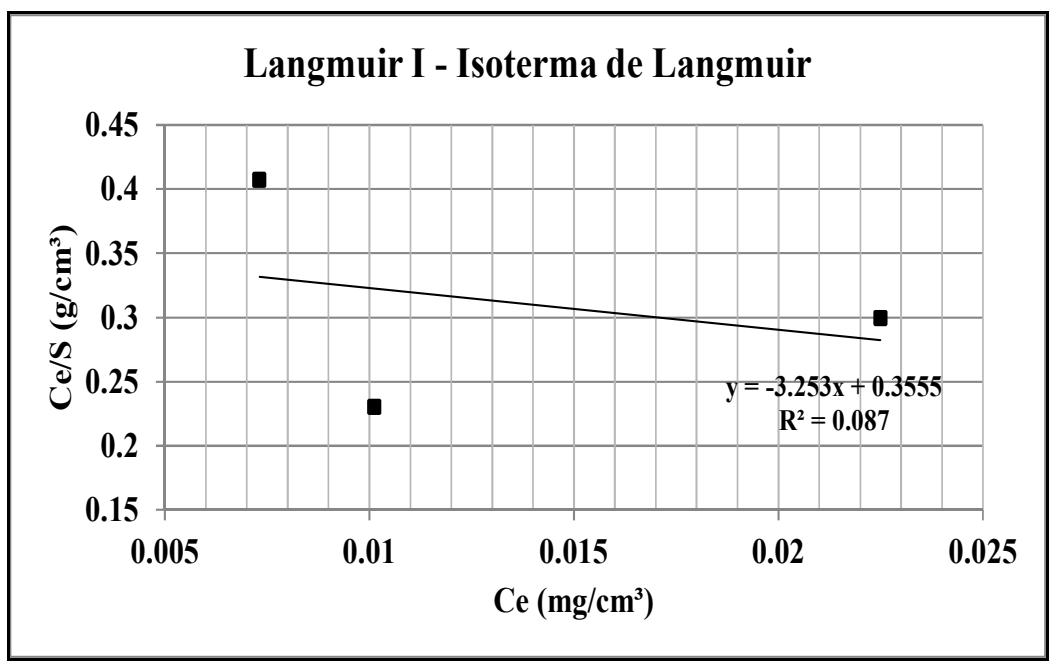

Figura 5.64- Ajuste dos dados experimentais de amônio ao modelo de Langmuir ( Langmuir I)

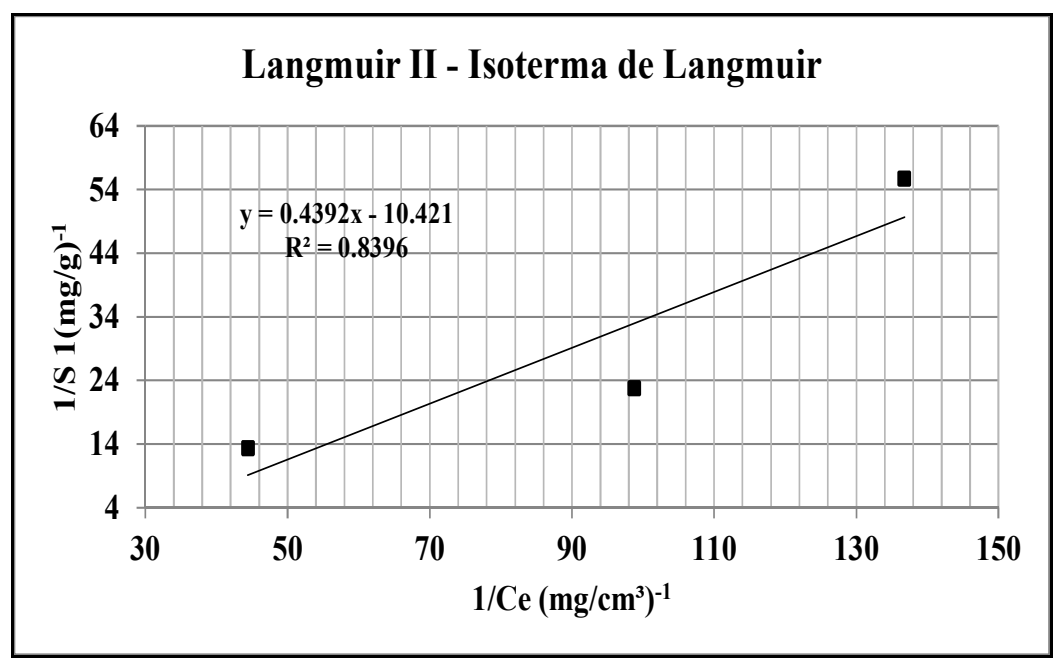

Figura 5.65 Ajuste dos dados experimentais de fosfato ao modelo de Langmuir ( Langmuir II) 
A Tabela 5.31 mostra os coeficientes de determinação para cada um dos ajustes realizados.

Tabela 5.31Coeficientes de determinação para ajuste dos modelos das isotermas

\begin{tabular}{cc}
\hline Modelo & $\begin{array}{c}\text { Coeficiente de } \\
\text { Determinação R }\end{array}$ \\
\hline Linear & 0,9144 \\
Freundlich & 0,8605 \\
Langmuir I & 0,087 \\
Langmuir II & 0,8396 \\
Langmuir por regressão $_{\text {não linear }}{ }^{2}$ & 0.9832 \\
\hline
\end{tabular}

1 regressão não linear feita por meio do software comercial Mathematica 9.0 da Wolfram Research

A Tabela 5.32 mostra os resultados dos fatores de retardamento obtidos com os três métodos utilizados. Os valores de retardamento do amônio foram maiores do que os retardamentos obtidos para o fosfato. Esses resultados diferem dos resultados obtidos em outras pesquisas (OLIVEIRA et al., 2004; MARTINEZ; SILVA; PEREIRA, 2010). A despeito disso, os retardamentos obtidos tanto para fosfato quanto para o amônio encontramse muito superiores do que os valores obtidos por outros pesquisadores (ANAMI, et al. 2007; OLIVEIRA et al., 2004; MARTINEZ; SILVA; PEREIRA, 2010). Esses retardamentos altos podem indicar que o mecanismo de sorção pode estar atuando mais fortemente do que o esperado neste material inconsolidado devido à combinação com o retardamento físico que pode estar ocorrendo no material. No entanto, o retardamento depende dos métodos utilizados para sua determinação, das concentrações iniciais das soluções percolantes e das características do material, fazendo com que simples comparações não sejam adequadas, visto as peculiaridades de cada pesquisa.

Novamente os retardamentos do amônio obtidos com o método de van Genuchten e Parker (1984) para a situação em que a área acima da curva de chegada é igual ao $R_{d}$, são iguais àqueles obtidos a partir da Equação 74 na situação em que o número de Péclet é calculado a partir do $D_{h}$ obtido com o método proposto por Singh (1998).

$$
H=R_{d}\left[1+\left[\frac{1}{P}\right]\right]
$$


Isto indica que neste método o balanço de massa esta sendo considerado adequadamente, e que a equação completa de Ogata (1958) e Ogata e Banks (1961) provavelmente seria a mais adequada para analisar o transporte de solutos no solo desta pesquisa.

Para as situações em que no cálculo do número de Péclet foi considerado o $D_{h}$ obtido pelo método de Brigham (1974) e por Bear (1962), nota-se que os retardamentos ficaram menores do que os valores obtidos com os outros métodos, em especial àquele obtido com o método proposto por Brigham. Isto sugere que os $D_{h}$ do amônio obtidos com estes métodos provavelmente não representam bem a dispersão deste íon no solo estudado.

Tabela 5.32 Fatores de retardamento obtidos com diferentes métodos para amônio

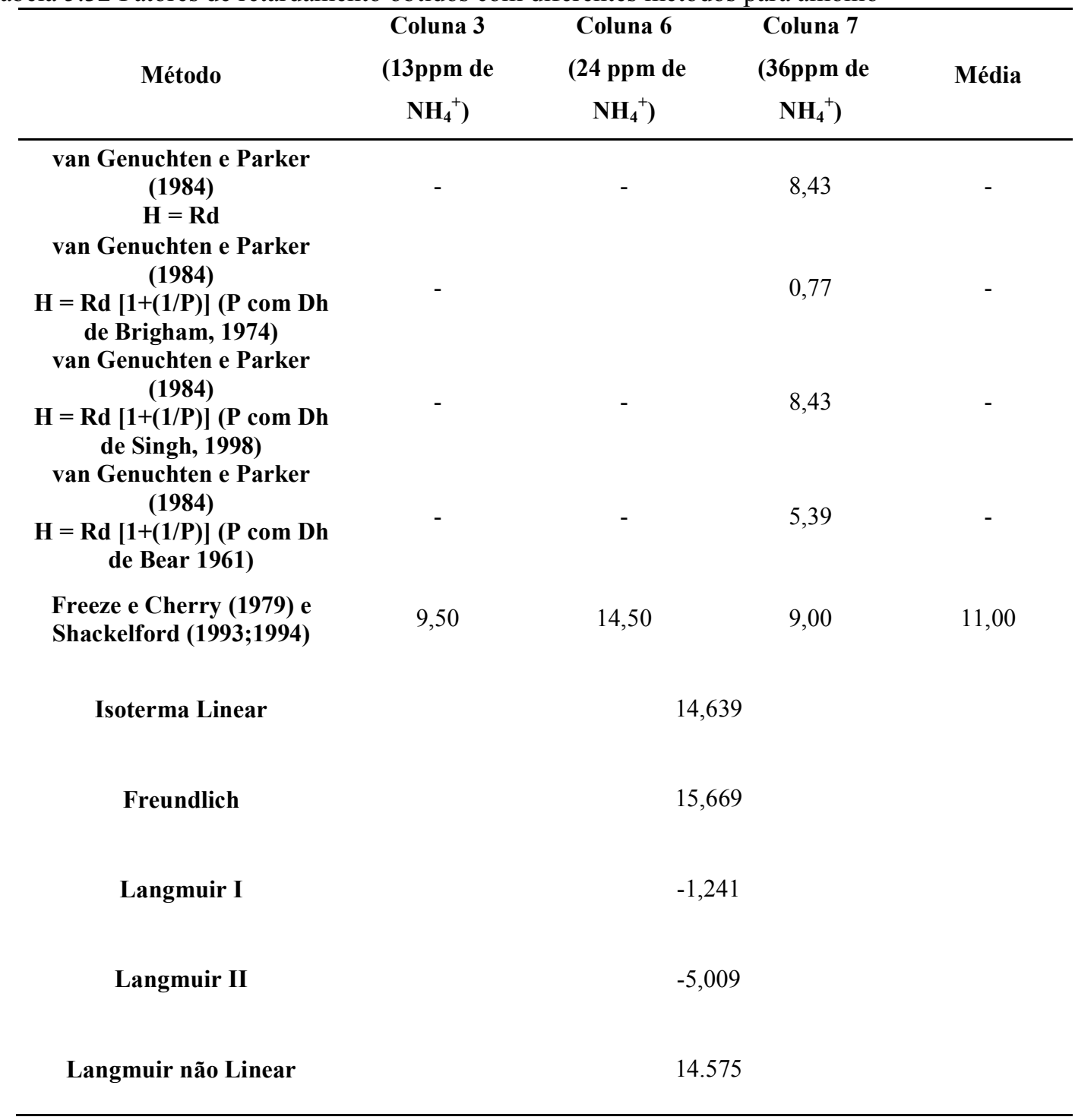


Os valores de retardamentos obtidos com o método proposto por Freeze e Cherry (1979) e Shackelford (1994) não possuem um padrão em relação à concentração inicial, diferentemente de Jellai et al. (2010), que, ao testarem 6 concentrações iniciais diferentes de amônio, o retardamento foi maior quanto maior a concentração inicial, para as condições da pesquisa. A coluna 6 apresentou uma retardamento de amônio cerca de 55\% maior do que as outras colunas. As colunas 3 e 7 apresentaram valores de retardamento próximos daqueles obtidos com o método proposto por van Genuchten e Parker (1984). Observando a Tabela 5.2 (características físico-químicas do material), nota-se que o máximo $S(0,075157 \mathrm{mg} / \mathrm{g})$ para a isoterma de sorção de $\mathrm{NH}_{4}{ }^{+}$é maior do que a CTC do solo $(0,00152 \mathrm{mg} / \mathrm{g})$ o que indica que a retenção do amônio neste solo não está ocorrendo por troca catiônica, mas sim por mecanismos físicos.

Em relação aos retardamentos do amônio obtidos com os ajustes das isotermas, constata-se que os ajustes lineares dos dados experimentais aos modelos de Langmuir não permitiram o cálculo do retardamento, apesar de a linearização de Langmuir II ter apresentado um coeficiente de determinação de 0,8396 . Isto porque os parâmetros $b$ e $S_{m}$ resultaram em valores negativos para os ajustes de Langmuir I e Langmuir II, respectivamente, fazendo com que o retardamento ficasse negativo, o que é incoerente com o processo, já que isto significa que a velocidade do soluto é maior do que a velocidade linear média da água. Por outro lado, o ajuste não linear dos dados experimentais ao modelo de Langmuir teve um coeficiente de determinação de 0.9832, além de valores de retardamento de amônio muito próximos daqueles obtidos por meio das outras isotermas. Os ajustes para as isotermas Linear e de Freundlich resultaram em valores muito próximos entre si (14,639 e 15,669 para a isoterma Linear e de Freundlich, respectivamente). No entanto, os solos possuem capacidade de sorção limitada, o que não é representado por estas duas isotermas, acreditando-se que o retardamento obtido com o ajuste não linear do modelo de Langmuir seja o que melhor represente o comportamento do amônio neste material.

Assim como verificado para o fosfato, os retardamentos do amônio obtidos por meio das isotermas resultaram em valores superiores quando comparados com os outros métodos utilizados. Como a obtenção do $R_{d}$ por meio de isotermas resulta em apenas um valor para todo o material, pode estar subestimando ou superestimando o retardamento do íon no solo. No entanto, percebe-se que o uso das isotermas parece resultar em valores coerentes, principalmente quando os dados experimentais estiverem bem ajustados aos modelos. Além disso, a construção da isoterma leva em consideração o que está ocorrendo no solo com as 
massas sorvidas e não sorvidas pelo solo, ou seja, considera o comportamento real de sorção do íon pelo material.

Como algumas curvas de chegada não alcançaram o equilibrou da concentração relativa e não seguiram o padrão de quanto maior a concentração inicial, maior o fator de retardamento, houve dificuldade na determinação do fator de retardamento por todos os métodos utilizados. Esta complexidade na determinação $R_{d}$ para o amônio é esperada visto que o $\mathrm{N}$ em contato com o solo possui um comportamento muito intricado. A despeito disso, por se tratar de colunas com solos naturais, as imperfeições presentes no material podem ter dificultado a obtenção dos fatores de retardamento. Apesar das dificuldades encontradas na determinação dos parâmetros de transporte do amônio, acredita-se que o mecanismo predominantemente deve ser físico, devido às características de dupla porosidade deste solo, como mencionado previamente. Contudo, parte do transporte deve estar ocorrendo por mecanismos químicos de adsorção não específica.

\subsection{COEFICIENTE dE DISPERSÃo hIDRODINÂMICA: MÉTOdO dE OGATA (1958) E OGATA E BANKS (1961)}

O método proposto por Ogata (1958) e Ogata e Banks (1961) não se mostrou adequado para o calculo do $D_{h}$ para nenhum dos íons estudados nesta pesquisa. Isto deu-se pelo fato de que a relação $(\mathrm{L}-\mathrm{vt})$ da Equação 54 resultou em valores negativos, o que fornece um valor de $D_{h}$ imaginário.

$$
\frac{C}{C_{0}}=\frac{1}{2}\left[\operatorname{erfc}\left(\frac{L-v t}{2 \sqrt{D_{h} t}}\right)\right]
$$

Este método poderia ser utilizado para colunas de solo com comprimentos maiores, o que tornaria a relação $L$ - vt positiva para os dados experimentais obtidos nesta pesquisa, e permitiria a obtenção do $D_{h}$.

No caso do sódio, para o mesmo comprimento de coluna utilizado nesta pesquisa, caso a velocidade linear média fosse menor, na ordem de $10 \mathrm{E}-04 \mathrm{~m} / \mathrm{min}$, a relação $(\mathrm{L}-\mathrm{vt})$ poderia ser positiva, o que permitiria o cálculo do $\mathrm{D}_{\mathrm{h}}$ por este método. No caso do fosfato e do amônio, caso a velocidade fosse na ordem de $10 \mathrm{E}-05 \mathrm{~m} / \mathrm{min}$, a relação $(L-v t)$ poderia ser positiva, o que permitiria o cálculo do $D_{h}$ por este método. 
Desta maneira, este método não deve ser utilizado para qualquer ensaio de coluna, sendo que ele é adequado para situações em que a velocidade linear média seja suficientemente pequena a ponto de permitir que a relação $(\mathrm{L}-\mathrm{vt})$ seja positiva. Em geral, velocidades pequenas são obtidas em situações em que o mecanismo de transporte predominante é a difusão. Com a velocidade média na ordem de $10 \mathrm{E}-02 \mathrm{~m} / \mathrm{min}$ e $10 \mathrm{E}-$ $03 \mathrm{~m} / \mathrm{min}$ na percolação do $\mathrm{Na}^{+}$e $\mathrm{NH}_{4}{ }^{+}$e $\mathrm{PO}_{4}{ }^{3-}$, respectivamente, observa-se que há uma parcela do transporte em que o mecanismo predominante é a advecção.

Assim, mesmo sendo indicado para solos arenosos, como o solo deste trabalho, o método pode não ter sido adequado para as colunas aqui estudadas por se tratarem de colunas indeformadas que possuem forte presença de macroporos, além de outras irregularidades naturais presentes nos solos que podem, aumentar a velocidade linear média, tornar parcela significativa do transporte em advectivo e, assim, dificultar o uso deste método. Outro ponto a ser observado é que, o método proposto por Ogata (1958) e Ogata e Banks (1961) é indicado para solos arenosos com granulação grossa, mas os solos das colunas aqui estudadas possuem a maior parte dos grãos contidos no intervalo granulométrico de areia fina a média, como pode ser observados nas curvas granulométricas (Figura 5.2).

\subsection{ANÁlISE DAS TRAJETÓRIAS DE TRANSPORTE}

Devido à macroporosidade observada neste material durante as caracterizações, realizou-se a análise da trajetória de transporte por acreditar que os macroporos exerceriam papel fundamental no transporte de soluto neste solo. As Figuras 5.66a até 6.66f mostram a realização da análise da trajetória de transporte. Nota-se que, apesar de distribuir igualmente a solução de azul de metileno na parte superior da coluna, há um local onde o fluxo ocorre mais rápido do que no restante da coluna. Isto pode ser observado na Figura6.66c, onde a mancha no papel filtro mostra o local onde o fluxo se dava de maneira preferencial (destaque na foto). Após ocorrer esta mancha o ensaio foi encerrado e a coluna foi cortada transversalmente (Figura 5.66d).

Observa-se que o azul de metileno possui um retardamento em relação à água (Figura 5.66e e 5.66f) e que ele não foi detectado na saída da coluna. Este foi um resultado bastante interessante, visto que mesmo após inserir 1,5 litros de solução, o azul de metileno continua na parte superficial da coluna. A retenção do azul de metileno mostra que o solo possui uma sorção muito significativa, contrariando o que é esperado para solos arenosos. Isto auxilia a 
entender os valores de fator de retardamento altos, principalmente para os cátions. Assim é possível que os mecanismos químicos estejam atuando fortemente no retardamento dos cátions, assim como os mecanismos físicos.
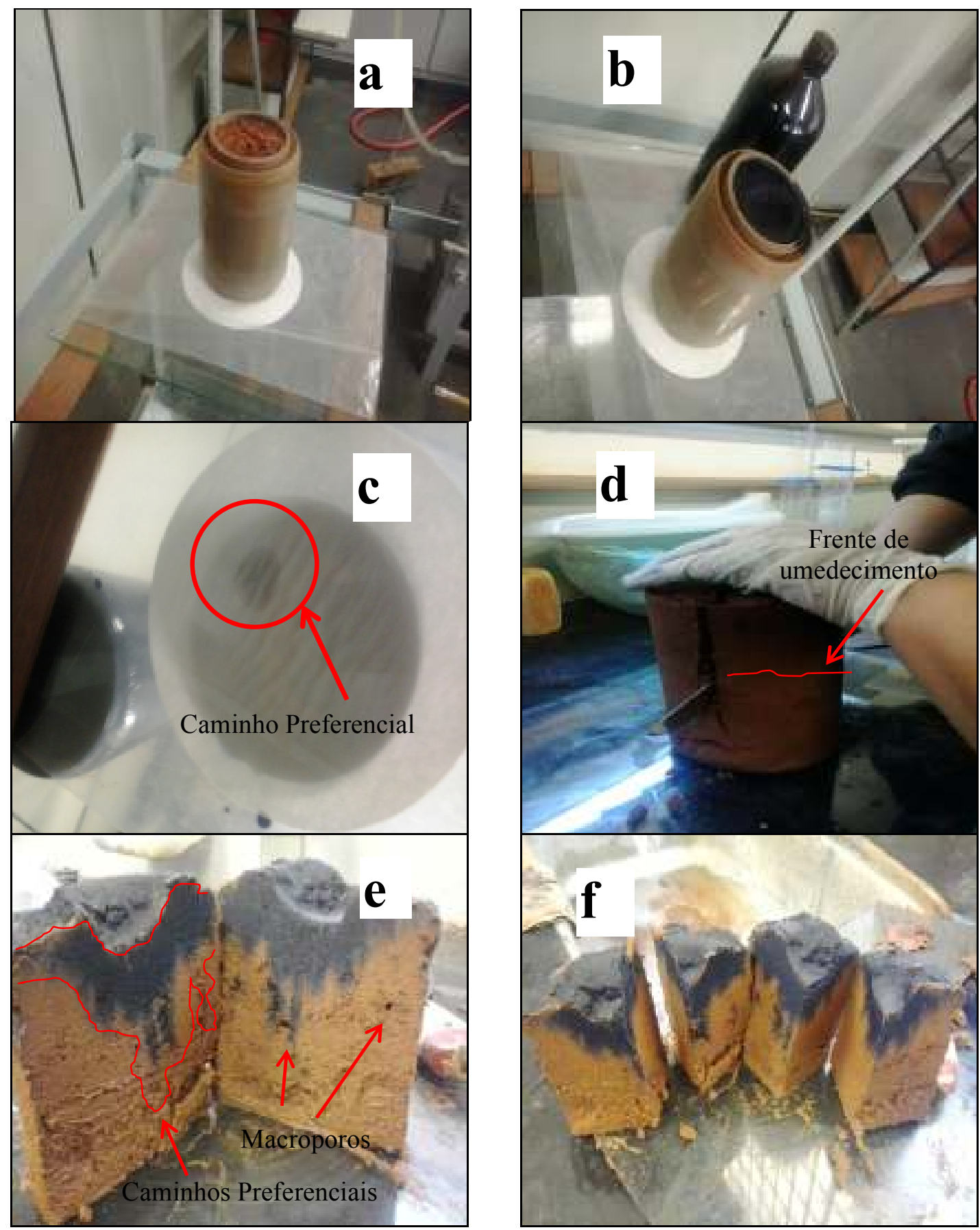

Figura 5.66 Ensaio de trajetória de transporte: a:antes do ensaio; b:aplicação da solução de azul de metileno; c:constatação de caminho preferencial; d:corte transversal da coluna; e-f: coluna aberta mostrando macroporos e caminhos preferenciais 
As Figuras 5.66e e 5.66f mostram macroporos presentes em toda a seção da coluna (destaque na foto). Estas Figuras também mostram que o azul de metileno não foi distribuído igualmente por toda a coluna sendo que em alguns locais ele alcançou maiores profundidades. No entanto, percebe-se que a movimentação desta solução não ocorreu de maneira igual por toda a seção da coluna e que onde havia macroporos houve maior percolação da solução de azul de metileno, assim como esperado.

\subsection{ANÁlise do SOLO}

Após a percolação das soluções de $\mathrm{NaCl}$ e $\left(\mathrm{NH}_{4}\right) 2 \mathrm{HPO} 4$ foram realizadas análises físico-químicas do solo. A Tabela 33 apresenta os resultados dessas análises.

Tabela 5.33 - Parâmetros físico-químicos do solo após percolação das soluções

\begin{tabular}{llllllll}
\hline COLUNA & $\mathbf{3}$ & $\mathbf{6}$ & $\mathbf{7}$ & $\mathbf{8}$ & $\mathbf{9}$ & $\mathbf{1 0}$ & $\begin{array}{c}\text { ANTES DO } \\
\text { ENSAIO }\end{array}$ \\
\hline $\mathbf{P H}_{(\mathrm{H} 2 \mathrm{O})}$ & 5.70 & 6.02 & 5.60 & 6.85 & 6.80 & 6.75 & 5,23 \\
$\mathbf{P H}_{(\mathrm{KCL})}$ & 4.63 & 4.92 & 4.62 & 5.19 & 5.12 & 5.16 & 4,20 \\
$\mathbf{\Delta \mathbf { p H }}$ & $-1,07$ & $-1,10$ & $-0,98$ & $-1,66$ & $-1,68$ & $-1,59$ & $-1,03$ \\
$\mathbf{P C Z}$ & 3,56 & 3,82 & 3,64 & 3,53 & 3,44 & 3,57 & 4,18 \\
$\mathbf{C . E}$ & 80,00 & 160,00 & 282,00 & 56,00 & 58,00 & 60,00 & 55,70 \\
\hline
\end{tabular}

Em comparação com as medições feitas no solo antes da percolação das soluções de $\mathrm{NaCl}$ e $\left(\mathrm{NH}_{4}\right)_{2} \mathrm{HPO}_{4}$, nota-se que houve aumento do $\mathrm{pH}$ em $\mathrm{H}_{2} \mathrm{O}$ e em $\mathrm{KCl}$ em todas as colunas de solo. No caso das colunas que foram percoladas com $\mathrm{NaCl}$, este aumento do $\mathrm{pH}$ pode estar associado à redução da quantidade de $\mathrm{H}^{+}$devido à formação de $\mathrm{HCl}$. Em se tratando das colunas percoladas com $\left(\mathrm{NH}_{4}\right)_{2} \mathrm{HPO}_{4}$, o aumento do $\mathrm{pH}$ pode se relacionar com a formação de $\mathrm{H}_{2} \mathrm{PO}_{4}{ }^{-}$que reduz q quantidade de $\mathrm{H}+$ no solo. Como também houve o aumento do $\mathrm{pH}$ em $\mathrm{KCl}$, o $\Delta \mathrm{pH}$ permaneceu negativo, sendo que para as colunas percoladas com as soluções de $\mathrm{NaCl}$, permaneceu quase inalterado e para as colunas percoladas com as soluções de $\left(\mathrm{NH}_{4}\right)_{2} \mathrm{HPO}_{4}$ resultou em valores mais negativos. Isto pode estar relacionado com o aumento da quantidade de cargas negativas presentes neste solo pelo aumento do $\mathrm{pH}$, ou seja, aumento da concentração de $\mathrm{OH}^{-}$. O PCZ teve redução em todas as colunas de solo, porém continua abaixo do pH em água, indicando que o balanço de cargas neste solo continua sendo negativo.

Em se tratando da condutividade elétrica, percebe-se que para as colunas percoladas com as soluções de $\mathrm{NaCl}$ houve aumento da C.E. que foi maior quanto maior a concentração 
da solução inicial percolada. Para as colunas percoladas com as soluções de $\left(\mathrm{NH}_{4}\right)_{2} \mathrm{HPO}_{4}$, nota-se que esteve presente o padrão de quanto maior a concentração inicial da solução, maior foi a C.E. do solo ao final do ensaio, porém o aumento foi muito pequena, mostrando que ao final do ensaio a quantidade de íons na solução do solo não foi aumentada em decorrência, principalmente, das ligações entre os compostos do fosforo e $\mathrm{N}$ com os íons presentes no solo. 


\section{CONCLUSÕES E RECOMENDAÇÕES}

Esta dissertação teve como objetivo geral o estudo dos mecanismos de transporte de sódio, fosfato e amônio em colunas indeformadas de material inconsolidado residual de arenitos da Formação Adamantina e com isso concluiu-se que:

1) A utilização de efluentes de esgotos em solos agrícolas pode trazer diversos benefícios principalmente em termos de redução do consumo de água e fertilizantes, mas, quando usada de maneira indiscriminada, pode causar problemas sérios como por exemplo, alterações na estrutura dos solos e contaminação dos reservatórios subterrâneos;

2) Ensaios de caracterização foram fundamentais na interpretação dos possíveis mecanismos de transporte presentes no material;

3) A dupla porosidade presente no solo, bem como os macroporos foram fundamentais na determinação dos parâmetros de fluxo do solo, fazendo com que ao valores de $k$ e $v$ obtidos com os ensaios de coluna representassem principalmente o fluxo que percolava pelos macroporos;

4) A condutividade hidráulica mostrou-se coerente com valores esperados para solos arenosos, apesar de se acreditar que os valores de $k$ foram fortemente influenciados pela macroporosidade do material;

5) O ensaio de trajetória de transporte permitiu que se constatasse a existência de caminhos preferenciais. Além disso, verificou-se que a sorção que estava ocorrendo neste solo era significativa, justificando os altos valores de retardamento obtidos, principalmente dos cátions. Este ensaio não é normalmente realizado em estudos de transporte de solutos, mas permitiu que se visualizasse com muita clareza tanto a sorção quanto a movimentação em caminhos preferenciais. Assim, acredita-se que este tipo de análise deva ser incluída com maior frequência nos estudos dos mecanismos de transporte de solutos nos solos;

6) O solo, apesar de arenoso e com baixa CTC, apresentou sorção significativa, chamando a atenção para o fato que não basta apenas focar na textura do solo, deve-se analisar o conjunto das características de carga, mineralógicas, físicas, físico-químicas e químicas;

7) A determinação do coeficiente de dispersão hidrodinâmica e do fator de retardamento para os três íons estudados foi fortemente influencia pela macroporosidade;

8) Para o sódio e o amônio os principais mecanismos de transporte atuantes são a advecção e a adsorção não específica, especialmente devido às características de carga deste solo; 
9) Para o fosfato, os principais mecanismos de transporte atuantes são a advecção e a adsorção específica por óxidos e hidróxidos de alumínio e de ferro que, mesmo não tendo sido constatado na DRX, está presente em forma não cristalina neste solo, como pôde ser verificado com as altas quantidades na análise de EDS;

10) A análise dos modelos conceituais dos métodos utilizados permitiu que se percebesse as limitações de cada método e que se analisasse com maior cuidado os valores obtidos, relacionando-os com as características físicas, químicas, físico-químicas e mineralógicas do solo;

11) O método de obtenção do $D_{h}$ sugerido por Ogata (1958) e Ogata e Banks (1961) não permitiu o cálculo dos valores de dispersão hidrodinâmica para nenhum dos íons estudados, devido às altas velocidades lineares médias obtidos nos ensaios de coluna;

12) O $D_{h}$ do sódio poderia ser obtido com o método proposto por Ogata (1958) e Ogata e Banks (1961) caso a velocidade linear média fosse na ordem de 10E-04 m/min;

13) O $D_{h}$ do fosforo e do amônio poderiam ser obtidos com o método proposto por Ogata (1958) e Ogata e Banks (1961) caso a velocidade linear média fosse na ordem de 10E-03 $\mathrm{m} / \mathrm{min}$;

14) Fazer o caminho contrário e verificar se o $D_{h}$ obtido resulta em uma velocidade próxima a que se mediu em campo ou em laboratório, pode auxiliar na escolha do $D_{h}$ que melhor represente o solo estudado;

15) A construção de isotermas por meio de ensaio de colunas, apesar de não ser um método comumente utilizado, mostrou-se uma boa ferramenta para determinação do retardamento dos íons, percebido, principalmente, pelo bom ajuste dos dados experimentais aos modelos das isotermas. Com este método pôde-se perceber que a isoterma linear não foi a que melhor representou nenhum dos íons estudados. Isto porque as concentrações utilizadas nesta pesquisa são altas e permitem que o solo atinja a máxima sorção e a saturação, o que não é representado pela isoterma linear;

16) Os modelos propostos para obtenção dos parâmetros de transporte são baseados em solos homogêneos e deformados, que não representam a realidade dos materiais;

17) Não existe um único método adequado para determinar os parâmetros de transporte do solo. A modelagem do transporte de contaminantes deve ser feita com cautela e o modelador deve analisar não apenas o valor final, mas sim o modelo conceitual bem como as limitações relacionadas a cada método e ao material estudado. 


\section{REFERÊNCIAS BIBLIOGRÁFICAS}

ABEDI-KOUPAI, J. et al. Effect of treated wastewater on soil chemical and physical properties in an arid region. Plant Soil and Environmental, v.52, n.8, p.335-344. 2006

ABO-GHOBAR, H. M. Influence of irrigation water quality on soil infiltration. Irrigation Science, v.11, n.1, p.13-19, 1993.

ADEEL, Z.; LUTHY, R. G. Sorption and transport kinetics of a nonionic surfactant through an aquifer sediment. Environmental science \& technology, v. 29, n. 4, p. 1032-1042, 1995.

ADRIANO, D. C. Trace elements in terrestrial environments: biogeochemistry, bioavailability, and risks of metals. Springer, 2001. 867p.

ADRIANO, D.C. Trace elements in the terrestrial environmental. New York: SpringerVerlang, 1986. $533 \mathrm{p}$

AGGELIDES, S.M.; LONDRA, P.A. Effects of compost produced from town wastes and sewage sludge on the physical properties of a loamy and clay soil. Bioresource Technology, v.71, p.253-259, 2000.

AHUMADA, I. et al. Sequential extraction of heavy metals in soils irrigated with wastewater. Communications in Soil Science and Plant Analysis, v.30, n.9-10, p.1507-1519. 1999

AIELLO, R.; CIRELLI, G.L.; CONSOLI, S. Effects of reclaimed wastewater irrigation on soil and tomato fruits: A case study in Sicily (Italy). Agricultural Water Management, v.93, n.1-2, p.65-72. 2007

AL SALEM, S.S. Environmental considerations for wastewater reuse in agriculture. Water Science and Technology, v.33, n.10-11, p.345-353. 1996

ALLOWAY, B.J. Soil processes and the behavior of metals. In: B.J. ALLOWAY (Editor), Heavy metals in soils.2nd ed. London: Blackie Academic and Professional, 1995b. p. 3-10.

ALLOWAY, B.J. The origins of heavy metals in soils. In: B.J. ALLOWAY (Editor), Heavy metals in soils.2nd ed. London: Blackie Academic and Professional, 1995a. p. 38-57.

ALMEIDA, F. F. M; MELO, M. S. A bacia do Paraná e o vulcanismo mesozóico. In: São Paulo, Instituto de Pesquisas Tecnológicas do Estado de São Paulo - IPT, Mapa geológico do Estado de São Paulo. São Paulo, monografia, n.6, v. 1,p.46-81, 1981.

ALVAREZ-BERNAL, D. et al. Effects of tanneries wastewater on chemical and biological soil characteristics. Applied Soil Ecology, v.33, n.3, p.269-277. 2006

ANAMI, M.H. et al. Deslocamento miscível de nitrato e fosfato proveniente de água residuária da suinocultura em colunas de solo. Revista Brasileira de Engenharia Agrícola e Ambiental, v.12, n.1, p.75-80. 2008

ANGELOVA, V. et al. Bio-accumulation and distribution of heavy metals in fibre crops (flax, cotton and hemp). Industrial Crops and Products, v.19, n.3, p.197-205. 2004 
ANGIN, I.; YAGANOGLU, A.V.; TURAN, M. Effects of Long-Term Wastewater Irrigation on Soil Properties. Journal of Sustainable Agriculture, v.26, n.3, p.31-42. 2005

ASSOCIAÇÃO BRASILEIRA DE GEOLOGIA DE ENGENHARIA E AMBIENTAL ABGE. Ensaios de permeabilidade em solos - orientações para sua execução no campo.Boletim nº. 4. São Paulo, In: OLIVEIRA, A. M. S., CORRÊA FILHO, D. (Coord.), 1996.

ASSOCIAÇÃO BRASILEIRA DE NORMAS TÉCNICAS -ABNT NBR 13600: Solo Determinação do teor de matéria orgânica por queima a $440{ }^{\circ} \mathrm{C}$. Rio de Janeiro, 1996. 2p.

NBR 6508: Grãos de solos que passam na peneira de 4,8 mm: determinação da massa específica: método de ensaio. Rio de Janeiro, 1984a. 7 p.

NBR 7181: Solo - análise granulométrica. Rio de Janeiro, 1984c. 13 p.

AZAROFF, L. V.; BUERGER, M. J. The powder method in X-ray crystallography. 1953.342p.

BAETSLE, L.H. Computational Methods for the Prediction of Underground Movement of Radionuclides. Journal of Nuclear Safety,v.8, n.9, p.576-588, 1967.

BALKS, M.R.; BOND, W.J.; SMITH, C.J. Effects of sodium accumulation on soil physical properties under an effluent-irrigated plantation. Soil Research, v.36, n.5, p.821-830. 1998

BALKS, M.R.; MCLAY, C.D.A.; HARFOOT, C.G. Determination of the progression in soil microbial response, and changes in soil permeability, following application of meat processing effluent to soil. Applied Soil Ecology, v.6, n.2, p.109-116. 1997

BAUMHARDT, R. L.; WENDT, C. W.; MOORE, J. Infiltration in response to water quality, tillage, and gypsum. Soil Science Society American Journal, Madison, v.56, n.1, p.261-266, 1992.

BEAR, J. Dynamics of fluids in porous media. American ElseVier, Nova York, 1972. 242p.

. Some experiments in dispersion. Journal of Geophysical Research, v. 66, n. 8, p. 2455-2467, 1961.

BENITES, V. M.; MENDONÇA, E. S. Propriedades eletroquímicas de um solo eletropositivo influenciadas pela adição de diferentes fontes de matéria orgânica. Revista Brasileira de Ciência do Solo, v. 22, p. 215-221, 1998.

BOLZONELLA, D. et al. Anaerobic Fermentation of Organic Municipal Solid Wastes for the Production of Soluble Organic Compounds. Industrial \& Engineering Chemistry Research, v.44, n.10, p.3412-3418. 2005

BOWER, H.; CHANEY, R. Land treatment of wastewater. Advances in Agronomy, v.26, p.133-176. 1974

BRADL, H.B. Adsorption of heavy metal ions on soils and soils constituents. Journal of Colloid and Interface Science, Birkenfeld ,v. 277, n. 1, p. 1-18, 2004. 
BRASIL. Lei n 12.305 de 2 de agosto de 2010. Institui a Política Nacional de Resíduos Sólidos; altera a Lei no 9.605, de 12 de fevereiro de 1998 e dá outras providências. Diário Oficial da União, Brasília, DF, 03 ago. 2010, seção 1.

Resolução CONAMA nº 357 de 17 de março de 2005. Dispõe sobre a classificação dos corpos de água e diretrizes ambientais para o seu enquadramento, bem como estabelece as condições e padrões de lançamento de efluentes, e dá outras providências. Conselho Nacional de Meio Ambiente, Brasília, 2005.

BRIGHAM, W. E. Mixing equations in short laboratory cores. Old Society of Petroleum Engineers Journal, v. 14, n. 1, p. 91-99, 1974.

BRIGHAM, W.; REED, P.; DEW, John. Experiments on mixing during miscible displacement in porous media. Society of Petroleum Engineers Journal, v. 1, n. 1, p. 1-8, 1961.

BUDDEMEIER, R. W.; HUNT, J. R. Transport of colloidal contaminants in groundwater: radionuclide migration at the Nevada Test Site.Applied geochemistry, v. 3, n. 5, p. 535-548, 1988.

CAILlÉRE, S., HÉNIN, S.; RAUTUREAU,M. Minéralogie des argiles. Vol. 1 - Structure et p'ropiétés físico-chimiques. Masson ed. Paris. 1982b.184p.

. Minéralogie des argiles. Vol. 2 - Classification et nomenclature. Masson ad. Paris. 1982a. 189p.

CASAGRANDE, J. C.; CAMARGO, O. A. Adsorção de fosfato em solos com caráter ácrico avaliada por um modelo de complexação de superfície. Revista brasileira de ciência do solo, v. 21, n. 3, p. 353-360, 1997.

CHAKRABARTI, C. Residual effects of long-term land application of domestic wastewater. Environment International, v.21, n.3, p.333-339. 1995.

CHANG, A.C. et al. Sequential Extraction of Soil Heavy Metals Following a Sludge Application1. Journal of Environmental Quality., v.13, n.1, p.33-38. 1984

CHAPRA, S. C. Surface Water Quality Modeling.Nova York: McGraw-Hill, 1997. 215p.

CHEN, M. Pollution of ground water by nutrients and fecal coliforms from lakeshore septic tank systems. Water, Air, \& Soil Pollution, v.37, n.3, p.407-417. 1988

CHERNICHARO, C.A.D.L. Reatores anaeróbios: v.5. Belo Horizonte: Departamento de Engenharia Sanitária e Ambiental - Universidade Federal de Minas Gerais, Princípios do tratamento biológico de águas residuárias 1997. 246 p.

CHERNICHARO, C.A.L. et al. Reatores anaeróbios de manta de lodo. In: J.R. CAMPOS (Editor), Tratamento de esgotos sanitários por processo anaeróbio e disposição controlada no solo. Rio de Janeiro: ABES, 1999, 250p.

CLANTON;, C.J.; LACK, D.C. Hydraulic properties of soils as affected by surface application of wastewater. Transactions of American Society of Agricultural Engineering, v.30, n.3, p.683-687. 1987 
CLEARY, R.W. Qualidade da água subterrânea. In: PORTO, L.L. (Org.) Hidrologia Ambiental. São Paulo, EDUSP, p.211-293, 2001.

COELHO, M. R.; VIDAL-TORRADO, P. Caracterização e gênese de perfis plínticos desenvolvidos de arenito do Grupo Bauru: II-mineralogia. Revista Brasileira de Ciência do Solo, v. 27, n. 03, p. 495-507, 2003

COMPANHIA AMBIENTAL DO ESTADO DE SÃO PAULO. Tratamento se esgotos e efluentes industriais por digestor anaeróbio de fluxo ascendente: Série Didática Água, v.39. São Paulo: CETESB, 1990. 40p.

COOK, F.J.; KELLIHER, F.M.; MCMAHON, S.D. Changes In Infiltration And Drainage During Wastewater Irrigation Of A Highly Permeable Soil. J. Environ. Qual., v.23, n.3, p.476-482. 1994

COOK, F.J.; KELLIHER, F.M.; MCMAHON, S.D. Changes In Infiltration And Drainage During Wastewater Irrigation Of A Highly Permeable Soil. J. Environ. Qual., v.23, n.3, p.476-482. 1994

CORDAZZO, J.; MALISKA, C. R.; CORSEUIL, H. X. Solução numérica do problema de derramamento de gasolina acrescida de álcool no solo. In: II Congresso de Engenharia de Processos do MERCOSUL. Artigo técnico, v. 13, 1999. Disponível em:< http://www.sinmec.ufsc.br/sinmec/artigos/cordazzo/cordazzo_enpromer-99.pdf $>$. Acesso em 23 de abril de 2013,

CORRÊA, R.S.; MELO FILHO, B.; BERNARDES, R.S. Deposição de esgoto doméstico para controle de poluição e revegetação induzida em área degradada. Revista Brasileira de Engenharia Agrícola e Ambiental, v.4, n.2, p.252-256. 2000.

COURAUCCI FILHO, B. et al. Remoção natural de patógenos no sistema de pós-tratamento por escoamento superficial no solo. In: VI Simpósio Ítalo Brasileiro de Engenharia Sanitária e Ambiental. Anais...Vitória, ES, 2002. 5p.

CRANK, J. The mathematics of diffusion. Clarendon Oxford, 1975. 357p.

CUNHA, L. Uso do biodigestor para tratamento de dejetos suínos. 2007. 72p. Dissertação (Mestrado em Química). Universidade Federal de São Catarina, 2007.

CURTIN, D.; SYERS, J.K. \& BOLAN, N.C. Phosphate sorption by soil in relation to exchangeable cation composition and pH. Australian Journal of Soil Research, v. 31, n. 2, p.137-149, 1992.

SILVA, W. T. L. et al. Avaliação físico-química de efluente gerado em biodigestor anaeróbio para fins de avaliação de eficiência e aplicação como fertilizante agrícola. Quimica Nova, v. 35, n. 1, p. 35-40, 2012.

DAEE - Departamento de Águas e Energia Elétrica. 1990. Plano estadual de recursos hídricos: Primeiro plano do Estado. Síntese. São Paulo.97 p.

DAEE, IG, IPT, e CPRM. Mapa de água subterrânea do Estado de São Paulo Escala 1:1.000.000 - Nota Explicativa. São Paulo, 3v. 119P, 2005. 
DAEE. Plano estadual de recursos hídricos: 2004/2007. São Paulo, 2006.92p.

DOMENICO, P. A.; SCHWARTZ, F. W. Physical and chemical hydrogeology, Wiley. New York, p. 824, 1990.

DUARTE, A.S. et al. Efeitos da aplicação de afluente tratado no solo: $\mathrm{pH}$, matéria orgânica, $\mathrm{P}$ e potássio. Revista Brasileira de Engenharia Agrícola e Ambiental. v. 12, n. 3, p. 302-310, 2008

DUARTE, R.P.S.; PASQUAL, A. Avaliação do cádmio $(\mathrm{Cd})$, chumbo $(\mathrm{Pb})$, níquel $(\mathrm{Ni})$ e zinco ( $\mathrm{Zn}$ ) em solos, plantas e cabelos humanos. Engenharia na Agricultura, v.15, n.1, p.46-58. 2000.

DUBE, A. et al. Adsorption and migration of heavy metals in soil. Polish Journal of Environmental Studies, v.10, n.1, p.1-1. 2001.

DUFFUS, J. "Heavy metals "- a meaningless term? . Pure Applied Chemistry, v.74, n.5, p.793-807. 2002.

DURNER, W. Hydraulic conductivity estimation for soils with heterogeneous pore structure. Water Resources Research., v.30, n.2, p.211-223. 1994.

EMPRESA BRASILEIRA DE PESQUISA AGROPECUÁRIA - EMBRAPA. Centro Nacional de Pesquisa de Solos. Manual de métodos de análise de solo. Rio de Janeiro, 1997. $212 p$.

Centro Nacional de Pesquisa de Solos, Sistema Brasileiro de Classificação de Solos. Brasília, SPI, 1999, 412p.

EVANGELOU, V. P.; PHILlIPS, R. E. Cation exchange in soils In: TABATABAI, M.A.; SPARKS, D.L. (Ed.). Chemical Processes in Soil. Wisconsin: Soil Science Society of America, Inc. Madison, 2005. p. 343-410.

FACTOR, T. L.; ARAÚJO, J.A.C.; VILELLA JÚNIOR, V. E. Produção de pimentão em substratos e fertirrigação com efluente de biodigestor. Revista Brasileira de Engenharia Agrícola e Ambiental, v. 12, n. 2, p. 143-149, 2008.

FAUSTINO, A.S. Estudos físico-químicos de efluente produzido por fossa séptica biodigestora e o impacto do seu uso no solo. 2007. 122 p. Dissertação(Mestrado em Química) - Departamento de Química, Universidade Federal de São Carlos, São Carlos, SP, 2007.

FAZELI, M.S. et al. Enrichment of heavy metals in paddy crops irrigated by paper mill effluents near Nanjangud, Mysore district, Karnatake, India. Environmental Geology, v.34, n.4, p.297-302. 1998.

FEIDEN, A.; CEREDA, M. Avaliação da eficiência de lagoas de tratamento de resíduos líquidos, manejo, uso e tratamento de subprodutos da industrialização da mandioca. São Paulo: Fundação Cargill, v.4, p.186-201, 2001.

FEIGIN, A.; RAVINA, I.; SHALHEVET, J. Irrigation with treated sewage effluent: management for environmental protection.Berlin: Springer-Verlag., 1991. 224 p. 
FERNANDES, L. A.Estratigrafia e evolução geológica da parte oriental da Bacia Bauru (Ks, Brasil). 1998. 158p. Tese (Doutorado em Geociências). Instituto de Geociências da Universidade de São Paulo,1998.

FERNANDES, M.A. Condutividade hidráulica não saturada de um solo arenoso: aplicação do infiltrômetro de disco. 2011. 161 p. Dissertação (Mestrado em Geotecnia) Escola de Engenharia de São Carlos, Universidade de São Paulo, São Carlos, SP, 2011.

FETTER, C. W. Contaminant hydrogeology. Prentice Hall, Upper Saddle River, EUA, 1993. 500p.

FONTES, M. P. F.; CAMARGO, O.A.; SPOSITO, G. Eletroquímica das partículas coloidais e sua relação com a mineralogia de solos altamente intemperizados. Scientia Agricola, v. 58, n. 3, p. 627-646, 2001.

FREDLUND, D. G.; XING, A; HUANG, S. Predicting the permeability function for unsaturated soils using the soil-water characteristic curve. Canadian Geotechnical Journal, v. 31, n. 4, p. 533-546, 1994.

FREDLUND, D.G.; RAHARDJO, H. Soil Mechanics for Unsaturated Soils. New York: John Wiley \& Sons, Inc., 1993. 507 p

FREDLUND, D.G.; XING, A. Equations for the soil-water characteristic curve. Canadian Geotechnical Journal, v.31, n.4, p.521-532. 1994.

FREEZE, R. A.; CHERRY, J. A. Groundwater, Prentice-Hall, Englewood Cliffs, Nova Jersey 1979. $604 \mathrm{p}$.

FRENDLICH, H. M. A. Concerning adsorption in solutions. Journal of Physical Chemistry, v. 57, p. 385-92, 1906.

FULLER, W.H.; WARRICK, A.W. Soil in waste treatment and utilization. CRC Press. v.2, 1986, 235p.

GARDNER, W.R. Some Steady-State Solutions of the Unsaturated Moisture Flow Equation With Application to Evaporation From A Water Table. Soil Science, v.85, n.4, p.228-232. 1958

GERBA, C.P.; MELNICK, J.L.; WALLIS, C. Fate of Wastewater Bacteria and Viruses in Soil Journal of the Irrigation and Drainage Division, v.101, n.3, p.157-174. 1975

GERSCOVICH, D.M.S.; SAYÃO, A.S.F.J. Evaluation of the soil-water characteristic curve equations for soils fromBrazil. In: Third International Conference on Unsaturated Soils. Anais... Recife, PE. p. 295-300, 2002.

GHARAIBEH, M.; ELTAIF, N.; AL-ABDULLAH, B. Impact of Field Application of Treated Wastewater on Hydraulic Properties of Vertisols. Water, Air, \& Soil Pollution, v.184, n.1, p.347-353. 2007.

GILES, C. H.; SMITH, D; HUITSON, A. A general treatment and classification of the solute adsorption isotherm. I. Theoretical. Journal of Colloid and Interface Science, v. 47, n. 3, p. 755-765, 1974. 
GLOAGUEN, R.A.B.G. Efeito da irrigação com efluente de esgoto tratado nas propriedades físico-hídricas de um latossolo. 2005. 119 p. Tese (Doutorado em Solos e Nutrição de Plantas) - Escola Superior de Agricultura Luiz de Queiroz, Universidade de São Paulo, Piracicaba, SP, 2005.

GOMES, M.A.F, et al. Nutrientes vegetais no meio ambiente: ciclos biogeoquímicos, fertilizantes e corretivos. Embrapa Meio Ambiente. Documentos, 18. Jaguariúna: Embrapa Meio Ambiente, 2000. 50 p.

HALLIWELL, D.J.; BARLOW, K.M.; NASH, D.M. A review of the effects of wastewater sodium on soil physical properties and their implications for irrigation systems. Australian Journal of Soil Research, v.39, n.6, p.1259-1267. 2001.

HARUVY, N. Agricultural reuse of wastewater: nation-wide cost-benefit analysis. Agriculture, Ecosystems \&amp; Environment, v.66, n.2, p.113-119. 1997

HAVLIN, J. et al. Soil fertility and fertilizers: An introduction to nutrient management. 7ed. Upper Saddle River, NJ: Pearson Prentice Hall, 2005. 515p.

HAYES, M.H.B.; EDWARD, C.C. Humic Substances: considerations of compositions, aspects of structure, and environmental influences. Soil Science, v.166, n.11, p.723-737. 2001

HAYNES, R.J. Effects of liming on phosphate availability in acid soils: a critical review. Plant Soil, v.68, p.289-308, 1982.

HIESTER, K.; VERMEULEN, T. Saturation performance of ion-exchange and adsorption columns. Chemical Engeneering Progress, v. 48, n. 10, p. 505-516, 1952.

HIGGINS, G.H. Evaluation of the Groundwater Contamination Hazard From Underground Nuclear Explosives. Journal of Geophysical Research, v.64, p.1509-1519, 1959.

HILLEL, D. et al. Fundamentals of soil physicsNew York: Academic Press, 1980. 413 p.

HILLEL, D. Solo e água: fenômenos e princípios físicos. Porto Alegre: Universidade Federal do Rio Grande do Sul, 1970. 231 p

INTERNATIONAL ASSOCIATION ON WATER QUALITY. Actived sludge model: Scientific and Technical Reports. London: IAWQ, 1995. 103p.

IRVINE, S.A.; REID, D.J. Field prediction of sodicity in dryland agriculture in central Queensland, Australia. Australian Journal of Soil Research, v.39, p.1349-1357. 2001

JARVIS, N.J.; MESSING, I. Near-Saturated Hydraulic Conductivity in Soils of Contrasting Texture Measured by Tension Infiltrometers. Soil Science Society of America Journal, v.59, n.1, p.27-34. 1995

JELLALI, S. et al. Dynamic sorption of ammonium by sandy soil in fixed bed columns: Evaluation of equilibrium and non-equilibrium transport processes.Journal of environmental management, v. 91, n. 4, p. 897-905, 2010.

JENNY, H. Factors of soil formations: a system of quantitative pedology. 1. ed. New York: Dover Publications, Inc., 1994. 281 p 
JIMÉNEZ-CISNEROS, B. Wastewater reuse to increase soil productivity. Water Science and Technology, v.32, n.12, p.173-180. 1995

JNAD, I. et al. Subsurface drip dispersal of residential effluent. II. Soil hydraulic characteristics. Transactions of the ASAE, v.44, n.5, p.1159-1165. 2001

JONG VAN LIER, Q.; LIBARDI, P.L. Variabilidade dos parâmetros da equação que relaciona a condutividade hidráulica com a umidade do solo no método do perfil instantâneo. Revista Brasileira de Ciência do Solo, v.23, n.4, p.1005-1014. 1999

JONGE, L. W.; KJAERGAARD, C.; MOLDRUP, P. Colloids and colloid-facilitated transport of contaminants in soils. Vadose Zone Journal, v. 3, n. 2, p. 321-325, 2004.

JURY, W. A; GARDNER, W.R; GARNER,W.R.Soil physics. John Wiley and Sons, Inc., 1991.328P.

KABALA, C.; SINGH, B.R. fractionation and mobility of copper, lead, and zinc in soil profiles in the vicinity of a copper smelter. Journal of Environmental Quality, v.30, n.2, p.485-492. 2001

KABATA-PENDIAS, A.; PENDIAS, H. Trace metals in soils and plants. 3rd. ed. Boca Raton: CRC Press, 2001. 413 p

KEENEY, D.R. In: Fairbridge, R.W.,FINKL, C.W. (Eds) Encyclopaedia of soil science. Stroudsburg, Pa: Dowden, Hutchinson \& Ross, p.8-9, 1979.

KENG, J. C-W.; UEHARA, G. Chemistry, mineralogy and taxonomy of Oxisols and Ultisols. Proceedings Soil and Crop Science Society, v. 33, p. 119-126, 1974.

KESWICK, B.H.; GERBA, C.P. Viruses in groundwater. Environmental Science \& Technology, v.14, n.11, p.1290-1297. 1980

KESWICK, B.H.; WANG, D.-S.; GERBA, C.P. The Use of Microorganisms as GroundWater Tracers: A Review. Ground Water, v.20, n.2, p.142-149. 1982

KHAN, S. et al. Health risks of heavy metals in contaminated soils and food crops irrigated with wastewater in Beijing, China. Environmental Pollution, v.152, n.3, p.686-692. 2008

KHASAWNEH, F. E. et al. The role of phosphorus in agriculture. American Society of Agronomy, Crop Science Society of America, Soil Science Society of America., 1980.

KIZILOGLU, M.F. et al. Effects of wastewater irrigation on soil and cabbage-plant (brassica olerecea var. capitate cv. yalova-1) chemical properties. Journal of Plant Nutrition and Soil Science, v.170, n.1, p.166-172. 2007

KNOX, R.C.; SABATINI, D.A.; L.W. CANTER. Subsurface Transport and Fate Processes. Lewis Publishers, Boca Raton, 1993. 279p.

KOÖPPEN, W. Das geographische System der Klimate-Handbuch der Klimatologie, Vol. 1, Part C, Gebr. Borntrager Verl., Berlin, v. 388, 1936. 
KOOREVAAR, P.; MENELIK, G.; DIRKSEN, Christiaan. Elements of soil physics. Elsevier, 1983.

KRUZIC, A.P. Natural Treatment and On-Site Processes. Water Environment Research, v.69, n.4, p.522-526. 1997

KUAI, L.; VERSTRAETE, W. Ammonium removal by the oxygen-limited autotrophic nitrification-denitrification system. Applied and Environmental Microbiology, v. 64, n. 11, p. 4500-4506, 1998.

KUMAR SHARMA, R.; AGRAWAL, M.; MARSHALL, F. Heavy metal contamination of soil and vegetables in suburban areas of Varanasi, India. Ecotoxicology and Environmental Safety, v.66, n.2, p.258-266. 2007

LADO, M.; BEN-HUR, M.; ASSOULINE, S. Effects of effluent irrigation on seal formation, infiltration, and soil loss during rainfall. Soil Science Society of America Journal, v.69, n.5, p.1432-1439. 2005

LANGE, L. C. et al. Estudo do transporte de contaminantes em meios porosos aplicado a aterros de disposição de resíduos sólidos urbanos.Alternativas para disposição de resíduos sólidos urbanos para pequenas comunidades: coletânea de trabalhos técnicos. Rio de Janeiro, ABES/RIMA, p. 85-92, 2002.

LANGMUIR, I. The constitution and fundamental properties of solids and liquids. Part i. Solids. Journal of the American Chemical Society, v. 38, n. 11, p. 2221-2295, 1916.

LAPIDUS, L; AMUNDSON, N. R. Mathematics of adsorption in beds. VI. The effect of longitudinal diffusion in ion exchange and chromatographic columns. The Journal of Physical Chemistry, v. 56, n. 8, p. 984-988, 1952.

LEITE, A.L. Migração de íons inorgânicos em alguns solos tropicais, com ênfase nos processos de sorção e difusão molecular. 2001. 274 p. Tese (Doutorado em Geotecnia) Escola de Engenharia de São Carlos, Universidade de São Paulo, São Carlos, SP, 2001.

LEONG, E.C.; HE, L.; RAHARDJO, H. Factors affecting the filter paper method for total and matric suction measurements. ASTM Geotechnical Testing Journal, v.25, n.3, p.322-333. 2002

LEONG, E.C; RAHARDJO, H. Permeability Functions for Unsaturated Soils. Journal of Geotechnical and Geoenvironmental Engineering, v.123, n.12, p.1118-1126. 1997a

Review of Soil-Water Characteristic Curve Equations. Journal of Geotechnical and Geoenvironmental Engineering, v.123, n.12, p.1106-1117. 1997a

LEVY, G.J. et al. Soil Hydraulic Conductivity Changes Caused by Irrigation with Reclaimed Waste Water. Journal of Environmental Quality., v.28, n.5, p.1658-1664. 1999

LIBARDI, P.L. Dinâmica da Água no Solo. Piracicaba: USP/ESALQ - Departamento de Física e Meteorologia, 1995. 497 p. 
LIEFFERING, R.E.; MCLAY, C.D.A. The effect of strong hydroxide solutions on the stability of aggregates and hydraulic conductivity of soil. European Journal of Soil Science, v.47, n.1, p.43-50. 1996

LOOKMAN, R. et al. Batch-test study on the dechlorination of 1, 1, 1-trichloroethane in contaminated aquifer material by zero-valent iron. Journal of contaminant hydrology, v. 74, n. 1, p. 133-144, 2004.

MA, L.Q.; RAO, G.N. Chemical Fractionation of Cadmium, Copper, Nickel, and Zinc in Contaminated Soils. J. Environ. Qual., v.26, n.1, p.259-264. 1997

MAGESAN, G.N. et al. Hydraulic conductivity in soils irrigated with wastewaters of differing strengths: Field and laboratory studies. Australian Journal of Soil Research, v.37, n.2, p.391-402. 1999

MAIA, A.D. Avaliação da geração de drenagem ácida de minas em um solo fabricado em laboratório contendo sulfeto de ferro e matéria orgânica. 2004.170 p. Dissertação (Mestrado em Engenharia Civil) - Programa de Pós-graduação em Engenharia (COPPE), Universidade Federal do Rio de Janeiro, Rio de Janeiro, 2004.

MANCUSO, P.C.S. O reuso da água e sua possibilidade na região metropolitana de São Paulo. 1992. 132 p. Tese (Doutorado em Saúde Pública) - Faculdade de Saúde Pública, Universidade de São Paulo, São Paulo, SP, 1992.

MAPANDA, F. et al. The effect of long-term irrigation using wastewater on heavy metal contents of soils under vegetables in Harare, Zimbabwe. Agriculture, Ecosystems \&amp; Environment, v.107, n.2-3, p.151-165. 2005

MARINHO, F.A.M. Medição de sucção com o método do papél filtro In: X Congresso Brasileiro de Mecânica dos Solos e Engenharia de Fundações. Foz do Iguaçu, PR. Anais X Congresso Brasileiro de Mecânica dos Solos e Engenharia de Fundações.1994. p. 515522.

MARINHO, F.A.M.; OLIVEIRA, O.M. The Filter Paper Method Revisited ASTM Geotechnical Testing Journal, v.29, n.3, p.250-258. 2006

MARTELLI, L.F.A. Avaliação quantitativa e qualitativa da matéria orgânica de solo sob a aplicação de efluente de esgoto tratado em biodigestor anaeróbio. 2011. 119 p. Dissertação (Mestrado em Química). Instituto de Química de São Carlos, Universidade de São Paulo, São Carlos, 2011.

MARTINEZ, M.A; SILVA, J.B.G; PEREIRA, D. R. Modelagem do movimento de sais no solo. Manejo da salinidade na agricultura: Estudos básicos e aplicados. 22p. 2010.

MATHAN, K.K. Studies on the influence of long-term municipal sewage-effluent irrigation on soil physical properties. Bioresource Technology, v.48, n.3, p.275-276. 1994

MATSUMURA-TUNDISI, T. et al. A new species of Notodiaptomus Kiefer (Crustacea, Copepoda, Calanoida, Diaptomidae) from Brazil. Brazilian Journal of Biology, v. 70, n. 3, p. 867-870, 2010. 
McBRIDE, M.B. Surface chemistry of soil minerals. In: DIXON,J.B. \& WEED, S.B., (Ed). Minerals in soil environments. 2.ed.Madison, Soil Science Society of Agronomy, p.35-88, 1989.

MEKARU, T.; UEHARA, G. Anion adsorption in ferruginous tropical soils. Soil Science Society of America Journal, v. 36, n. 2, p. 296-300, 1972.

MELI, S. et al. Influence of irrigation with lagooned urban wastewater on chemical and microbiological soil parameters in a citrus orchard under Mediterranean condition. Science of the Total Environment, v.285, n.1-3, p.69-77. 2002.

MELO, R. F. et al. Miscible displacement of basic cations from cassava processing wastewater in soil columns. Revista Brasileira de Engenharia Agrícola e Ambiental, v. 10, n. 2 , p. $456-465,2006$.

MENDES, R.M. Estudo das propriedades geotécnicas de solos residuais não saturados de Ubatuba (SP). 2008. 236 p. Tese (Doutorado em Engenharia Civil) - Escola Politécnica da Universidade de São Paulo, Departamento de Engenharia de Estruturas e Geotécnica, São Paulo, SP, 2008.

MENDONÇA, J. L. G.; GUTIERRE, T. M. C. O potencial hidrogeológico do Grupo Bauru no Estado de São Paulo.Águas Subterrâneas, 2000.

MENDONÇA, J.L.G; ARAGONI, A. V. Determinação horizontal e vertical de argilitos e siltitos marrom e esverdeados na formação adamantina e suas relações com a explotação de aguas subterrâneas.Águas Subterrâneas, n. 1, 1986.

METCALF, J.S.; EDDY, F.B. Wastewater Engineering: tratament, disposal and reuse. 3d. Singapura: McGraw-Hill, inc. International Edition, Civil Engineering Series, 1991. 1334 p.

MIGUEL, M.G.; VILAR, O.M. Study of the water retention properties of a tropical soil. Canadian Geotechnical Journal, v.46, n.9, p.1084-1092. 2009

MILANI, E. J.; FRANÇA, A. B.; SCHNEIDER, R. L. Bacia do Paraná. Boletim de Geociências da PETROBRÁS, v. 8, n. 1, p. 69-82, 1994.

MILANI, E. J.Evolução tectono-estratigráfica da Bacia do Paraná e seu relacionamento com a geodinâmica fanerozóica do Gondwana sul-ocidental. 2v. 1997. 254p. Tese (Doutorado em Geociências) - Universidade Federal do Rio Grande do Sul, Porto Alegre, 1997.

MINHAS, P.S.; SHARMA, D.R. Hydraulic conductivity and clay dispersion as affected by application sequence of saline and simulated rain water. Irrigation Science, v.7, n.3, p.159167. 1986.

MITCHELL, J.K. Conduction phenomena: from theory to geotechnical practice. Geotechnique, v.41, n. 3, p. 299-340, 1991.

MITCHELL, R.; NEVO, Z. Effect of bacterial polysaccharide accumulation on infiltration of. Applied microbiology, v.12, p.219-223. 1964 
MOHAMMAD RUSAN, M.J.; HINNAWI, S.; ROUSAN, L. Long term effect of wastewater irrigation of forage crops on soil and plant quality parameters. Desalination, v.215, n.1-3, p.143-152. 2007

MOHAMMAD, M.J.; MAZAHREH, N. Changes in Soil Fertility Parameters in Response to Irrigation of Forage Crops with Secondary Treated Wastewater. Communications in Soil Science and Plant Analysis, v.34, n.9-10, p.1281-1294. 2003

MOREIRA, C.S. Adsorção competitiva de cádmio, cobre, níquel e zinco em solos. 2004. 120f. Dissertação (Mestrado em Agronomia) - Escola Superior de Agricultura "Luiz de Queiroz”, Universidade de São Paulo, Piracicaba, 2004.

NOGUEIRA, J.B. Mecânica dos Solos: ensaios de laboratórioSão Carlos, SP: EESC-USP, 2005, 80p.

NOGUEIRA, L. A. H. Biodigestão: a alternativa energética. Nobel, 1986, 93p.

NOVAES; A.P.D. et al. Utilização de uma fossa séptica biodigestora para melhoria do Saneamento Rural e desenvolvimento da Agricultura Orgânica. Comunicado Técnico 46. São Carlos: Embrapa Instrumentação Agropecuária, 2002, 14 p.

OFOSU-ASIEDU, K. et al. Sewage re-use for irrigation in Athi River town Kenya: Its implications on public health, p. 343-346 p, 1999.

OGATA, A. Dispersion in porous media. 1958. 121 p. (Tese de Doutorado). Northwestern University, 1958.

OGATA, A., BANKS, R. B. A solution of the differential equation of longitudinal dispersion in porous media. US Geological Survey Artigo Profissional n. 411-A, USGS, Washington D.C. 1961.

OLIVEIRA, E. M.M., et al. Fatores de retardamento e coeficientes de dispersão-difusão de fosfato, potássio e amônio em solos de Minas Gerais. Revista Brasileira de Engenharia Agrícola e Ambiental, v. 8, n. 2-3, p. 196-203, 2004.

ORGANISATION FOR ECONOMIC CO-OPERATION AND DEVELOPMENT Decision of the council on the reduction of transfrontier movements of wastes. Final amendment. OECD, 1994, 10p.

PALMER, C. M. Contaminant Hydrogeology. Boca Raton: CRC Press, 1996, 235p.

PANARAT, T. Cassava-based adsorbent for removing water from ethanol vapor. In: Philadelphia, PA, The 2008 Annual Meeting, Fundamentals and Applications of Adsorption and Ion Exchange.2008

PARFITT, R.L.et al. Adsorption on hydrous oxides: II. Oxalate, benzoate and phosphate on gibbsite. Journal of Soil Science, v. 28, n.1, p. 40-47, 1977.

PAULA E SILVA, F.; CAVAGUTI, M. Nova caracterização estratigráfica e tectônica do Mesozóico na Cidade de Bauru - SP. Revista Geociências, v.13 , n.1, p. 83-99, 1994. 
PAULA E SILVA, F.; CHENG, H.K.; CAETANO-CHANG, M.R. Perfis de referência do Grupo Bauru (K) no Estado de São Paulo. Geociências, v. 22, n. especial, p. 21-32, 2003

PAULA E SILVA, F.; CHENG, H.K.; CAETANO-CHANG. Estratigrafia de subsuperfície do Grupo Bauru (K) no Estado de São Paulo. Brazilian Journal of Geology, v. 35, n. 1, p. 77 $88,2005$.

PEIXOTO, V.C. Análise paramétrica e dimensionamento de poço de infiltração para fins de drenagem urbana. 2011. 111 p. Dissertação (Mestrado em Geotecnia), Escola de Engenharia de São Carlos, Universidade de São Paulo, São Carlos, SP, 2011.

PEJON, O.J. Mapeamento geotécnico regional da folha de Piracicaba-SP (escala 1.100.000) estudo de aspectos metodológicos, de caracterização e de apresentação de atributos. 1992. 2 vols., 224 p. Tese (Doutorado em Geotecnia) - Escola de Engenharia de São Carlos, Universidade de São Paulo, São Carlos, SP, 1992.

PERKINS, T.; JOHNSON,O. A Review of Diffusion and Dispersion in Porous Media, Society of Petroleum Engineers Journal, v. 2, p. 70-84, 1963.

PICKENS, J. F.; GRISAK, G. E. Scale-dependent dispersion in a stratified granular aquifer.Water Resources Research, v. 17, n. 4, p. 1191-1211, 1981.

PICKENS, John F.; GRISAK, Gerald E. Scale-dependent dispersion in a stratified granular aquifer.Water Resources Research, v. 17, n. 4, p. 1191-1211, 1981.d region. Plant Soil and Environmental, v.52, n.8, p.335-344. 2006

PONÇANO, W. L. Mapa geomorfológico do Estado de São Paulo - Escala 1:1.000.000. Instituto Tecnológico de São Paulo (IPT). São Paulo:1981.

PONGRÁCZ, E.; POHJOLA, V.J. Re-defining waste, the concept of ownership and the role of waste management. Resources, Conservation and Recycling, v.40, n.2, p.141-153, 2004.

QIAN, Y. L.; MECHAM, B. Long-term effects of recycled wastewater irrigation on soil chemical properties on golf course fairways. Agronomy Journal, v. 97, n. 3, p. 717-721, 2005.

QUADROS, D.G.D. et al. Anaerobic digestion of goat and sheep wastes in a continuous reactor of flexible PVC. Revista Brasileira de Engenharia Agrícola e Ambiental, v.14, n.3, p.326-332. 2010

RAIJ, B. Fertilidade do Solo e Adubação Piracicaba: Porfatos, 1991. 343 p

RAIJ, B. van. Determinação do ponto de carga zero em solos. Bragantia, v.32, p.337-347, 1973

RAMIREZ-FUENTES, E. et al. Characteristics, and carbon and nitrogen dynamics in soil irrigated with wastewater for different lengths of time. Bioresource Technology, v.85, n.2, p.179-187. 2002

REICHARDT, K. Dinâmica da matéria e da energia em ecossistemas. Piracicaba: USP/ESALQ - Departamento de Física e Meteorologia, 1996. 505p. 
REICHARDT, K. Processos de transferência no sistema solo-planta-atmosfera.Campinas, São Paulo.: Fundaçao Cargill, 1985. 445 p

RENGASAMY, P.; OLSSON, K. Irrigation and sodicity. Soil Research, v.31, n.6, p.821837. 1993

RIBAS, T.B.; NETO, P.F. Disposição no solo de efluentes de esgoto tratado visando à redução de coliformes termotolerantes. Revista Ambi-Água, v.3, n.3, p.81-94. 2008

RICE, C.R. Soil Clogging during Infiltration of Secondary Effluent. Journal of Water Pollution Control Federation, v.46, n.4, p.708-716. 1974

RICHARDS, L.A. Diagnosis and improvement of saline and alkalisoilsWashington DC: Staff U.S. SalinityLaboratory, 1954

RICHARDS, L.A. The Usefullness of Capillary Potential to Soil- Moisture and Plant investigators Journal of Agricultural Research, v.37, p.719-742. 1928

ROBERTSON, B.K.; ALEXANDER, M. Growth-linked and cometabolic biodegradation: possible reason for occurrence or absence of accelerated pesticide biodegradation. Pesticide Science, v.41, p.311-318, 1994.

ROCHA et al. Hidrogeologia das bacias dos rios Aguapeí, Peixe e paranapanema no Estado de São Paulo. In: Simpósio Regional de Geologia, 2. (1979) Atas... Rio Claro: SB, v.2, p.85100,1979

RODRIGUES, L.A; SILVA, M. C. P. Adsorção de íons fosfato em óxido de nióbio hidratado. Química. Nova, v. 32, n. 5, p. 1206-1211. 2009.

RODRIGUES, L.N. et al. Crescimento e produção de bagas da mamoneira irrigada com água residuária doméstica. Revista Brasileira de Engenharia Agrícola e Ambiental, v.13 (suplemento), p.825-835. 2009

RODRIGUES, R.A. A influência do esgoto doméstico como fluido de saturação no colapso de um solo arenoso. 2003. 130 p. Dissertação (Mestrado em Engenharia Civil) Faculdade De Engenharia, Universidade Estadual Paulista, Ilha Solteira, 2003.

ROSSI, P.; MIRANDA, J. H.; DUARTE, Sérgio N. Curvas de distribuição de efluentes do íon nitrato em amostras de solo deformadas e indeformadas. Engenharia Agrícola, v. 27, n. 3, p. 675-682, 2007.

ROWE, R. K.; CAERS, C. J.; BARONE, F. Laboratory determination of diffusion and distribution coefficients of contaminants using undisturbed clayey soil.Canadian Geotechnical Journal, v. 25, n. 1, p. 108-118, 1988.

ROWE, R.K., QUIGLEY, R.M., BOOKER, J.R., 1995. Clayey barrier systems for waste disposal facilities. E \&FN Spon, London. 1995, 350p.

ROY, W.R.; KRAPAC, I.G.; GHOU, S.F.J.; GRIFFIN, R.A. Batch-type procedures for estimating soil adsorption of chemicals. Technical Resource Document, EPA/530-SW-87006-F: Cincinnati, 1992. 
SAAE Sistemas de Tratamento de Esgoto. Aracruz, ES. Serviço Autônomo de Água e Esgoto. 2006. 14p.

SAIERS, J. E.; HORNBERGER, G. M. The role of colloidal kaolinite in the transport of cesium through laboratory sand columns. Water Resources Research, v. 32, n. 1, p. 33-41, 1996.

SALOMÃO, F.X.T.; ANTUNES, F.S. Solos em pedologia. In: OLIVEIRA, A.M.S; BRITO, S.N.A (Eds). Geologia de Engenharia. São Paulo: Associação Brasileira de Geologia de Engenharia, p. 87-100, 1998.

SALOMONS, W. Environmental impact of metals derived from mining activities: Processes, predictions, prevention. Journal of Geochemical Exploration, v.52, n.1-2, p.5-23. 1995

SANTOS, A.P.R.D. Efeito da irrigação com efluente de esgoto tratado, rico em sódio, em propriedades químicas e físicas de um argissolo vermelho distrófico cultivado com capim-tifon 85. 2004. 95 p. Dissertação (Mestrado em Solos e Nutrição de Plantas) - Escola Superior de Agricultura "Luiz de Queiroz", Universidade de São Paulo, Piracicaba, 2004.

SANTOS, J. S.; LIMA, V.S.A.; BORGES JÚNIOR, J.C.F. Displacement of solutes in soil columns with domestic and swine raising wastewater.Revista Brasileira de Engenharia Agrícola e Ambiental, v. 14, n. 11, p. 1226-1233, 2010.

SCHEIDEGGER, A. E. Physics of flow through porous media. Toronto; University of Toronto, 1963. 313p.

SCHIPPER, L.A. et al. Impact of Land-Applied Tertiary-Treated Effluent on Soil Biochemical Properties. Journal of Environmental Quality., v.25, n.5, p.1073-1077. 1996

SCHNOOR, Jeraid L. Chemical fate and transport in the environment. John Wiley \& Sons, Inc.: New York, p. 1-24, 1992.

SHACKELFORD, C D. Critical concepts for column testing. Journal of Geotechnical Engineering, v. 120, n. 10, p. $1804-1828,1994$.

SHACKELFORD, C. D. Column testing for geoenvironmental applications. In: GeoEnvironmental Issues Facing the Americas. ASCE, p. 117-125, 1994.

. Contaminant transport. In: DANIEL, E.D. (Ed.) Geotechnical practice for waste disposal. Springer US, p. 33-65, 1993.

SILVA, M. L. N. et al. Ponto de efeito salino nulo e suas relações com propriedades mineralógicas e uímicas de latossolos brasileiros. Pesquisa Agropecuária Brasileira, v. 31, n. 9, p. 663-671, 1996.

SIMS, J.T.; PIERZYNSKI, G.M. Chemistry of Phosphorus in Soils. In: TABATABAI, M.A.; SPARKS, D.L. (Ed.). Chemical Processes in Soil. Wisconsin: Soil Science Society of America, Inc. Madison, 2005. p. 151-192.

SINGH, S. K. Estimating dispersion coefficient and porosity from soil-column tests. Journal of environmental engineering, v. 128, n. 11, p. 1095-1099, 2002. 
. Estimation of dispersion coefficient from data on soil column test. In: IX National Symposium on Hydrogeology (Amritsar).National Institute of Hydrology. Anais... Roorkee, India, p.336-340, 1998.

SINGH, U; UEHARA, G. Electrochemistry of the double-layer: principles and applications to soils. In: Sparks, D.L. (Ed.) Soil Physical Chemistry. Florida : CRC Press, 1986. p. 1-38.

SOARES P.C., LANDIM P.M.B., FÚLFARO V.J., SOBREIRO NETO A.F. 1980. Ensaio de caracterização do Cretáceo no Estado de São Paulo: Grupo Bauru. Revista Brasileira de Geociências, v.10, n. 3, p. 177-185, 1980.

SOARES, M.R. Coeficiente de distribuição $\left(K_{\mathbf{D}}\right)$ de metais pesados em solos do Estado de São Paulo. 2004. 214f. Tese (Doutorado em Agronomia) - Escola Superior de Agricultura "Luiz de Queiroz", Universidade de São Paulo, Piracicaba, 2004.

SOUZA SANTOS, P. Ciência e tecnologia de argilas. $2^{\mathrm{a}}$ ed. São Paulo, Edgard Blücher, 1989. 408p.

SOUZA, E.S.D. Método de escoamento superficial no solo: quantificação e biodisponibilidade de metais no efluente, percolado, solo e planta. 2003. 219 p. Dissertação (Mestrado em Engenharia Civil) - Faculdade de Engenharia Civil, Universidade Estadual de Campinas, Campinas, SP, 2003.

SPARLING, G.P.; SCHIPPER, L.A.; RUSSELL, J.M. Changes in soil properties after application of dairy factory effluent to New Zealand volcanic ash and pumice soils. Australian Journal of Soil Research v.39, n.3, p.505-518. 2001

SPOSITO, G. The chemistry of soils. Oxford University press, 1989.277p.

STEVENSON, F. J.; COLE, M. A. The phosphorus cycle. Cycles of soil carbon, nitrogen, phosphorus, sulfur micronutrients. Nova York: Wiley Interscience, 1986. p.250.

STEWART, L.W.; RENEAU, R.B. Spatial and Temporal Variation of Fecal Coliform Movement Surrounding Septic Tank-Soil Absorption Systems in Two Atlantic Coastal Plain Soils1. Journal of Environmental Quality., v.10, n.4, p.528-531. 1981

STOKES, R. H.; ROBINSON, R. A. Interactions in aqueous nonelectrolyte solutions. I. Solute-solvent equilibria. The Journal of Physical Chemistry, v. 70, n. 7, p. 2126-2131, 1966.

STRAUB, T.M. et al. Synergistic inactivation of Escherichia coli and MS-2 coliphage by chloramine and cupric chloride. Water Research, v.29, n.3, p.811-818. 1995

SUGUIO K.; FÚLFARO V.J.; AMARAL G.; GUIDORZI L.A. Comportamentos estratigráficos e estrutural da Formação Bauru nas regiões administrativas 7 (Bauru), 8 (São José do Rio Preto) e 9 (Araçatuba) no Estado de São Paulo. In: SBG/Núcleo SP, Simpósio de Geologia Regional, 1. Atas... São Paulo, SP, p. 231 -247, 1977

TACK, F.M.G, MEERS, E. Assisted Phytoextraction: Helping Plants to Help Us. Elements, v. 6, n.6, p.383-388, 2010.

TAM, N.F.Y.; WONG, Y.S. Retention and distribution of heavy metals in mangrove soils receiving wastewater. Environmental Pollution, v.94, n.3, p.283-291. 1996 
TANG, C. et al. Assessment of groundwater contamination by nitrates associated with wastewater irrigation: A case study in Shijiazhuang region, China. Hydrological Processes, v.18, n.12, p.2303-2312. 2004

TARCHITZKY, J. et al. Wastewater effects on montmorillonite suspensions and hydraulic properties of sandy soils. Soil Science Society of America Journal, v.63, n.3, p.554-560. 1999

TAVARES, G.A.; BENDASSOLLI, J.A. Implantação de um programa de gerenciamento de resíduos químicos e águas servidas nos laboratórios de ensino e pesquisa no cena/usp. Química Nova, v.28, n.4, p.732-738. 2005

TAVARES, T.M.; CARVALHO, F.M. Avaliação da exposição de populações humanas a metais pesados no ambiente: exemplos do Recôncavo Baiano. Química Nova, v.15, n.2, p.147-153. 1992

TESSIER, A.; CAMPBELL, P.G.C.; BISSON, M. Sequential extraction procedure for the speciation of particulate trace metals. Analytical Chemistry, v.51, n.7, p.844-851. 1979

THOMAS, R.E.; SCHWARTZ, W.A.; BENDIXEN, T.W. Soil Chemical Changes And Infiltration Rate Reduction Under Sewage Spreading. Soil Science Society of America Journal, v.30, n.5, p.641-646. 1966

TOLEDO, M.C.M.; OLIVEIRA, S.M.B.; MELFI, A.J. Intemperismo e formação do solo. In: e.a. TEIXEIRA (Editor), Decifrando a Terra.2nd ed. São Paulo: Oficina de Textos, 2003. p. 139-166.

TOMSON, M.B. et al. Contaminant-soil interactions. In: R.P. LANNO (Editor), Contaminated soils: from soil-chemical interaction to ecosystem management. Prague: Society of Environmental Toxicology and Chemistry (SETAC), p. 251-290, 2003.

TORAN, L.; PALUMBO, A. V. Colloid transport through fractured and unfractured laboratory sand columns. Journal of Contaminant Hydrology, v. 9, n. 3, p. 289-303, 1992.

TOZE, S. Reuse of effluent water: benefits and risks. Agricultural Water Management, v.80, n.1-3, p.147-159. 2006

TRAVIS, C. C.; ETNIER, Elizabeth L. A survey of sorption relationships for reactive solutes in soil. Journal of Environmental Quality, v. 10, n. 1, p. 8-17, 1981

VAN GENUCHTEN, M. T.; WIRIENGA, P.J. Solute dispersion coefficients and retardation factors. Methods of soil analysis. Part 1. Physical and mineralogical methods, p. 1025-1053, 1986.

VAN GENUCHTEN, M. T; PARKER, J. C. Boundary conditions for displacement experiments through short laboratory soil columns. Soil Science Society of America Journal, v. 48, n. 4, p. 703-708, 1984.

VAN GENUCHTEN, M.T. A Closed-form Equation for Predicting the Hydraulic Conductivity of Unsaturated Soils1. Soil Science Society American Journal, v.44, n.5, p.892-898. 1980. 
VANAPALLI, S.K. et al. Model for the prediction of shear strength with respect to soil suction. Canadian Geotechnical Journal, v.33, n.3, p.379-392. 1996

VANAPALLI, S.K.; FREDLUND, D.G.; PUFAHL, D.E. The influence of soil structure and stress history on the soil - water characteristics of a compacted till. Geotechnique, v.49, n.2, p.143-159. 1999.

VANDEVIVERE, P.; BAVEYE, P. Saturated hydraulic conductivity reduction caused by aerobic bacteria in sand columns. Soil Science Society of America Journal, v.56, n.1, p.113. 1992.

VAZQUEZ-MONTIEL, O.; HORAN, N.J.; MARA, D.D. Management of domestic wastewater for reuse in irrigation. Water Science and Technology, v.33, n.10-11, p.355-362. 1996.

VIDAL, M. et al. Spatial and temporal hydrochemical changes in groundwater under the contaminating effects of fertilizers and wastewater. Journal of Environmental Management, v.60, n.3, p.215-225. 2000.

VILAR, O.M. Introdução à mecânica dos solos não saturados. EESC/USP:Departamento de Geotecnia. São Carlos, SP, Notas de aula da disciplina mecânica dos solos não saturados. 2009. $30 \mathrm{p}$.

VILAR, O.M. Resistência ao Cisalhamento. Escola de Engenharia de São Carlos Universidade de São Paulo, São Carlos, SP, Apostila. 2002. 80p.

VILELlA JUNIOR, L. V. E.; ARAÚJO, J. A. C.; FACTOR, T.L. Comportamento do meloeiro em cultivo sem solo com a utilização de biofertilizante. Horticultura Brasileira, Brasília, v.2, n.2, p.153-157, 2003.

VINTEN, A.J.A.; MINGELGRIN, U.; YARON, B. The Effect of Suspended Solids in Wastewater on Soil Hydraulic Conductivity: II. Vertical Distribution of Suspended Solids1. Soil Science Society of America Journal., v.47, n.3, p.408-412. 1983

VON SPERLING, M. Introdução à qualidade das águas e ao tratamento de esgotos: v.1. 2. ed. Belo Horizonte: Departamento de Engenharia Sanitária e Ambiental - Universidade Federal de Minas Gerais, 1996. 243 p

. Princípios do tratamento biológico de águas residuárias: introdução à qualidade das águas e ao tratamento de esgotos: v1, 3ed. Belo Horizonte: Universidade Federal de Minas Gerais, 2005. $252 \mathrm{p}$

WASHBURN E.W. The dynamics of capillary flow. Physical Review, v.17,p. 273-283, 1921.

WENTZEL, M. C. et al. Batch test for characterisation of the carbonaceous materials in municipal wastewaters. Water S. A., v. 25, n. 3, p. 327-336, 1999.

WENTZEL, M. C.; MBEWE, A.; EKAMA, G. A. Batch test for measurement of readily biodegradable COD and active organism concentrations in municipal waste waters. WATER SA-PRETORIA-, v. 21, p. 117-117, 1995. 
WESTERHOFF, G. P. Un update of research needs for water reuse. In: Water reuse symposium. 1984. p. 1731-42.

WILSON, M. J. A Handbook of Determinative Methods in Clay Mineralogy. New York, Blakie \& Son Limited, 1939. 308p.

YEH, T.C. J.; GELHAR, L. W.; GUTJAHR, A. L. Stochastic analysis of unsaturated flow in heterogeneous soils: 1. Statistically isotropic media. Water Resources Research, v. 21, n. 4, p. 447-456, 1985.

YIM, M.W.; TAM, N.F.Y. Effects of Wastewater-borne Heavy Metals on Mangrove Plants and Soil Microbial Activities. Marine Pollution Bulletin, v.39, n.1-12, p.179-186. 1999.

YONG, R.N., MOHAMED, A.M.O, WARKENTING, B.P. Principles of contaminant transport in soils. Amsterdam:Elsevier Science Publishers B.V,1992. 327p. (Developments in Geotechnical Engineering, 73).

ZUQUETTE L.V., SILVA JR. E.M., GARCIA A. Aspectos de Sorção para os Materiais Inconsolidados da Região de São Carlos (SP), Brasil. Revista da Escola de Minas, Ouro Preto, v.61, n.2, p.219-230, 2008.

ZUQUETTE, L.V., PEJON, O.J., RODRIGUES, J.E., PARAGUASSÚ, A.B., GANDOLFI, $\mathrm{N}$., Solute Breakthrough Curves ( $\mathrm{Na}, \mathrm{Cu}, \mathrm{Zn}$ and $\mathrm{Cd}$ ) for Sandy Unconsolidated material from Botucatu Formation of São Paulo State. In International Symposium on Recent Developments in Soil and Pavement Mechanics. Anais... Rio de Janeiro, v. 1, p. 459-464, 1997. 